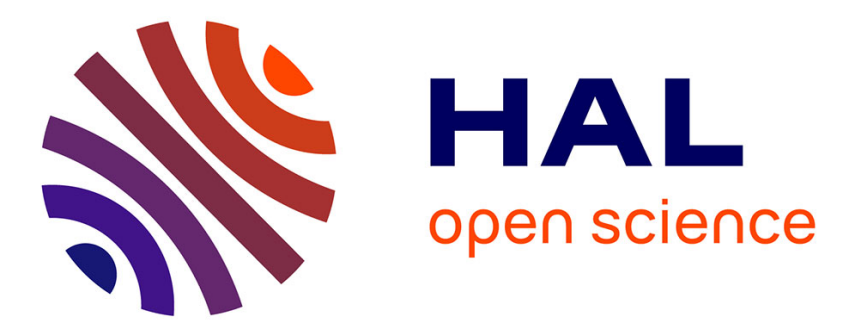

\title{
Implementing cluster policies : organizational dilemmas, pathologies and evaluation. The case of a French policy-driven cluster
}

Anna Glaser

\section{> To cite this version:}

Anna Glaser. Implementing cluster policies: organizational dilemmas, pathologies and evaluation. The case of a French policy-driven cluster. Business administration. Ecole Nationale Supérieure des Mines de Paris, 2014. English. NNT : 2014ENMP0063 . tel-01144071

HAL Id: tel-01144071

https://pastel.archives-ouvertes.fr/tel-01144071

Submitted on 20 Apr 2015

HAL is a multi-disciplinary open access archive for the deposit and dissemination of scientific research documents, whether they are published or not. The documents may come from teaching and research institutions in France or abroad, or from public or private research centers.
L'archive ouverte pluridisciplinaire HAL, est destinée au dépôt et à la diffusion de documents scientifiques de niveau recherche, publiés ou non, émanant des établissements d'enseignement et de recherche français ou étrangers, des laboratoires publics ou privés. 
École doctorale $n^{\circ} 396$ : Économie, Organisation et Société

Doctorat ParisTech

TH È S E

pour obtenir le grade de docteur délivré par

l'École nationale supérieure des mines de Paris

Spécialité "Sciences de gestion"

présentée et soutenue publiquement par

\section{Anna GLASER}

le 16 décembre 2014

IMPLEMENTING CLUSTER POLICIES:

ORGANIZATIONAL DILEMMAS, PATHOLOGIES AND EVALUATION.

THE CASE OF A FRENCH POLICY-DRIVEN CLUSTER.

(LA MISE EN OEUVRE DES POLITIQUES DE CLUSTER :

DILEMMES ORGANISATIONNELS, PATHOLOGIES ET EVALUATION.

LE CAS D'UN POLE DE COMPETITIVITE FRANCAIS.)

Directeurs de thèse :

MM. Jean-Michel SAUSSOIS (ESCP Europe) et Thierry WEIL (Mines ParisTech)

Jury

Mme Catherine CHASTENET DE GERY

Professeur, Novancia Business School Paris

Examinateur

Mme Ana COLOVIC

Professeur, NEOMA Business School

Rapporteur

Mme Frédérique PALLEZ

Professeur, Mines ParisTech

Examinateur

Mme Anne-Laure SAIVES

Professeur, Université du Québec à Montréal

Rapporteur

M. Jean-Michel SAUSSOIS

Professeur Emérite, ESCP Europe

Examinateur 

Mines ParisTech n'entend donner aucune approbation ni improbation aux opinions émises dans cette thèse. Ces opinions doivent être considérées comme propres à l'auteur. 


\section{PREFACE}

In order to better understand this thesis, it is necessary to have some background information regarding my research journey and my intellectual confrontations so far. I did my Master at the Vienna University of economics and business (WU Wien), specializing in tourism \& leisure management and with additional courses in regional \& urban planning ${ }^{1}$. It was the regional \& urban planning courses that were highly motivating, so I decided to do my master thesis with Prof. Edward Bergman from the regional \& urban planning institute. Prof. Bergman works for example on cluster life cycles (Bergman, 2008) or methodology issues regarding cluster studies (Bergman \& Feser, 1999a, 1999b).

Prof. Bergman proposed me to candidate to the NEURUS programme in order to intensify my master thesis research experience. NEURUS stands for "Network for European and United States Regional and Urban Studies" and is an international consortium of universities dedicated to the collaborative study of urban and regional development issues ${ }^{2}$. This consortium paved my way to acquire my first research scholarship and to conduct my first research semester abroad. I spent this research semester at the UNC Chapel Hill (North Carolina, USA) in the department of City \& Regional Planning and under the supervision of Prof. Harvey Goldstein (for example working on the link between industrial growth and regional clustering (Feser, Renski, \& Goldstein, 2008)).

In my Master Thesis I studied the research triangle park in North Carolina. The title of my master thesis was "The Impact of Mergers on Regional Systems - The Case of North Carolina" (A. Glaser, 2007) and focused on the impact (regarding innovation, firm establishments, employment and research collaborations) of the 1995 pharmaceutical merger between Glaxo and Burroughs Wellcome in and around the research triangle park. The methodologies I used for this master thesis were shift-share analysis and network analysis.

Retrospectively, I owe a lot to this NEURUS programme because, even though at that time I was not at all conscious about it, it showed me how research can be done in Europe and the United States. It allowed me to expose my first research endeavours to various professors in

\footnotetext{
${ }^{1}$ Already during my undergraduate studies I took additional courses in geography at the University of Vienna (the main university in Austria).

${ }^{2}$ For further information: http://www.neurusinfo.org/
} 
the urban/regional studies and planning field during NEURUS seminars, for example the current American coordinator Prof. Feser $(2008 ; 2000)$ or the current European coordinator Prof. Van Steen (Pellenbarg \& Van Steen, 2001, 2003) which were already active at my time as well.

Even though the NEURUS programme prepares the students to continue with a $\mathrm{PhD}$ thesis, I decided that working in the "real world" is a better choice then continuing an academic endeavour. However, after one year in the policy evaluation department at the International Labour Organisation in Geneva and two years in a market research company (TNS Sofres) in Paris, I decided that I am ready again to confront myself to a new "academic journey".

The only thing I knew when I took the decision to go back to the academic world was that I wanted to continue studying this "regional system" phenomenon and the innovation and entrepreneurial activities that are happening within these "regional systems". My profound motivation regarding this topic was properly in the beginning to identify why some regions succeed and others don't and finally what "one" (be it public or private actors) can do to help the local actors to "survive" in a globalized and highly competitive world.

I thus looked for a $\mathrm{PhD}$ programme in the Paris Region and I was luckily admitted to the management $\mathrm{PhD}$ programme at ESCP Europe, with Prof. Jean-Michel Saussois, as well as to the French doctoral programme at Mines ParisTech, with Prof. Thierry Weil. Working with Prof. Weil and the Cluster observatory ("Observatoire des pôles de compétitivité") at Mines ParisTech (and the members of this observatory I met during my application process (such as Prof. Frédérique Pallez or Ass. Prof. Philippe Lefebvre) was a great opportunity.

ESCP Europe, while providng a very stimulating research context, did not have a dedicated research unit on clusters but only on public management more broadly. I thought that the combination of both intensive focus on clusters at Mines ParisTech and more broadly public management ${ }^{3}$ at ESCP Europe would be a perfect combination. I am immensely grateful to

\footnotetext{
${ }^{3}$ Prof. Saussois was not particularly focusing on clusters but more broadly on public management, but when I started my PhD he was working on a cluster study with colleagues from Novancia Business School to investigate the entrepreneurial dynamics in French clusters (Bonnafous-Boucher \& Saussois, 2010). This research project also financed me a short fieldwork trip to Austria to investigate the differences with the French system and to write a research note about the Austrian system (A. Glaser, 2011).
} 
my advisors because even though it was sometimes a difficult endeavour, it gave me a very rich learning and studying experience.

Table 1 summarizes the background of my three research supervisors. All three professors and their research environments strongly influenced how I conceive research in general and cluster research in particular. As Table 1 shows, the common denominator between all three researchers is that they are interested in studying regional clusters. However, besides this common denominator, the manner of how they perceive clusters and conduct research is very different.

Table 1: Comparison of my master and PhD theses supervisors' environments

\begin{tabular}{|c|c|c|c|}
\hline & $\begin{array}{c}\text { Prof. Edward } \\
\text { Bergman }\end{array}$ & $\begin{array}{c}\text { Prof. Thierry } \\
\text { Weil }\end{array}$ & $\begin{array}{c}\text { Prof. Jean-Michel } \\
\text { Saussois }\end{array}$ \\
\hline My supervisor for & Master thesis & PhD thesis & PhD thesis \\
\hline Nationality & American & French & French \\
\hline Master in & City Planning & Engineering & Management \\
\hline PhD in & $\begin{array}{l}\text { Urban \& Regional } \\
\text { Development }\end{array}$ & Physics & Sociology \\
\hline $\begin{array}{l}\text { HDR (French } \\
\text { Qualification for } \\
\text { Ph.D. Supervisor) }\end{array}$ & n.a. & Management & Sociology \\
\hline $\begin{array}{l}\text { Last institutional } \\
\text { affiliation }\end{array}$ & $\begin{array}{l}\text { Vienna university of } \\
\text { Economics and Business } \\
\text { (Austria) }\end{array}$ & $\begin{array}{l}\text { Mines ParisTech (a French } \\
\text { engineering school) }\end{array}$ & $\begin{array}{l}\text { ESCP Europe } \\
\text { (a French management } \\
\text { school) }\end{array}$ \\
\hline Research collective & $\begin{array}{l}\text { Network for European and } \\
\text { United States Regional and } \\
\text { Urban Studies } \\
\text { (multinational consortium) }\end{array}$ & $\begin{array}{l}\text { French cluster observatory } \\
\text { ("Observatoire des pôles } \\
\text { de compétitivité") at } \\
\text { Mines ParisTech }\end{array}$ & $\begin{array}{l}\text { Centre for Research and } \\
\text { Development in Public } \\
\text { Management } \\
\text { ("Centre de Recherche et } \\
\text { Développement en } \\
\text { Management Public") at } \\
\text { ESCP Europe }\end{array}$ \\
\hline $\begin{array}{l}\text { Institutional } \\
\text { affiliation in the } \\
\text { USA (permanent or } \\
\text { for research period) }\end{array}$ & $\begin{array}{l}\text { University of } \\
\text { Pennsylvania, UNC } \\
\text { Chapel Hill }\end{array}$ & Stanford University & $\begin{array}{l}\text { Georges Washington } \\
\text { University }\end{array}$ \\
\hline $\begin{array}{l}\text { Common } \\
\text { denominator }\end{array}$ & $\begin{array}{l}\text { interest in Regional } \\
\text { Clusters }\end{array}$ & $\begin{array}{l}\text { interest in Regional } \\
\text { Clusters }\end{array}$ & $\begin{array}{l}\text { interest in Regional } \\
\text { Clusters }\end{array}$ \\
\hline
\end{tabular}

Retrospectively, when I started my $\mathrm{PhD}$ I had a more economic approach to clusters (by conducting shift-share analyses, network analyses, or looking at quantitative indicators of regional differences) than a management (or public management) approach to clusters. I was at a certain distance regarding the actual local actors that are situated within the clusters and the public policies that are put in place to foster their development. However, the French cluster policy and my $\mathrm{PhD}$ supervisors influenced me to completely change my approach to the subject. 
When I started my PhD, Prof. Weil (T. Weil, 2010; T. Weil \& Fen Chong, 2008), thanks to his large and detailed knowledge on the subject and his intensive relationship with practitioners on the field (be it within the French cluster organisations or at the French political level), had just accessed the raw data of the national cluster policy evaluation ${ }^{4}$. This French cluster evaluation (CMI \& BCG, 2008) not only evaluated the policy in itself but also the 71 cluster organisations located on the French territory. It was an ideal starting point for my $\mathrm{PhD}$. For me, at least in the beginning, it "simply" presented an opportunity to continue quantitative analyses regarding regional cluster differences, something I started during my Master Thesis. However, very fast I realized that the collected data and the notion of cluster was not the same as the data and the cluster notion I was used to during my Master Thesis.

Instead of studying spontaneous clusters (Chiaroni \& Chiesa, 2006) by for example analyzing a cluster's life cycle (Bergman, 2008) or by analysing a cluster's internal structure (Morrison \& Rabellotti, 2009; Salman \& Saives, 2005) or internal-external relations (Boschma \& Ter Wal, 2007) through network studies, I was suddenly confronted to a highly political cluster construct. Meaning the political wish to support emerging or nascent clusters at a certain location. Fromhold-Eisebith \& Eisebith (2005) or Chiaroni \& Chiesa (Chiaroni \& Chiesa, 2006) call this type of clusters "policy-driven clusters".

The data I started working with in the beginning of my $\mathrm{PhD}$ were the reflection of this highly political construct called French "clusters" (for example which type of local actors are governing the policy-driven cluster, how much fund does the policy-driven cluster have, who are its "members" meaning who has paid its membership fee). The work with this data was transformed into two articles: (1) one article which was published in the journal "European Planning Studies" and which focuses on how pre-existing R\&D activities of a region influence the performance of these policy-driven cluster initiatives (performance i.e. the amount of state funding received by the cluster members for their R\&D projects) (Gallié, Glaser, Mérindol, \& Weil, 2013a), and (2) another article (in the revision phase for the journal Entrepreneurship \& Regional Development) focuses on how the governance structure

\footnotetext{
${ }^{4}$ See Chapter 1, Section 2 for a detailed explanation of the French cluster policy and the conducted evaluations. ${ }^{5}$ A previous version of this article was presented at three conferences: at the European Academy of Management (EURAM) conference (T. Weil, et al., 2010a), at the European Localized Innovation Observatory (EUROLIO) conference (Mérindol, et al., 2010) and at the European Group for Organizational Studies (EGOS) conference (T. Weil, et al., 2010b).
} 
of policy-driven cluster influences its capability to attract resources (A. Glaser, Gallié, \& Weil, 2012) ${ }^{6}$.

In parallel of this work with Prof. Weil on the performance differences between the various policy-driven cluster initiatives that were set up on the French territory thanks to the national cluster policy, I was also working with Prof. Saussois on the historical development of the French industrial policy (Porcher, Glaser, \& Saussois, 2010). Prof. Saussois has a rich knowledge on the policy developments in France and the United States thanks to his research endeavours on industrial policies at both sides of the Atlantic (Saussois, 1988, 1990). He thus wanted me to step one step backwards in order to look at this French "cluster policy" from a more distant level and how it is inserted in a French historical and cultural context.

Even though working on the performance of cluster initiatives with Prof. Weil and on a more global historical approach of industrial policies with Prof. Saussois, I realized very fast that somehow a "wall" is separating me from them. My knowledge on regional innovation systems (Asheim \& Isaksen, 1997; Cooke, Uranga, \& Etxebarria, 1998; Tödtling \& Kaufmann, 2001) acquired during my Master Thesis was not helping me in really understanding the French context and what they were talking about. I was suddenly confronted to terms and notions that were completely new for me but which were apparently necessary to really understand the French system and how it tries to create regional innovation systems, be it ${ }^{7}$

- at a political-institutional level, for example DIRECCTE, DREAL, DRAAF, CIADT, DATAR, DGCIS, GTI, ANR, OSEO, FUI, or CDC and their relations to each other,

- at a political-functioning level, meaning the relation between the State and its different regions, of a unitary country like France compared to the federal countries like USA or Austria I was used to when studying clusters,

- at a political-policy level, for example SPL, CRITT, RRIT, or Technopoles, or

- at a political-historical level, for example Jacobin, Girondin, Colbert, or Général de Gaulle and the planification à la française,

\footnotetext{
${ }^{6}$ A previous version of this article was presented at the Association Internationale de Management Stratégique (AIMS) conference (A. Glaser, Gallié, Mérindol, \& Weil, 2010).

${ }^{7}$ For the time being I will not explain the terms listed hereinafter. A French cluster scholar will know what these terms mean, a foreign scholar will probably, just like me in the beginning, not know what these terms mean. I will come back to these terms little by little throughout the thesis.
} 
I knew that if I really want to understand the French policy-driven cluster system, I had to immerge into the system and not only stay with my quantitative data. I had to get in contact with the actors on the field; otherwise I would have had the impression that my conclusions, so far only drawn from my quantitative analysis and from my slowly starting theoretical knowledge on the French system, are maybe wrong. I thus decided with my $\mathrm{PhD}$ supervisors to start conducting a qualitative study in one of the 71 French cluster organisations (see Chapter 5 for a detailed description of my methodology and data collection process). At that point I really felt like Henry in Jules Verne's book "A journey to the center of the earth" (1864) who is sitting at the bench of a black hole where the bottom was completely invisible (see Box 1).

\section{Box 1: Henry's adventure and thoughts}

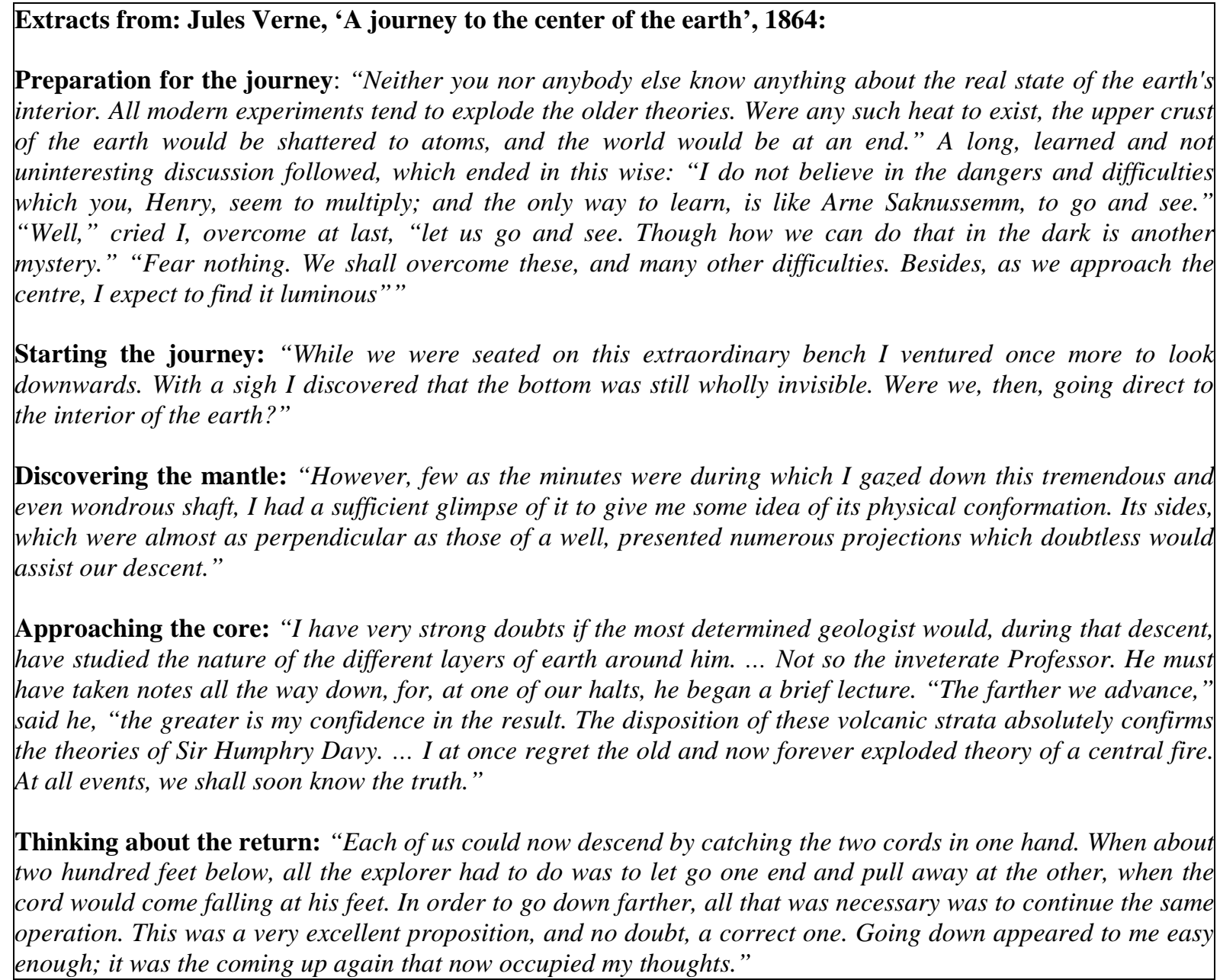

Still afraid about the French political system, like Henry who is afraid to start climbing down the earth, I particularly wanted to focus on how the cluster organisation creates innovation and linkages between its actors (thus still highly influenced by the regional innovation system 
literature I initially knew). During several months, I regularly participated in a range of internal and external meetings of a cluster organisation situated in the Paris Region.

However, very fast I realized that the day-to-day occupation of the cluster organisation was less on innovation put for example on labelling, the management of internal conflicts, the management of their (sometimes conflictual) relationships with cluster members or the French national or regional cluster administrations, or the (sometimes difficult) negotiation of responsibilities with other political entities of the region regarding additional services to local actors. The political part of the system was thus again much more present in my observations than the innovation part (which existed but was not the main part).

Thanks to this first qualitative fieldwork, I started to apprehend the system a little bit better, but I still felt that I needed to go one step further down in order to really understand (or at least try to) the French policy-driven cluster system, its relation to innovation and the role of the political institutions in this system. I thus felt that the core of my journey was not reached yet or expressed in a methodology language that I did not reach "theoretical saturation" (Eisenhardt, 1989; B. G. Glaser \& Strauss, 1967 (2009)) and that I still did not really understood how the French try to construct regional innovation systems.

I thus started to conduct interviews with cluster members to get to know how they actually construct R\&D projects and which role the local (political) cluster organisation plays in this endeavour. My first qualitative results were then presented at several conferences such as at the Public and Non-Profits (PNP) Doctoral Student Professional Development Consortium of the Academy of Management (AOM) conference (A. Glaser, 2012a), the Proximity Days (organised by MOSAIC at HEC Montréal) conference (A. Glaser, 2012b) and the Danish Research Unit for Industrial Dynamics (DRUID) conference (A. Glaser, 2013b).

In parallel to this qualitative fieldwork, the attended conferences and the constant reading of the cluster literature, some additional elements considerably helped me to continuously try to confront my fieldwork observations and to making sense of what I observed on the field.

On the one hand two research collectives:

- The cluster observatory at Mines ParisTech: The first important research collective that helped me to confront my fieldwork observations was the cluster observatory 
("observatoire des pôles de compétitivité") ${ }^{8}$ at Mines ParisTech of which I am a member since the beginning of my thesis. The cluster observatory particularly helped me through the monthly seminars that we organised. In these monthly seminars we always invited researchers and cluster practitioners (cluster managers, representatives of the State and the regional authorities, CEO's of companies, academics, consultants...) to expose a certain cluster issue during one hour followed by one hour discussion with all participants. This platform allowed me to confront my single cluster case study observations to the reality of other clusters and thus allowed me to identify if what I observed is particular related to my cluster observation or also the reality in other clusters. Additionally to the monthly seminars, this cluster observatory also allowed me to be integrated in a research collective, retrospectively maybe one of the most valuable things during my $\mathrm{PhD}$. It was extremely enriching to exchange regularly, additionally to my two $\mathrm{PhD}$ supervisors ${ }^{9}$, with three other French cluster specialised. Prof. Frédérique Pallez (particularly interested in public administration and evaluation (Aggeri \& Pallez, 2005; Fen Chong \& Pallez, 2008; Fixari \& Pallez, 2014; Pallez, 2014b)), Ass. Prof. Philippe Lefebvre (particularly interested in the management of policy-driven cluster initiatives (Lefebvre, 2008, 2013)), and Dr. Emilie-Pauline Gallié (particularly interested in R\&D collaborations and proximity (Gallié, 2009; Gallié \& Guichard, 2005)).

- The GEME at UQAM Montréal: The second important research collective was my visiting semester at UQAM Montréal with Prof. Anne-Laure Saives (particularly interested in the strategic value of clusters for firms (Desmarteau \& Saives, 2003; Salman \& Saives, 2005)). This visiting semester happened exactly in the middle of my qualitative fieldwork, after my observation and interview period within the cluster organisation and before my interviews with the cluster members. My integration in the $\mathrm{GEME}^{10}$ research team which focuses, amongst others, on Canadian clusters, allowed me to confront my French observations to external parties and to gain some additional distance to my French data.

On the other hand two intensive guided theoretical reflections:

\footnotetext{
${ }^{8} \mathrm{http}: / /$ observatoirepc.org/

${ }^{9}$ It was also very important to exchange with all my colleagues at ESCP Europe, even though they were not specialised in cluster studies, they always gave me extremely valuable advices.

${ }^{10}$ The GEME stands for "Groupe d'Études en Management des Entreprises". Within the GEME research unit there are two teams: the GEME-Bio team focusing on the biotechnology industry and the GEME-AERO team focusing on the aeronautics industry.
} 
- Focus on cluster evaluations: The first important theoretical reflections concern my work and my debates with Prof. Pallez and Dr. Gallié on policy-driven cluster evaluations. We first analysed the French 2008 policy-driven cluster evaluation (Gallié, Glaser, Lefebvre, \& Pallez, 2012) and then compared this French to other European policy-driven cluster evaluations (Gallié, Glaser, \& Pallez, 2014) ${ }^{11}$. One important conclusion of this work on the French policy-driven cluster evaluation and its comparison to international examples is that the act of evaluating cluster policies might not only serve to evaluate the performance of the cluster policy but also clarify the underlying objectives of the policy. Most of the time it is only at the moment when an evaluation has to be conducted that the policy-driven cluster "leaders" decide on the actual "objects" that are important to evaluate. These "objects" then reveal the objective of the policy. Again this work on evaluations of cluster policies not only allowed me to apprehend a large variety of cluster policies but also position the French way of doing into an international context.

- Focus on organisational studies: The second important theoretical reflections were my debates with Prof. Saussois. Whenever I talked with Prof. Saussois (an organizational sociologist in his heart) about my fieldwork observations, he constantly proposed me to look at traditional organisational and sociology studies (like for example (Brunsson, 1989; Crozier, 1964 (2010); Gouldner, 1954 (1964); Hofstadter, 1979 (1999); Selznick, 1949; Sennett, 1992 (1977), 2012)). He thus oriented me towards apprehending these French policy-driven cluster constructs like organizational entities where similar power plays and hierarchical issues emerge like in traditional organisations.

As one can see, I completely dived into the French cluster policy system and tried to make sense of my observations from different angles. My research process was also a highly abductive one (Dubois \& Gadde, 2002) constantly going back and forth between data and theory $^{12}$. Somewhen during my PhD I had the impression that I completely lost my initial objectives namely how one can analyze regional systems and help local actors particularly

\footnotetext{
${ }^{11}$ A previous version of this article was for example presented at the Regional Science Association International - British and Irish Section (RSAI-BIS) (Gallié, Glaser, \& Pallez, 2010) and at the Seminar of the Institute for Public Management and Economic Development (IGPDE) in 2012.

${ }^{12}$ This confrontation with the French system also lead to an article (accepted by the DRUID conference in 2013) where I tried to look at the system through the eyes of Richard Sennett (A. Glaser, 2013a)
} 
regarding innovation. Instead I was just observing political tension and problems at every level.

The first time I heard about that it can be completely normal to be in "confrontation" or "depressed" with one's fieldwork was during a PhD methodology course on ethnographic methods (held by Christina Garsten (Garsten, 2013)) at ESCP Europe. Pollard (2009) for example summarizes the difficulty of ethnographic fieldwork in 24 feelings: "alone, ashamed, bereaved, betrayed, depressed, desperate, disappointed, disturbed, embarrassed, fearful, frustrated, guilty, harassed, homeless, paranoid, regretful, silenced, stressed, trapped, uncomfortable, unprepared, unsupported and unwell.” Even though I cannot identify with all of these feelings, I certainly crossed the majority of them.

However, at that time I was profoundly convinced that my research endeavour is far away from an ethnographic methodology. I was convinced that it is a classical case study analysis (Eisenhardt, 1989; Yin, 2009) where I just had to define the number of cases and the units of analysis studied. One is not allowed to forget that I was coming from a quantitative background during my master thesis thus anything which was based on a highly qualitative data collection process was frightening me (also intensified through the fact that my mother tongue is not French). However, as I was moving down the latter (from first looking only at the quantitative evaluation data of the French cluster policy over the policy-driven cluster organisation observations to interviewing the policy-driven cluster actors) in order to completely apprehend the French policy-driven cluster system it was more and more difficult for me to define the number of cases studied or the attached units of analysis. The units of analysis were constantly moving when further descending to the core of the cluster policy as also the initial focus on innovation was fading away.

It was only during the final writing up of my research and the intensive studying of other PhDs on French clusters that were recently defended (Bardet, 2011; Berthinier-Poncet, 2012; Chabault, 2009; Dang, 2011; Fen Chong, 2009; Lallemand, 2013) that I realized that one of the added values of my $\mathrm{PhD}$ compared to the other $\mathrm{PhDs}$ on French cluster policies was maybe the fact that I am simply not French. As an Austrian researcher studying the French system, I somehow had a different position compared to the other PhDs on French cluster policies. I was more an external observer that just discovered the system and my cluster knowledge has maybe developed a little bit more in an international context and not only in a 
French context. Things that seemed obvious to French scholars were not at all obvious for me as an Austrian scholar.

Additionally, my thesis, compared to the other thesis on the French policy-driven clusters, is written in English language. Automatically when writing in English one addresses itself not to a French community that knows the French system but to an international community that might not know the French system. Bourdieu (1982) for example underlines that there are no neutral words and hat language is not only a communication tool but also reflects the social reality of the ones who use the language. The explanation of the policy-driven cluster system to a non French speaking person has to be much more detailed but at the same time simplified and has to be constantly compared with other international examples in order to try making the observed French elements more comprehensive to an external research community.

These reflections on my position regarding my research and my methodology, lead me to the conclusion that my data collection regarding the French policy-driven cluster system actually started at the first day of my $\mathrm{PhD}$. That studying policy-driven clusters is a highly systemic endeavour and that all these different manners of confronting me to the French system lead me to conduct a single case study with an ethnographic (Garsten, 2013) and grounded theory (B. G. Glaser \& Strauss, 1967 (2009)) approach. All the different levels of my analysis (from the quantitative analysis to the qualitative analysis, from the discussions with French scholars and international scholars) form a whole to apprehend in detail "What is a cluster?" and particularly "What is a French policy-driven cluster?".

I would like to finish this preface with referring to inspiring scholars, such as Coase (1937), Rosenberg (1982) or Jacobs (1961), that see research as a life journey. At the beginning one does not really know towards what one is heading, one has a certain interest and feeling and start doing research. However, it is only at the end of one's career that the whole makes sense. Coase (1988, p. 47), for example nearly 50 years after his influential book "The nature of the firm" (1937) admits that in the beginning he only had a vision, and now at the end of his career he has dreams but still he does not know if at the end he will discover what he thought that he will discover:

\footnotetext{
"It has been said that young men have visions and old men have dreams. My dream is to construct a theory which will enable us to analyze the determinants of the institutional structure of production. In "The Nature of the Firm" the job was only half done [...] My dream is to help complete what I started some fifty-five years ago and to take part in the development
} 
of such a comprehensive theory. [...] I intend to set sail once again to find the route to China, and if this time all I do is to discover America, I won't be disappointed." (Coase, 1988, p. 47).

In the beginning of my $\mathrm{PhD}$ I thought that I will focus on analysing regional systems and the innovation processes happening in this regional systems. However, during the research process I realized that my incomprehension of the French system and the strong political component has to be integrated in the analysis, a political component that is strongly varying between different countries implementing cluster policies. From the outside it looks the same, from the inside it is definitely not the same, strongly impacting multi-country cluster analyses.

This thesis is the wish to make the French system comprehensible to outsiders, and on the other hand this thesis is the wish to discuss the different structural, political, organisational and evolutionary diseases that might emerge when implementing cluster policies around the world and which all actors involved in cluster policies should be conscious about. Probably 50 years from now, when I look back to this thesis again, I will just see it as a little point in my general knowledge on clusters. This thesis is just an additional element in my research endeavours of studying regional systems and helping local actors to better understand how to succeed in a globalized world. 


\section{TABLE OF CONTENTS}

PREFACE. iii

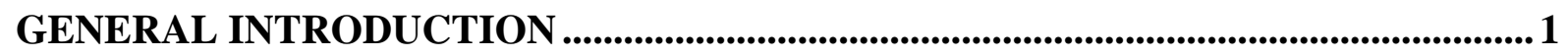

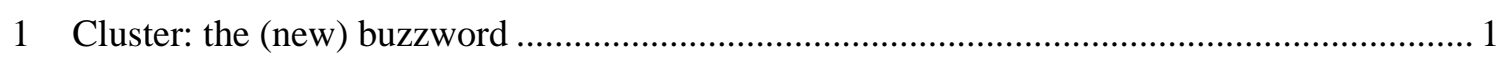

2 The rising implementation of cluster policies .................................................................... 2

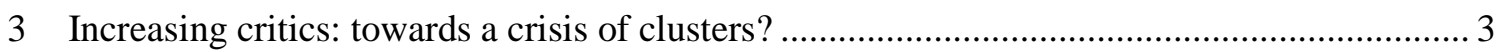

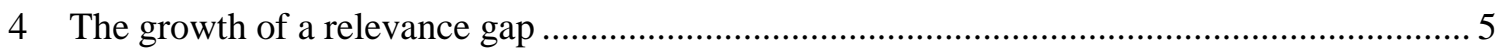

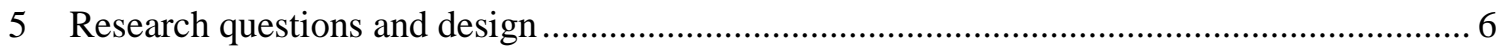

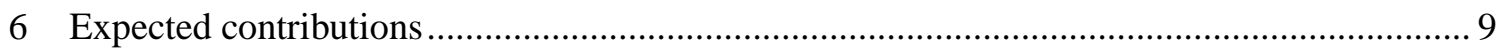

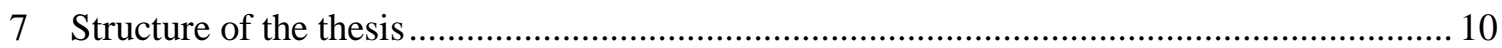

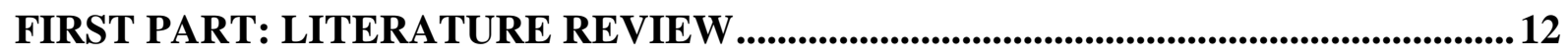

Chapter 1: An archaeology of cluster research ........................................................ 13

1 Economic growth: the knowledge and institutional turns ..................................................... 15

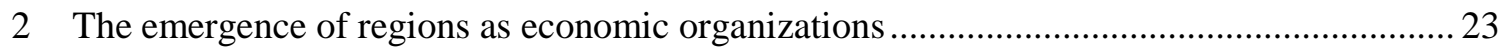

3 The rise of (regional) competitive advantage ..................................................................... 41

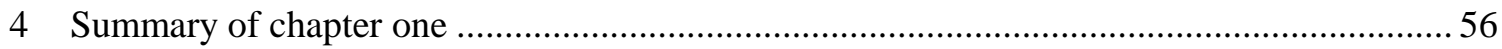

Chapter 2: Dilemmas and pathologies in policy-driven clusters .................................59

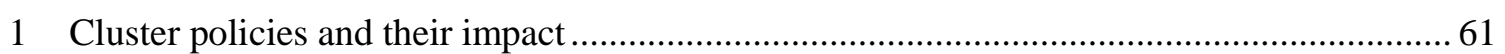

2 Identifying cluster dilemmas \& pathologies: a systematic review ......................................... 71

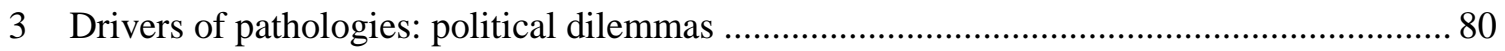

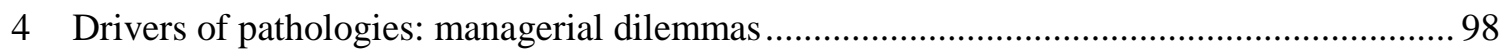

5 Drivers of pathologies: structural dilemmas ..................................................................... 123

6 Summary of chapter two: overview of organisational dilemmas ......................................... 132

Chapter 3: Literature gap and problem statement ........................................................ 135

SECOND PART: RESEARCH DESIGN AND EMPIRICAL CONTEXT ....................139

Chapter 4: Research design ............................................................................................. 140

1 Using a "case study" approach: justification and usefulness .............................................. 141

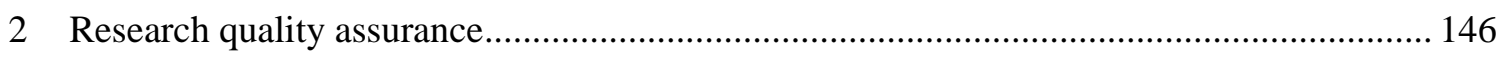

Chapter 5: Cluster policies in Europe: complexification and saturation................... 162

1 European Union and the saturation of cluster policies .......................................................... 163

2 France and cluster policies: traditions and renewal.......................................................... 170

Chapter 6: The case of the French "competitiveness cluster" policy ........................... 181 
1 The specificities of the French "competitiveness cluster" policy.......................................... 182

2 Policy-driven clusters in the Paris Region ............................................................................. 194

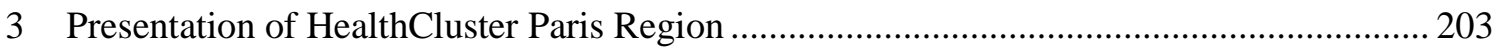

THIRD PART: EMPIRICAL CASE STUDY - RESULTS \& DISCUSSION................ 210

Chapter 7: HCPR's governance: facing dilemmas \& developing pathologies .......... 211

1 Defining objectives, a difficult task: HCPR's performance contract ....................................2 212

2 Managing the ecosystem: A cluster stuck in organisational dilemmas? .............................. 224

Chapter 8: Which role does HCPR play in the set-up of R\&D projects? ................ 246

1 Overview of ICT \& Health project leaders and their organisations ..................................... 248

2 Finding subsidies: Being friend and judge - a schizophrenic situation ................................ 258

3 Finding partners: "Las Vegas" weddings thanks to "Meetic"............................................... 273

4 Finding ideas: Doctors can't be find at "Meetic" events.......................................................... 306

Chapter 9: Discussion: how dilemmas drove cluster pathologies in HCPR .............. 320

1 The identification of HCPR's four side-effect pathologies ..................................................... 323

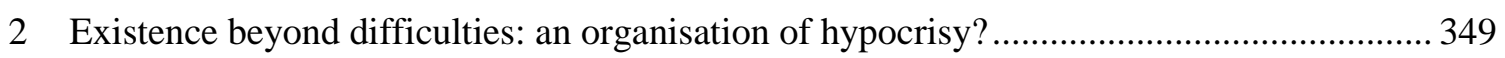

3 Enriching the "management model" of cluster policy evaluations .........................................352

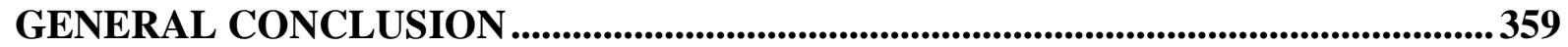

1 Theoretical, methodological and managerial contributions .................................................. 359

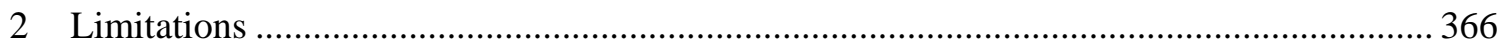

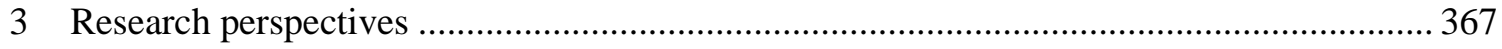

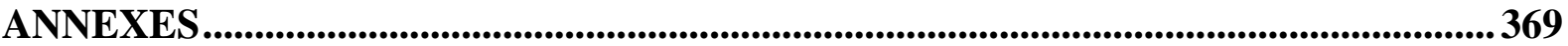

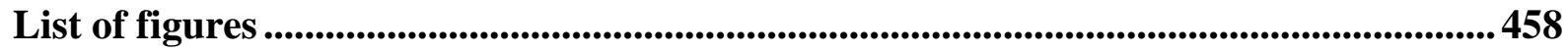

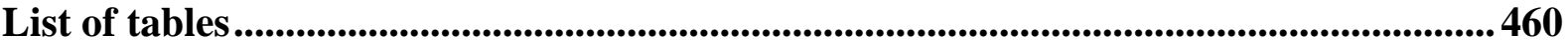

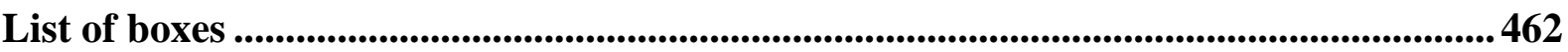

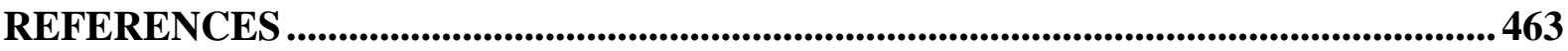

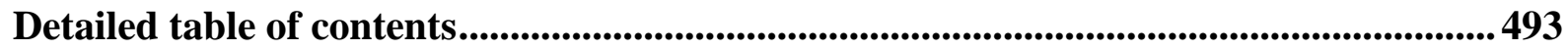




\section{GENERAL INTRODUCTION}

\section{Cluster: the (new) buzzword}

The academic cluster literature started to intensify during the 1990s, and literally exploded in the beginning of the $21^{\text {st }}$ century (Cruz \& Teixeira, 2009). The birthplace of the cluster policy fashion in the literature (Porter, 1998c) and among governments (OECD, 1999, 2009; Sölvell, Lindqvist, \& Ketels, 2003) can though be traced back to the 1980s. The 1980s experienced three important shifts of thought. First, the period experienced a shift from neoclassical (exogenous) economic growth models (Solow, 1956, 1957; Swan, 1956) to endogenous economic growth models (Lucas, 1988; Romer, 1986). Economic growth was no longer only explained by labour and capital accumulation but also by knowledge accumulation. Additionally, an increased role was attributed to institutions for fostering economic growth. Second, the period experienced a shift from a mass production era, where the region did not play an important role, to a post-mass production era, where the region played an important role (Storper, 1997). The region was increasingly considered as a crucial element where flexible specialization takes place (Christopherson \& Storper, 1986; Piore \& Sabel, 1984; Storper \& Christopherson, 1987) and where embedded actors (Granovetter, 1985) have a higher capacity for innovation and knowledge acquisition (Aydalot, 1986; Aydalot \& Keeble, 1988; Jaffe, 1986; Oakey, 1984). Finally, the concept of comparative advantage (Ohlin, 1933; Ricardo, 1817 (1821)), for a long time used to explain national success, was increasingly criticised by Porter (1990). Porter (1990) developed the concept of competitive advantage explaining that every nation or region goes through different development stages which can be influenced by government authorities. The large diffusion of the concept of "cluster" will be analysed in the first part of this thesis through an "archeological" analysis of the notion.

These shifts of thoughts, embedded in an increased global competition, led policy makers to take example on highly successful regions. The two regions that were particularly scrutinized are the Third Italy in Emilia-Romagna (Italy) (Becattini, 1979; Capecchi, 1990; Putnam, 1993; Trigilia, 1986) and Silicon Valley in California (USA) (Miller \& Cote, 1985; Rogers \& Larsen, 1984; Saxenian, 1983, 1990, 1991, 1994; T. Weil, 2010). Scholars and governments started to reflect on how to "grow" (Miller \& Cote, 1985), "breed" (DeBresson, 1989), or "clone" (D. Rosenberg, 2002) these successful regions so that every nation could have its competitive hub. 
The objective during the 1990s was to decorticate the natural conditions of "spontaneous clusters" to be able to create "policy-driven clusters" (Chiaroni \& Chiesa, 2006). In policydriven clusters, there is a "strong commitment of governmental actors whose willingness [is] to set the conditions for the development of the [...] cluster" (Chiaroni \& Chiesa, 2006, p. 1073). The real breakthrough of the cluster idea and that governments can take the faith of their regions in their hands, came with the publication of Porter's seminal work on clusters (Porter, 1998b, 1998c). Porter (1998c, p. 78) who scrutinized in detail a multitude of "healthy regions" in the United States summarized that these healthy regions or "clusters" are "geographic concentrations of interconnected companies and institutions in a particular field." Additionally, "many clusters include governmental and other institutions [...] that provide specialized training, education, information, research and technical support" (Porter, 1998c, p. 78). Porter (1998c, p. 79) established mappings of these healthy regions and called it "the anatomy" of a cluster that governments could strive for.

\section{The rising implementation of cluster policies}

Using the cluster approach (Porter, 1998c) to foster a country's competitiveness started to emerge during the 1990s and since then the approach experienced a considerable entry into the policy realm, be it for example in Europe (Ahedo, 2004; Fromhold-Eisebith \& Eisebith, 2005; Gallié, Glaser, Mérindol, \& Weil, 2013b; Lefebvre, 2013), America (Altenburg \& Meyer-Stamer, 1999; Arthurs, Cassidy, Davis, \& Wolfe, 2009; Ciravegna, 2012; Doloreux \& Shearmur, 2009), Asia (Nishimura \& Okamuro, 2011a, 2011b) or Africa (Cammett, 2007). The cluster policy approach combines under one header traditionally separated policies, such as regional, science \& technology and industrial policies (OECD, 2007).

The specificities of cluster policy approach appear to be the following;

- compared to the traditional science \& technology policy approach, cluster policy does not focus on financing individual single sector projects but on financing collaborative research (OECD, 2007);

- compared to the traditional industrial policy approach, cluster policy does not focus on national champions but on supporting common needs of firm groups, particularly the needs of SMEs (OECD, 2007); 
- compared to the regional policy approach, cluster policy does not redistribute from leading to lagging regions but tries to build competitive regions by fostering networks among local actors (OECD, 2007).

Cluster policies try to build policy-driven clusters (Chiaroni \& Chiesa, 2006) by fostering networks among local actors. This particularly happens through financing collaborative research and supporting common needs of local firm groups (Nishimura \& Okamuro, 2011b; Sölvell, et al., 2003). The objective of cluster policies is to transform agglomerations of noninterconnected local actors into "functioning" policy-driven clusters where local actors are interconnected and innovate together. In fine, this process is supposed to be leading to a greater competitiveness of the individual actors and the whole region (Schmiedeberg, 2010).

In order to replicate conditions of spontaneous clusters and start building policy-driven clusters, government authorities establish cluster organisations employing cluster managers (Coletti, 2010). Two recent studies underline that one of the most important elements of these cluster organisation managers is to foster networks among people and firms (Coletti, 2010; Sölvell, et al., 2003). The tasks of these managers embrace for example "fostering exchanges between cluster members [...], networking with stakeholders, lobbying, identifying and integrating new cluster members, strategy development for the cluster [...], organising events" (Coletti, 2010, p. 685).

\section{$3 \quad$ Increasing critics: towards a crisis of clusters?}

Numerous governments around the world have implemented cluster policies (Sölvell, 2008; Sölvell, et al., 2003) and the European Union has put cluster policies to advance innovations in Europe at the centre of its strategy recommendations (European Commission, 2006), as knowledge management is considered as crucial (Saussois, 2000). Europe currently counts approximately 1205 cluster organisations ${ }^{13}$. However, there has been recently an increasing amount of academic literature that has a very critical stance regarding the positive impact of cluster policies and how they are implemented (Hospers, 2005; Kiese \& Wrobel, 2011; Shearmur, 2011a). The critics of the academics are of multiple nature:

- Shaky theoretical basis: Several academics criticise that government authorities have rushed ahead with implementing cluster policies based on the ideas of Michael Porter

\footnotetext{
${ }^{13}$ European Cluster Observatory: www.clusterobservatory.eu (2010)
} 
(1990 (1998), 1998c) even though the cluster concept in itself continues to stay on a very shaky theoretical ground (Kiese \& Wrobel, 2011; R. Martin \& Sunley, 2003; Nathan \& Overman, 2013);

- Multiplication of objectives, closed system thinking and disconnection to local specificities: Some other predominant critics are for example that cluster policies combine too many different objectives (Burfitt \& Macneill, 2008), that governments consider the region as a closed system (H. Bathelt \& Dewald, 2008; Rugman, 1992; Shearmur, 2011a), or that best practice examples serve as role models and are then implemented in regions without taking into account the specific local characteristics (Eklinder-Frick, Eriksson, \& Hallén, 2014; Hospers, 2005; G.-J. Hospers, P. Desrochers, \& F. Sautet, 2009);

- High entanglement of actors. Policy-driven clusters are highly complex because there exists an entanglement of different action spaces (for example governments, policydriven cluster managers, policy-driven cluster members) with different views (Brachert, Titze, \& Kubis, 2011; Kiese \& Wrobel, 2011; Sellar, Emilova, PetkovaTancheva, \& Mcneil, 2011; Steinle, Schiele, \& Mietzner, 2007; T. Weil \& Fen Chong, 2009). This complexity leads some other authors to argue that the outcome of policydriven clusters cannot be "manipulated" and thus a better approach would be to abandon cluster policies altogether and to focus instead on "agglomeration policies" (Nathan \& Overman, 2013, p. 397).

While practitioners implemented cluster policies, academics have not yet fully embraced an analysis of these implementation processes. Scholars continued studying the characteristics of clusters, by for example focusing on clusters' life cycle (Audretsch \& Feldman, 1996; Bergman, 2008; Menzel \& Fornahl, 2010), on clusters' internal structure (Morrison \& Rabellotti, 2009; Salman \& Saives, 2005), on clusters' internal vs. external relations (Harald Bathelt, Malmberg, \& Maskell, 2004; Boschma \& Ter Wal, 2007; Huggins \& Johnston, 2010; Lechner \& Dowling, 2003; Maskell, Bathelt, \& Malmberg, 2006), on clusters' network facilitators (Ingstrup, 2010; McEvily \& Zaheer, 2004; Mesquita, 2007), or the importance of trust between actors in clusters (Cooke, 1996; Cooke \& Wills, 1999; MacKinnon, Chapman, \& Cumbers, 2004; Murphy, 2006; Ottati, 1994). However, they somehow seem to ignore the rise of the managerial issues that went along with the implementation of cluster policies. Be it for example the managerial issues regarding fostering innovation (Lefebvre, 2013), regarding implementing the cluster policy (Burfitt, Macneill, \& Gibney, 2007), or evaluating the cluster 
policy (Gallié, et al., 2014). This doctoral dissertation aims at taking these managerial and organisationnal challenges into account.

\section{The growth of a relevance gap}

The consequence of this drift between academics and practitioners is the progressive constitution of a "relevance gap", i.e. a growing alienation between academics and practitioners (Kiese \& Wrobel, 2011; R. Martin \& Sunley, 2003). This leads to the paradox situation that even though "libraries of incredibly useful books and articles on clusters" exists (Swords, 2013, p. 369), they seem not to be focusing on the challenges practitioners face when actually building policy-driven clusters. As we will demonstrate in our literature review, cluster literature mostly continues describing how a cluster looks like. Swords (2013, p. 369) recently pointed to the problem that "the translation of clusters into, and then through local and national policy" is not studied in the cluster literature. In the same stream of research, Ebbekink \& Lagendijk (2013, p. 737) point to the fact that scholars have to start investigating “cluster policy as a policy challenge”.

The academic community somehow still tries to define what a cluster is and what the conceptual differences are between clusters and similar concepts such as global, national, regional, sectoral or 'combined"14 innovation systems (Asheim, Smith, \& Oughton, 2011; Edquist, 2001; Niosi, 2011). The plenary debate of the 2013 DRUID conference even raised the polemic question ${ }^{15}$ if the systems of innovation (SI) approach is still a promising line of research. We will argue in this doctoral dissertation that the cluster and SI approach is more than ever a promising line of research but has lost track of its most basic elements: the practitioners on the field who try to put the theoretical cluster concept, mainly Porter's cluster concept (McDonald, Huang, Tsagdis, \& Tüselmann, 2007), into action. Governments around the world heavily used and still use the various cluster and SI approaches to frame their innovation policies (Edquist, 2005). Abandoning the research on clusters and SIs would be like abandoning en route all the authorities and governments that believed in these concepts and consequently invested a considerable amount of public money ${ }^{16}$.

\footnotetext{
${ }^{14}$ For Edquist (2001), a combined system corresponds for example to a sectoral and regional innovation system, which according to him relates for example to the cluster concept of Porter (1998c).

${ }^{15}$ Source (10/02/2013): http://druid8.sit.aau.dk/registrant/index/login/cid/13

${ }^{16}$ For example, the French government invested 3 billion Euros in its competitiveness cluster policy between 2005 and 2011 and the Walloon government plans to invest 618 million Euros in its cluster policy between 2006 and 2014.
} 
The multitude of components constituting the clusters and $\mathrm{SI}^{17}$ (Edquist, 2001, 2005), the endless range of activities that influence the development, the diffusion and use of innovation $^{18}$ (see Edquist, 2005, p. 191 for a complete list), the boundless quantity of observable relations among components and between components and activities ${ }^{19}$ (Edquist, 2005), and the multitude of different stakeholders involved (e.g. public authorities, policydriven cluster managers, policy-driven cluster beneficiaries) make the cluster and SI approach look like a conceptual "monster" where one does not know which element to prioritise. Instead of getting absorbed into this academic whirl of concepts and relations, and thus developing ivory-tower theories that risk not helping policy makers at all, we emphasise in this thesis a return to the practitioners in clusters and SI and the identification of the dilemmas they face when trying to build policy-driven clusters.

\section{$5 \quad$ Research questions and design}

The critics regarding policy-driven clusters are rising over the last years. Yet, it is still necessary to understand deeper the drivers of these critics as well as to address them in a constructive manner in order to help the practitioners on the field overcome their difficulties. When scrutinizing the policy-driven cluster literature, we will demonstrate that governments constantly face a multitude of cornelian dilemmas, i.e. a set of decisions and choices for which there is no "one best choice". They have to decide upon these dilemmas without knowing if in fine the decision taken will really lead to the development of a policy-driven cluster that gains international visibility and competitive advantage. For example during the set-up phase, those that implement cluster policies have to decide if they privilege direct subsidies or indirect subsidies (Nishimura \& Okamuro, 2011b), if they focus on regional development or industrial excellence (T. Weil \& Fen Chong, 2008; Younès, 2011), if they implement a policy-driven cluster organisation at national or at local level (Burfitt \& Macneill, 2008; Perry, 2005).

\footnotetext{
${ }^{17}$ Organisations (i.e. the players or actors as for example companies, universities, venture capital organisations and public innovation policy agencies institutions) and institutions (i.e. the rules of the game as for example the legal system, norms, routines standards)

${ }^{18}$ For example R\&D, competence building, formation of new product markets, incubating, financing

${ }^{19}$ For example between organisations (competition, transaction, networking) or between organisations and institutions (the influence of institutions on organisations, the organisational embeddedness in the institutional environment)
} 
In this thesis, we will study these organisational dilemmas and their consequences in policydriven clusters. Facing a dilemma means that there is no "one best choice", so by going in one direction one certainly produces also negative effects, or side-effect pathologies, that in some cases might hinder the policy-driven cluster to function effectively. We will define "pathology" in a cluster setting as the visible managerial symptoms that policy-driven clusters may endure. These pathologies are directly generated by "organizational dilemmas", by having privileged one direction over another. The challenge in cluster policy study is to pinpoint these side-effect pathologies and their associated dilemmas in order to improve cluster policy implementation and to better adapt the cluster policy to the local settings. In this thesis, we will not give an answer to whether one dilemma direction or another is better. Instead, we will first summarize and establish a taxonomy of the different dilemmas that we identified in the literature, by using a systematic literature review (SLR) methodology (Denyer \& Neely, 2004; Pittaway, Robertson, Munir, Denyer, \& Neely, 2004; Tranfield, Denyer, \& Smart, 2003). Second, we will empirically analyse the extent to which these dilemmas produce organisational pathologies in a French policy-driven cluster situated in the Paris Region: the HealthCluster Paris Region (HCPR $)^{20}$ is analysed in the second part of this doctoral dissertation.

HCPR is a policy-driven cluster that consecutively received a low performance evaluation, from national cluster policy evaluators (CMI \& BCG, 2008; Erdyn, Technopolis, \& BearingPoint, 2012) but also from academics (Bonnafous-Boucher \& Saussois, 2010). HCPR thus represents an "extreme case" (Eisenhardt, 1989; Flyvbjerg, 2006) in the cluster landscape, a case of a pathologic policy-driven cluster. This pathologic case allows, in a Popperian falsification tradition, to look at a "black swan" and to start a new critical reflection process (Flyvbjerg, 2006, p. 228; Popper, 1959) on how a policy-driven cluster works and which pathologies it might produce. As HCPR is an extreme case, we see the pathologies through a magnifying glass. There are numerous policy-driven clusters in France that seem to encounter much less difficulties (the "white swans") (see for example (Bidan \& DhermentFérère, 2009; Chabault, 2008; Retour, 2009b; Therme, 2008)) than HCPR. The knowledge gained through the in-depth analysis of cluster pathologies in an extreme case will prove to be precious, because it will help us rethink how a policy-driven cluster actually works and what can be improved during the management of the implementation and evaluation processes.

\footnotetext{
${ }^{20}$ Name changed.
} 
We study HCPR by using a case study methodology (Eisenhardt \& Graebner, 2007; Flyvbjerg, 2006; Yin, 2009) that combines observation, interviews, documents and archival data. Even though we were continually embedded and confronted with our cluster policy fieldwork (as we will explain in the research design chapter), we had two main qualitative fieldwork periods. The first main qualitative fieldwork period took place between September 2010 and January 2011, and the second main fieldwork period took place between November 2011 and March 2012. Using a longitudinal approach in case studies (Eisenhardt \& Graebner, 2007; Leonard-Barton, 1990) is particularly recommended when operating in nascent research fields (Edmondson \& McManus, 2007), as it is the case for cluster policy implementation and the study of its challenges. The methodological issues and details processes for data collection and analysis will be presented in chapter 4 .

Overall, we will argue in this thesis that it is necessary to shift from the sole study of the "anatomy of clusters" (Porter, 1998c) to the deeper study of "pathology of clusters". The traditional static cluster approach has become a dynamic approach with organisational dilemmas (see Figure 1). The thesis that we defend in this doctoral dissertation can be formulated as follows:

Implementing cluster policies produce organisational dilemmas that generate sideeffect pathologies.

And we defined three associated Research Questions (RQs):

RQ1: What are the organisational dilemmas that can be observed in the implementation of the French cluster policy (the case of HCPR)?

RQ2: To which extend do these organisational dilemmas generate side-effect pathologies?

RQ3: How can the knowledge of these pathologies benefit to cluster policy (implementation and evaluation)? 
Figure 1: Problem statement and Research Questions

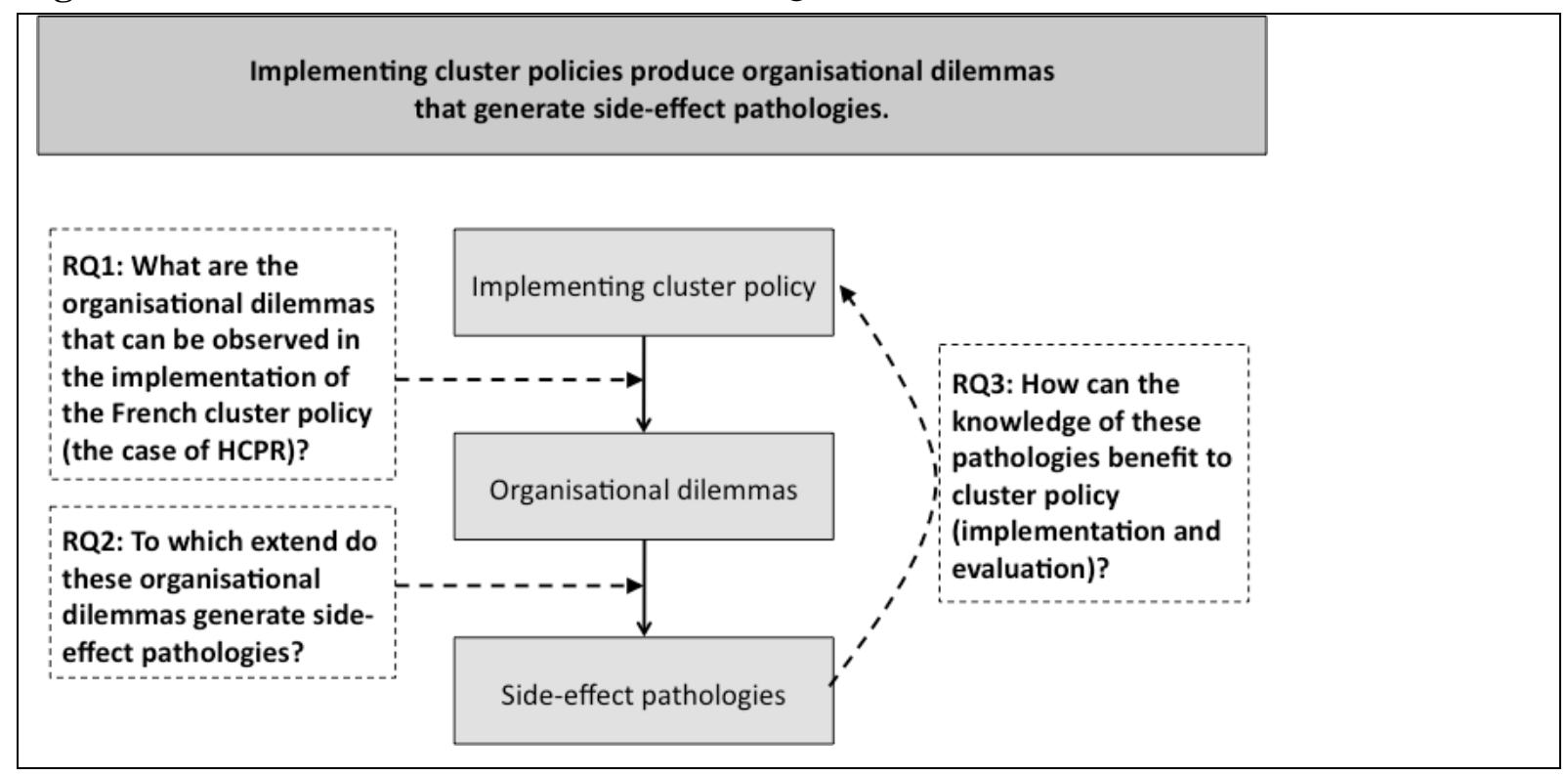

\section{Expected contributions}

This thesis is expected to make several theoretical, methodological and managerial contributions.

Expected theoretical contributions: We wish to contribute to the new critical line of research that urges academics to start focusing on the dilemmas of policy driven-clusters that emerge when transforming the theoretical cluster concept into the policy realm (Burfitt \& Macneill, 2008; Burfitt, et al., 2007; Ebbekink \& Lagendijk, 2013; Swords, 2013). We wish to contribute to the cluster policy literature by first establishing a taxonomy of potential cluster dilemmas and second by identifying the caused pathologies. Second, by studying a pathogenic case, we offer the academic community a look at an extreme case that will help rethinking how a policy-driven cluster works, can be better implemented and evaluated. The studies of "black swans" are particularly important to get new scientific conversations going (Flyvbjerg, 2006).

Expected methodological contribution: We wish to contribute to the study of policy-driven clusters from different angles. Previous research has already shown that policy-driven clusters have highly entangled actors (T. Weil \& Fen Chong, 2009) with competing strategic objectives (Brachert, et al., 2011; Kiese \& Wrobel, 2011; Sellar, et al., 2011; Steinle, et al., 2007). Our case study set-up will allow us to study HCPR from different angles (for example 
the operational team, the cluster members, or other policy-driven clusters of the region). Second, we also wish to contribute to the systematic literature review (SLR) methodology (Denyer \& Neely, 2004; Pittaway, et al., 2004; Tranfield, et al., 2003) that will be used in this thesis to scan the cluster policy literature in order to frame the literature of a nascent field.

Expected managerial contribution: We wish to contribute to the cluster policy evaluation literature (Bellandi \& Caloffi, 2010b; Diez, 2001; Gallié, et al., 2012; Raines, 2003; Schmiedeberg, 2010; Sölvell \& Williams, 2013), by focusing on the study of cluster organisation effectiveness (Gallié, et al., 2014). We wish to improve the evaluations that take an "in the action" (Chanut, 2009) cluster policy evaluation approach. We hope to improve the methodology and indicators of cluster policy evaluations by pinpointing the different dilemmas of policy-driven clusters and the potential pathologies that emerge. The thesis wishes to contribute to the "management model" of cluster policy evaluations (Gallié, et al., 2014). On the other hand, we wish to contribute to the cluster policy implementation field (Burfitt, et al., 2007; Foray, David, \& Hall, 2011; Nauwelaers, 2001). We will summarize the different implementation dilemmas to help the ones who implement policy-driven clusters to structure their reflections in a more systematic manner.

\section{$7 \quad$ Structure of the thesis}

Figure 2 presents the structure of the thesis, divided in three parts and nine chapters. 
Figure 2: Structure of thesis

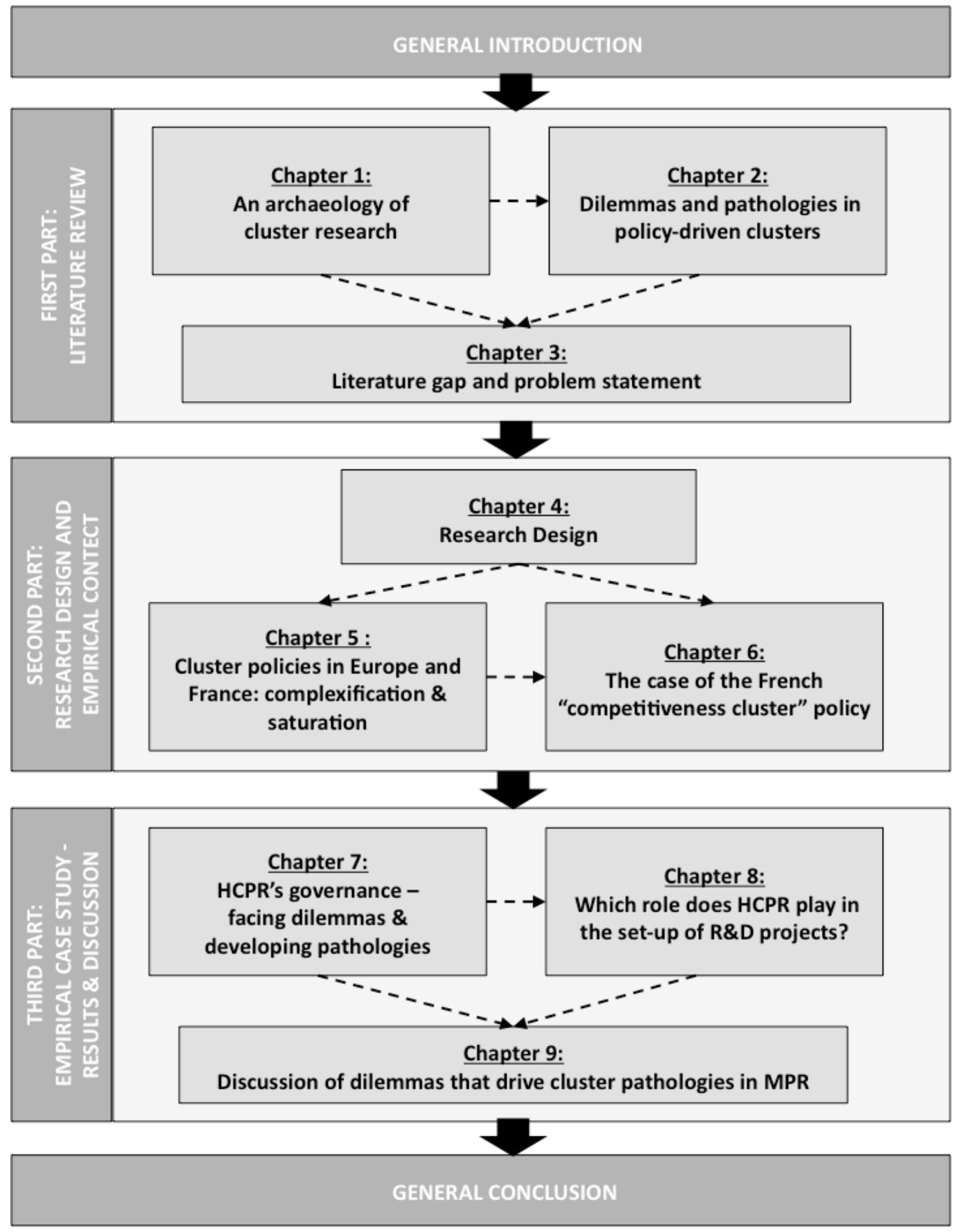




\section{FIRST PART: LITERATURE REVIEW}

This literature review is split in three chapters. In the first chapter, we embed this research in an historical context, in order to highlight genealogies of the "cluster" notion. In the second chapter, we focus on the most recent academic literature on clusters and particularly on the cluster-policy literature: this allows us to review the dilemmas encountered when implementing cluster policies. In the third and final chapter of this literature review, we identify research gaps and formulate the research questions that are empirically tested in this thesis.

We use two different types of methodologies to conduct this literature review. In the first chapter, we mostly conduct a descriptive and narrative literature review as traditionally done in the business and management fields (Denyer \& Neely, 2004). According to Denyer \& Neely (2004, p. 133) this type of literature review, if done wisely, "can provide the reader with an overview of the different perspectives in a field of study, including its key methodological and theoretical traditions." However, this type of literature review, when done poorly, also "run the risk of only reflecting the reviewer's perspective or position" (Denyer \& Neely, 2004, p. 133).

In the second chapter, focusing on the cluster policy literature, we apply a more systematic literature review (SLR) methodology (Leseure, Bauer, Birdi, Neely, \& Denyer, 2004a; Pittaway \& Cope, 2007; Pittaway, et al., 2004; Thorpe, Holt, Macpherson, \& Pittaway, 2005; Tranfield, et al., 2003). The main difference between a traditional descriptive or narrative literature review and a SLR is that, in the latter, "the [investigation] process is reported openly in the same way that empirical research would be" (Pittaway, et al., 2004, p. 480). This exact description of the literature investigation process "should enable readers, whether academics, practitioners or policy-makers, to determine for themselves the reasonableness of the decisions taken and the appropriateness of the conclusions" (Denyer \& Neely, 2004, p. 133). We use a SLR approach to investigate the current state of the "cluster policy" research stream not only to overcome any type of critics that might be associated with a descriptive and narrative literature review, but also to render our literature review as useful as possible for further research on this topic. 


\section{Chapter 1: An archaeology of cluster research}

Cluster research started to intensify in the 1980s and then exploded in the 1990s. The following historical review not only allows us to understand the political and societal context of the period but also the paradigm changes that happened during this time. If we wish to better understand cluster research that started to intensify in the 1990s (see Figure 3) and then exploded with governments implementing cluster policies at the beginning of the $21^{\text {st }}$ century, it appears necessary to turn back the clock for 30 years and understand what happened during the 1980s. The events, discussions and publications of this period still heavily influence today's governments and policy decisions.

Hereinafter, we give a brief overview of some of the important cornerstones of this period: economic growth, region and competitive advantage. Undertaking this "archaeological" (Foucault, 1966 (1994)) work and discussing the general context that surrounded the birthplace of modern cluster research is all the more necessary as a cluster is a highly systemic research object. Researchers who are concentrated on a certain research object sometimes lose sight of why they are actually focusing on this particularly object. The object thus becomes a mere theoretical object, with little societal implications. A relevance gap emerges (Mesny \& Mailhot, 2012), something increasingly underlined by cluster policy scholars (Kiese \& Wrobel, 2011; R. Martin \& Sunley, 2003). However, cluster research was born out of a specific societal context and with the intent to perform a societal impact. If we wish to go forward in improving the currently adopted cluster policies around the world, we first have to understand again (and relearn) under which context cluster research intensified and cluster policies emerged. The following theoretical journey is a try to dismantle and analyse the "thought-styles" (Fleck, 1935 (1980)) of the 1980s in order to understand why cluster policies emerged. Even though we are now as well embedded in a certain "thoughtstyle" we will try to show that a certain shift happened during the last 30 years of cluster research and that we are now confronted with new challenges compared to the 1980s and 1990s. 
Figure 3: Evolution of the articles published on 'clusters' (1962-2007)

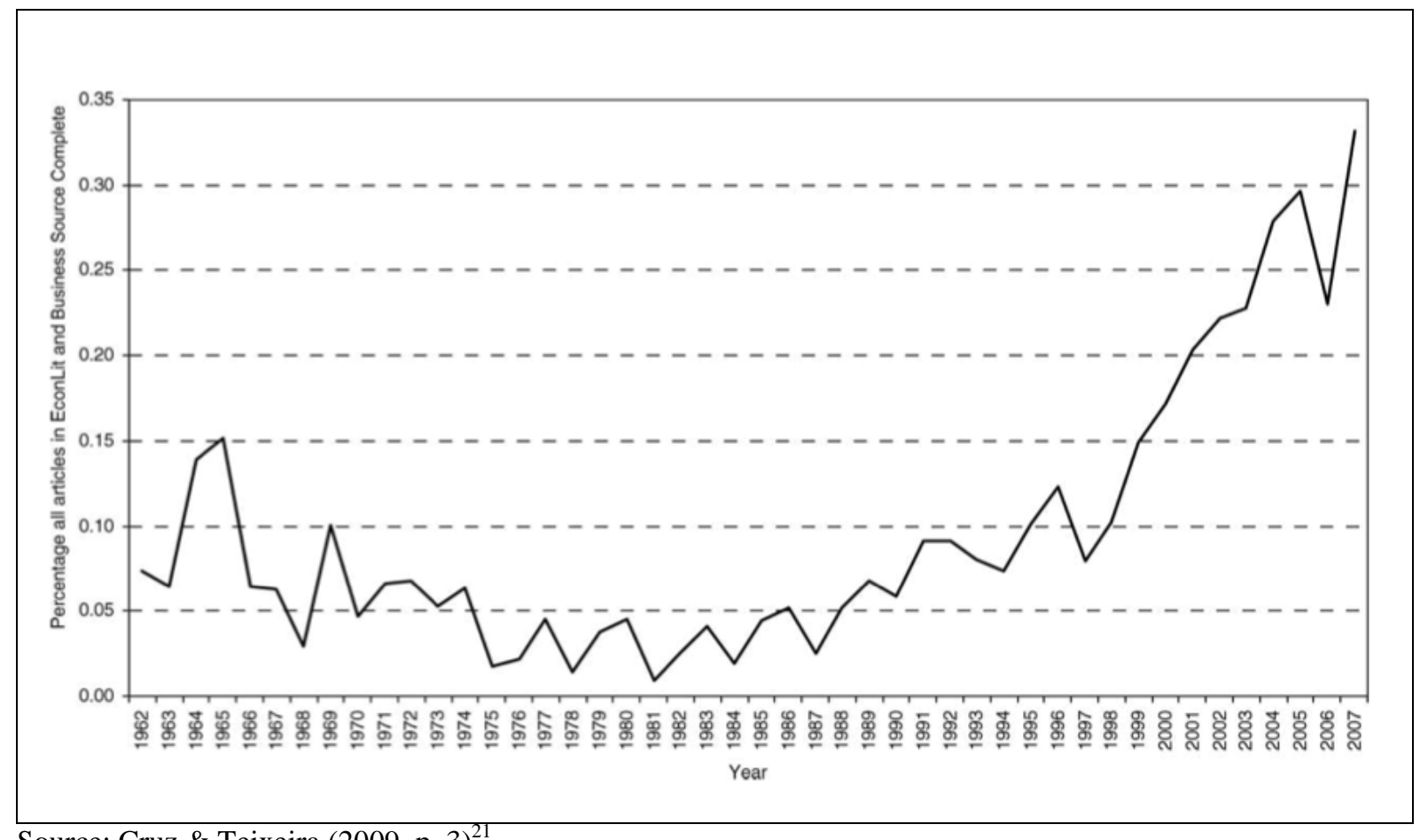

Source: Cruz \& Teixeira (2009, p. 3) $)^{21}$

\section{Box 2: Content of chapter one}

1 Economic growth: the knowledge and institutional turns .......................................15

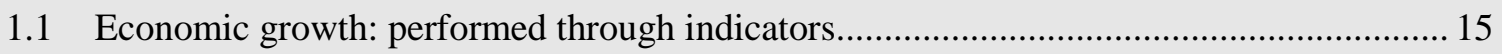

1.2 Economic growth models: from exogenous to endogenous ............................................ 16

1.3 Economic growth: the rising importance of institutions .............................................. 20

2 The emergence of regions as economic organizations.......................................................23

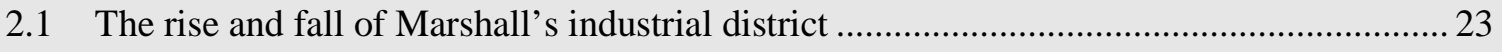

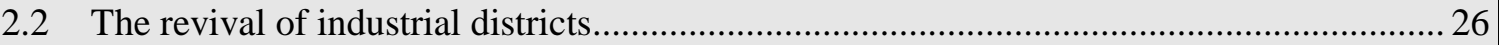

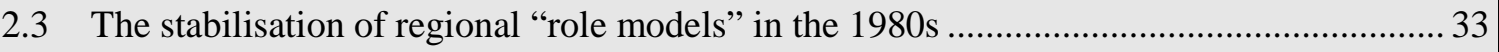

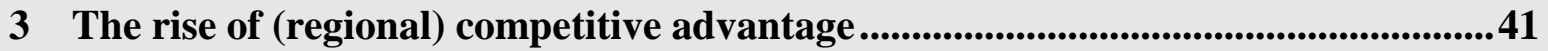

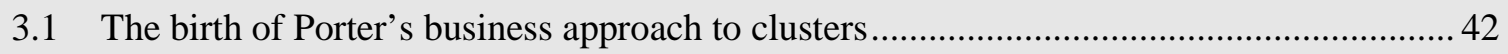

3.2 The competitive advantage of regions and nations ......................................................... 45

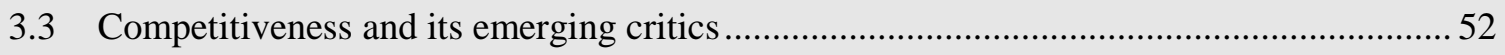

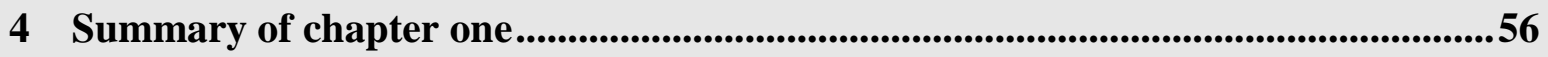

${ }^{21}$ ad Figure 3: Cruz \& Teixeira (2009, p. 3) conducted their search in Business Source Complete and EconLit databases (EBSCO), they identified 2940 relevant articles, they used following keywords: “cluster $\square$ and industry $\square$ (thus considering these words' derivations, such as clustering, clusterized, industrial, etc.), in addition to some of their close-to-synonymous concepts, namely agglomeration, external economies, spatial concentrations, and industrial districts" 


\section{Economic growth: the knowledge and institutional turns}

"Economic growth" is indeed a large and complex field of research ${ }^{22}$, and not the central object of our research. However, it is useful for management scholars interested in clusters to understand, at least schematically, the debates on economic growth - its indicators, theoretical models and the role of institutions - that emerged shortly before the "hype" of cluster research began in the 1990s, and that subsequently led to cluster policies implemented by governments around the world.

\subsection{Economic growth: performed through indicators}

When economists analyse the economic situation (or "healthiness") of a country, they look at annual changes of different macroeconomic variables as for example household consumption, export rate, import rate, private consumption, government's financial balance, etc. (Lequiller \& Blades, 2006). However, the most important indicator economist look at is the gross domestic product (GDP) and its variations from one period to the next. ${ }^{23}$

For now exactly 70 years ${ }^{24}$, governments around the world constantly strive to increase their $\mathrm{GDP}^{25}$. In order to increase a country's GDP, government authorities have to find the "right" policies to positively stimulate the economic actors and consequently their outcomes. Theories that explain what leads to economic growth, measured by GDP increase, vary over time and, as we will see hereinafter, generally stay vague. A Harvard economist recently said that economic growth remains a mystery: "What makes some countries rich and others poor? Economists have asked this question since the days of Adam Smith. Yet after more than two hundred years, the mystery of economic growth has not been solved" (Helpman, 2004, p. ix).

\footnotetext{
${ }^{22}$ In case the reader is not an economist and a novice to economic growth theories, but interested in deepening its knowledge about it, we can recommend following readings: the undergraduate textbook of economic growth by Weil (2012), the graduate textbook of economic growth by Barro \& Sala-i-Martin (2003) and the handbook of economic growth by Aghion \& Durlauf $(2005,2014)$.

23 "GDP combines in a single figure, and with no double counting, all the output (or production) carried out by all the firms, non-profit institutions, government bodies and households in a given country during a given period, regardless of the type of goods and services produced, provided that the production takes place within the country's economic territory." (Lequiller \& Blades, 2006, p. 15)

${ }^{24}$ In 1934, Simon Kuznets (the chief architect of the United States national accounting system) presented the newly developed GDP measure to the American Congress. In 1944, exactly ten years later, leaders of the allied nations reunited in Bretton Woods and decided to use the GDP as the primary measure for economic growth (Costanza, Hart, Talberth, \& Posner, 2009).

${ }^{25}$ We will not discuss in this thesis if the GDP is the right indicator to measure the "healthiness" of a country. See for example Costanza et al (2009) for an informative discussion on this subject.
} 
Economic growth theories only enter reality when they are somehow "performed" by countries, governments and economic actors. However, every country is different so that economic theories, developed on an aggregate level, might turn out differently on the field. Lucas (1988, p. 41) formulated it this way "[...] there is no one pattern of growth to which all economies conform, so a useful theory needs also to capture some forces for change in these patterns, and a mechanics that permits these forces to operate." In other words, economic growth and all policy measures that go along with it are constantly confronted to our "bounded rationality" (Simon, 1955) which limits us to find the "absolute truth" and only allows us to find the best solution under particular circumstances.

\subsection{Economic growth models: from exogenous to endogenous}

Economic growth theories generally follow the curve of a life cycle: they are born, they experience growth and a peak period, before they start declining again to ultimately being replaced by "better" growth theories (but sometimes growth theories also experience revivals) (for a discussion of the different waves see for example Barro \& Sala-i-Martin, 2003; Helpman, 2004; Maier \& Tödtling, 2002; Snowdon, 2006). During the peak period of an economic growth theory, the academic community particularly concentrates on a few mainstream models until an alternative theory gains enough momentum to start a new cycle, putting a new economic growth model in the centre of attention. Starting a new wave is a difficult endeavour as following retrospective reflection of one of the fathers, Paul M. Romer, of a new wave trying to introduce knowledge into the models shows:

\footnotetext{
"My greatest regret is the shift I made while working on these external effects models, a shift that took me away from the emphasis on research and knowledge [...] I am now critical of this work, and I accept part of the blame. Looking back, I suspect that I made this shift toward capital and away from knowledge partly in an attempt to conform to the norms of what constituted convincing empirical work in macroeconomics. No international agency publishes data series on the local production of knowledge and inward flows of knowledge. If you want to run regressions, investment in physical capital is a variable that you can use, so use it I did. I wish I had stuck to my guns about the importance of evidence [...]." (Romer, 1994, p. 20)
}

Hereinafter, we focus on two important economic growth paradigms that managed to impose their worldviews on the academic community. The two waves under scrutiny happened during the second half of the $20^{\text {th }}$ century: the neoclassical growth theories (also called exogenous growth theories) mainly stimulated by Robert M. Solow $(1956,1957)$ and Trevor W. Swan (1956) in the middle of the 1950s, and 30 years later, the endogenous growth theories mainly stimulated by Paul M. Romer (1986) and Robert E. Lucas (1988). 


\subsubsection{The neoclassical (or exogenous) economic growth model}

In the neoclassical growth models there are three factors that contribute to the long-term growth of countries: capital accumulation, labour input, and technical progress (Maier \& Tödtling, 2002, p. 64). This means, that "sustained increase in real GNP ${ }^{26}$ must be due either to an increase in the quantity of capital and labor used in production or due to a more efficient use of these inputs (e.g., technical and/or organizational progress)" (Gilpin, 2001, p. 110). However, the neoclassical growth models do not put technical progress within the equation of the model (i.e. technical progress is not an endogen factor of the model), but they put technological progress outside of the model (i.e. technical progress is considered to be an exogenous factor of the model). This means, that for Solow (1956, 1957), "technology (unlike capital and labor) cannot be observed or measured directly" (Gilpin, 2001, p. 111), it is thus not part of the model but the residual of the equation.

The neoclassical growth theories are therefore unable to explain why economic change or innovation happens, the theory "assumes that progress in technology is produced by random scientific and technological breakthroughs" (Gilpin, 2001, p. 112). The incapacity of the model to explain the reasons for technical progress paired with the fact that Solow's model predicts declining growth rates in the long run ${ }^{27}$ "leads to the conclusion that government policies can do little to accelerate the long-term rate of economic growth" (Gilpin, 2001, p. 110).

This neoclassical (or exogenous) economic growth model dominated scientific thoughts from the 1950s up to the 1980s. According to Helpman (2004), there were some exceptions that tried to integrate explanations for technical progress into their models (for example Arrow (1962) or Uzawa (1965)) but for the majority of economists, technical progress stayed an exogenous factor of economic growth that cannot be manipulated intentionally.

\footnotetext{
${ }^{26}$ GNP means "Gross national product". However, GNP is no longer used and was replaced by GNI (or gross national income). As already discussed, "GDP measures the total production occurring within the territory", while "GNI measures the total income (excluding capital gains and losses) of all economic agents residing within the territory (households, firms and government institutions)." (Lequiller \& Blades, 2006, p. 18)

${ }^{27}$ Solow's model predicts declining growth rates in the long run. The model assumes thus that in the end all nations will converge to the same level of development
} 


\subsubsection{The endogenous economic growth model}

What happened in the 1980s? Snowdon (2006, pp. 81-83) lists a whole list of possible reasons why economists finally accepted an endogenous economic growth model, that considers technical change as an internal factor and not as an external residual. Snowdon (2006, p. 82) mentions for example that there was an increasing awareness that developing countries did not seem to catch up with developed countries (something they were meant to do according to the neoclassical model), the availability of new data sets, the collapse of the Soviet Union, as well as other reasons.

Romer (1986) and Lucas (1988) initiated a considerable revival of interest in economic growth theories by introducing endogenous economic growth models that were finally accepted by the academic community. Hereinafter, a very simplistic summary of the new approach:

"[...] the new theory incorporates technological progress and advances in knowledge as
endogenous factors within the growth model. Technological advance is considered endogenous
because technological innovations are the result of conscious investment decisions taken by
entrepreneurs and individual firms. Firms are assumed to invest in research and development
activities for the same reasons that they invest in other factors of production; that is, on the
basis of the expected profitability of the investment. In effect, the new growth theory assumes
that knowledge, technology, and/or "know-how" constitute a separate factor of production in
addition to capital and labour" (Gilpin, 2001, pp. 112-113).

Knowledge is thus only considered as an "official" economic factor, leading to economic growth, for little less than 30 years.

\section{Knowledge as a factor of production}

The first major revolution that endogenous growth theories initiated was the integration of knowledge as a third factor, next to capital and labour, in their economic growth models. Lucas (1988) for example based its argumentation heavily on the works of Jane Jacobs (1961, 1969). Jane Jacobs observed the city like an anthropologist and illustrated with a multitude of examples what happens on the sidewalks, parks, or public spaces of cities. She gives a very thick and detailed description of how a city works and her work was and still is a crucial masterpiece for community and urban planners. The reason why Lucas (1988) comes back to the works of Jacobs is because she describes in a very illustrative manner how information and knowledge is transported in a city. Jacobs (1961) credits this knowledge flow in the city to the multitude of public characters, i.e. "anyone who is in frequent contact with a wide circle of people and who is sufficiently interested to make himself a public character" 
(Jacobs, 1961, pp. 89-90). These public characters live and work within a city's boundary and it is through these public characters that information travels easily: "his main qualification is that he is public, that he talks to lots of different people. In this way, news travels that is of sidewalk interest” (Jacobs, 1961, pp. 89-90).

Lucas (1988) thus picks up the ideas and observations of Jacobs and integrates them into his economic growth models. For him, capital and labour alone can no longer explain why cities exist. He argues that if we consider that economic actors act in a rational manner, then they would have no reason to stay somewhere where land is more expansive than somewhere else. So for Lucas (1988) there must be another explanation why economic actors stay within the city and this explanation is the knowledge gain one can earn in a city compared to when being outside of a city:

\begin{abstract}
"If we postulate only the usual list of economic forces, cities should fly apart. The theory of production contains nothing to hold a city together. A city is simply a collection of factors of production - capital, people and land - and land is always far cheaper outside cities than inside. Why don't capital and people move outside, combining themselves with cheaper land and thereby increasing profits? [...]. Cities are centered on wholesale trade and primary producers, and a theory that accounts for their existence has to explain why these producers are apparently choosing high rather than low cost modes of operation. It seems to me that the 'force' we need to postulate account for the central role of cities in economic life is of exactly the same character as the 'external human capital' I have postulated as a force to account for certain features of aggregative development." (Lucas, 1988, pp. 38-39)
\end{abstract}

Investments in knowledge thus play an important role because the more a firm invests in knowledge, the more knowledge will circulate between the economic actors at a certain location. When a firm invests in knowledge, Romer (1986, p. 1003) considers that "knowledge cannot be perfectly patented or kept secret". Therefore, "the creation of new knowledge by one firm is assumed to have a positive external effect on the production possibilities of other firms" (Romer, 1986, p. 1003). There will always be externalities that cannot be protected by a firm and therefore the investment in knowledge by one firm is considered by Romer (1986) to have a multiplier effect ${ }^{28}$.

\title{
The role of public policy in economic growth
}

The second major revolution of endogenous growth theories is that it integrates the possibility that the growth rate does not need to decline in the long run (as do the neoclassical growth

\footnotetext{
${ }^{28}$ We would like to alert the reader that there is a major difference between Jacobs (1969) and Romer (1986) understanding under which circumstances these knowledge spillovers occur (see for example Beaudry \& Schiffauerova, 2009). For pedagogical reasons, we will not yet enter this debate but come back to this point when we will focus on the region.
} 
theories), meaning that in the end, there is a possibility that countries do not converge to the same level of development (Helpman, 2004):

\begin{abstract}
"The new growth theory is important because it permits or even encourages the use of government policies to increase the long-term rate of economic growth. [...] [it] assumes that increasing returns to scale and positive investment economies can lead to an increased growth rate, especially in high-tech sectors. [...] [additionally, it] suggests that government policies, through promotion of increased national savings and investment rate and also increased support for $R \& D$, can lead to a sustained higher rate of economic growth" (Gilpin, 2001, p. 113).
\end{abstract}

This has of course an important impact on the role public policies can play in economic growth. Instead of being considered as "useless in the long run" because all countries will anyhow converge to the same level, they might actually be a crucial indicator to differentiate the economic growth patterns of countries. For example, Morgan \& Nauwelaers (2003 (1999)) underlined that even the World Bank changed its mind about State intervention in order to foster innovation and economic growth:

\begin{abstract}
"The state is gradually being rehabilitated as a necessary and legitimate agent in economic development, after a period when it was denigrated, especially in the UK and the US, as a 'dead hand' on social and economic process. That the state has a positive role to play in promoting innovation and economic development was recently affirmed by no less an institution than the World Bank, which in the past has been criticised for extolling the market over the state and for downplaying the institutional architecture of market-based economies." (Morgan \& Nauwelaers, 2003 (1999), p. 11) 29 $^{29}$
\end{abstract}

Instead of being a "dead hand", the World Bank started thus to explicitly recommend state intervention and to be an "animator" of the emerging knowledge economy.

\title{
1.3 Economic growth: the rising importance of institutions
}

The discussions about economic growth during the 1980s went hand in hand with a revival of institutional theories, an important cornerstone to better understand today's cluster policies. Hereinafter, we thus particularly concentrate on the revival of institutional theories in economics and their possible impact on economic growth (North, 1986, 1989, 1990) ${ }^{30}$. Romer (1986) and Lucas (1988) were not the only ones at that time who wanted to overcome the

\footnotetext{
${ }^{29}$ Morgan \& Nauwelaers (2003 (1999)) refer to a speech that James D. Wolfenshon, the president of the World Bank between 1995 and 2005, held during a Keynote speech at Peking University in 2002: "We at the Bank fully support this move towards embracing the potential of the "Knowledge Economy" and see our role as a catalyst, a facilitator, a broker and a connector, positioned at a major intersection in the network economy, connecting global learning opportunities together with investment assistance for local development." Source: http://www.polity.org.za/article/wolfensohn-implementing-a-global-partnership-for-poverty-reduction29052002-2002-05-29 (15/05/2014)

${ }^{30}$ For the time being we will not particularly focus on institutional theories in economics treating "only" transaction costs (Coase, 1937, 1988; Commons, 1931; Williamson, 1973), or on institutional theories in sociology (for example Gouldner, 1954 (1964); Selznick, 1949) having impacted organization theories (DiMaggio \& Powell, 1983; March \& Olsen, 1984; Meyer \& Rowan, 1977; W. R. Scott, 1987).
} 
established growth theories, for example Matthews (1986) or North $(1986,1989)$ had the same endeavour. However, compared to economists like Romer and Lucas, who were particularly focusing on formal economic growth models, economists like Matthews (1986) and North $(1986,1989)$ had a more historical approach.

The objective of North (1990, p. 3) was to appreciate "the role of institutions in economic performance" and to develop an "analytical framework to integrate institutional analysis into economics and economic history”. North tried, in a similar manner as Romer and Lucas, to overcome the neoclassical economists by proposing another explanation for economic growth (North, 1989), this time the focus laid less on knowledge externalities and more on institutions.

North (1990, p. 3) defines institutions as the "rules of the game in a society". For North (1990, p. 3), institutions "structure incentives in human exchange, whether political, social, or economic". More precisely, he underlines that "they consist of both informal constraints (sanctions, taboos, customs, traditions, and codes of conduct), and formal rules (constitutions, laws, property rights)" (North, 1991, p. 97). According to North, these existing "rules of the game" differ from country to country and might explain that economic growth differs as well. For North, organizations are a group of individuals that pursue a common goal and at the same time organizations are also the actors of the system that can change the institutions. However, this change happens "incrementally rather than in discontinuous fashion” (North, 1990, p. 6). For North, compared to neoclassical scholars, human interaction is not optimal. So there has to be a third person that structures the exchange, but not only for disciplinary reasons.

Also for Matthews (1986, p. 915), institutions construct themselves over time, step by step, where every new step is influenced by the previous step. However, Matthews (1986, p. 914), compared to North (1990) is particularly reluctant regarding experimenting with institutions on a national level. He particularly underlines that institutions are very complex, "mисh more complicated than appears on the surface" which also means that "it may be quite difficult to see why an institution has arisen and what purposes it currently serves". For Matthews (1986) experimenting with these institutions would lead to a "random walk" where one does not know the end destination. Matthews (1986, p. 917) underlines that experimentation on a single firm level would be fine "because it does not much matter for the economy as a whole 
if it does not work". However, he is more reluctant to experiment with institutions on a national level, "we have to recognise candidly that institutional changes can easily lead in the long run to results that are quite different from intended" (Matthews, 1986, p. 917).

North (1990) on the other hand underlines the importance of the State and according to him the State should go beyond a simplistic Public Choice theory, which sees the State only from a redistribution angle. However, North (1990, p. 99) also points out that once a certain path is taken this path is difficult to change as "the network externalities, the learning process of organizations, and the historically-derived subjective modelling of the issues reinforce the course”. The choice to go in a certain direction might thus have a huge impact. A mediocre development might thus continue in a mediocre path. These words are particularly interesting to retain when discussing cluster policies.

A major cornerstone of the 1980s was thus the turn from exogenous to endogenous economic growth theories and thus everything which goes along: a focus on knowledge, knowledge externalities, knowledge investment, the assumption that countries do not converge to the same development level, and the increasing role accredited to institutions in economic growth. Additionally this went hand in hand with the rise of institutional theories and the role institutions, or more particularly the State, might play in economic growth. We will see that this development is particularly important when we start discussing cluster policies in chapter 2. In the next section we will focus on another important change: the emergence of the region as an economic organization. 


\section{The emergence of regions as economic organizations}

Regional economics experienced a strong revival during the 1980s. Storper (1997, p. 3) summarises this re-emergence as following: "Something funny happened in the early 1980s. The region, long considered an interesting topic to historians and geographers, but not considered to have any interest for mainstream western social science, was rediscovered [...]”. Even though, regional development was studied by researchers before the 1980s, what was new was that the region was suddenly considered as a "unit of social life in contemporary capitalism equivalent to [...] markets, states or families" and there was the assumption that it might be a "fundamental basis of economic and social life 'after mass production'” (Storper, 1997, p. 3). Again, in order to understand what Storper exactly means by "after mass production" and why the "region" emerged as a unit of analysis in the 1980s, we have to dig further down the history.

We first discuss in detail the seminal propositions of Marshall on regions, then discuss the revival of Marshallian industrial districts during the 1980s and finally focus on the most emblematic cluster "role models" that were "created" during this period.

\subsection{The rise and fall of Marshall's industrial district}

Even though the main focus of Marshall's work was not specifically on clusters or industrial districts, Marshall (1890 (1920)) is widely cited in cluster studies because of his chapter: "The concentration of specialized industries in particular localities". In this chapter, he describes his observation gained from studying England's industrial organization at the end of the $19^{\text {th }}$ century. He observed that skilled and fortunate workers often "gathered within the narrow boundaries of a manufacturing town or a thickly peopled industrial district" (1890 (1920), p. IV.X.6).

Marshall draws five main observations of why this happens (see Table 2):

- Knowledge circulation: First of all he observed that knowledge circulates "in the air" within these industrial districts, that new ideas are immediately passed on to other manufactures and that "the mysteries of the trade become no mysteries" (p. IV.X.7).

- Specialisation through division of labour: The second important observation concerns the economies of scale the individual manufacturer can make through the division of 
labour within an industrial district. When machinery is expensive, he observed that the different manufactures specialize in one task of the value chain, which allows them to save money because they can use their machinery more efficiently at full capacity.

- Pool of skilled workers: The third important point of industrial districts according to Marshall is the pool of skilled workers which attracts employers because they know that they will find skilled employees at this location, and which attracts more employees because they know that they will easily find work.

- Physical conditions: Then Marshall also observes that some industrial districts seem to exist because the physical conditions (for example easy access, specific natural resources) of the location are favourable for the industry.

- Patronage of a court: The "patronage of a court" is the last important point that Marshall mentions and that according to him explains why industries locate in a certain location. Under patronage of a court, he understands how kings, lords or other important personalities have the power to "invite" artisans to locate in a certain location. These rulers created in a certain manner "artificial" industrial districts where they wished to have the industry set $\mathrm{up}^{31}$. Another reason to deliberately set up an industrial district was for example when the location was specialized in mining but did not offer any other jobs, particularly for women or children, which were not strong enough to do the hard physical work. Marshall gives the example of Barrow, a village known for its railway and mining activities, where a textile district was set up "deliberately on a large scale in order to give variety of employment in a place where previously there had been but little demand for the work of women and children" ( $p$. IV.X.10).

\footnotetext{
${ }^{31}$ Two concrete examples Marshall gives to underline the benefits the "patronage of a court" brought for the different artisans in advancing their skills: "[...] the mechanical faculty of Lancashire is said to be due to the influence of Norman smiths who were settled at Warrington by Hugo de Lupus in William the Conqueror's time" (p. IV.X.4); "[...] the greater part of England's manufacturing industry before the era of cotton and steam had its course directed by settlements of Flemish and other artisans; many of which were made under the immediate direction of Plantagenet and Tudor kings" (p. IV.X.4).
} 
Table 2: Co-location: main advantages and reasons according to Marshall

\begin{tabular}{|c|c|}
\hline Topic & Marshall's observations \\
\hline $\begin{array}{l}\text { Knowledge } \\
\text { circulation }\end{array}$ & $\begin{array}{l}\text { "Good work is rightly appreciated, inventions and improvements in machinery, in } \\
\text { processes and the general organization of the business have their merits promptly } \\
\text { discussed: if one man starts a new idea, it is taken up by others and combined with } \\
\text { suggestions of their own; and thus it becomes the source of further new ideas." (1890 } \\
(1920), \text { p. IV.X.7) }\end{array}$ \\
\hline $\begin{array}{l}\text { Specialisation } \\
\text { through division } \\
\text { of labour }\end{array}$ & $\begin{array}{l}\text { "The economic use of expensive machinery can sometimes be attained in a very high } \\
\text { degree in a district in which there is a large aggregate production of the same kind [...]. } \\
\text { For subsidiary industries devoting themselves each to one small branch of the process of } \\
\text { production, and working it for a great many of their neighbours, are able to keep in } \\
\text { constant use machinery of the most highly specialized character, and to make it pay its } \\
\text { expenses [...] and its rate of depreciation very rapid." (1890 (1920), p. IV.X.8) }\end{array}$ \\
\hline $\begin{array}{l}\text { Pool of skilled } \\
\text { workers }\end{array}$ & $\begin{array}{l}\text { "[...] a localized industry gains a great advantage from the fact that it offers a constant } \\
\text { market for skill. Employers are apt to resort to any place where they are likely to find a } \\
\text { good choice of workers with the special skill which they require; while men seeking } \\
\text { employment naturally go to places where there are many employers who need such skill } \\
\text { as theirs and where therefore it is likely to find a good market." (1890 (1920), p. IV.X.9) }\end{array}$ \\
\hline $\begin{array}{l}\text { Physical } \\
\text { conditions }\end{array}$ & $\begin{array}{l}\text { "[...] such as the character of the climate and the soil, the existence of mines and } \\
\text { quarries in the neighbourhood, or within easy access by land or water." (1890 (1920), p. } \\
\text { IV.X.3) }\end{array}$ \\
\hline $\begin{array}{l}\text { Patronage of a } \\
\text { court }\end{array}$ & $\begin{array}{l}\text { "When an Eastern potentate changed his residence [...] the deserted town was apt to } \\
\text { take refuge in the development of a specialized industry, which had owed its origin to the } \\
\text { presence of the court. But very often the rulers deliberately invited artisans from a } \\
\text { distance and settled them in a group together." (1890(1920), p. IV.X.4) }\end{array}$ \\
\hline
\end{tabular}

Besides the advantages of co-location and the reasons of industries to co-locate, Marshall (1890 (1920)) also stressed the negative effects of co-location as for example the increasing "ground-rents" and the "competition for dwelling space" within the city limits which forced a lot of companies to go to the suburbs of cities or to the neighbouring regions. Additionally, even though Marshall favours specialization for knowledge spillovers, Marshall also points out the high risk of a one-sided industrial specialization ${ }^{32}$ :

\begin{abstract}
"A district which is dependent chiefly on one industry is liable to extreme depression, in case of a falling-off in the demand for its produce, or of a failure in the supply of the raw material which it uses. This evil again is in a great measure avoided by those large towns or large industrial districts in which several distinct industries are strongly developed. If one of them fails for a time, the others are likely to support it indirectly; and they enable local shopkeepers to continue their assistance to workpeople in it." (1890 (1920), p. IV.X.12)
\end{abstract}

Marshall was an influential economist of his time, but not particularly for his works on industrial districts. However, one century later, he is one of the most cited authors in regional research (Cruz \& Teixeira, 2009). Today, researchers studying clusters constantly retake his observations just discussed and develop them further. In the following chapters we first present why Marshall's observations experienced a revival (during the mass production period industrial districts and thus regions were not in the center of attention) and underline

\footnotetext{
${ }^{32}$ In the second half of the 20th century, Detroit and its automotive industry experienced exactly what Marshall tried to alert about at the end of the 19th century.
} 
the strong focus on his idea of "knowledge circulation" within industrial districts, although, criticized by Krugman (1991 (1993)).

\subsection{The revival of industrial districts}

For economists interested in institutions (North, 1989) and economists interested in knowledge externalities (Lucas, 1988) it might have been the fight against neoclassical theories that spurred their rebirth during the 1980s. For scholars interested in the region (be it geographers, economists, political scientists, etc.) this rebirth seems to be related to additional explanations. According to Storper (1997), and others that we discuss hereinafter, the increasing interest in the "region" as a unit of analysis for economic studies might have been initiated by a change in the production system. Storper for example underlines that in the early 1980s the production system moved from a mass-production system to a "post-Fordist, flexible, learning based" system (1997, p. 4) and that in this process "the region" was suddenly (re)considered as a "fundamental basis of economic and social life" (1997, p. 3). Hereinafter we discuss three important developments regarding the region as a new unit of analysis: flexible specialization, innovation and embeddedness.

\subsubsection{The region, a locus for flexible specialization}

At the beginning of the $20^{\text {th }}$ century the production system changed considerably compared to the production system of the $19^{\text {th }}$ century and thus the time Marshall did its observation of industrial districts in England. When Marshall wrote Principles of Economics (1890 (1920)), the production system was still mainly organized in crafts and so within one industrial district, several different crafts participated in the production of a certain product. In other words, the production system was based on a "vertically disintegrated, small-firm industrial system" (Rocha, 2013, p. 100).

However, at the beginning of the $20^{\text {th }}$ century the craft production system was replaced by a mass production system that exploded after the end of WWII. Piore \& Sabel (1984) call this change in production system at the beginning of the $20^{\text {th }}$ century, the "first industrial divide". Instead of having predominantly vertically disintegrated companies, the first industrial divide lead to big vertically integrated companies which paved the way to mass production and mass consumption. Vertically integrated companies have the different production steps assembled within one company and are thus able produce an increased amount of standardized products 
in a much faster and cheaper way than before. One prominent example is the Ford Motor Company founded in 1903. The mass production system initiated mass consumption and led, especially after WWII, to strong economic growth and wealth, known in France as "the glorious thirty" or in Germany and Austria as the "economic miracle".

However, this production system that procured increasing wealth and nearly full employment started to fall apart in the 1970s. Again it is difficult to pinpoint the exact causes of this change (for example some important events of the 1970s: end of the Bretton Woods system, oil crisis, stock market crash). Jones (2007, p. 150), a business history scholar, for example points out that at that moment a "new global economy" has started to emerge and that "from the late 1970s, deregulation and Iiberalization stimulated increased globalization." According to Jones (2007), this was accompanied with "China's adoption of market-oriented policies and opening to foreign investors in 1979" (p. 150), one decade later by the "collapse of Communism in Russia and Eastern Europe" (p. 150) but also an "accelerating growth in India" (p. 151). Finally, this opening up of boarders, deregulation, and liberalization "resulted in significant geographical shifts in economic power" (Jones, 2007, p. 151).

This geographical shift in economic power might have helped China or India, but was perceived as a threat by the western world. In the beginning of the 1980s, American scholars like Piore \& Sabel's (1984) perceived the economic situation as extremely gloom as this introduction to their famous book called "The second industrial divide" shows:

"The times are troubled indeed when the good news is almost indistinguishable from the bad.
Economic downturns no longer seem mere interruptions in the march to greater prosperity;
rather, they threaten to destroy the world markets on which economic success has dependent
since the end of World War II. Meanwhile, upturns avert disaster without solving the problems
of unemployment and slow growth, which have become chronic in almost all the advanced
countries. No theory seems able to explain recent events, let alone predict what will happen
next." (Piore \& Sabel, 1984, p. 3)

Today, exactly thirty years later, the opening words of Piore \& Sabel's book might be seen as still very accurate. Has something changed? One of the punching bags of the observed and frightened economic decline in the 1980s was the vertical integrated company which was able to produce at large scale for minimal cost, but which was perceived as not flexible and unable to adapt to fast changing and increasingly demanding (global) consumer tastes. Piore \& Sabel (1984, p. 6) identified two strategies "for relaunching growth in the advanced countries". 
The first strategy was build "on the dominant principles of mass-production technology" (Piore \& Sabel, 1984, p. 6). They argued that if one wishes to maintain this system, it "requires a dramatic extension of existing regulatory institutions, including a redefinition of economic relations between the developed and the developing worlds" (p. 6). However, for them another additional promising strategy was to go "back to those craft methods of production that lost out at the first industrial divide" (p. 6).

The second strategy, called by Piore \& Sabel (1984) “flexible specialization", was thus in a certain manner a modern version of the production system Marshall already described at the end of the $19^{\text {th }}$ century. Instead of having one big vertically integrated company, smallspecialized companies located in a certain region might be more capable to compete in the new globalized economy. Sabel (1984, p. 344) underlines that "[...] there is a growing consensus [...] that changes in the conditions of competition in mass markets for standard goods are a the root of the crisis, and that the reorientation of industry toward the production of more specialized goods by more flexible technologies and more skilled workers will be on of the principal outcomes".

In the same stream of research, Christopherson and Storper (Christopherson \& Storper, 1986; Storper \& Christopherson, 1987) dedicated a whole research stream to the role of flexible specialization and the social and economic impacts of this new mode of production and thus confirmed the observation of Piore \& Sabel. Christopherson and Storper (Christopherson \& Storper, 1986; Storper \& Christopherson, 1987) particularly focused on Hollywood's film industry where a vertically integrated studio system (i.e. production, distribution and exhibition were combined under one roof) has predominated up to the 1980s but then shifted to a vertical disintegration system. Storper \& Christopherson (1987, p. 115) underline that the shift towards vertical disintegration considerably changed the importance of urban centres. According to them "flexible specialization creates powerful agglomeration tendencies at the regional level" (1987, p. 115) and that this is "further strengthening external economies".

Also Allen J. Scott (1988a, 1988b), an American geographer and political scientist, focused in his research on the impacts of these "new" flexible production systems. Scott (1988a, p. 174) called these production systems "new industrial spaces" in contrast to the "rigid structure" of "mass production". For Scott (1988a, p. 174), these "new industrial spaces" are "characterized by an ability to change process and product configurations with great 
rapidity". Additionally, "they are [...] typically situated in networks of extremely malleable external linkages and labour market relation. [...] they tend as far as possible to externalize production processes by buying in services and products that might otherwise by supplied internally [...]” (A. J. Scott, 1988a, p. 174). The sectors in which these new production systems were established experience a "vigorous revival of entrepreneurial behavior, renewed market competition and active technological innovation" (A. J. Scott, 1988a, p. 174).

There are two particularities of Scott's analysis. First, Scott already started to mention the role of increased technological innovation in these "new industrial spaces" a topic of increasing important in the following years. Second, instead of concentrating on urban centres (Christopherson \& Storper, 1986; Storper \& Christopherson, 1987), Scott had a more regional approach to these flexible production systems (Hudson, 1989; Komninos, 2002), also an approach that intensified in the following years.

However, we would like to underline that the flexible production system "hype" was also criticized. For example Gertler (1988) warns the research community of the "perils of generalization”. Gertler (1988) criticizes that a lot of research done on flexible specialization bases its arguments on the automotive sector. However, according to Gertler (1988) the automotive sector was (already for the vertical integrated company) and will always stay a specific case. Gertler (1988, p. 430) admits that "significant changes are happening" but argues that the flexible specialization is not something completely new and challenges "the assertion that these changes are all-pervasive and present a distinct break with the past and the dawning of a new era of production". For him it is just an "intensification and development of historical trends established long ago" (Gertler, 1988, p. 430). Additionally, Gertler (1988, p. 431) warns that "the flexibilization of the firm represents first and foremost an ideology to undermine the power and rigidity of labour so that firms can achieve greater levels of current and future profitability".

At the same time as Piore \& Sabel, Christopherson \& Storper or Scott started to focus on flexible specialization and the new role of the region in this process for companies also other researchers started to focus on the role of the region in the economic system. However, instead of having a pronounced flexible specialization approach, the focus laid more on innovation. 


\subsubsection{The region, a locus for innovation}

Besides the focus on flexible specialization, the region was also increasingly considered as the new locus of innovation. In the beginning of the 1980s, several researchers started to investigate this assumed relationship between innovation and region.

Oakey et al (1980) studied if technological change varies between the regions in Britain. Their study showed that there exist regional variations of innovative activity. In this early study, they concluded that this might be particularly due to the variances on non-production workers (or skilled workers). Some years later, in another study, Oakey (1984) went one step further and investigated for example the impact of various regional resources (as for example finance, labour and technical information) on innovation in high technology SMEs located in Britain and the USA. This time the focus laid particularly on the role of government aid, which was more developed in the USA than in Britain for high tech companies.

Another early researcher focusing on these questions is Jaffe (1986). Jaffe (1986), who studied if the R\&D productivity of firms was increased if located next to other R\&D intensive firms or "technological neighbours". Jaffe (1986) concluded, based on American company data sources, that this was the case for R\&D intensive firms. However, firms with low own R\&D suffer from very strong R\&D intensive neighbours.

These studies were important bricks to get the research stream going. However, their visibility was maybe weaker due to their scattered results on some regional data. Philippe Aydalot, a French regional and urban economist, founded an association that tried to bundle the investigation efforts of researchers interested in this interplay between innovation and region. In 1984, Philippe Aydalot founded a research group called the "European Research Group on Innovative milieus“ (“Le Groupe de Recherche Européen sur les Milieux Innovateurs”, abbreviation: GREMI). The particularity of this well-known research group ${ }^{33}$ was that they set up a common methodology and studied a multitude of regions with the same hypotheses, the same criteria and the same questions (Matteaccioli \& Tabariés, 2006). This allowed a high comparability of results and a certain "industrialisation" of the research question. The

\footnotetext{
${ }^{33}$ We think the GREMI example is a great "role model" how research on such a complicated topic can be done. Instead of pursing individual research agendas in social sciences, we should much more often bundle our research effort to increase the quality and impact of our findings. Also Porter (1990 (1998)) collaborated with several research teams in order to conduct a multi-country study using the same methodology.
} 
objective of the GREMI was to study "the relations between technical innovation and territory” (Matteaccioli \& Tabariés, 2006, p. 3).

Even though the title stipulates "European Research Group", not only European research teams participated but also North-American research teams (Matteaccioli \& Tabariés, 2006). Instead of taking a "company" approach or a "technology" approach to tackle the question of how innovation emerges and gets fostered, the research group decided to take an explicit "milieu" approach. The question among the GREMI scholars (Aydalot, 1986; Aydalot \& Keeble, 1988; Camagni, 1991; Maillat \& Lecoq, 1992; Maillat \& Perrin, 1992; Maillat, Quévit, \& Senn, 1993) thus laid less on flexible specialisation or employment questions but on how the local environment and culture stimulates the innovativeness of the companies:

"Il s'agit de se demander quelles conditions extérieures à l'entreprise sont nécessaires pour la
naissance de l'entreprise et l'adoption de l'innovation. On considère que l'entreprise (et
l'entreprise innovante) ne préexiste pas aux milieux locaux, mais qu'elle est sécrétée par eux.
Les milieux sont considérés comme des « pouponnières » d'innovations et d'entreprises
innovantes. Ce choix implique que les comportements innovateurs ne sont pas nationaux, mais
qu'ils dépendent de variables définies au niveau local ou régional. L'accès à la connaissance
technologique, les injonctions d'un tissu industriel, l'impact de la proximité d'un marché,
l'existence d'un pool de travail qualifié... Ce sont là des facteurs d'innovation qui vont
déterminer sur un territoire national des zones de plus ou moins grande innovativité.”
(Aydalot, 1986)

The idea that the "region" plays an increasing role for the innovation process started in the 1980s together with the changes happening in economic growth theories and the orientation towards a knowledge economy. During the 1990s this regional innovation literature further developed and lead to different innovation system literature streams as for example national innovation systems (Lundvall, 1992), regional innovation systems (Cooke, 1992), or learning regions (Asheim, 1996; Florida, 1995). However, another concept that is important to understand in this context is the notion of "embeddedness". The economic actors were increasingly seen as embedded in a certain regional milieu that will lead them to be more innovative.

\subsubsection{The region, a locus for embeddedness}

The last important concept that emerged during the 1980s and that is important for cluster studies concerns embeddedness (Granovetter, 1985). Embeddedness put at the forefront the role of sociology in economic reflections and thus the role of humans - and human interactions - in economic systems. Not only economists or geographers but also economic sociologists tried to add their knowledge to the profound changes that were happening during 
the 1980s. In the case of economic sociology, Swedberg (2003) for example puts forward that economic sociology experienced maybe a revival due to external factors such as Thatcherism $^{34}$ or Reaganism ${ }^{35}$. Swedberg (2003) joins the list of different types of political and societal factors (see also Snowdon (2006) or Rocha (2013)) that try to explain this intensification and renewal in economics, geography and sociology during the 1980s. However, this research does not base its argumentation on political or societal factors to explain their "rebellion" or "revival" of the 1980s, but on the criticism of neoclassical thinking (or in the case of the regional economies discussion on the death of mass production systems in developed countries).

Granovetter is considered as the father of the economic sociology revival (Swedberg, 2003). Particularly due to his famous article "Economic action and social structure: the problem of embeddedness" (Granovetter, 1985). In this article Granovetter (1985) critics that there is no "middle ground" to analyse social structure and relations. He criticizes that social relations are either "oversocialized" by sociologists, that consider economic actors as "obedient to the dictates of consensually developed systems of norms and values" (1985, p. 483), or "undersocialized" by neoclassical economists, that consider economic actors as rational and "atomized" individuals. At the contrary, Granovetter argues that "most behavior is closely embedded in networks of interpersonal relations" $(1985$, p. 505) and that this would avoid to undersocialize or oversocialize human actions:

\begin{abstract}
"The embeddedness argument stresses [...] the role of concrete personal relations and structures (or "networks") of such relations in generating trust and discouraging malfeasance. The widespread preference for transacting with individuals of known reputation implies that few are actually content to rely on either generalized morality ${ }^{36}$ or institutional arrangements ${ }^{37}$ to guard against trouble." (Granovetter, 1985, p. 490)
\end{abstract}

It is thus this embeddedness in a social network which builds trust and which might impact the economic outcome of the individual. Granovetter also criticizes institutionalists like Williamson (1973), because the question should not centre on markets or hierarchies but on embeddedness of the economic actor. For Granovetter, relying only on explanations of the institutional framework, "discourage[s] the detailed analysis of social structure" which he considers as the "key to understanding how existing institutions arrived at their present state" (Granovetter, 1985, p. 505). Granovetter concludes his article with encouraging sociologists

\footnotetext{
${ }^{34}$ Prime minister of the United Kingdom from 1979 to 1990.

${ }^{35}$ President of the United States from 1981 to 1989.

${ }^{36}$ Granovetter uses "generalized morality" in reference to his thoughts about "oversocialization".

${ }^{37}$ Granovetter uses "institutional arrangements" in reference to his thoughts about "undersocialization".
} 
to start debating again the role of human actions in economic domains. He believes that "there is a place for sociologists in the study of economic life but that their perspective is urgently required there" and that "sociologists have unnecessarily cut themselves off from a large and important aspect of social life” (Granovetter, 1985, p. 507).

During the twentieth century, sociology was for a long time considered as the "science of leftovers" and as "a pseudoscience that had nothing to offer [to economists]" (Granovetter, 1990, p. 89). However, the re-emergences of new institutional theories, also stimulated sociologists like Granovetter to participate again in this scientific debate and the new economic sociology was born, re-integrating human actors and their exchanges in the core of economic debates. According to Swedberg (2003, p. 34), the basic approach of the new economic sociology is that the "core economic phenomena should be analyzed with the help of sociology" and that three approaches are particularly helpful in this endeavours "network theory, organization theory, and cultural sociology”. These different approaches are used to analyse "economic organizations", which is not to be understood as a firm, but as "the organization of whole economies" (2003, p. 53). One of these economic organizations are for example industrial districts (Swedberg, 2003). This shift of thought is similar to Becattini's (1979) thoughts. Already at the end of the 1970s, Becattini (1979) wrote that in order to understand the particularity of industrial districts, the "unit of analysis" had to shift from the "single firm" to the "cluster" level (characterized by "interconnected firms located in a small area") $)^{38}$.

To sum up, the 1980s also experienced an important revival of the role of social interactions in economic discussions. Besides, understanding the role of knowledge externalities and institutions for economic growth, sociologists advocated to concentrate as well on the embedded human interaction to explain change and economic development. Finally, the region experienced a revival as a locus of where all these observations seem to take place.

\subsection{The stabilisation of regional "role models" in the 1980s}

In this last part, we focus on two regional "role models" that emerged during the 1980s. The Italian economist Sebastiano Brusco (1982) and the American political scientist AnnaLee Saxenian (1983), started to focus on the economic organization of regions. However, instead

\footnotetext{
${ }^{38}$ according to Brusco (1990, p. 14).
} 
of primarily focusing on the changing production system or solely on the role of innovation and embeddedness, Brusco's and Saxenian's focus laid more on observed performance differences between regions and the wish to explore the causes. By doing so, they underlined the superior economic performance of these regions and created two role models that are still seen as the main examples why we are implementing cluster polices today. Even though $10000 \mathrm{~km}$ apart, not only Brusco (1982) and Saxenian (1983), but a range of economists, economic sociologists, economic geographers and political scientists scrutinized these two regions during the 1980s: California (in the United States of America) and Emilia-Romagna (in Italy). The common denominator of both regions was a superior economic performance compared to other regions in the respective countries. Even though the explanations that were put forward and the angle of analysis are slightly different, both regions served as major role models in the subsequent cluster "hype". We think it is important to focus on these two role models when discussing cluster policies, as elements of their success were subsequently tried to be replicated in other regions (with more or less success). We will first focus on EmiliaRomagna (and its ceramic industry) before discussing California (and its semiconductors industry in Silicon Valley).

\subsubsection{Emilia-Romagna: The third Italy}

Emilia-Romagna, just beneath Italy's Northern regions, gained in fame because of its superior economic performance and better resistance to crisis in the 1970s and 1980s (Brusco, 1982). The region is part what scholars named the "Third Italy"39. The term "Third Italy" was first coined $^{40}$ by Bagnasco (1977). The main characteristics of the "Third Italy" were the "dense networks of flexible, strongly related, small and medium-sized firms in craft-based industries [...] in a number of specialized industrial districts". The industrial organization of the "Third Italy" thus stood in sharp contrast to the "industrial heartland of the North" (First Italy; vertically integrated companies specialized in mass production), and the "backward South" (Second Italy) (Boschma, 1998, p. 1). Several scholars tried to describe and understand the special characteristics that made the success of Emilia-Romagna and the "Third Italy" (Becattini, 1979, 1990, 2002; Brusco, 1990; Capecchi, 1990; Putnam, 1993; Pyke, Becattini, \& Sengenberger, 1990; Trigilia, 1986).

\footnotetext{
${ }^{39}$ Several important writings of the period were only published in Italian language. For example the book of Bagnasco (1977) discussing the "Third Italy", or the article of Becattini (1979) discussing the industrial districts of Northern Italy. Due to our lack of Italian, we had to read secondary literature in order to understand their writings. The secondary literature on which we base our argumentations is mentioned in the footnotes so that the main text is not overcharged with citations.

${ }^{40}$ according to Brusco (1990)
} 
Becattini (1979), one of the major scholars studying the "Third Italy", studied it through the lens of the works of Marshall (1890 (1920)), and is thus one of those who initiated the revival of Marshall's observations to analyse modern industrial districts ${ }^{41}$. However, the focus of Becattini (1979) (and others studying the region) laid much more on the "historical and territorial-specific sociocultural factors" $" 42$ to explain the regional particularities. This is different compared to Marshall (1890 (1920)) who did not pay much attention to these factors. However, the major common denominator of the English industrial districts at the end of the $19^{\text {th }}$ century and the Italian industrial districts at the end of the $20^{\text {th }}$ century is this particularity of small firms specialising in a certain tasks, and the localised division of labour for production.

Becattini (1990, p. 38) defines an industrial district as "a socio-territorial entity which is characterized by the active presence of both a community of people and a population of firms in one naturally and historically bounded area". In this definition of industrial districts, Becattini (1990) mentions several important concepts. First, Becattini (1990) underlines the importance of a "community of people" in the region. For Becattini (1990, p. 39), a "good" community is a community with a "relatively homogeneous system of values and views". Second, Becattini (1990) mentions that a "population of firms" has to be present in the "historically bounded area". For Becattini (1990, p. 39), the different firms in the region are not installed there accidentally. He argues that as the population of firms represent a "localised realisation of a division of labour", the firms are not only attracted by "preexisting localising factors" but are "rooted in the territory" (1990, p. 40). To understand this strong connection with the territory, Becattini (1990, p. 39) argues that one has to understand the historical development of the region.

These arguments go hand in hand with the arguments of Putnam (1993), an American public policy researcher who conducted an in-depth study of twenty Italian regions. The particularly of this study was that in 1970, Italy simultaneously established 15 ordinary and 5 special regions. This represented a unique opportunity for researchers to investigate the birth and development of new institutions. The central question of Putnam's research was: “What are the conditions for creating strong, responsive, effective representative institutions?" (Putnam,

\footnotetext{
41 according to Brusco (1990)

42 according to Rocha (2013, p. 98)
} 
1993, p. 6). The main condition he identified as crucial for effective representative institutions was strong "social capital" in the region. For Putnam (1993, p. 167), social capital can be described as "features of social organization, such as trust, norms, and networks, that can improve the efficiency of society by facilitating coordinated actions". This for example also includes "norms of reciprocity and networks of civic engagement" (1993, p. 167).

A good example of Putnam's (1993) social capital theory is the Emilia-Romagna Region. One of the particularity of the Emilia-Romagna Region was that "the Italian Communist and Socialist parties had an absolute majority" (Capecchi, 1990, p. 28) in the Region after WWII up to the 1980s. Several studies were particularly interested in this political dimension that might explain the success of this Region (Brusco, 1982; Trigilia, 1986). The governing Communist party in Emilia-Romagna was for example actively helping the local companies to get started, co-ordinating associations for the local artisans or providing day-care centres for children so that women can work (Capecchi, 1990). For example this included the establishment of a ceramics centre ${ }^{43}$ in the region, or the provision of a centralised service regarding "information [...] [on] patents, and foreign markets" (p. 32), the provision of professional training or the help to start co-operations with universities. However, all this help was not rigid but very flexible and tailored to the individual needs of the companies. Capecchi (1990, p. 32) underlines that "the point to stress about these undertakings is their flexibility [...]. Flexible specialisation of the production system was taken as a model also in the area of services to the firms". This was very helpful for training the local entrepreneurs and helping them to survive but also created a common spirit among them.

Another reason, next to the regional social capital, that might explain the strong solidarity among the local population might have been the consciousness (or readiness) to join forces in order to survive, not against a global threat, but a national threat: "This "common" management of industrialisation in Emilia-Romagna has had a "common enemy", the national government which, being Christian-Democrat, has traditionally supported the large enterprises of the north and threatened the factories of Emilia” (Capecchi, 1990, p. 28).

From an organizational theory point of view the "readiness" of organizational members is often discussed in change management articles (Armenakis, Harris, \& Mossholder, 1993).

\footnotetext{
${ }^{43}$ For information: the Emilia-Romagna region is specialized in ceramics.
} 
Readiness is defined as "the cognitive precursor to the behaviours of either resistance to, or support for, a change effort" (Armenakis, et al., 1993, pp. 681-682). In an organizational context change managers need to influence their organizational members' "beliefs, attitudes, and intentions regarding the extent to which changes are needed and the organization's capacity to successfully make those changes" (Armenakis, et al., 1993, p. 681). Applied to the Emilia-Romagna Region, we could say that the ruling parties have successfully managed to influence the population's readiness.

\subsubsection{California: Silicon Valley}

The industrial organisations of two areas in California were particularly investigated during the 1980s: Silicon Valley and its semi-conductor industry (Miller \& Cote, 1985; Rogers \& Larsen, 1984; Saxenian, 1983, 1990, 1991, 1994) and Hollywood and its motion picture industry (Christopherson \& Storper, 1986, 1989; Storper \& Christopherson, 1987). We already discussed the Hollywood and its motion picture industry in the flexible specialization section. In this section we will now focus on Silicon Valley. We will see that the circumstances of Silicon Valley's performance fame are (slightly) different compared to the Emilia-Romagna Region in Italy.

Silicon Valley is located in the Northern part of California, more precisely in the southern part of the San Francisco Bay Area. The history of Silicon Valley is very rich thus we will not summarize it in detail (see for example Rogers \& Larsen, 1984; Saxenian, 1983, 1994; T. Weil, 2010). Hereinafter, we will just point to the most important developments that we consider relevant for the subsequent development of cluster policies that try to replicate the Silicon Valley model.

Santa Clara County, the part of the Bay area were Silicon Valley is located today, was still a "peaceful agricultural valley" in 1940, but by 1970 "the region had gained international fame as [...] the capital of the semiconductor industry and the densest concentration of 'high technology' enterprises in the world" (Saxenian, 1983, p. 7). The question is what happened in-between? As in the Emilia-Romagna region, the political environment of the epoch played an important role in the industrial growth of the region. However the reasons were much different. At the end of WWII and the beginning of the Cold War, the government of the United States of America decided to invest a considerable amount of money in university research "to develop war-related technologies" (Saxenian, 1994, p. 11). The two universities 
that benefited most from these subsidies were the Massachusetts Institute of Technology (MIT) in Eastern Massachusetts (on the East coast) and Stanford University in Northern California (Saxenian, 1994). The cutting edge research, which was done thanks to these investments, spore the development of technical skills and therefore the development of human capital. This again attracted companies and initiated new firm formations (Saxenian, 1994). Compared to the Emilia-Romagna region, the formation of the Silicon Valley was not due (at least in the beginning) to a regional government providing associational help and training for local companies. In the Silicon Valley, the government help was targeted to university research that triggered firm attraction.

However, even though Silicon Valley and Route $128^{44}$ received research subsidies, their respective starting points and developing paths were not at all the same (Saxenian, 1994). The Route 128 was already a successful and established hub for technological innovation before the government started its research investments, while the area of Silicon Valley was an agricultural region (Saxenian, 1994). The total employment in the high technology sector (Figure 4), or more particularly in electronic components and semiconductors firms (Figure 5), differed considerably. Silicon Valley was still far behind in numbers of high technology jobs during the 1950s. However, this changed in the 1970s, when Silicon Valley took the incontestable lead until today.

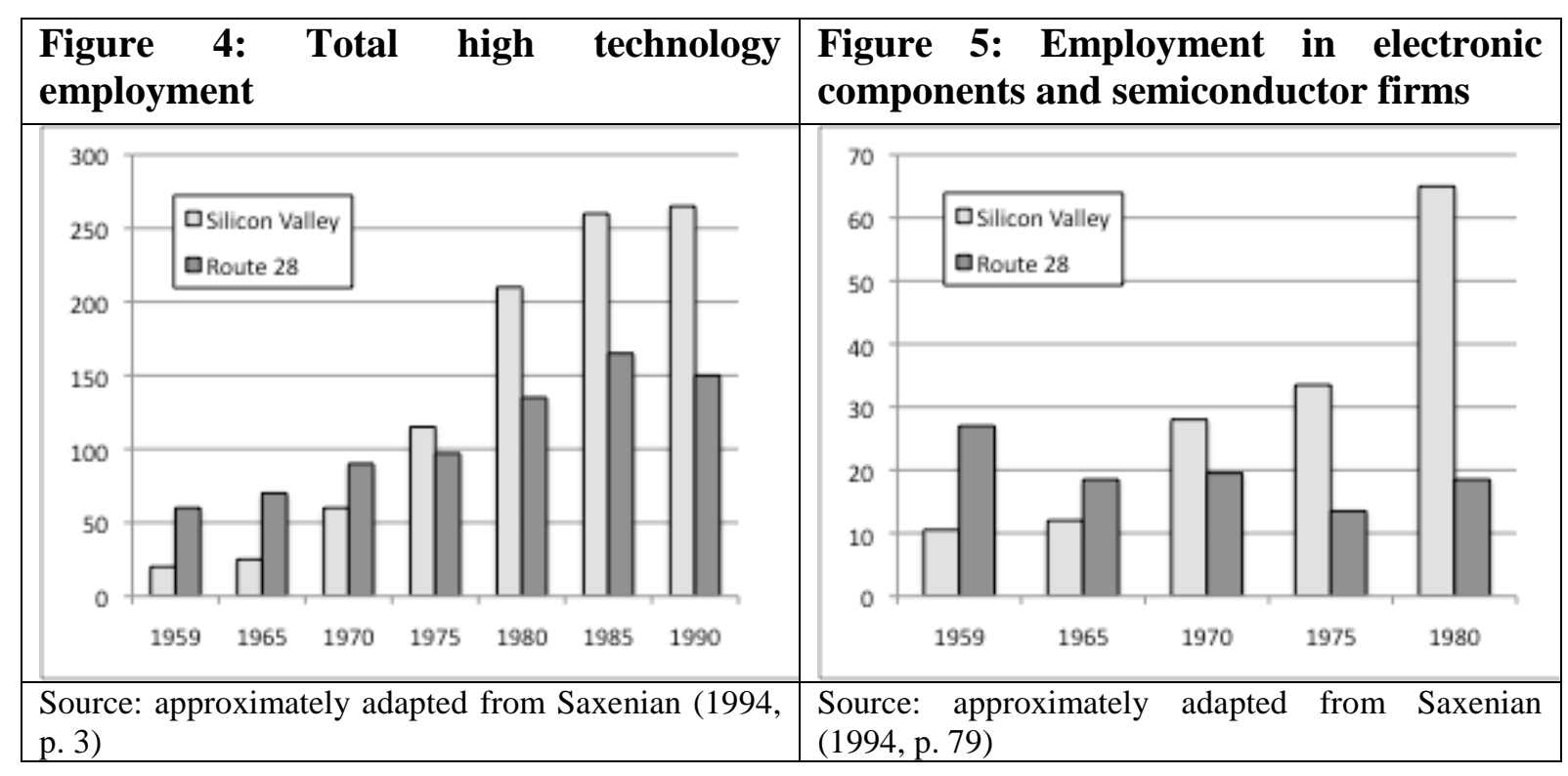

\footnotetext{
${ }^{44}$ For a detailed case study of Route 128 see Dorfman (1983)
} 
Saxenian (1994) tried to explain the differences between these two regions in order to understand the cause that lead to these different developments. One the one hand, she underlines that "both Stanford and MIT encouraged commercially oriented research and courted federal research contracts" (Saxenian, 1994, p. 12). However, one the other hand she points out that "MIT's leadership focused on building relations with government agencies and seeking financial support from established electronics producers" while "Stanford's leaders, lacking corporate or government ties or even easy proximity to Washington, actively promoted the formation of new technology enterprises and forums for cooperation with local industry" (Saxenian, 1994, p. 12).

The relationship between the universities and the local industry were thus substantially different in the two regions. While the MIT, close to Washington, focused on official connections with government agencies and big established companies, Stanford knew that the distance to these established companies and Washington was too far (Saxenian, 1994). The pioneers of Silicon Valley "saw themselves as outsiders to the industrial traditions of the East" (Saxenian, 1994, p. 29). This distance "facilitated experimentation with novel and productive relationships" (1994, p. 27) and created "a more flexible industrial system, one organized around the region and its professional and technical networks rather than around the individual firm" (Saxenian, 1994, p. 30). Collaboration, mutual help, informal relationships, openness and no secrets were the main premises of this local culture.

On the other hand, for the firms situated at Route 128, there was no urgency to change something because they were the leader in technological innovation and so the "technology enterprises adopted the autarkic practices and structures of an earlier generation of East Coast businesses" (Saxenian, 1994, p. 59). The local culture continued as before and was characterised by "secrecy and territoriality ruled relations between individual and firms, traditional hierarchies prevailed within firms, and relations with local institutions were distant - even antagonistic" (Saxenian, 1994, p. 59). This had as a consequence that "the regional economy remained a collection of autonomous enterprises, lacking social or commercial interdependencies” (Saxenian, 1994, p. 59).

There are certain similarities between Silicon Valley and Emilia-Romagna. Emilia-Romagna knew that they are disadvantaged as the government mainly focused on the "First Italy". The consequence was that they created a common culture of mutual aid and exchange, similar to 
Silicon Valley. In both cases, there was an underlying understanding that in order to succeed, they really had to battle together and try something new; there was a "readiness" of the local population to create a common culture. Besides this common feeling of being an outsider, Silicon Valley and Emilia-Romagna have not that much in common (see Table 3). Silicon Valley focuses on the high technology industry and the government particularly helped with research funding. Emilia-Romagna is characterised by a craft based industry where government intervention mainly deals with forming associations and training. Also Porter (1990, p. 73) mentioned that “companies gain advantage against the world's best competitors because of pressure and challenge". The importance of this "outsider" feeling in order to generate a strong local culture and economic growth might be an element of particular importance for cluster policy studies.

Table 3: Differences and similarities between Silicon Valley and Emilia-Romagna

\begin{tabular}{|l|c|c|}
\hline & Silicon Valley & Emilia-Romagna \\
\hline Craft based industry & $\mathrm{X}$ & \\
\hline High technology industry & $\mathrm{X}$ & \\
\hline $\begin{array}{l}\text { Government helped mainly in the } \\
\text { form of research subsidies }\end{array}$ & & $\mathrm{X}$ \\
\hline $\begin{array}{l}\text { Government helped mainly in the } \\
\text { form of associations, professional } \\
\text { training }\end{array}$ & & \\
\hline "Outsider" feeling because of & Route 128 & \\
\hline
\end{tabular}




\section{The rise of (regional) competitive advantage}

In the 1980s, besides the reconsideration of the existing growth theories and the consideration of the region as a crucial element where the economy is organised, the 1980s also represent the birthplace of modern strategic management, and the creation of the notion "competitive advantage" at the firm, regional or national level by Michael Porter (1985 (1998)).

The writings of Michael Porter heavily influenced companies and strategic management research (Barney, 1986, 1991; Huggins \& Izushi, 2011) but also governments around the world in their quest for competitiveness (Lundequist \& Power, 2002; McDonald, et al., 2007). The central idea of Porter's work concerns "the nature of competition" (Huggins \& Izushi, 2011). In order to understand Porter's theories, its critics and the differences compared to the scholars discussed so far we have to understand Porter's particular "thought-style" (Fleck, 1935 (1980)) which is somehow different to the scholars already discussed. Porter at the beginning of his career had a strong company approach, a point of differentiation compared to the other researchers already discussed. However, Porter such as the authors we already discussed also tried to overcome neoclassical economic thoughts (Aktouf, Chennoufi, \& Holford, 2011)

In 1999, a poll conducted among Strategic Management Society members elected Porter as "the most influential strategic management scholar over the previous twenty-five years" (Huggins \& Izushi, 2011, p. 1) and even though Porter influenced governments and businesses around the world like maybe nobody else, his research was criticized by a large number of scholars (for example by geographers (R. Martin \& Sunley, 2003; Swords, 2013), by business scholars (Davies \& Ellis, 2000; Dunning, 1993; McDonald, et al., 2007), or by policy scholars (Motoyama, 2008)). Hereinafter we will try to explain this ambiguity, understand these critics and why he nevertheless managed to become the guru of competitiveness clusters. We split this section on competitive advantage in three different parts: First we present the birth and development of Porter's business approach to clusters, then we discuss the meaning of competitiveness for regions and nations, and finally we focus on the critical voices against Porter and national competitiveness. 


\subsection{The birth of Porter's business approach to clusters}

In the preface of Porter's first book he wrote that his research situates "at the intersection between the mainstream economic research in industrial organization and the preoccupation of research in business administration with problems of the manager" and that he believes that "innovative research and teaching in both economics and administration will benefit greatly from exposure to the other's territory" (Porter, 1976, p. xi). Using concepts and theories form other disciplines is considered as crucial to facilitate the production of new knowledge (Greckhamer, Koro-Ljungberg, Cilesiz, \& Hayes, 2008; Schmidt, 2007) and Porter is definitely somebody who did it in an extremely successful manner (see Porter, 1981). Porter was "[...] the first author to bring together [...] industrial organization economics and strategic manager - in order to provide a better discussion of the strategic choices made by firms" (Aktouf, et al., 2011, p. 76). However, he did not stop at the intersection between industrial organization economics and strategic management. In his later works he also transcended the barriers versus economic geography or regional science (Huggins \& Izushi, 2011). As we already saw with Romer (1994) it is difficult to impose new ideas and theories within one discipline, doing it across different disciplines is even more complicated as the worldviews, vocabulary, or methodologies vary and simply being understood is already a challenge. The four most influential books of Porter are "Competitive Strategy" (Porter, 1980 (1998)), "Competitive Advantage" (Porter, 1985 (1998)), "The competitive advantage of nations" (Porter, 1990 (1998)) and "On competition" (Porter, 1998d). However, the two earlier books (1980 (1998), 1985 (1998)) stand in contrast to the two later books (1990 (1998), 1998d). Table 4 briefly summarizes the evolution of Porter's ideas $^{45}$.

\footnotetext{
${ }^{45}$ For a more detailed discussion of Porter's work we can recommend following book: Huggins, R. and H. Izushi, Eds. (2011). Competition, competitive advantage, and clusters: the ideas of Michael Porter. Oxford, Oxford University Press.
} 
Table 4: Evolution of Porter's ideas on competition

\begin{tabular}{|c|c|c|c|c|}
\hline & $\begin{array}{l}\text { Competitive } \\
\text { Strategy (1980) }\end{array}$ & $\begin{array}{l}\text { Competitive } \\
\text { Advantage (1985) }\end{array}$ & $\begin{array}{l}\text { The competitive } \\
\text { advantage of } \\
\text { nations (1990) } \\
\end{array}$ & $\begin{array}{l}\text { On Competition } \\
\text { (1998) }\end{array}$ \\
\hline $\begin{array}{l}\text { Main level of } \\
\text { analysis }\end{array}$ & Industry & Firm & Nation & Region \\
\hline Observation & $\begin{array}{l}\text { Cross-industry } \\
\text { variations \& Intra- } \\
\text { industry variations in } \\
\text { profitability }\end{array}$ & $\begin{array}{l}\text { Differences in the } \\
\text { translation of generic } \\
\text { strategies into } \\
\text { actions }\end{array}$ & $\begin{array}{l}\text { Lack of a convincing } \\
\text { explanation of a } \\
\text { nation's influence on } \\
\text { its competitiveness }\end{array}$ & $\begin{array}{l}\text { Clusters enhance } \\
\text { productivity }\end{array}$ \\
\hline $\begin{array}{l}\text { Key } \\
\text { questions }\end{array}$ & $\begin{array}{l}\text { What factors } \\
\text { determine the } \\
\text { attractiveness of } \\
\text { industries for long- } \\
\text { term profitability? \& } \\
\text { What is the source of } \\
\text { intra-industry } \\
\text { variations in } \\
\text { profitability? }\end{array}$ & $\begin{array}{l}\text { How does a firm put } \\
\text { the generic strategies } \\
\text { (cost, differentiation, } \\
\text { focus) into practice } \\
\text { in order to create } \\
\text { competitive } \\
\text { advantage? }\end{array}$ & $\begin{array}{l}\text { What are the sources } \\
\text { of high levels of } \\
\text { productivity and } \\
\text { long-run } \\
\text { productivity growth } \\
\text { achieved by a } \\
\text { nation's successful } \\
\text { internationally } \\
\text { competing firms? }\end{array}$ & na \\
\hline Results & $\begin{array}{l}\text { - Profit potential in } \\
\text { an industry is } \\
\text { determined by the } \\
\text { collective strength of } \\
\text { five forces } \\
\text { - Profit potential of } \\
\text { firms is determined } \\
\text { by a firm's ability to } \\
\text { (1) analyze the } \\
\text { sources of each of } \\
\text { the five forces; ( } 2) \\
\text { find a position in the } \\
\text { industry where it can } \\
\text { best defend itself } \\
\text { against competitive } \\
\text { forces or influence } \\
\text { them in it's favour. }\end{array}$ & $\begin{array}{l}\text { - Value a firm } \\
\text { creates stems from } \\
\text { (1) the many discrete } \\
\text { activities it performs } \\
\text { in designing, } \\
\text { producing, } \\
\text { marketing, } \\
\text { delivering and } \\
\text { supporting products; } \\
\text { (2) its ability to } \\
\text { identify and map } \\
\text { those activities and } \\
\text { to put them in } \\
\text { accordance with the } \\
\text { chosen strategy } \\
\text { - But overall } \\
\text { industry structure } \\
\text { (five forces) has an } \\
\text { impact on value } \\
\text { creation }\end{array}$ & $\begin{array}{l}\text { Identification of four } \\
\text { sets of determinants } \\
\text { of national } \\
\text { advantage: firm } \\
\text { strategy, structure } \\
\text { and rivalry; demand } \\
\text { conditions; related } \\
\text { and supporting } \\
\text { industries; factor } \\
\text { conditions }\end{array}$ & $\begin{array}{l}\text { The concept of } \\
\text { clusters helps to } \\
\text { capture important } \\
\text { linkages, } \\
\text { complementarities, } \\
\text { and spillovers of } \\
\text { technology, skills, } \\
\text { and information that } \\
\text { cut across firms and } \\
\text { industries }\end{array}$ \\
\hline $\begin{array}{l}\text { Competitive } \\
\text { performance } \\
\text { measurement }\end{array}$ & \multicolumn{2}{|c|}{$\begin{array}{l}\text { Goal for firm: profitability } \\
\text { Measurement: comparing receipts and costs } \\
\text { Type: financial measure } \\
\text { Improvement through: for example pricing } \\
\text { strategies }\end{array}$} & \multicolumn{2}{|c|}{$\begin{array}{l}\text { Goal for national or regional economies: } \\
\text { productivity } \\
\text { Measurement: output produced per unit input } \\
\text { Type: physical measure } \\
\text { Improvement through: technical efficiency or } \\
\text { technological progress }\end{array}$} \\
\hline Framework & Five Forces & Value Chain & Diamond & $\begin{array}{l}\text { Cluster (already at } \\
\text { the core of the } \\
\text { diamond) }\end{array}$ \\
\hline Disciplines & \multicolumn{2}{|c|}{ Industrial Economics, Strategic management } & \multicolumn{2}{|c|}{$\begin{array}{l}\text { Industrial Economics, Strategic management, } \\
\text { Economic geography, Regional science }\end{array}$} \\
\hline Audience & \multicolumn{2}{|l|}{ firms and industries } & \multicolumn{2}{|c|}{ governments and policy makers } \\
\hline
\end{tabular}

Source: based on the first chapter of Huggins \& Izushi (2011, pp. 1-22) 
For the time being it is important to underline that the main level of analysis varies considerably between the different books. While the first book concentrates on an industry level, the second book digs down on the company level, the third book takes again a broader view by focusing on the nation, and the last book digs down again, but this time not to analyse firms but regional advantages. Each of the four books is associated with one main concept: the five forces ${ }^{46}$ concept to analyse an industry (Porter, 1980 (1998)), the value chain ${ }^{47}$ concept to analyse firms (Porter, 1985 (1998)), the diamond ${ }^{48}$ concept to analyse a nation's advantages (Porter, 1990 (1998)) and the cluster concept to further develop the diamond model on a regional level (Porter, 1998d).

The audiences of these books are not the same. In the first two books Porter particularly focused on firms and industry, in order to give recommendations for managers. In the last two books, the focus laid more on governments and policy makers. This also changed Porter's views regarding the role of innovation and cooperation (see Table 5). Innovation is only treated as a marginal feature in the first two books while being one of the central elements for competitive advantage in the last two books. Also the role of cooperation is not really treated in the first two books, but is, like innovation, an important element in the last two books, particularly regarding knowledge exchange (Huggins \& Izushi, 2011).

\section{Table 5: Porter's major contradictions}

\begin{tabular}{|l|l|l|}
\hline & $\begin{array}{l}\text { Competitive Strategy (1980) \& } \\
\text { Competitive Advantage (1985) }\end{array}$ & $\begin{array}{l}\text { The competitive advantage of nations } \\
\mathbf{( 1 9 9 0 ) \&} \\
\text { On Competition (1998) }\end{array}$ \\
\hline $\begin{array}{l}\text { Role of } \\
\text { innovation }\end{array}$ & $\begin{array}{l}\text { is only a marginal feature in the proposed } \\
\text { tactics }\end{array}$ & $\begin{array}{l}\text { very important, creates competitive } \\
\text { advantage }\end{array}$ \\
\hline $\begin{array}{l}\text { Role of } \\
\text { cooperation }\end{array}$ & no role, sole focus upon competition & $\begin{array}{l}\text { very important, creates competitive } \\
\text { advantage; coexists with competition }\end{array}$ \\
\hline
\end{tabular}

Source: based on Huggins \& Izushi (2011)

According to Porter (Porter, 1985 (1998), 1990 (1998)), competitive advantage for a firm signifies not the same as for a nation or region. The goal for a firm is profitability measured

\footnotetext{
${ }^{46}$ Porter's five forces (1980): threat of new entrants, intensity of rivalry among existing competitors, threat of substitute products, bargaining power of buyers and bargaining power of suppliers

47 Porter's value chain (1985): isolation of nine categories of activities; four support activities (firm infrastructure, human resource management, technology development, procurement) and five primary activities (inbound logistics, operations, outbound logistics, marketing and sales, services)

${ }^{48}$ Porter's diamond (1990): firm strategy, structure and rivalry; demand conditions; related and supporting industries; factor conditions
} 
by comparing receipts and costs. It is thus a financial measure that can be improved through for example pricing strategies. The goal for a nation however is productivity measured by output produced per unit input. The national productivity measure is more a physical measure that is improved through technical efficiency or technological progress. This progress and efficiency can be gained by innovation: "A nation's competitiveness depends on the capacity of its industry to innovate and upgrade" (Porter, 1990, p. 73). The ideas on innovation and technical progress are in vogue at the end of the 1980s, as we have already seen with Romer's (1986) and Lucas's (1988) discussions on the importance to integrate "technological change" or Aydalot's (1986) discussion on innovative milieus.

Hereinafter we will now dig deeper into the development of Porter's view on the productivity of nations and regions, which is particularly important for cluster researchers. For this we will discuss the rise of the competitiveness' notion, Porter's advisory role in Ronald Reagan's government in the 1980s and the difference between comparative advantage (Ohlin, 1933; Ricardo, 1817 (1821)) and competitive advantage of nations (Porter, 1990 (1998)).

\subsection{The competitive advantage of regions and nations}

Besides the changes happening on a research and political sphere during the 1980s, we have to recall that the economy was also more and more struggling during the 1980s. Economic growth and regional competitiveness was not in the centre of attention during the period after World War II up to the 1970s because the economy in the developed countries was doing well. However, this started to change in the 1970s and was strongly visible in the 1980s.

The discussed changes had a strong impact on how national competitiveness was perceived in an increasing globalised world. Krugman (1994, p. 29) calls it the "rhetoric of competitiveness" or "competitiveness metaphor". In the beginning of the 1990s, Krugman wrote that "the view that, [...], each nation is 'like a big corporation competing in the global marketplace' - has become pervasive among opinion leaders through out the world" (1994, p. 29). An illustrative example of the influence of this "competitiveness" quest on politician is for example the establishment of an "advisory committee on industrial competiveness" by Ronald Reagan in 1983. 


\title{
3.2.1 An opportunity to apply the notion at national level
}

In 1981 Ronald Reagan (Republican Party) succeeded Jimmy Carter (Democratic Party) as the 40iest president of the United States. Beginning of the 1980s the economic situation of the United States was very gloom, which was one of the reasons of Carter's defeat in the America's presidential elections of $1980 \mathrm{~s}^{49}$. The election of a republican president went along with profound changes regarding the direction of American policy (Duiker, 2009). Instead of continuing to promote a social welfare state, Reagan considerably cut spending in social areas, cut taxes and invested heavily in military (Duiker, 2009). Even though his approach is considered as conservative and in opposition to social welfare policies, this did not mean that Reagan believed in deficit reduction (as conservative parties might do today). Instead, Reagan considerably increased the American deficit in order to relaunch the economy: "In 1980, the total government debt was around $\$ 930$ billion, by 1988, the total debt had almost tripled, reaching \$2.6 trillion” (Duiker, 2009, p. 173).

Retrospectively, an important initiative of Ronald Reagan was the establishment of an "advisory committee on industrial competiveness"

Annex 1 for more detail). Ronald Reagan explained the role of the committee as follows:

\begin{abstract}
"I charged the Commission with advising me and my administration on ways to strengthen the competitiveness of U.S. industry. This nation's greatest competitive advantage in the past were ideas that helped America grow. We need to put the power of ideas to use again, for the good of our future. [...]. To sustain high rates of real economic growth, we must continue to create new "miracles" of high technology - miracles both for innovation and for modernization of the major areas of our economy in manufacturing, agriculture, and services. The Commission members I am appointing today are distinguished leaders from large and small businesses, from labor, and from academia. [...]. The Commission will focus its attention on [...]:

- Identifying the problems and opportunities for the private sector to transform new knowledge and innovations into commercial products, services, and manufacturing processes.

- Recommending policy changes at all levels of government to improve the private sector's ability to compete in the international marketplace and to maintain and create opportunities for American workers. "51
\end{abstract}

\footnotetext{
49 Americas economic situation in the 1970s and 1980s: "The period from 1973 to the mid-1980s was one of economic stagnation, which came to be known as stagflation - a combination of high inflation and high unemployment. In 1984, median family income was 6 present below that of 1973. The economic downturn stemmed at least in part from a dramatic rise in oil prices [...] By 1980s, the Carter administration was facing two devastating problems. High inflation and a noticeable decline in average weekly earnings were causing a perceptible drop in American living standards." (Duiker, 2009, p. 173)

${ }_{50}$ Source: Ronald Reagan: "Executive Order 12428 - President's Commission on Industrial Competitiveness," June 28, 1983. Online by Gerhard Peters and John T. Woolley, The American Presidency Project. http://www.presidency.ucsb.edu/ws/?pid=41529 (accessed 15/05/2014)

51 "Statement on Establishment of the President's Commission on Industrial Competitiveness", August 4, 1983. Online by Gerhard Peters and John T. Woolley, The American Presidency Project. http://www.presidency.ucsb.edu/ws/?pid=41678 (accessed 15/05/2014)
} 
The committee had as objective to find new ways to generate economic growth in order for the USA to succeed in the future. The emphasis of the committee should particularly lie on the identification of problems and opportunities as well as the recommendation of policies. In 1983, one of the academic scholars that was appointed by Ronald Reagan to participate in this advisory committee on industrial competiveness was Michael Porter (1985 (1998)). In 1985, the commission published a final report named "Global Competition - The New Reality",52 and particularly emphasized the lack of investment or policy frameworks in four areas: technology, capital resources, human resources and international trade.

In 1986, John A. Young (president of the Hewlett-Packard Co) who also chaired Reagan's initial committee on industrial competiveness decided to found the "Council on competitiveness" ${ }^{\text {53 }}$. Retrospectively, Ronald Reagan initiated a national reflection on competitiveness that still prevails today. Today, this council on competitiveness is a nongovernmental organization and similar to the times of Reagan's initial idea includes “corporate CEOs, university presidents, labor leaders and national laboratory directors".

The council wishes to be a "powerful 'brain trust","54 which tries to ensure America's prosperity in the future. In order to become member of this elite circle one has to be invited, however once invited to the network, the Council membership gives access to all important policy makers ranging from national to regional level. Additionally, the membership allows to be invited to policy dialogues and conferences. Michael Porter, nearly thirty years later, still occupies a place in the executive committee of this Council on competitiveness.

For Porter, the appointment to Reagan's “advisory committee on industrial competiveness" had an impact on his subsequent ideas and thoughts. The writings of Porter from the 1980s onwards are influenced by this quest for national competitiveness something he considered was not accurately grasped at that time (Porter, 1990). The participation of Porter in Reagan's advisory committee on competitiveness has helped him as well to increase his already existing notoriety to become one of the most influential policy advisors in the world.

\footnotetext{
${ }^{52}$ The final report "Global Competition - The New Reality" of the commission on industrial competitiveness was published in 1985 and can be accessed here:

http://www.wedc.wa.gov/Download\%20files/Global_Competition-The New_Reality.pdf (accessed 15/05/2014)

${ }^{53}$ See: http://www.compete.org/ (accessed 15/05/2014)

${ }^{54}$ See: http://www.compete.org/ (accessed 15/05/2014)
} 


\subsubsection{From "comparative advantage" to "competitive advantage of nations"}

Porter, stimulated by its participation in Reagan's advisory committee on industrial competitiveness, more and more criticized the dominant views of "comparative advantage" (Ohlin, 1933; Ricardo, 1817 (1821)). Porter (1990, p. 73) particularly criticizes that "there is a growing tendency to experiment with various policies intended to promote national competitiveness - from efforts to manage exchange rates to new measures to manage trade to policies to relax antitrust". He argues that these experiments "usually end up only undermining [competitiveness]" and that instead "new perspective and new tools" are needed (Porter, 1990, p. 73). Very simplistic, he argues that: "We need to know, very simply, what works and why. Then we need to apply it." (Porter, 1990, p. 73).

However, Porter also tried to overcome a certain deterministic body of thought. According to Porter (1990 (1998), intro.), in a "modern global economy" every country has its future in its hands, nevertheless which resources it possesses in the beginning. This means that "prosperity is a nation's choice" and that "competitiveness is no longer limited to those nations with a favourable inheritance” (Porter, 1990 (1998), intro.). Instead "nations choose prosperity if they organize their policies, laws, and institutions based on productivity" (Porter, 1990 (1998), intro.)

It is the national productivity, the "only meaningful concept of competitiveness at the national level" (Porter, 1990 (1998), Ch. 1, Sec. 2), that has to be stimulated and increased in order to generate more wealth. Porter identified four sources of competitive advantage (commonly known as the diamond model): (1) factor condition, (2) firm strategy, structure, and rivalry, (3) demand conditions, and (4) related and supporting industries. Each of these four sources is increasingly present in the four stages of national competitive development that he identified as well (see Table 6). The first stage of national competitive development is factor-driven, the second stage investment-driven and the third stage innovation-driven. According to Porter (Porter, 1990 (1998)), it is this innovation-driven stage that, according to Porter, that generates the greatest wealth and that countries should strive for. However, as soon as a country enters the wealth-driven stage it is declining again.

Porter completely reinterpreted the comparative advantage (Ohlin, 1933; Ricardo, 1817 (1821)) debate. First, for Porter (1990 (1998)) location still matters besides a shrinking world and globalization. Second, nations do not have to detect a comparative advantage to challenge 
their "competitors" but "simply" create their own "competitive advantage". In the centre of this idea lies the cluster concept, for Porter "the basic unit of analysis in understanding national advantage" (Porter, 1990 (1998), Ch. 10). Finally, if we think in the mind frame of organisational scholars, Porter might be closer to organisational learning scholars (Argyris \& Schön, 1978; Nonaka \& Takeuchi, 1995) than to population ecology scholars (Hannan \& Freeman, 1977, 1989 (1993)).

Table 6: Porter's stages of development intersected with his sources of competitiveness

\begin{tabular}{|c|c|c|c|c|c|}
\hline & \multicolumn{4}{|c|}{ Sources of competitive advantage (Diamond model) } \\
\hline & & Factor condition & $\begin{array}{l}\text { Firm strategy, } \\
\text { structure, and } \\
\text { rivalry }\end{array}$ & $\begin{array}{l}\text { Demand } \\
\text { conditions }\end{array}$ & $\begin{array}{l}\text { Related and } \\
\text { supporting } \\
\text { industries }\end{array}$ \\
\hline \multirow{4}{*}{$\begin{array}{l}\text { Stages of } \\
\text { national } \\
\text { competitive } \\
\text { development }\end{array}$} & $\begin{array}{l}\text { 1. Factor- } \\
\text { driven }\end{array}$ & $\begin{array}{l}\text { Basic factors are } \\
\text { the essential } \\
\text { source of } \\
\text { advantage }\end{array}$ & & & \\
\hline & $\begin{array}{l}2 . \\
\text { Investment- } \\
\text { driven }\end{array}$ & $\begin{array}{l}\text { Basic factors } \\
\text { remain an } \\
\text { advantage; more } \\
\text { advanced factors } \\
\text { are created }\end{array}$ & $\begin{array}{l}\text { Motivation of } \\
\text { individuals and } \\
\text { firms is high; } \\
\text { domestic rivalry } \\
\text { is intense }\end{array}$ & $\begin{array}{l}\text { Size and growth } \\
\text { of domestic } \\
\text { demand } \\
\text { becomes an } \\
\text { advantage }\end{array}$ & \\
\hline & $\begin{array}{l}\text { 3. Innovation- } \\
\text { driven }\end{array}$ & $\begin{array}{l}\text { Advanced and } \\
\text { specialized factors } \\
\text { are created and } \\
\text { upgraded; } \\
\text { selective factor } \\
\text { disadvantages }\end{array}$ & $\begin{array}{l}\text { Firms develop } \\
\text { global strategies }\end{array}$ & $\begin{array}{l}\text { Demand } \\
\text { sophistication } \\
\text { becomes an } \\
\text { advantage; } \\
\text { domestic } \\
\text { demand begins } \\
\text { internationalizin } \\
\mathrm{g} \text { through a } \\
\text { nation's } \\
\text { multinationals }\end{array}$ & $\begin{array}{l}\text { Related and } \\
\text { supporting } \\
\text { industries are } \\
\text { well developed }\end{array}$ \\
\hline & $\begin{array}{l}\text { 4. Wealth- } \\
\text { driven }\end{array}$ & $\begin{array}{l}\text { Cumulative past } \\
\text { investment in } \\
\text { factor creation } \\
\text { persists as an } \\
\text { advantage }\end{array}$ & $\begin{array}{l}\text { Motivation falls, } \\
\text { rivalry ebbs }\end{array}$ & $\begin{array}{l}\text { Demand } \\
\text { advantages } \\
\text { narrow to } \\
\text { present or past } \\
\text { wealth-related } \\
\text { industries }\end{array}$ & Clusters thin \\
\hline
\end{tabular}

Source: based on Porter (1990 (1998), Ch. 10, Sec. 2)

Porter started to develop its cluster concept in its book on the competitive advantage of nations (Porter, 1990 (1998)) and further refined the concept the following years (Porter, 1998a, 1998b, 1998c, 2000a, 2000b, 2001, 1998d; Porter \& Stern, 2001). Generally Porter (Porter, 1998c, p. 78) defines clusters as “critical masses - in one place - of unusual competitive success in particular fields".

More precisely, Porter (1998b, p. 215) defines a cluster as a "a geographically proximate group of interconnected companies and associated institutions in a particular field, linked by 
commonalities and complementarities". The geographic scope of a cluster can take multiple forms, ranging "from a single city or state to a country or even a network of neighbouring countries" (Porter, 1998b, p. 215). However, the boundaries of a cluster are defined "by the linkages and complementarities across industries and institutions that are most important to competition” (Porter, 1998c, p. 79).

According to Porter (1998b, p. 215), the actors of the cluster vary but "most include endproduct or service companies; suppliers of specialized inputs, components, machinery, and services; financial institutions; and firms in related industries." Next to these core cluster actors, clusters also count a range of additional actors. Such as

\begin{abstract}
"firms in downstream industries [that is, channels or customers]; producers of complementary products; specialized infrastructure providers; government and other institutions providing specialized training, education, information, research, and technical support [such as universities, think tanks, vocational training providers]; and standards-setting agencies. Government agencies that significantly influence a cluster can be considered part of it." (Porter, 1998b, p. 215)
\end{abstract}

Between 1998 and 2001, the "Council on competitiveness" launched, together with Porter and his consultancy group Monitor, a "Clusters of Innovation" initiative ${ }^{55}$. This initiative had as objective to investigate "healthy regions", "to map" them and based on these findings "develop the right policy recommendations" (Porter, 2001, p. ix). The assumption was, that "competitiveness and innovation are concentrated in clusters, or interrelated industries, in which the region specializes" (Porter, 2001, p. ix). So in order for a nation "to produce highvalue products and services that support high wage jobs", governments have to "creat[e] and strengthen[...] these regional hubs of competitiveness and innovation" (Porter, 2001, p. ix).

For example, in order to support healthy clusters and regions, the report (Porter, 2001) recommends to implement an explicit cluster development program to raise awareness among the local actors, to specifically recruit companies for the region after analysing the existing value chain and its gaps, or to detect opportunities at the intersection of different clusters to further enhance growth. Also national, regional and local governments need to implement the right policies, particularly focusing on innovation and encouraging cluster development, to further strengthen the regional and national competitiveness.

\footnotetext{
${ }^{55}$ Source: "Council on competitiveness" website (http://www.compete.org/publications/detail/220/clusters-ofinnovation-initiative-regional-foundations-of-us-competitiveness/) (accessed 06/05/2014)
} 
The clusters of innovation initiative catapulted Porter to one of the most wanted policy advisor in the world as this citation nicely summarizes:

"From the OECD and the World Bank, to national governments such as the United Kingdom, France, Germany, the Netherlands, and New Zealand, to regional government agencies, and to local and city governments (including various US states), policymakers at all levels have been eager to receive his advice. [...] [But also] an expanding array of developing countries in Asia, Latin America, the Middle East, and Africa [...] vie for his expertise in economic development policy” (Huggins \& Izushi, 2011, pp. 3-4).

The particularity of Porter's approach was that he mapped the different actors of a cluster like he did for the different functions of a company (the value chain) (Porter, 1985 (1998)) in order to determine the missing chain elements of the region and the potential dangers to create an endogenous competitive advantage. However, the Porterian "mapping" approach stays a relative static approach. For example he recommends that "regions should [...] identify gaps within clusters, and seek to attract companies to fill them” (Porter, 2001, p. xvi). Porter, analysing the wine cluster in California and mapping the different local actors and their linkages, called this representation "the anatomy of the California wine cluster" (Porter, 1998c, p. 79).

To summarize, Porter, at the end of the 1980s and embedded in the though style of his time, advocated that every country could take into his own hand the creation of its competitive advantage. He underlines that "the most important sources of prosperity are created not inherited" (Porter, 2001, p. x). According to him, government authorities at every level need to foster the "right" elements in order to pass to the next stage of national competitive development (from the factor-driven stage to the innovation-driven stage). At the centre of Porter's reflections on national competitiveness stands the concept of "productivity" that can only be sustained in the long run by continuous innovation:

"The only meaningful concept of competitiveness at the national level is productivity. The
principal goal of a nation is to produce a high and rising standard of living for its citizens. The
ability to do so depends on the productivity with which a nation's labor and capital are
employed. Productivity is the value of the output produced buy a unit of labor or capital. [...]
Sustained productivity growth requires that an economy continually upgrade itself. [...] [A
nation's companies] must finally develop the capability to compete in entirely new,
sophisticated industries." (Porter, 1990, pp. 76-77)

In the end of the 1980s we thus observed a shift from "comparative advantage" to "competitive advantage". Governments around the world were eager to start creating their own "competitive advantage". The end of the 1980s and beginning of the 1990s were thus a 
paradigm change of how to consider competitiveness. However, as we will see in the next section, this shift also created strong criticisms from plenty of scholars.

\subsection{Competitiveness and its emerging critics}

The increased worldwide competition (Thurow (1992 (1993)) compares it to a chess play) ${ }^{56}$ was increasingly debated by policy makers and academics alike. For example, Krugman (1994, p. 29) stresses that during this time a "whole industry of councils on competitiveness, "geo-economists" and managed trade theorists has sprung up in Washington", all trying to help the USA gain the competitiveness race of the $21^{\text {st }}$ century. Additionally to the rise of competitiveness advisors, the establishment of a global competitiveness index also reflects this new development of "competitiveness thinking" at the national level. Since the 1979, the World Economic Forum (WEF) ${ }^{57}$ publishes an annual competitiveness report and since 2004 the WEF also introduced a global competitive index ${ }^{58}$. Each country started to strive for its competitiveness by implementing policies to reach the "innovation stage" of development.

Today we even rank regions like companies (see Table 7). CEOs such as local and national authorities strive for the same objective: creating innovation within their defined boundaries. However, this quest for national competitiveness is also firmly criticized out of several reasons.

\footnotetext{
${ }^{56}$ See Krugman (1994) for a list of bestsellers on the global competitiveness race of this time

${ }^{57}$ The WEF is a foundation that allows worldwide economic and political leaders to exchange on the economic options of the planet. Porter regularly participates in the discussions of the WEF.

${ }^{58}$ The WEF, similar to Porter's definition, defines competitiveness as a "set of institutions, policies, and factors that determine the level of productivity of a country" (WEF, 2011, p. 4). The index used for the ranking is composed out of three components: (1) basic requirements (e.g. infrastructure, institutions, macroeconomic stability, health, primary education), (2) efficiency enhancers (e.g. Higher education and training, technological development, size of the market, financial market development, efficiency of the market), and (3) innovation and sophistication factors (e.g. business sophistication). The weight attributed to each of these components varies according to the degree of development of the country. The index attributes a higher weight on innovation and sophistication factors for highly developed economies than for less developed economies. Today the main underlying paradigm is that innovation leads to higher productivity, which again will lead to higher wealth. The global competitive index allows the WEF to rank the majority of all nations (142 nations in 2011) according to their respective "competitiveness".
} 
Table 7: Top ten most innovative companies and regions in Europe

\begin{tabular}{|c|l|l|}
\hline Rank & Companies (Country) $)^{\mathbf{5 9}}$ & Regions (Country) $^{\mathbf{6 0}}$ \\
\hline 1. & ARM Holdings (UK) & Stockholm (SE) \\
\hline 2. & Pernod Ricard (FR) & Västsverige (SE) \\
\hline 3. & Danone (FR) & Oberbayern (DE) \\
\hline 4. & Essilor International (FR) & Etelä-Suomi (FI) \\
\hline 5. & Reckitt Benckiser (UK) & Karlsruhe (DE) \\
\hline 6. & Diageo (UK) & Stuttgart (DE) \\
\hline 7. & L'Oreal (FR) & Braunschweig (DE) \\
\hline 8. & Beiersdorf (DE) & Sydsverige (SE) \\
\hline 9. & Dassault Systemes (FR) & Île de France (FR) \\
\hline 10. & Technip (FR) & Östra Mellansverige (SE) \\
\hline
\end{tabular}

Source for company ranking: Sharf (2012), Source for region ranking: Hollanders (2006)

\subsubsection{The critic of competition between territories}

For example, Krugman (1994, p. 29) underlines that this competitiveness race leads countries to compete with each other like companies (Krugman, 1994). For Krugman (1994, p. 29) "thinking in terms of competitiveness leads, directly and indirectly, to bad economic policies on a wide range of issues, domestic and foreign, whether it be in health care or trade" (p. 30). Additionally he warns that "competitiveness is a meaningless word when applied to national economies and the obsession with competitiveness is both wrong and dangerous" ( $\mathrm{p}$. 44). Also Delaplace (2011) and Gaffard (2008) argue that it would be dangerous to think that territories and regions are in competition to each other.

\subsubsection{The critic of blindness on knowledge and innovation}

Krugman (1991 (1993), p. 54) also firmly criticized the increased focus on local knowledge spillovers and the ignorance that other location factors might be more important. He describes this increased blindness and focus on only one type of location factor as falling in a “"megatrends' style of thought”. He might have been right but was not able to avoid the trend that already started.

\footnotetext{
${ }^{59}$ Ranking criteria for companies: "The Innovation Premium is a measure of how much investors have bid up the stock price of a company above the value of its existing business based on expectations of future innovative results (new products, services and markets). Members of the list must have $\$ 10$ billion in market capitalization, spend at least $1 \%$ of their asset base on $R \& D$ and have seven years of public data." (http://www.forbes.com/ accessed: 18/04/2013)

${ }^{60}$ Ranking criteria for regions: The ranking is based on seven indicators (for a detailed explication of the calculation see (Hollanders, 2006)): (1) Human Resources in Science and Technology, (2) Participation in lifelong learning, (3) Employment in medium-high and high-tech manufacturing, (4) Employment in high-tech services, (5) Public R\&D expenditures, (6) Business R\&D expenditures, (7) EPO patent applications
} 
Twenty years later, Shearmur (2011b), in a certain Krugmannian manner continues this criticism. The cluster policies' that were implemented at the end of the $20^{\text {th }}$ century and beginning of the $21^{\text {st }}$ century, based on Porter's ideas, strongly focus on local buzz, networks and knowledge but rather ignore other agglomeration factors, equally important for creating innovation. For Shearmur (2011b, pp. 1238-1239), in order to maintain or create "proximities" between local actors "physical infrastructure and basic services (such as air transport, highway maintenance, hotels, etc.) are also required”. He argues that by only focusing on "intangible resources such as governance, networks, and knowledge" the hoped positive outcomes of policy-driven clusters might not be happening (Shearmur, 2011b, pp. 1238-1239).

Today, for plenty of politics but also academics, innovation and networking are at the core of cluster policies. For example Capron (2011, p. 107) underlines that "cluster policy is considered as one of the main strategic priorities for successfully promoting innovation”. Not surprisingly, a range of researchers automatically try to address the innovation and networking issue in their research endeavours (see for example (Cumbers, Mackinnon, \& Chapman, 2003; Huggins \& Johnston, 2009; Mans, Alkemade, Van der Valk, \& Hekkert, 2008; McDonald, et al., 2007)) and generally focus less on other important agglomeration factors.

\subsubsection{The critic of regions as closed systems}

Nations and then clusters were somehow more and more considered as closed systems that can be managed in order to increase their competitiveness (Shearmur, 2011a). These developments lead to the belief, that if nations or clusters are organised in the "right manner", they can climb up the ladder to reach the innovation-driven stage and competitive advantage as defined by Porter (1990 (1998)). However, this closed system thinking is strongly criticized (H. Bathelt \& Dewald, 2008; Rugman, 1992; Shearmur, 2011a).

For example, Rugman (1992) firmly criticized a study Porter (1991) conducted on the Canadian economy. Porter (1991), scrutinizing the Canadian economy by applying his diamond model, concludes that Canada is weak in "developing global competitive advantage" as it is still mainly specialized in resources. According to Porter's stages of national development thinking, resources belong to the "old economic order" which will not allow a sustainable long-term growth. However, Rugman (1992) argues that Porter's 
arguments are incorrect because the diamond model does not take into account that each nation is highly interlinked with other nations and that this is not at all taken into consideration in the diamond model:

"[...in order] to become globally competitive, Canadian managers need to design strategies across both the U.S. and Canadian diamonds. They need to benchmark decisions on a North American basis, not just a Canadian one. Yet Porter rejects this approach [...]. Porter's oldfashioned, naïve and politically mischievous viewpoint is inconsistent with Canada's support of the free trade agreement, tax reform, constitutional renewal and other economic, social and political measures aimed at improving, the climate for doing business in a Canadian economy that is interdependent with a that of the U.S." (Rugman, 1992, p. 59)

Shearmur (2011a) such as Rugman (1992) argue that every nation or cluster is integrated in a broader regional and national system and therefore necessarily interlinked with other systems. One regional system might for example be the helping hand of another regional system. For Bathelt \& Dewald (2008, p. 163), Porter created a confusion of the concept because he applied it "to the competitiveness of both national industry bundles and inter-linked regional industry networks".

Additionally, according to Porter, an important element of every cluster to compete internationally is to possess a local value chain. In case one important chain element is missing, entrepreneurship should be fostered to plug the hole. However, some researchers are completely opposed to this value chain view. The results of McDonald et al. (2007, p. 46) who analysed clusters in the UK show that "that there is no strong evidence that established local supply chains are significantly associated with international competitiveness." However, they identified that "there is a link between established local supply chains and employment growth" but at the same time they underline that "this need not be a strong indicator of long-term regional competitiveness in terms of international competitiveness" (McDonald, et al., 2007, p. 46). According to their results, supporting a complete value chain within a closed system might bring an employment growth in the short-run but not an international competitive position in the long run. 


\section{Summary of chapter one}

Figure 6 summarizes graphical the different elements discussed in chapter one. On the one hand, the research sphere of the 1980s was characterized by the paradigm shift of economic growth theories (focus on knowledge and institutions), the change of production, an increasing role attributed to the region as a place where the economy is organized, and the shift from comparative advantage to competitive advantage. On the other hand the political and societal sphere was characterised by the opening of the Chinese market and the end of the cold war, the start of a power shift of economic activity, the oil crises, the abandon of Keynesian economics with the arrival of Thatcher and Reagan, and the rise of the computer ${ }^{61}$ and the Internet. The two spheres were, in a certain manner, characterized by antagonistic developments: increasing globalisation, global integration and economic liberalism vs. increasing regionalisation and institutionalism.

\section{Figure 6: Timeline of events 1980s}

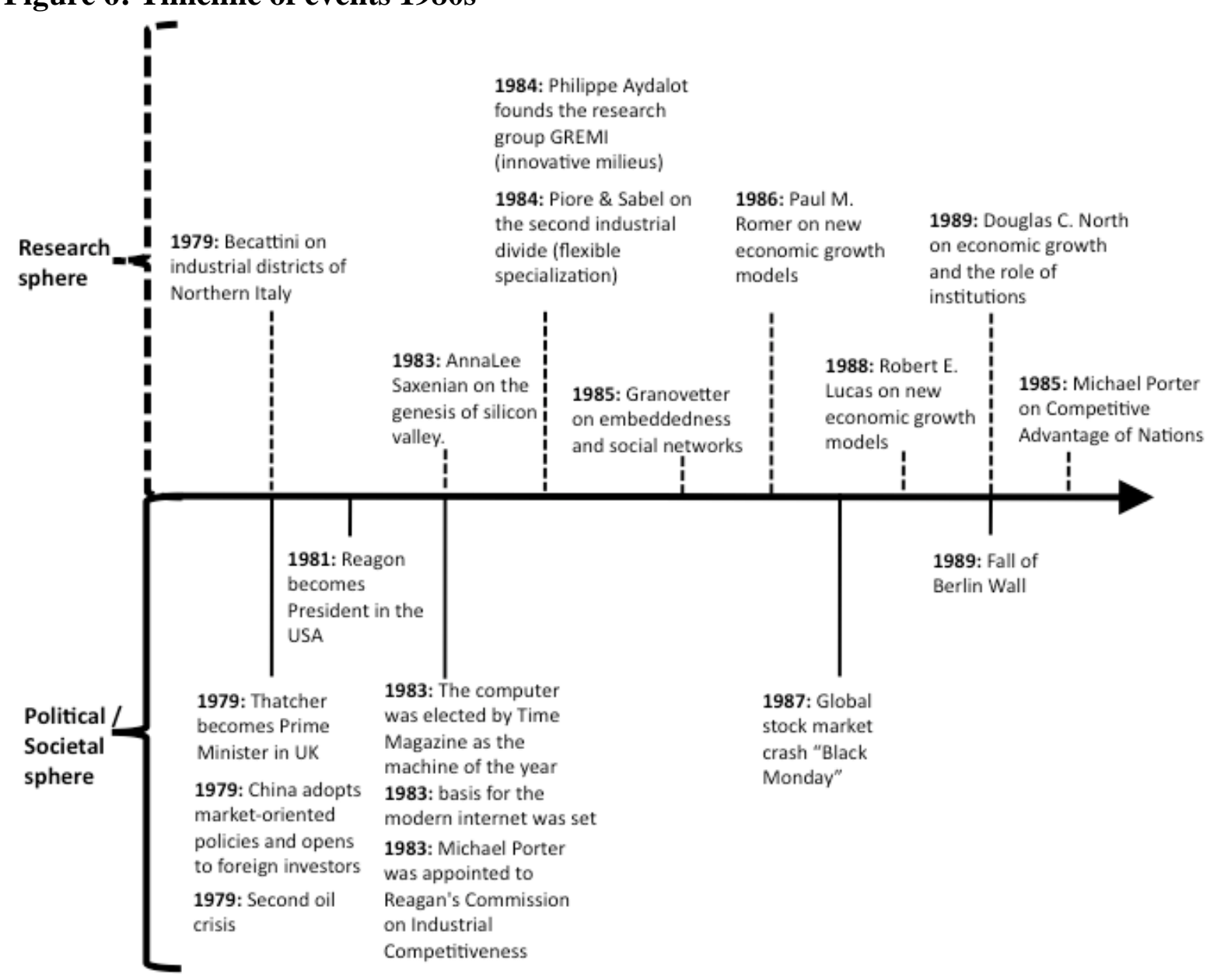

\footnotetext{
${ }^{61}$ The computer was elected by Time Magazine as the machine of the year in 1983 (Time Magazine, 1983).
} 
The 1980s witnessed three major shifts in the research realm that constitute important elements for the birth of cluster studies. The main differences are summarized in Table 8 .

Table 8: Summary of research shifts during the 1980s

\begin{tabular}{|l|l|l|}
\hline & \multicolumn{1}{|c|}{ From } & \multicolumn{1}{|c|}{ To } \\
\hline $\begin{array}{l}\text { Focus on } \\
\text { economic } \\
\text { growth }\end{array}$ & $\begin{array}{l}\text { - Neoclassical (or exogenous) economic } \\
\text { growth models. Focus on labour and capital } \\
- \text { Institutions play a minor role in economic } \\
\text { growth }\end{array}$ & $\begin{array}{l}\text { - Endogenous economic growth models. } \\
\text { Focus on labour, capital and knowledge } \\
- \text { Institutions play a role in economic growth }\end{array}$ \\
\hline $\begin{array}{l}\text { Focus on } \\
\text { regions }\end{array}$ & $\begin{array}{l}\text { - Region plays a minor role during the mass } \\
\text { production era. } \\
\text { - Embeddedness in social networks plays a } \\
\text { minor role on the economic outcome of the } \\
\text { individual. }\end{array}$ & $\begin{array}{l}\text { Regions play a role in the post-mass } \\
\text { production era (innovation \& flexible } \\
\text { specialization) } \\
\text { Embeddedness in social networks } \\
\text { influences the economic outcome of } \\
\text { individuals }\end{array}$ \\
\hline $\begin{array}{l}\text { Focus on } \\
\text { competitive } \\
\text { advantage }\end{array}$ & $\begin{array}{l}\text { - Prevailing concept to discuss national } \\
\text { success: comparative advantage } \\
- \text { every nation has its own relative advantage } \\
\text { compared to competitors, the objective is to } \\
\text { identify this relative advantage }\end{array}$ & $\begin{array}{l}\text { Prevailing concept to discuss national } \\
\text { success: competitive advantage } \\
\text {-every nation is master of its destiny and if it } \\
\text { wishes to increase its wealth has to strive for } \\
\text { innovation }\end{array}$ \\
\hline
\end{tabular}

The first important shift concerns how economic growth is perceived. Up to the 1980s neoclassical (exogenous) economic growth models dominated. The main focus was on labour and capital while institutions played a minor role. From the 1980s onwards, endogenous economic growth models emerged. The focus not only laid on labour and capital but also on knowledge. Additionally, institutions started to play an increasing role in economic growth.

The second important shift concerns the new discovered role of the region. During the mass production era regions did not play a major role and also the embeddedness in social networks was not considered as an important element to increase the economic outcome of individuals. However, this changed during the post-mass production era or the knowledge economy where innovation and flexible specialization gained in importance. Innovation and knowledge was now considered to be embedded in regions with dense networks.

The third important shift is regarding national success. The prevailing concept up to the 1980s was comparative advantage, where the credo was that very nation has its own relative advantage compared to competitors. The objective was to identify this relative advantage. From the 1990s onwards the prevailing concept to discuss national success was competitive advantage, where every nation is master of its destiny and if it wishes to increase its wealth has to strive for innovation. 
During the last 25 years, the cluster concept somehow took on a life of its own. Swords (2013) for example recently tried to study the cluster legitimization process in the UK. By mobilizing Latour's actor-network-theory, Swords explains that it was a back and forward process of actors criticising the new trend but on the other hand legitimatizing it through the increased concentration on the phenomenon. On the one hand, it was the interplay between "academics" that "act[ed] as consultants" and "helped legitimize and reproduce clusters", and the academics who "heavily critiqued the concept" (Swords, 2013, p. 380). On the other hand, it was the interplay between the central governments that wanted to create competitiveness and the regional actors, "bound by central government to foster [clusters]", even though they were not always "convinced of clusters' efficacy" (Swords, 2013, p. 380). Swords (2013, p. 380), underlines that the cluster concept "gained size and strength as clusters were simultaneously promoted and critiqued".

In this chapter we tried to underline that even though the cluster concept experienced a strong legitimization process, a great distance emerged between the beginnings of the study of the cluster concepts and the recent developments. A world lies between Romer's or Luca's economic growth theories, Porter's cluster idea and his mapping approach and finally two neighbouring regions trying to "build" clusters. The whole idea to reach economic growth and competitive advantage by focusing on regions emerged during the 1980s. Since then, a longue road was travelled and governments around the world now establish policy-driven clusters on their territories (Motoyama, 2008; Swords, 2013). Governments currently believe, be it in developed countries or developing countries, that policy-driven clusters are the key to competitiveness and economic growth (OECD, 2007, 2009). However, little is actually known about these initiatives (foreword of Michael Porter in (Sölvell, et al., 2003, p. 5)). The literature on cluster policies and initiatives compared to the economic or geographic cluster literature still stays in the background (Swords, 2013). One has the feeling that the accelerating political and managerial reality on clusters, is drifting apart from the academic reality on cluster research. The drift between academics and policy makers and cluster managers is often related to the fuzziness of the cluster concept in itself, enclosing too many different objectives, not knowing to which regional entity it should be applied. The static mapping approach and the focus on the structure which Porter even calls "the anatomy" (Porter, 1998c, p. 79) of a cluster has become a dynamic approach with managerial challenges. In the next chapter we will now focus on the dilemmas and pathologies that emerge by implementing policy-driven clusters. 


\section{Chapter 2: Dilemmas and pathologies in policy-driven clusters}

In the $21^{\text {st }}$ century, policy-driven clusters have completely entered the policy realm. They have become a "buzz word" for policy-makers (Lundequist \& Power, 2002, p. 699). Having policy-driven clusters on its territory was suddenly considered to be important for creating "healthy regions", and hopefully regional and national competitiveness. Ahedo (2004, p. 1099) for example underlined that even regional industry associations suddenly changed their name "from 'Interest Groups' to 'Cluster Organizations'” as it was considered that they "can easily function as 'cluster-organizations'” in order to foster "collaboration and cooperation between firms and other related actors". However, some argue that governments were and are just "riding the wave of new regionalist fashions" (Swords, 2013, p. 369) and that all the hype is just a "flavor of the month" (Doloreux \& Shearmur, 2009, p. 526) instead of showing real results.

Clusters were long-time considered as the "economic weapons of a country" (Aziz \& Norhashim, 2008). However, policy-driven clusters are somehow "often poorly designed" (Aiginger, 2007, p. 297) and are not always keeping up with their "natural" counter-parts (Doloreux \& Shearmur, 2009, p. 526). Cluster policies started to be more and more "under fire" because they are not reaching the expected goals (Ebbekink \& Lagendijk, 2013). The general malaise regarding the results of policy-driven clusters seems more complex than the criticisms on Michael Porter we already discussed (i.e. that competitiveness applied to territories creates competition between territories, a certain blindness on knowledge and innovation, or the belief that territories function as closed systems). At the beginning of the $21^{\text {st }}$ century, more than 10 years after Porter $(1990$ (1998)) first introduced his cluster concept, Martin \& Sunley (2003, p. 5) underlined that even though "cluster concept" is very "seductive", the fuzziness of the concept will lead to increased policy problems. But what are exactly these policy problems? One of the objectives of Porter's "Cluster of Innovation" initiative (1998 - 2001) was to investigate "healthy regions" and to develop policy recommendations (Porter, 2001, p. ix). However, even though policy-driven clusters should replicate these healthy regions, Martin \& Sunley's (2003, p. 5) underlined that the "the cluster concept should carry a public policy health warning”. Also Hospers et al (2009, pp. 297-298) advocated that the best motto for officials in charge for cluster policy is perhaps: "If you can't help, please do not harm". In a somehow strange manner, policy-driven clusters, that were meant to help countries to succeed, are apparently not always able to do so. We 
therefore have to start investigating "cluster policy as a policy challenge" (Ebbekink \& Lagendijk, 2013, p. 737). By conducting a literature review focusing on these cluster policy dilemmas, we might finally lay the foundation stone to start investigating the treatments that in fine will probably cure these diseases. In this second chapter we will now focus on the study of the dilemmas and pathology of policy-driven clusters.

\section{Box 3: Content of chapter two}

\section{Cluster policies and their impact}

1.1 Cluster policies: a new weapon to succeed in a globalized world?

1.2 The relevance gap in cluster policy research.

1.3 Positive impact of policy-driven clusters

2 Identifying cluster dilemmas \& pathologies: a systematic review .............................71

2.1 What is cluster dilemmas and pathology?

2.2 The need for a review of policy-driven cluster dilemmas and pathologies

2.3 A Systematic Literature Review

2.4 Organisational dilemmas as drivers of cluster pathologies

3 Drivers of pathologies: political dilemmas ...................................................................8.80

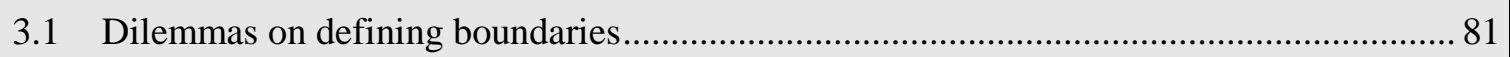

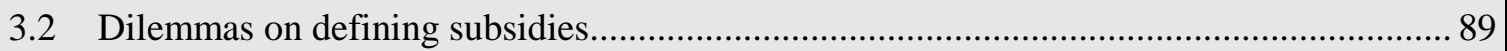

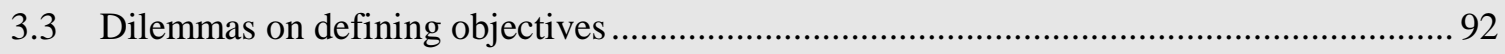

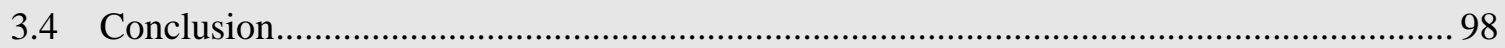

4 Drivers of pathologies: managerial dilemmas ........................................................98

4.1 Dilemmas on managing actor involvement ................................................................... 100

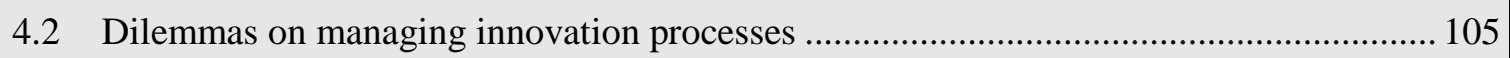

4.3 Dilemmas on managing collaboration processes ............................................................. 116

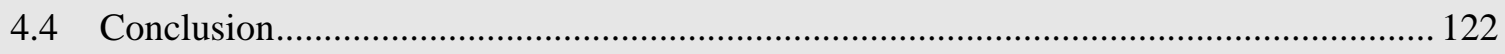

5 Drivers of pathologies: structural dilemmas...................................................123

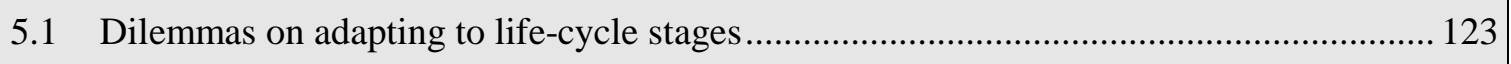

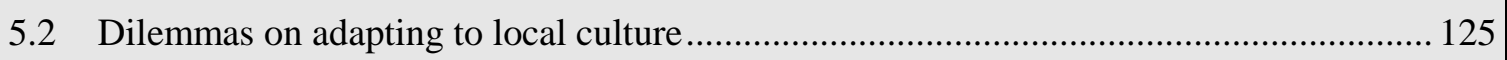

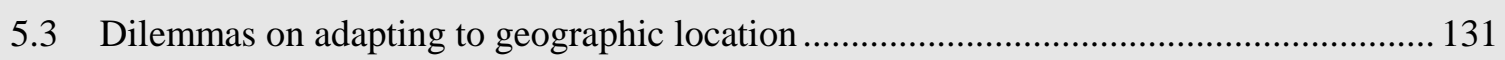

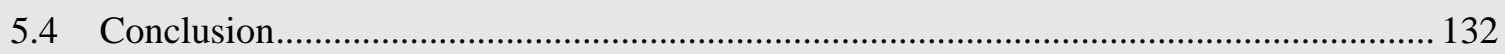

6 Summary of chapter two: overview of organisational dilemmas............................. 132 


\section{Cluster policies and their impact}

In this section we will start explaining the important gap that exists between practitioners and academics, which leaves ample room to a lot of policy-driven cluster problems that are not addressed in the literature. In a second step, we explain what pathology means in medicine and how we could apply it to cluster studies. Finally, even though our literature review focuses on the study of dilemmas and pathologies, plenty of positive effects of cluster policies are also discussed in the literature. We will shortly come back to these positive effects.

\subsection{Cluster policies: a new weapon to succeed in a globalized world?}

From the beginning of the 1990s onwards, governments around the world increasingly strived to create their own "healthy regions" 62 in order to win the global competitiveness race within the newly emerging knowledge-dominated economy ${ }^{63}$. Clusters were considered as one of these national elements in order to help creating and fostering regionally interconnected knowledge hubs. Porter's views on clusters had the biggest impact on "policy-makers and opinion-formers" in the United State and in Europe (McDonald, et al., 2007).

The word cluster though is source of a lot of confusion. For example Silicon Valley is called a cluster but differs to clusters that are fostered by specific policies. Instead of talking about "spontaneous clusters", which have "been a result of the spontaneous concentration of the key factors enabling [the cluster's] birth and development" (Chiaroni \& Chiesa, 2006, p. 1073), Chiaroni \& Chiesa (2006, p. 1073) talk about "policy-driven clusters", "where the trigger was the strong commitment of governmental actors whose willingness was to set the conditions for the development of the [...] cluster" (Chiaroni \& Chiesa, 2006, p. 1073). These policy-driven clusters are initiated by cluster policies that are meant to upgrade a "mere agglomeration to a regional (innovation) system" (Schmiedeberg, 2010, p. 390). From the 1990s onwards, cluster policies were increasingly considered "as a promising approach to strengthen the innovative capacities of regional systems, leading to greater competitiveness of a region and its actors" (Schmiedeberg, 2010, p. 390). Similarly to Schmiedeberg (2010), Doloreux \& Shearmur (2009, p. 526) underline that the a cluster policy "aims at harnessing

\footnotetext{
initiatives62 Expression stems from Porter (2001, p. ix)

${ }^{63}$ Powell and Snellman (2004, p. 199) define the key component of a knowledge economy as the "greater reliance on intellectual capabilities than on physical inputs or natural resources".
} 
local interactions, knowledge spillovers, and institutions in order to encourage local growth and competitiveness".

Several scholars consider that the Silicon Valley belongs to the category of "spontaneous clusters". However, it is important to underline, as already discussed, that also in Silicon Valley the State invested a considerable amount of money in university research. The difference with an explicit "policy-driven cluster" is that this did not happen under the header of a "cluster development program" (Porter, 2001) and all the additional activities that go along with such a program (e.g. collaboration support, regional marketing, etc.) (Sölvell, 2008; Sölvell, et al., 2003).

Normally a cluster policy implements one or several cluster initiatives on its territory. Cluster initiatives are "organised actions carried out to launch, develop and manage clusters with the involvement of involving private industry, public authorities and/or academic institutions are called 'cluster initiatives"” (Coletti, 2010, p. 681). Very often these cluster initiatives "entail a cluster organisation", which "are intermediate bodies employing people in charge of animating clusters, the so-called cluster managers" (Coletti, 2010, p. 679). However, according to Coletti (2010), cluster manager might be a too narrow description of his/her tasks. A better nomination would be "cluster facilitator" because he/she is "a networker and a facilitator of relations" who "manages weak and strong ties with cluster members, potential members and stakeholders and, when a shared vision emerges, she encourages its collective realisation" (Coletti, 2010, p. 686).

Even though the World Bank changed its mind regarding state intervention in order to foster innovation and economic growth at the end of the $20^{\text {th }}$ century (Morgan \& Nauwelaers, 2003 (1999)), policies supporting research and economic activities within a specific country in order to stay competitive are not very new (Maguire \& Davies, 2007). Government intervention in the name of scientific progress and thus a superior competitive position compared to other nations is a recurrent theme in history. Box 4 for example gives an illustrative example of how the United States some decades ago already faced and discussed similar policy issues as today. However, the novelty with cluster policies is that they try to group under one header several types of policies that were historically treated separately. It is important to place cluster policies in this broader context of policies, in order to better understand the current dilemmas of cluster policies. 


\section{Box 4: Government intervention in the name of scientific progress - a recurrent theme}

United States, 1940s (Jankowski, 2001, pp. 5-6): "Prior to World War II, the federal government's role in the
science system of United States was relatively minor and its funding for research and development ... was
generally small. However, successful wartime experiences demonstrated the potential for productive
partnerships among the federal, industrial, and academic research sectors might be extended to peacetime
needs as well." Therefore, President Roosevelt asked in November 1944 to addressee these questions: "(1) the
declassification of secret wartime research results, (2) the need to develop a program to support health-
related research, (3) conditions through which the government could provide aid to research activities in
public and private organizations, and (4) the feasibility of creating a program for developing scientific
talent." The report (Bush, 1945), that was published one year later, gave the answers to Roosevelt's questions
and highlighted the importance of government subsidies for scientific progress regarding the nation's health
prosperity and security. Also under President Truman the reflections on the intervention of the State continued
as a Scientific Review Board was created and its chairman, John Steelman, argued that "the U.S. must
continually strengthen and expand its domestic economy and foreign trade through constant expansion of
scientific knowledge and consequent steady improvement of technology."

\subsubsection{Cluster policies: polyvalent by nature}

At the end of the $20^{\text {th }}$ century, "industrial policy seemed to phase out" (Aiginger, 2007, p. 297). However, "due to globalisation, outsourcing, low growth and high unemployment (specifically in Europe)" new types of policies re-emerged that particularly focused on clusters (Aiginger, 2007, p. 297). The underlying credence of the new emerging policies is that by stimulating regional economic actors to "join forces" and to innovate together, global competition can be faced. Nations enter in a certain manner into a war for competitiveness and cluster policies are considered to be one of these weapons to win this "war".

The OECD (2007, p. 41) outlines how the traditional policies have evolved into new approaches, that today cumulate into cluster policies and initiatives (see Table 9):

- Regional policy: Whereas the old approach to regional policy was mainly concerned with redistributing all kinds of capitals (human capital, financial capital, etc.) "from leading to lagging regions", the new approach to regional policy concentrates on "building competitive regions by bringing local assets and actors together". The idea behind this approach is to collectively awake the intrinsic forces of the region to create the region's competitive advantage. The chances of prosperous regional development are evaluated much higher than by simply allocating external help to the region.

- Science and Technology Policy: Whereas the old approach to science and technology policy consisted mainly in financing "individual, single-sector projects in basic research", the new approach to science and technology policy concentrates on the "financing of collaborative research involving networks with industry and links with commercialisation”. The idea behind this approach is that first of all, real creative 
ideas spark better together than alone and that second, strong links with commercialisation partners are needed to bring inventions really to the market.

- Industrial and enterprise policy: Whereas the old approach to industrial and enterprise policy consisted mainly in allocating subsidies to firms, particularly national champions, the new approach to industrial and enterprise policy is to support "common needs of firm groups and technology absorption (especially SMEs)". The idea behind this approach is that particularly SMEs drive national growth and SMEs are more important in the new flexible specialization approach vs. the old mass production approach.

Table 9: Policy streams influencing cluster policies

\begin{tabular}{|l|l|l|l|}
\hline Policy stream & Old approach & New approach & Cluster programme focus \\
\hline $\begin{array}{l}\text { Regional } \\
\text { policy }\end{array}$ & $\begin{array}{l}\text { Redistribution } \\
\text { from leading to } \\
\text { lagging regions }\end{array}$ & $\begin{array}{l}\text { Building } \\
\text { competitive regions } \\
\text { by bringing local } \\
\text { actors and assets } \\
\text { together }\end{array}$ & $\begin{array}{l}\text { - Target or often include lagging regions } \\
\text { - Focus on smaller firms as opposed to larger } \\
\text { firms, if not explicitly than de facto } \\
\text { - Broad approach to sector and innovation targets } \\
\text { - Emphasis on engagement of actors }\end{array}$ \\
\hline $\begin{array}{l}\text { Science and } \\
\text { technology } \\
\text { policy }\end{array}$ & $\begin{array}{l}\text { Financing of } \\
\text { individual, } \\
\text { single-sector } \\
\text { projects in basic } \\
\text { research }\end{array}$ & $\begin{array}{l}\text { Financing of } \\
\text { collaborative } \\
\text { research involving } \\
\text { networks with } \\
\text { industry and links } \\
\text { with } \\
\text { commercialisation }\end{array}$ & $\begin{array}{l}\text { - Usually a high-technology focus } \\
\text { - Both take advantage of and reinforce the spatial } \\
\text { impacts of R\&D investment } \\
\text { - Promote collaborative R\&D instruments to } \\
\text { support commercialisation } \\
\text { - Include both large and small firms; can } \\
\text { emphasise support for spin-offs and start-ups }\end{array}$ \\
\hline $\begin{array}{l}\text { Industrial and } \\
\text { policy }\end{array}$ & $\begin{array}{l}\text { Subsidies to } \\
\text { firms; national } \\
\text { champions }\end{array}$ & $\begin{array}{l}\text { Supporting } \\
\text { common needs of } \\
\text { firm groups and } \\
\text { technology } \\
\text { absorption } \\
\text { (especially SMEs) }\end{array}$ & $\begin{array}{l}\text { Programmes often adopt one of the following } \\
\text { approaches: } \\
\text { - Target the drivers of national growth } \\
\text { - Support industries undergoing transition and } \\
\text { shedding jobs } \\
\text { - Help small firms overcome obstacles to } \\
\text { technology absorption and growth } \\
\text { - Create competitive advantages to attract inward } \\
\text { investment and branding for exports }\end{array}$ \\
& & &
\end{tabular}

Source: OECD (2007, p. 41)

\subsubsection{The ancestors of cluster policies}

A bibliometric analysis on the different policies influencing cluster policies (see Figure 7) also reveals that cluster policies are the newest form of policies that only emerged at the end of the $20^{\text {th }}$ century. Science and research policies are the oldest ones, particularly prominent after the second world war, followed by the emergence of several new policies at the end of the 1960s and beginning of the 1970s such as regional policies, industrial policies, structural policies and technology policies. Not surprisingly, innovation policies emerged during the 1980s. 
Figure 7: The ancestors (or siblings?) of today's cluster polices

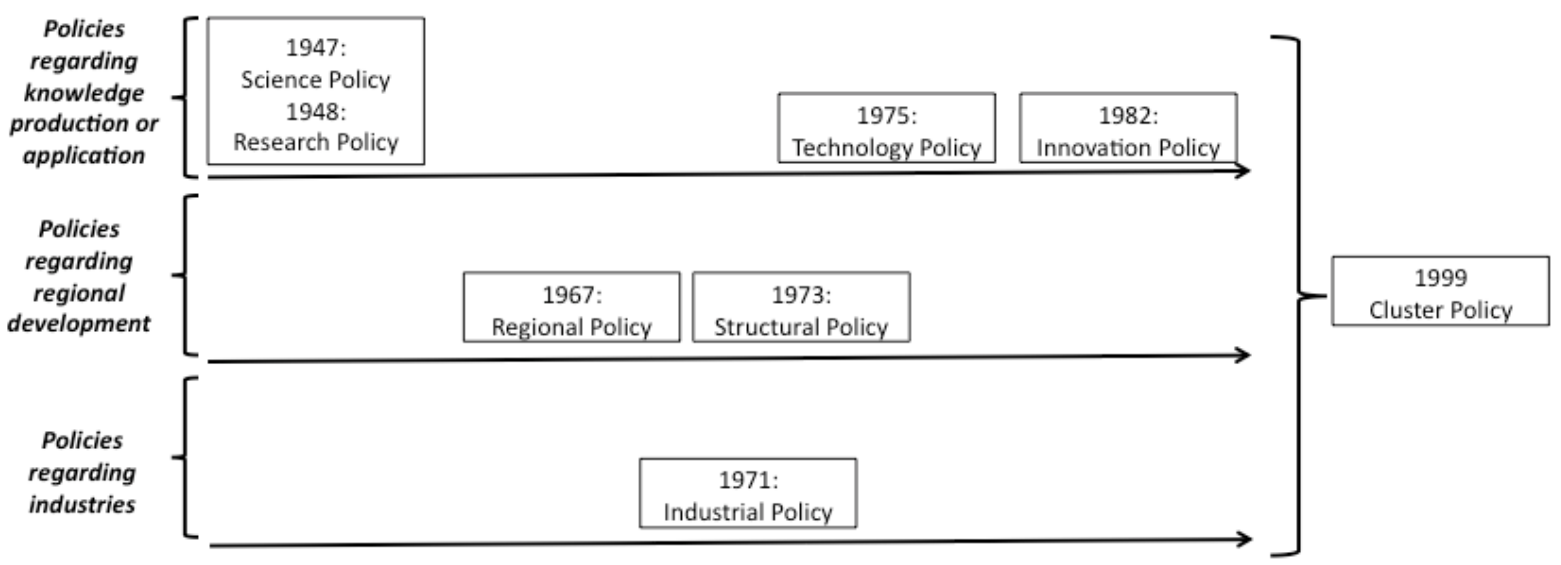

Note: The date corresponds to the first mention of the policy in the title, abstract or keyword of an article referenced in the academic article database Scopus ${ }^{64}$. This implies that the policy might have already been discussed in the corpus of a text. (see Annex 2 for a list of the corresponding academic articles).

Even though cluster policies are implemented throughout the world, they are considerably less discussed by the academic research community compared to the other types of policies (see Figure 8 and Figure 9). Research on regional policies and innovation policies are the most prominent at the moment. What is particularly interesting is research on "industrial policy" and "technology policy" experienced an enormous boom of interest in the middle of the 1990s, but both are now surpassed by "regional policy" and "innovation policy" research.

\section{Figure 8: Cluster Policy vs. Science, Research, Technology and Innovation Policy}

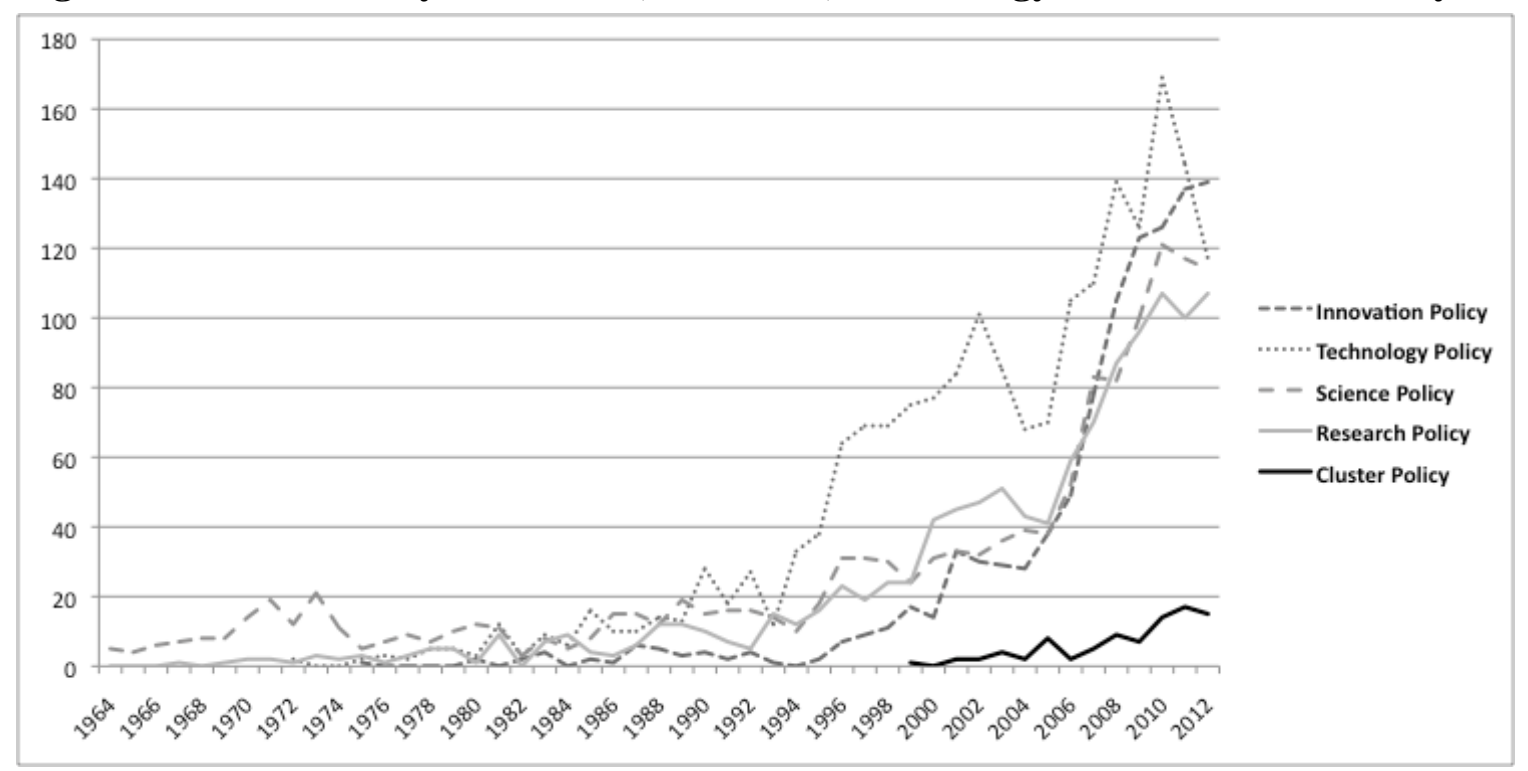

Note: Bibliometric analysis, Scopus database ${ }^{64}$ (01/04/13) ( $x=$ date of publication, $y=$ number of articles)

\footnotetext{
${ }^{64}$ Date: 01/04/13; Database: Scopus; Search Criteria: Search for "[x] policy" OR "[x] policies" in "Article Title, Abstract, Keywords“; $[\mathrm{x}]$ = Science, Research, Regional, Structural, Industrial, Technology, Innovation or Cluster; Data Range: "all years to present"; Document Type: Article; Subject Areas: "Social Sciences \& Humanities" AND "Physical Sciences"
} 
Figure 9: Cluster Policy vs. Industrial, Regional and Structural Policy

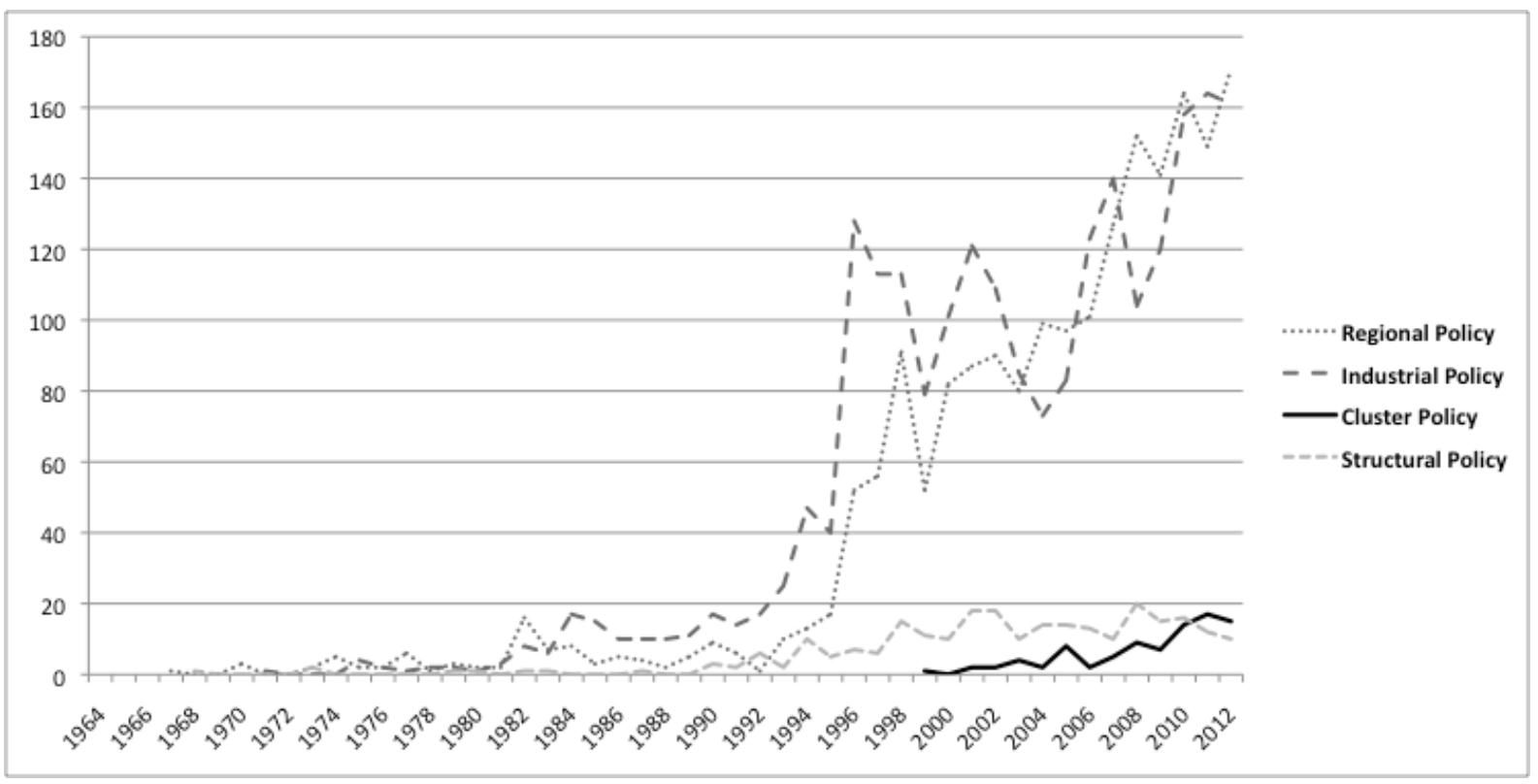

Note: Bibliometric analysis, Scopus database ${ }^{64}(01 / 04 / 13)(x=$ date of publication, $y=$ number of articles)

\subsubsection{Cluster policy: just a new industrial policy?}

Even though academics defend a range of opinions of what cluster policies are, Porter (2000a) advocates that there is a strong difference between industrial policy and cluster theory (not explicitly referring to cluster policies). On the one hand, industrial policy is based "on a view of international (or, more generally, locational) competition in which some industries offer greater wealth-creating prospects than others" and where "desirable industries (e.g., high tech, growing) should be "targeted" for support" (Porter, 2000a, p. 27). The focus lies thus on “what a nation (location) competes in" (Porter, 2000a, p. 27).

On the other hand, "the concept of clusters rests on a broader and dynamic view of competition among firms and locations, based on the growth of productivity" (Porter, 2000a, p. 27). According to Porter's logic (2000a, p. 27), the regional actors themselves can create their own regional advantage and so "all clusters can be desirable" as "all offer the potential to contribute to prosperity". Instead of targeting only certain industries as in the traditional industrial policy, "all existing and emerging clusters deserve attention" (Porter, 2000a, p. 27). In a certain manner Porter advocates that supporting already emerging clusters, nevertheless which field they are in, corresponds to a more egalitarian view of governmental intervention, than targeting only one industry or national leader. 
This view is criticised by Hospers et al. (2009) as, according to them, governments implementing cluster policies similarly to when implementing industrial policies also have to decide which clusters to help, either by "picking winners" or by "backing losers". A better approach according to Hospers et al. (2009) would thus be if governments only intervene once the cluster has emerged in form of "cluster marketing" to help the cluster gaining a better international visibility. More over it was shown that policy-driven cluster often encourage the internationalisation of companies (S. Andersson, Colovic, \& Lamotte, 2014; Colovic, 2013) or entrepreneurship (de Géry, Laviolette, \& Bonnafous-Boucher, 2013).

Some conclude that governments can only contribute little to the performance of a cluster (G.J. Hospers, et al., 2009, p. 298) and should therefore concentrate on their "ex-post" role in form of "brand[ing] the success of clusters after they have emerged spontaneously in the market [...] by tak[ing] into account and promote the particularities and realities of an area". For Hospers et al. (2009, p. 298) it is this "Regional Realism" which will make the difference between the regions instead of the running behind a certain role model.

\subsection{The relevance gap in cluster policy research}

One of the main general problems constantly addressed by policy-driven cluster researchers is the growing gap between practitioners introducing cluster polices and academics studying clusters in general. While academics are still debating about the right definitions ${ }^{65}$, practitioners have somehow "rush[ed] to employ 'cluster ideas'” (R. Martin \& Sunley, 2003, p. 5). This had the consequence that the general "cluster ideas" have "run ahead of many fundamental conceptual, theoretical and empirical questions" (R. Martin \& Sunley, 2003, p. 5) and that cluster policies stay "on shaky theoretical and empirical foundations" (Nathan \& Overman, 2013, p. 383).

The theoretical consequence of this growing gap is that "conventional cluster theory" is unable to "explain the spread and functions of such [cluster] policies" (Kiese \& Wrobel, 2011, p. 1691). Kiese \& Wrobel (2011, p. 1708) alert the cluster community that a strict line has to be drawn between "clusters" and "cluster policies, initiatives and organizations" as “conceptual differences” exist. In 2013, also Swords (2013, p. 369) underlined that "libraries of incredibly useful books and articles on clusters" exists. However, "there remains an

\footnotetext{
${ }^{65}$ Aiginger (2007, p. 297) for example underlines that "no commonly accepted definition exists" for clusters and "concepts differ across nations, regions, stage of development and over time".
} 
absence of work which interrogates the translation of clusters into, and then through local and national policy” (Swords, 2013, p. 369).

So even though the cluster literature is constantly growing (see Figure 3), little is still known regarding the dilemmas when the spontaneous cluster concept passes into the public policy realm and from the public policy realm into the operationalization realm (Swords, 2013). Policy-driven clusters stay somehow in a theoretical no man's land and additionally continue to be criticised as "good intentions are overshadowed by bad outcomes" (Aiginger, 2007, p. 297).

\subsection{Positive impact of policy-driven clusters}

Even though we will focus in this chapter on the policy-driven cluster dilemmas, it does not mean that cluster policies do not create positive effects. A range of the reviewed cluster policy articles mention the positive effects that policy-driven clusters can obtain. Spontaneous clusters, increase for example untraded interdependences (Storper, 1995) such as tacit knowledge exchange (Gertler, 1995, 2003), knowledge creation dynamics (Saives, Ebrahimi, Desmarteau, \& Garnier, 2007), collective learning (Lawson \& Lorenz, 1999); or trust building, thanks to an increased face-to face interactions (Harald Bathelt, et al., 2004; Waxell \& Malmberg, 2007).

One part of the cluster policy literature shows, that policy-driven clusters, which try to replicate the conditions of spontaneous clusters, are able to do so. Lundequist \& Power (2002, p. 697), for example state that there is not one ideal type of cluster initiatives but that "whatever shape cluster initiatives take [...] they can be seen as useful regional development tools [...] to build competitiveness and competence”. Or Karaev et al. (2007) reviewed the literature regarding the influence of a cluster approach on the competitiveness of SMEs. They conclude that the literature shows that "establishing clusters" is "an efficient tool for overcoming the size limitations of SMEs" (Karaev, et al., 2007, p. 830). Additionally, the policy-driven cluster creates a "geographical proximity" which goes along with all the positive "agglomeration effects" such as "higher specialization, innovation and knowledge transfer" (Karaev, et al., 2007, p. 830). These "agglomeration effects" allow the SMEs to reduce their costs which again "improv[es] the competitiveness of industrial sectors, regions and nations" (Karaev, et al., 2007, p. 830). 
Hereinafter, we mention some of the most important positive effects cited by the cluster policy literature and give some concrete empirical examples:

- Greater visibility: One important positive effect of policy-driven clusters is the greater visibility that they create for their members. Lundequist \& Power (2002), conducted and in-depth study of Swedish cluster initiatives and highlighted the positive effect of joint marketing efforts in order to create greater visibility for the individual company. Also Felzensztein et al. (2012), who conducted a survey (among clustered and nonclustered low-tech firms) in Chile, show the positive effects of joining forces in marketing efforts. Finally, Fromhold-Eisebith \& Eisebith (2005, p. 1265), studying German and Austrian clusters, also come to the same result, by underlying the "better visibility and image of the industry group" thanks to the membership in a policydriven cluster (Fromhold-Eisebith \& Eisebith, 2005, p. 1265).

- Greater adaptability: Another important positive effect of policy-driven clusters is the greater adaptability of the member companies to unforeseen economic changes or events. Gadille et al. (2013, p. 340), who conducted an in-depth analysis of a French aeronautic cluster underline that the French cluster policy "stimulate(s) important changes within local economic structures”. Particularly, because independent SMEs join forces due to the cluster policy and that they "are better able to respond to changing competitive conditions than the more traditional enterprises within the region" (Gadille, et al., 2013, p. 340).

- Better relations with the public authority: Another important positive effect seems to be the construction of a more constructive dialogue between the public and the private sector. The Basque country was an early adopter of cluster policies during the 1990s. Ahedo (2004) conducted an in-depth analysis of the cluster policy in the Basque country that through the implementation of cluster-associations created a dynamic of "Industry-Government collaboration" (Ahedo, 2004, pp. 1110-1111). For Ahedo (2004, p. 1111) the "traditional lack of regional Industry-Government relations has been replaced by a limited but promising dynamic of dialogue and interaction between an empowered and committed regional government and more pro-active and self-organizing regional industrial sectors and SMEs”. Also Santisteban (2006, p. 37) analyzing cluster policies not only in the Basque country but also in Catalonia concludes that these policies have, in both regions, "stimulated different forms of 
collaboration between the empowered regional governments and the regional industrial-business systems”.

- Increased knowledge exchange: Not surprisingly, as it is the core of the cluster concept, one of the most often cited advantages of policy-driven clusters is the increased knowledge exchange between the policy-driven cluster members. This increased knowledge exchange can be observed in a multitude of clusters (Guisard, Le Bas, \& Nief, 2010; Lundequist \& Power, 2002; Saives \& Desmarteau, 2005). Lundequist \& Power (2002, p. 699) conducted and in-depth study of Swedish cluster initiatives and particularly underlined the positive effect of the establishment of meeting places and competence support structure as for example: "informal firm networks for inter-exchange of knowledge and experiences" or "targeted educational programmes”. Also Guisard et al. (2010), who did an in-depth investigation of a cluster situated in the Lyon region (Lyon Urban Trucks and Bus Cluster, France), particularly focused on the "think tanks" that were set up by the local cluster organisation. According to Guisard et al. (2010, p. 673) these "think tanks" are "discussion and creativity meetings" to bring together a wide variety of local actors in order "to enhance the collective knowledge base" of the cluster. The interviewed participants in the cluster initiative seem to positively evaluate these local knowledge enhancement activities as they create a community feeling and discussions that would not take place otherwise. Also Bidan \& Dherment-Férère (2009) discuss the cognitive levels of value creation process that is happening in the French clusters thanks to the various initiatives. Finally, also Fromhold-Eisebith \& Eisebith (2005, p. 1265), studying German and Austrian clusters, underline that policy-driven clusters allow "increased exchanges of information".

- Increased networking: Another important positive effect of policy-driven clusters is the stimulation of networking between the local actors. Coletti (2010, p. 682), who analyzed the data of a large European survey on cluster managers' skills and training needs, points to the strong networking benefits of cluster organisations thanks to the cluster managers which "facilitate the establishment of strategic alliances and networks, identify[...] core people with already established mutual trust, attract[...] potential partners and help[...] them to create relationships which will bring enhanced cooperation". Also, Fromhold-Eisebith \& Eisebith (2005, p. 1265) underline the "new collaboration" benefit of policy-driven clusters. 
- Increased performance: Research has often highlighted the fact that companies "need to optimize the location of their activities in order to remain competitive" (Colovic \& Mayrhofer, 2011, p. 1481). Nishimura \& Okamuro (2011b), who investigated the Japanese cluster policy by conducting a survey among R\&D-intensive SMEs, conclude that the cluster policy's indirect networking or coordination support seems to be important and beneficial for the companies. For example, companies participating in the cluster and collaborating with local universities seem to apply for more patents, without degrading the quality (Nishimura \& Okamuro, 2011a). Or Li \& Geng (2012) conducted a survey among clustered and non-clustered low-tech or medium-low tech firms in China. Their results show that clustered and non-clustered firms have a different perception regarding shared resources ${ }^{66}$ and additionally the business performance of clustered firms is higher than the performance of non-clustered firms.

All these examples show that cluster policies do "get something going" and create a certain dynamism and hopefully reach "the ultimate aim" of cluster initiatives, namely "continued economic growth and development" (Aziz \& Norhashim, 2008, p. 372). For that it is important to continue pursuing studies that investigate successful examples and the benefits of cluster policies. However, we think that it is as important to complement these studies with the identification of the potential obstacles or "policy challenges" (Ebbekink \& Lagendijk, 2013, p. 737). Our knowledge on both, benefits and obstacles, might allow governments to conceive more successful cluster policies.

\section{Identifying cluster dilemmas \& pathologies: a systematic review}

For chapter one of this literature review we opted for a descriptive and narrative literature review, as traditionally done in the business and management field (Denyer \& Neely, 2004). However, in chapter two of this literature review we decided to conduct a more structured literature review. We use a methodology called "systematic literature review" (SLR) (Tranfield, et al., 2003) that emerged in the United Kingdom among medical professionals (Mulrow, 1994; Thorpe, et al., 2005). These medical professionals underlined the necessity that only through a systematic review of past literature, intelligent policies might be implemented for the future. Descriptive and narrative literature reviews are often biased

\footnotetext{
${ }^{66}$ Shared resources, i.e. "common reputation, intensity of exchange and combination of resources, mutual trust between firms, network of collective learning and knowledge-sharing, dense atmosphere of co-petition, and participation and support of the local institutions" (Li \& Geng, 2012, p. 363)
} 
because they only reflect the authors' perspective which ultimately reduces the utility of these reviews for policy recommendations (Denyer \& Neely, 2004). Therefore, due to the explosion of articles and contradicting opinions, more and more scholars urge researchers to conduct SLRs (Leseure, et al., 2004a; Pittaway \& Cope, 2007; Pittaway, et al., 2004; Thorpe, et al., 2005; Tranfield, et al., 2003).

Particularly for studying dilemmas and obstacles, a systematic literature review is important to help practitioners advance in their diagnoses. To explore the different dilemmas of policydriven clusters, a SLR seems thus highly valuable. The literature reviews "should enable readers, whether academics, practitioners or policy-makers, to determine for themselves the reasonableness of the decisions taken and the appropriateness of the conclusions" (Denyer \& Neely, 2004, p. 133, p. 133). The main difference between a traditional descriptive or narrative literature review and an SLR is that in the latter "the [investigation] process is reported openly in the same way that empirical research would be” (Pittaway, et al., 2004, p. 480, p. 480). SLR thus include a detailed methodology section, to render explicit on which data the interpretations and conclusions are based, which makes their thought process more clear and creates transparency (Thorpe, et al., 2005).

Tranfield et al. (2003) were the first who adapted the SLR methodology to the field of management. Denyer \& Neely (2004, p. 133, p. 133) (based on Tranfield et al 2003) summarized in a consistent manner the most important elements that have to be followed in an SLR, for example "development of clear [..] aims and objectives; [...] a comprehensive search of all potentially relevant articles; the use of explicit, reproducible criteria in the selection of articles for review; [...] a synthesis of individual studies using an explicit analytical framework; a balanced, impartial and comprehensible presentation of the results."

\subsection{What is cluster dilemmas and pathology?}

We finished the first chapter of this literature review by referring to Porter's "anatomy of clusters" view (Porter, 1998c, p. 79). In this chapter we dive into the core of this thesis by using another type of medical terminology: pathology. In this thesis, we wish to study organisational dilemmas and their consequences in policy-driven clusters. Facing a dilemma means that there is no "one best choice", so by going in one direction one certainly produces also negative effects, or side-effect pathologies, that in some cases might hinder the policy- 
driven cluster to function effectively. We will define "pathology" in a cluster setting as the visible managerial symptoms that policy-driven clusters may endure. These pathologies are directly generated by "organizational dilemmas", by having privileged one direction over another. We consider, that the challenge in cluster policy study is to pinpoint these side-effect pathologies and their associated dilemmas in order to improve cluster policy implementation and to better adapt the cluster policy to the local settings. Today a rising amount of literature concentrates on the different types of "challenges" in policy-driven clusters (Burfitt \& Macneill, 2008; Ebbekink \& Lagendijk, 2013).

Pathology is a Greek word and means "the study of suffering" (Duffin, 2010, p. 40). In medicine, the central objective of studying pathology is to "construct, recognize and treat diseases" and thus to help the patient. In cluster studies, the central objective of studying the pathology of clusters is to first identify the different types of "suffering" of the involved stakeholders (the pathologies) and then to identify why they suffer (the dilemmas). We consider that the understanding of clusters' organisational dilemmas is crucial in order to help governments and cluster managers to notice and pinpoint the potential obstacles of cluster policies and in a second step to actively work against these obstacles, to study the obstacles and to improve the potential positive impacts of cluster policies.

So far, the problems of policy-driven clusters are not really addressed and thus not well understood (Ebbekink \& Lagendijk, 2013; Swords, 2013). Medicine does not only study the anatomy and physiology ${ }^{67}$ of the human body but also its pathology. So why not fully introduce the study of pathology, "the study of suffering" (Duffin, 2010, p. 40), in cluster studies?

In medicine, the study of pathology is built on observations, in order to "build" a "disease concept". In doing so, different aspects have to be taken into consideration by the observer: "the patient, the illness, and the presumed cause" (Duffin, 2010, p. 40). Why only a presumed cause? Because "a cause is implied in the concept construct for a disease even when the cause is unknown" (Duffin, 2010, p. 40). Once different types of disease concepts

\footnotetext{
${ }^{67}$ In medicine, physiology "is the study of the function of living beings" and thus "stands both in relation and in opposition to anatomy, the study of structure" (Duffin, 2010, p. 40). If we draw the analogy with cluster studies, the physiology of clusters would be the theoretical functioning of the clusters or the traditional cluster literature that focuses on networking and innovation. This "cluster physiology" literature is very important, has to be understood when studying clusters, constitutes the main part of the cluster literature and is already well developed.
} 
are build they "are given characteristics (symptoms), names (diagnoses), life expectancies (course), anticipated outcomes (prognoses), and recommended treatments" (Duffin, 2010, p. 40). In this chapter we will try to identify and group the different types of organisational dilemmas that are discussed in the cluster policy literature.

In the following literature review we identify groups of dilemmas that go along with cluster policies. We will dig into the symptoms of these different organisational dilemmas and also see that in order to understand the different dilemmas, cluster policy researchers need to adopt a very interdisciplinary approach. However, cluster policy researchers first need to break out of the traditional cluster literature streams (such as (Asheim, 1996; Aydalot, 1986; Becattini, 1989; Cooke, 1992; Marshall, 1890 (1920); Porter, 1990, 1998c; Saxenian, 1994) ${ }^{68}$ in order to bring policy-driven cluster studies on another level of understanding and usefulness for the practitioners.

\subsection{The need for a review of policy-driven cluster dilemmas and pathologies}

The aim of this policy-driven cluster review is to explore all empirical studies that have been conducted on policy-driven clusters in order to summarize the identified obstacles and difficulties encountered by the involved actors.

\subsection{A Systematic Literature Review}

\subsubsection{Search for articles}

The first step of a SLR is to constitute a database of articles that will then be reviewed in detail. The first time we downloaded in a systematic manner and read through the "cluster policies" literature was in March 2013. However, at that time, our ideas were not yet structured enough to make sense of our fieldwork, the classical cluster literature, the management literature and the cluster policy literature. However, little by little we detected this "pathology" problem in our fieldwork data. At the beginning of 2014 we went back to our cluster policy database and reviewed the database once again. The literature suddenly made much more sense. The last update of our literature review was done on the $25^{\text {th }}$ April 2014.

\footnotetext{
${ }^{68}$ Examples of traditional "cluster" schools: Italian industrial districts (Becattini, 1979, 1989), innovative milieu (Aydalot, 1986), new industrial spaces (A. J. Scott, 1988b), industry clusters (Porter, 1990 (1998), 1998c), national innovation systems (Lundvall, 1992), regional innovation systems (Cooke, 1992), or learning regions (Asheim, 1996; Florida, 1995).
} 
The main database we used for the literature review is Scopus and we used following general search parameters in Scopus:

- Document type: article

- Subject areas: physical sciences, social sciences \& humanities

- Language: English, French, German

- Source type: journals

- Search term location: in Article title, abstract, keywords

The aim of a SLR is "to bring together as many already existing evidence-based studies as possible that are relevant to the research being undertaken, irrespective of their published location, or even disciplinary background" (Thorpe, et al., 2005, p. 258). For policy-driven cluster studies this means that we were not specifically looking in regional studies, economics, management studies or sociology, but took a very interdisciplinary approach. In order to advance in policy-driven cluster research, we privileged focusing on the dilemmas instead of on a specific disciplinary stance.

The crucial element was to define the "right" keywords in order to cover the whole spectrum of the policy-driven cluster literature that might be useful to study and analysis the diseases of our fieldwork observations and at the same time not to drawn in the existing general cluster literature (be it the spontaneous clusters, policy-driven clusters or general "regional system" literature). A helping element was that we already went through the cluster policy literature and that we knew approximately the keywords that will be useful for analysing policy-driven clusters. Finally, we used following keywords to constitute our final policy-driven cluster literature database: cluster polic*, clusterpolitik, politique* de* pôle*, cluster initiative*, policy-driven cluster*, cluster promotion, promotion of cluster*, cluster promotion polic*, cluster organi?ation*, cluster management, cluster manager*, cluster building, breeding cluster*, growing cluster*, breeding innovation cluster*, growing innovation cluster*, cluster governance.

Additionally we had two criteria for keeping an article in our database. The first criterion was that the article was really dealing with regional clusters and not for example with clusters in computer programming. The second criteria concerned the quality of the journal in order to base our conclusions on quality results. At the beginning we just wanted to retain articles that were published in journals listed in the Harzing's (2013) quality journal list, nevertheless 
from which disciplinary stance. However, we soon realized that several important articles to understand the particularities of cluster policies were published in specialized or national journals which were not included in the Harzing's (2013) quality journal list. For example the German journal "Zeitschrift für Wirtschaftsgeographie", where German cluster specialists publish their articles (for example (H. Bathelt \& Dewald, 2008; H. Bathelt \& Zeng, 2005; Kiese, 2008)), or the French journal "Politiques et Management Public" where French cluster specialists publish their articles (for example (Gallié, et al., 2012; Gallié, et al., 2014; Sabine Menu, 2011)), or the European specialist journal "European Urban and Regional Studies" where for example also Spanish researcher (Santisteban, 2006) publish their cluster policy articles (particularly important when one does not speak Spanish and can not consult the local journals). We therefore decided to enlarge our quality criteria and also include journals that are either listed among the best 10000 journals on the website "http://www.journalranking.com" and/or that are cited more often than 5 times in the Scopus database.

After excluding several articles according to the two criteria just cited, we also included some articles that were not referenced in Scopus. According to the SLR methodology adding "key references which had been missed by the systematic search process [...] [is a useful step] to compensate for the rigidity of "mechanistic" searches" (Leseure, Bauer, Birdi, Neely, \& Denyer, 2004b, p. 172). We added articles that were for example only accessible through a French journal database named CAIRN (for example (Bidan \& Dherment-Férère, 2009; Schmitt, 2011)). Finally, the database counted 139 published articles. However, in our discussion we also included conference papers (for example (T. Weil \& Fen Chong, 2009)) or PhDs from French colleagues (for example (Chabault, 2009)) but we did not count these "working papers" as official published articles.

\subsubsection{Analysis of articles}

All 139 articles citations were downloaded into Endnote and based on the abstracts coded into homogenous groups. Even though coding of abstracts is sometimes criticised (Pittaway, et al., 2004) due to some quality issues, it is also considered a useful tool "for creating a thematic structure around which more detailed reviewing can take place” (Pittaway \& Cope, 2007, p. 481). Due to our previous reading on the topic, we already developed a feeling for the subject that helped us in the coding process. After the abstract coding we then read through the articles in order to analyse which type of dilemmas and obstacles the different articles exactly identified. The result of this step is summarized hereinafter. 
Before summarizing the content, we just want to give some general information regarding the articles. First of all, the articles came from a variety of disciplines (see Table 10), ranging for example from public sector management to marketing over entrepreneurship and innovation management. However, the discipline "Public Sector Management" is, not surprisingly, the discipline that most often talks about cluster policies, policy-driven cluster management, or policy-driven cluster promotion, etc. The top journals that publish articles these topics are for example Environment and Planning C, European Planning Studies and Regional Studies.

Table 10: Articles dealing with cluster policy, management, promotion, etc.

\begin{tabular}{|c|c|c|}
\hline Discipline $^{69}$ & $\begin{array}{c}\text { \# of } \\
\text { Articles }\end{array}$ & Examples of journals per discipline \\
\hline Public Sector Management & 62 & $\begin{array}{l}\text { Environment and Planning C: Government and Policy; } \\
\text { European Planning Studies; Regional Studies }\end{array}$ \\
\hline Economics & 17 & $\begin{array}{l}\text { World Development; Research Policy; Regional Science } \\
\text { and Urban Economics; Journal of Economic Geography }\end{array}$ \\
\hline Innovation & 14 & $\begin{array}{l}\text { International Journal of Technology Management; Industry } \\
\text { and Innovation; Journal of Technology Transfer; } \\
\text { Technovation }\end{array}$ \\
\hline General \& Strategy & 7 & Policy Studies; European Management Journal \\
\hline Entrepreneurship & 5 & $\begin{array}{l}\text { Entrepreneurship and Regional Development; International } \\
\text { Entrepreneurship and Management Journal; International } \\
\text { Journal of Entrepreneurship and Innovation Management }\end{array}$ \\
\hline $\begin{array}{l}\text { Management Information Systems, } \\
\text { Knowledge Management }\end{array}$ & 5 & $\begin{array}{l}\text { Knowledge Management Research and Practice; Maritime } \\
\text { Policy and Management }\end{array}$ \\
\hline Sociology & 5 & $\begin{array}{l}\text { International Journal of Urban and Regional Research; } \\
\text { Growth and Change }\end{array}$ \\
\hline Marketing & 4 & $\begin{array}{l}\text { Industrial Marketing Management; Journal of Business and } \\
\text { Industrial Marketing }\end{array}$ \\
\hline $\begin{array}{l}\text { Operations Research, Management } \\
\text { Science, Production \& Operations } \\
\text { Management }\end{array}$ & 4 & $\begin{array}{l}\text { Journal of Manufacturing Technology Management; } \\
\text { Service Industries Journal }\end{array}$ \\
\hline International Business & 2 & $\begin{array}{l}\text { Asia Pacific Business Review; International Business } \\
\text { Review }\end{array}$ \\
\hline Others & 14 & \\
\hline TOTAL & 139 & \\
\hline
\end{tabular}

Source: policy-driven cluster literature review (see explanations in this section), 2014

Another important and interesting result is that the articles cover a large range of countries and a large range of cluster initiatives (see Table 11 and Table 12). This cluster policy literature review has shown that cluster policies are really implemented around the world reaching from the USA to Japan, to Bulgaria and New Zealand. In the Table 11 there is an overrepresentation of articles coming from France this is due to the fact that we had access to

\footnotetext{
${ }^{69}$ The disciplines and associated journals correspond to the categorization established by Harzing's (2013) quality journal list. In case a journal was not listed in Harzing's quality journal list, we tried to put the journal into the discipline category that corresponds the best.
} 
a national French journal database but not for example to a national German database. Another interesting observation is that cluster policy studies are mainly qualitative, but in Asia they are exclusively quantitative. Table 11 and Table 12 do not include theoretical papers on policy-driven clusters that we found during our literature review. However, they are numerous as well (see for example (Aiginger, 2007; Aziz \& Norhashim, 2008; H. Bathelt \& Dewald, 2008; Burfitt \& Macneill, 2008; Ebbekink \& Lagendijk, 2013; G. J. Hospers \& S. Beugelsdijk, 2002; G. J. Hospers, et al., 2009; Karaev, et al., 2007; R. Martin \& Sunley, 2003; Nathan \& Overman, 2013; Raines, 2003)). This large variety of results coming from different countries has made this analysis particularly interesting and on the other hand it corresponds exactly to what a medical SLR advocates: that all types of results on a certain "medical issue" should be reviewed in order to advance in the knowledge of a certain medical problem.

Table 11: Examples of cluster policy articles per country ${ }^{70}$ (European countries)

\begin{tabular}{|c|c|c|}
\hline COUNTRY & EMPIRICAL QUALITATIVE & EMPIRICAL QUANTITATIVE \\
\hline \multicolumn{3}{|l|}{ Europe } \\
\hline Austria & $\begin{array}{lcc}\text { Fromhold-Eisebith } \quad \& \quad \text { Eisebith, } & \text { 2005; } \\
\text { MacNeill \& Steiner, 2010) } & & \\
\end{array}$ & \\
\hline Belgium & $\begin{array}{l}\text { (Bayenet \& Wunderle, 2009; Capron, 2011; } \\
\text { Hermans, Castiaux, Dejardin, \& Lucas, 2012; } \\
\text { Van Haeperen, Lefèvre, \& Dejardin, 2009) }\end{array}$ & \\
\hline Bulgaria & (Sellar, et al., 2011) & \\
\hline Europe & $\begin{array}{l}\text { (Chiaroni \& Chiesa, 2006; De Propris, 2007; } \\
\text { Gallié, et al., 2014; Hospers, 2005) }\end{array}$ & (Coletti, 2010) \\
\hline Finland & (Sotarauta, 2012) & \\
\hline France & $\begin{array}{l}\text { (Bidan \& Dherment-Férère, 2009; Bocquet \& } \\
\text { Mothe, 2010; Carré, Lefebvre, \& Madeuf, } \\
\text { 2008; Delaplace, 2011; Gadille, et al., 2013; } \\
\text { Gaffard, 2008; Gallié, et al., 2012; Gallié, et } \\
\text { al., 2014; Guisard, et al., 2010; Lefebvre, } \\
\text { 2013; Sabine Menu, 2011; S. Menu, 2012; } \\
\text { Schmitt, 2011; Younès, 2012) }\end{array}$ & $\begin{array}{l}\text { (Fontagné, Koenig, Mayneris, \& Poncet, } \\
\text { 2013; Gallié, et al., 2013b; A. Glaser, et al., } \\
\text { 2012; P. Martin, Mayer, \& Mayneris, 2011) }\end{array}$ \\
\hline Germany & $\begin{array}{l}\text { (Champenois, 2012; Domdey \& Hazouard, } \\
\text { 2008; Fromhold-Eisebith \& Eisebith, 2005; } \\
\text { Kiese \& Wrobel, 2011; Sternberg, Kiese, \& } \\
\text { Stockinger, 2010) }\end{array}$ & $\begin{array}{l}\text { (Engel, Mitze, Patuelli, \& Reinkowski, 2013; } \\
\text { Falck, Heblich, \& Kipar, 2010) }\end{array}$ \\
\hline Netherlands & $\begin{array}{l}\text { (Klein Woolthuis, Lankhuizen, \& Gilsing, } \\
\text { 2005; Van Klink \& De Langen, 2001) }\end{array}$ & (Mans, et al., 2008) \\
\hline Norway & (Gausdal, 2008) & \\
\hline Spain & $\begin{array}{l}\text { (Ahedo, 2004; Martinez, Belso-Martinez, \& } \\
\text { Mas-Verdu, 2012; Santisteban, 2006) }\end{array}$ & \\
\hline Sweden & $\begin{array}{l}\text { (Hallencreutz \& Lundequist, 2003; Lundequist } \\
\text { \& Power, 2002) }\end{array}$ & $\begin{array}{l}\text { (Eklinder-Frick, et al., 2014; Eklinder-Frick, } \\
\text { Eriksson, \& Hallén, 2012) }\end{array}$ \\
\hline United Kingdom & $\begin{array}{l}\text { (Burfitt \& Macneill, 2008; Burfitt, et al., 2007; } \\
\text { Swords, 2013) }\end{array}$ & $\begin{array}{l}\text { (Cumbers, et al., 2003; Huggins \& Johnston, } \\
\text { 2009; Learmonth, Munro, \& Swales, 2003; } \\
\text { McDonald, et al., 2007; Sadler, 2004) }\end{array}$ \\
\hline
\end{tabular}

\footnotetext{
${ }^{70}$ In case the methodology was mixed, I put it in the quantitative column. In case the paper was theoretical but used a lot of concrete empirical examples I added it in the qualitative column.
} 
Table 12: Examples of cluster policy articles per country ${ }^{71}$ (Not European countries)

\begin{tabular}{|l|l|l|}
\hline COUNTRY & EMPIRICAL QUALITATIVE & EMPIRICAL QUANTITATIVE \\
\hline North America & \multicolumn{1}{|c|}{$\begin{array}{l}\text { (Doloreux \& Shearmur, 2009; Rutherford \& } \\
\text { Holmes, 2007; Salazar \& Holbrook, 2007) }\end{array}$} & (Arthurs, et al., 2009) \\
\hline USA & (Sternberg, et al., 2010) & (James, 2005; Peters, 2005) \\
\hline Asia & & (Li \& Geng, 2012) \\
\hline China & (Kitagawa, 2005, 2007) & (Nishimura \& Okamuro, 2011a, 2011b) \\
\hline Japan & & (Chiu, 2009) \\
\hline Taiwan & (Cammett, 2007) & \\
\hline Africa & & \\
\hline $\begin{array}{l}\text { Morocco \& } \\
\text { Tunisia }\end{array}$ & & \\
\hline Oceania & (Perry, 2005, 2007) & \\
\hline New Zealand & (Liyanage, 1995) & (Felzensztein, et al., 2012; Giuliani, 2013; \\
\hline Australia & & Visser \& de Langen, 2006) \\
\hline Latin America & & \\
\hline Chile & & \\
\hline Costa Rica & (Ciravegna, 2012) & \\
\hline Mexico & (Martinez, et al., 2012) & \\
\hline Latin America & (Altenburg \& Meyer-Stamer, 1999) & \\
\hline
\end{tabular}

\subsection{Organisational dilemmas as drivers of cluster pathologies}

The literature shows that cluster policies have positive impacts but also negative impacts. Those who implement cluster policies constantly face a set of dilemmas that generate sideeffect pathologies. These pathologies are rarely studied in the cluster literature. Burfitt \& Macneill (2008) already started to investigate the variety of dilemmas faced by cluster policies. In their theoretical paper they identified two main dilemmas "operational and managerial challenges" and "political challenges". To the "operational and managerial" challenges they count the identification of clusters and the management of cluster policies, while to the "political challenges" they count the designation of clusters, the drawing of boundaries and the relationship between cluster organizations and politics.

We tried to be independent from their analysis when doing the SLR and finally our SLR lead to similar results (see Figure 10). We were able to identify (1) political dilemmas of policydriven clusters (such as defining boundaries, subsidies and objectives), (2) organisational dilemmas of policy-driven clusters (such as managing multiple actors, innovation and collaboration), and (3) structural dilemmas of policy-driven clusters (such as adapting the policy-driven cluster to the life-cycle, to the local culture or to the geography) that might turn into side-effect pathologies. In this chapter we thus build on Burfitt \& Macneill's (2008)

\footnotetext{
${ }^{71}$ In case the methodology was mixed, I put it in the quantitative column. In case the paper was theoretical but used a lot of concrete empirical examples I added it in the qualitative column.
} 
preliminary theoretical work but considerably extend it thanks to our SLR and the identified empirical cluster policy studies in the literature.

To sum up once again, from a theoretical point of view we first have to understand which dilemmas exist because dilemmas can create side-effect pathologies (in this literature review). However, on the field one has to first thoroughly decompose the general view and identify the different pathologies before it is possible to go "upstream" again (towards the dilemma) and give sense to the whole.

Figure 10: A framework for the study of pathology in policy-driven clusters

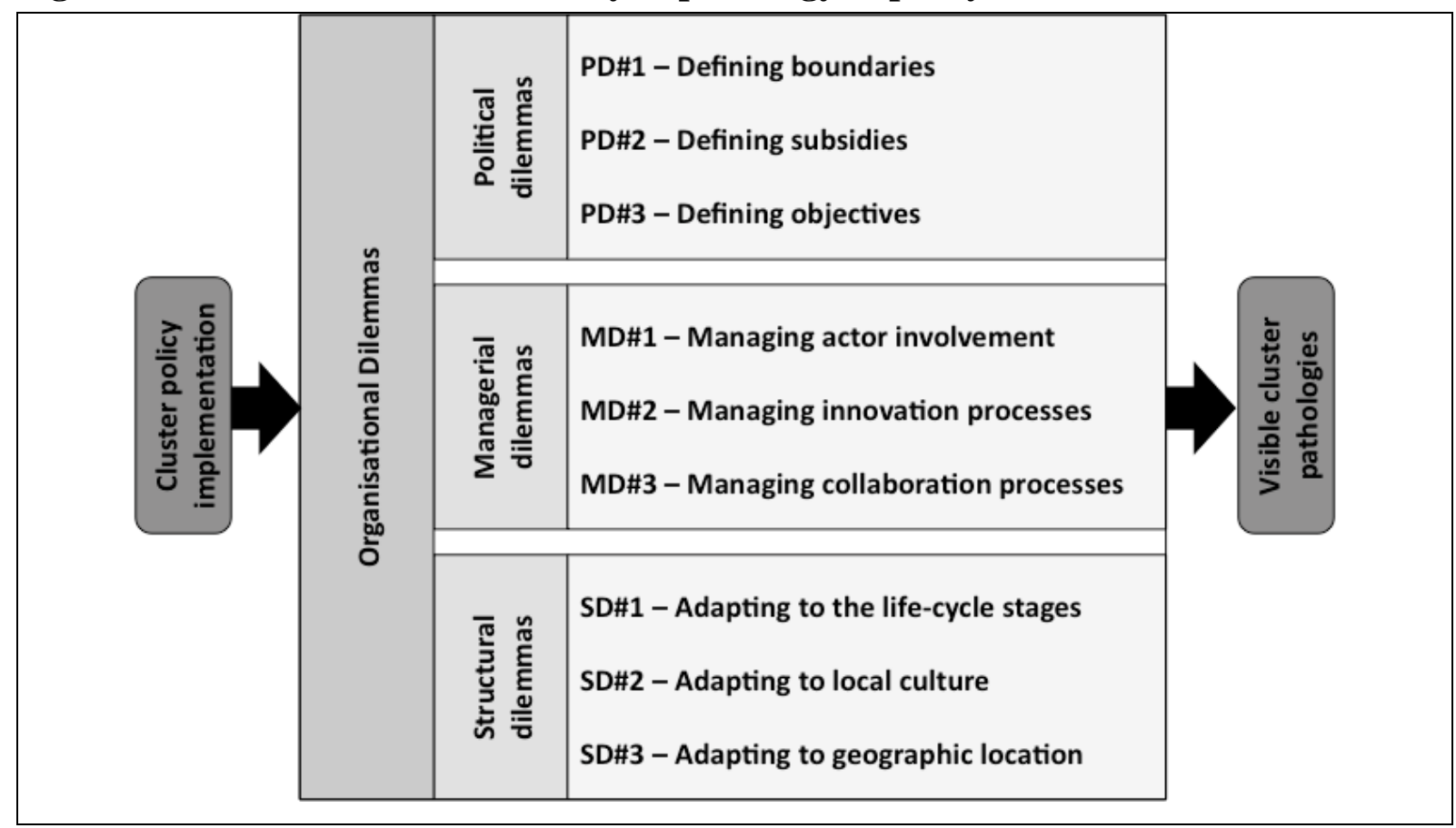

\section{Drivers of pathologies: political dilemmas}

The first types of dilemmas that we identified in the literature are of political nature. We are able to distinguish three different types of political dilemmas that seem to have a strong impact on the performance of policy-driven clusters (see Figure 11). These three dilemmas emerge because of decisions that have to be taken regarding the boundaries of policy-driven clusters, regarding the subsidies of policy-driven clusters, and regarding the fuzziness of the objectives of policy-driven clusters. 
Figure 11: Political dilemmas of policy-driven clusters

\begin{tabular}{|c|c|c|}
\hline \multirow{6}{*}{ 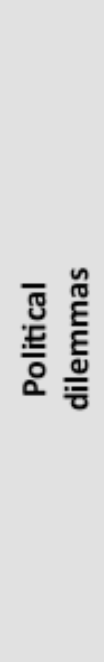 } & \multirow{2}{*}{ PD\#1 - Defining boundaries } & $\begin{array}{c}\text { PD\#1a - Geographical boundary: } \\
\text { local vs. non-local }\end{array}$ \\
\hline & & $\begin{array}{l}\text { PD\#1b - Organisational boundary: local vs. national / members vs. } \\
\text { ecosystem / thematic vs. regional entity }\end{array}$ \\
\hline & \multirow{2}{*}{ PD\#2 - Defining subsidies } & PD\#2a - Subsidies type: direct vs. indirect \\
\hline & & PD\#2b - Subsidies structure: one-shop vs. multiple shop strategies \\
\hline & \multirow{2}{*}{ PD\#3 - Defining objectives } & PD\#3a-General objective: industrial excellence vs. regional dev. \\
\hline & & PD\#3b - Motivation: intrinsic motivation vs. policy prescription \\
\hline
\end{tabular}

\subsection{Dilemmas on defining boundaries}

There are two different boundary dilemmas that policy-driven clusters face: What is the geographical boundary (local vs. non-local)? \& What is the organisational boundary (local vs. national / members vs. ecosystem / thematic vs. regional entity)? Hereinafter we discuss both types of boundary dilemmas.

\subsubsection{Geographical boundary: local vs. non-local}

Governments launch cluster policies to spore the competitiveness on their territories. However, Mans et al (2008, p. 1383) underline that "just labelling a cluster is not expected to be enough to reap the benefits ascribed to clusters", therefore policy makers "include incentives for the cluster partners to actually function as a cluster." Based on the literature discussed in chapter one, we know that this "functioning" of spontaneous clusters is particularly related to the networking component of the local actors. In policy-driven clusters, the incentives to motivate the local actors to collaborate (and thus to transform the region into a "functioning" policy-driven cluster) are very often based on R\&D subsidies as for example done in the French case (Gallié, et al., 2013b) or in the Japanese case (Kitagawa, 2005; Nishimura \& Okamuro, 2011b). These R\&D subsidies are regional bound and only allocated to companies situated in a geographical defined area, the policy-driven cluster area. This is done so that the policy-driven cluster is incited to start "functioning" like a spontaneous cluster. 
However, several academics advocate that cluster policies should not only foster local relationships (Kitagawa, 2005; Nishimura \& Okamuro, 2011a) and that regional authorities should actually shift "to a regional innovation systems approach", meaning that they should focus "equally on the regional and more global dimensions of knowledge networks" (Huggins \& Johnston, 2009, p. 227). The theoretical question of what is the right regional scale for applying cluster policies is a vivid point of discussion in the academic cluster policy literature (Gaffard, 2008). From the beginning onwards, Porter's idea that governments should create a competitive advantage within a specific territory, ignoring thus in a certain manner the interrelations with other territories and countries, was firmly criticized (Rugman, 1992).

Even though a range of studies show that extra-regional collaborations are important for the local companies, governments often decide otherwise when implementing policy-driven clusters. Hereinafter, we first recall the large range of studies that investigate the impact of local cluster networks vs. non-local networks on companies. All studies point in the same direction, namely that non-local networks and collaborations are extremely important for the competitiveness and development of companies co-located in the same region. However, the problem seems to lie somewhere else. In the second section, we come back to the political sphere, which, even though results point into the direction that non-local collaborations are more profitable than local collaborations for companies, stick to the wish to foster local cluster networks. Based on a very scarce literature on this subject, we shortly discuss that overcoming these somehow obvious geographical scale problems is more difficult for politicians than imagined by pure cluster academics. Finally, in the last section, we present some ideas of academics how to overcome this "policy-driven cluster scale" dilemma.

\subsubsection{The benefits of non-local networks}

Plenty of studies exist that investigate which benefits companies reap when collaborating with local cluster actors vs. collaborating with non-local actors. For example already in 2003, Cumbers et al. (2003) investigated a spontaneous oil cluster in Scotland and drew important conclusions for cluster policies. Cumbers et al. (2003, p. 1703) conclude that "regional networks are important in providing support for innovation" but that companies clustered at one location are not only interested in local partnerships. Among the analyzed companies they conclude that "more innovative SMEs [make] greater use of external networks than less innovative firms" (Cumbers, et al., 2003, p. 1703). They particularly underline that more 
successful SMEs distinguish themselves by their "ability to draw upon localised assets yet simultaneously being plugged into wider networks" (Cumbers, et al., 2003, p. 1703). Even though "the local milieu remains important as a source of competitive advantage for firms" (Cumbers, et al., 2003, p. 1703) it is the wider network a company possesses that in fine makes the necessary difference.

Some years later also McDonald et al. (2007) and Huggins \& Johnston (2009), both analyzing UK clusters, draw similar conclusions. Huggins \& Johnston (2009, p. 227) observe that "more innovative SMEs possess a balance of inside and outside the region knowledge networks" and McDonald et al (2007) conclude that national and international linkages are as important as local once. It is "the balance between local, national, and international networks in the context of both flows of goods and services, and flows on information and knowledge" that "need to be central in cluster policies" (McDonald, et al., 2007, p. 47).

Additionally, McDonald et al (2007) strongly criticizes Michael Porter's idea that strong regional networks and local supply chains are necessary for good performance. Their results show that this is not the case and that this might be one of the reasons why the currently implemented cluster policies do not reach their goals: "The current Porter-type views on cluster policy may not be sufficient to create even the bedrock conditions that would permit clusters to provide a good basis for attaining regional development objectives" (McDonald, et al., 2007, p. 47).

However not only in the United Kingdom (Cumbers, et al., 2003; Huggins \& Johnston, 2009; McDonald, et al., 2007) companies seem to profit from non-local partnerships. Also Mans et al (2008, p. 1383) studying "self-declared" clusters in the Netherlands conclude that "location does not seem to matter much for cooperation". The "geographical concentration" in cluster policies "should thus play a minor role" (Mans, et al., 2008, p. 1383). Instead, they recommend that cluster policies should focus on "social cohesiveness" particularly "in hightechnology sectors" (Mans, et al., 2008, p. 1383). By social cohesiveness Mans et al (2008) mean direct and indirect connections between local and non-local actors.

Even when we go beyond the European boarders, the results are the same. For example the Japanese cluster policy, analyzed by Nishimura \& Okamuro (2011a), also tries to foster partnerships between local actors. However, Nishimura \& Okamuro (2011a, p. 138) results 
suggest "that local firms collaborating with partners outside the cluster show higher $R \& D$ productivity both in terms of quantity and quality." According to them, the Japanese local cluster support system should thus help the local companies to find partners that are interested in the same research topic nevertheless where these partners are located.

Finally, also on the South American continent the results are the same. Martinez et al (2012, p. 657), who conducted an in-depth analysis of one Mexican and one Spanish cluster, also conclude that even though local closeness is important and should be fostered, "key knowledge players are usually involved in extra-clusters networking”. They not only underline that collaborating with outside partners is important but they also indicate that a “mere reliance on localized knowledge may result in declining trajectories". Cluster policies that overemphasis the creation of local connections might thus even create negative effects for the companies.

\subsubsection{Public authorities insist on fostering local networks for policy-driven clusters}

Nearly all academics investigating the importance of local vs. non-local collaborations come to the same conclusions, namely that non-local collaborations are extremely important for the companies. For example Champenois (2012, p. 812), studying the German BioRegio cluster initiative concluded that "a more selective policy targeted at sustaining the most promising ventures and entrepreneurs, without the 'artificial' ' geographical limits imposed by such cluster policies, could have been more relevant for enhancing entrepreneurship in a sustainable way”.

However, politicians implementing cluster policies continue to insist on subsidising companies located within the policy-driven cluster. One important element that seems to be constantly forgotten by the academic cluster research community is the fact that cluster policies are embedded in a highly complex institutional setting where for example regional authorities from one region might not be willing to invest money in actors that are situated in other regional entities.

These dilemmas were recently underlined by Gaffard (2008, p. 271), Chabault (2009) or Younès (2011) who all studied the French policy-driven clusters. Chabault (2009) for example underlined that during the set-up phase of the French cluster policy some regional 
authorities were arguing about their respective responsibilities regarding clusters that were spread out across the boarders of two administrative regions. Some industrials who wished to apply for the set-up of a policy-driven cluster in their regions (and thus profit from the French policy-driven cluster subsidies), considered that the policy-driven cluster perimeter should be best situated between two regions because the most interesting actors for working towards a certain technology or market are situated across the boundaries of two administrative regions. However, some regional authorities were not happy about this and refused to sign the policydriven cluster framework contract with the State because for them the geographical perimeter was important. The regional authorities considered that having a policy-driven cluster that is situated across two regions generates administration and responsibility problems. Even though, not really discussed in the cluster-policy literature, one is not allowed to forget that they are also in competition to each other for attracting companies to their territory.

Even though we found several examples on the French case, it was not possible to track down examples from other countries. However, MacNeill \& Steiner (2010, p. 444) underlined that "geographical limits of clusters are unlikely to be contiguous with administrative boundaries". Therefore, they consider that the "coordination within multilevel or multi-area governance" (2010, p. 444) is a real challenge.

A recent theoretical article from Ebbekink \& Lagendijk (2013, pp. 736-737), two Dutch cluster specialist, also perfectly underline this political problem: "the academic debate on cluster reinforcement has focused too much on economic-geographical aspects. It has thus tended to ignore the complex institutional context in which policy-making is undertaken." For them, understanding these policy challenges "should clearly be the basis from which effective cluster policies are to be developed” (Ebbekink \& Lagendijk, 2013, pp. 736-737).

We think that Ebbekink \& Lagendijk (2013, p. 737) are right when they say that we have to start investigating "cluster policy as a policy challenge". Our cluster pathology research endeavour tries to go in this direction. In this manner, we might also overcome on the one hand the permanent observation that yes "economic activity is spatially concentrated" and companies clustering are more successful than not clustered companies but on the other hand the permanent criticism that "the cluster concept is far less useful as an analytical tool or as a means for making policy" (Nathan \& Overman, 2013, p. 397). Maybe we just have to create 
awareness and have to understand the obstacles that limit the policy to unfold its whole potential.

\subsubsection{Going beyond the local vs. non-local collaboration dichotomy}

No other cluster disease seems to be studied in so much detail on an academic level but at the same time so much ignored from the cluster policy world (which might also show that the academic world simply has not understood the policy world...). Studying the networks of local actors is an old theme of regional cluster studies so it is no surprise that this topic is also one of the most studied topics in cluster policy studies. In order to overcome the problems of cluster policies regarding local vs. non-local collaborations, some of the cluster policy specialists argue that new ways have to be taken.

Instead of applying in an artificial manner the advantages of spontaneous clusters, Perry (2005, p. 833) proposes that governments should instead base their "policy intervention [...] on determining how best to work with groups of variable significance and character". Some authors thus propose to change specific elements of the current cluster policies and to also change their names. For example Bathelt \& Dewald (H. Bathelt \& Dewald, 2008, p. 163) propose to introduce "relational cluster policies" or Nathan \& Overman (2013, p. 397) propose to introduce "agglomeration policies".

Bathelt \& Dewald (2008, p. 163) argue to turn towards a "relational cluster policy" and to focus more on a "multidimensional cluster approach" that focuses more on the "action space" instead of a geographic space. For them "a multidimensional cluster approach" has several advantages, because it "highlights the role of agency in economic interaction, focuses on the action space of cluster agents, and goes beyond the regional and national scale" $(\mathrm{H}$. Bathelt \& Dewald, 2008, p. 163). Additionally, such an approach attributes a higher importance to external relations as well.

Nathan \& Overman (2013) even go one step further and push for abandoning the word "cluster" which might constantly introduce a wrong image of what should actually be fostered. Nathan \& Overman (2013) reviewed the literature regarding the "appropriate spatial scale for industrial policy" and then urge for turning to an "agglomeration policy" instead of pursuing cluster policies. They argue that "if we cannot manipulate cluster 
outcomes directly, a better basis for policy is to focus on market failures that affect individual firms and people within the cluster" (Nathan \& Overman, 2013, p. 397).

By better understanding "market failures", Nathan \& Overman (2013, p. 397) hope to understand where the real problems lie, both on a structural level (for example "access to finance”), but also on an individual cluster actor level. (Nathan \& Overman, 2013, p. 397) Some concrete examples of an agglomeration policy would be: "encouraging entrepreneurship, subsidizing venture or other early stage finance, building workforce skills and management capacity, and helping firms forge international links" or "co-working spaces and accelerators" for young companies (Nathan \& Overman, 2013, p. 397). Additionally, compared to a cluster policy, an agglomeration policy is a more "horizontal policy", "targeting aspects of places rather than sectors as a means of encouraging growth" (Nathan \& Overman, 2013, p. 399).

Nathan \& Overman (2013), similar to Ebbekink \& Lagendijk (2013) (who focus on "cluster policy as a policy challenge") and our own approach (who focus on the "pathology of clusters"), also turn the wheel around. Instead of investigating the potential positive effects of clusters and cluster policies they propose to focus on the challenges. Due to the highly systemic nature of clusters, positive effects of certain actions are always very difficult to track down and to justify. However, by focusing and analysing the negative effects and challenges of policy-driven clusters, more targeted help might be offered to the practitioners.

Be it Bathelt \& Dewald's (2008) who advocated a "relational cluster policy" or Nathan \& Overman (2013) who advocated an "agglomeration policy", the common denominator is to overcome the problems of a cluster policy's restraint geographic perimeter where collaborations should be fostered. Bathelt \& Dewald (2008) solve the problem by only focusing on the collaboration aspect and Nathan \& Overman (2013) solve the problem by only focusing on the location aspect. However, the advantage of both proposed policies is that collaboration and location are not intermingled anymore such as in cluster policies. Given that administrative boundaries might always exist, the approach of Nathan \& Overman (2013) might thus be more realistic. 


\subsubsection{Organisational boundary: local vs. national}

Besides the geographical boundary dilemma there also exists an organisational boundary dilemma. One of the main elements of policy-driven clusters is the establishment of a new organisation or the appointment of an existing organisation to function as a dedicated cluster organisation. This cluster organisation is then responsible for "building" a policy-driven cluster in a certain sector at a certain location (Ebbekink \& Lagendijk, 2013). However, most of time other types of industrial support structures were already present in the region or at the national level before the policy-driven cluster with its dedicated organisation was launched (e.g. trade unions ${ }^{72}$ ). The question is thus two-fold: (1) in the case of a new organisation: Which role does this new organisation play in relation to the "traditional" organisations? (2) in case of appointing an existing organisation: At which level should this organisation be situated (e.g. regional, national, inter-regional?)?

Perry (2005) , studying several cluster initiatives in New Zealand ${ }^{73}$, underlines that it is important to dedicate some thoughts on the advantages and disadvantages of having several small fragmented local organisations or a more centralised national organisation. When we want to illustrate Perry's (2005) thoughts with a concrete example, we could question if it is more advantageous to have several not interconnected local cluster organisations specialised in biotechnology on its territory, or better to have only one national biotechnology support organisation with regional branches. These thoughts are particularly important "because firms have limited resources to devote to participation in collective groups" (Perry, 2005, p. 848).

Table 13 summarizes the advantages and disadvantage of local vs. national policy-driven support structures. On the one hand, small local organisations might be a better motivation for local actors to participate but knowledge might also be spread out among too many different places on the national territory (Perry, 2005). On the other hand, concentrating the efforts on a national level might decrease the membership but increase the valuable output (Perry, 2005). Burfitt \& Macneill (2008), supports more the idea that national organisation bring more

72 For example Rutherford \& Holmes (2007, p. 194) criticise that the cluster literature does not take into consideration the traditional "unions and industrial relations institutions". They argue that these "traditional collective bargaining structures" should play a central role in the innovation efforts of a region because they have more legitimacy to do so.

${ }^{73}$ There are two interesting elements regarding cluster policies in New Zealand. First of all it is such as France or Japan a unitary country. Second, in the beginning of the 1990s New Zealand received policy advices from Porter and his team. They even published a book with the title "Upgrading New Zealand's competitive advantage" (Crocombe, Enright, Porter, \& Caughey, 1991). 
disadvantages than advantages. They argue that drawing the boundaries of the cluster too large and thus integrating too many different structures and interest groups might also have negative consequences as they might no longer be able to "meaningfully act as vehicles for policy delivery” (Burfitt \& Macneill, 2008, p. 500).

Table 13: Advantages and disadvantages of local vs. national support structures

\begin{tabular}{|l|l|l|}
\hline Local organisation & Advantage & Disadvantage \\
\hline National organisation & $\begin{array}{l}\text { Higher motivation to participate, more } \\
\text { members }\end{array}$ & $\begin{array}{l}\text { Knowledge too much spread out, } \\
\text { decrease of valuable outcome } \\
\text { valuable outcome }\end{array}$ \\
& $\begin{array}{l}\text { Lower motivation to participate, less } \\
\text { members } \\
\text { Policy objectives might not be well } \\
\text { applied }\end{array}$ \\
\hline
\end{tabular}

Source: based on (Perry, 2005) and (Burfitt \& Macneill, 2008)

However, the question of the right organisational boundary of policy-driven cluster organisations might depend on the size of the country. In smaller countries, such as New Zealand (Perry, 2005), a national organisation might be better as too many initiatives might dilute the collective actions. However, in big countries, such as the United States, local organisations might be the better solution.

However, not only the level of the organisation needs attention. Also the amount of already existing structures is important to take into consideration. During the last two decades more and more company support organisations sprung up like mushrooms in order to help companies succeed in the global competitiveness race. Skelcher (2000, p. 4), calls this phenomenon the congested state, where "a complex of networked relationships between public, private, voluntary and community actors have created a dense, multi-layered and largely impenetrable structure for public action." Burfitt et al (2008) stresses that understanding the interplay of all these networks are important to decide how the cluster policy will and can unfold in this system.

\subsection{Dilemmas on defining subsidies}

The subsidies allocated to policy-driven clusters are another important element of discussion. There are two main dilemmas that evolve around policy-driven cluster subsidies problem: deciding on the type of subsidies (Burfitt \& Macneill, 2008; S. Menu, 2012; Nishimura \& Okamuro, 2011b; T. Weil \& Fen Chong, 2009), and subsidies support structure (Chabault, 2009; Guisard, et al., 2010; Lallemand, 2013). 


\subsubsection{Subsidies type: direct vs. indirect}

Another important problem is the type of subsidies that are associated with the policy-driven cluster policy. Partnership research, even though fostered by governments, has several pitfalls and overcoming these pitfalls seems difficult (Pallez, 2014a). Nishimura \& Okamuro (2011b) investigated the Japanese cluster policy implemented by the Japanese government in $2001^{74}$. More particularly they investigated the impact of the different support programmes on the local cluster actors. In the Japanese cluster policy programme, the government particularly focused on R\&D support (55 billion yen between 2001 and 2004; represents $96.5 \%$ of the "cluster subsidies") while the focus on indirect networking or coordination support was quite small (2 billion yen between 2001 and 2004; represents 3.5\% of the policy-driven cluster subsidies) (Nishimura \& Okamuro, 2011b). This is nearly identical to the French cluster policy subsidies investments. In total, the French government has spent three billion Euros for the competitiveness cluster policy between 2005 and 2012. The three billion Euros had two usages: a small portion (3.3\%), reinforced by membership fees and local authorities, was used for the functioning of the clusters organisations while the main portion (96.7\%) was dedicated to the specific projects (R\&D projects, innovation platforms, or collective actions covering very different themes).

One of the main conclusions of Nishimura \& Okamuro (2011b) is that the Japanese cluster policy's indirect networking or coordination support is important and beneficial for the R\&Dintensive SMEs. However, compared to this indirect networking or coordination support their findings show that the direct $R \& D$ support seems to be less important. One explanation of these findings might be that "in order to avoid the criticism of wasting public funds, the government may finance projects with lower risks and higher private returns, which would be undertaken even in the absence of public subsidies" (Nishimura \& Okamuro, 2011b, p. 724). In the case of direct subsidies, the government might have a risk aversion attitude. Additionally, direct subsidies might also be used for more individualistic reasons and less for collective reasons.

For example Weil \& Fen Chong (2009), studying French cluster policies, point to the fact that "some companies which were used to receive large subsidies from the state, were told that

\footnotetext{
${ }^{74}$ In Japan such as in France the State plays a major role in the cluster policy (see (Kitagawa, 2007) for an explanation of the Japanese cluster policy system)
} 
the money now will flow mostly through the cluster policy". The consequence is thus that some policy-driven cluster actors showed an opportunistic reason to start or to join a policydriven cluster, more driven by the fact to access $R \& D$ subsidies and less driven by building a sustainable policy-driven cluster environment. However, Weil \& Fen Chong (2009, p. 15) also argue that it was not always "pure window-dressing" and that the strict policy-driven cluster R\&D subsidies rules (i.e. to involve also SMEs and research and training institutes in the $R \& D$ consortium) forced the large companies to generate a local dynamic.

Even though at some point the actors have to collaborate with each other, the question remains which impact this behaviour might have on the wish to create a sustainable policydriven cluster environment with mutual trust and tacit knowledge exchange. Menu (2012), also studying French cluster initiatives are a little bit more negative than Weil \& Fen Chong (2009). Menu (2012) studied two policy-driven clusters located in the region Brittany and she concluded that "in both cases [..] the cluster strategy was, at the end of the day, a summary of large firms' (and academics) own interests on $R \& D$ issues" (p. 831-832). For example, instead of integrating SMEs in the strategic decisions of the policy-driven cluster, "SMEs were marginalized both in lobbying activities and in the executive committees” (p. 830).

Menu (2012) explains these observations with the particularity of the French culture. Menu (2012, p. 830) observed that the "bargaining between actors within the clusters and outside was of hierarchical nature". She explains this by the "French dirigisme" nature of which the cluster policy is just another example, but also by "the close ties between ministry and industry". These strong ties, where SMEs have difficulties to enter, are "close ties born during school days (Grandes Ecoles) and/or by belonging to common civil service corps" (2012, p. 830). According to Menu (2012) it is this powerful elite which somehow navigates the policy-driven cluster interests and orients them towards their own benefits.

Menu (2012) explains her observations by referring to the particularity of the French culture, but Burfitt \& Macneill (2008), primarily studying cluster policies in the UK and therefore not embedded in the French culture, draw similar conclusions as Menu (2012). Burfitt \& Macneill (2008, p. 500) even think that following the wishes of a few, constitute one of the greatest dangers of cluster policies: "cluster institutions are open to influence [...] by powerful business actors [and] [...] the greatest concern relates to their 'capture' by particular institutional or political interests”. Burfitt \& Macneill (2008, p. 500) refer in this context to 
Andersson et al. (2004, p. 71) who already alerted to this "government failure" problem where "individual needs" are privileged "at the expense of an economy-wide perspective". 75

\subsubsection{Subsidies structure: one-shop vs. multiple shop strategies}

The last point we identified concerns the complexity of the cluster support structure. Burfitt \& Macneill (2008, p. 500), by referring to Enright (2003), underline that "the danger of cluster organizations" is to be "overtaken by 'bureaucracies"”. That at the end, the support structure, which is actually meant to help the policy-driven cluster, is "squeezing out firmoriented development” (Burfitt \& Macneill, 2008, p. 500). Additionally, Burfitt \& Macneill (2008, p. 500) question if the support structures that wish to create a regional dynamism, would be better exerted and cheaper when provided by private support services.

Guisard et al. (2010) and many other French cluster researchers (Chabault, 2009; Erdyn, et al., 2012; Gallié, 2008; Lallemand, 2013) observe exactly this and underline that the French policy-driven cluster and innovation support mechanisms are generally perceived as quite complicated due to the multitude of different agencies involved.

\subsection{Dilemmas on defining objectives}

Another political dilemma that we identified in the cluster policy literature concerns the objective of the policy and the drivers that motivate the actors to participate in the adventure.

In the first chapter we have already discussed that cluster policies try to combine several policies that were historically treated separately. In political terms this also means that a range of different political authorities with a range of different objectives try to push their agenda into the cluster policy effort (Burfitt \& Macneill, 2008). This problem was also identified by Burfitt \& Macneill (2008, pp. 498-499) who stress that the "holistic nature" of cluster policies which was particularly appreciated in the beginning "may ultimately represent one of its greatest weaknesses" and that the varying objectives "can distort its objectives and dilute its value as a tool for economic development”.

In the 1980s scholars started to discuss how to "grow the next Silicon Valley" (Miller \& Cote, 1985) or how to "breed innovation clusters" (DeBresson, 1989, p. 1). Several other

\footnotetext{
${ }^{75}$ The "abuse" of government aid in a cluster policy context were also addressed by Enright (2003).
} 
researchers followed in order to investigate how and if governments can "clone" Silicon Valley's in their countries (Bresnahan \& Gambardella, 2004; G.-J. Hospers, et al., 2009; D. Rosenberg, 2002; Christian Saublens, 2007; Zhang, 2003). Even though governments consecrate a high amount of public resources to such policies (Fen Chong, 2009), the results stay very mixed.

Some authors argue that one of the reasons why the results stay mixed is because the cluster concept is simply too fuzzy and ill-defined (Markusen, 2003; R. Martin \& Sunley, 2003), touching too many policy areas. Academics are themselves not always one and the same opinion where cluster policies stand regarding all the different traditional policy streams.

Some authors think that cluster policies have simply become one of the major axes of industrial policies (Aiginger, 2007; Capron, 2011) or that it is simply a "new approach to industrial policy" (Guisard, et al., 2010). Others again argue that "cluster policy is... a wellknown instrument in innovation policy" (Mans, et al., 2008, p. 1375), that cluster policies are "a powerful instrument at the intersection between regional and industrial policy" (Schmiedeberg, 2010, p. 389) or that "cluster policies can be regarded as regional, industrial, or technological policies" (Nishimura \& Okamuro, 2011a, p. 118). Boekholt \& Thuriaux (1999, p. 382) and Nishimura \& Okamuro (2011a), similar to the OECD (2007), situate cluster policies at the boundaries of three different policies namely "industrial policy (including SME policy), regional development policy, and science and technology $(S \& T)$ policy”. However, the boundaries stay very blurry.

Discussions about cluster policies and the underlying ambiguity of multiple (maybe sometimes contradictory) objectives is far from closed among academics. However, when the operationalisation phase of cluster policies starts, this ambiguity of objectives creates problems on the field. When we dig further into the cluster policy literature we can identify two main issues that can lead to potential dilemmas: industrial excellence vs. regional development objectives; and an absence of an intrinsic motivation to build the policy-driven cluster.

\subsubsection{General objective: industrial excellence vs. regional development}

Several authors criticise that it is difficult to combine industrial excellence objectives with regional development objectives. For example Sternberg et al (2010) compared the 
institutional settings and multi-level government specificities of cluster policies implemented in North Carolina (USA) and Bavaria (Germany). They concluded that compared to the USA, German "clusters are usually not identified through academic mapping exercises, but rather through top-down political decisions, open bargaining, or negotiations among stakeholders behind closed doors" (Sternberg, et al., 2010, p. 1077). This leads to the problem that "in Germany cluster policies are generally troubled by the traditional orientation of regional policy towards the goal of spatial equity, which is fundamentally at odds with the growth and competitiveness focus of cluster policy” (Sternberg, et al., 2010, p. 1077).

Sternberg et al (2010) came to this critical conclusion regarding the German cluster policy, which according to them is too much oriented towards regional development than on focusing on competitiveness and excellence. If we look at research that is done on the French cluster policy the picture does not look much different. In 2005, France decided to label simultaneously 67 clusters on its territory. For some authors (T. Weil \& Fen Chong, 2008) the high amount of labelled clusters in France was the proof that the French government finally privileged a more regional policy approach (with the objective to also help less performing regions) than an industrial "excellence" policy approach only focusing on the most or potentially most performing systems (for example such as Germany and its BioRegio competition). The orientation of the French cluster policy was not transparent as well (Younès, 2011) but such as in the German case (Sternberg, et al., 2010, p. 1077) happening "behind closed doors".

The main problem of the regional vs. industrial development dichotomy is that regional development is often associated with helping regions and local actors that struggle to keep up with the national or global competition. However, some authors fear that a regional policy intermingled with an industrial policy can lead to helping industrial branches that will anyhow die at some point.

For example Hospers et al (2009, p. 297) heavily criticise Porter's opinion that cluster policies are "a horizontal and market-friendly approach" that is better than the classical industrial policy. Hospers et al (2009, p. 297) argue that cluster policies are also simply "reduced to industries". Additionally, cluster policies such as traditional industrial policies function by targeting a certain beneficiary. An industrial policy targets certain companies the cluster policy targets certain cluster, and each time the question of whom to choose is crucial 
but at the same time "a risky venture because of large information asymmetries between entrepreneurs and policy makers” (G. J. Hospers, et al., 2009, p. 297). For Hospers et al (2009, p. 297) "particular problems emerge when it comes to high-tech cluster policy and low-tech cluster policy". For them supporting high-tech clusters is like an "industrial policy of 'picking winners"” while a low-tech cluster policy is a "backing losers" policy (G. J. Hospers, et al., 2009, p. 297).

Similar to Hospers et al (2009), also Giuliani (2013) or Burfitt \& Macneill (2008) underline that "backing losers" might actually be extremely dangerous. Giuliani (2013, p. 1417) stresses that "in a growing cluster, new employment and market opportunities emerge and naturally replace those lost due to exiting firms", if policies intervene that try to "help the weakest firms to survive" this might have a negative impact on the region. Burfitt \& Macneill (2008) even go one step further and say that helping clusters that are on the terminal decline might even "manipulate [...] the cluster designation process [which] may [...] reinforce lock-in by supporting traditional declining clusters on the basis of their political backing or by crowding out the development of realistic new ones by promoting politically-motivated (high tech) fantasies". So instead of a natural painful decline that creates space for a new start and a healing process, the suffering process is prolonged and the healing process postponed.

A recent quantitative article studying a French cluster policy (SPL) shows that the State actually had an involuntary and hidden "backing losers" approach and that the results of this policy "are not very positive" (P. Martin, et al., 2011). Even though the policy initially did not want to help "lagging regions", the results showed that this was exactly done and that "the policy targeted firms in regions and sectors that were experiencing difficult times in terms of productivity and therefore competitiveness" (P. Martin, et al., 2011, p. 119). They concluded that this might be "bureaucratic continuity" as the agency in charge of this policy (the DATAR) was initially responsible to "promote territorial equity", something they somehow could not abandon. In the end the results show that the "the policy did not succeed in reversing the relative decline in productivity for the targeted firms [and] the policy had no effect on the employment and exports of firms" (P. Martin, et al., 2011, p. 120).

The literature shows that cluster policies need to be alerted regarding the divergent regional vs. industrial development objectives. On the one hand, governments have to be alerted not to pursue a "consensus policy" between different political agendas instead of a policy that 
pursues one goal that the policy tries to fulfil in the best possible manner (Sternberg, et al., 2010; T. Weil \& Fen Chong, 2008; Younès, 2011). On the other hand, governments have to be alerted regarding the "backing losers" phenomenon and the prolongation of the regional suffering process (Burfitt \& Macneill, 2008; Giuliani, 2013; G. J. Hospers, et al., 2009).

\subsubsection{Motivation: intrinsic motivation vs. policy prescription}

We already discussed that successful historical examples, like Silicon Valley and the EmiliaRomagna region, had one common characteristic, namely an external "challenger" that they wanted to surpass (in the case of Silicon Valley the Route 128, in the case of Emilia-Romagna the First Italy). As the objectives of policy-driven clusters, are often very blurry, actors can reinterpret them and develop an intrinsic motivation to build the policy-driven cluster.

These drivers and objectives do not have to be homogenous among the different actors involved in policy-driven clusters. For example, Sellar et al (2011) studies the implementation of cluster policies in Bulgaria. In their research, they clearly show how the cluster policy is situated at different institutional levels and each of these "different groups" use the cluster concept for their own purposes. Sellar et al (2011) particularly focused on "the articulation of cluster policies at European Union level, Bulgarian national level and local level”. Their results show that at the European Union level the cluster concept is used "as part of its innovation strategy and a tool to compete with the United States in the generation of new knowledge” (2011). However, at the Bulgarian national level things already look quite different even though they also brand it as cluster policy. The Bulgarian government sees “cluster policies as a tool for economic reconstruction" (2011). After the end of communism, the high-tech industry collapsed and the economy went down. Innovation is less important than the reconstruction of the economy. So the money for the cluster policy is particularly used to inject "capital in a cash-poor economy and [to conduct] substantial reforms of the public sector" (2011). If we go another step down, to the local level, we can add a third interpretation of the cluster concept. The local level is strongly dependent from foreign investors so it primarily used the cluster concept as a marketing tool to attract these foreign investors (Sellar, et al., 2011). Also Perry (2005), studying New Zealand cluster initiatives underlined that there are different rationalities co-existing in the policy-driven cluster context.

There are plenty of reasons why economic entities decide to join forces (Child \& Faulkner, 1998; Huxham \& Vangen, 2005; Noteboom, 2004; Sullivan \& Skelcher, 2002). Among the 
most cited reasons are for example the access to resources based on the resource-based theory (Barney, 1991; Penrose, 1959); cost minimisation based on the transaction cost theory (Coase, 1937; Williamson, 1985); shared risk; or learning and innovation (Powell, 1998; Powell, Koput, \& Smith-Doerr, 1996). Even though most of the cluster literature is based on a resource based or learning and innovation argumentation, policy-driven clusters might need another type of analysis.

In a more public management domain and more precisely in the community-building domain, another driver to join forces is often discussed: shared vision. Himmelman (1996) says that in order to reach a change in a community, a shared vision has to be created. This shared vision can be created in a continuum between collaborative betterment and collaborative empowerment.

On the one extreme we find collaborative betterment that "begins within public, private, or nonprofit institutions outside the community and is brought into the community" (Himmelman, 2002, p. 5). The process of collaboration is not launched within the community in an endogen manner, but the community "is invited into a process designed and controlled by larger institutions" (Himmelman, 2002, p. 5).

On the other extreme, we find collaborative empowerment that "begins within the community and is brought to public, private, or nonprofit institutions" (Himmelman, 2002, p. 5). In the collaborative empowerment strategy the community itself starts the collaboration process without an outside hierarchy dictating the conditions. Generally, if governments want to create shared vision by using empowerment, two types of basic activities are necessary: "(1) organizing a community in support of a collaborative purpose determined by the community; and (2) facilitating a process for integrating outside institutions in support of this community purpose” (Himmelman, 2002, p. 6).

Installing the "right" drivers and objectives for a policy-driven cluster is a challenging endeavour. Particularly, because passing from a more betterment condition to a more preferable empowerment condition is not obvious "because institutions usually cannot easily secure the confidence and trust of those they initially exclude from meaningful decisionmaking” (Himmelman, 2001, p. 283). Even though Himmelmann (2001) does not explicitly focus on policy-driven clusters, his research seems important to take into account in a policy- 
driven cluster context. Particularly, when governments define policy-driven cluster objectives that then have to be transformed by regional actors into concrete actions.

\subsection{Conclusion}

In this section we discussed all the "political dilemmas" that we identified in the cluster policy literature. Table 14 summarizes the three main political dilemmas (policy-driven cluster boundaries, policy-driven cluster subsidies, and policy-driven cluster objectives \& motivations) and their attributed symptoms discussed in this section.

\section{Table 14: Political dilemmas}

\begin{tabular}{|c|c|c|}
\hline Main dilemmas & Associated dilemmas & Examples of authors \\
\hline \multirow[t]{2}{*}{$\begin{array}{l}\text { Defining } \\
\text { boundaries } \\
\text { (PD\#1) }\end{array}$} & $\begin{array}{l}\text { PD\#1a - Geographical boundary: local vs. non- } \\
\text { local (difficulty to privilege political vs. } \\
\text { practitioner reality) }\end{array}$ & $\begin{array}{l}\text { (Chabaud, } \text { Messeghem, \& } \\
\text { Sammut, 2011; Ebbekink \& } \\
\text { Lagendijk, 2013; Gaffard, 2008; } \\
\text { Kitagawa, 2005; Younès, 2011) }\end{array}$ \\
\hline & $\begin{array}{l}\text { PD\#1b - Organisational boundaries: local vs. } \\
\text { national (difficulty to decide on the right level and } \\
\text { entity to manage the policy-driven cluster) }\end{array}$ & $\begin{array}{l}\text { (Burfitt \& Macneill, 2008; Perry, } \\
\text { 2005; Rutherford \& Holmes, 2007) }\end{array}$ \\
\hline \multirow[t]{2}{*}{$\begin{array}{l}\text { Defining subsidies } \\
\text { (PD\#2) }\end{array}$} & $\begin{array}{l}\text { PD\#2a - Subsidies type: indirect vs. direct } \\
\text { subsidies (difficulty to decide how to foster } R \& D \\
\text { networks) }\end{array}$ & $\begin{array}{l}\text { (Burfitt \& Macneill, 2008; S. } \\
\text { Menu, 2012; Nishimura \& } \\
\text { Okamuro, 2011b; T. Weil \& Fen } \\
\text { Chong, 2009) }\end{array}$ \\
\hline & $\begin{array}{l}\text { PD\#2b - One-shop vs. multiple shop strategies: } \\
\text { (advantages and disadvantages of both, always } \\
\text { depends on the perspective) }\end{array}$ & $\begin{array}{l}\text { (Burfitt \& Macneill, 2008; } \\
\text { Chabault, 2009; Guisard, et al., } \\
\text { 2010; Lallemand, 2013) }\end{array}$ \\
\hline \multirow[t]{2}{*}{$\begin{array}{l}\text { Defining } \\
\text { objectives (PD\#3) }\end{array}$} & $\begin{array}{l}\text { PD\#3a - General objective: industrial excellence } \\
\text { vs. regional development objectives (difficulty to } \\
\text { decide, consensus between different political } \\
\text { agendas instead of a policy that pursues one goal) }\end{array}$ & $\begin{array}{l}\text { (Burfitt \& Macneill, 2008; } \\
\text { Giuliani, 2013; G.-J. Hospers, et } \\
\text { al., 2009; Sternberg, et al., 2010; T. } \\
\text { Weil \& Fen Chong, 2008; Younès, } \\
\text { 2011) }\end{array}$ \\
\hline & $\begin{array}{l}\text { PD\#3b - Motivation: intrinsic motivation vs } \\
\text { policy prescription (difficulty to find the right } \\
\text { balance between guiding the policy-driven clusters } \\
\text { and leaving them enough space to develop } \\
\text { motivation) }\end{array}$ & $\begin{array}{l}\text { (Himmelman, 1996; Perry, 2005; } \\
\text { Sellar, et al., 2011) }\end{array}$ \\
\hline
\end{tabular}

\section{Drivers of pathologies: managerial dilemmas}

The second type of policy-driven cluster dilemmas that we identified in the literature is of managerial nature. As already discussed in chapter one, a huge amount of grey literature has emerged that tries to help policy-driven cluster managers in their management endeavours (CLOE, 2006; Cluster Navigators Ltd., 2001; DTI, 2004; GTZ, 2007a, 2007b; Innovation America, 2007). Generally these policy-driven cluster manuals read like a pell-mell of different business school disciplines, focusing for example on how policy-driven cluster managers can set up business plans, conduct stakeholder analyses, or cluster marketing (GTZ, 
2007a, 2007b). However, they do not look from an organisational point of view on these public management challenges, something that though starts to emerge and is particularly important in policy implementation (Saussois, 2008).

Also academics start focusing on these management issues as the article from Coletti (2010) shows. Coletti (2010) exploits data from a global policy-driven cluster manager survey. The results reflect the general policy objectives of policy-driven clusters and not the implementation dilemmas encountered on the field (for example who should be the leader?). For example the most important tasks mentioned by policy-driven cluster managers are: "fostering exchanges between cluster members (e.g. networking), networking with stakeholders, lobbying, identifying and integrating new cluster members, strategy development for the cluster (e.g. identification of market opportunities), organising events" (Coletti, 2010, p. 685). Similar results were already obtained by Sölvell (2003, p. 10) who advocated that the most important elements of cluster initiatives is to foster networks among people and firms. ${ }^{76}$

However, below this first level of objectives there is a richness of managerial dilemmas that emerge by setting up policy-driven clusters within a defined geographical and organisational boundary in which one tries to foster networking and innovation. Innovation is for example not mentioned as one of the main policy-driven cluster objectives in the surveys of Coletti (2010) or Sölvell (2003) (only at the $8^{\text {th }}$ and $4^{\text {th }}$ place respectively), as cluster policies somehow implicitly assume that networking will automatically lead to innovation.

We are able to distinguish three different types of managerial dilemmas that seem to have a strong impact on the performance of policy-driven clusters (see Figure 12). These three dilemmas emerge because of the difficulty to manage the multiple actors involved in policydriven clusters as well as the wish to foster innovation and collaboration within a defined

\footnotetext{
76 Coletti (2010) also focuses on the skills that cluster managers need to have, here he identified that the most important skills for cluster managers are "knowledge of the cluster's specific sector/industry, communicative skills (e.g. presentation, mediation, negotiating), leadership capabilities, team management”. Nearly 15 years early Cooke (1996, p. 170) also already tried to identify the necessary skills of cluster managers and came to similar results: "Whichever personnel occupy whatever roles in the Network "hearts" - the Innovation Centres they must: have the five key networking skills [Reciprocity, Trust, Learning, Partnership, Decentralism]; be psychologically open, enthusiastic, "fanatical"; combine technology/business management/and marketing skills; must be able to convince firms to become members/associates/subscribers/supporters/users of the network, its hubs and spokes; must themselves be innovative, initiative-taking; must be well-networked within their country and beyond to innovation centres and systems"
} 
entity named "policy-driven cluster" but that is very "open" compared to a traditional organisational setting.

Figure 12: Managerial dilemmas of policy-driven clusters

\begin{tabular}{|c|c|c|}
\hline \multirow{5}{*}{ 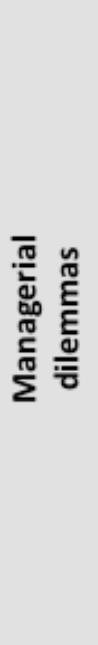 } & \multirow{2}{*}{$\begin{array}{l}\text { MD\#1 - Managing } \\
\text { actor involvement }\end{array}$} & MD\#1a - Leadership: who is in charge? \\
\hline & & MD\#1b - Learning: learning capacity vs. administrative straightjacket \\
\hline & $\begin{array}{l}\text { AD\#2 - Managing } \\
\text { inovation processes }\end{array}$ & $\begin{array}{l}\text { MD\#2a - Which stage matters most? } \\
\text { Creativity vs. Research vs. Development }\end{array}$ \\
\hline & \multirow{2}{*}{$\begin{array}{l}\text { MD\#3 - Managing } \\
\text { collaboration processes }\end{array}$} & MD\#3a - How to foster collaboration? - People-driven vs. Space-driven \\
\hline & & MD\#3b - Who collaborates? Even vs. uneven partners \\
\hline
\end{tabular}

\subsection{Dilemmas on managing actor involvement}

The first important point to discuss concerns the complex nature of policy-driven clusters, particularly due to the multiple actors involved and their conflicting views. We first focus on the difficult question of leadership in policy-driven clusters and then on the necessity to accept that policy-driven cluster actors have a learning capacity that can be hindered by an "administrative straightjacket”.

\subsubsection{Leadership: who is in charge?}

The leadership issue in policy-driven clusters is increasingly treated by cluster policy scholars and identified as a major dilemma. The objective of cluster policies is to make collaborate a variety of different actors but this obliges "policy-makers not only [to] mov[e] outside their traditional departmental boundaries but also [to] engag[e] with a wide range of relational issues amongst firms, institutions and other actors each with their own raison d'être, culture and spatial scale of operation" (MacNeill \& Steiner, 2010, p. 444). However, it is not evident that the policy-makers manage to bring all these different types of actors around one table in order to work constructively together. 
In order to handle this high complexity, Lundequist \& Power (2002, p. 698) conclude that it is particularly important "to give authorization to one or a few people to act as cluster 'drivers'." They call them "civic entrepreneurs", coming either "from the public or the private sector." These civic entrepreneurs have to be in the center of the policy-driven cluster and "have a capacity to act as a network broker between sectors and individual interests." Hereinafter, we shortly discuss two cluster policy examples where the "civic entrepreneur" theory seems to be employed (Bavaria and Austria) and two other examples where the "civic entrepreneur" theory seems not to be employed (France and UK) and therefore causing several leadership problems.

For example, Menu (2012) analyzed the French policy-driven cluster leadership system (in Brittany) and also the German policy-driven cluster leadership system (in Bavaria). In the Bavarian policy-driven clusters the leadership question seems well organised by giving one "civic entrepreneur" the responsibility for all policy-driven clusters situated in the region and thus having concentrated in one local person several responsibilities and also the necessary authority to get things done. However, the situation is quite different in France. Menu (2012, p. 830) argues that it is not that easy to "understand leadership" in French policy-driven clusters because one also has to take into account the "policy dimension". Menu (2012, p. 831) underlines that the French policy-driven clusters are, compared to the Bavarian policydriven clusters, "weak institutionalized clusters" where leadership emerged only slowly and difficultly. Additionally there is no regional umbrella structure but all regional policy-driven clusters depend directly from the state. The French state requires from each of the local policy-driven cluster leaders "to follow central guidelines" (for example to draft a strategic administrative plans) but on the other hand does not accord enough "resources to enact them efficiently" (S. Menu, 2012, p. 831). The result is that the French system, compared to the Bavarian system, looses a considerable amount of time with administrative and reporting tasks and has thus less time to for animating the local network.

The German (Bavaria) policy-driven cluster leadership system seems similar to the Austrian (Styria) leadership system. In both cases, a policy-driven cluster leader sets the general strategy but at the same time allows the local actors to actively participate in the strategy development. According to MacNeill \& Steiner (2010, p. 445), in the Austrian case, the leadership system is handled in a post-modern' participative management style, i.e. "conceived as an open participative process" allowing "trial[s] and error [s]". According, to 
them this creates a favourable policy-driven cluster environment and the policy-driven cluster management results are better than when using a new public sector management approach.

MacNeill \& Steiner (2010, p. 445) distinguish between two forms of policy-driven cluster leadership. On the one hand, they identify "cluster coordination as mutual strategy development” which they relate to Gibney et al.'s (2009) “"post-modern' participative management style" (the case of Styria). On the other hand, they identify a "traditional partnership working where a hierarchical leader sets a strategy and goals within the 'partnership"' who then do not participate in the amelioration of the process. They relate this traditional approach to Gibney et al.'s (2009) “'New Public Sector Management”” approach. The French case, seems thus more similar to this new public sector management leadership style while the Austrian and German cases discussed in the literature seems closer to the postmodern participative management style.

Similar to the French case, also the UK (West Midlands) seems to adopt a more hierarchical approach to policy-driven cluster management. Burfitt et al (2007, p. 1288) analyzed a medical technology cluster in the West Midlands and conclude, such as Menu (2012) for the French case, that not only "resources" were low but that the "institutional capacity and leadership [...] [was] weak”. This was amplified because of two reasons. First the cluster privileged "avoid[ing] division amongst key regional players [...] over the creation of a workable definition of the cluster" (Burfitt \& Macneill, 2008, p. 500) and second "local and regional public bodies [had] limited autonomy with regard to national government" (Burfitt, et al., 2007, p. 1288). The combination of all these factors seems to hinder the emergence of a positive cluster development.

To sum up, local leadership and a dynamic cluster development seem to be particularly hindered when resources are low, strategy is not built in a participative manner, and the central state keeps too much administrative power compared to the local cluster organisations (Burfitt, et al., 2007; MacNeill \& Steiner, 2010; S. Menu, 2012).

\subsubsection{Learning: learning capacity vs. administrative straightjacket}

Another important element to take into consideration when implementing cluster policies is the learning capacity of the involved actors. These cluster actors gain, little by little, more experience. If the different policy-driven cluster actors are allowed to and if the cluster policy 
is not too rigid, they might improve their functioning and so slowly construct a better cluster policy. However, several cluster policy specialists underline that policymakers tend to keep cluster policies in an "administrative straightjacket” (Ebbekink \& Lagendijk, 2013, p. 740).

The following examples will show that several countries seem to have similar problems regarding the administrative rigidity when implementing cluster policies. According to Burfitt \& Macneill (2008, p. 497), the managerial dilemmas that policymakers are facing by implementing cluster policies is particularly due to the fact that they traditionally "conceptualiz[e] the policy process as a largely linear phenomenon where traditional, professional project management skills were at a premium". However, in the cluster policy case they have to move "towards [...] [a] more fluid 'relational' processes that favour association, interaction and collaboration between individuals, institutions, firms and other concerned groups." The logic behind this new type of policy is not the same as in traditional industrial or regional policies.

For example, Ebbekink \& Lagendijk (2013, p. 738), argue that the "policy processes" are happening in "isolation", "occur at too much of a distance" and that the "communication circuits [are] institutionalized and bureaucratized in impenetrable structures". Therefore they urge for privileging "policy leverage" instead of "cluster building” by assigning an important role to "civic entrepreneurs" (2013, p. 738). For them policy leverage is among others concentrated on "breaking through administrative barrier" and consists of "collective strategy-building” meaning "an ongoing, informal strategic dialogue between "all” cluster stakeholders" which will collectively allow to learn and create action (2013, p. 738).

Also Sotarauta (2012, p. 792) criticizes that "the policy process is believed to proceed in linear discrete stages" and that policy makers are seen as "passive recipient[s] of given recommendations in an expert-driven and technocratic policy process." Instead of a linear process, Sotarauta (2012, p. 792) after conducting an in-depth study of a Finish cluster policy, argues that "policy making is a learning process in which theory, policy practice, and feedback from the "real world" coevolve constantly" and that this process is more an "evolutionary story”.

Lundequist \& Power (2002), who conducted in-depth studies of Swedish cluster initiatives, also conclude that the cluster policy process is not a linear process. Lundequist \& Power 
(2002, p. 697) underline that "policy-makers and practitioners all too often view cluster initiatives as programmatics to be developed and implemented along some sort of uni-linear timeline”. Instead of this uni-linear timeline approach, Lundequist \& Power (2002, p. 697) show with their Swedish case studies that a "successful cluster building involves a more reciprocal process that can be described as an on-going conversation amongst various stakeholders (or even stockholders) in economic development."

Also several studies analysing the French cluster policy come to the same conclusion (Carré, et al., 2008; Gadille, et al., 2013; Gallié, et al., 2012; T. Weil \& Fen Chong, 2009) ${ }^{77}$. The study of Weil \& Fen Chong (2009) needs particular attention because they analyzed in detail the learning capacity of the different cluster actors and conclude that a cluster is in fact "an ecology of fast and slow learners" (T. Weil \& Fen Chong, 2009, p. 18) Their analysis of the French cluster policy shows that "the government has been a slow learner" while the different cluster managers are fast learners and the different cluster members "usually adapt quite well after some experimentation. Those with high stakes or smart opportunists stay, others leave or become sleeping participants" (T. Weil \& Fen Chong, 2009, pp. 18-19). Compared to the other studies they not only identified that the actors of the policy-driven clusters are "learning" and evolving but that they also have different learning speeds.

The fact that each learning process needs actually an "organisational learning time" which might not always be very fast is also underlined by Carré et al. (2008). Carré et al. (2008) even considers that according a cluster this "organisational learning time" is an essential dimension of the success of the policy. They particularly alert to the fact that the learning path might be much longer when the local actors are not used to working together and in metropolitan regions where the cooperation is even more difficult.

To sum up, taking into consideration the learning capacity of the different actors is an important element in order to help the cluster policy unfold in an effective manner.

\footnotetext{
${ }^{77}$ The results of the article where I participated (Gallié, et al., 2012) will be presented in the third part (results and discussion).
} 


\subsection{Dilemmas on managing innovation processes}

Another important point to discuss is the management of innovation ${ }^{78}$ in policy-driven clusters. Even though ample literature exists on innovation management in organisations, the literature focusing on innovation management in policy-driven cluster is very scarce (Bocquet \& Mothe, 2010; Lefebvre, 2013). This tendency of not addressing innovation management in policy-driven clusters is also reflected in policy-driven cluster surveys. In several surveys (Coletti, 2010; Sölvell, et al., 2003), innovation management, compared to networking efforts, is not mentioned as one of the top priorities for policy-driven cluster managers. This is somehow a great paradox in the policy-driven cluster reality and academic literature, as fostering innovation is actually one of the core objectives of every cluster policy. Therefore, Lefebvre (2013) recently thus to pass from an "accidental brokering to purposeful brokering" process in clusters in order to foster innovation.

A large body of cluster literature treats the advantages of face-to-face interactions within territories (Gertler, 1995, 2003; Lawson \& Lorenz, 1999; Maskell \& Malmberg, 1999; Storper, 1995; Storper \& Venables, 2004). The underlying assumption is that through face-toface interactions, people can more easily transfer tacit knowledge (Nonaka, 1991; Polanyi, $1966)^{79}$. Additionally, the co-location of companies also creates more trust between the companies which facilitates the installation of institutional norms of cooperation (Lawson \& Lorenz, 1999; Storper \& Venables, 2004). Finally, these circumstances increase the innovation potential of clustered companies as well as the competitive advantage of the whole nation (Porter, 1990, 2000a; Porter \& Stern, 2001). Some academics though, like for example the geographers Torre (2008) or Shearmur (2011a), have a critical stance regarding clusters and innovation. Both argue that the role of permanent geographic proximity on innovation remains questioned.

\footnotetext{
78 Innovation is defined as "the successful implementation of creative ideas" (Amabile, 1996, p. 1) or the "commercial exploitation" of new ideas (Swann, 2009, p. 25) that means that "a common feature of an innovation is that it must have been implemented. A new or improved product is implemented when it is introduced on the market. New processes, marketing methods or organisational methods are implemented when they are brought into actual use in the firm's operations" (OECD \& Eurostat, 2005, p. 47). Most of the literature (for a comparison between process, product and organisational innovation also see Boer \& During (2001)) distinguishes four types of innovations (OECD \& Eurostat, 2005, p. 46): "the implementation of a new or significantly improved product (good or service), or process, [or] a new marketing method, or a new organisational method". (Organisational innovation: for example "a new organisational method in business practices, workplace organisation or external relations” (OECD \& Eurostat, 2005, p. 46)). Cluster policies particularly focus on product innovations.

${ }^{79}$ Explicit knowledge is codified and can be communicated over long distances. Tacit knowledge is noncodified, predominantly transferred through face-to-face interactions and thus place bound.
} 
In case authors do agree that proximity triggers knowledge exchange and innovation, a controversial persists regarding the type of proximity needed in order to generate knowledge spillovers between regional actors. Beaudry \& Schiffauerova (2009, p. 320) did a great literature review on the topic and conclude that three different opinions persist: specialisation, diversity and competition (see Table 15). The academics that argue that specialization is needed in order to facilitate knowledge spillovers and thus innovation base themselves on the MAR (or Marshall-Arrow-Romer) model which was formalized by Glaeser et al $(1992)^{80}$. The ones that claim that regional diversity is an important source of knowledge spillovers base their research on the works of Jacobs $(1961,1969)$. Finally, the ones that advocate that regional specialisation is important coupled with high competition, base their work on Porter (1998b). However, the discussion about who is "right" is far from closed.

Table 15: Sources of knowledge spillovers in clusters

\begin{tabular}{|l|c|c|c|}
\hline & MAR & Jacobs & Porter \\
\hline Specialization & + & - & + \\
\hline Diversity & - & + & - \\
\hline Competition & - & - & + \\
\hline
\end{tabular}

Source: Beaudry \& Schiffauerova (2009, p. 320)

So besides the fact that cluster researchers are still not sure what exactly triggers knowledge spillovers, governments have implemented cluster policies. They did this, as already discussed, mainly based on Porter's cluster concept, thus privileging regional specialisation. The question is in a certain manner no longer which type of proximity generates knowledge spillovers but what can policy-driven cluster managers do in order to foster knowledge spillovers and innovation in specialist policy-driven clusters. However, the process leading to an innovation is treated like a black box. Chiaroni \& Chiesa (2006) underlined that the cluster literature constantly tries to describe clusters but does not focus on the dynamics of the cluster and ignores this black box.

In this section thus we do not focus on the relationship between proximity and innovation but on the role that policy-driven cluster managers play in fostering innovation among the members of their policy-driven cluster. Hereinafter we fist discuss which types of processes lead to innovation, and then we will focus on the dilemmas of the creativity process, the

\footnotetext{
${ }^{80}$ The MAR model is based on the works of Marshall (1890 (1920)), Arrow (1962) and Romer (1986) (thus MAR).
} 
research process and development process. We will see that each process needs a slightly different type of management and can be harmed by certain behaviours.

\subsubsection{Introduction: processes leading to innovation}

The literature stipulates that "management cannot ensure innovation success", however they “can influence its odds" (Van de Ven, Polley, Garud, \& Venkataraman, 1999, p. 11). This contemporary approach of innovation ${ }^{81}$ takes into account that a social environment has to be created and managed in order to foster the processes that lead to innovations (Caraça, Lundvall, \& Mendonça, 2009).

It is important to distinguish the processes that lead to an innovation and the innovation itself (i.e. the successful commercialisation). The processes that lead to innovations are "complex, uncertain, somewhat disorderly, and subject to changes of many sorts" like for example "market environment, production facilities and knowledge, and the social contexts" (Kline \& Rosenberg, 1986, p. 375). What is important, is finding the right activities ${ }^{82}$ and environmental conditions that might positively influence the processes leading to innovation.

Historically the process leading to innovation was seen as a linear process (Swann, 2009), going from research over invention to development and finally to hopefully an innovation. Today researches have shown that there are multiple processes leading to innovation and that these processes are not linear but more complex that go back and forward between various stages $^{83}$. It is a permanent process between exploration of new ideas and exploitation of results (March, 1991) (see Figure 13).

\footnotetext{
81 The traditional approach towards creativity and innovation was very person-centered, meaning that the "conventional wisdom" was that "creativity is something done by creative people" (Amabile, 1996, p. 1). According to Amabile (1996, p. 1) academic research helped to understand the "backgrounds, personality traits, and work styles of outstandingly creative people" but this traditional approach "ignored the role of the social environment in creativity and innovation”.

${ }^{82}$ These innovation activities might be of "scientific, technological, organisational, financial and commercial" nature, all "intended to, lead to the implementation of innovations" (OECD \& Eurostat, 2005, p. 47).

${ }^{83}$ see (Caraça, et al., 2009; Swann, 2009) for a discussion of the new processes leading to innovation
} 
Figure 13: Processes and intermediary results leading to innovation

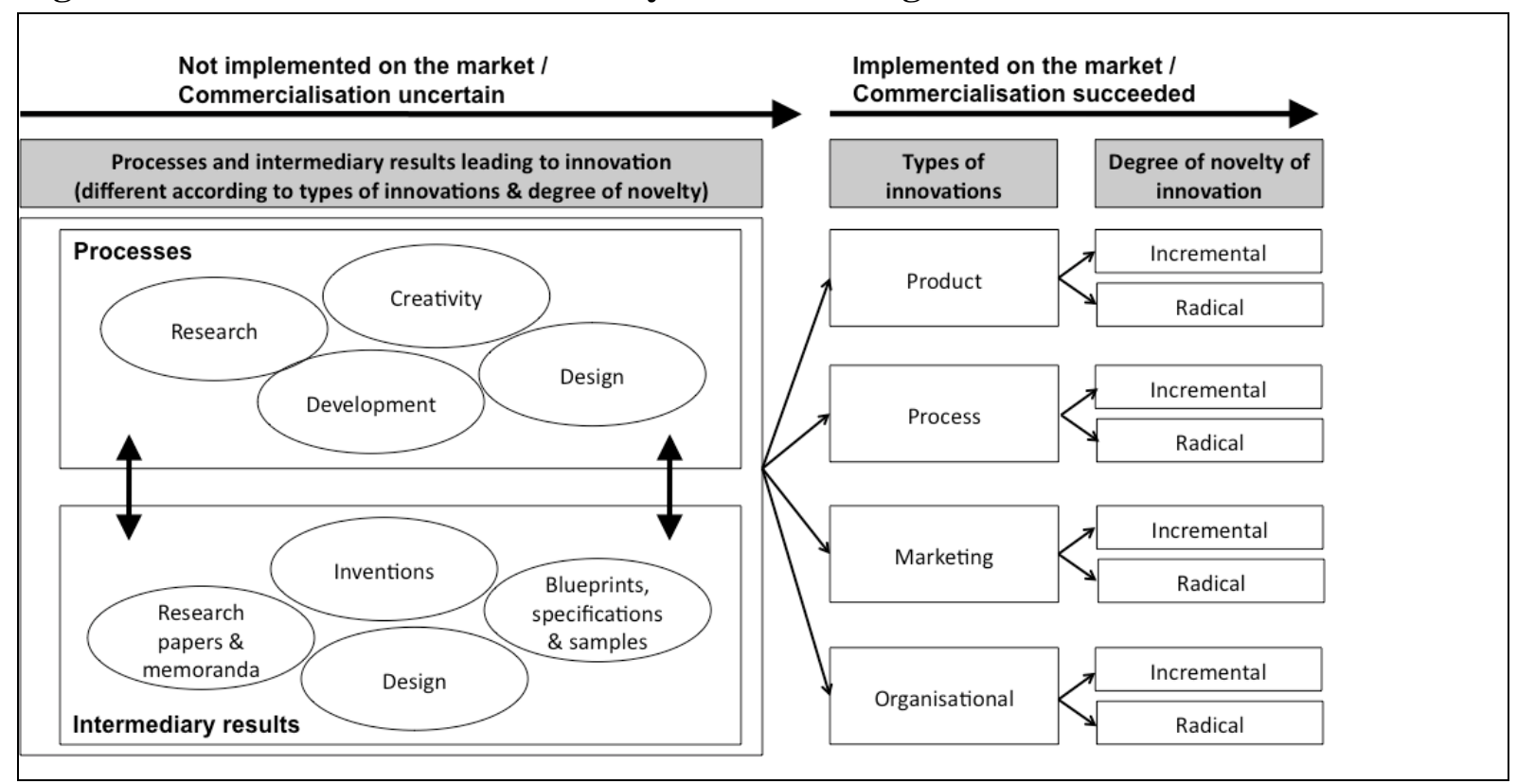

Source: slightly inspired by Swann (2009)

Swann (2009, p. 26) distinguishes four different types of exploration processes that might lead to innovation in the end: a creativity process, a research ${ }^{84}$ process, a development process and a design ${ }^{85}$ process. All of these processes intermingle and create together different types of intermediary results: (1) inventions ${ }^{86}$ in the form of new "ideas, sketches or models for a new product or process, that may often be patented" (Swann, 2009, p. 25); (2) "new scientific knowledge, hypotheses and theories" that are "expressed in research papers and memoranda" (Swann, 2009, p. 26), (3) "blueprints, specifications and samples” (Swann, 2009, p. 26), or (4) design ${ }^{87}$ that makes "a product stand out" ${ }^{\text {" } 88}$.

These intermediary results are important in order to summarise the accumulated knowledge, to render the knowledge explicit and thus to better advance towards innovation. The different

\footnotetext{
${ }^{84}$ Research can be split into basic research and applied research, but I will not distinguish between these two types of research in this thesis. Basic research definition: "Basic research is experimental or theoretical work undertaken primarily to acquire new knowledge of the underlying foundation of phenomena and observable facts, without any particular application or use in view" (OECD, 2002, p. 30). Applied research definition: "Applied research is also original investigation undertaken in order to acquire new knowledge. It is, however, directed primarily towards a specific practical aim or objective" (OECD, 2002, p. 30).

${ }^{85} \mathrm{We}$ will not discuss the design process in more detail, as it is the less important process for the time being in policy-driven clusters. See Annex 16 for a short introduction to design thinking.

${ }^{86}$ Compared to innovations, inventions are not commercialised yet.

${ }^{87}$ Design can be considered as a process but also as a results (Swann, 2009).

${ }^{88}$ Design "adds the extra dimension to any product" (John Harvey Jones, cited by Swann, 2009, p. 26). Design is expressed in the form of "the quality of the way it matches the purpose, skills and personality of the user, of the visual communication which goes with it, of the environment in which it is sold, and of the image of its maker" (Bernsen cited by Swann, 2009, p. 26).
} 
processes and intermediary results already show that the innovation process is highly complex and that a constant back and forward between different processes and intermediary results exists.

Hereinafter, we will now discuss each of the four innovation processes and the factors that influence these processes ${ }^{89}$. In the end we underline the common and contradicting factors between the four processes.

\subsubsection{Which stage matters most? - Creativity vs. Research vs. Development}

Three processes simultaneously lead to innovation: creativity, research and development. However, all of them need another organisational environment to be efficiently fostered.

\subsubsection{Creativity process}

First of all, we concentrate on the creativity process. Until recently, companies still thought that they just had to invest "in extensive internal research laboratories, hire the most brilliant people [...] and then wait patiently for novel products to emerge" (Chesbrough, 2007, p. 12). However, today, the increasing developing costs coupled with an increasingly short product life cycle (Chesbrough, 2007) force companies to improve their innovation processes in order to be faster than their competitors. However, a consequence of these acceleration tendencies is that "creativity gets killed" (Amabile, 1998, p. 77), particularly if no social environment favourable for creativity (and all other processes leading to innovation) is build (Amabile, 1996).

Amabile (1998, p. 77) argues that creativity gets killed "much more often than it gets supported". This is due to work environments that are meant to "maximize business imperatives such as coordination, productivity, and control" but in doing so hinder the development of creativity, the most elementary corner stone of innovation (Amabile, 1998, p. 77). Amabile (1998) and Amabile et al (Amabile, Conti, Coon, Lazenby, \& Herron, 1996) distinguish several factors that are particularly important in the creativity processes:

\footnotetext{
${ }^{89}$ We only focus on factors that can be influenced by management and we do not focus on context factors such as "external background data (such as socio-political continuity or the legal system) [...] and internal background data (such as the legal form or the size of the organization)" (Ernst, 2002, p. 3) and we do not go into the psychological dimensions of expertise, creative-thinking skills, and motivation (Amabile, 1998).
} 
supervisory encouragement and no evaluation culture ${ }^{90}$; organisational encouragement ${ }^{91}$; different types of work group features such as diversity, trust, respect but at the same time no "shotgun weddings" ${ }^{92}$; control over one's work ${ }^{93}$; resources (particularly time and money) ${ }^{94}$; challenging work ${ }^{95}$; and regularly participation in expertise \& creative thinking conferences ${ }^{96}$.

In the cluster policy literature, two topics regarding creativity start to emerge: the impact of financial incentives and the problem of innovation lock-in.

\section{Avoiding financial incentives}

Bocquet \& Mothe (2010) analyse two French policy-driven clusters by comparing their "knowledge identification" phases, their "knowledge acquisition and utilization" phases, and finally the role of the policy-driven cluster governance in this process. The results show that

\footnotetext{
${ }^{90}$ Supervisory encouragement and no evaluation culture: A good supervisor has to set goals, be supportive or shows confidence (1996, p. 1166). Additionally in order to develop a passion for the subject "people need to feel as if their work matters to the organization" (1998, p. 83). In highly creative organisation these are not extrinsic but intrinsic rewards. However, very often different "layers of evaluation" hinder the creative process (1998, p. 83). This "evaluation culture" does not spore creativity as people then focus on "the external rewards and punishments associated with their output" $(1998$, p. 83). Such an evaluation culture "creates a climate of fear, which again undermines intrinsic motivation" (1998, p. 83). In case an idea is not accepted by the hierarchy, it is important to encourage the person to continue his/her efforts despite the drawback: "If people do not perceive any "failure value" for projects that ultimately do not achieve commercial success, they'll become less and less likely to experiment, explore, and connect with their work on a personal level" (1998, p. 83).

${ }^{91}$ Organisational encouragement: Creativity is even more fostered if not only the supervisors encourage it but the entire organization: allocating rewards (not in monetary form), mandating "collaboration and information" sharing, exposing employees "to various approaches of problem solving" $(1998$, p. 84). However, all kinds of political agendas (being "cliquish" or "at war with one another") threaten creativity and the fluid circulation of knowledge.

${ }^{92}$ Work group features (diversity and trust but no "shotgun weddings"): Another important element is the composition of the work group. A work group that best spores creativity is "a diversely skilled work group in which people communicate well, are open to new ideas, constructively challenge each other's work, trust and help each other, and feel committed to the work they are doing" (1996, p. 1166). However diversity is not everything as three other features are important in order for the work group to succeed (1998, p. 82): (1) "share excitement over the team's goal"; (2) "willingness to help [...] teammates through difficult periods and setbacks"; (3) "recognize the unique knowledge and perspective that other members bring to the table". However, "shotgun weddings" (meaning "the most eligible employee is wed to the most eligible - that is, the most urgent and open - assignment") are "one of the most common ways managers kill creativity" (1998, p. 81). ${ }^{93}$ Control over one's work: Another important creativity enhancer is to have "sense of control over one's work" (1996, p. 1166). However, only freedom regarding the means (or process) is important for creativity not the ends: "People will be more creative, [...], if you give them freedom to decide how to climb a particular mountain. You needn't let them choose which mountain to climb" (1998, p. 81).

${ }_{94}$ Resources: The main resources that affect creativity are primarily time and money. On a second level only, physical space $(1998$, p. 82). If there is for example a time crunch to beat a competitor, time pressure can stimulate creativity. However, fake deadlines or impossibly tight deadlines, kill creativity as creativity and exploring new concepts simply takes time. Adding more resources above a certain level does not boost creativity, but below this level it might have a negative impact.

${ }^{95}$ Challenging work: Managers have to match the right people with the right assignments. To enhance creativity it is important to work on "challenging tasks and important projects" (1996, p. 1166).

${ }^{96}$ Expertise \& creative thinking conferences: Finally, "regular scientific seminars and professional conferences will undoubtedly add to the scientist's expertise in hemophilia and related fields. And training in brainstorming, problem solving, and so-called lateral thinking” (1998, p. 80) are important as well.
} 
the most successful policy-driven cluster shows three different characteristics (2010, p. 236). First, the policy-driven cluster employed a more egalitarian approach during the knowledge identification phase, not only focusing on "technical knowledge that is crucial for the leading firms" but focusing on "focus on 'general' knowledge to support the growth of (all) cluster firms" (Bocquet \& Mothe, 2010, p. 236). Second, during the knowledge acquisition and utilization phase the policy-driven cluster counted on "strong (non-financial) incentives to make firms interact in a transversal logic" which allowed the "emergence of a shared cognitive orientation" (Bocquet \& Mothe, 2010, p. 236). Finally, the most successful policydriven cluster acted more like a "knowledge activist" (Von Krogh, Nonaka, \& Ichijo, 1997) than a simple "knowledge broker" (J. S. Brown \& Duguid, 1998). The more successful policy-driven cluster thus took an active role in the knowledge (or creativity) creation process by avoiding financial incentives.

\section{Avoiding lock-in}

Innovations can be distinguished according to their degree of novelty. The majority of the literature, in an Schumpeterian manner, distinguishes between two broad categories, radical and incremental innovation ${ }^{97}$. A big dilemma of policy-driven cluster managers is to orient policy-driven cluster members towards promising new fields and to create ideas for new radical innovations ${ }^{98}$. However, this orienting towards promising new ideas goes along with a potential innovation lock-in that in the end prevents radical innovations to develop.

For example, Visser (2009, p. 190) alerts that clusters also go along with "diminishing marginal returns of horizontal learning based on pure spillovers may yield cognitive and technological lock-in" and that this problem has to be taken into consideration when implementing cluster polices. Also Hermans et al. (2012), studying the Belgium cluster policy, underline that there is a risk of an idea lock-in within a region. This lock-in "would arise from the choices made at both the cluster and the project levels [...] once investments are made according to those choices, a lock-in may prevent local firms from experiencing alternatives and opening new paths" (Hermans, et al., 2012, p. 624). Cluster policies seem to

\footnotetext{
${ }^{97}$ While "incremental innovation introduces relatively minor changes to the existing product, exploits the potential of established design" and "draws from no dramatically new science", "radical innovation, in contrast, is based on a different set of engineering and scientific principles and often opens up whole new markets and potential applications" (Henderson \& Clark, 1990, p. 9).

${ }^{98}$ Even though different stimuli are needed to foster incremental and radical innovations (Koberg, Detienne, \& Heppard, 2003; Verganti, 2011), we will not go into this detail of discussion. For example Christensen (1997) and Verganti (2011) argue that a close relationship with consumers might be profitable for incremental innovation but not for radical innovation which needs to be based on science.
} 
have the tendency to orient the local actors towards a certain direction privileged by the government. Schmitt (2011) for example underlines the important role of the French cluster policy in promoting green growth thanks to targeted investments into this sector. Even though this is highly appreciated, it nevertheless shows that the cluster policies are not only used to promote innovation but also to direct innovation in certain directions.

Agogué (2012) did empirical tests in French clusters to show that the actors of a cluster follow a certain path and have a cognitive fixation on certain topics. The local cluster actors are kind of trapped into a certain world-view that is difficult to leave without a proper management tool to help them thinking out of the box. Even though not directly focusing on the lock-in problem but on social capital, Eklinder-Frick et al (2012, p. 800) come to a similar conclusion namely that too much "bonding can also over-embed companies in their social context" which then has a negative impact on their innovation capacity. For Eklinder-Frick et al (2012, p. 800) "this highlights the importance of the managerial role in leading and defining the tasks of a regional strategic network and the complexity of encouraging other actors to participate."

However, even though a lot of cluster policies would like to strive towards radical innovations. It is important to underline that the knowledge bases are not the same in each kind of industry. Some cluster specialists underline that the knowledge bases vary between the different industries and regional innovation systems (Asheim \& Gertler, 2005). Some industries use more a synthetic approach meaning that they are more based on incremental innovation (for example application or novel combination of existing knowledge, applied research, importance of tacit knowledge, innovation is less disruptive) (Asheim \& Gertler, 2005). Other industries use more an analytical approach meaning that they are more based on radical innovation (for example the use of scientific knowledge is highly important, the knowledge creation processes is more based on formal models, codified science, rational process, knowledge input and outputs more codified) (Asheim \& Gertler, 2005). For governments implementing policy-driven clusters, it is important to acknowledge that different types of industries will be more or less prone for radical innovation.

\subsubsection{Research process}

In a second step, we focus on the positive factors influencing research. Broadly we found two different approaches. 
The first approach is mainly based in the management and medical literature and focuses on how to manage scientists effectively in order to improve their research performance (Bland \& Ruffin, 1992; Chawla \& Singh, 1998; La Porte, 1965; Ryan \& Hurley, 2007). Scientist are for example positively influenced by (Bland \& Ruffin, 1992; Chawla \& Singh, 1998; La Porte, 1965; Ryan \& Hurley, 2007): the perception of conceptually exciting research programmes, autonomy in project selection, decentralized organization, distinctive culture, leadership with research expertise, using participatory management practices, appropriate rewards, clear goals, access to facilities and resources (particularly human resources), diversity of the research group, frequent and effective communication (within and outside the research group), positive group climate / work environment.

The second research stream is mainly based in the public policy literature and focuses on the positive effects of triple helix collaborations ${ }^{99}$ (i.e. between universities, the industry and the government) on research performance (Etzkowitz \& Leydesdorff, 1997, 2000; Leydesdorff, 2000). Tödtling et al. (2009) for example underlines that the policy-driven cluster support structures have to be adapted to the varying cluster realities. Tödtling et al. (2009) investigated if different types of innovation rely on specific kinds of knowledge interaction. Their results show that for firms trying to develop more "advanced innovations" cooperating "with universities and research organizations" is crucial while "firms having introduced less advanced innovations rely more on knowledge links with business services" (Tödtling, et al., 2009, p. 59). The support structure of a policy-driven cluster thus should be adapted to the local reality.

\subsubsection{Development process}

Third, we focus on the process leading to development, more precisely to product development, as this is the predominant type of innovation in policy-driven clusters (compared to process, marketing or organisational innovation). Ernst (2002), who himself considerably draws from the research results of (Cooper \& Kleinschmidt, 1995), gives a large summary of the different factors that need to be implemented to foster new product

\footnotetext{
${ }^{99}$ Triple helix: The triple helix literature (Etzkowitz \& Leydesdorff, 1997, 2000; Leydesdorff, 2000), underlines the positive effects on research when universities, the industry and governments cooperate by creating for example contracts or other types of industrial liaisons for knowledge and technology transfer. In a certain manner, this can be considered as the main cornerstone of cluster policies and that the whole cluster literature heavily draws from this idea to foster innovation. However, we have to keep in mind that it is only one part of the different processes leading to innovation.
} 
development (NPD) in organisations. The most important success factors for NPD are (Cooper \& Kleinschmidt, 1995; Ernst, 2002): thorough planning phase ${ }^{100}$; continuous commercial assessment ${ }^{101}$; oriented towards market needs ${ }^{102}$; integration of customers into early and later phases of the NPD; creation of a dedicated project organization ${ }^{103}$; cross $^{2}$ functional teams ${ }^{104}$; strong and responsible project leader with sufficient know-how and devotion to project; autonomy and responsibility of the entire project ${ }^{105}$; intensive communication among team members; material support that goes beyond the R\&D budget (expenditures for market research and market launch are important for success as well); top management that has enough autonomy to stop a NPD project before the official end, in case a commercial failure is looming; independent work to develop own ideas; support for unofficial projects (that may have been stopped); the availability of internal "venture capital" for creative ideas; offering orientation and strategic framework to the sum of single NPD projects; also long-term projects that go beyond short- and medium-term NPD projects; regular reviews by senior management whether the aims of the entire NPD programme are being reached.

One important element in the development is to be fast enough to the market to reap the financial benefits. One major dilemma for policy-driven clusters that try to foster exchange between their members is to protect their ideas. Guisard et al. (2010, pp. 674-675) underlined that one of the main problems of these organised cluster-policy meetings is the "secrecy limit”, meaning what to reveal and what not to reveal among potential competitors in the region. According to Guisard et al. (2010, pp. 674-675), "participants will often feel uncomfortable about whether to speak or not to speak, without ever really being clear about the boundary." The question that emerges is what policy-driven cluster managers do in order

\footnotetext{
${ }^{100}$ Planning: A thorough planning phase is necessary to select the best project for development. This comprises: evaluation of ideas; technical/market-directed feasibility studies; commercial evaluation of project; exact definitions of project concept, target market, and the relative increase in benefits of the new product for the customer compared to competitor's product.

${ }^{101}$ Continuous commercial assessment: The commercial assessment should not only take place in the planning phase but "during all phases of the NPD process". This means unprofitable NPD projects can be terminated if necessary.

${ }^{102}$ Market needs: the NPD process has to be oriented towards the needs of the market through market research, the understanding and evaluation of customer needs, accurate prognosis of the market potential, and the execution of test markets

${ }^{103}$ Creation of a dedicated project organization: must ensure that project will not be effected by daily routines/departmental influences; assignment of people to the team; enough time to work on project; project leader has access to team leaders from other departments

${ }^{104}$ Cross-functional team: contributes to the resolution of possible interface problems; particularly members from R\&D, Marketing and Production should be associated.

${ }^{105}$ Autonomy and responsibility of the entire project: Can be fostered by implementation of project-specific material or non-material performance incentives
} 
to foster the free knowledge circulation but at the same time overcome this secrecy problem felt by the policy-driven cluster members.

\subsubsection{Summary}

The innovation management literature is very rich and detailed regarding the factors that positively or negatively influence the different processes leading to innovation. However, for the time being academics, focusing on policy-driven clusters, are rarely addressing innovation management in general and these differences in particular. Chiu (2009, p. 46) underlines that "the mechanisms that help translate cluster membership into higher innovativeness are not well understood." Table 16 summarizes the different processes and which influence factors are important for which phase. As we can see, some elements are important for several processes leading to innovation (e.g. diversity of team members) while others seem to have contradictory impacts (e.g. an evaluation culture discourages creativity but is important in the development process; monetary rewards are also important in the development process but limiting the creativity process).

Table 16: Factors that influence the processes leading to innovation

\begin{tabular}{|c|c|c|c|}
\hline Influence factors & $\begin{array}{l}\text { Creativity } \\
\text { Process }\end{array}$ & $\begin{array}{l}\text { Research } \\
\text { Process }\end{array}$ & $\begin{array}{l}\text { Development } \\
\text { Process }\end{array}$ \\
\hline Diversity of team members & $\mathrm{X}$ & $\mathrm{X}$ & $\mathrm{X}$ \\
\hline Constant information sharing \& knowledge exchange & $\mathrm{X}$ & $\mathrm{X}$ & $\mathrm{X}$ \\
\hline Importance of work and failures permitted & $\mathrm{X}$ & $\mathrm{X}$ & \\
\hline \multicolumn{4}{|l|}{ 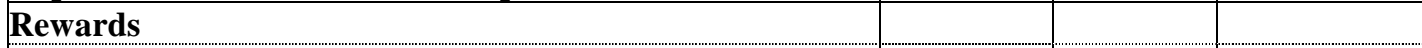 } \\
\hline rewards, but not in monetary form & $X$ & & \\
\hline rewards (which types of rewards not defined) & & $X$ & \\
\hline rewards in monetary form & & & $X$ \\
\hline Projects integrated in the general organisational strategy & & & $\mathrm{X}$ \\
\hline Decentralized organization, project organization & & $\mathrm{X}$ & $\mathrm{X}$ \\
\hline Culture is important & $\mathrm{X}$ & $\mathrm{X}$ & \\
\hline Resources to accomplish project (time, money, physical) & $\mathrm{X}$ & $\mathrm{X}$ & $\mathrm{X}$ \\
\hline Project team identity, trust and mutual understanding & $\mathrm{X}$ & $\mathrm{X}$ & \\
\hline Integration of consumers in the process & & & $\mathrm{X}$ \\
\hline Freedom \& Autonomy & $\mathrm{X}$ & $\mathrm{X}$ & $\mathrm{X}$ \\
\hline \multicolumn{4}{|l|}{ Supervision encouragement } \\
\hline Supervision very important & $\mathrm{X}$ & $\mathrm{X}$ & \\
\hline $\begin{array}{r}\text { Responsible project leader but enough distance in case of } \\
\text { looming commercial failure }\end{array}$ & & & $\mathrm{X}$ \\
\hline \multicolumn{4}{|l|}{ Evaluations } \\
\hline Discouragement if evaluation culture & $X$ & & \\
\hline Regular reviews regarding goal accomplishment & & & $X$ \\
\hline Exact project planning (prior to development) & & & $\mathrm{X}$ \\
\hline $\begin{array}{l}\text { Development of expertise and/or innovation process } \\
\text { capabilities important }\end{array}$ & $\mathrm{X}$ & & \\
\hline
\end{tabular}

Source: own compilation, based on the different authors cited in this section 


\subsection{Dilemmas on managing collaboration processes}

The underlying theory justifying cluster polices is that "all cluster participants need assistance in [...] strengthening their levels of cooperation, increasing mutual trust and developing effective private/public dialogue" (Karaev, et al., 2007, p. 830), in fine these actions should lead to an increased innovation capacity of the policy-driven cluster. In organisations, managers can influence face-to-face communication by using two types of tools: organizational structure and space (Allen \& Henn, 2007). In regions, regional authorities or policy-driven cluster managers can organise for example networking and knowledge exchange events (Guisard, et al., 2010; Lefebvre, 2013). However, very often the ultimate tool that governments use to try creating a functioning policy-driven cluster with plenty of face-to-face contact is the subsidising of collaborative $R \& D$ projects between the local cluster actors (see for example the French case (Gallié, et al., 2013b), the Japanese case (Nishimura \& Okamuro, 2011a), or the Australian case (Liyanage, 1995)).

Several different definitions exist for collaboration ${ }^{106}$, but one of the most widely accepted one is that collaboration is "any situation in which people are working across organizational boundaries towards some positive end" (Huxham \& Vangen, 2005, p. 4). Collaboration is only one stage out of a continuum of "working together" strategies. Himmelman (2001, p. 277) defines four types of strategies: "networking, coordinating, cooperating, and collaborating." Reilly (2001, p. 55) underlines that these different strategies are "a continuum" and that "moving from cooperation to coordination to collaboration moves generally from low to high formality."

Cluster definitions generally have three points in common: spatial proximity, knowledge and network (Cruz \& Teixeira, 2009). The network element plays a particular role as the interaction and communication between firms is the key element that distinguishes a simple agglomeration of firms from a cluster (Antonelli, 2000). The cluster literature heavily focuses on the manner these collaboration processes are initiated. This starts with analyzing the

\footnotetext{
${ }^{106}$ Collaboration definitions, for example: "(1) the pooling of appreciations and/or tangible resources, e.g., information, money, labor, etc., (2) by two or more stakeholders, (3) to solve a set of problems which neither can solve individually" (Gray, 1985, p. 912) or "collaboration takes place when people from different units work together in cross-unit teams on a common task or provide significant help to each other. [...] In all cases, collaboration needs to involve people: if all that is going on is shipping data back and forth between units, that's not collaboration" (Hansen, 2009, p. 14).
} 
institutional context among regional innovation system specialists (Asheim, 1996; Cooke, 1996) and continues with more strategy orientated management scholars who define the roles of broker organizations ${ }^{107}$ (Chaskin, 2001), knowledge brokers ${ }^{108}$ (Arikan, 2009) or trust facilitators ${ }^{109}$ (Mesquita, 2007) in clusters.

\subsubsection{How to foster collaboration? - People-driven vs. Space-driven}

Second, we focus on the different tools that support collaborations. In the literature there are indeed multiple and various alternatives and propositions to characterize this role of bridging communities in order to foster innovation through enhanced collaborations. "Tools" that contribute to fostering innovative collaborations are either incarnated in people or in physical meeting spaces where communities meet and exchange ${ }^{110}$. To schematize we can say that there are two modes of enhancing collaborations in policy-driven clusters either collaborating through (people) or collaborating in (places). Hereinafter we discuss these two tools. However, as we will see, additional to the cluster policy literature, we also mobilized some of the management literature as for the time being the policy-driven cluster literature on these different processes is simply too scarce.

\footnotetext{
${ }^{107}$ Broker organizations are "local intermediaries responsible for fostering and convening partnerships and networks of relations among existing organizations." (Chaskin, 2001, p. 143)

${ }^{108}$ Definition of knowledge brokers: "Knowledge brokers are parties such as technology brokers, licensing consultants, information search companies, public industrial development agencies, and trade associations. These entities help firms find knowledge partners." (Arikan, 2009, p. 669). However, the notion "knowledge broker" has several definitions in the literature. The institutions in a RIS resemble more to Arikan's (2009) definition, as it stays much broader, than to the definitions of Hargadon (1998) or Brown \& Duguid (1998). Hargadon (1998, p. 210) defines knowledge brokers as firms which "span multiple markets and technology domains and innovate by brokering knowledge from where it is known to where it is not". Brown and Duguid (1998, p. 103) define knowledge brokers as: “...involves participation rather than mediation. [Knowledge brokers] are a feature of overlapping communities, whereas translators work among mutually exclusive ones."

${ }^{109}$ Definition of trust facilitators: "Trust facilitators are individuals, governmental agencies, or independent organizations that leverage their reputation and abilities in gridlocked interfirm relationships and [...] help create momentary opportunities for trust to resurface and shift firms out of their noncollaborative inertia." (Mesquita, 2007, p. 73)

${ }^{110}$ Additionally to people and places, boundary objects can also get conversations going (J. S. Brown \& Duguid, 1998; Star \& Griesemer, 1989). Even though boundary objects are often discussed in the management literature, we have not identified any article on policy-driven clusters that treat this topic. That is the reason why we do not integrate boundary objects in the main text. According to Brown \& Duguid (1998, p. 104) "boundary objects are objects of interest to each community involved but viewed or used differently by each of them". Boundary objects can for example be "physical objects, technologies, or techniques shared by the communities" (J. S. Brown \& Duguid, 1998, p. 104). Through these boundary objects the different communities get "intentionally or unintentionally" into contact with each other (J. S. Brown \& Duguid, 1998, p. 104). For some others the boundary object is also something that is constantly transformed by the involved actors (Holford, Ebrahimi, Aktouf, \& Simon, 2008) as "actors continually co-construct [...] and re-construct[...] it in both the physical and imaginary sense." (Holford, et al., 2008, p. 10).
} 


\subsubsection{People}

Lester \& Piore (2006) for example use the metaphor of the manager as a hostess ${ }^{111}$ who gets the conversation going between people. Another important metaphor is the "translator" (J. S. Brown \& Duguid, 1998; Star \& Griesemer, 1989) who is able to "frame the interests of one community in terms of another community's perspective” (J. S. Brown \& Duguid, 1998, p. 103). The challenge of the translator is to "be sufficiently knowledgeable about the work of both communities to be able to translate” (J. S. Brown \& Duguid, 1998, p. 103). Finally, McEvily \& Zaheer (2004, p. 189) talk about network facilitators who "create trust by taking deliberate actions that include identifying shared interests, developing common expectations, leveraging a critical mass of influence, and compressing networks in physical space and time” (McEvily \& Zaheer, 2004, p. 189). The common denominator of all these metaphors is that one person has to combine the right people, be very knowledgeable about the different actors and start the conversation.

In policy-driven clusters these persons are the policy-driven cluster managers, they are the public characters already described by Jacobs (1961) fifty years ago. These policy-driven cluster managers create "spaces" to foster exchange between parties (e.g. researchers, practitioners, industrials) which otherwise don't have an institutional connection. We could also say that they try to eliminate the structural holes of the system (Burt, 1992) by creating connections to weak ties, more suitable to acquire new knowledge (Granovetter, 1973).

For example policy-driven cluster managers have to take into account the structural elements or their members. Bellandi \& Caloffi (2010a, pp. 71-72) resume them in four points: (1) the policy-driven cluster actors have "different nature, knowledge and competencies", it is thus the role of the policy-driven cluster manager to balance these differences; (2) additionally there are also "weak ties and strong ties" which have to be balanced; (3) not all policy-driven cluster members are stable members, some are also just "temporary members" of the network, a balance has thus to be found and (4) finally, actions have to be organised in order to "bridge[...] organizations within and across parts of relational space 112 ". Even though the

\footnotetext{
111 "The lessons of the cocktail party can be summarized in a series of distinct but closely related roles for the manager: Step One: choose the guests; Step Two: initiate the conversation; Step Three: keep the conversation going; Step Four: refresh the conversation with new ideas" (Lester \& Piore, 2006, pp. 57-58); "The highest compliment that can be paid to the hostess is that she has introduced people who will continue to see and interact with each other long after they have left the party." (Lester \& Piore, 2006, p. 57)

${ }_{112}$ A relational distance between two actors can emerge due to differences in "language, systems of incentives and objectives, timescales of reference, etc" (2010a, pp. 71-72)
} 
article of Bellandi \& Caloffi (2010a, pp. 71-72) is highly interesting as it shows that "specific territorial and sectoral contexts" seem to play a role in the establishment of a local innovation network, it is based on a quantitative network analysis and thus somehow lacks a real in depth discussion of the main challenges of creating these links.

\subsubsection{Physical meeting spaces}

The last important element are physical spaces that reduce distance between the involved actors (Allen, 1977; Allen \& Henn, 2007; Morris, 2002). On the one hand it is important to think about how to reduce distance (Allen \& Henn, 2007, p. 63). For example, "the placement of a coffee pot, a conference room, or shared instrumentation" can overcome communication problems and overcome distances in organisations (Allen \& Henn, 2007, p. 63).

On the other hand, more general, it is important to think about the place where knowledge exchange actually should happen on a regular bases. According to Morris $(2002$, p. 1) "one of the most important factors that influences the productivity of knowledge is the place in which work occurs". These facilities can either be for example "an office building, a home office, or a research laboratory” (Morris, 2002, p. 1). Also Nonaka (Nonaka, 1991; Nonaka \& Konno, 1998) insisted on the importance of $b a$, which can, among others, be a physical space. The ba is important for every organisation, as it is a "shared space for emerging relationship" and a "foundation for knowledge creation" (Nonaka \& Konno, 1998, p. 40). Within the created ba, the collective and individual knowledge of the company can be advanced (Nonaka \& Konno, 1998, p. 40).

In policy-driven clusters, policy-driven cluster managers can organise these spaces on a regular or temporary bases. According to Maskell, et al (2006, p. 997) temporary clusters are "short-lived hotspots of intense knowledge exchange, network building and idea generation". These temporary clusters are for example "trade fairs, exhibitions, conventions, congresses, and conferences" where "business people and professionals come together regularly". Also the workshops and think tanks organised by the French policy-driven cluster organisations and analysed by Guisard (2010) and Lefebvre (2013), can be considered as temporary clusters. Guisard et al. (2010) identified that one of the benefits of the studied French policydriven clusters is to organise discussion and creativity meetings for knowledge exchange. The three main objectives of these meetings were "knowledge dissemination, establishing 'communities' and the development of creativity" (Guisard, et al., 2010). Also Lefebvre 
(2013) studied the innovation management efforts of French policy-driven clusters. He concluded that there are three major types of knowledge management tools used by French clusters: "cluster-wide networking, permanent workgroups on the various strategic themes of the cluster, and ad hoc working groups based on emerging subthemes" (Lefebvre, 2013, p. 239). All of these different initiatives form a system of trying to help local actors getting more innovative.

Additionally to the temporary clusters, which are organised occasionally, there are also permanent physical places that can support the development of collaborations in policy-driven clusters. For example in Paris there exists a place called "la cantine" (the canteen). This "la cantine" was founded in 2008, and it is a space that allows SMEs in the ICT to exchange, to host different kinds of events, but also provides space for "coworking" (for some hours people go there to exchange and work) (Le Barzic \& Distinguin, 2010). "La Cantine" is closely associated to Cap Digital, a policy-driven cluster organisation located in the Paris Region and specialised in the ICT sector.

\subsubsection{Who collaborates? Even vs. uneven partners}

As we have seen in the innovation management section, having a diversity of team members is positive for the innovation potential of the team members. However, collaborating with different companies and people can also have a negative impact on one's capacity.

Collaboration is seen as having the highest formality of "working together", but it is also an angle and a devil at the same time. On the one hand, "collaboration [...] when fully achieved, can produce the greatest benefits of mutual action" (Himmelman, 2001, p. 278), but on the other hand "bad collaboration is worse than no collaboration" (Hansen, 2009, p. 1). Policydriven clusters try to foster collaborations between the local companies, but the question is if this is always that desirable.

Giuliani (2013) conducted a longitudinal study of a wine cluster in Chile. Giuliani (2013) focused on the network formation process and knowledge exchange opportunities between the local actors. Giuliani (2013) underlined that connecting the wrong companies, particularly high performing with low performing companies, might have a negative impact for the region. For Giuliani (2013, p. 1417), this is particularly the case if "measures designed to foster the networking of firms [...] try to connect technological leaders with laggard firms". 
The problem is that "[technological leaders] will not be keen to invest time in interacting with and passing knowledge to weak firms; and [laggard firms] are unlikely to be able to absorb and learn from the strongest firms" (Giuliani, 2013, p. 1417). Instead of doing something good to the region, connecting the wrong companies might also bear a considerable risk. Huggins \& Johnston (2009, p. 252) draw a similar conclusion, saying that there is a risk that SMEs turn to policy-driven clusters if they actually need help or face challenges they can not tackle alone: "The relationship between networking and firm performance is complex, with SMEs appearing to engage more in networking activities with knowledge support organisations when they are facing certain competitive pressures" (Huggins \& Johnston, 2009, p. 252). Connecting them with large groups might thus have a negative consequence as well.

Additionally, large groups might be simply difficult to handle as well, particularly for small companies. Younès (2012, p. 835) conducted a qualitative longitudinal study of linkage formation in a French cluster located in the Paris Region. She focused on the formation process and the obstacles of intersectoral collaborations. Her study shows that obstacles for intersectoral formations between cluster actors are due to both "local arrangements" but also “employees' work within firms". This second point is particularly interesting for cluster policy researchers. Younès (2012, p. 835) particularly stresses that the problem of collaboration often stems from divergent strategic goals inside the company and not necessarily from finding partners: "in some cases policy does succeed in making firms from different sectors cooperate, but these partnerships are difficult to maintain - a problem that results from negotiations inside large firms with conflicting economic goals and a lack of experience in measuring knowledge benefits." 


\subsection{Conclusion}

In this section we discussed all the "managerial dilemmas" that we identified in the cluster policy literature. Table 17 summarizes the three main managerial dilemmas (managing actor involvement, managing innovation processes, managing collaboration processes) and their associated dilemmas discussed in this section.

Table 17: Managerial dilemmas

\begin{tabular}{|c|c|c|}
\hline $\begin{array}{l}\text { Main } \\
\text { dilemmas }\end{array}$ & Associated dilemmas & Examples of authors \\
\hline \multirow{2}{*}{$\begin{array}{l}\text { Managing } \\
\text { actor } \\
\text { involvement } \\
(\text { MD\#1) }\end{array}$} & $\begin{array}{l}\text { MD\#1a - Leadership: who is in charge? } \\
\text { (difficulties to decide on which level the } \\
\text { leadership should be bundled) }\end{array}$ & $\begin{array}{l}\text { (Burfitt, et al., 2007; Lundequist \& Power, } \\
\text { 2002; MacNeill \& Steiner, 2010; S. Menu, } \\
\text { 2012) }\end{array}$ \\
\hline & $\begin{array}{l}\text { MD\#1b - Learning: learning capacity vs. } \\
\text { administrative straightjacket (difficulties to } \\
\text { constantly adapt the policy to learning } \\
\text { capacity of actors) }\end{array}$ & $\begin{array}{l}\text { (Burfitt \& Macneill, 2008; Carré, et al., } \\
\text { 2008; Ebbekink \& Lagendijk, 2013; Gadille, } \\
\text { et al., 2013; Gallié, et al., 2012; Lundequist } \\
\& \text { Power, 2002; Sotarauta, 2012; T. Weil \& } \\
\text { Fen Chong, 2009) }\end{array}$ \\
\hline \multirow[t]{3}{*}{$\begin{array}{l}\text { Managing } \\
\text { innovation } \\
\text { processes } \\
\text { (MD\#2) }\end{array}$} & \multirow{3}{*}{$\begin{array}{l}\text { MD\#2a - Which stage matters most? } \\
\text { Creativity vs. Research vs. Development } \\
\text { to foster creativity: Failures permitted, no } \\
\text { monetary rewards, no evaluation culture, } \\
\text { culture and trust is important, etc. } \\
\text { to foster research: cooperating between } \\
\text { universities, companies and governments, } \\
\text { exciting research programmes, autonomy } \\
\text { in project selection, distinctive culture, etc. } \\
\text { to foster development: regular reviews } \\
\text { necessary, exact project planning, rewards } \\
\text { in monetary form, in case of looming } \\
\text { commercial failure possibility to abandon } \\
\text { project, etc. }\end{array}$} & $\begin{array}{l}\text { Creativity: (Agogué, 2012; Bocquet \& } \\
\text { Mothe, 2010; Eklinder-Frick, et al., 2012; } \\
\text { Hermans, et al., 2012; Lefebvre, 2013; } \\
\text { Schmitt, 2011; Visser, 2009) } \\
\text { (management literature: (Amabile, 1996, } \\
\text { 1998; Amabile, et al., 1996)) }\end{array}$ \\
\hline & & $\begin{array}{l}\text { Research: (Etzkowitz \& Leydesdorff, 1997, } \\
\text { 2000; Leydesdorff, 2000; Tödtling, et al., } \\
\text { 2009) } \\
\text { (management \& medical literature: (Bland } \\
\text { \& Ruffin, 1992; Chawla \& Singh, 1998; La } \\
\text { Porte, 1965; Ryan \& Hurley, 2007)) }\end{array}$ \\
\hline & & $\begin{array}{l}\text { Development: (Guisard, et al., 2010) } \\
\text { (management literature: } \quad \text { (Cooper \& } \\
\text { Kleinschmidt, 1995; Ernst, 2002)) }\end{array}$ \\
\hline \multirow{2}{*}{$\begin{array}{l}\text { Managing } \\
\text { collaboration } \\
\text { processes } \\
(\text { MD\#3) }\end{array}$} & $\begin{array}{l}\text { MD\#3a - How to foster collaboration? - } \\
\text { People-driven vs. Space-driven (which } \\
\text { tools are the best for which objective?) }\end{array}$ & $\begin{array}{l}\text { (Bellandi \& Caloffi, 2010a; Guisard, et al., } \\
\text { 2010; Le Barzic \& Distinguin, 2010; } \\
\text { Lefebvre, 2013; Maskell, et al., 2006) }\end{array}$ \\
\hline & $\begin{array}{l}\text { MD\#3b - Who collaborates? Even vs. } \\
\text { uneven partners (even though diversity is } \\
\text { important for innovation, linking strong } \\
\text { and weak partners / SMEs and large } \\
\text { companies might bear risks) }\end{array}$ & $\begin{array}{l}\text { (Giuliani, 2013; Huggins \& Johnston, 2009; } \\
\text { Younès, 2011) }\end{array}$ \\
\hline
\end{tabular}




\section{Drivers of pathologies: structural dilemmas}

In the two previous sections we identified and discussed the different political and managerial dilemmas found in the literature. In this section we now focus on the structural dilemmas of policy-driven clusters. Structural dilemmas are the "soil" on which every policy-driven cluster is build. This "soil" has to be taken into consideration as well, because if ignored dilemmas can emerge. We are able to distinguish three different types of structural dilemmas (see Figure 14): adapting the policy-driven cluster to the life-cycle stages, adapting the policydriven cluster to the local culture and adapting the policy-driven cluster to the geographic location.

\section{Figure 14: Structural characteristics of policy-driven clusters}

\begin{tabular}{|c|c|c|}
\hline \multirow{6}{*}{ 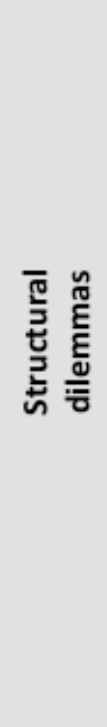 } & $\begin{array}{l}\text { SD\#1 - Adapting } \\
\text { to the life-cycle stages }\end{array}$ & SD\#1a - Degree of cluster developement \\
\hline & \multirow{3}{*}{$\begin{array}{l}\text { SD\#2 - Adapting } \\
\text { to local culture }\end{array}$} & SD\#2a - Type of state governance: federal vs. unitary country \\
\hline & & SD\#2b - Type and sector of activity of policy-driven cluster actors \\
\hline & & SD\#2C - Degree of closeness between regional actors \\
\hline & \multirow{2}{*}{$\begin{array}{l}\text { SD\#3 - Adapting } \\
\text { to geographic location }\end{array}$} & SD\#3a - Degree of development \\
\hline & & SD\#3b - Degree of urbanisation \\
\hline
\end{tabular}

\subsection{Dilemmas on adapting to life-cycle stages}

An important point to take into consideration when implementing policy-driven clusters is the evolutionary nature of policy-driven clusters and its members. The cluster policy literature particularly focuses on the life cycle stage of policy-driven clusters and the associated risks when the policy-driven cluster actions are not adapted to the stage of development of the policy-driven cluster. 
Van Klink \& De Langen (2001) insist that clusters should not be considered as static but as "dynamic" and from an "evolutionary perspective". Each policy-driven cluster is influenced by its antecedence and goes through different stages of development. In the embryonic stage basic networking elements are for example not even existent (Aziz \& Norhashim, 2008). In the development stage (Van Klink \& De Langen, 2001), the cluster experiences an above average growth compared to the average industry growth however the relations within the cluster are still unstable. In the expansion stage these relationships are stabilized and internally oriented (Van Klink \& De Langen, 2001). In the maturation phase, the growth starts to slow down and falls below average compared to the average industry growth (Van Klink \& De Langen, 2001). When this happens, the cluster needs to enter into a transformation phase in order to survive, otherwise the cluster might decline (Aziz \& Norhashim, 2008). In this transition stage, the relationships in the cluster are again unstable (Van Klink \& De Langen, 2001).

A particular case is this last phase where a cluster either manages to enter into a real transition or declines. Sadler (2004) for example studied an old industrial region in the UK. Sadler (2004) underlines that cluster policies have to be aware and take into account the evolution of the cluster because at some point it might be important to "abandon" the current industrial orientation of a cluster and reorient the cluster in another direction: "The ongoing process of change might involve the deconstruction of one kind of cluster [...] and the potentially intensified significance of another cluster" (Sadler, 2004, p. 65). However, Sadler (2004) also underlines that it is not at all sure if the remaining connected actors of the region will be able to enter into a transformation phase and if the whole cluster discourse "simply detracts from the need to take a more holistic approach to regional development” (Sadler, 2004, p. 65).

An important dynamic element to consider when using cluster policies on its territory is thus the life cycle stage of the cluster that the policy wishes to develop. Before implementing a cluster policy, governments need to analyze the stage of development of the cluster they would like to foster in order to determine which type of policy they should actually implement. The cluster policy also needs to know what to do with a declining cluster and when maybe it is necessary to abandon investments.

The different stages call thus for a pro-active policy making adapted to every stage of the policy-driven cluster, ranging from raising awareness and linkages between actors in the 
beginning towards internationalisation and looking for new ways of development during the maturation phase. Fromhold-Eisebith \& Eisebith (2005) argue that not only the ways of helping the local actors should change with the development of the policy-driven cluster but also the involvement of the public authorities. A governments' top-down approach might be useful in the beginning, but a private bottom-up approach better in a more advanced stage of a cluster's development ${ }^{113}$.

\subsection{Dilemmas on adapting to local culture}

Some authors argue that an important element when implementing cluster policies is to take into account the local culture. Among the European authors on cluster policies, Gert-Jan Hospers, a Dutch economic geography professor, is maybe one of the most critical voices regarding the European Union best practice cluster endeavours. Already in 2002, Hospers \& Beugelsdijk (2002, p. 396), wrote a critical theoretical paper regarding cluster policies and that the best practice stance of the European Union might lead to replications that are not useful for the specific countries and regions. The different world-wide cluster examples should more be seen as "inspirations" rather than "recipes for successful regional economic development" that can be "transferred mechanically" (G.-J. Hospers \& S. Beugelsdijk, 2002, p. 396). Governments should privilege "unique cluster-based strategies based on an assessment of region-specific structural and cultural characteristics" (G.-J. Hospers \& S. Beugelsdijk, 2002, p. 396). Additionally, Hospers \& Beugelsdijk (2002, p. 396) argue that “if the preconditions for clustering in a region are absent, governments should not try to create a cluster from scratch."

Also three years later, Hospers (2005) continues to firmly criticise the cluster policy best practice approach of the European Commission. For Hospers (2005, p. 457) running behind a Silicon Valley best-practice example is not very useful and the Commission should better favour diversity among European regions, because only by encouraging diversity the "local authorities will be stimulated to attune their clusters to area-specific assets as much as possible.”:

\footnotetext{
"Borrowing successful policies from elsewhere is seen as a means to speed up European regional development and achieve it at lower cost. This EU-driven trend of benchmarking leads to the set-up of regional policies with similar objectives, instruments and policy
}

${ }^{113}$ Fromhold-Eisebith \& Eisebith (2005, pp. 1265-1266) argue that a "large strategic, comprehensive public efforts are probably the better way for improving cluster basics in raising awareness and numbers of includable organizations. After foundations are laid potential ought to get further effectuated by a private promotion initiative." 
concepts. Everywhere in Europe policy-makers claim to aim for 'regional competitiveness' by creating 'framework conditions' for the formation of 'high-tech clusters'."( "at best, they can provide some inspiration, but they entirely fail to be recipes for successful regional development." (p.456)

And again in 2009, not tired from their claims, and this time integrating more concrete case study examples, Hospers et al. (2009, p. 286) continue to repeat that "policy makers should move away from strategy aimed at trendy 'Silicon Somewheres' towards a no-nonsense approach of 'Regional Realism”'.

Hospers et al. (2009) arguments and case studies are supported by several other empirical studies. Fore example, Santisteban (2006) conducted an in-depth analysis of the Basque Country's and Catalonia's cluster policy initiatives. Even though both regions were motivated in the 1990 s to start implementing cluster policies, the concrete realisation, support mechanisms and evolution of the policies were quite different. For Santisteban (2006, p. 36), these examples underline very well that "specific industrial policies" have to be "directed at the particular needs of each regional industrial-business system" and that it is not possible to ignore the regional pre-conditions and local cultures.

Another interesting study concerning cluster policies and local culture was conducted by James (2005). James (2005) conducted an in-depth case study of the high tech cluster in Salt Lake City, Utah. The Salt Lake City case is definitely an extreme case to study cluster policies because there is a strong local Mormon culture. One main result of James's study is that "physical proximity is less important than cultural or 'relational' proximity" (James, 2005, p. 1212). Shared cultural conventions, norms, attitudes, values beliefs are much more important for doing business than geographical proximity. The Salt Lake City case shows that non-like firms (meaning not being Mormon) are excluded in favour of firms of similar culture, leading cluster policies to fail in their main objective, namely bridging connections between heterogeneous local actors ${ }^{114}$.

Finally, two last interesting study of local culture and cluster policy are an article written by Menu (2010) and an article written by Martinez et al. (2012). Menu (2010) compared three

\footnotetext{
114 'Dominant tendency within cluster policies is to install the 'right' mix of institutional components deemed necessary for an innovative regional economy. In contrast, the present results suggest that the physical proximity of firms and other regional institutions, the first usual indicator of a cluster, does not necessarily guarantee or automatically generate the cooperative interactions widely theorized to underpin information and knowledge spillovers within the region." (James, 2005, p. 1212)
} 
regions - Bretagne in France, Bavaria in Germany and the North-East of England - in order to analyse how the regional identities of the three regions play a role in the capability of the regions to mobilize the actors to strengthen the local cluster development. Menu (2010) concludes that the regional identity seems to play a dynamic resource for economic mobilisation and that a region like Bavaria with a strong cultural heritage might have it much easier than a region like the North-East of England where far less regional identity exist and which thus needs another type of help.

Martinez et al. (2012) on the other hand compared a Spanish and a Mexican cluster and also conclude that "knowledge networks differ depending on geographical specific characteristics and the resources of the main players. [...] Policy makers should prepare customized public programs based on the particular structure of each cluster" (Martinez, et al., 2012, p. 657). Additionally, such as James (2005) and his Utah case study, Martinez et al. (2012) conclude that just being close to each other is not enough. What counts is being embedded in a functioning knowledge network.

Also Doloreux \& Shearmur (2009, p. 526), analysing Canadian cluster policies, conclude that the Canadian cluster policies did not have the desired effect as they were not adapted to the local clusters characteristics. Or Perry (2005, p. 846), analysing New Zealand's cluster initiatives, criticizes that "there has been too much haste in seeking to draw policy implications from 'natural' clustering experiences" without taking into account the New Zealand circumstances.

The problem is that politics currently belief in an universal "cluster credo", applying the same recipe to all types of territories (Ebbekink \& Lagendijk, 2013). Additionally, it is very difficult to measure "local culture", and to put it in words. One starting point could be to analyse the type of state governance, the type and sector of the policy-driven cluster actors and the degree of closeness between them.

\subsubsection{Type of state governance: federal vs. unitary country}

The type of state governance might also have an impact on how to conceive the right policy for the policy-driven cluster. A difference might exist between unitary and federal countries. For example Salazar \& Holbrook (2007, p. 1139) urges that policy makers in federal countries "need to take into account the specific institutional architecture existing in federal 
countries to fully appreciate research and innovation patterns at national and regional levels" as the implementation process of policy-driven cluster initiatives seem different with other dilemmas than in unitary states. Or Cammett (2007, p. 1889) argues that the fostering of policy-driven cluster development and innovation is very different in "state-dominated political economies" and "political economies". Cammett (2007, p. 1889) explains that "state-dominated political economies may be more amenable to implementing macroeconomic and infrastructure-related measures" while "political economies with more organized business communities may be better equipped to [immediately] pursue [...] interfirm linkages". Also when we recall our discussions on enacting leadership in policy-driven clusters, a strong dichotomy can be observed between unitary states (UK and France) and federal states (Germany and Austria).

Cluster initiatives face the dilemma where they should be anchored, this problem particularly emerges in unitary countries.

\subsubsection{Type and sector of activity of policy-driven cluster actors}

The general local specificities discussion goes hand in hand with the local actors discussion. The type of local actors that actually forms the cluster. In 1996, Markusen, (1996, pp. 298299) published a seminal work where she distinguished five different variants of industrial districts (i.e. Marshallian industrial district, Italian industrial district, Hub-and-spoke districts, Satellite industrial platforms, State-anchored industrial districts). All these different types of industrial districts vary regarding the type of local actors present in the cluster: for example predominantly SMEs in Marshallian industrial districts but large headquarter firms in satellite industrial platforms. So not surprisingly the current cluster policy literature starts to mention that the management structure should be adapted to the type of local actors.

For example Altenburg \& Meyer-Stamer (1999) identified three different types of clusters in the Latin American region ("Survival clusters of micro- and small-scale enterprises", "more advanced and differentiated mass producers", "clusters of transnational corporations") and argues that each of these different clusters needs a particular management style. A considerable amount of cluster policy studies focus on SMEs cluster (Cumbers, et al., 2003; Huggins \& Johnston, 2009; Karaev, et al., 2007; Li \& Geng, 2012), be it in the United Kingdom or in China. 
Another important element that goes hand in hand with the type of the local companies is the sector of activity. For example Coletti (2010) distinguishes between Science \& Technology clusters (high-tech and medium high-tech sectors) and Industry \& Services clusters (mediumtech and low-tech). Based on a cluster manager survey in different European countries, Coletti (2010) concludes that the competences of the cluster managers but also their tasks and duties depend on the type of the clusters. For example in Science \& Technology clusters networking and lobbying was perceived as more important than in the Industry \& Services clusters. Coletti (2010, p. 686) assumes that the reason for this is the fact that R\&D resources come, most of the time, from public funds. On the other hand the "identification and integration of new cluster members, identification of market opportunities and organisation of events are comparably more valuable" in Industry \& Services clusters than in Science \& Technology clusters. Also McDonald et al (2007, p. 46), analyzing UK clusters, underline that differences have to be drawn between high technology sectors and manufacturing sectors when implementing cluster policies. Their results showed that high technology sectors are much more international oriented and therefore "promoting deep and established clusters" might be less important. To sum up, policy-driven cluster management needs to adapt their services to the type of their local company structure but also to the sector of activity. However, this would mean that an ex-ante evaluation would be necessary, something rarley done (Gallié, et al., 2012).

\subsubsection{Degree of closeness between regional actors}

Another important point to take into consideration before implementing policy-driven clusters is the already existing closeness between the local actors. Even when support structure are implemented, in case the support structure is not adapted to the local environment the management effort seems useless. Eklinder-Frick et al (2014) conducted a longitudinal study of a Swedish cluster initiative. They collected quantitative and qualitative data at two points of time in order to analyze how social capital influences, positively or negatively, innovation processes in the network. Their conclusion was that "despite the aim and effort to generate innovation, the network failed to do so" (Eklinder-Frick, et al., 2014, p. 10). One main obstacle that they identified was that the managers of the policy-driven cluster have not enough analyzed the social structure of the local network which hinders all innovation initiatives as they are not adapted to the local environment. Eklinder-Frick et al (2014, p. 10) underline that policy-driven cluster managers have to "understand[...] and balanc[e] both 
collective and individual behavior in network settings" in order to "improve[...] the strategic managing of innovation networks" (Eklinder-Frick, et al., 2014, p. 10).

Ciravegna (2012), studying ICT clusters in Costa Rica, also underlines that one of the main difficulties in Costa Rica is the reluctance of universities to collaborate with the private sector. For Costa Rican universities collaborating with the private sector is still seen as something bad. So even though the government wishes to implement cluster policies "social obstacles to linkage formation" have to be addressed first in order to reach the wished outcomes (Ciravegna, 2012, p. 577). Without doing this initial analysis, the proposed help (like for example innovation activities), might fail.

Finally, more general, Fromhold-Eisebith \& Eisebith (2005) alert that the type of policy has to be adapted to the existing network in the region. In regions "where most actors have so far been operating isolated from each other" the best type of "(initial) choice" would be "explicit public cluster policies" because they have a "higher internal and external signal value" (Fromhold-Eisebith \& Eisebith, 2005, p. 1265). However, in regions where infrastructure already exists and companies are already slightly connected with each other, than bottom-up initiatives would be better.

To sum up, having a good knowledge regarding the closeness of local actors seems to be a crucial element for implementing successful cluster policies ${ }^{115}$.

\footnotetext{
${ }^{115}$ Also the management literature distinguishes that there are different phases of collaborations (Gray, 1985; Huxham \& Vangen, 2005; Kreiner \& Schultz, 1993; Lester \& Piore, 2006). In each phase other types of initiatives are important: The first step often underlines that the "right" kind of members have to be put together (Huxham \& Vangen, 2005). Lester \& Piore (2006) have invented the metaphor of the hostess in this context. The hostess has to invite the right kind of people for the cocktail party so that interesting conversations will emerge. The first step is always concentrated on identifying the problem or the question that needs to be tackled and to identify a requisite number of stakeholders that will be able to communicate on this topic (Gray, 1985). However, sometimes it is also just an accidental encounter between two people that gets the conversation going (Kreiner \& Schultz, 1993). Once the encounter has taken place, it is important to empower the members to participate so that no member stays behind (Huxham \& Vangen, 2005), but also to keep the conversation going between the members and to refresh the conversation when necessary (Lester \& Piore, 2006). Additionally the members have to belief in a positive outcome, recognize interdependence and consider the endeavour as legitimate (Gray, 1985). At the end of course, the objective is to form a formalized collaboration between the different members to plan the work and make things happen. However, the maybe important point is to reuniting the right kind of people in the beginning and to create an opportunity to discover a collaboration occasion and to have an animator that creates the bases for a lively conversation among participants.
} 


\subsection{Dilemmas on adapting to geographic location}

Another element to take into consideration is the geographic location of the clusters. De Propris (2007, p. 341) for example underlines that "clusters can be both engines for local development in lagging regions and centres of excellence in the best performing regions". In each case, the cluster policy should be adapted accordingly. The literature discusses this issue from two similar but slightly different angles: from the less developed countries vs. developed countries angle (degree of development), and from the urban regions vs. periphery regions angle (degree of urbanisation). Both literature streams are discussed hereinafter.

\subsubsection{Degree of development}

Cluster policies are a worldwide phenomenon. Less developed countries generally consider cluster policies as a chance to catch up with the developed world. They incorporated Porter's "American dream" that every country can construct it's own competitive advantage and reach the innovation development stage. For example Bathelt \& Zeng (2005) analysed the industrial structure of the metropolitan region Nanning in Southern China where no cluster policy existed in 2005. They recommend that the implementation of a cluster policy in a less developed region such as Nanning, could be " a useful tool to stimulate development if [...] formulated with care” (p. 1). Also Altenburg \& Meyer-Stamer (1999), analyzing several Latin American region, or Li \& Geng (2012) analyzing Chinese clusters underline that cluster policies have to be adapted to the different circumstances prevailing in less developed countries. Altenburg \& Meyer-Stamer (1999) particularly insist on the fact that the Latin American clusters are considerably different from the "complex and innovative clusters" in the developed world. According to Altenburg \& Meyer-Stamer (1999, p. 1708) the local clusters have "main deficiencies in common" particularly regarding their innovation capacity, "but the ways to overcome these deficiencies have to be very different."

\subsubsection{Degree of urbanisation}

Some other authors argue that cluster policies not only have to differ between less developed countries and developed countries but also within developed countries, namely between urban regions and periphery regions. Peters (2005), an American research, for example argues that other types of support policies need to be developed for the periphery regions as the cluster policies that are normally applied to core regions do not work in periphery regions. Also Doloreux \& Shearmur (2009) studying the effect of cluster policies implemented in three 
Canadian regions draw a quite pessimistic conclusion regarding the cluster policies' effects. According to them the cluster policies are often not adapted to and appropriate in all circumstances. Doloreux \& Shearmur (2009, p. 526) conclude that clustering is actually a spontaneous process but additionally it is difficult to build clusters in non-urban regions where no entrepreneurship and collaboration culture exist. For them, "it is unlikely that cluster policies will succeed unless the [...] sector is already concentrated in or near a large urban area and already has some tradition of entrepreneurship and inter-firm collaboration" (Doloreux \& Shearmur, 2009, p. 526)

\subsection{Conclusion}

In this section we discussed the structural dilemmas of policy-driven clusters. Table 18 summarizes the result of the literature review.

\section{Table 18: Structural dilemmas}

\begin{tabular}{|c|c|c|}
\hline $\begin{array}{l}\text { Main } \\
\text { dilemmas }\end{array}$ & Associated dilemmas & Examples of authors \\
\hline $\begin{array}{l}\text { Adapting to } \\
\text { life-cycle } \\
\text { stages (SD\#1) }\end{array}$ & $\begin{array}{l}\text { SD\#1a - Degree of cluster developement: } \\
\text { Every stage of a policy-driven cluster needs } \\
\text { a particular treatment }\end{array}$ & $\begin{array}{l}\text { (Aziz \& Norhashim, 2008; Fromhold- } \\
\text { Eisebith \& Eisebith, 2005; Gallié, et al., } \\
\text { 2013b; Sadler, 2004; Van Klink \& De } \\
\text { Langen, 2001) }\end{array}$ \\
\hline $\begin{array}{l}\text { Adapting to } \\
\text { local culture } \\
\text { (SD\#2) }\end{array}$ & $\begin{array}{l}\text { Considering the local culture (no best } \\
\text { practices): Not running behind a best } \\
\text { practice example but adapting cluster } \\
\text { policies to the particularities of the local } \\
\text { culture. By differentiating the policy } \\
\text { according to the type of state governance } \\
\text { (SD\#2a), the type and sector of activity of } \\
\text { local actors (SD\#2b) (for example science } \\
\text { \& technology vs. industry \& services), and } \\
\text { the degree of closeness between regional } \\
\text { actors }(S D \# 2 c)\end{array}$ & $\begin{array}{l}\text { (Altenburg \& Meyer-Stamer, } 1999 \text {; } \\
\text { Cammett, 2007; Ciravegna, 2012; Coletti, } \\
\text { 2010; Eklinder-Frick, et al., 2014; Eklinder- } \\
\text { Frick, et al., 2012; Fromhold-Eisebith \& } \\
\text { Eisebith, 2005; Hospers, 2005; G.-J. } \\
\text { Hospers \& S. Beugelsdijk, 2002; G.-J. } \\
\text { Hospers, et al., 2009; James, 2005; } \\
\text { Markusen, 1996; Martinez, et al., 2012; } \\
\text { McDonald, et al., 2007; S. Menu, 2010; } \\
\text { Salazar \& Holbrook, 2007; Santisteban, } \\
\text { 2006) }\end{array}$ \\
\hline $\begin{array}{l}\text { Adapting to } \\
\text { geographic } \\
\text { location } \\
\text { (SD\#3) }\end{array}$ & $\begin{array}{l}\text { Considering the geographic location: The } \\
\text { degree of development (SD\#3a) and also } \\
\text { the degree of urbanisation (SD\#3b) are } \\
\text { important elements to take into } \\
\text { consideration. }\end{array}$ & $\begin{array}{l}\text { (Altenburg \& Meyer-Stamer, 1999; H. } \\
\text { Bathelt \& Zeng, 2005; Doloreux \& } \\
\text { Shearmur, 2009; Li \& Geng, 2012; Peters, } \\
\text { 2005) }\end{array}$ \\
\hline
\end{tabular}

\section{Summary of chapter two: overview of organisational dilemmas}

In the second chapter of the literature review we dug into the cluster policy literature in order to present and discuss the various cluster dilemmas that develop due to the fact that this "geographical and economic" cluster concept entered into the "policy and management" realm. Several researchers have a quite critical stance regarding cluster policies (Doloreux \& Shearmur, 2009, p. 526; Hospers, 2005). In order to start addressing these criticism and 
maybe overcoming them we decided to conduct a systematic literature review (Tranfield, et al., 2003) on cluster polices implemented around the world. This global cluster policy review allowed us to distinguish three types of cluster dilemmas - political, managerial and structural - that by themselves do not represent any diseases but in case they are not taken into account can have a negative impact on the policy-driven clusters and might hinder their full potential. Table 19 gives a detailed overview of all the different dilemmas identified in the literature. 
Table 19: Overview of organisational dilemmas in the cluster policy literature

\begin{tabular}{|c|c|c|c|}
\hline $\begin{array}{l}\text { Dilemma } \\
\text { category }\end{array}$ & $\begin{array}{l}\text { Main } \\
\text { dilemma } \\
\text { name }\end{array}$ & Associated dilemmas & Examples of authors \\
\hline \multirow[t]{6}{*}{ Political } & \multirow{2}{*}{$\begin{array}{l}\text { PD\#1 - } \\
\text { Defining } \\
\text { boundaries }\end{array}$} & $\begin{array}{l}\text { PD\#1a - Geographical boundary: } \\
\text { local vs. non-local }\end{array}$ & $\begin{array}{l}\text { (Chabaud, et al., 2011; Ebbekink \& Lagendijk, 2013; } \\
\text { Gaffard, 2008; Kitagawa, 2005; Younès, 2011) }\end{array}$ \\
\hline & & $\begin{array}{l}\text { PD\#1b - Organisational boundary: } \\
\text { local vs. national }\end{array}$ & $\begin{array}{l}\text { (Burfitt \& Macneill, 2008; Perry, 2005; Rutherford \& } \\
\text { Holmes, 2007) }\end{array}$ \\
\hline & \multirow[t]{2}{*}{$\begin{array}{l}\text { PD\#2 - } \\
\text { Defining } \\
\text { subsidies }\end{array}$} & $\begin{array}{l}\text { PD\#2a - Subsidies type: direct vs. } \\
\text { indirect }\end{array}$ & $\begin{array}{l}\text { (Burfitt \& Macneill, 2008; S. Menu, 2012; Nishimura } \\
\& \text { Okamuro, 2011b; T. Weil \& Fen Chong, 2009) }\end{array}$ \\
\hline & & $\begin{array}{l}\text { PD\#2b - Subsidies structure: one- } \\
\text { shop vs. multiple shop strategies }\end{array}$ & $\begin{array}{l}\text { (Burfitt \& Macneill, 2008; Chabault, 2009; Guisard, et } \\
\text { al., 2010; Lallemand, 2013) }\end{array}$ \\
\hline & \multirow[t]{2}{*}{$\begin{array}{l}\text { PD\#3 - } \\
\text { Defining } \\
\text { objectives }\end{array}$} & $\begin{array}{l}\text { PD\#3a - General objective: } \\
\text { industrial excellence vs. regional } \\
\text { dev. }\end{array}$ & $\begin{array}{l}\text { (Burfitt \& Macneill, 2008; Giuliani, 2013; G.-J. } \\
\text { Hospers, et al., 2009; Sternberg, et al., 2010; T. Weil \& } \\
\text { Fen Chong, 2008; Younès, 2011) }\end{array}$ \\
\hline & & $\begin{array}{l}\text { PD\#3b - Motivation: intrinsic } \\
\text { motivation vs. policy prescription }\end{array}$ & (Himmelman, 1996; Perry, 2005; Sellar, et al., 2011) \\
\hline \multirow[t]{7}{*}{ Managerial } & \multirow[t]{2}{*}{$\begin{array}{l}\text { MD\#1 - } \\
\text { Managing } \\
\text { actor } \\
\text { involvement }\end{array}$} & $\begin{array}{l}\text { MD\#1a - Leadership: who is in } \\
\text { charge? }\end{array}$ & $\begin{array}{l}\text { (Burfitt, et al., 2007; Lundequist \& Power, 2002; } \\
\text { MacNeill \& Steiner, 2010; S. Menu, 2012) }\end{array}$ \\
\hline & & $\begin{array}{l}\text { MD\#1b - Learning: learning } \\
\text { capacity vs. administrative } \\
\text { straightjacket }\end{array}$ & $\begin{array}{l}\text { (Burfitt \& Macneill, 2008; Carré, et al., 2008; Ebbekink } \\
\text { \& Lagendijk, 2013; Gadille, et al., 2013; Gallié, et al., } \\
\text { 2012; Lundequist \& Power, 2002; Sotarauta, 2012; T. } \\
\text { Weil \& Fen Chong, 2009) }\end{array}$ \\
\hline & \multirow[t]{3}{*}{$\begin{array}{l}\text { MD\#2 - } \\
\text { Managing } \\
\text { innovation } \\
\text { processes }\end{array}$} & \multirow[t]{3}{*}{$\begin{array}{l}\text { MD\#2a - Which stage matters } \\
\text { most? Creativity vs. Research vs. } \\
\text { Development }\end{array}$} & $\begin{array}{l}\text { Creativity: (Agogué, 2012; Bocquet \& Mothe, 2010; } \\
\text { Eklinder-Frick, et al., 2012; Hermans, et al., 2012; } \\
\text { Lefebvre, 2013; Schmitt, 2011; Visser, 2009) } \\
\text { (management literature: (Amabile, 1996, 1998; } \\
\text { Amabile, et al., 1996)) }\end{array}$ \\
\hline & & & $\begin{array}{l}\text { Research: (Etzkowitz \& Leydesdorff, 1997, 2000; } \\
\text { Leydesdorff, 2000; Tödtling, et al., 2009) } \\
\text { (management \& medical literature: (Bland \& Ruffin, } \\
\text { 1992; Chawla \& Singh, 1998; La Porte, 1965; Ryan \& } \\
\text { Hurley, 2007)) }\end{array}$ \\
\hline & & & $\begin{array}{l}\text { Development: (Guisard, et al., 2010) } \\
\text { (management literature: (Cooper \& Kleinschmidt, } \\
\text { 1995; Ernst, 2002)) }\end{array}$ \\
\hline & \multirow[t]{2}{*}{$\begin{array}{l}\text { MD\#3 - } \\
\text { Managing } \\
\text { collaboration } \\
\text { processes }\end{array}$} & $\begin{array}{l}\text { MD\#3a - How to foster } \\
\text { collaboration? - People-driven vs. } \\
\text { Space-driven }\end{array}$ & $\begin{array}{l}\text { (Bellandi \& Caloffi, 2010a; Guisard, et al., 2010; Le } \\
\text { Barzic \& Distinguin, 2010; Lefebvre, 2013; Maskell, et } \\
\text { al., 2006) }\end{array}$ \\
\hline & & $\begin{array}{l}\text { MD\#3b - Who collaborates? Even } \\
\text { vs. uneven partners }\end{array}$ & $\begin{array}{l}\text { (Giuliani, 2013; Huggins \& Johnston, 2009; Younès, } \\
\text { 2011) }\end{array}$ \\
\hline \multirow[t]{3}{*}{ Structural } & $\begin{array}{l}\text { SD\#1 - } \\
\text { Adapting to } \\
\text { the life-cycle } \\
\text { stages }\end{array}$ & $\begin{array}{l}\text { SD\#1a - Degree of cluster } \\
\text { developement }\end{array}$ & $\begin{array}{l}\text { (Aziz \& Norhashim, 2008; Fromhold-Eisebith \& } \\
\text { Eisebith, 2005; Gallié, et al., 2013b; Sadler, 2004; Van } \\
\text { Klink \& De Langen, 2001) }\end{array}$ \\
\hline & $\begin{array}{l}\text { SD\#2 - } \\
\text { Adapting } \\
\text { to local } \\
\text { culture }\end{array}$ & $\begin{array}{l}\text { SD\#2a - Type of state governance: } \\
\text { federal vs. unitary country } \\
\text { SD\#2b - Type and sector of activity } \\
\text { of policy-driven cluster actors } \\
\text { SD\#2c - Degree of closeness } \\
\text { between regional actors }\end{array}$ & $\begin{array}{l}\text { (Altenburg \& Meyer-Stamer, 1999; Cammett, 2007; } \\
\text { Ciravegna, 2012; Coletti, 2010; Eklinder-Frick, et al., } \\
\text { 2014; Eklinder-Frick, et al., 2012; Fromhold-Eisebith } \\
\text { \& Eisebith, 2005; Hospers, 2005; G.-J. Hospers \& S. } \\
\text { Beugelsdijk, 2002; G.-J. Hospers, et al., 2009; James, } \\
\text { 2005; Markusen, 1996; Martinez, et al., 2012; } \\
\text { McDonald, et al., 2007; S. Menu, 2010; Salazar \& } \\
\text { Holbrook, 2007; Santisteban, 2006) }\end{array}$ \\
\hline & $\begin{array}{l}\text { SD\#3 - } \\
\text { Adapting } \\
\text { to geographic } \\
\text { location }\end{array}$ & $\begin{array}{l}\text { SD\#3a - Degree of development } \\
\text { SD\#3b - Degree of urbanisation }\end{array}$ & $\begin{array}{l}\text { (Altenburg \& Meyer-Stamer, 1999; H. Bathelt \& Zeng, } \\
\text { 2005; Doloreux \& Shearmur, 2009; Li \& Geng, 2012; } \\
\text { Peters, 2005) }\end{array}$ \\
\hline
\end{tabular}




\section{Chapter 3: Literature gap and problem statement}

During the 1980s and 1990s, Western economies experienced profound transformations. Economic growth has been more and more driven by the production of knowledge, the collaborations between economic actors at regional level, and the structure provided by institutions. These knowledge-, regional- and institutional- turns have triggered renewed innovation and competitiveness policies in which a country's competitiveness is no longer measured by its sole capacity to produce but by its capacity to innovate. In this new economic paradigm, the concept of "cluster" was progressively praised by public and private economic actors, as it appears as a powerful articulator to create and share knowledge, to foster innovative and collaborative projects and to generate growth and competitiveness at a regional scale. Political actors, companies and academics progressively mobilized clusters to spore competitiveness, and even create a "national competitive advantage". As a result, cluster policies, cluster initiatives, and cluster organizations multiplied.

However, the term "cluster" in itself is often ill defined and source of confusion (R. Martin \& Sunley, 2003).

- First, clusters actually already existed before they entered the political realm. It is thus necessary to distinguish between policy-driven clusters and spontaneous clusters. Instead of focusing on "spontaneous clusters", which have "been a result of the spontaneous concentration of the key factors enabling [the cluster's] birth and development" (Chiaroni \& Chiesa, 2006, p. 1073), and which have been abundantly studied in the literature, we will focus in this thesis on "policy-driven clusters", "where the trigger was the strong commitment of governmental actors whose willingness was to set the conditions for the development of the [...] cluster" (Chiaroni \& Chiesa, 2006, p. 1073). For instance, the Silicon Valley is often considered as a cluster, but it strongly differs to the clusters that are fostered by a specific public policy;

- While some researchers consider policies that foster policy-driven clusters to be an "economic weapon" (Aziz \& Norhashim, 2008) that will help the country to stay upfront in the global competitiveness race, other scholars tend to be more critic towards cluster policies. They argue that policy-driven clusters are not reaching their 
goals and that politics' belief in a universal "cluster credo" is not realistic (Ebbekink \& Lagendijk, 2013). Some researchers even argue that policy-driven clusters just became a "flavor of the month" (2009, p. 526) or essentially a "buzz word" for policymakers (Lundequist \& Power, 2002, p. 699);

- Finally, there seems to be a growing discrepancy between policy-driven clusters' goals on the one hand, and their means and processes on the other. This discrepancy is related to the fact that policy-driven clusters are by nature multi-level organizational objects, that put together policy makers, local agencies, companies of all sizes, universities,... Thus, the distinction between the initial intentions of cluster policies and their operationalization on the field becomes blurry. Therefore, Kiese \& Wrobel (2011, p. 1708) recently alerted the cluster policy research community to draw a strict line between "clusters vs. cluster policies, initiatives and organizations" and that the associated research streams are not the same. Swords (2013, p. 369) for example also underlined that the transformation of a cluster policy into concrete policy-driven cluster actions creates several dilemmas that are not addressed by the research community: "despite libraries of incredibly useful books and articles on clusters, there remains an absence of work which interrogates the translation of clusters into, and then through local and national policy”. Also Ebbekink \& Lagendijk (2013, p. 737) point to the fact that we have to start investigating "cluster policy as a policy challenge”.

In this literature review we have shown that their exists numerous dilemmas that those who implement policy-driven clusters have to face. However, sometimes a "wrong" direction might hinder the cluster policies to reap the main benefits that were predicted during the 1980s and 1990s, namely generating more innovation, increasing employment and competitiveness. The objective of this thesis is to focus on these dilemmas that emerge when implementing policy-driven clusters. These dilemmas are particularly emerging due to the "multi-level and multi-actor" nature of policy-driven clusters (Burfitt \& Macneill, 2008, p. 492; T. Weil \& Fen Chong, 2009). In the beginning of the $21^{\text {st }}$ century, Martin \& Sunley's (2003, p. 5) underlined that the "the cluster concept should carry a public policy health warning" and also recently Hospers et al (2009, pp. 297-298) advocate that the best motto for officials in charge for cluster policy is perhaps: "If you can't help, please do not harm". In order to overcome a "simple" health warning or the avoidance of cluster policies because one 
does not want to do any harm, we considered necessary in a first step to establish a taxonomy of potential dilemmas produced by the implementation of policy-driven clusters and in a second step to analyse which kind of side-effect pathologies these dilemmas create.

Instead of continuing to analyse in a Porterian manner the "anatomy of clusters", we suggest to study the organisational dilemmas that policy-driven clusters face and that generate sideeffect pathologies. We thus propose to start studying the "pathology of clusters". This approach enables us to address the problems of policy-driven clusters, little studied and not well understood so far (Ebbekink \& Lagendijk, 2013; Swords, 2013). Burfitt \& Macneill (2008) already started to investigate the different challenges faced by cluster policies. In their theoretical paper they identified for example two main challenges "operational and managerial challenges" and "political challenges". To the "operational and managerial" challenges they count for example the identification of clusters and the management of cluster policies, while to the "political challenges" they count the designation of clusters, the drawing of boundaries and the relationship between cluster organizations and politics. In this thesis, we conducted a systematic literature review (SLR) (Tranfield, et al., 2003) to explore empirical cluster policy case studies that were conducted all over the world. This type of systematic literature review, stemming from the medical realm (Mulrow, 1994; Thorpe, et al., 2005), allowed us to establish a taxonomy of different pathologies, based on existing empirical studies and to enlarge the first work of Burfitt \& Macneill (2008).

To sum up, we define "pathology" in a cluster setting as the visible managerial symptoms that policy-driven clusters may endure. In this thesis we wish to demonstrate how some of these pathologies are directly generated by "organizational dilemmas", i.e. a set of decisions and choices for which there is no "one best choice". By privileging one direction over another in such dilemmas, side-effect pathologies can emerge.

Our problem statement is:

Implementing cluster policies produce organisational dilemmas that generate sideeffect pathologies. 
And we defined three associated research questions:

RQ1: What are the organisational dilemmas that can be observed in the
implementation of the French cluster policy (the case of HCPR)?
RQ2: To which extend do these organisational dilemmas generate side-effect
pathologies?
RQ3: How can the knowledge of these pathologies benefit to cluster policy
(implementation and evaluation)?

Figure 15 schematizes the relations between our different research questions. From a theoretical point of view we first have to understand which dilemmas exist because dilemmas can create side-effect pathologies. However, on the field one has to first thoroughly decompose the general view and identify the different pathologies before it is possible to go "upstream" again (towards the dilemma) and give sense to the whole. Going upstream from the field will also allow identifying how the knowledge of these pathologies benefit to cluster policy implementation and evaluation.

Figure 15: Problem statement and research questions

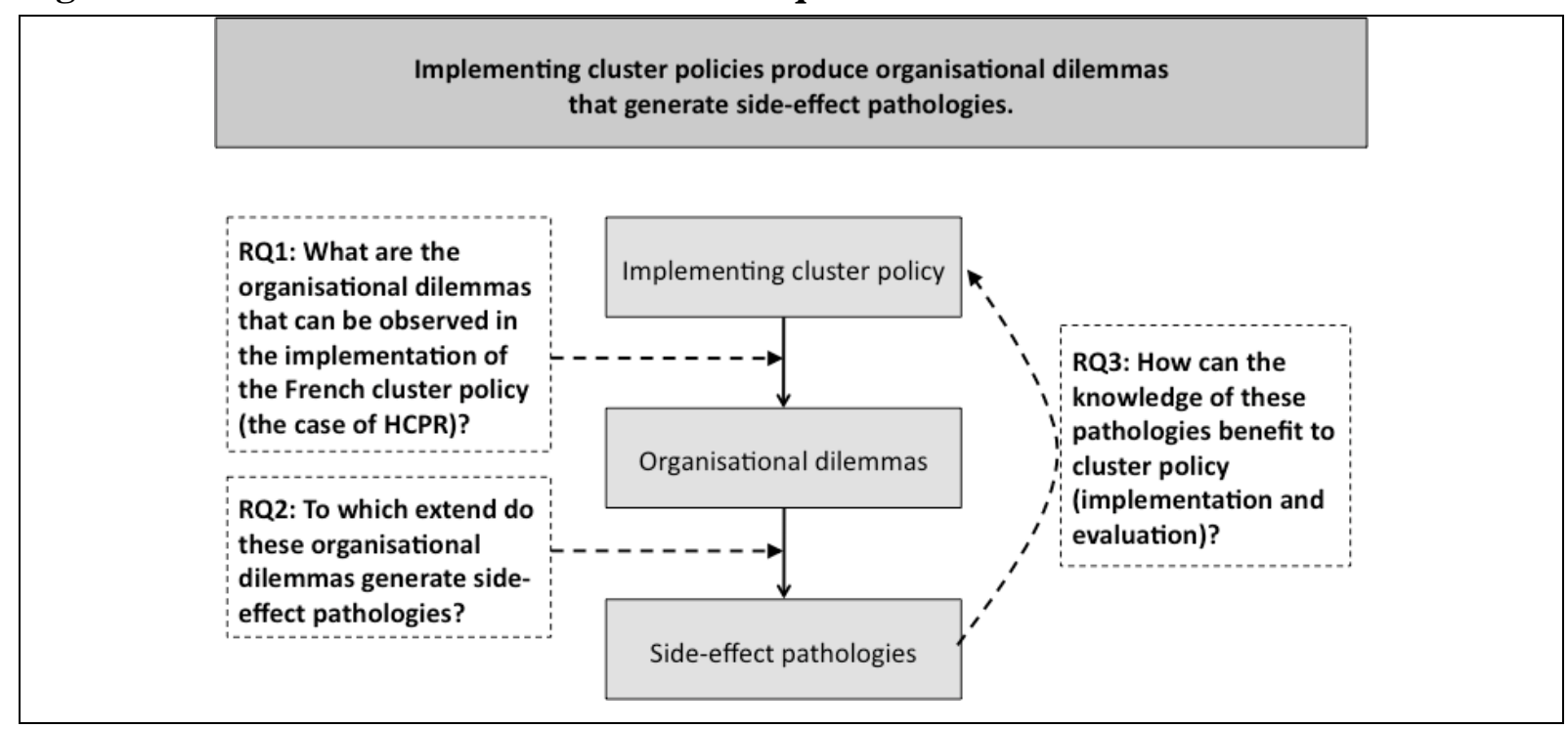

This thesis will allow us to make a theoretical contribution to the cluster policy literature because for the time being, there is not only the problem that "few empirical studies with micro data have been conducted [...] on the effects of cluster policies" (Nishimura \& Okamuro, 2011b, p. 715), but also that view studies about cluster policy challenges exist (Burfitt \& Macneill, 2008; Ebbekink \& Lagendijk, 2013). 


\section{SECOND PART: RESEARCH DESIGN AND EMPIRICAL CONTEXT}

The second part of this thesis concentrates on the research design and the empirical context. In chapter four we present the research design of our case study. We justify our case study approach and discuss our research quality criteria. In chapter five and six we give a detailed description of the empirical context of our case study. In chapter five we first embed the French cluster policy in its European context and then discuss the French relationship to policy driven clusters. Finally, in chapter six we explain in detail the specificities of the French cluster policy under review, give an overview of the policy-driven clusters in the Paris Region, and finally focus on HCPR, the cluster that will be under review during our fieldwork.

\section{Box 5: Content of second part}

Chapter 4: Research design

1 Using a "case study" approach: justification and usefulness

2 Research quality assurance

Chapter 5: Cluster policies in Europe: complexification and saturation.

1 European Union and the saturation of cluster policies

2 France and cluster policies: traditions and renewal

Chapter 6: The case of the French "competitiveness cluster" policy

1 The specificities of the French "competitiveness cluster" policy 182

2 Policy-driven clusters in the Paris Region

3 Presentation of HealthCluster Paris Region 


\section{Chapter 4: Research design}

In this chapter we first explain the reasons that drove us to choose a single "case study" methodology approach (Eisenhardt, 1989; Flyvbjerg, 2006; Yin, 2009). Additionally, as case studies are often criticised (Flyvbjerg, 2006) we give a detailed justification why we are convinced that it is the best approach to tackle our three research questions. Second, we focus on the different research quality criteria (Gibbert, Ruigrok, \& Wicki, 2008; Yin, 2009) such as external validity, construct validity, reliability and internal validity to assure the value of our research.

\section{Box 6: Content of chapter four}

1 Using a "case study" approach: justification and usefulness

2 Research quality assurance

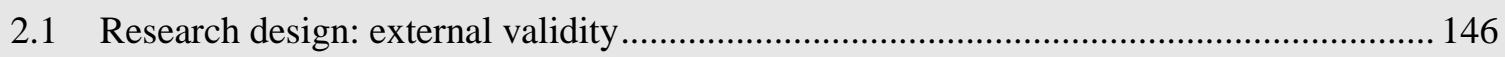

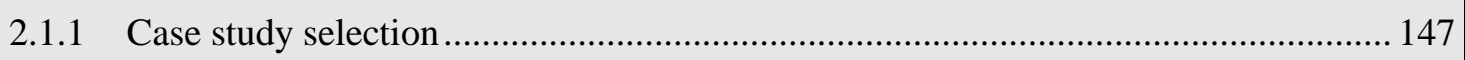

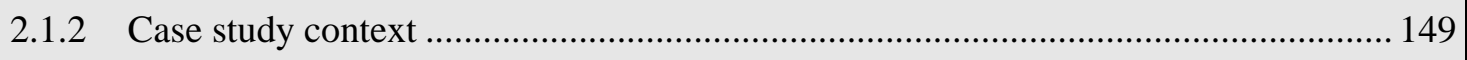

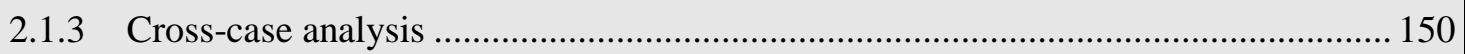

2.2 Data collection: construct validity and reliability …................................................. 150

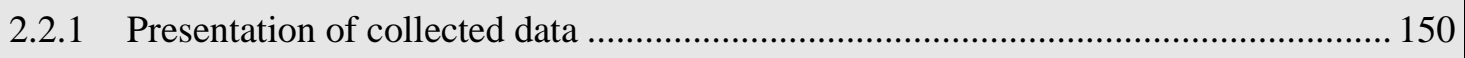

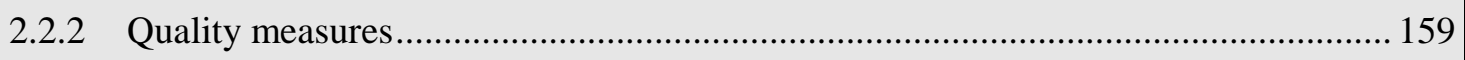

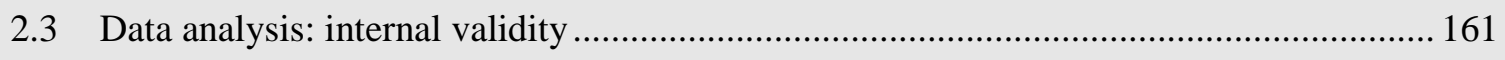




\section{Using a "case study" approach: justification and usefulness}

The type of research methodology we chose for this thesis is the case study approach (Eisenhardt, 1989; Yin, 2009). The case study approach is a widely used and accepted methodology in cluster studies (Angel, 1991; Dayasindhu, 2002; Feldman \& Francis, 2003; Harrison, Cooper, \& Mason, 2004; Lissoni, 2001; Longhi, 1999; Maillat, Lecoq, Nemeti, \& Pfister, 1995; Van Klink \& De Langen, 2001; Waxell \& Malmberg, 2007), and more particularly also in cluster policy and policy-driven cluster studies (Bidan \& DhermentFérère, 2009; Chabault, 2008; Champenois, 2012; Kaiser, 2003; Retour, 2009b).

There are three main reasons why we consider that the case study approach is the best approach for investigating our three research questions:

- First of all, case studies are particularly useful "in the critical, early phases of a new management theory, when key variables and their relationships are being explored" (Gibbert, et al., 2008, p. 1465). For the time being our knowledge on the challenges of implementing cluster policies is very limited (Burfitt \& Macneill, 2008; Ebbekink \& Lagendijk, 2013; Swords, 2013). In order to develop a stronger theory of policydriven cluster management and implementation we still need more exploratory studies that will allow us to formulate more precise hypothesis.

- Second, case studies "are typically carried out in close interaction with practitioners, and they deal with real management situations" (Gibbert, et al., 2008, p. 1465). Therefore, the case study approach "represent a methodology that is ideally suited to creating managerially relevant knowledge” (Gibbert, et al., 2008, p. 1465). Cluster studies are increasingly confronted with a relevance gap (Kiese \& Wrobel, 2011; R. Martin \& Sunley, 2003; Swords, 2013) due to the difficult process of transforming the theoretical knowledge of the "cluster" concept into an operational knowledge on how to manage policy-driven clusters. Using a case study approach will thus allow us to increase our capacity to produce "relevant knowledge", important for the ones who whish to implement and evaluate policy-driven clusters.

- Finally, the case study approach is recommended by Schmiedeberg (2010) as one of several cluster policy evaluation methodologies, next to econometric methods, systemic approaches (i.e. I/O-analysis, Network analysis, Benchmarking), cost-related approaches, and reporting. The advantage of using a case study approach to evaluate 
cluster policies "lies in their intuitive understanding, flexibility and in-depth view" which allows showing "the mechanisms of cluster development in detail" (Schmiedeberg, 2010, p. 404).

However, even though case studies bring numerous advantages, they are also heavily criticized (Flyvbjerg, 2006). Flyvbjerg (2006) summarized these criticisms in five points and argues why these criticisms are, according to him, not true. We share the opinion of Flyvbjerg (2006, p. 221) and discuss his arguments hereinafter. This will allow us to further confirm that a case study is particularly adapted to our research endeavour.

"Context-dependent knowledge" criticism: The first criticism that is often put forward is that "context-dependent knowledge", as produced in case studies, is less valuable than "contextindependent knowledge", as produced with for example econometric methods. Through the discussion of several examples, Flyvbjerg (2006) argues why this is, according to him, not true. We will just pick up one point that is particularly appealing to us as a young researcher with the objective to improve our understanding of cluster policy implementation and evaluation. Flyvbjerg (2006, p. 223) underlines that case studies "are important for researchers' own learning processes in developing the skills needed to do good research" and to become in the long run specialists of their field. As already explained in the preface of this document, in our Master thesis (A. Glaser, 2007) but also at the beginning of our $\mathrm{PhD}$ (Gallié, et al., 2013b; A. Glaser, et al., 2012) we analysed clusters with quantitative data and statistical procedures and thus stayed at "great distance to the object of study" (Flyvbjerg, 2006, p. 223). At the beginning of our $\mathrm{PhD}$ we had access to the official French cluster-policy evaluation data (CMI \& BCG, 2008) that allowed us to do statistical analysis regarding the performance differences of policy-driven clusters. We identified performance differences according to policy-driven clusters' pre-existing R\&D activities (Gallié, et al., 2013b) and their governance structures (A. Glaser, et al., 2012). Additionally we classified the different policy-driven clusters in more homogenous sub-groups. However, little by little, we increasingly questioned whether policy-driven clusters can and should be measured by for example their capacity to attract R\&D subsidies or the number of SMEs in their governance board, and what this information actually tells us. It was clear for us that if we wish to continue working in the cluster policy field and more particularly in the evaluation field (Gallié, et al., 2012; Gallié, et al., 2014) we had to dig into the policy-driven clusters and leave our office and go to the field. It was at this point that our "journey to the centre of 
cluster policies" started to prevent doing research that "leads to ritual academic blind alleys, where the effect and usefulness of research becomes unclear and untested" (Flyvbjerg, 2006, p. 223). We are convinced that in order to produce accurate "context-independent knowledge", researchers have to first learn and produce "context-dependent knowledge". This thesis should thus also be seen as one element in our learning path towards becoming a policy-driven cluster specialist that in fine will be able to draw from its "context-dependent knowledge" developed thanks to this research, to generate more reliable interpretations when facing "context-independent knowledge" in the future.

“Generalisation" criticism: The second criticism that is constantly put forward by critics is that generalisation is not possible from a single case study, so case studies "cannot contribute to scientific development” (Flyvbjerg, 2006, p. 227). However, Flyvbjerg (2006, p. 227) argues that "a purely descriptive, phenomenological case study without any attempt to generalize can certainly be of value". Case studies are even essential for the generalisation of theories as they allow a constant "critical reflexivity", particularly in social sciences (Flyvbjerg, 2006, pp. 227-228). For Popper something is true ("all swans are white”) as long as the argument is not falsified (1959). However, as soon as "one observation does not fit with the proposition" (the "black swan"), the proposition "is considered not valid generally and must therefore be either revised or rejected" (Flyvbjerg, 2006, p. 228; Popper, 1959). This process leads to "further investigations and theory building" (Flyvbjerg, 2006, p. 228). Case studies, because they are close to the field, are ideal devices to keep the scientific engine going and to bring "falsification" elements to contradict generalised theories. For example, the general political tenor in France is that subsidising collaborative R\&D projects will help building a functioning cluster ecosystem. The president of the policy-driven cluster that we investigated also put forward during a speech that his objective is to create a cluster spirit where everybody is working together in a trust relationship. This can certainly be the case, but our data also show that the R\&D subsidies associated to the policy-driven cluster can create distrust between the policy-driven cluster governance and the companies. Additionally, the subsidies linked to the policy-driven cluster seem to create more lobbying behaviour than idea generation moments. Even though there are policy-driven clusters in France where everything seems to function perfectly, the knowledge we gained from our "black swan" case study will help rethinking how a policy-driven cluster works, can be implemented and evaluated. 
"First stage of research" criticism: This criticism is directly linked to the "generalisation criticism. There is a general belief that case studies are "most useful for generating hypotheses" and "other methods are more suitable for hypotheses testing and theory building” (Flyvbjerg, 2006, p. 221). However, Eckstein (1975), a political scientist, even argues that case studies are "better for testing hypotheses than for producing them" (Flyvbjerg, 2006, p. 229). For this the case selection process is though very important (Flyvbjerg, 2006). In order for a case study to bring an added value, it has to be chosen carefully, as a "representative case or a random sample" might be less useful for generating new knowledge (Flyvbjerg, 2006, p. 229). For Flyvbjerg (2006, p. 229). “atypical or extreme cases often reveal more information because they activate more actors and more basic mechanisms in the situation studied". We will still discuss our case selection process in more detail in the "research quality assurances" section, for the time being we just underline that our case study is an "atypical" case in the Paris Region, as the investigated policy-driven cluster is, among the Paris Region policy-driven clusters, the lowest ranked policy-driven cluster during the first (CMI \& BCG, 2008) and second official cluster policy evaluation (Erdyn, et al., 2012). Finally, this case study is also a-typical because of the number and intensity of difficulties, especially managerial difficulties that this specific cluster experienced. This troubled situation has driven us to specifically highlight pitfalls, dilemmas and pathologies that would of course not be as present in a majority of clusters.

"Subjective bias" criticism: Another major criticism regarding case studies is the assumption that they have the "tendency to confirm the researcher's preconceived notions" (Flyvbjerg, 2006, p. 221). However, Flyvbjerg (2006, p. 221) gives a range of examples that show that "researchers who have conducted intensive, in-depth case studies typically report that their preconceived views, assumptions, concepts, and hypotheses were wrong and that the case material has compelled them to revise their hypotheses on essential points". When we left our office in 2010 to start our "journey to the centre of cluster policies", we were most motivated to understand how collaboration and innovation is created by policy-driven cluster organisations. When we started our investigation process we already knew that HCPR is apparently a special case, was evaluated low during the first policy-driven cluster evaluation (CMI \& BCG, 2008), but we still thought that this will improve during the second policydriven cluster phase and we will be able to observe how they build collaboration and foster innovation in the region. We were interested in working on the main assumption of why policy-driven clusters exist: innovation and collaboration. Both topics are intensively 
discussed in the cluster literature (Engel, et al., 2013; Giuliani, 2007; Lefebvre, 2013; Liyanage, 1995). However, our fieldwork led us to completely revise our initial assumption because behind the scene the observed "pathologies" were too strong, innovation and collaboration were somehow pushed in the background, as our fieldwork discussion will show. Also Flyvbjerg (1998) conducted an in-depth case study on "urban politics and planning in the city of Aalborg" and observed little by little that his initial hypotheses were not accurate any more. At some point this experience was very "frustrating" because he thought that all his collected data was worthless (Flyvbjerg, 2006). It took him some time to realize that he had to change his initial assumptions and change his angle of observation. Today he thinks that "one must be prepared for such incidents" (Flyvbjerg, 2006, p. 231) and that it even increases the value of in-depth case studies. We completely understand what he means because we had a very similar fieldwork experience.

"Not possible to develop propositions" criticism: Finally, the last criticism that is often put forward is that "it is often difficult to summarize and develop general propositions and theories on the basis of specific case studies" (Flyvbjerg, 2006, p. 221). Flyvbjerg (2006) argues, that this is not the objective of in-depth case studies and that the "thick" descriptions are important. By saying this Flyvbjerg (2006) takes a different stance than other case study specialist such as Eisenhardt (1989) and Yin (2009)). According to Flyvbjerg (2006), these "thick" descriptions allow capturing a wide audience with different interests to learn in the best possible manner from the new insights and use the new findings for their own research endeavours. However, a lot of in-depth case study researcher are "haunted" by the question "Who will want to learn about a case like this, and in this kind of detail?" (Flyvbjerg, 2006, p. 237) and thus find it difficult to assume a detailed description. However, for Flyvbjerg (2006) this should not be "haunting" them and refers to Nietzsche (1969, p. 238) who says that it is the "focus on "little things"” that counts. We also had a lot of difficulties in finding the right balance between on the one hand assuming a very thick description and on the other hand trying to summarize our ideas and slightly gaining in abstraction something that is advocated by case study specialists such as Eisenhardt (1989) and Yin (2009). We hope to have found a good balance between both approaches. 


\section{Research quality assurance}

According to Yin (2009), Eisenhardt (1989) or Gibbert et al. (2008) there are several criteria that need to be respected in order to build high quality case studies: external validity, construct validity, reliability, and internal validity. Every quality test is associated to a certain research phase and has specific measures that need to be taken into account (see Table 20). Hereinafter, we will now discuss the different quality criteria in the light of our case study.

Table 20: Case study quality criteria

\begin{tabular}{|l|l|l|}
\hline Research Phase & Tests & Measures \\
\hline \multirow{2}{*}{ Research Design } & \multirow{2}{*}{ External validity } & 1. Clear rational for case study selection \\
\cline { 3 - 3 } & & 2. Detailed description of case study context \\
\cline { 3 - 3 } & & 3. Cross-case analysis \\
\hline \multirow{2}{*}{ Data collection } & \multirow{2}{*}{ Construct validity } & 1. Data triangulation \\
\cline { 3 - 3 } & \multirow{2}{*}{ Reliability } & 2. Establishment of a clear chain of evidence \\
\cline { 3 - 3 } & & 1. Case study protocol \\
\hline \multirow{2}{*}{ Data analysis } & \multirow{2}{*}{ Internal validity } & 1. Theory triangulation \\
\cline { 3 - 3 } & & 2. Pattern matching \\
\cline { 3 - 3 } & & 3. Clear research framework \\
\hline
\end{tabular}

Source: (Gibbert, et al., 2008; Yin, 2009)

\subsection{Research design: external validity}

We already addressed the problem of "generalizability", also called "external validity" (Gibbert, et al., 2008), when we discussed the criticisms that are often addressed to case study researchers (see section one of this chapter and the discussion of Flyvbjerg's (2006) article). The problem is that there is an "intuitive belief that theories must be shown to account for phenomena not only in the setting in which they are studied, but also in other settings" (Gibbert, et al., 2008, p. 1468). However, case studies, be it single or multiple, do not "allow for statistical generalization" (Gibbert, et al., 2008, p. 1468), i.e. to draw conclusions that can be applied to the whole population. However, even though no statistical generalization is possible with case study research, analytical generalization is possible (Eisenhardt, 1989; Gibbert, et al., 2008; Yin, 2009). According to Yin (2012, p. 18), analytical generalization uses “a study's theoretical framework to establish a logic that might be applicable to other situations." The end result is a "carefully posed theoretical statement, theory, or theoretical 
proposition [...] that is believed to be applicable to other situations" (Yin, 2013, p. 68) ${ }^{116}$. In order to allow an analytical generalization, several criteria need to be explained: why a certain case study was selected, the context of the case study, and the cross-case analysis (Gibbert, et al., 2008).

\subsubsection{Case study selection}

In order to improve external validity the case study selection process has to be made explicit. However, before we can define how we selected the case, we have to define what kind of cases we are looking at. We use a single-case design (2009). However, it is difficult to stick to Yin's (2009, p. 46) basic types of design if one wishes to analyse cluster policies and policydriven clusters. If we stick to Yin's basic single-case design we could say that the general context of our case is the French cluster policy and the case is the policy-driven cluster called HCPR. The objective is to identify pathologies that have emerged within this setting. These pathologies are identified through a multitude of different observation points (to be discussed in the data collection sub-section). However, this would simplify a situation that is more complex, because cluster policies and policy-driven clusters are both embedded in a specific national context. Cluster policies (and thus also the implemented policy-driven clusters) are not the same in Austria and in France. For the study of cluster policies and policy-driven clusters, a better context description is the country, having a particular cluster policy case, which has itself one or several policy-driven cluster cases attached (see Figure 16).

Our main cluster policy case is situated in France and our main policy-driven cluster is HCPR. However, the analysis of HCPR's pathologies would have never been possible without observing other contexts and cases as well. Since 2009 we were able to analyse for example the cluster policy evaluations that were conducted in Germany, Austria and Belgium (Gallié, et al., 2014). Additionally, we conducted interviews with other French policy-driven clusters (Cap Digital and Sytematic), assisted in the French cluster observatory, and also conducted interviews with non-French policy-driven clusters (A. Glaser, 2011). Only this broad approach allowed us to better see and analyse the particularities of HCPR and to in fine enrich our understanding of cluster policy evaluations.

116 "The generalization can take the form of a lesson learned, working hypothesis, or other principle” (Yin, 2013, p. 68) 
Regarding the case selection one question emerge: Why HCPR? The reason to analyse the French cluster policy (and not for example the Austrian) was opportunism (Girin, 1989). The reason to analyse HCPR was a more active choice. HCPR was the lowest rated policy-driven cluster in the Paris Region after the first cluster policy evaluation (CMI \& BCG, 2008). We started our cluster policy investigations with analysing performance differences of French policy-driven clusters (Gallié, et al., 2013b; A. Glaser, et al., 2012), it was thus the most interesting choice to do our qualitative case study in a policy-driven cluster that was evaluated as "low" performing. However, the interesting point is that HCPR was also badly evaluated at the end of the $2^{\text {nd }}$ cluster policy phase (2012), at the end of our fieldwork. In 2012, HCPR received the lowest grade (among 3 levels: very powerful, powerful, less powerful) and was the only "world class cluster" 117 that received such a low grade. 4 of the other world class clusters received the "very powerful" and 2 the "powerful" grade. At the beginning the picture was not that clear yet, but at the end of our fieldwork, we were able to say that HCPR is in an extreme case (Eisenhardt, 1989; Flyvbjerg, 2006). Generally we can say that "there is a great deal to learn from projects that failed to complete their goals or to deliver promised benefits." (Shipp, Chang, \& Wisniewski, 2005, p. 6) ${ }^{118}$, they are much more interesting to analyse and allow drawing new conclusions that could not be drawn when sticking to best practice examples (Flyvbjerg, 2006). For the study of pathologies, an extreme case like HCPR is particularly interesting and valuable. This allows developing better and more accurate insights of the potential problems of policy-driven clusters and in fine the development of better evaluation criteria and better policy implementations.

\footnotetext{
${ }^{117}$ Three cluster levels exists: world class clusters, aspiring world class clusters, national clusters

${ }^{118}$ Idea for looking into the report of Shipp et al.(2005) stems from Schmiedeberg (2010)
} 
Figure 16: Research design: Context and cases

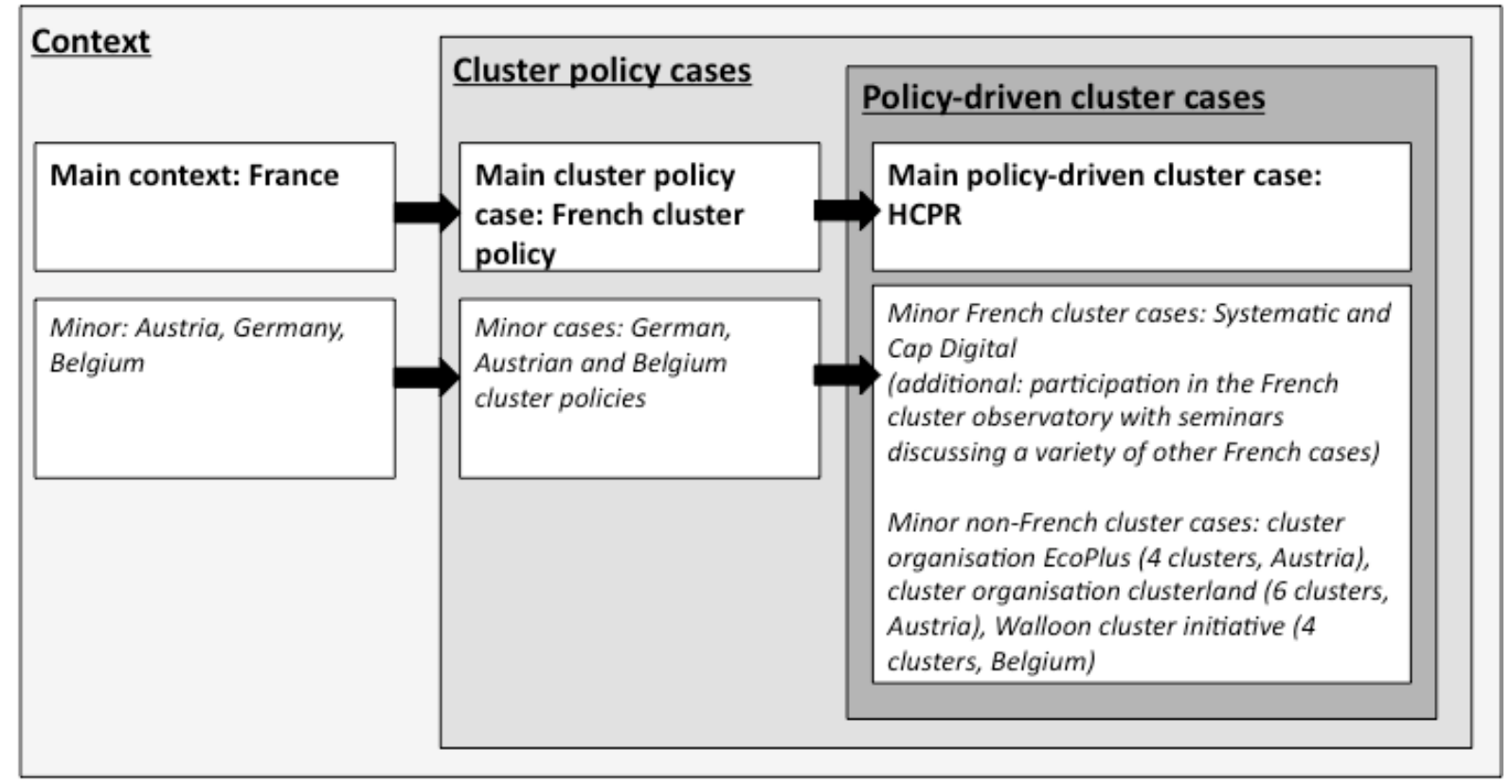

\subsubsection{Case study context}

Another important element that needs to be explained in detail in order to guarantee an external validity is the context of the case study (Flyvbjerg, 2006; Gibbert, et al., 2008; Yin, 2009). We dedicated chapter 5 and 6 entirely to this cause.

In chapter 5, we start with drawing a link between all our contexts (France, Austria, Germany and Belgium) by first discussing the European Union's approach to cluster policies (Context 1). This allows us to see that there is a general run towards cluster policies as a tool that is meant to allow fostering innovation and regional competitiveness. Then we focus on France and discuss its ambiguous situation between decentralisation and centralisation tendencies inbetween cluster policy has to be "lived". Finally, we present the different French initiatives that are meant to build "regional systems" of innovation.

In chapter 6, we then only focus on the French "competitiveness cluster policy" (politique de pôle de compétitivité) that was launched in 2004. We will present the specificities of the policy and how it was implemented. Then we focus on the policy-driven clusters in the Paris Region, by first presenting the economic situation of the Paris Region and then the different policy-driven clusters that are implemented in the region. Finally we will present HCPR and some statistical indicators that will allow us to better apprehend our qualitative case study results. 


\subsubsection{Cross-case analysis}

Finally, the last measure that is meant to guarantee external validity is cross-case analysis (Eisenhardt, 1989; Gibbert, et al., 2008). On the one hand, Eisenhardt (1989) argues that four to ten case studies are necessary to start analytical generalization. On the other hand, Flyvbjerg (2006) argues that this is already possible by conducting only one single in-depth case study. Our research lays somehow in-between these two spheres. On the one hand, we only analysed in detail the pathologies of one policy-driven cluster. However, as already mentioned in the "case study selection" sub-section, we also investigated some minor cases (see Figure 16). We did not do an exact cross-case analysis between HCPR and the minor cases, however the knowledge gained in the minor cases was crucial for the understanding of HCPR. According to Eisenhardt (1989) our analytical generalization potential would thus be weak, but according to Flyvbjerg (2006) a thick-description of our fieldwork will allow us to overcome validity critics.

\subsection{Data collection: construct validity and reliability}

Hereinafter we now focus on data collection. We first present our collected data and then discuss construct validity and reliability issues.

\subsubsection{Presentation of collected data}

Figure 17 gives a general overview of the different data collection phases during our fieldwork. Even though we were continually embedded and confronted with our cluster policy fieldwork (as we will explain hereinafter), we had two main qualitative fieldwork periods. The first main qualitative fieldwork period took place between September 2010 and January 2011, and the second main fieldwork period took place between November 2011 and March 2012. Using a longitudinal approach in case studies (Eisenhardt \& Graebner, 2007; LeonardBarton, 1990) is particularly recommended when operating in nascent research fields (Edmondson \& McManus, 2007) as it is the case for cluster policy implementation and the study of its challenges. Hereinafter, we discuss three different data collection levels: cluster policy data, policy-driven cluster organisation data, and policy-driven cluster member data. 
Figure 17: Empirical investigation journey

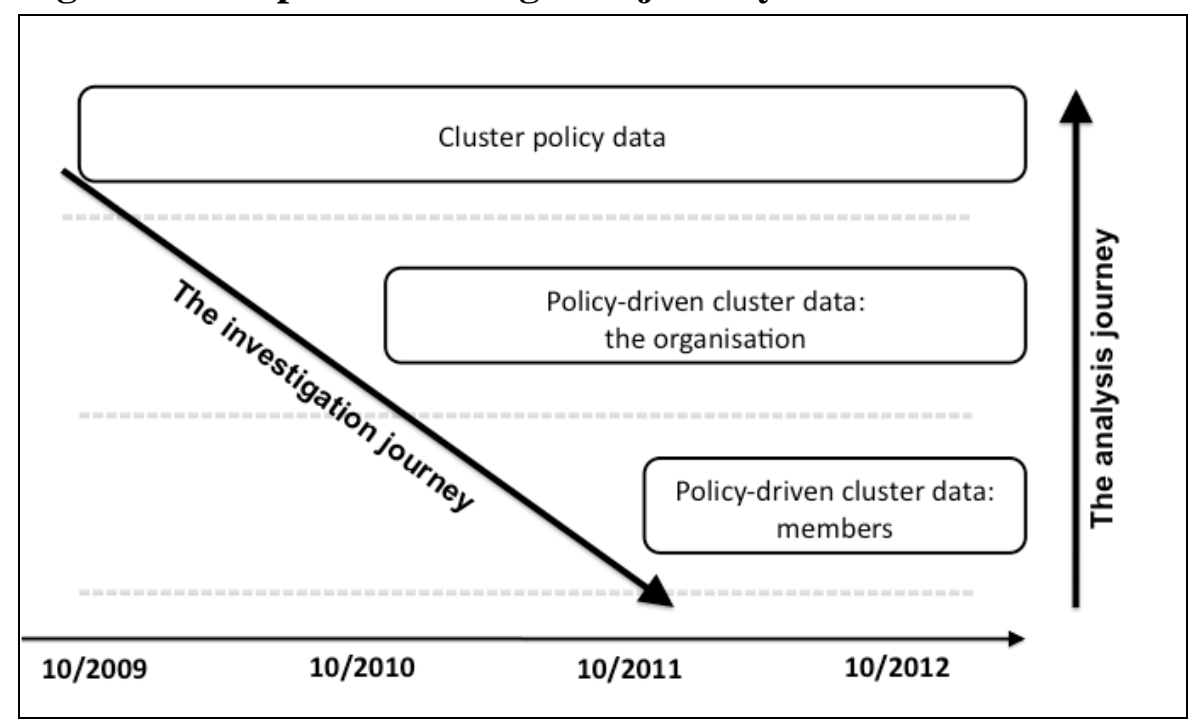

\subsubsection{Cluster policy data}

We started our thesis in October 2009, thus our thesis covers exactly the second phase ${ }^{119}$ of the French cluster policy ${ }^{120}$. Right at the beginning of our thesis we got access to the data of the national cluster evaluation that took place in 2008. We started exploring this data to detect performance differences between French policy-driven clusters regarding their pre-existing R\&D activities (Gallié, et al., 2013b) and their governance structure (A. Glaser, et al., 2012) (see Annex 20). Furthermore, we also worked on cluster policy evaluation more generally by first conducting and in-depth analysis of the French cluster policy evaluation (Gallié, et al., 2012) (see Annex 18) and then by positioning this French cluster policy evaluation in a European context (Gallié, et al., 2014) (see Annex 19). Finally, we also regularly participated in the seminars organised by the French cluster observatory of which we are member (observatoire des pôles de compétitivité). All these elements, together with the reading of official reports, the reading of the work of colleagues, and the comparison of the French cluster policy with other European examples (Gallié, et al., 2014), helped us understanding what the French cluster policy is, how it functions and its particularities. However, we also realised that we need to open the "black box" to better analyse the more abstract evaluation and performance data we were handling. This led us to investigate policy-driven cluster organisations and its members.

\footnotetext{
${ }^{119}$ The $1^{\text {st }}$ phase of the policy lasted from 2005 to 2008 and finished with an official cluster evaluation in 2008 . The $2^{\text {nd }}$ phase of the cluster policy lasted from 2009 to $2012^{119}$ and concluded as well with an official cluster evaluation in 2012. The $3^{\text {rd }}$ phase of the French cluster policy will last from 2013 to 2018.

${ }^{120} \mathrm{We}$ started our thesis on the $1^{\text {st }}$ October 2009.
} 


\subsubsection{Policy-driven cluster data: the organisation}

We started our thesis in October 2009, and the first fieldwork experience was the HealthCluster Paris Region's (HCPR) performance signature in November 2009 at which we assisted. In June 2010, we contacted and interviewed one of the steering committee presidents and asked for authorization to observe the efforts of HCPR's operational team more closely. This authorization was given. From September 2010 to January 2011 (5 months), we integrated the operational team of HCPR. Due to the limited office space of HCPR, we were not granted authorization to work there permanently. However, we were regularly informed and granted authorization to participate in internal meetings among the operational team, external meetings between the operational team and important partners of the region, and official cluster organisation events (see Table 21). In total, after adding the three meetings at which we assisted after the 5 months period (end of 2011 and 2012) we assisted and observed 65 hours of meetings and events. Before and after these meetings and events we had plenty of occasions to discuss in an informal manner with the operational team. Very often the information we gained from these informal discussions (for example on the way home of an event in the metro) were more insightful than the event itself.

Table 21: Source of evidence: Observations of events and meetings

\begin{tabular}{|c|c|c|c|c|c|c|}
\hline \# & Date & Objective of meeting / event & Location & $\begin{array}{l}\text { Source of } \\
\text { evidence }\end{array}$ & $\begin{array}{c}\text { Length } \\
\text { of event } \\
\text { (in min.) }\end{array}$ & Recorded \\
\hline 1 & $10 / 11 / 09$ & $\begin{array}{l}\text { HCPR's performance contract signature } \\
\text { event }\end{array}$ & \begin{tabular}{|l|} 
Bourse de \\
Paris \\
\end{tabular} & $\begin{array}{l}\text { Observation of } \\
\text { event }\end{array}$ & 240 & yes \\
\hline 2 & $04 / 10 / 10$ & "France - Sweden" Medical workshop & ARD & $\begin{array}{l}\text { Observation of } \\
\text { event }\end{array}$ & 120 & no \\
\hline 3 & $05 / 10 / 10$ & $\begin{array}{l}\text { 1st meeting between Polinvest and } \\
\text { HealthCluster to discuss the action plan for } \\
\text { the Biotech/Health Network }\end{array}$ & $\begin{array}{l}\text { Bourse de } \\
\text { Paris }\end{array}$ & $\begin{array}{l}\text { Observation of } \\
\text { meeting (external) }\end{array}$ & 75 & no \\
\hline 4 & $06 / 10 / 10$ & $\begin{array}{l}\text { 1st meeting between "Paris } \\
\text { Developpement" and HealthCluster. } \\
\text { Meeting initiated by "Paris } \\
\text { Developpement" to exchange on the } \\
\text { respective competencies. }\end{array}$ & HealthCluster & $\begin{array}{l}\text { Observation of } \\
\text { meeting (external) }\end{array}$ & 120 & no \\
\hline 5 & $07 / 10 / 10$ & $\begin{array}{l}\text { 1st meeting between CCIP and } \\
\text { HealthCluster to discuss the action plan for } \\
\text { the Biotech/Health Network }\end{array}$ & $\begin{array}{l}\text { CCIP (Bourse } \\
\text { de commerce) }\end{array}$ & $\begin{array}{l}\text { Observation of } \\
\text { meeting (external) }\end{array}$ & 150 & no \\
\hline 6 & $14 / 10 / 10$ & $\begin{array}{l}\text { MeetInnov event (HealthCluster had a } \\
\text { stand and presented) }\end{array}$ & $\begin{array}{l}\text { Pavillon } \\
\text { Baltard } \\
\text { (Nogent-sur- } \\
\text { Marne) }\end{array}$ & $\begin{array}{l}\text { Observation of } \\
\text { event }\end{array}$ & 500 & no \\
\hline 7 & $18 / 10 / 10$ & $\begin{array}{l}\text { 2nd meeting between UbiFrance and } \\
\text { HealthCluster to discuss the action plan for } \\
\text { the Biotech/Health Network }\end{array}$ & HealthCluster & $\begin{array}{l}\text { Observation of } \\
\text { meeting (external) }\end{array}$ & 90 & no \\
\hline 8 & $20 / 10 / 10$ & $\begin{array}{l}\text { Discussion of the different action plans for } \\
\text { the Biotech/Health Network }\end{array}$ & HealthCluster & $\begin{array}{l}\text { Observation of } \\
\text { meeting (internal) }\end{array}$ & 150 & no \\
\hline 9 & $20 / 10 / 10$ & $\begin{array}{l}\text { 2nd meeting between Polinvest and } \\
\text { HealthCluster to discuss the action plan for } \\
\text { the Biotech/Health Network }\end{array}$ & HealthCluster & $\begin{array}{l}\text { Observation of } \\
\text { meeting (external) }\end{array}$ & 60 & no \\
\hline
\end{tabular}




\begin{tabular}{|c|c|c|c|c|c|c|}
\hline 10 & $20 / 10 / 10$ & $\begin{array}{l}\text { 1st meeting between ADDVDM and } \\
\text { HealthCluster to discuss the action plan for } \\
\text { the Biotech/Health Network }\end{array}$ & HealthCluster & $\begin{array}{l}\text { Observation of } \\
\text { meeting (external) }\end{array}$ & 60 & no \\
\hline 11 & $21 / 10 / 10$ & $\begin{array}{l}\text { 1st meeting between Optics Valley and } \\
\text { HealthCluster to discuss the action plan for } \\
\text { the Biotech/Health Network }\end{array}$ & HealthCluster & $\begin{array}{l}\text { Observation of } \\
\text { meeting (external) }\end{array}$ & 90 & no \\
\hline 12 & $25 / 10 / 10$ & HealthCluster Convention & \begin{tabular}{|l|} 
Cité \\
Universitaire
\end{tabular} & $\begin{array}{l}\text { Observation of } \\
\text { event }\end{array}$ & 510 & yes \\
\hline 13 & $26 / 10 / 10$ & $\begin{array}{l}\text { 3rd meeting between CCIP, AFNOR and } \\
\text { HealthCluster to discuss the action plan for } \\
\text { the Biotech/Health Network }\end{array}$ & $\begin{array}{l}\text { CCIP (Bourse } \\
\text { de commerce) } \\
\end{array}$ & $\begin{array}{l}\text { Observation of } \\
\text { meeting (external) }\end{array}$ & 300 & no \\
\hline 14 & $27 / 10 / 10$ & $\begin{array}{l}\text { 2nd meeting between Optics Valley and } \\
\text { HealthCluster to discuss the action plan for } \\
\text { the Biotech/Health Network }\end{array}$ & HealthCluster & $\begin{array}{l}\text { Observation of } \\
\text { meeting (external) }\end{array}$ & 90 & no \\
\hline 15 & $30 / 11 / 10$ & $\begin{array}{l}\text { TIC \& Bio day workshop organised by } \\
\text { Opticsvalley }\end{array}$ & $\begin{array}{l}\text { Campus les } \\
\text { Cordeliers } \\
\text { (University } \\
\text { Pierre and } \\
\text { Marie Curie) } \\
\end{array}$ & $\begin{array}{l}\text { Observation of } \\
\text { event }\end{array}$ & 450 & yes \\
\hline 16 & $24 / 01 / 11$ & $\begin{array}{l}\text { Discussion of the different action plans for } \\
\text { the Biotech/Health Network }\end{array}$ & HealthCluster & \begin{tabular}{|l|} 
Observation of \\
meeting (internal)
\end{tabular} & 120 & no \\
\hline 17 & $21 / 10 / 11$ & HealthCluster Convention & \begin{tabular}{|l|} 
Cité \\
Universitaire \\
\end{tabular} & $\begin{array}{l}\text { Observation of } \\
\text { event }\end{array}$ & 510 & yes \\
\hline 18 & $11 / 01 / 12$ & $\begin{array}{l}\text { Project labelling committee meeting for } \\
\text { project P7 }\end{array}$ & HealthCluster & $\begin{array}{l}\text { Observation of } \\
\text { meeting (labelling) }\end{array}$ & 15 & no \\
\hline 19 & $31 / 01 / 12$ & Defi biotech santé HealthCluster - Launch & \begin{tabular}{|l|} 
Bourse de \\
commerce
\end{tabular} & $\begin{array}{l}\text { Observation of } \\
\text { event }\end{array}$ & 240 & no \\
\hline & & & & & $\begin{array}{l}\text { total } \\
3890 \\
\text { min. } \\
=65 \\
\text { hours } \\
\end{array}$ & \\
\hline
\end{tabular}

Additionally, we also conducted 8 one-to-one interviews (see Table 22) with HCPR's operational team and its steering committee president, and 4 one-to-one interviews with other support structures of the Paris Region (Systematic, Cap Digital, Opticsvalley). In average these interviews lasted 78 minutes, were recorded and transcribed. Finally, the operational team also provided us with important internal documents (see Table 23) as for example the performance contract, documents related to the new developed services, ICT \& Health workshop minutes, mapping documents, etc. However, we consider important to mention that sometimes it was very difficult to get these internal documents, as everything had to be validated by the governance and some documents were promised to us but never handed out.

In September and October 2011, 8 months after we stopped our intensive observational phase, we conducted 2 follow up interviews with employees of the operational team and participated at one additional cluster organisation event of HCPR (the annual convention 2011). The policy-driven cluster analysis is heavily concentrated on one policy-driven cluster organisation. 
However, additionally to the investigation of HCPR, we also conducted two interviews with Systematic representatives, one interview with a Cap Digital representative and one interview with an Optics Valley representative. Besides this we also regularly participated in seminars organised by the French cluster observatory (observatoire des pôles de compétitivité, Mines ParisTech) at which we are member. Finally, we were also able to interview three Austrian cluster managers (A. Glaser, 2011). These comparison points allowed us to get a better grasp about the particularities of HCPR.

Table 22: Source of evidence: Interviews with Policy-driven cluster/other support entity

\begin{tabular}{|c|c|c|c|c|c|c|}
\hline \# & $\begin{array}{l}\text { Policy-driven } \\
\text { cluster or other } \\
\text { support entity } \\
\end{array}$ & Type of interview partner & Date & $\begin{array}{c}\text { Source of } \\
\text { evidence }\end{array}$ & $\begin{array}{l}\text { Interview } \\
\text { length } \\
\text { (in } \\
\text { minutes) } \\
\end{array}$ & $\begin{array}{l}\text { Recorded \& } \\
\text { Transcribed }\end{array}$ \\
\hline 1 & Cap Digital & Operational team member & $26 / 01 / 11$ & $\begin{array}{l}\text { Face to Face } \\
\text { interview }\end{array}$ & 100 & yes \\
\hline 2 & HealthCluster & $\begin{array}{l}\text { Steering committee president } \\
\text { (Development \& animation) (X) }\end{array}$ & $06 / 07 / 10$ & $\begin{array}{l}\text { Face to Face } \\
\text { interview }\end{array}$ & 75 & no \\
\hline 3 & HealthCluster & $\begin{array}{l}\text { Operational team members } \\
\text { (Development \& animation) (A, } \\
\mathrm{B}, \mathrm{D})\end{array}$ & $10 / 09 / 10$ & $\begin{array}{l}\text { Face to Face } \\
\text { interview }\end{array}$ & 60 & no \\
\hline 4 & HealthCluster & $\begin{array}{l}\text { Operational team member } \\
\text { (Development \& animation) (A) }\end{array}$ & $05 / 10 / 10$ & $\begin{array}{l}\text { Face to Face } \\
\text { interview }\end{array}$ & 100 & yes \\
\hline 5 & HealthCluster & $\begin{array}{l}\text { Operational team member } \\
\text { (Development \& animation) (B) }\end{array}$ & $13 / 01 / 11$ & $\begin{array}{l}\text { Face to Face } \\
\text { interview }\end{array}$ & 70 & yes \\
\hline 6 & HealthCluster & $\begin{array}{l}\text { Operational team member } \\
(\mathrm{R} \& D)(C)\end{array}$ & $13 / 01 / 11$ & $\begin{array}{l}\text { Face to Face } \\
\text { interview }\end{array}$ & 90 & yes \\
\hline 7 & HealthCluster & $\begin{array}{l}\text { Steering committee president } \\
\text { (Development \& animation) }(\mathrm{X})\end{array}$ & $18 / 01 / 11$ & $\begin{array}{l}\text { E-mail } \\
\text { conversation }\end{array}$ & - & - \\
\hline 8 & HealthCluster & $\begin{array}{l}\text { Operational team member } \\
(\mathrm{R} \& D)(\mathrm{C})\end{array}$ & $14 / 10 / 11$ & $\begin{array}{l}\text { Face to Face } \\
\text { interview }\end{array}$ & 90 & yes \\
\hline 9 & HealthCluster & $\begin{array}{l}\text { Operational team member } \\
\text { (Development \& animation) (A) }\end{array}$ & $21 / 10 / 11$ & $\begin{array}{l}\text { Face to Face } \\
\text { interview }\end{array}$ & 30 & yes \\
\hline 10 & OpticsValley & Operational team member & $19 / 01 / 11$ & $\begin{array}{l}\text { Face to Face } \\
\text { interview }\end{array}$ & 110 & yes \\
\hline 11 & Systematic & General Director & $28 / 07 / 10$ & $\begin{array}{l}\text { Face to Face } \\
\text { interview }\end{array}$ & 105 & yes \\
\hline 12 & Systematic & Operational team member & $28 / 01 / 11$ & $\begin{array}{l}\text { Telephone } \\
\text { interview }\end{array}$ & 30 & yes \\
\hline & & & & & $\begin{array}{r}\text { total } 860 \\
\text { average } 78\end{array}$ & \\
\hline
\end{tabular}

\section{Table 23: Source of evidence: Documentations and Archival records}

Internal documents: For example performance contract, documents related to the new developed services, general assemble presentations, convention presentations, ICT \& Health workshop minutes, mapping documents, ICT \& Health project documents

Photos of HCPR's office and events

Factiva news paper search about HealthCluster

Presentations that are accessible on the different websites (Cap Digital, Systematic, HealthCluster) 


\subsubsection{Policy-driven cluster data: the members}

In 2012 the DGCIS and the DATAR presented a report, entitled "The R\&D projects of the policy-driven clusters subsidised by the Single Interministerial Fund (FUI): first technological and economic benefits", which revealed the first results of the competitiveness clusters' research projects. The first page of the report discloses the following statement: (1) "The competitiveness clusters [is] a policy in favour of the decompartmentalisation of innovation actors"; (2) "Collaborative $R \& D$ projects [are] the heart of the competitiveness clusters' business"; (3) "Until today, the competitiveness clusters have contributed to the emergence of 1000 collaborative $R \& D$ projects subsidies by the State, in the framework of the FUI, as well as regional and local authorities".

The question which triggered us from the beginning onwards was how exactly the policydriven clusters have participated in these collaborative R\&D projects, something that the government claims that they have done. Therefore we also interviewed project leaders that submitted at least one project to the ICT \& Health initiative. The objective of these interviews was to better understand which role policy-driven clusters play in collaborative research projects. In order to understand which role policy-driven clusters play in collaborative research projects we first needed to understand how project leaders create collaborative research projects. We thus had three objectives when interviewing the project leaders:

- $\quad 1^{\text {st }}$ objective: Who are the project leaders and their associated organisations?

- $\quad 2^{\text {nd }}$ objective: How do project leaders create collaborative research projects? This main question can be split in several sub-questions: How do project leaders find project ideas?, How do project leaders find project partners?, How do project leaders find subsidies?

- $\quad 3^{\text {rd }}$ objective: Which role do the policy-driven clusters play in this process?

To investigate these questions, HCPR provided us with a list of all projects that were submitted for labelling to the ICT \& Health initiative for FUI11 and FUI12 funding. Out of this list we were able to contact and interview 10 "project leaders" who had submitted at least one project to the ICT \& Health initiative and thus to one of the three Parisian policy-driven clusters (Systematic, HealthCluster, Cap Digital) between 2009 and 2012 (FUI9 to FUI14), and at least one project between 2010 and 2011 (FUI11 and FUI12) (see Annex 6 for the email template we used to contact them). The projects submitted between 2010 and 2011 were 
our selection criteria to integrate the project leader in our investigation. The project leader has thus at least once in his life submitted a project to a policy-driven cluster and thus was at least once in his live in contact with a policy-driven cluster.

Besides the 10 project leaders (see Table 24, signed with *) we also conducted 8 interviews with additional project consortium partners (for example academics, doctors,...). In total we conducted 18 semi-structured interviews with an average recording time of $85 \mathrm{~min}$. (ranging from approximately $30 \mathrm{~min}$. to $210 \mathrm{~min}$ ). The interviews were conducted face-to-face or by telephone (one per e-mail), using a semi-structured interview guideline (see Annex 7). The interviews were digitally recorded and transcribed.

Table 24: Source of evidence: Interviews with R\&D project leaders and their partners

\begin{tabular}{|c|c|c|c|c|c|c|}
\hline \# & $\begin{array}{l}\text { Type of interview } \\
\text { partner }\end{array}$ & Data & Source of evidence & $\begin{array}{c}\text { Interview } \\
\text { length } \\
\text { (in minutes) } \\
\end{array}$ & $\begin{array}{l}\text { Recorded \& } \\
\text { Transcribed } \\
\end{array}$ & $\begin{array}{c}\text { Project } \\
\text { case \# }\end{array}$ \\
\hline 1 & Academic & $30 / 11 / 11$ & Telephone Interview & 35 & yes & $\mathrm{P9}$ \\
\hline 2 & Academic & 24/01/12 & Telephone Interview & 35 & yes & P7 \\
\hline 3 & Association* & $01 / 12 / 11$ & Face to Face Interview & 120 & yes & $\mathrm{P} 6$ \\
\hline 5 & Doctor & $31 / 01 / 12$ & Face to Face Interview & 30 & yes & P7 \\
\hline 4 & Doctor & $07 / 03 / 12$ & Telephone Interview & 45 & yes & P9 \\
\hline 6 & Doctor & $06 / 02 / 12$ & Telephone Interview & 30 & yes & $\mathrm{P} 7$ \\
\hline 7 & Large Group* & 29/11/11 & Telephone Interview & 45 & yes & P1 \\
\hline 8 & Medium-sized company* & $06 / 12 / 11$ & Face to Face Interview & 180 & yes & $\mathrm{P} 7$ \\
\hline 9 & Micro-enterprise* & $30 / 11 / 11$ & Telephone Interview & 65 & yes & $\mathrm{P} 2$ \\
\hline 10 & SME & $14 / 02 / 12$ & E-mail correspondence & - & - & $\mathrm{P} 9$ \\
\hline 11 & SME & $03 / 02 / 12$ & Telephone Interview & 50 & yes & $\mathrm{P} 7$ \\
\hline 12 & SME* & $15 / 02 / 12$ & Face to Face Interview & 165 & yes & $\mathrm{P} 9$ \\
\hline 13 & SME* & $12 / 12 / 11$ & Face to Face Interview & 100 & yes & P5 \\
\hline 14 & SME* & $22 / 11 / 11$ & Face to Face Interview & 30 & yes & $\mathrm{P} 3$ \\
\hline 15 & SME* & $23 / 11 / 11$ & Face to Face Interview & 60 & yes & $\mathrm{P} 4$ \\
\hline 16 & SME* & $23 / 11 / 11$ & Face to Face Interview & 120 & yes & P8 \\
\hline 17 & SME* & $02 / 12 / 11$ & Face to Face Interview & 210 & yes & $\mathrm{P} 10$ \\
\hline 18 & SME & 09/01/12 & Face to Face Interview & 120 & no & P8 \\
\hline & & & & $\begin{array}{r}\text { total } 1440 \\
\text { average } 85\end{array}$ & & \\
\hline
\end{tabular}

Legend: *project leader

Additionally to the 18 interviews we also consulted several additional documents (see Table 25) as for example project documents that were sent to us by the project leaders or project documents found on the Internet. Additionally we continued to track all projects on the official funding websites to know if they were finally funded or not. 
Table 25: Source of evidence: Other documentations

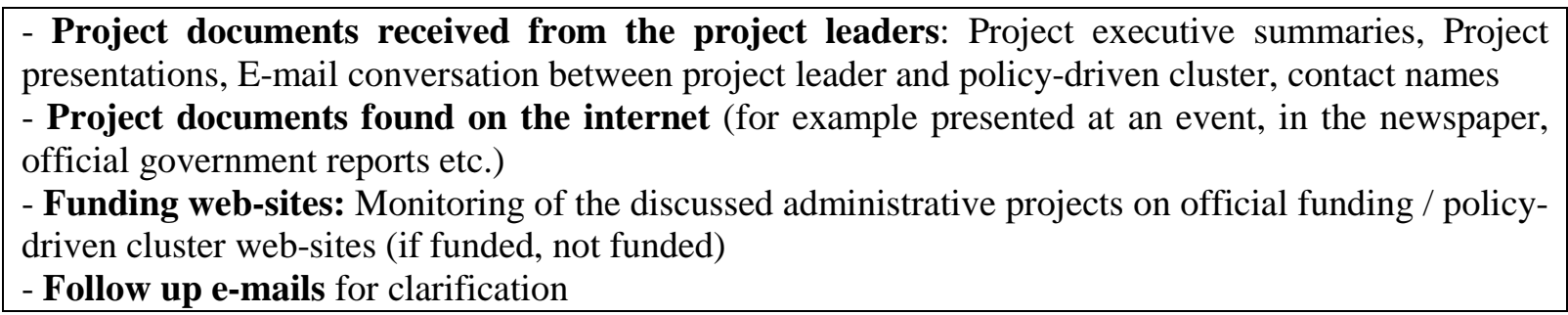

We started every interview with an open question: "Please tell me about the genesis of the [name of project] collaboration project? Tell me about the initiation of the project: how did everything begin?". As our underlying objective was to understand the role of the policydriven cluster in the innovation process of the selected projects, we did not insist on the role of the policy-driven cluster at the beginning of the interview (see Annex 7). We specifically focused on the role and the help of the cluster organisation in the second part of the interview. Initially we planned an in-depth investigation of ten projects (the ones that were provided to us by HCPR), but we were never able to solely stick to the project under investigation because the project often stemmed from several previous "unsuccessful" submissions (either not labelled, or labelled but not financed) or the project was just one of several projects in the portfolio of our interview partner (as we will see the project partners are very integrated in the collaborative research world), so our interview partner often drifted away. During the interviews, the project leaders thus never stuck to the one project we were initially interested in. Investigating one project thus actually meant investigating several projects, something that we were not completely aware in the beginning but we discovered during our interviews. The repeated submissions of similar projects were neither taken into account in the official cluster evaluations, nor observed or discussed during our observation period in the cluster organisation. In total, these 10 project leaders have told us the genesis of 30 collaborative research projects submitted to one of the three cluster organisations.

For example, after every "unsuccessful" submission (either not labelled, or labelled but not financed) of a project (1) the content of the project might change (instead of covering two themes within one project, the partners might have decided to split the project in two separate projects), (2) the project partners between the different submissions might change (adding partners or abandoning partners), (3) the targeted subsidies might change (passing for example from ANR to FUI to special project calls), and thus (4) the relation to the initially contacted policy-driven cluster might change as well (bad experiences, project content not in 
line with the initial policy-driven cluster any more, no need for the policy-driven cluster because other type of subsidies, etc.)

The reality was thus much more complex than initially assumed. We thus realized that our angle of analysis, strongly influenced by our top down investigation journey, was not useful for our underlying research objective. For two projects we stuck to our initial plan and not only interviewed the project leader but also a selection of project partners. However, our research objective was not to gain an in-depth knowledge of collaboration projects itself but to understand the role of policy-driven clusters for the project leaders in their innovation process. We thought that the entry point is the "collaboration project" that was provided to us by the cluster organisation and measured in the cluster evaluations, but a better entry point to understand the role of cluster organisations is the project leader and its organisation.

Finally, we decided the most appropriate manner to investigate our research questions is to change our angle. Instead of focusing on projects, we focused on project leaders, ideas, partners, and subsidies. This shift of focus, from solely project to different units, also has a second advantage for the analysis of our data. As already mentioned, the organisational "cluster" blindness we acquired due to the literature but also due to our observational period within the policy-driven cluster, lead us to believe that the policy-driven cluster has a particular stand for the project leaders. However, as we will discuss hereinafter, it seems important to reposition the efforts of policy-driven clusters into a broader context. Such a broadening is possible only if we put the project leaders and his ideas, partners, subsidies in the centre of our focus. Focusing for example on project leaders, will not only allow us to discuss the role of the policy-driven cluster but also the role of other organisations or activities in the innovation process of the project leader. The question is: "Which role does the policy-driven cluster play compared to all other organisations or activities?"

To sum up, during the interviews, the 10 project leaders considered important to explain us 19 project ideas in order for us to understand their relationship with policy-driven clusters and the genesis of their collaborative research projects. ${ }^{121}$ However, a project in project leader terms is not the same as a project in policy-driven cluster or cluster evaluation terms. For a

\footnotetext{
${ }^{121}$ The cluster actors even mentioned more than 19 projects during the interviews. These other projects were either targeted towards European Union subsidies or just mentioned very shortly. This is the reason why we decided to concentrate our analysis on the projects that were sufficiently explained during the interviews and targeted towards French subsidies.
} 
cluster actor a project is an idea, an idea that he defends most of the time until it is subsidised at some point. The project leader might submit this idea several times to a policy-driven cluster and subsequently for financing. Every time he submits his idea he changes either only slightly (e.g. by adding just a II behind the name) or considerably the project name but the idea behind the project name stays the same. However, for the policy-driven cluster and for the cluster evaluation every submitted project counts as a project, nevertheless if the idea behind the project stayed the same or not. We observed thus that 19 project ideas (in the reality of project leaders) were submitted between 1 and 3 times for labelling and (sometimes for) financing (see Table 42 at the end of chapter 8). In policy-driven cluster or cluster evaluation terms we thus did not observe 19 project ideas but 30 administrative projects. Table 26 summarizes the number of investigated units by level. In chapter 8 , we will discuss the idea finding processes for 19 project idea cases and the subsidies finding processes for 30 administrative project cases. Additionally, the ten project leaders told us about approximately 65 project partner initiations.

Table 26: Number of observation units

\begin{tabular}{|l|c|}
\hline & $\#$ \\
\hline Project leaders & 10 \\
\hline Number of projects: in project leader terms (=idea) & 19 \\
\hline Number of projects: in policy-driven cluster terms (=administrative) & 30 \\
\hline
\end{tabular}

\subsubsection{Quality measures}

In the data collection process it is important to look for construct validity and reliability (Gibbert, et al., 2008; Yin, 2013). Hereinafter we briefly discuss how we tried to assure both data collection quality measures.

\subsubsection{Construct validity: data triangulation and chain of evidence}

The first measure that is used to assure the quality of collected data is construct validity (Gibbert, et al., 2008; Yin, 2013). Construct validity is defined as the "quality of the conceptualization or operationalisation of the relevant concept" (Gibbert, et al., 2008, p. 1466) and "refers to the extent to which a study investigates what it claims to investigate". Our hypothesis is that implementing cluster policies produce organisational dilemmas that generate side-effect pathologies. When we started our fieldwork at HCPR we knew that the organisation was not functioning very well but the problem statement was not yet defined. In the beginning, we "just" wanted to observe how the organisation tries to foster innovation and 
collaboration. However, little by little we observed certain pathologies that where constantly repeating it. For example inefficiency due to conflicting points of view between the operational team and the governance team, inefficiency because of the difficulty to collaborate with other policy-driven clusters, distrust because of the subsidies associated to the policy-driven cluster. We observed these situations through the different actors we met on the field within HCPR, but also by interviewing other cluster managers in the region who told us their view on HCPR and also by conducting interviews with project leaders. These various views allowed us to see the problems from several perspectives. Additionally, we constantly talked with different people on the field but also with colleagues about our observations. During the monthly seminars we organised at Mines ParisTech (French cluster observatory) we were additionally able to confront our observations with the realities of other policydriven clusters (that were often functioning much better). This allowed us to effectively triangulate our data. Our fieldwork discussion (Chapter 7 and 8) will additionally clearly discuss our different data points and establish (at least we hope) a clear chain of evidence that explains how we came to our results discussed in Chapter 9.

\subsubsection{Reliability: Case study protocol and database}

The second measure that is used to assure the quality of the collected data is reliability. In order to increase reliability, Yin (2013) and Gibbert et al. (2008) argue to keep a case study protocol and a case study database. Reliability is assured when the researcher enables "subsequent researchers to arrive at same insights if they conduct the study along the same steps again” (Gibbert, et al., 2008, p. 1468). In order to do this one should respect "transparency" and allow "replication" (Gibbert, et al., 2008, p. 1468). At the beginning of this subsection we presented in a detailed and transparent manner how we collected our data. Additionally, we provide in Annex 6 the e-mail template we used to contact the project leaders and in Annex 7 the used interview guide. We also classified our data in a coherent manner on our computer and kept an excel file where we kept two excel files (one for the project leaders and one for HCPR) where we constantly added every new data source that we collected (indicating for example the date, the interviewed person, the observed situation, the received document). This will allow us to continue exploiting our data in the future. 


\subsection{Data analysis: internal validity}

Finally, the last point that is necessary to look at to assure the quality of a case study is internal validity. Internal validity is the "causal relationships between variables and results" (Gibbert, et al., 2008, p. 1466) and is particularly important to keep in mind when analysing the data. Internal validity can be improved by theory triangulation, pattern matching, and a clear research framework (Gibbert, et al., 2008). However, the problem is that we are conducting research in a nascent research field (Edmondson \& McManus, 2007). Normally, mature research fields have already established constructs and measures on which they heavily rely (Edmondson \& McManus, 2007). However, cluster policy research and the study of its implementation challenges is new (Burfitt \& Macneill, 2008; Ebbekink \& Lagendijk, 2013). In nascent research endeavours few formal measures exist and evidence of construct still needs to be established (Edmondson \& McManus, 2007). Our theoretical framework was only developed after our fieldwork took place because it was the fieldwork that allowed us to see the existent literature in another way. Our theoretical framework is thus also part of our results. However, this also bears the high risk that the theoretical framework is not stable yet and that further research is necessary to confront and test it in other settings. However, with the help of pattern identification (Edmondson \& McManus, 2007), the goal of data analysis in nascent research fields, we were able to triangulate our empirical data but also our SLR data. In our literature review we conducted a systematic literature review (SLR) (Denyer \& Neely, 2004; Pittaway, et al., 2004, p. 480) that allowed us to identify a range of dilemmas governments and those in charge of policy-driven clusters face when implementing cluster policy. Our fieldwork is an a-typical case that allows in a perfect manner to observe certain of the dilemmas discussed in the literature. In our discussion part we will come back to these different literature points in order to position our results in the light of the existing findings on the subject. 


\section{Chapter 5: Cluster policies in Europe: complexification and saturation}

This is the first of two context chapters (Chapter 5 and Chapter 6). In this chapter we first draw the general picture of cluster policy development in Europe. This will allow us to position our case study, the French cluster policy, in the current European cluster policy context. Then, in a second step we discuss the different French cluster policies and we will particularly focus on the difficult relationship between France's situation between centralisation and decentralisation where cluster policy has to be "lived".

\section{Box 7: Content of chapter five}

1 European Union and the saturation of cluster policies ........................................163

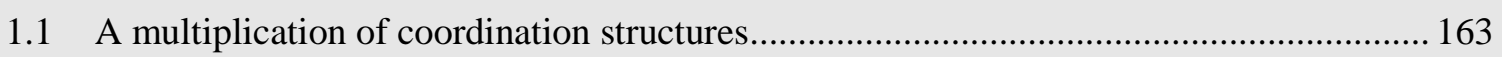

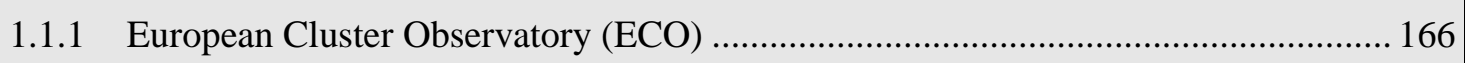

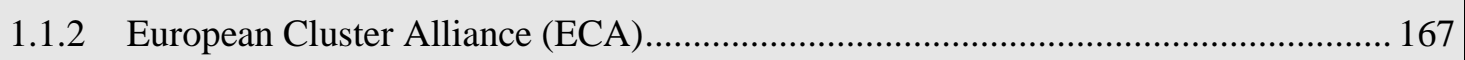

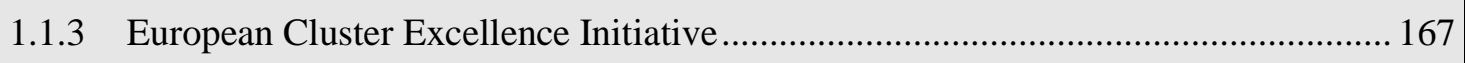

1.2 Towards a saturation of policy-driven clusters ......................................................... 169

2 France and cluster policies: traditions and renewal .............................................170

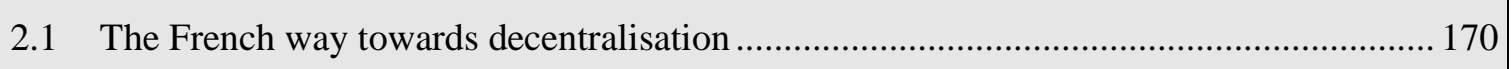

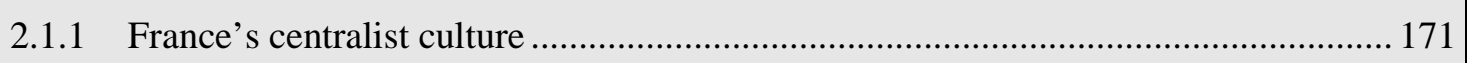

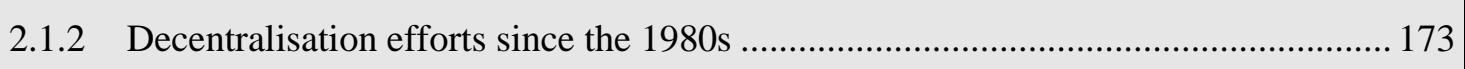

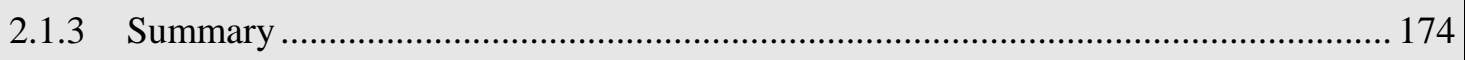

2.2 Between centralisation and decentralisation: living the cluster policy ............................ 174

2.2.1 National open calls for tender: Bottom-up or top-down initiatives? .......................... 176

2.2.2 Large variety of "regional system" initiatives ..................................................... 177 


\section{European Union and the saturation of cluster policies}

The European Union started to discuss the importance of policy-driven clusters in official documents during the 1990s and slowly integrated cluster policies in its main economic policy objectives during the 2000s. In the beginning it was a typical Porterian cluster mapping exercise, but little by little it developed to important policy-driven cluster management supports.

\subsection{A multiplication of coordination structures}

In the 1980s and 1990s, not only the United States were afraid about their national competitiveness also in Europe the fear to fall behind was (is) big. Annex 3 shows an excerpt of the opening words of a European Commission's White Paper ${ }^{122}$ entitled "Growth, competitiveness, employment. The challenges and ways forward into the 21st century" published in 1993. These hesitating opening words not to be able maybe to create enough jobs, are not much different than the opening words of Piore \& Sabel's (1984) book nearly one decade earlier, or the words we read in today's newspapers two decades later.

France, like other Western countries, started to struggle with its economy during the 1970s. Between 1958 and 1973 France still had an average GDP growth rate of 5.2, but this average GDP growth rate plunged to 2.2 between 1981 and 1992. Also when we look at the general GDP contribution to global growth we see that the contribution of European countries like Germany, France or Italy, was declining since the 1970s, while China's or India's contribution were on a constant rise (see Figure 19). The American contribution to global growth final plunged as well (from the millennium decade onwards), but much later than in the European countries.

\footnotetext{
${ }^{122}$ The European Commission regularly publishes two types of Papers: "Green Papers" and "White Papers". Both types of papers are important official documents for debates and proposals for actions within the European Union. The "Green Papers" are the "discussion documents to stimulate debate and consultations" whereas the "White Papers" are "concrete Commission proposals for EU action" (Source: http://ec.europa.eu/about/index_en.htm, accessed 15/05/2014)
} 
Figure 18: GDP growth rate in France 1950-1992

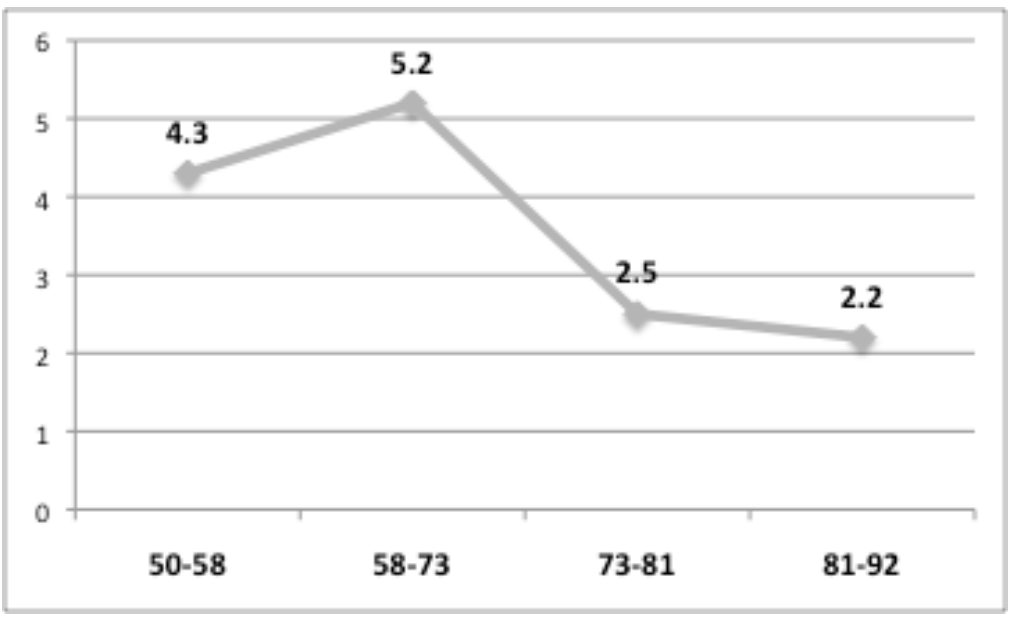

Source: based on data compiled by Crafts \& Toniolo (1996)

Figure 19: Contribution to global growth per country and decade (\%)

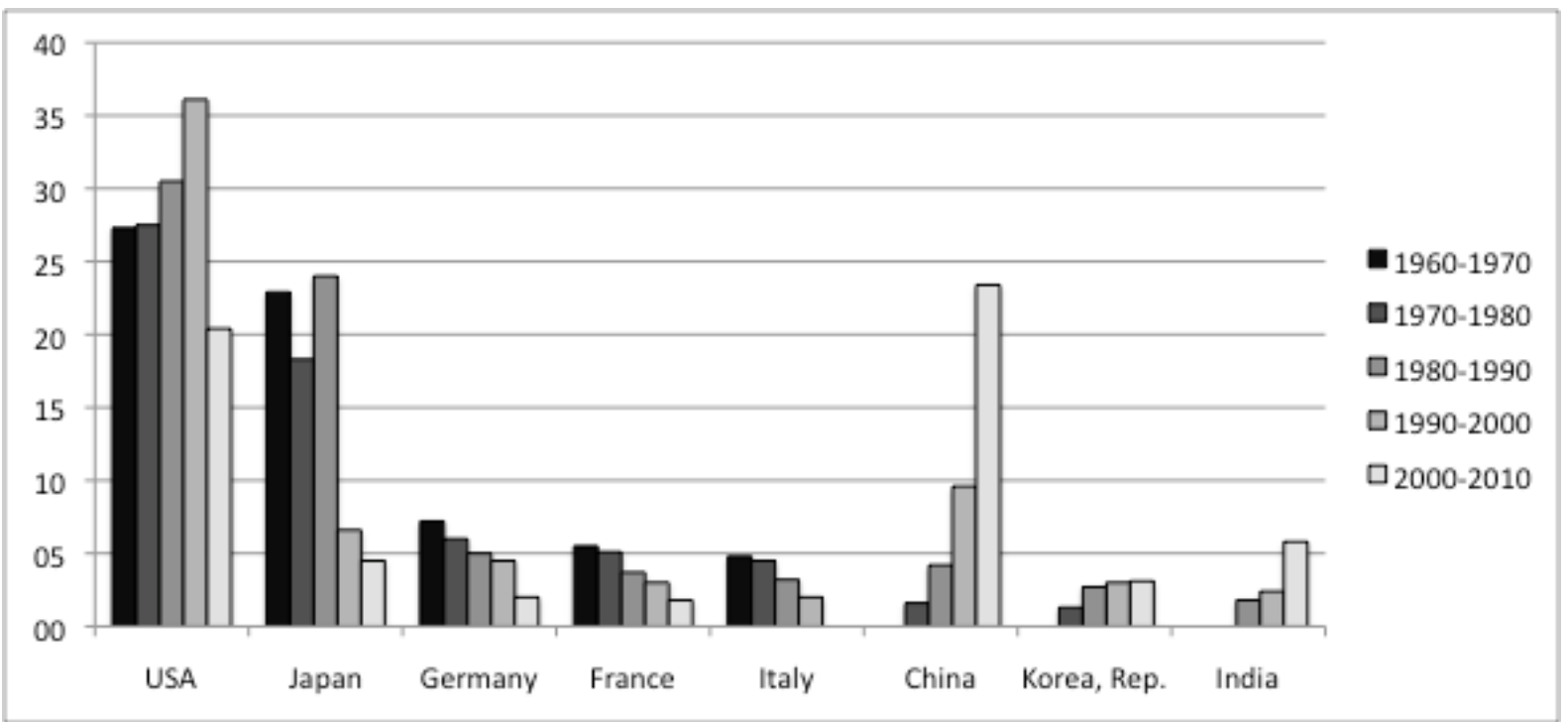

Source: based on data compiled by Yifu Lin \& Rosenblatt (2012) ${ }^{123}$

In June 1993, Jacques Dolores ${ }^{124}$ underlined that "the root cause of European unemployment was a lack of competitiveness with the United States and Japan and that the solution was a program of investment in infrastructure and high technology" (Krugman, 1994, p. 29). In order to strengthen the European competitiveness, the European Commission also recommended in a White Paper the development of policy-driven clusters:

"Better interaction between supply and demand must be strongly encouraged by [..]
stimulating the development of 'clusters' of competitive activities that draw on the regional
diversity of the Community. The proliferation within the Community of 'clusters' that combine
industrial, technological and geographical advantages may hold one of the keys to job

123 "Calculation is based on the change in constant dollar GDP (at market exchange rates) of the particular country as a share of the change in constant dollar GDP of the world." (Yifu Lin \& Rosenblatt, 2012, p. 14)

${ }^{124}$ The president of the European Commission between 1985 and 1995 
creation. This requires the active involvement of all the actors concerned, something which can be greatly facilitated by structural measures taken at Community and national level. In this area, [...], the main emphasis should be on a horizontal, transsectoral and multidisciplinary approach." (Commission of the European Communities, 1993, p. 65)

Focusing public policies on clusters slowly started to be considered as important in order to maybe overcome what is known as the "European Paradox" (European Commission, 1995). The European paradox is that even though the EU has an excellent scientific record, its "major weaknesses lies in its inferiority in terms of transforming the results of technological research and skills into innovations and competitive advantages" (European Commission, 1995, p. 5).

However, it was not until the end of the $20^{\text {th }}$ century that clusters and the fostering of policydriven clusters started to be integrated in the European Union policy discourse. It started with the Lisbon Strategy in 2000 and the objective to become "the most competitive and dynamic knowledge-based economy in the world" by developing "better policies for the information society and $R \& D^{\prime \prime 125}$. The ultimate objective was full employment in Europe until 2010. An objective largely missed, due to other macro economical events. This shows that it is difficult to predict an exact outcome in policy related fields.

Subsequently, the $6^{\text {th }}$ European Union Framework Programme ${ }^{126}$ (2002-2006) for Research and Technological Development (FP6) ${ }^{127}$ was particularly oriented towards contributing "to the creation of the European Research Area (ERA) by improving integration and coordination of research in Europe" which was considered as too fragmented at that time. One element of the FP6 was dedicated to a specific programme to structure the European Research Area; and one of the concrete actions within this programme was to overcome the European Paradox by "facilitating the creation of groupings or clusters of SMEs that have similar innovation needs" ${ }^{\prime 128}$.

\footnotetext{
${ }^{125}$ See Annex 3 for an excerpt of the "European Council" presidency conclusion held on the 23rd and 24th March 2000.

${ }^{126}$ The FP is the main instrument for funding research and development across different European countries. The objectives of the multiyear Framework Programmes of the European Union are to strengthen "the scientific and technological bases of industry and encourage its international competitiveness while promoting research activities in support of other EU policies." Within these general objectives concrete priorities are fixed and projects financed. (see: http://ec.europa.eu/research/fp6/pdf/fp6-in-brief_en.pdf ; accessed 01/06/2014)

${ }^{127}$ FP6 budget: 17.5 billion euros (2002-2006) (see: http://ec.europa.eu/research/fp6/pdf/fp6-in-brief_en.pdf ; accessed 01/06/2014)

${ }^{128}$ Source: "The Sixth Framework Programme in brief": http://ec.europa.eu/research/fp6/pdf/fp6-in-brief_en.pdf ; accessed 01/06/2014
} 
From 2006 onwards, policy-driven clusters definitely entered into the centre of the European Union's preoccupation. In 2006, the European Commission published an important framework communication $(\operatorname{COM}(2006) 502$ final) that puts "cluster policies" to advance innovations in Europe at the centre of its strategy recommendations (European Commission, 2006).

Not surprisingly, when the FP6 ended in 2006, the subsidies programmes that followed, the FP7 (2007-2013) ${ }^{129}$ and particularly the Competitiveness and Innovation Framework Programme (CIP) ${ }^{130}$ (2007-2013), were, among others, important funding sources to coordinate and advance research and initiatives to foster European policy-driven clusters. Hereinafter we shortly present, in a chronological order, a selection of important spontaneous and policy-driven cluster projects and initiatives.

\subsubsection{European Cluster Observatory (ECO) $)^{131}$}

In 2002, the Observatory of European SMEs ${ }^{132}$ already underlined in a report on clusters, that few mapping and monitoring practices of clusters (be it spontaneous or policy-driven clusters) are in place in the EU. Subsequently, Sölvell's Ivory Tower consultancy firm (in a certain manner the European Michel Porter) was asked in 2004 to map all clusters (regarding concentration and specialization) that are situated in the ten new EU member countries ${ }^{133}$. The final EU10 cluster mapping report (Ketels \& Sölvell, 2006) was based on an extended version of the Porter's cluster mapping methodology and gave the first complete picture of the geographic concentration and specialization of clusters in the EU10 countries. In 2006, the European Commission awarded an additional grant to Sölvell and its Center for Strategy and Competitiveness (CSC) at the Stockholm School of Economics (SSE) to extent its cluster mapping to all European countries. In 2007, a dedicated website was set up "The European cluster observatory" to make the mapping results and data publicly available. The focus of the

\footnotetext{
${ }^{129}$ FP7 budget: over 50 billion euros (2007-2013)

(see: http://ec.europa.eu/research/fp7/pdf/fp7-inbrief_en.pdf accessed 01/06/2014)

${ }^{130}$ CIP budget: 3.621 billion euros (2007-2013)

(see: http://europa.eu/legislation_summaries/information_society/strategies/n26104_en.htm accessed 01/06/2014)

${ }^{131}$ See: http://www.clusterobservatory.eu/index.html (accessed 01/06/2014)

132 "The Observatory of European SMEs was established by the Commission in December 1992 in order to improve monitoring of the economic performance of SMEs in Europe. Its task is to provide information on SMEs to policy-makers at the national and European level, researchers, SME organisations and to SMEs themselves." (European Commission, 2002, p. 5)

${ }^{133}$ EU enlargement 2004 (EU 10): Cyprus, Czech Republic, Estonia, Hungary, Latvia, Lithuania, Malta, Poland, Slovakia, and Slovenia
} 
mapping lies on classical economic indicators (e.g. employment rates, FDI, exports, and growth in numbers of firms). However, additionally the website also regroups other types of information like cluster scoreboards per country or policy-driven cluster organisation mappings. The objective of the ECO is to provide data on the framework conditions that shape regional competitiveness and to give an overview of European's spontaneous and policy-driven cluster landscape.

\subsubsection{European Cluster Alliance (ECA) ${ }^{134}$}

The ECA was launched in 2006 and is "an open platform established to maintain a permanent policy dialogue at EU level among national an regional public authorities responsible for developing cluster policies and managing or funding cluster programmes in their countries or regions. " 135 It is thus a platform that tries to give all those that are involved in conceiving cluster policies an exchange and learning environment. The platforms activities: regular workshops, expert reviews, case studies, best practice examples and recommendations regarding new policies and projects, etc. French members in this platform are for example the national policy-driven cluster coordination body "France Cluster", regional representatives from the Paris Region, the Greater Lyon Authority, the Provence-Alpes-Côte d'Azur Region, etc., but also financing bodies like OSEO. OSEO plays an important part in this network as it is one of the bodies that also subsidises the platform.

\subsubsection{European Cluster Excellence Initiative}

Sölvell et al. (2003) define cluster initiatives as "organised efforts to increase growth and competitiveness of clusters within a region, involving cluster firms, government and/or the research community". Cluster initiatives are thus the managerial part of cluster policies. What do policy-driven cluster managers have "to do" to reach the objectives fixed by the cluster policies (i.e. competitiveness and growth)? ${ }^{136}$

In 2003, Sölvell et al. (2003) conducted the first global cluster initiative survey addressed to the organisations in charge of "managing" the policy-driven clusters. In the foreword of Sölvell et al's (2003, p. 5) Cluster Initiative Greenbook, Michael Porter underlined that "surprisingly little systematic knowledge of these initiatives, their structure, and their

\footnotetext{
${ }^{134}$ See: http://www.eca-tactics.eu/ (accessed 01/06/2014)

135 See: http://www.eca-tactics.eu/ (accessed 01/06/2014)

${ }^{136}$ see also the Cluster Initiative Performance Model developed by Sölvell et al. (2003)
} 
outcomes" exist and that Sölvell et al's Greenbook is a "pioneering effort to fill this gap". The global cluster initiative survey revealed that the five most common objectives of these initiatives are heavily concentrated on networking and innovation: "(1) foster networks among people, (2) promote expansion of existing firms, (3) establish networks among firms, (4) facilitate higher innovativeness, (5) promote innovation, new technologies" (Sölvell, et al., 2003, p. 10). The strong concentration on innovation and networking is not surprising.

Besides Sölvell et al.'s (2003) Greenbook on cluster initiatives, several practitioners' manuals for policy-driven cluster manager emerged approximately at the same time (CLOE, 2006; Cluster Navigators Ltd., 2001; DTI, 2004; GTZ, 2007a, 2007b; Innovation America, 2007). For example the GTZ manuals (GTZ, 2007a, 2007b) read more like a pell-mell of different business school disciplines, focusing for example on how policy-driven cluster managers can set up business plans, conduct stakeholder analyses, or cluster marketing, than the preoccupation of the classical cluster disciplines of the 1980s and 1990s, like for example economic growth, regions and competitive advantage.

Besides the emergence of manuals, also cluster management courses were set up. In 1998, the first non-profit cluster organisation for cluster practitioners was founded: "The Competitiveness Institute" (TCI). The TCI is a "global network of cluster practitioners dedicated to facilitating the spread and success of cluster-based competitiveness initiatives through networking" ${ }^{\prime 37}$. Cluster Facilitator or Management Trainings were also proposed by private companies like "Cluster Navigators" (2001), business schools like IESE Business School in Spain (since 2006: "Clusters Summer School") ${ }^{138}$, think-tanks like France Cluster (since 2010: "Cycle Inter-Preneur") ${ }^{139}$ or successful cluster organisation themselves like Clusterland Austria (since 2008: "Cluster Academy") ${ }^{140}$.

Finally, in continuation of all these developments, the European Commission launched the "European Cluster Excellence Initiative" (ECEI) in 2009. The intention of the European cluster excellence initiative was "to develop training materials and set up an approach for quality labelling of cluster management, in order to help cluster managers achieve high levels

\footnotetext{
${ }_{137}$ source: http://www.tci-network.org (accessed on 12/12/2010)

138 source: http://www.iese.edu/en/events/OtrosEventos/BCSS2010/Introduction/Introduction.asp (accessed on 12/12/2010)

${ }_{139}$ source: http://www.franceclusters.fr/dossier.php?idpage=12 (accessed on 12/12/2010)

${ }^{140}$ source: http://www.clusterland.at (accessed on 12/12/2010)
} 
of excellence in their duties and to succeed in the peer-assessments." ${ }^{\text {141 }}$ The European cluster excellence initiative was thus a further step away from the initial mapping endeavours as proposed by the European cluster observatory towards a far more managerial approach of clusters. The ECEI, which was financed between 2009 and 2012:

- created a uniform set of cluster management quality indicators a quality labelling system for professional cluster management;

- developed a standardized set of training materials for cluster managers;

- set up the European Cluster Managers' Club for recognition of and exchange on professional cluster management;

- supported the development of the European Cluster Collaboration Platform (ECCP), a "LinkedIn" for cluster organisations and SMEs." 142

All these initiatives are now continued and further developed by different structures as for example the European Secretariat for Cluster Analysis (ESCA), the cluster competitiveness foundation, or the European Cluster Group (ECG).

\subsection{Towards a saturation of policy-driven clusters}

Before we turn to France and its cluster policies, we also need to mention the European Cluster Memorandum. All the developments we just described lead to a strong increase of policy-driven clusters in Europe. In $2007^{143}$, at the demand of the Council, the European Commission (more precisely the Directorate-General for Enterprise and Industry) prepared a report on all ongoing EU activities on clusters and gives an overview of cluster mapping and policies in Europe (European Commission, 2007). This report served for the establishment of a "European Cluster Memorandum" (The High Level Advisory Group on Clusters, 2008).

The European Cluster Memorandum, prepared by the High Level Advisory Group on Clusters ${ }^{144}$, was “addressed to all cluster policy stakeholders working at regional, national and EU level" with the objective to alert the European Commission "to reinforce their efforts

\footnotetext{
141 source: http://www.cluster-excellence.eu (accessed: 12/12/2010)

142 Source: Cluster excellence initiative (http://www.cluster-excellence.eu/fileadmin/_clusterexcellence/downloads/121009_Brochure_ECEI_EXIT_Strategy_dst.pdf ; accessed 15/06/2014)

${ }^{143}$ Following the European framework communication (COM(2006) 502 final) that put cluster policies at the center of the European innovation strategy.

${ }^{144}$ The High Level Advisory Group on clusters was chaired by Pierre Laffitte and composed out of a range of important economic company support structures (for example EUROCHAMBRES, Brussels Enterprise Agency, Competence Networks Germany) and policy advisors.
} 
and cooperation to better and faster respond to the new challenges that clusters are facing today in Europe." 145 According to the High Level Advisory Group on Clusters (2008, p. 8) "Europe needs better cluster policies rather than more cluster policies" and the objective of this memorandum was to contribute to this process by "providing clear orientation and support for translating this political commitment into real action throughout Europe”. One of the main recommendations was to support "the emergence and growth of world class clusters in Europe" (The High Level Advisory Group on Clusters, 2008, p. 8). This exclamation followed the creation of the European Cluster Policy Group (ECPG) in $2008^{146}$. The creation of the European Cluster Policy Group is thus an interesting turning point: a shift, away from an increasing number of different national cluster policies and initiatives in Europe towards a more collaborative and European promotion of some world-class policy-driven clusters. We can thus observe a first maturation and saturation stage of policy-driven clusters in Europe.

\section{France and cluster policies: traditions and renewal}

In this section we thus now dig deeper into how France tried to foster policy-driven clusters on its territory and tried to foster competitiveness and growth. France introduced its first national cluster policy in 1997 (SPL see Annex 5) and a second modified version in 2004 ("politique de pôles de compétitivité" - competitiveness cluster policy), the policy under review in this research. This development was in line with other European countries. For example the Styria Region (in Austria) introduced a cluster initiative in 1995 (Clement \& Welbich-Macek, 2007), the Basque Region (in Spain) introduced a cluster initiative in 1997 (Ahedo, 2004), and Wallonia (in Belgium) introduced a cluster initiative in 2001 (Lepage, 2009). Hereinafter, we present the large variety of "regional system" initiatives implemented on the French territory. However, before doing so, we have to shortly present the French general political functioning and its decentralisation efforts.

\subsection{The French way towards decentralisation}

For a long time France was considered to be a highly centralistic state, where the power is concentrated in the Paris Region. However, since the beginning of the 1980s this started to

\footnotetext{
${ }^{145}$ Source: http://www.rralur.si/en/koncani-projekti/clunet/cluster-memorandum/ (accessed 01/06/2014)

${ }^{146}$ Commission Decision (2008/824/EC) :

http://eur-lex.europa.eu/LexUriServ/LexUriServ.do?uri=OJ:L:2008:288:0007:0011:EN:PDF $15 / 06 / 2014)$ 
change. Hereinafter, we will first summarize the origin of France's centralist culture and then discuss the decentralisation efforts.

\subsubsection{France's centralist culture}

France has a centralistic culture, which is strongly visible and grounded in its history. In this section, we will not go back to De Tocqueville's (1856 (1988)) writings and we do not discuss in detail the "ancien régime" and absolute monarchy which lasted up to the French revolution. The only point that is important to keep in mind is that during the "ancien régime" the basis of a very centralistic State was already laid, centred around the different kings and rulers situated in the Paris Region. In this section, we will start our explanations with the conflicting tradition between Jacobin and Girondin movements that emerged during the French revolution (1789-1799) and the political consequences derived from this opposition because they are still visible today. In the end we draw the link with our main subject, the French cluster policy, as this policy crystallizes very well the difficult and conflicting relationship between Jacobin and Girondin tendencies in France.

Up to the French revolution, the Jacobin Club united the most influential names of the French revolution and thus the resistance against the ruling order. However, within the Jacobin Club two different streams of thought developed from 1792 onwards (Gévart, 2006). On the one hand, the Girondin movement ${ }^{147}$ who was afraid of a "Parisian" dictatorship and privileged a more federal system (and thus decentralist system) (Gévart, 2006). The Girondins were for a Republic of the citizen, organised on a local level, but with some sort of central control (Gévart, 2006). On the other hand, the Jacobin movement ${ }^{148}$ who was against war and for a strong unified and republican nation (and therefore centralist system) (Gévart, 2006): "In the Jacobin view, a weak state was a threat to freedom and the republican values ${ }^{149}$ that the nation expressed" (Larsen, 2005, p. 88). It was the Jacobin movement that imposed itself in the end and that prevailed officially up to 1982 (Gévart, 2006).

The "French centralist soul" is not only visible in the strong concentration of economic activity in the Paris Region but also in how the French government (situated in Paris) was and

\footnotetext{
${ }^{147}$ Three of the most influential chefs of the Girondin movement were deputies of the Grionde department (Gévart, 2006).

${ }^{148}$ The Jacobin movement kept the name "Jacobin" because this movement continued to meet regularly in the former offices of the Jacobin Club (Gévart, 2006).

${ }_{149}$ Republican values in France means against Monarchy and a strong State that unifies the country and all different communities.
} 
still is implementing and guiding its industrial policy. In 1946, France installed a "Commissariat général du Plan", an institution responsible for elaborating four-year indicative plans ${ }^{150}$ that allows the head of the government to "identify economic priorities and to focus the resources of the state on a few key sectors" (Thibault, 2008, p. 46). Additionally, the objective of these plans (in total X plans up to 1992) were "to guarantee the necessary industrial development but also national independence" (Thibault, 2008, p. 47). According to Jean Monnet, the director of the Commissariat, this "planification à la française" should be a place for "consultation and cooperation" (Thibault, 2008).

It was particular under Général de Gaulle (president from 1959 to 1969) that the State saw itself as the "captain of industry" with the plan in the centre of its preoccupations (Thibault, 2008). This "captain of industry” view of the State was particular visible in a speech Général de Gaulle gave in 1966 where he affirmed that: "The policy of France is not decided upon at the trading floor of the stock exchange" ${ }^{, 151}$ and that the State was defining the principal orientation and that the national industry has to follow (Thibault, 2008). Still today the State acts as the "captain of industry" as the recent example with Alstom ${ }^{152}$ shows.

In addition to the "captain of industry" view, the government of Général de Gaulle decided to create in 1963 the DATAR ("French Delegation for Territorial Development and Regional Action" ${ }^{153}$. The DATAR was created due to the observation of an increasing disequilibrium between Paris and the rest of France in terms of wealth and jobs. The DATAR should help to overcome this disequilibrium and by doing this, the delegation was meant to contribute to a better implementation of the general plan. The responsibilities of the DATAR were little by little extended away from only trying to delocalising jobs from urban to peripheral regions

\footnotetext{
${ }^{150}$ For an overview of the content of each of the plans developed by the "Commissariat général du Plan" see Thibault (2008, pp. 47-48)

${ }^{151}$ translation: "La politique de la France ne se fait pas à la corbeille"; Source of English translation: "The Routledge Dictionary of Cultural References in Modern French" by Michael Mould (2011)

${ }^{152}$ General Electric, a US company, wanted to acquire Alstom, a French company. The French government intervened to block the transaction. "French law permits government intervention to block acquisitions of companies deemed to be of national importance." See http://www.bloomberg.com/news/2014-06-20/france-totake-20-percent-stake-in-alstom-in-deal-with-ge.html (accessed 20/06/2014)

${ }^{153}$ The DATAR changed its name two times since its foundation:

1963-2005: DATAR: "Délégation à l'aménagement du territoire et à l'action régionale" - "French Delegation for Territorial Development and Regional Action"

2006-2009: DIACT: "Délégation interministérielle à l'aménagement et la compétitivité des territories" - "Interministerial delegation for regional planning and competitiveness"

since end of 2009: DATAR: "Délégation interministérielle à l'aménagement du territoire et à l'attractivité régionale" - "French Delegation for Territorial Development and Regional Attractivity"
} 
and towards being the contact person for the European commission to discuss the eligibility of French regions for the structural funds as well as being its administrator (Gévart, 2006).

\subsubsection{Decentralisation efforts since the $1980 \mathrm{~s}$}

The DATAR particularly gained in importance in 1982 (Thibault, 2008). In 1982, under the presidency of François Mitterrand (socialist party, president from 1981 to 1995), France passed several laws to pave the way away from a centralist system and towards a more decentralist, and thus Girondin system (Gévart, 2006). These laws paved the way for more regional autonomy and away from a pyramidal system where the central state is on the top and the subsequent entities (such as regions, departments, or municipality) have no power (Gévart, 2006).

Within this new and more decentralist structure the DATAR was responsible for putting in place the contractual arrangements between the central State and the regional authorities (Thibault, 2008). However, these decentralisation developments were also negative for the DATAR that, as a central State organ, was responsible for a national coherence. The multiplication of decision centers throughout the French territory and the decreasing budget allocated to the DATAR lead to its strong loss of power (Gévart, 2006). Some voices even wanted to suppress the delegation (Gévart, 2006). However, the DATAR survived and still operates today.

Additionally, the developments towards decentralisation at the beginning of the 1980s were also the advent of the end of the national industrial plan implemented by the Commissariat général du Plan. The last full plan was implemented between 1989 and 1992, and the plan that started in 1993 was finally abandoned (Thibault, 2008). However, compared to the DATAR that "survived" the decentralisation movements, the "Commissariat général du Plan" closed its doors in 2006. The State's decreasing focus on industry can even be observed when looking at the titles of the French industrial ministries (see Annex 4 for a list of all French minister titles since the beginning of the $5^{\text {th }}$ republic). Up to the middle of the 1990 s, the title of the ministers of industry always included the word "Industry". However, this changed radically from 1997 onwards, were economy and financed was put at the centre of the title. In 2012, economy and finance, lost against the word recovery. However, the word "industry" has either vanished or considerably decreased in importance (instead of being the first word of the title, it was pushed to the end). 


\subsubsection{Summary}

To summarize, also in France, the 1980s represented a period of profound changes that go hand in hand with the literature already discussed in this thesis. On the one hand, the French regions gained in importance during the 1980s, as the State forced itself by adopting new laws to give more power to the regions. On the other hand, the national industrial plan was finally abandoned. This is in line with the observed changing production system during the 1980s. A shift away from industrial policies and big vertically integrated companies, and towards more flexible and smaller innovative companies at a regional level. France, embedded in the global world, followed somehow the fashion of its decade, away from a policy favouring national champions at a national level and towards cluster support at the local level (Brette \& Chappoz, 2007).

\subsection{Between centralisation and decentralisation: living the cluster policy}

In the previous section we tried to explain to a maybe non-French reader of this thesis the French centralist culture but at the same time its decentralisation ambitions. In this section we will discuss the French policy-driven cluster supports. From the 1980s onwards, decentralisation took place regarding regional planning (Plunket \& Torre, 2009), but the centralist forces did not completely vanish.

The French cluster policies are built on this ambiguous relationship between centralisation and decentralisation, which render the whole French political system rather complex. The last French cluster policy evaluation report for example dedicated a whole chapter on the perceived complexity of the system (Erdyn, et al., 2012), also recent French PhD theses underlined this fact (Chabault, 2009; Lallemand, 2013), or a recent academic report dedicated to the French research and innovation policies and the regional R\&D attractiveness (Gallié, 2008).

Menu (2012, p. 831) for example says that it is "a mix of state dirigisme and local mobilizations". Additionally, Menu (2011, p. 106) concludes that these "new modes of governance" only have "limited effects". For Menu (2011, p. 106), who also has a deep knowledge of the German cluster policy system (particularly the Bavarian clusters), the French cluster policy has mainly been "a tool for the French Government for a new "mise en 
scène" of its role as a key actor in the industry”. This is heavily criticized by Menu (2011) who argues that research has already shown that a more local governance for clusters seems to be more efficient. However, there are some French regions which are highly active in structuring their regional innovation system on the local level, as for example Nord-Pas-deCalais (Malaterre-Vaille, 2010) or the PACA region (Scandella, 2008).

However, there are also opposing voices like Fixari \& Pallez (2014) who pledge not to have a too simplistic view regarding the complexity of the French cluster ecosystem. Fixari \& Pallez (2014) argue that yes there is an administrative complexity but maybe sometimes an additional layer of coordination might be preferable than a spontaneous simplification. They argue that the "administrative simplification, is a thinking .... that should become more complex" (Fixari \& Pallez, 2014, p. 27). Instead of just focusing on the sheer number of structures or appellation and criticizing their increase, new structures might also bring an amelioration for certain actors. All depends who is the observer of the system. Finally, Fixari \& Pallez (2014) argue that there is also just a "complexity feeling" because of the sheer cognitive difficulty to capture a highly systemic system. Even though the discussions of Fixari \& Pallez (2014) are highly interesting, there is nevertheless a big challenge to explain this system to a non-French audience in English without getting lost what French people themselves call the "mille-feuille administratif" 154.

Hereinafter, we first discuss the basic characteristics of the French policy-driven cluster initiatives. We particularly focus on the question if the French cluster policy is a bottom-up or top-down initiative (Fromhold-Eisebith \& Eisebith, 2005) and second we present the large variety of policy-driven initiatives implemented on the French territory.

\footnotetext{
${ }^{154}$ A "mille-feuille" is a famous French pastry composed out of several layers of puff pastry and pastry cream. Literal translated mille-feuille means thousand leaves. The term "mille-feuille administratif" makes an allusion to the manifold layers of public administration. This expression is deeply anchored in the consciousness of the French population and often mentioned in the newspapers. However, even though different prime ministers regularly formulate the wish to simplify this "mille-feuille administratif" (see for example recently the current prime minister Manuel Valls: http://www.francetvinfo.fr/politique/remaniement/gouvernement-valls/commentvalls-veut-simplifier-radicalement-le-millefeuille-territorial_572017.html , 08/04/2014), it seems that the consciousness of the problem and the reality of action does not convert. Without elaborating this topic further, but for me, Crozier's analysis of the French culture, might contribute in explaining the French incapacity of finding a solution to the "mille-feuille" problem. Crozier wrote his work 50 years ago, it would be interesting to do a similar study in the innovation age. This would also be a highly interesting avenue for further research.
} 


\subsubsection{National open calls for tender: Bottom-up or top-down initiatives?}

There are two important basic characteristics one has to understand before immersing into the policy-driven cluster initiatives implemented by the French State to foster clusters on its territory. On the one hand the French tradition of open calls for tender and on the other hand the importance of labels.

In order to mobilize the different actors on the French territory (be it for example training institutes, research institutes, companies, regional authorities, or trade unions) to join forces around a project to structure their own policy-driven cluster in their region, the State has since the 1990s adopted the tradition to regularly launch open calls for tender. These open calls for tender then mobilize the local actors around a specific project to structure ex nihilo, or in continuation of existing projects, the "regional systems". The specific objectives vary according to the tender, for example more oriented towards innovation, industrial production or regional development. In the rest of this section, we will thus not use the word policydriven cluster but just "regional system".

Once the deadline of the tender has passed and the project leaders of the potential "regional systems" have submitted their applications, the state (in the form of an expert committee) evaluates all the projects and decides if the project fulfils the necessary criteria set out in the tender. If yes, the State then attributes an official State label to this "regional system" project. First of all, the State label is important because it is perceived as a quality stamp. Second, having a label brings an increased visibility on the regional, national or international level. Finally, maybe the most important point, the label makes the "regional system" project eligible to a certain amount of State subsidies (either directly or through additional calls of tender where only the labelled projects can apply to).

These national calls for tender also raise an important theoretical question. For example Fromhold-Eisebith \& Eisebith (2005, p. 1256) analysed institutional forms of cluster promotions and separated these forms into roughly two opposing categories: (1) "top-down" clusters, organized and initiated by public authorities, and (2) "bottom-up" clusters, organized and initiated by "private industrial initiatives and organizations". To which category do the French "regional systems" initiatives count, knowing that they are created through open calls for tender where mobilized actors could apply to? 
For example, on the one hand, Lallemand (2013, p. 138), analysing the policy-driven cluster initiative launched by the French government in 2004 ("politique des pôles de compétitivité"), considers that this French initiative belongs to the "bottom-up" clusters. She justifies this point of view by arguing that the actors take a deliberate decision to submit the project to the State. This bottom-up opinion is also supported by Fontagné et al (2013, p. 898), who even underline that "the French competitiveness clusters policy can be said to be an archetypal modern industrial policy" as "projects emanate from the firms and the regions, within the framework defined by the calls for tender." For Fontagné et al (2013, p. 898) such an initiative can not be a top-down approach "whereby the public authorities decide everything”.

On the other hand, Berthinier-Poncet (2012, p. 68), also analysing the French policy-driven cluster initiative launched by the French government in 2004 ("politique des pôles de compétitivité"), argues that this initiative belongs to the "top-down" clusters as the State makes the necessary impulse and closely monitors the system. Also in one of our articles we argued that it is closer to a top-down initiative: "although French competitiveness clusters evolve in line with their own strategy, they are all embedded in a top-down national policy." (Gallié, et al., 2013b, p. 1660). However, our nuanced description of the French policy (Gallié, et al., 2013b), already implicitly underlined that the answer regarding French cluster policies is probably: "it depends", “it depends from which angle one looks at it". We will come back to this point in our discussion.

\subsubsection{Large variety of "regional system" initiatives}

France counts different types of "regional system" initiatives that are launched by open calls for tender at the State level since the 1990s. Hereinafter, we now list the main French examples of "regional system" policies and then classify them according to the main public policy actions they wish to cover. However, we not discuss them in detail and limit ourselves to just giving some main references.

For the "regional system" initiatives launched before the 1990s, the State did not launch open calls for tender, for example:

- the "Technopoles" initiative ("Technopoles") launched in the 1970s (Burnier \& Lacroix, 1996; Cooke, 2001; Longhi \& Quéré, 1993); 
- the "Business incubators" initiative ("Pépinières d'entreprise") launched in the 1980s (Benko, 1989);

- the "Regional Center of innovation and technology transfer" ("Centre régional d'innovation et de transfert de technologie" (CRITT)) launched in the beginning of the 1980s;

- the "Conversion Poles" initiative ("Pôle de conversion") launched in 1984 (Chappoz \& Poisat, 2000; Chautard \& Zuindeau, 2001; Tuppen \& Thompson, 1994);

However, from the 1990s onwards, in a more decentralist tendency, the State privileged one or several open calls for tender to decide which of the submitted "regional system" projects will receive the "label", for example:

- the "Local productive systems" initiative ("Systèmes productifs locaux" (SPL)) launched in 1997 (Grossetti, 2004; Guillaume, 2008; Pommier \& Boilève, 2002) ${ }^{155}$;

- the "Research and technological innovation networks" initiative ("Réseaux de recherche et d'innovation technologique" (RRIT)) launched in 1998 (Merlin, 2003; Ministère, 2002; OECD, 2004) $)^{156}$;

- the "competitiveness cluster" initiative ("Pôles de compétitivité") ${ }^{157}$ launched in 2004 (Duranton, Martin, \& Mayer, 2008; Jacquet \& Darmon, 2005; Retour, 2009c; T. Weil \& Fen Chong, 2008);

- the "Carnot institutes network" initiative ("Institut Carnot") ${ }^{158}$ launched in 2006 (Guinot, 2010) ${ }^{159}$, or

- the "Business cluster" initiative ("Grappes d'entreprises") ${ }^{160}$ launched in 2009 (DATAR, 2010, 2011)

In the beginning of this section we discussed the different traditional policies (regional, science and technology, industrial and enterprise policy) that now cumulate into just one type

\footnotetext{
${ }^{155}$ A productive local system (SPL) is a group of companies, mainly SMEs that put resources in common and develop synergies on a territory, to increase their economic efficiency (09/04/2010 : www.datar.gouv.fr). Annex 5 summarizes the SPL initiative and the differences with the "competitiveness cluster" initiative.

${ }_{156}$ See also: http://www.cnrs.fr/Cnrspresse/n402/html/n402loietmesures2.htm (accessed 30/06/2014)

${ }^{157}$ See the project website: http://competitivite.gouv.fr/ (accessed 30/06/2014)

${ }^{158}$ See the project website: http://www.instituts-carnot.eu/ (accessed 30/06/2014); or website of the national research agency: http://www.agence-nationale-recherche.fr/financer-votre-projet/impact-de-la-recherche-etcompetitivite/les-instituts-carnot/ (accessed 30/06/2014)

159 To gain a good general overview of the French efforts regarding regional development and regional innovation policies we can recommend following articles and reports: Tuppen \& Thompson (1994), Gallié (2008), the OECD (2010) and Godet (2010).

${ }^{160}$ See the project website: http://www.datar.gouv.fr/grappes-dentreprises (accessed 30/06/2014)
} 
of policy: cluster policies (OECD, 2007). Table 27 summarizes the just listed policies supporting the development of French "regional systems", and classifies them according to their main focus of public action. As we can see from Table 27, the "Competitiveness cluster" policy but also the "Business cluster" initiative are the most global policies as they cover all three types of public action. For France, it is the "Competitiveness cluster" initiative that is today the flagship of France's policy-driven cluster initiatives as it encompasses a more international orientation than the more local and smaller "business cluster" initiative. The "Competitiveness cluster" initiative launched in 2004 seems to answer simultaneously the entire fields necessary to support the innovation systems promoted by the Lisbon strategy and, more recently, by the EU 2020 strategy.

Table 27: Examples of policies supporting "regional systems" in France

\begin{tabular}{|c|c|c|c|c|}
\hline Launch & Different French policies & $\begin{array}{l}\text { Regional } \\
\text { policy }\end{array}$ & $\begin{array}{c}\text { Science and } \\
\text { technology } \\
\text { policy }\end{array}$ & $\begin{array}{c}\text { Industrial and } \\
\text { enterprise } \\
\text { policy }\end{array}$ \\
\hline $1970 \mathrm{~s}$ & $\begin{array}{l}\text { "Technopoles" } \\
\text { ("Technopoles") }\end{array}$ & $X$ & $\mathrm{X}$ & \\
\hline $1980 \mathrm{~s}$ & $\begin{array}{l}\text { "Business incubator" } \\
\text { ("Pépinières d'entreprise") }\end{array}$ & $\mathrm{X}$ & & $\mathrm{X}$ \\
\hline $1980 \mathrm{~s}$ & $\begin{array}{l}\text { "Regional Center of innovation and technology } \\
\text { transfer" } \\
\text { ("Centre régional d'innovation et de transfert de } \\
\text { technologie" (CRITT)) }\end{array}$ & & $\mathrm{X}$ & $\mathrm{X}$ \\
\hline 1984 & $\begin{array}{l}\text { "Conversion Poles" } \\
\text { ("Pôle de conversion") }\end{array}$ & $X$ & & \\
\hline 1998 & $\begin{array}{l}\text { "Local productive systems" } \\
\text { ("Systèmes productifs locaux" (SPL)) }\end{array}$ & $X$ & & $\mathrm{X}$ \\
\hline 1998 & $\begin{array}{l}\text { "Research and technological innovation } \\
\text { networks" } \\
\text { ("Réseaux de recherche et d'innovation } \\
\text { technologique" (RRIT)) }\end{array}$ & & $\mathrm{X}$ & $\mathrm{X}$ \\
\hline 2004 & $\begin{array}{l}\text { "Competitiveness cluster" } \\
\text { ("Pôles de compétitivitê") }\end{array}$ & $\mathbf{X}$ & $\mathbf{X}$ & $\mathbf{X}$ \\
\hline 2006 & $\begin{array}{l}\text { "Carnot institutes network" } \\
\text { ("Institut Carnot") }\end{array}$ & & $\mathrm{X}$ & $\mathrm{X}$ \\
\hline 2009 & $\begin{array}{l}\text { "Business cluster" } \\
\text { ("Grappes d'entreprises") }\end{array}$ & $X$ & $\mathrm{X}$ & $X$ \\
\hline
\end{tabular}

Source: inspired from Fen Chong (2009, p. 56) and further developed

French counts a multitude of different initiatives that try to structure its "regional systems". Therefore, it is also important to underline that little by little a strong juxtaposition of different initiatives emerged, particularly because previous initiatives are normally not abandoned but continue to exist in parallel to the new initiatives. This might show the strong wish of the French State not to abandon created local dynamics and to constantly improve its efforts to structure the "regional systems" located on its territory. However, passing from one 
type of "regional system" project to the next also creates problems of acceptance (Bardet, 2011) as little by little different initiatives juxtapose each other creating confusion of responsibilities between the different projects and incomprehension among the beneficiaries but also competition between the regional systems. Additionally, some regions (such as the PACA region), using their increased power thanks to the 1982 decentralisation laws, privilege to additionally also launch their own regional initiatives (Scandella, 2008). The French system can therefore be perceived as highly complex, even though, as already mentioned, the complexity always depends from which perspective one looks at it (Fixari \& Pallez, 2014).

However, there are some initiatives that try to reduce the complexity by ignoring the different types of policies and instead focusing on the main objective, namely helping those that manage "regional systems" to do their best. For example there is the "France Clusters" platform ${ }^{161}$ or the RETIS innovation association ${ }^{162}$ both supported by the State. For example "France Clusters" was previously called "French club of industrial districts" ("club français des districts industriels" (CDIF)). The club adopted its current name in 2009 to have a more international name. However, the club already exists since 1997. Today they have approximately 150 French "regional systems" as members (be it for example "Local productive systems", "Business clusters" or "competitiveness clusters"). "France Clusters" tries to be a platform of exchange, access to other "regional systems" (local and international), expertise and training for all French "regional system" managers on the French territory.

Additionally, in 2011, France Cluster also supported the creation of a French-German Master called "Management of clusters and regional networks" ("Animateur de cluster et de réseaux territoriaux" / "Management von Clustern und regionalen Netzwerken”), the first and only of this type in Europe ${ }^{163}$. This master, delivered by the University of Strasbourg and the Hochschule in Kehl further underlines the increasing professionalization of this sector.

\footnotetext{
${ }^{161}$ See the initiative's website: http://www.franceclusters.fr/ (accessed 20/06/2014).

162 See the initiative's website: http://www.retis-innovation.fr/ (accessed 20/06/2014). RETIS stands for "Recherche, Education, Territoires, Interventions, Sociabilités" and is the French national branch of the IASP that labels technopoles.

${ }^{163}$ See the Master's website: http://www.master-clustermanager.eu/ (accessed 20/06/2014)
} 


\section{Chapter 6: The case of the French "competitiveness cluster" policy}

In this chapter we now describe the case of the French "competitiveness cluster" policy and HCPR. We first describe the specificities of the French cluster policy, how it was set-up and implemented. Then we will turn to the one of the clusters that the cluster policy initiated: HCPR. The policy-driven cluster we investigated is situated in the Paris Region and more particularly specialized in biotechnologies \& health. We first focus on the particularity of the Paris Region's economic indicators, second we focus on the policy-driven clusters situated in the Paris Region, and finally on HCPR in particular. In doing so we lay the ground stone for our fieldwork analysis. As discussed in the literature review, the type of activity of the policydriven cluster (Coletti, 2010; McDonald, et al., 2007) but also its geographical location (Altenburg \& Meyer-Stamer, 1999; H. Bathelt \& Zeng, 2005; Doloreux \& Shearmur, 2009; Li \& Geng, 2012; Peters, 2005) are important characteristics that need to be discussed and presented to guarantee an external validity (Yin, 2013).

\section{Box 8: Content of chapter six}

1 The specificities of the French "competitiveness cluster" policy ...........................182

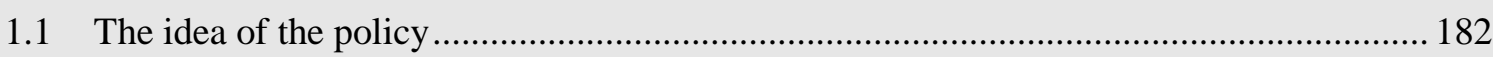

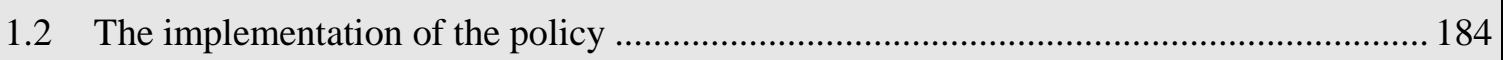

2 Policy-driven clusters in the Paris Region....................................................................194

2.1 The economic context of the Paris Region.................................................................... 195

2.2 Overview of the policy-driven clusters in the PR …...................................................... 201

3 Presentation of HealthCluster Paris Region ...........................................................203

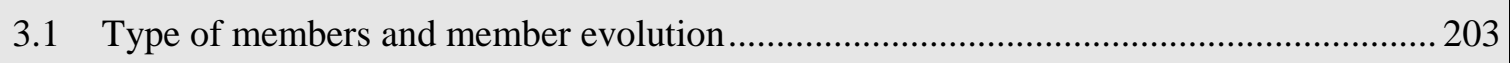

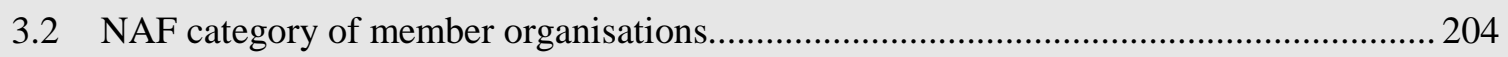

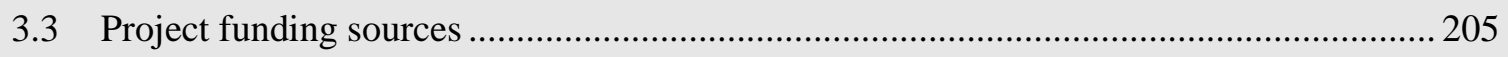

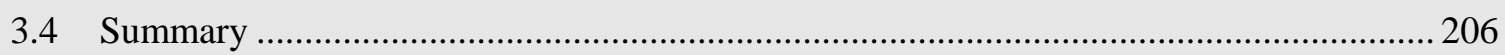




\section{The specificities of the French "competitiveness cluster" policy}

We first discuss the emergence of the cluster policy idea, then focus on the implementation of the policy and finally look at some emerging organisational dilemmas that can be observed.

\subsection{The idea of the policy}

As we have already seen, France's GDP growth rate (see Figure 18) as well as its contribution to global growth (see Figure 19) declined considerably during the 1980s and 1990s. In 2002, under these quite gloom macroenvironmental circumstances, the CIADT ${ }^{164}$ approved to launch new initiatives to revitalize the French territory (Younès, 2011). The French prime minister at that time (Mr Jean-Pierre Raffarin) decided to commission two reports: one with the DATAR (2004) and one with a parliamentarian called Christian Blanc ${ }^{165}$ (2004) to dig into the subject of economic and regional development. However, instead of being complementary to each other, the two reports defended two opposing opinions (Younès, 2011). Table 28 synthesises and opposes the two reports.

Initially, the two reports had two different objectives: to describe the French current situation (DATAR, 2004), and to review what is done in terms of fostering regional networks in other countries (Blanc, 2004). However, the two reports also gave recommendations what they considered should be done in France and here the opinions went in opposite direction: According to the DATAR (2004) the industry is the most important element for jobs, national wealth and competitiveness, but the industry is in difficulties (due to an increased global and European competition) and should be supported. The entities that play a central role in this process are the large companies, because only the large companies are able to create employment (and not the SME). Additional, the report considered important to foster networks in a Markusen (1996) "hub-and-spoke" style, this means fostering typical clientsupplier networks where a main company is surrounded by a multitude of SMEs. Finally, one main theoretical inspiration for the DATAR (2004) report was the new economic geography

\footnotetext{
${ }^{164}$ Interministerial Committee on Regional Planning and Development, this committee is responsible for national policy decisions ("Comité interministériel d'aménagement et de développement du territoire")

${ }^{165}$ Christian Blanc is a former chairman of RATP, Air France, and Merrill Lynch (Younès, 2011). Cohen (2007, p. 223) underlines that appointing important personalities is a recurrent tradition in France which also represents the French Jacobin mentality: "In France, a country stemming from the Jacobin tradition, problems of public action enter the national agenda after ritually designating prestigious personalities to write a report to the President".
} 
theory developed by Krugman (1991 (1993)), placing international trade and exports in the center for national job creation and growth. According to Christian Blanc (2004), innovation is the most important element for jobs, national wealth and competitiveness. Breakthrough innovations are not able to develop because there exists an old and inflexible regional organisation of actors, still inspired by Taylorism and not adapted to modernity. To turn the wheel around, Blanc (2004) recommends the fostering of proximity at the regional level in order to get the different actors to talk and work with each other. At the centre of Blanc's (2004) arguments stay the SMEs. The SMEs have to be supported because they have a higher regional anchorage than large companies. Additionally, networks between research and teaching institutes and SMEs have to be strengthened. The best way to strengthen these networks is to set up a governance and specific performance objectives. Finally, one main theoretical inspiration for Blanc (2004) was the competitive advantage and cluster theory of Porter (1990 (1998)).

Table 28: Two opposing views: the conflicting base of the French cluster policy

\begin{tabular}{|c|c|c|}
\hline & DATAR (2004) report & C. Blanc (2004) report \\
\hline $\begin{array}{l}\text { Main objective of } \\
\text { report }\end{array}$ & $\begin{array}{l}\text { Describing the French situation, } \\
\text { finding the reasons for the } \\
\text { deindustrialisation }\end{array}$ & $\begin{array}{l}\text { Describing what is done in other countries in } \\
\text { terms of fostering regional networks }\end{array}$ \\
\hline $\begin{array}{l}\text { Reason for gloom } \\
\text { economic situation } \\
\text { in France }\end{array}$ & $\begin{array}{l}\text { Globalisation and enlargement of } \\
\text { the European Union (increased } \\
\text { competition) }\end{array}$ & $\begin{array}{l}\text { Old and inflexible regional organisation of } \\
\text { actors, inspired by Taylorism and not adapted to } \\
\text { the modernity }\end{array}$ \\
\hline Main problems & $\begin{array}{l}\text { High location costs hinders } \\
\text { industrial development }\end{array}$ & $\begin{array}{l}\text { Higher education oriented towards engineering } \\
\text { and management; R\&D in the Paris Region and } \\
\text { production in the regions; lack of breakthrough } \\
\text { innovation }\end{array}$ \\
\hline $\begin{array}{l}\text { Key element for } \\
\text { jobs, national } \\
\text { wealth and } \\
\text { competitiveness }\end{array}$ & $\begin{array}{l}\text { Industry; exporting and conducting } \\
\text { foreign investments }\end{array}$ & $\begin{array}{l}\text { Innovation; fostering proximity and easy tacit } \\
\text { knowledge exchange; the regional level is the } \\
\text { best level for innovation }\end{array}$ \\
\hline Central role & $\begin{array}{l}\text { Large companies because they } \\
\text { create employment (compared to } \\
\text { SMEs) }\end{array}$ & $\begin{array}{l}\text { SMEs because they have a higher regional } \\
\text { anchorage (compared to the large companies) }\end{array}$ \\
\hline Network type & $\begin{array}{l}\text { Company networks; particularly } \\
\text { client-supplier networks; } \\
\text { implementing necessary financing } \\
\text { structure and infrastructure }\end{array}$ & $\begin{array}{l}\text { Networks between research and teaching } \\
\text { institutes and SME networks; set up of } \\
\text { structured networks with governance and } \\
\text { performance objectives }\end{array}$ \\
\hline $\begin{array}{l}\text { Centralist vs. } \\
\text { Decentralist }\end{array}$ & $\begin{array}{l}\text { Centralist: the State plays a major } \\
\text { role in organising the initiative; } \\
\text { administrative organisation is not } \\
\text { criticized }\end{array}$ & $\begin{array}{l}\text { Decentralist: Against the high centralisation in } \\
\text { France; delegation of specific State function to } \\
\text { the regional level to better manage the regional } \\
\text { economic actors; administrative organisation is } \\
\text { criticized }\end{array}$ \\
\hline $\begin{array}{l}\text { Theoretical } \\
\text { inspiration }\end{array}$ & $\begin{array}{l}\text { Inspired by the new economic } \\
\text { geography of Krugman (1991 } \\
\text { (1993)) }\end{array}$ & $\begin{array}{l}\text { Inspired by the competitive advantage and } \\
\text { cluster theory of Porter (1990 (1998)) }\end{array}$ \\
\hline
\end{tabular}

Source: Summary based on Younès's (2011, pp. 51-59) analysis

\footnotetext{
${ }^{166}$ Report is based on studies of different clusters in the United-States and other European countries.
} 
The government and the different ministries based their reflexions regarding the concrete terms and conditions of the planned French cluster policy on these two reports. Three ministries were particularly integrated in these reflections: the Ministry of Industry, the Ministry of Research and the Ministry of Regional Planning (Younès, 2011). However, the two opposing reports, created more opposing views when exposed to three different ministries (see Table 29).

Whereas the Ministry of Regional Planning put a great emphasis on maintaining a territorial equilibrium and also investing in regions that are less developed, the Ministry of Industry had the exact opposite view by emphasising the selection of national champions that are already known and that can be promoted rapidly on an international level. For the Ministry of Research, universities and research centres play a crucial role in regional and national growth, and therefore they should be put in the centre of any policy-driven cluster initiative.

The fuzziness of the cluster concept, allowed building a broad consensus among the different parties. Based on the two reports and the different views of the ministries, the French cluster policy ("politique de pôles de compétitivité”) was born in 2004.

Table 29: Three different ministries: the basis for conflicting interests

\begin{tabular}{|l|l|l|l|}
\hline Principal position & \multicolumn{1}{|c|}{ Ministry of Industry } & \multicolumn{1}{|c|}{ Ministry of Research } & \multicolumn{1}{|c|}{$\begin{array}{c}\text { Ministry of Regional } \\
\text { Planning }\end{array}$} \\
& $\begin{array}{l}\text { National champions, fight } \\
\text { against international } \\
\text { competition, support the } \\
\text { sectors and big } \\
\text { companies that are } \\
\text { already well positioned } \\
\text { internationally and which } \\
\text { are most important for } \\
\text { the Nation }\end{array}$ & $\begin{array}{l}\text { Innovative milieus, } \\
\text { universities and research } \\
\text { centres play the most } \\
\text { important role for } \\
\text { growth, regional } \\
\text { anchorage is important }\end{array}$ & $\begin{array}{l}\text { Territorial equilibrium } \\
\text { must be maintained, } \\
\text { SMEs in the center, } \\
\text { construction regional } \\
\text { networks, also structural } \\
\text { weak regions must be } \\
\text { supported (and not only } \\
\text { national champions) }\end{array}$ \\
\hline Closer to & DATAR (2004) report & C. Blanc (2004) report & $\begin{array}{l}\text { Both reports but closer to } \\
\text { C. Blanc (2004) }\end{array}$ \\
\hline
\end{tabular}

Source: Summary based on Younès's (2011, pp. 60-66) analysis

\subsection{The implementation of the policy}

In this section we focus on the set up of the policy. We will first present the set-up of the policy and then focus on several challenges regarding the liberty of policy-driven clusters vs. public authorities. 


\subsubsection{A centralised implementation...}

In a first step, we discuss the conditions of the national call for tender that grants the official policy-driven cluster label. In a second step, we discuss the main financial subsidies associated to this cluster policy label and to which the labelled policy-driven clusters can apply. Finally, in a third step, we focus on the governance structure of policy-driven clusters.

\subsubsection{Call for tender}

In 2004, the CIADT $^{167}$ published a press kit where it explained the new French cluster policy and announced a national call for tender regarding the implementation of policy-driven clusters - called "pôles de compétitivité" ("competitiveness clusters") - on the French territory (CIADT, 2004). The French cluster policy was conceived to be mainly built around subsidies for collaborative $R \& D$ projects that the future policy-driven cluster members could apply for. Additionally, each policy-driven cluster was meant to set up a governance structure.

The French policy-driven clusters should combine on "a given territory, companies, training centers and research units", all "committed to a partnership approach for synergies around innovative projects" (CIADT, 2004, p. 5). Additionally, they should have "the critical mass necessary for an international visibility" (CIADT, 2004, p. 5). Depending on the structure of the policy-driven cluster "the partnership [should] be organized around a market, a technological field or industry". This wide definition let all options open. On the one hand, "clusters dominated by technology, where research and development are preeminent" were invited to candidate, as well as "cluster[s] predominantly industrial, more structured by the density of production and commercialization" (CIADT, 2004, p. 5). The only thing which was important was that a potential policy-driven cluster applicant should be composed out of three types of actors - i.e. companies, training centers, and research units - and pursue three objectives - i.e. partnership, innovation, and international visibility (CIADT, 2004, p. 5). Additionally, the different actors of the policy-driven cluster should be concentrated "in the same region" (CIADT, 2004, p. 5).

Besides these central elements and the strong orientation towards innovation (following the ideas stipulated in the report of Blanc (2004) and thus influenced by Porter (1990 (1998))),

167 “Comité interministériel d'aménagement et de développement du territoire” 
the press kit (CIADT, 2004) showed that the different ministries privileged a broad consensus between the opinions of the various ministries. The announcement of the cluster policy left plenty of room of interpretation, targeting a very large number of heterogeneous actors situated on the whole French territory.

The first tender to apply for an official policy-driven cluster label was launched at the end of 2004. According to Jacquet and Darmon (2005, p. 77) (cited by (Chabault, 2009)) the submitted projects were evaluated according to following criteria:

- Targeted markets, growth perspective, competitive position of France

- Critical size of the retained technology, competitive advantage on the market or markets, coherence of the proposition

- Development strategy of the policy-driven cluster

- Accordance of training objective with development strategy

- Quality of the partnerships

- Stability of the planned governance, characteristics of the organisation

- Realistic nature of the R\&D projects, in line with the policy-driven cluster's strategy

105 potential policy-driven clusters applied ${ }^{168}$ to the first tender and in 2005 the first 67 selected policy-driven clusters were announced. At the end of the first phase France counted for 71 policy-driven clusters (see Figure 20). Instead of focusing on key sectors or key regions, the French policy opted to focus on a wide range of different sectors and to select one or several policy-driven clusters in nearly all of its 27 regions. For example, HealthCluster Paris Region (the policy-driven cluster we study in our empirical part) is one out of seven policy-driven clusters in the Paris Region and one out of seven policy-driven clusters specialised in the Biotechnology/Health sector in France. Finally, to prevent criticism to only be a regional development policy, the 71 clusters were categorised into three categories ( 7 world-class policy-driven clusters, 11 potentially world-class policy-driven clusters and 53 national policy-driven clusters). This allowed accentuating those policy-driven clusters having the critical mass and competence to succeed internationally.

The different policy-driven clusters covered the whole French territory and all possible industry sectors, reflecting the French industrial variety. The policy-driven clusters ranged

\footnotetext{
${ }^{168}$ Some applicants were already structured around the previous "local productive system" (SPL) initiative.
} 
from traditional industries such as textile, automobile, or wood to technologies such as nuclear or biotechnology. The common denominator of all these policy-driven clusters was to fulfil a range of different objectives, for example strengthening the industrial activities on the territory, increase the attractiveness and international visibility of France, develop employment in the local area, develop new partnerships thanks to subsidised R\&D projects, develop new innovations capable to succeed in a globalised market, or increase the competitiveness of the companies (Bardet, 2011; Chabault, 2009). The rules were the same for every type of policy-driven cluster.

The wish of the State that the policy-driven clusters reach a critical mass, lead to the fact that SMEs of all industries were accepted to join the policy-driven clusters nevertheless if they were active in R\&D or not (Bardet, 2011). However, another requirement of the state was that it is not enough to only have a certain number of local actors that join the policy-driven cluster; it was also asked that the policy-driven cluster members participate in the collaborative R\&D projects. Today, France counts its third policy-driven cluster phase (see Figure 20, the empirical fieldwork of this thesis is situated in the $2^{\text {nd }}$ phase). Once a new phase is approved, the state guarantees to continue financing the policy at least until the end of the newly announced phase (currently at least up to 2018). The first and second phase both ended with an official policy-driven cluster evaluation (see Annex 18 and Annex 19 for two articles on this topic). Figure 20 shows that the number of policy-driven clusters was not stable but evolved with time due to additional labels, mergers and loss of policy-driven cluster labels. Today, June 2014, France counts 71 official policy-driven clusters on its territory. 
Figure 20: Main milestones of the French cluster policy ${ }^{169}$

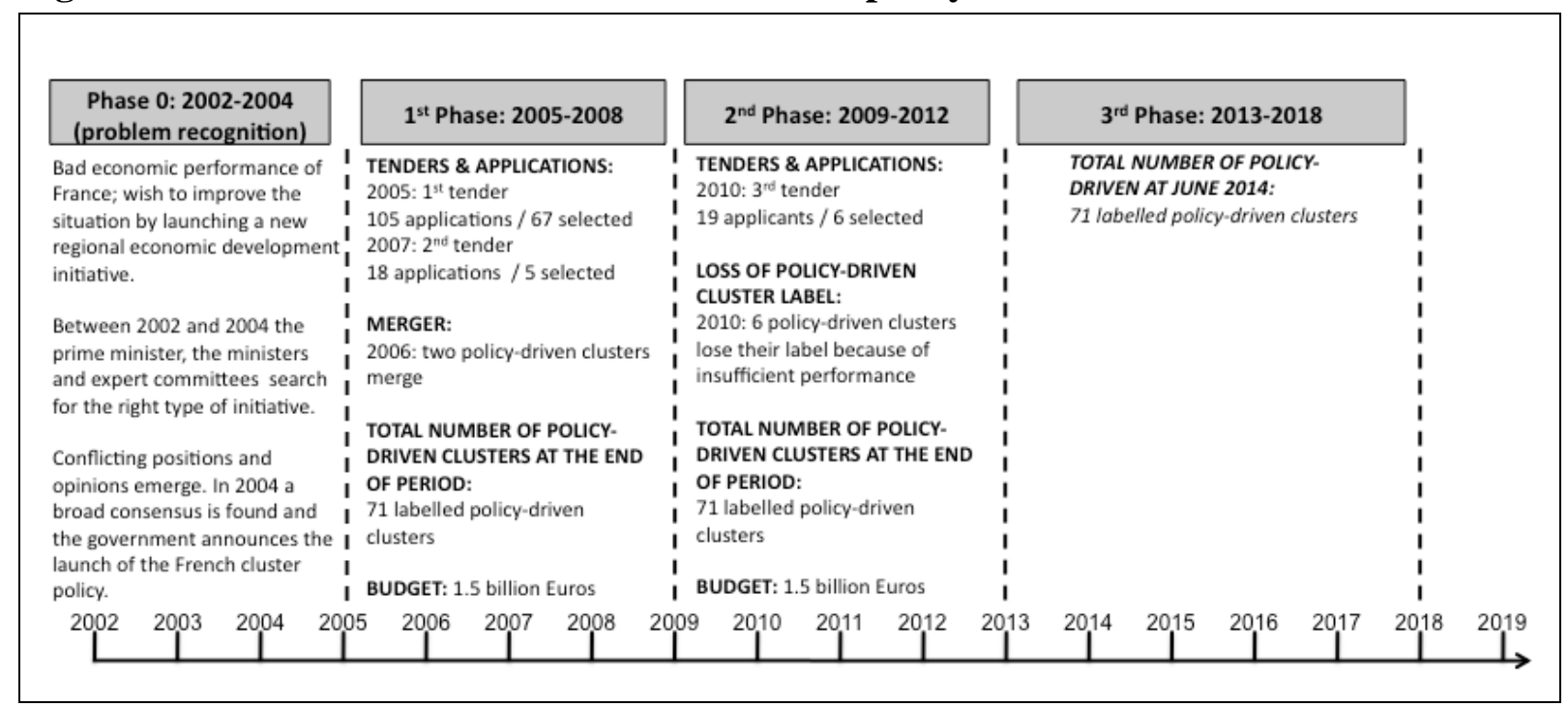

Source: own compilation but slightly inspired by Lallemand (2013, p. 140)

\subsubsection{Main financial subsidies}

The R\&D projects, around which the policy-driven cluster members should structure themselves, stand in the center of the French cluster policy. The policy-driven cluster members can apply for three different national subsidies. They can apply to the French National Research Agency (ANR), to the Unique Interministerial Fund (FUI) and to $\mathrm{OSEO}^{170}$. However, not only the national authorities subsidies the policy-driven cluster projects. For example, projects that are accepted by the FUI are then also co-financed by regional authorities. In case a project is not subsidised by a national fund, it can happen that the regional authority finances the project alone, particularly if the regional authority considers the project to be important for the local territory.

The three agencies (ANR, FUI, OSEO) distinguish themselves regarding which projects they except to subsidies. The funding from the French National Research Agency (ANR) finances research projects based on partnerships between public and private actors, or more rarely, just between public laboratories. The aim of the ANR is to fund exploratory research projects that focus on developing new knowledge, meaning they are relatively distant from the market. ANR selects projects based on criteria of scientific excellence and then grants a "policy-driven cluster bonus" to the projects selected that have been accredited by a policy-

\footnotetext{
169 The date of the "Tenders \& Applications" section corresponds to the announcement of the selected candidate. The tender itself was often launched in the previous year.

${ }^{170}$ Today called Bpifrance
} 
driven cluster, indicating that the project is in line with the policy-driven cluster's strategy. The budgets of the projects are generally not higher than 4 million Euros.

OSEO on the other hand supports innovation and economic development of French SMEs, whether they are members of a policy-driven cluster or not. There are various types of aid for SMEs (e.g. technological transfer, funding for commercializing a new product). The budget of the OSEO projects is general not higher than 3 million Euros.

Finally, the Unique Interministerial Fund (FUI) is a one-stop shop that grants funding to joint research projects coming exclusively from policy-driven cluster projects. The FUI is thus the main funding entity for the policy-driven clusters. The fund brings together contributions from all ministries. To be eligible, projects must involve at least a minimum of two companies and a research laboratory. The projects financed must relate to innovations relatively close to the market. Local authorities can co-fund joint research projects funded by the FUI. The fund was set up in 2006 and issues regular project calls (most of the time twice a year). The financial subsidies do not go above $30 \%$ of the total budget (ranging from 1 to 10 million Euros) and are of $45 \%$ for SMEs situated in the R\&D zone of the policy-driven cluster.

In order to be eligible to apply to the main policy-driven cluster subsidies fund (FUI), projects have to reply to the national project calls and meet several criteria of which the most important are:

- Policy-driven cluster label. The submitted projects need at least one policy-driven cluster label from one of the 71 policy-driven cluster organisations. This policy-driven cluster label states that the quality of the project was officially recognised by one of the policy-driven clusters.

- Collaborative $R \& D$ projects. To be eligible, projects must involve at least a minimum of two companies and a private or public research laboratory/institute or training institute.

- Innovation. The projects financed must relate to innovations relatively close to the market and should develop one or several products / services with a strong innovative content. 
- Economic impact. The projects should have an impact on the national territory in terms of employment, investment, sector development or economic change anticipation.

- Geographical proximity. The project should be composed out of companies conducting R\&D primarily in the territory of the policy-driven cluster that attributed the label. Companies of the research consortium that are situated outside the defined policy-driven cluster perimeter (of the policy-driven cluster that attributed the label) are not eligible to the highest percentage of subsidies.

Additionally to the three main financing funds (OSEO, ANR and FUI), the "Caisse des dépôts et consignations" (CDC) (short "Caisse des dépôts" or in English "Deposits and Consignments Fund") brings an additional support to the policy-driven clusters. This happened particularly during the second policy phase (2009-2012) (Chabault, 2009). The CDC is an old government institution not necessarily oriented towards research but generally towards helping French companies and territories. For example three of the CDC programmes were oriented towards the policy-driven clusters (Bardet, 2011): strengthening the funds of the companies that participate in the policy-driven cluster, developing high speed internet on the whole French territory (together with the regional authorities), helping with real estate for companies and apartments for researchers to balance the urban-rural equilibrium.

To sum up, the French cluster policy, accompanied by the FUI and the other national funds, is responsible for accelerating the clustering process in a defined geographic area where maybe no collaboration or only a weak collaboration culture previously existed. The clustering process should be mainly advanced through collaborative R\&D projects.

\subsubsection{Governance structure}

Generally, the governance structure ${ }^{171}$ of a French policy-driven cluster can be split into two broad categories: strategic governance (comprising the supervisory board and the board of directors) and operational governance (comprising the management committee) (Bocquet \& Mothe, 2009).

\footnotetext{
${ }^{171}$ A more detailed discussion of the gouevrnance of French policy-driven clusters can be found in our paper entitled "Governance Structures as Determinants of Resource Attraction? Evidence from French Clusters" (A. Glaser, et al., 2012) (see Annex 20)
} 
The strategic governance is generally composed of the (1) supervisory board and the (2) board of directors. On the one hand, the supervisory board normally consists of different colleges (i.e. SMEs, large groups, research and/or training institutes or support entities), which meet a few times a year. The objective of the supervisory board ranges for example from deciding on the general strategic orientation of the policy-driven cluster, to nominating and supervising the board of directors, and to establishing links with the larger environment of the policy-driven cluster (e.g. other policy-driven clusters, institutions). On the other hand, the board of directors is composed of representatives of the supervisory board and the management committee. The board of directors watches if the general policy-driven cluster orientation, defined by the supervisory board, is correctly implemented by the management committee. Additionally, the board of directors for example raises new future oriented questions for the well functioning and development of the association. Each of the 71 French policy-driven clusters is steered by a different proportion of small and large companies, research and/or training institutes as well as support entities (e.g. local development agencies).

The operational governance (or management committee) is responsible for the operational day-to-day activities of the policy-driven cluster. There are three different options of who this management committee can be: either the activities are assured by a permanent team, or by local authorities, or by employees from large companies. Most of the French policy-driven clusters registered as an association with a permanent team. The objective of this management committee is for example to enhance new partnerships between local actors, build strategic collaborative research and development projects, and promote an overall environment conducive for policy-driven cluster members in general and for innovation in particular. One important element of their day-to-day operations is to help local actors to set up their research projects, help with the writing of the projects, to label the most promising projects, to help presenting the projects to the national financial authorities and to guarantee a follow up.

\subsection{2 ...that generates emerging organisational dilemmas}

Now we focus on the dependences between policy-driven clusters and governments. In total, for the time being we identified four strong dependences between policy-driven clusters and governments (see Table 30 for a summary). 


\subsubsection{State influence on the composition of the governance}

The first dependence concerns the state influence on the composition of the governance. The state, even though defining the general objectives and conditions (Jacquet \& Darmon, 2005, p. 77), decided not to intervene on the legal status of the policy-driven clusters. In order to be considered as an official policy-driven cluster (and thus receive the official label), the state just had to be convinced that there will be a stability of the planned governance and that this governance will help the regional actors reach the stipulated goals (particularly in fostering R\&D collaborations on the policy-driven cluster territory). Most of the potential policy-driven clusters opted for the status of a non-profit association. However, even though the sate did not intervene regarding the legal status of the policy-driven cluster, it did precise who should be involved in its governance. The official CIADT definition (CIADT, 2004) stipulates that companies (be it SMEs or large companies), training centers and research units should be the main actors of the policy-driven clusters. Therefore, all of these parties should be responsible for organizing in an equal and tripartite manner the policy-driven cluster's governance. All parties had to sign a framework contract with the state that specifies exactly this governance structure, the economic development strategy and the policy-driven cluster's R\&D zone.

\subsubsection{Role of the regional authorities in the governance structure}

The second dependence concerns the role of the regional authorities in the governance structure. Even though the companies, training centers and research units should distribute the governance among themselves and independently from national and regional authorities (Jacquet \& Darmon, 2005), the regional authorities de facto also play a major role in the functioning of the policy-driven clusters. Some regional authorities were strongly active in the set up of some of the policy-driven clusters, before they were submitted for labelling to the national tender. On the one hand, the regional authorities were involved because they wanted to guarantee a fit between the strategy of the policy-driven cluster and the strategy of the region (Bardet, 2011). On the other hand, the regional authorities are involved because they, such as the state, are responsible for financially supporting the policy-driven clusters. However, the fact that regional authorities are actually involved in the governance of the policy-driven clusters also led to considerable tensions (Chabault, 2009) as we will see with next point. 


\subsubsection{Conflicting opinions around the set up of the $R \& D$ zone}

The third dependences focuses on the conflicting opinions around the set up of the R\&D zone. Defining a policy-driven cluster's R\&D zone is a particular important element of the policy. Only those companies that are situated within a policy-driven cluster's R\&D zone are eligible to certain tax advantages and higher subsidies when applying for research funds with the national agencies. The main problem was though that regional authorities continued to think in administrative regional terms and industrials in excellence terms. For industrials it was important to set up well functioning policy-driven clusters including the most interesting and promising companies and research institutes in a certain domain. Industrials were not thinking in administrative regional terms but in excellence terms. The consequence was that the regional authorities did not always accept the proposed $R \& D$ zones of the industrials. The best R\&D zones for the industrials (sometimes spanning over several administrative regions) were not always the best $\mathrm{R} \& \mathrm{D}$ zones for the regional authorities (keen on respecting the administrative layers and boundaries). However, the problem was that the policy-driven clusters had to sign a framework contract with the regional and national authorities. The R\&D zone quarrels sometimes lead regional authorities to refuse to sign the "framework contract" and intensive negotiations with all parties were necessary in order to find a solution (Chabault, 2009).

\subsubsection{Financial resources are dependent on national authorities}

Even though the management committee has to assure the functioning of the cluster, its financial resources are quite scarce and strongly depended on national authorities. In total, the French government has spent three billion Euros for its cluster policy between 2005 and 2012 . However, only a small portion (3.3\%), reinforced by membership fees and local authorities, was used for the functioning of the policy-driven cluster, while the main portion (96.7\%) was dedicated to specific projects (R\&D projects, innovation platforms, or collective actions covering very different themes). The State preferred to invest relatively little into the structure and to reserve most of the money for R\&D projects. However, this does not mean that each policy-driven cluster is eligible to the same amount of research money or eligible the same number of R\&D projects. Subsidies for the projects are mostly distributed through official national calls for tender. Every policy-driven cluster has to motivate its members to submit potential R\&D projects. In a first step to the policy-driven cluster which scrutinizes the projects and if the scientific committees of each policy-driven cluster considers that the 
project might have a chance to get financial subsidies from the state, it attributes an official policy-driven cluster label to the project. The labelled projects can then, in a second step, be submitted to the national financial agencies (FUI, ANR, OSEO). The state did not allocate to each policy-driven cluster a certain amount of money that can then be used independently by the policy-driven cluster, either for structuring the ecosystem or financing research. The decision of granting financing to a particularly project is thus not situated with the policydriven cluster but with the national financial authorities. The policy-driven cluster continues to stay in a strong permanent dependence with the national authorities.

\subsubsection{Summary}

Based on secondary literature, we identified four dependences between policy-driven clusters and governments: regarding the composition of the governance, regarding the strong role of the regional authorities, regarding the set up of the R\&D zone, and regarding the financial resources (see Table 30).

Table 30: First dependences observations

\begin{tabular}{|l|l|l|}
\hline $\begin{array}{l}\text { Composition of the } \\
\text { governance }\end{array}$ & $\begin{array}{l}\text { Theoretically } \\
\text { State does not intervene regarding the legal } \\
\text { status of the policy-driven cluster }\end{array}$ & $\begin{array}{l}\text { But... } \\
\text { (be it SMEs or large companies), training } \\
\text { centers and research units should be } \\
\text { responsible for organizing in an equal and } \\
\text { tripartite manner the governance }\end{array}$ \\
\hline $\begin{array}{l}\text { Strong role of the } \\
\text { regional } \\
\text { authorities }\end{array}$ & $\begin{array}{l}\text { State underlines that the governance } \\
\text { should be independent from national and } \\
\text { regional authorities }\end{array}$ & $\begin{array}{l}\text { But de facto regional authorities play a } \\
\text { major role because of regional strategy } \\
\text { and financial subsidies reasons }\end{array}$ \\
\hline $\begin{array}{l}\text { Set up of the R\&D } \\
\text { zone }\end{array}$ & $\begin{array}{l}\text { The policy-driven cluster's R\&D zone } \\
\text { should reflect in the best possible manner } \\
\text { the most important actors of a certain } \\
\text { territory }\end{array}$ & $\begin{array}{l}\text { But de facto regional administrative } \\
\text { boundaries were difficult to overcome }\end{array}$ \\
\hline $\begin{array}{l}\text { Financial } \\
\text { resources }\end{array}$ & $\begin{array}{l}\text { Local governance has to structure the local } \\
\text { ecosystem }\end{array}$ & $\begin{array}{l}\text { But the state keeps the financial resources } \\
\text { tied to the national level }\end{array}$ \\
\hline
\end{tabular}

\section{Policy-driven clusters in the Paris Region}

We now focus on the policy-driven clusters in the Paris Region. We first discuss the Paris Region and its economic context, before looking at statistical indicators of the policy-driven clusters that are situated in the Region. 


\subsection{The economic context of the Paris Region}

In this section we first focus on the position of the Paris Region in France and then compare the Paris Region to nine other important core Regions Europe. This comparison will show us that the Paris Region is the economic and scientific hub of France but has a dangerous "stuck in the middle position" compared to London and Baden-Württemberg.

\subsubsection{A leading position in France}

The Paris Region is the economic and scientific hub of France. The Paris Region (in French: "île-de-France", regional code 75) is one out of 27 French Regions ${ }^{172}$. Table 31 presents some key figures of the Paris Region and the share the Region accounts for in France.

The population in the Paris Region is younger than the French average due to the high amount of higher education and research institutes situated in the Region. The education level is also much higher than in the rest of France as $40 \%$ of the Paris Region population has a higher education degree compared to only $29 \%$ on the whole French territory. Approximately 1/4 of the French jobs are situated in the Region, which produces $31 \%$ of the French GDP. The Region is also a hub for $R \& D$ as $1 / 3$ of the French $R \& D$ workforce is situated in the Region and $41 \%$ of the French R\&D money is spend there.

\footnotetext{
${ }^{172}$ In 2014, France counts 27 administrative regions. 22 regions are situated in Metropolitan France (Corse included) and 5 regions are situated in oversee.
} 
Table 31: Paris Region's key figures and the share it accounts for in France

\begin{tabular}{|c|c|c|c|}
\hline & Paris Region & France & Year \\
\hline Population & 11915000 & $18.2 \%$ & 2012 \\
\hline Age $0-29 *$ & $30.0 \%$ & $27.0 \%$ & 2012 \\
\hline Age 25-39* & $20.0 \%$ & $16.0 \%$ & 2012 \\
\hline Age 40-69* & $32.0 \%$ & $33.0 \%$ & 2012 \\
\hline Age 70 and over* & $18.0 \%$ & $34.0 \%$ & 2012 \\
\hline Higher education level among the 25-64 years* & $40.0 \%$ & $29.0 \%$ & 2010 \\
\hline C & na & $23.0 \%$ & 2012 \\
\hline GDP (€ million) & 607439 & $31.0 \%$ & 2011 \\
\hline GDP per capita & $€ 51118$ & na & 2011 \\
\hline R\&D workforce (including researchers) & 150000 & $37.0 \%$ & 2011 \\
\hline Researchers & 100000 & $40.0 \%$ & 2011 \\
\hline R\&D expenditure ( $€$ billion) & 18.4 & $41.0 \%$ & 2011 \\
\hline Exports (€ billion) & 78 & $18.0 \%$ & 2012 \\
\hline Imports (€ billion) & 134 & $26.0 \%$ & 2012 \\
\hline
\end{tabular}

* Comparison of the Paris Region with France

** EU27 data

Source: Data assembled from two reports: "Paris Region Key Figures 2014" Report ${ }^{173}$ \& CROCIS (2011)

\subsubsection{A comparison to other high performing European regions}

The Paris Region, compared to the rest of France, is definitely in an excellent position. Therefore, it seems more interesting to compare the Pairs Region to other high-performing regions in Europe.

In order to improve the statistical comparability of European regions, Eurostat ${ }^{174}$ has created the NUTS (Nomenclature of territorial units for statistics) classification ${ }^{175}$. The NUTS classification has three levels NUTS 1 ("major socio-economic regions"), NUTS 2 ("basic regions for the application of regional policies") and NUTS 3 ("small regions for specific diagnoses”). The Paris Region (Ile-de-France) is a NUTS 1 region. In total, Eurostat has currently defined 97 regions at the NUTS 1 level. Hereinafter we will compare the 10 richest (GDP 2008) NUTS 1 regions in Europe (see Figure 21) on several indicators as for example R\&D, GDP, Patents, etc. We retrieved the Eurostat data from the CROCIS (2011) report ${ }^{176}$. In general, London, Baden Württemberg and Bayern are the three regions, which are the most

173 The report "Paris Region Key Figures 2014" can be accessed here: http://www.parisregion.com/sites/default/files/key-figures-bd.pdf (accessed 03/06/2014)

174 Eurostat is the statistical office of the European Union situated in Luxembourg. (website: http://epp.eurostat.ec.europa.eu/ )

${ }^{175}$ Eurostat defines the NUTS classification as "a hierarchical system for dividing up the economic territory of the EU for the purpose of": (1) "the collection, development and harmonisation of EU regional statistics", (2) "Socio-economic analyses of the regions", (3) "Framing of EU regional policies". (source: http://epp.eurostat.ec.europa.eu/, accessed 03/06/2014)

${ }_{176}$ CROCIS = "Centre régional d'observation du commerce de l'industrie et des services" est un centre d'observation de la chambre de commerce et d'industrie de Paris. 
interesting to look at in order to compare and challenge the Paris Region. We will first concentrate on the London region and then on the two German regions.

Figure 21: The 10 richest NUTS 1 Regions in Europe in 2008

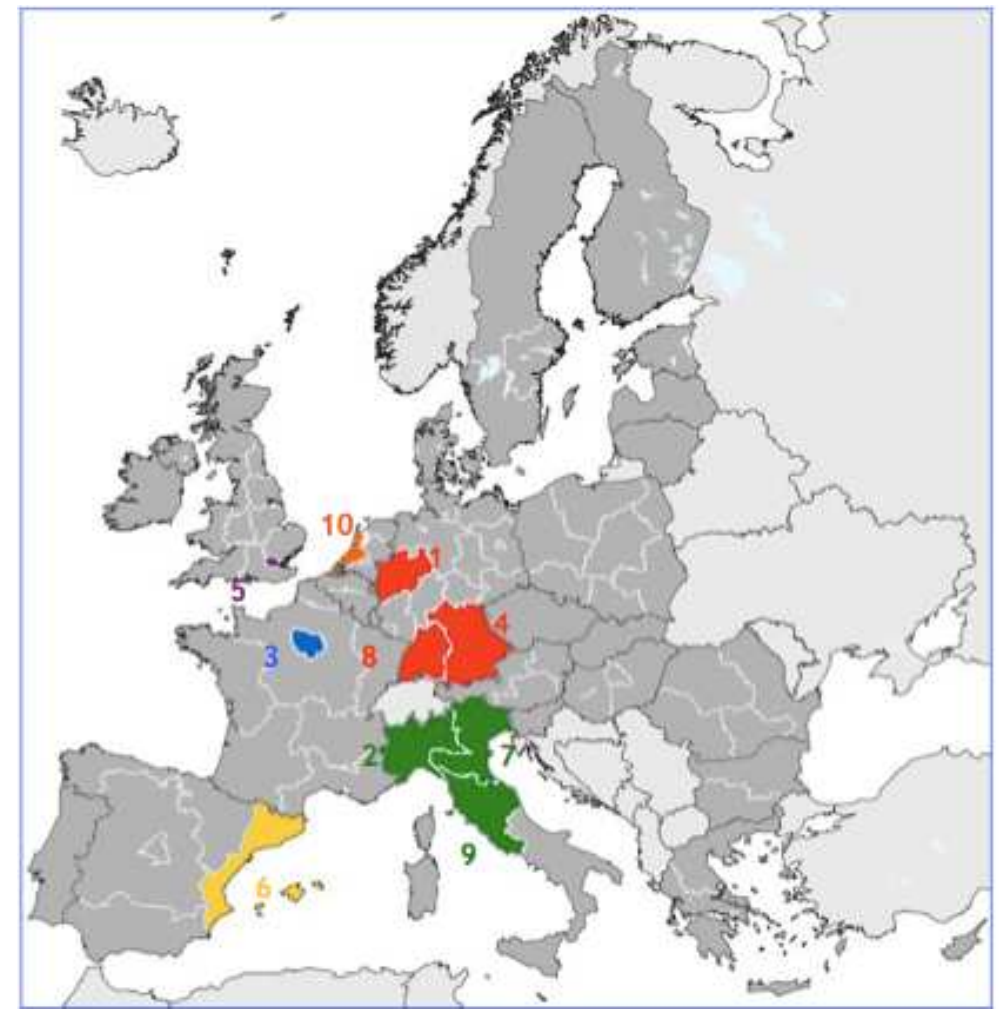

Legend A: Every number in the map corresponds to a NUTS 1 Region

- France: 3. Paris Region (Ile-de-France)

- Germany: 1. Nordrhein-Westfalen, 4. Bayern, 8. Baden-Württemberg

- Italy: 2. Nord-Ovest, 7. Nord-Est, 9. Centro

- Netherlands: 10. West-Nederland

- Spain: 6. Este

- UK: 5. London

Legend B: The order of the number corresponds to the GDP (in billions, in PPS, 2008) rank of the region. For example "1. Nordrhein-Westfalen" had the highest GDP (in billions, in PPS, 2008), followed by "2. NordOvest", etc.

Source: CROCIS (2011, p. 4) 
Table 32: Paris Region's position compared to other core European regions

\begin{tabular}{|c|c|c|c|c|c|c|c|c|c|c|c|c|c|c|}
\hline 苋 & 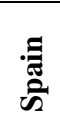 & $\ddot{2}$ & $\begin{array}{l}\stackrel{\circ}{\circ} \\
\text { க் }\end{array}$ & $\bar{\sim}$ & $\underset{\sim}{\stackrel{\sim}{\sim}}$ & $\begin{array}{l}\vec{n} \\
\tilde{n} \\
n\end{array}$ & $\begin{array}{l}\stackrel{0}{0} \\
\stackrel{\text { iे }}{ }\end{array}$ & ঐ̊ & $\bar{m}$ & $\begin{array}{l}\stackrel{\circ}{9} \\
\stackrel{m}{m}\end{array}$ & $\frac{\stackrel{\circ}{i}}{i n}$ & $\stackrel{8}{\circ}$ & $\begin{array}{l}\stackrel{0}{0} \\
\stackrel{\text { i }}{ }\end{array}$ & $\begin{array}{l}0 \\
0 \\
0 \\
2\end{array}$ \\
\hline 容 & 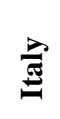 & $\stackrel{n}{=}$ & $\begin{array}{l}\stackrel{8}{+} \\
\stackrel{8}{8}\end{array}$ & $\stackrel{\infty}{\infty}$ & $\stackrel{\circ}{m}$ & 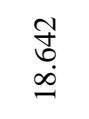 & 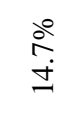 & $\stackrel{\stackrel{\circ}{ \pm}}{=}$ & 2 & 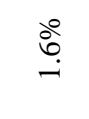 & $\begin{array}{l}\grave{0} \\
\infty \\
0 \\
0\end{array}$ & in & 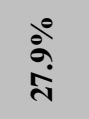 & $\stackrel{\substack{n \\
r}}{r}$ \\
\hline Ü & $\frac{\overrightarrow{2}}{\Phi}$ & 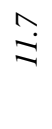 & $\begin{array}{l}\stackrel{\circ}{2} \\
\grave{2}\end{array}$ & ๙ิ & $\stackrel{\text { ते }}{\text { in }}$ & 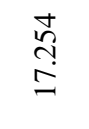 & $\stackrel{\stackrel{\circ}{+}}{\stackrel{5}{\Xi}}$ & 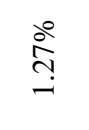 & dे & $\frac{8}{i}$ & $\begin{array}{l}\dot{b} \\
\dot{b} \\
\dot{0}\end{array}$ & ํㅗㅇ & $\begin{array}{l}\stackrel{0}{i n} \\
\infty \\
\infty\end{array}$ & $\frac{\infty}{\infty}$ \\
\hline 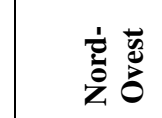 & 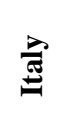 & $\stackrel{\infty}{\stackrel{\infty}{\imath}}$ & $\begin{array}{l}\stackrel{8}{+} \\
\dot{b}\end{array}$ & $\stackrel{\widehat{\lambda}}{\widehat{\lambda}}$ & $\frac{n}{m}$ & 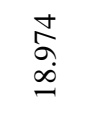 & $\begin{array}{l}\dot{b} \\
\dot{b}\end{array}$ & $\stackrel{\circ}{m}$ & d & $\stackrel{\circ}{\stackrel{2}{\leftrightarrows}}$ & $\begin{array}{l}\stackrel{0}{0} \\
\infty \\
\infty \\
0\end{array}$ & ذి & $\begin{array}{l}\stackrel{\infty}{0} \\
\infty \\
\stackrel{N}{0}\end{array}$ & $\stackrel{0}{\infty}_{\infty}^{\circ}$ \\
\hline 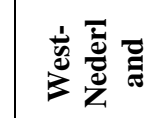 & $\overrightarrow{\mathbf{z}}$ & $\hat{\curvearrowright}$ & $\stackrel{\stackrel{\circ}{+}}{\stackrel{i}{i}}$ & 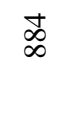 & ?ై & $\begin{array}{l}\overline{\text { స్ }} \\
\text { }\end{array}$ & $\begin{array}{l}\stackrel{8}{n} \\
\ddot{n} \\
m\end{array}$ & $\stackrel{\circ}{\stackrel{2}{I}}$ & $\stackrel{2}{2}$ & $\stackrel{\stackrel{m}{m}}{m}$ & 递 & $\stackrel{\Delta}{g}$ & $\begin{array}{l}\stackrel{\circ}{0} \\
\circ\end{array}$ & $\stackrel{\text { ஸे }}{\text { in }}$ \\
\hline 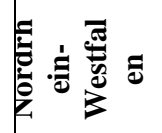 & 善 & $\stackrel{\circ}{\stackrel{0}{i}}$ & $\begin{array}{l}80 \\
0 \\
0\end{array}$ & $\stackrel{\infty}{\sim}$ & $\overrightarrow{\mathrm{i}}$ & $\begin{array}{l}\tilde{N} \\
\sigma \\
\infty\end{array}$ & $\begin{array}{l}\stackrel{0}{\infty} \\
\text { ì }\end{array}$ & $\stackrel{\stackrel{\infty}{\infty}}{\stackrel{\infty}{\sim}}$ & $\bar{\sigma}$ & $\stackrel{\stackrel{\ominus}{~}}{\ddot{c}}$ & $\stackrel{\stackrel{\leftrightarrow}{n}}{\stackrel{n}{i}}$ & $\stackrel{\stackrel{n}{n}}{n}$ & $\begin{array}{l}\stackrel{0}{\infty} \\
\ddot{\lambda}\end{array}$ & $\stackrel{\stackrel{\circ}{i}}{i n}$ \\
\hline 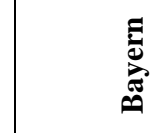 & 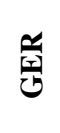 & 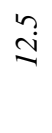 & $\begin{array}{l}\stackrel{d}{2} \\
\stackrel{b}{b}\end{array}$ & $\Sigma$ & $\stackrel{\vec{m}}{\vec{m}}$ & 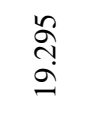 & $\begin{array}{l}\stackrel{\leftrightarrow}{+} \\
\stackrel{\sim}{\sim}\end{array}$ & $\begin{array}{l}\stackrel{\circ}{\infty} \\
i \\
i\end{array}$ & 今్ & $\frac{\Delta}{m}$ & $\frac{\circ}{\infty}$ & 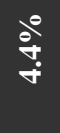 & 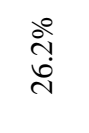 & $\begin{array}{l}\stackrel{0}{n} \\
n \\
6\end{array}$ \\
\hline 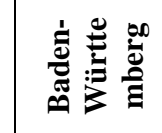 & 놉 & $\hat{\varrho}$ & $\stackrel{\circ}{\stackrel{8}{8}}$ & ষ্ল & $\underset{\text { di }}{\vec{m}}$ & $\begin{array}{l}\overrightarrow{\bar{\infty}} \\
\stackrel{0}{2}\end{array}$ & $\frac{\circ}{\circ}$ & $\frac{\stackrel{8}{5}}{9}$ & $\bar{్}$ & ڤें & $\begin{array}{l}\stackrel{\infty}{\infty} \\
\stackrel{1}{\wedge}\end{array}$ & $\begin{array}{l}\stackrel{0}{\infty} \\
\dot{+}\end{array}$ & $\stackrel{\stackrel{\circ}{\circ}}{\stackrel{m}{\dot{m}}}$ & ठ̊. \\
\hline$\stackrel{8}{\ddot{g}}=$ & 光 & $\stackrel{b}{\sim}$ & $\stackrel{\circ}{-\infty}$ & $\widehat{\infty}$ & $\tilde{g}$ & $\frac{\bar{\alpha}}{\vec{\pi}}$ & $\begin{array}{l}80 \\
6 \\
8 \\
8\end{array}$ & 过 & $\hat{N}$ & $\begin{array}{l}\infty \\
\infty \\
\dot{m}\end{array}$ & 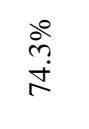 & $\frac{80}{a}$ & $\begin{array}{l}\stackrel{8}{b} \\
\infty\end{array}$ & 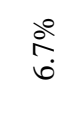 \\
\hline 施 & $\underset{\mathscr{E}}{\mathscr{E}}$ & $\stackrel{\curvearrowright}{=}$ & 总 & :ٌ & $\stackrel{\text { ì }}{\vec{f}}$ & 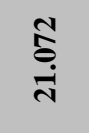 & ڤे & $\stackrel{\circ}{=}$ & ช్ర & $\stackrel{8}{i}$ & $\stackrel{\stackrel{\infty}{\infty}}{\stackrel{\infty}{i}}$ & $\begin{array}{l}\stackrel{\circ}{\infty} \\
\infty\end{array}$ & $\begin{array}{l}\stackrel{\circ}{0} \\
\stackrel{\text { I}}{ }\end{array}$ & $\begin{array}{l}\stackrel{0}{n} \\
\stackrel{n}{n}\end{array}$ \\
\hline \multirow[t]{2}{*}{ 煎 } & & & $\ddot{\omega}$ & $\overrightarrow{\widetilde{n}}$ & $\overrightarrow{\widetilde{N}}$ & $\overrightarrow{\widetilde{N}}$ & $\overrightarrow{\widetilde{n}}$ & $\overrightarrow{\mathrm{N}}$ & $\bar{m}$ & $\equiv$ & $\risingdotseq$ & 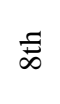 & $\stackrel{\Xi}{\infty}$ & छ \\
\hline & & 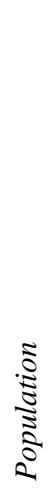 & 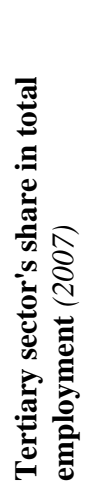 & 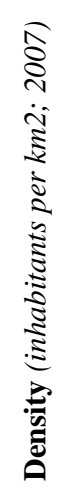 & 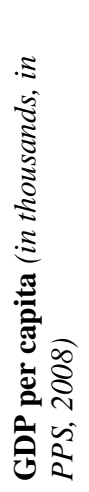 & 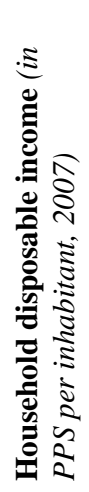 & 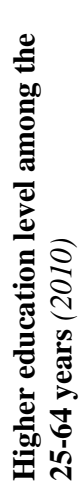 & 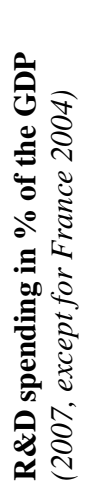 & 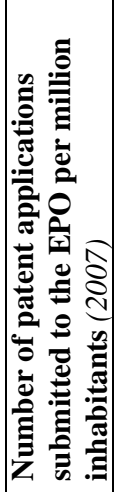 & 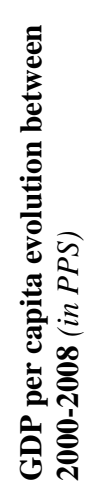 & 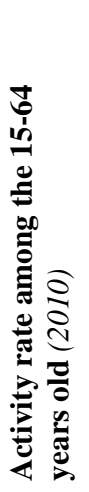 & 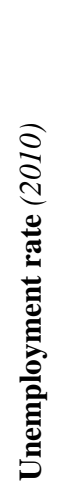 & 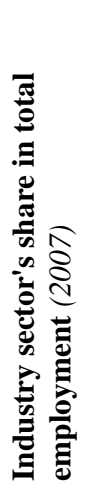 & 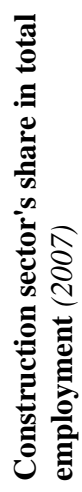 \\
\hline
\end{tabular}

Legend: dark boxes with white numbers $=1^{\text {st }}$ place; light grey boxes with black and bold numbers $=2^{\text {nd }}$ place; $P R=$ Paris Region, EPO = European Patent Office, $P P S=$ Power Purchasing Standard

Source: Data retrieved from following report: CROCIS (2011) 
The London and the Paris Region, both very densely populated regions, are very similar in several points. Both regions not only have the highest educated population but also the highest amount of employment in the tertiary sector (Paris Region: 81.6\%; London Region $81.1 \%$ ) far ahead of the other eight regions. Additionally, both regions are also the richest regions in terms of GDP per capita and household disposable income. However, the GDP per capita evolution between 2000-2008 was strong in London (3.8\%, the best progress among the 10 regions) but only $2.5 \%$ for the Paris Region (the $7^{\text {th }}$ place among the 10 regions under scrutiny). This means that even though the Paris Region is still one of the richest regions in Europe, its competitive edge was shrinking compared to the other richest regions during the first decade of the $21^{\text {st }}$ century. The London Region is suitable to compare the Paris Region regarding education and richness but not for $R \& D$ as the London Region, compared to the other core regions, is investing nearly nothing in R\&D (only $1.04 \%$ of its GDP) and has the lowest number of patent applications.

Regarding R\&D, the two regions, which are important to look at, are Baden-Württemberg and Bayern in Germany. Both regions have a "less" educated and rich population compared to London and Paris Region. However, both German regions have other excellent characteristics. In 2007, Baden-Württemberg spent $4.47 \%$ of its GDP for R\&D, which is considerably above the $3.0 \%$ objective fixed by the European Union's Lisbon strategy and also by far the highest percentage among the ten regions under scrutiny. This high investment in $R \& D$ is also reflected by the fact that the region submits the highest amount of patent applications to the European Patent Office (EPO). The Paris Region in comparison spends also a high amount of its GDP in R\&D (3.11\%, the second highest percentage) but is not able to transform this amount in actual patent applications as it submitted less than half the number of patents per inhabitant compared to Baden-Württemberg. Bayern, which invests "only" $2.81 \%$ of its GDP in R\&D is even more effective than Baden-Württemberg as it submitted nearly as many patent applications.

Bayern and Baden-Württemberg have thus a better R\&D performance than the Paris Region. Additionally, both German regions have the lowest unemployment rates (Bayern 4.4\%, Baden-Württemberg 4.8\%) and one of the highest industry shares in total employment (Bayern 26.2\%, Baden-Württemberg 31.8\%). The Paris Region in comparison has one of the highest unemployment rates $\left(8.9 \%, 8^{\text {th }}\right.$ place) and one of the lowest industry sector shares in total employment $\left(12 \%, 8^{\text {th }}\right.$ place $)$. 
Table 33: The Paris Region: "Stuck in the middle" in an European context

\begin{tabular}{|l|c|c|c|}
\hline & London & Paris Region & $\begin{array}{c}\text { Baden- } \\
\text { Württemberg }\end{array}$ \\
\hline $\begin{array}{l}\text { Growth: GDP per capita evolution between } \\
\text { 2000-2008 (in PPS) }\end{array}$ & $1^{\text {st }}$ & $2^{\text {nd }}$ & \\
\hline $\begin{array}{l}\text { Richness: GDP per capita (in PPS, 2008) \& } \\
\text { Household disposable income (in PPS per } \\
\text { inhabitant, 2007) }\end{array}$ & $1^{\text {st }}$ & $2^{\text {nd }}$ & \\
\hline $\begin{array}{l}\text { Education: Higher education level among the 25- } \\
\text { 64 years (2010) }\end{array}$ & $1^{\text {st }}$ & $1^{\text {st }}$ & $1^{\text {st }}$ \\
\hline $\begin{array}{l}\text { Tertiary sector: share in total employment } \\
\text { (2007) }\end{array}$ & $2^{\text {nd }}$ & $2^{\text {nt }}$ \\
\hline $\begin{array}{l}\text { R\&D spending: in \% of the GDP (2007, except } \\
\text { for France 2004) }\end{array}$ & & & $1^{\text {st }}$ \\
\hline $\begin{array}{l}\text { R\&D patent applications: Number of patent } \\
\text { applications submitted to the EPO per million } \\
\text { inhabitants (2007) }\end{array}$ & & $2^{\text {nd }}$ \\
\hline $\begin{array}{l}\text { Industry sector: share in total employment } \\
\text { (2007) }\end{array}$ & & & \\
\hline \begin{tabular}{l} 
Low unemployment (2010) \\
\hline
\end{tabular}
\end{tabular}

Source: Summary of the key learning points of Table 32 (only marked if one of the three regions ranked $I^{\text {st }}$ or $2^{\text {nd }}$ in a certain category)

To sum up, the three most interesting comparison regions for the Paris Region are London, Baden-Württemberg and Bayern. For simplicity reasons we just took Baden-Württemberg in order to graphically (see Table 33) underline the "stuck in the middle" position of the Paris Region.

The Paris Region seems to have no clear positioning neither "ignoring" R\&D and focusing only on education and the tertiary sector (like London with its high growth rate), nor showing a strong industry sector and a high R\&D transformation rate (like Baden-Württemberg with its low unemployment rate). Additionally, the PR has a high unemployment rate and a low growth rate compared to the other two leading regions. However, the PR stays of course the richest region in France and one of the richest regions in Europe but it is stuck between two extremes where "something" seems to work better. 


\subsection{Overview of the policy-driven clusters in the PR}

The Paris Region counts seven policy-driven clusters ${ }^{177}$ (see Table 34): two ICT policydriven clusters (one oriented towards digital content, the other towards complex systems), two engineering / services policy-driven clusters (one oriented towards urban sustainability and eco-technologies, the other towards finance), one aeronautics / space policy-driven cluster, one transportation policy-driven cluster, one biotechnologies / health policy-driven cluster.

In 2005, the state initially labelled five policy-driven clusters in the Paris Region, and granted two additional policy-driven clusters the official label in 2007. The official applicants for the policy-driven clusters in the Paris Region were a mixture of public, private or public/private institutions (see Table 34), ranging from the Paris Region economic development agency, in the case of HealthCluster Paris Region, to Thales, a CAC 40 company, in the case of Systematic Paris Region.

\footnotetext{
${ }^{177}$ Source: http://www.paris-region.com/ (accessed 01/05/2014). Note: The number of policy-driven clusters on the website of the Paris Region economic development agency stays stable over time as the agency only counts the policy-driven cluster organisations that are actually located on the Paris Region territory. However, the number of policy-driven clusters attributed to the Paris Region on the official policy-driven cluster website (http://competitivite.gouv.fr/) increases with time. For example on the 01/05/2014 the official policy-driven cluster website attributed 11 policy-driven clusters to the Paris Region (Advancity, ASTech PR, Cap Digital PR, Cosmetic Valley, Elastopôle, Finance Innovation, HealthCluster PR, Mov'éo, NOvalog, Systematic PR, Vitagora). However, one year earlier (on the 09/06/2013) the website attributed only 9 policy-driven clusters to the Paris Region (NOvalog and Vitagora were not included at that time). The reason of this "inflation" is that little by little the State allows the "policy-driven clusters" to extend their territories to other regions than their initial attributed region. This means that more companies can apply for a policy-driven cluster project label. For example NOvalog is originally situated in the Normandie Region. For the $3^{\text {rd }}$ policy-driven cluster phase the State allowed them to extend their territory to the Ile-de France Region (http://novalog.eu/?p=2680). Companies situated in the Ile-de-France Region are now allowed to apply for projects managed by NOvalog (situated in the Normandy Region).
} 
Table 34: Paris Region's policy-driven clusters

\begin{tabular}{|c|c|c|c|c|c|c|}
\hline Category* & Name** & Description** & $\begin{array}{l}\text { Label } \\
\text { led } \\
\text { in } * * *\end{array}$ & $\begin{array}{l}\text { Official } \\
\text { applicant for } \\
\text { label*** }\end{array}$ & $\begin{array}{l}\text { End of } 1^{\text {st }} \\
\text { Phase } \\
(05-08) \\
\text { Eval.**** }\end{array}$ & $\begin{array}{l}\text { End of } 2^{\text {nd }} \\
\text { Phase } \\
(09-12) \\
\text { Eval.**** } \\
*\end{array}$ \\
\hline $\begin{array}{l}\text { Aeronauti } \\
\text { cs / Space }\end{array}$ & $\begin{array}{l}\text { ASTech } \\
\text { Paris } \\
\text { Region }\end{array}$ & $\begin{array}{l}\text { consolidating the } \\
\text { region's positions in } \\
\text { aerospace, business } \\
\text { aviation, propulsion } \\
\text { systems \& aerospace } \\
\text { facilities }\end{array}$ & 2007 & $\begin{array}{l}\text { Private: Safran } \\
\text { (CAC 40) }\end{array}$ & $\begin{array}{l}\text { objectives } \\
\text { reached } \\
\text { (Cat. A.) }\end{array}$ & $\begin{array}{l}\text { Efficient } \\
\text { (Cat. B) }\end{array}$ \\
\hline $\begin{array}{l}\text { Bio- } \\
\text { technologi } \\
\text { es / Health }\end{array}$ & $\begin{array}{l}\text { HealthClu } \\
\text { ster Paris } \\
\text { Region }^{178}\end{array}$ & $\begin{array}{l}\text { guiding innovation in } \\
\text { human healthcare } \\
\text { (prevention, diagnosis, } \\
\text { therapies, associated } \\
\text { technologies), toward } \\
\text { industry, market \& } \\
\text { patient }\end{array}$ & 2005 & $\begin{array}{l}\text { Public: Paris } \\
\text { Region } \\
\text { economic } \\
\text { development } \\
\text { agency }\end{array}$ & $\begin{array}{l}\text { objectives } \\
\text { only } \\
\text { partially } \\
\text { reached } \\
\text { (Cat. B) }\end{array}$ & $\begin{array}{l}\text { Less } \\
\text { efficient } \\
\text { (Cat. C) }\end{array}$ \\
\hline \multirow{2}{*}{$\begin{array}{l}\text { Engineeri } \\
\text { ng / } \\
\text { Services }\end{array}$} & $\underset{179}{\text { Advancity }}$ & $\begin{array}{l}\text { developing the projects } \\
\text { promoting urban } \\
\text { sustainability and eco- } \\
\text { technologies }\end{array}$ & 2005 & $\begin{array}{l}\text { Public: } \\
\text { Polytechnicum } \\
\text { de Marne-la- } \\
\text { Vallée }^{180} \\
\end{array}$ & $\begin{array}{l}\text { objectives } \\
\text { reached } \\
\text { (Cat. A.) }\end{array}$ & $\begin{array}{l}\text { Efficient } \\
\text { (Cat. B) }\end{array}$ \\
\hline & $\begin{array}{l}\text { Finance } \\
\text { Innovatio } \\
\text { n }\end{array}$ & $\begin{array}{l}\text { developing a leading } \\
\text { European financial } \\
\text { information platform \& } \\
\text { training hub }\end{array}$ & 2007 & $\begin{array}{l}\text { Private/Public: } \\
\text { Paris } \\
\text { Europlace }^{181}\end{array}$ & $\begin{array}{l}\text { objectives } \\
\text { reached } \\
\text { (Cat. A.) }\end{array}$ & $\begin{array}{l}\text { Efficient } \\
\text { (Cat. B) }\end{array}$ \\
\hline \multirow[t]{2}{*}{ ICT } & $\begin{array}{l}\text { Cap } \\
\text { Digital } \\
\text { Paris } \\
\text { Region }^{182}\end{array}$ & $\begin{array}{l}\text { designing and } \\
\text { developing digital } \\
\text { content and services }\end{array}$ & 2005 & $\begin{array}{l}\text { Public: Paris } \\
\text { Region } \\
\text { economic } \\
\text { development } \\
\text { agency }\end{array}$ & $\begin{array}{l}\text { objectives } \\
\text { reached } \\
\text { (Cat. A.) }\end{array}$ & $\begin{array}{l}\text { Highly } \\
\text { efficient } \\
\text { (Cat. A) }\end{array}$ \\
\hline & $\begin{array}{l}\text { Systemati } \\
\text { c Paris } \\
\text { Region }^{183} \\
\end{array}$ & $\begin{array}{l}\text { designing, creating and } \\
\text { managing complex } \\
\text { systems }\end{array}$ & 2005 & $\begin{array}{l}\text { Private: Thales } \\
\text { (CAC 40) }\end{array}$ & $\begin{array}{l}\text { objectives } \\
\text { reached } \\
\text { (Cat. A.) } \\
\end{array}$ & $\begin{array}{l}\text { Highly } \\
\text { efficient } \\
\text { (Cat. A) }\end{array}$ \\
\hline $\begin{array}{l}\text { Trans- } \\
\text { portation }\end{array}$ & Mov'éo ${ }^{184}$ & $\begin{array}{l}\text { designing and } \\
\text { developing safer } \\
\text { transport systems - for } \\
\text { people and the } \\
\text { environment }\end{array}$ & 2005 & $\begin{array}{l}\text { Public: } \text { French } \\
\text { National } \\
\text { Institute for } \\
\text { Transport and } \\
\text { Safety } \\
\text { Research } \\
\text { (INRETS) }\end{array}$ & $\begin{array}{l}\text { objectives } \\
\text { reached } \\
\text { (Cat. A.) }\end{array}$ & $\begin{array}{l}\text { Highly } \\
\text { efficient } \\
\text { (Cat. A) }\end{array}$ \\
\hline
\end{tabular}

*Source: http://competitivite.gouv.fr/ (acc. 01/05/2014); **Source: http://www.paris-region.com/ (acc. 01/05/2014); ***CIADT Press Communication on the $12 / 07 / 2005 \&$ on the $05 / 07 / 2007 ; * * * *$ Source: $1^{\text {st }}$ phase evaluation report (CMI \& $\quad$ BCG, 2008); **** $\quad$ Source: http://www.elopsys.fr/IMG/pdf/valuation_individuelle_des_poles_de_competitivite-2.pdf (acc. 01/05/2014)

\footnotetext{
178 initially called "MédiTech Sante"

179 initially called "Ville et mobilité durables"

${ }^{180}$ Polytechnicum de Marne-la-Vallée: an association that regroups universities and research institutes.

${ }^{181}$ Paris Europlace: association founded in 1993 by private and public institutions. The association represents the major players in the financial market and promotes Paris as a financial market. (http://www.paris-europlace.net/) 182 initially called "Image, Multimédia et Vie Numérique"

183 sometimes also written as System@tic Paris Region. No name change since the beginning.

184 The policy-driven cluster was initially called "Vestapolis", was situated in the Paris Region and specialised in road safety. Mov'éo emerged following the merger between Vestapolis and Normandy Motor Valley in 2006.
} 
During the first policy-driven cluster phase (2005-2008) all but one policy-driven cluster reached its objectives. The only policy-driven cluster that did not reach its objectives during the first phase was HealthCluster Paris Region. Also during the second policy-driven cluster phase (2009-2012) HealthCluster Paris Region was the only local policy-driven cluster that was evaluated as "less efficient" (Category C), the lowest evaluation category. All other local policy-driven clusters were either evaluated highly efficient (Systematic, Cap Digital and Mov'éo) or efficient (ASTech Paris Region, Advancity, Finance Innovation).

\section{Presentation of HealthCluster Paris Region}

HealthCluster Paris Region is the only policy-driven cluster in the Paris Region that only partially reached its objectives during the first policy-driven cluster evaluation in 2008. In order to better situate the qualitative case study that will follow, it is interesting to dig a little bit deeper into the particularities of HealthCluster Paris Region compared to the other policydriven clusters in the region. In order to do so we looked at different statistical indicators: (1) Type of members and member evolution; (2) NAF category of member organisations, and (3) Project funding sources.

\subsection{Type of members and member evolution}

The first important indicator to situate a policy-driven cluster is its member structure and member evolution. Table 35 summarizes the member structure and member evolution of all policy-driven clusters in the Paris Region and also compares each policy-driven cluster to the average of all policy-driven clusters in the Paris Region. If we look at the absolute numbers, the two policy-driven clusters in the Paris Region that have the highest amount of members are Cap Digital and Systematic. Both policy-driven clusters have nearly the double amount of members than the average policy-driven cluster in the Region. The same is the case when we look more particularly at SME members, both policy-driven clusters, Cap Digital and Systematic, have also the highest absolute number and relative share of SME members. HealthCluster Paris Region has one of the fewest amounts of members and also a below average growth rate. However, such as Cap Digital, Systematic or Advancity it is a policydriven cluster that has an above average SME share among its members. So in terms of absolute number of members it is not at all comparable with Cap Digital or Systematic, but in terms of it's relative member structure it is. 
Table 35: Type of members

\begin{tabular}{|c|c|c|c|c|c|c|c|c|c|}
\hline & & $\begin{array}{c}\text { Average } \\
\text { of all } \\
\text { Paris } \\
\text { Region } \\
\text { policy- } \\
\text { driven } \\
\text { clusters }\end{array}$ & $\begin{array}{c}\text { Advancit } \\
\mathbf{y}\end{array}$ & $\begin{array}{l}\text { ASTec } \\
\text { h Paris } \\
\text { Region }\end{array}$ & $\begin{array}{c}\text { Cap } \\
\text { Digital } \\
\text { Paris } \\
\text { Region } \\
\end{array}$ & $\begin{array}{c}\text { Finance } \\
\text { Innovatio } \\
\mathbf{n}\end{array}$ & $\begin{array}{c}\text { HealthCluste } \\
\text { r Paris } \\
\text { Region } \\
\end{array}$ & $\begin{array}{c}\text { Mov'é } \\
\text { o }\end{array}$ & $\begin{array}{c}\text { Systemati } \\
\text { c Paris } \\
\text { Region }\end{array}$ \\
\hline \multirow[t]{2}{*}{$\begin{array}{l}\text { Total } \\
\text { members }\end{array}$} & 2007 & 157 & 83 & 67 & 288 & 118 & 109 & 159 & 276 \\
\hline & 2012 & 329 & 135 & 209 & 595 & 253 & 167 & 320 & 623 \\
\hline $\begin{array}{l}\text { Increase in } \\
\text { total } \\
\text { members }\end{array}$ & & $50 \%$ & $39 \%$ & $68 \%$ & $52 \%$ & $53 \%$ & $35 \%$ & $50 \%$ & $56 \%$ \\
\hline $\begin{array}{l}\text { SME } \\
\text { members }\end{array}$ & 2007 & 80 & 18 & 40 & 220 & 13 & 68 & 56 & 147 \\
\hline & 2012 & 242 & 106 & 129 & 521 & 162 & 131 & 189 & 456 \\
\hline $\begin{array}{l}\text { Increase in } \\
\text { SME } \\
\text { members }\end{array}$ & & $70 \%$ & $83 \%$ & $69 \%$ & $58 \%$ & $92 \%$ & $48 \%$ & $70 \%$ & $68 \%$ \\
\hline $\begin{array}{l}\text { Share of } \\
\text { SME } \\
\text { members } \\
\text { in Total } \\
\text { members }\end{array}$ & 2007 & $46 \%$ & $22 \%$ & $60 \%$ & $76 \%$ & $11 \%$ & $62 \%$ & $35 \%$ & $53 \%$ \\
\hline & 2012 & $72 \%$ & $79 \%$ & $62 \%$ & $88 \%$ & $64 \%$ & $78 \%$ & $59 \%$ & $73 \%$ \\
\hline
\end{tabular}

Source: 2007 data from the official policy-driven cluster evaluation in $2008^{185} ; 2012$ data from the official policy-driven cluster website (http://competitivite.gouv.fr/)

Note: Numbers in bold are above the average of all Paris Region policy-driven clusters.

\subsection{NAF category of member organisations}

The second important indicator to describe a policy-driven cluster concerns the sector of activity of its members. Table 36 and Table 37 summarize for each Paris Region policydriven cluster the five NAF codes ${ }^{186}$ that best represent the policy-driven cluster members. We only had access to the five most important NAF categories for every policy-driven cluster. The five most important NAF categories cover $60 \%$ of Advancity's members, $61 \%$ of ASTech Paris Region's members, $76 \%$ of Cap Digital's members, 72\% of Finance Innovation's members, 74\% of HealthCluster Paris Region's members, 57\% of Mov'éo's members, and $72 \%$ of Systematic Paris Region's members. This means that Mov'éo (57\%) is the most heterogeneous policy-driven cluster. Cap Digital (76\%) and HealthCluster Paris

\footnotetext{
185 Thierry Weil (Mines ParisTech) was able to access the raw data of the 2008 French policy-driven cluster evaluation.

${ }^{186}$ NAF code is the French equivalent of the American Standard Industrial Classification (SIC) code. NAF = "Nomenclature d'activités française" or "French classification of economic activities".
} 
Region (74\%) on the other hand are the most homogenous policy-driven clusters in the Region as 3/4 of their policy-driven cluster members are covered by only 5 NAF codes.

An important insight of the NAF category analysis is that Cap Digital and Systematic PR are not only similar in their member structure (high share of SMEs, high amount of members compared to the other local policy-driven clusters) both policy-driven clusters are also kind of similar regarding the activities of their members. For example $56 \%$ of Cap Digital's and $50 \%$ of Systematic PR's members belong to three NAF divisions, namely "Computer programming, consultancy \& related activities" (NAF 62), "Publishing activities" (NAF 58) and "Activities of head offices; management consultancy activities" (NAF70). HealthCluster Paris Region is somehow different.

Even though HealthCluster PR is also a SME policy-driven cluster like Cap Digital and Systematic, its members' activities are very different. HealthCluster PR is the only policydriven cluster that has half of its members belonging only to one category, namely "Scientific research and development" (NAF 72). HealthCluster is thus by far the most specialist policydriven cluster regarding its member structure. Systematic PR on the other hand is the most transversal policy-driven cluster as all of its five most important NAF categories are also highly present in at least three other local policy-driven clusters.

\subsection{Project funding sources}

Other important indicators to look at are the number of projects funded and the type of funding received (see Table 38). Cap Digital and Systematic PR are again the two policydriven clusters that stick out because nearly $60 \%$ of all projects funded in the PR can be accredited to members of these two policy-driven clusters. In absolute numbers they are again far ahead. However, it is HealthCluster PR that has the best output as in average 0.66 of its members participated in a cluster project while only 0.42 of Cap Digital's members and 0.41 of Systematic PR members participated in a policy-driven cluster project. Even though HealthCluster has far less members, the members it has seem to be (project wise) more integrated.

Another important element is the source of the funding as it indicates which type of $R \& D$ project is done. The aim of the ANR is to fund exploratory research projects that focus on 
developing new knowledge. The projects financed by the FUI have to relate to innovations relatively close to the market. OSEO (today called Bpifrance) supports innovation and economic development within French SMEs. HealthCluster PR (58\%) and Advancity (63\%) are the two policy-driven clusters that have most of their projects financed by the ANR, and are thus more oriented towards exploratory research projects. On the other hand ASTech PR $(69 \%)$ is the policy-driven cluster that has most of its projects financed by the FUI and which is thus more market oriented.

\subsection{Summary}

HealthCluster PR (the only biotechnology / health policy-driven cluster of the region) is a particular case within the Paris region. HealthCluster PR, was the only local policy-driven cluster that "only partially reached its objectives" during the first cluster evaluation in 2008 and the only local policy-driven cluster that was evaluated "less efficient" during the second policy-driven cluster evaluation in 2012. Additionally, it has one of the fewest members and also a below average growth rate.

However, such as Cap Digital, Systematic or Advancity it is a policy-driven cluster that has an above average SME share among its members. Additionally, HealthCluster is a particular case as it is a very homogenous and specialist policy-driven cluster. It is the only policydriven cluster of the region where $50 \%$ of its members belong to the same NAF category namely "Scientific research and development". Even though it has maybe less members than the other policy-driven clusters it is the policy-driven cluster with the best output as in average 0.66 of its members participated in a policy-driven cluster R\&D project, meaning that even though the policy-driven cluster organisation counts less members, at least the members that exist seem to be integrated in the policy-driven cluster. Not surprisingly, most HealthCluster PR projects are financed by the ANR, and are thus more oriented towards exploratory research than the market.

HealthCluster, compared to the other policy-driven clusters in the region, is somehow an extreme case, and thus the ideal policy-driven cluster to study pathologies. 
Table 36: Five most important ${ }^{187}$ NAF sectors per policy-driven cluster ${ }^{188}$ in 2012

\begin{tabular}{|c|c|c|c|c|c|c|c|c|}
\hline 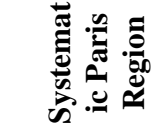 & 유 & 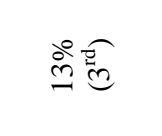 & & & $\stackrel{\circ}{\stackrel{0}{E}=}$ & 总庖 & & \\
\hline$\frac{a}{3}$ & & $\dot{c}^{\circ}=$ & & & 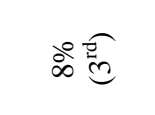 & 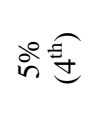 & & \\
\hline 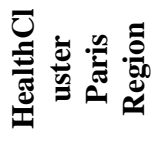 & $\stackrel{\overbrace{}}{\circ}$ & & $\stackrel{0}{i n}^{5}=$ & & $\stackrel{\circ}{\circ}$ & & & \\
\hline 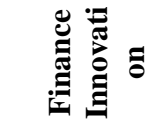 & $\stackrel{\circ}{\vec{n}}=$ & & & $\stackrel{\circ}{\circ}$ & 瓶 & $\stackrel{\circ 0}{=}$ & & \\
\hline 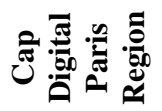 & $\stackrel{\circ}{\infty}$ & & & & 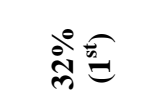 & 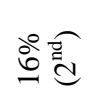 & $\stackrel{\text { ஸீ }}{2}$ & 잉 \\
\hline 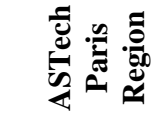 & & $\because \sqrt{0}=$ & & & 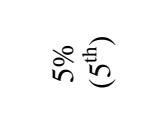 & & & \\
\hline 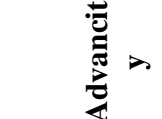 & 웅 & $\stackrel{0}{0}=$ & & & 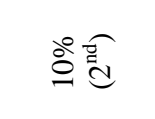 & 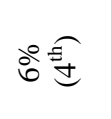 & & \\
\hline 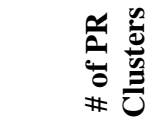 & in & 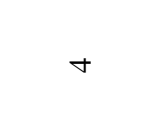 & - & - & $r$ & in & - & - \\
\hline 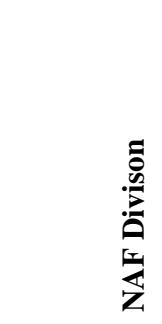 & 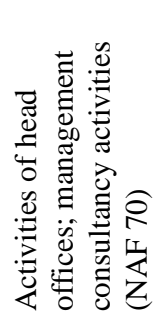 & 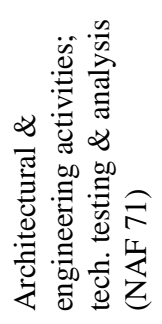 & 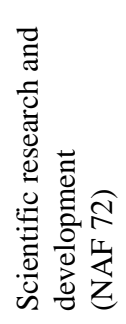 & 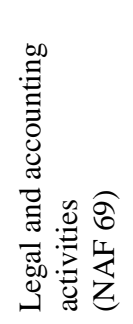 & 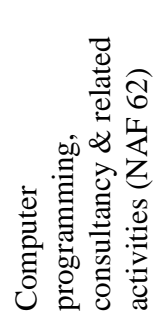 & 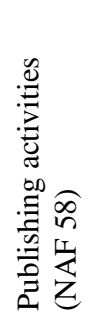 & 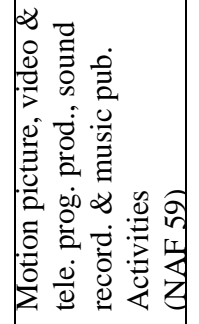 & 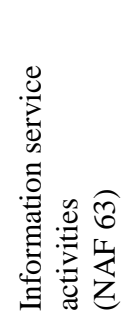 \\
\hline 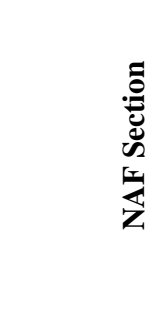 & \multicolumn{4}{|c|}{ 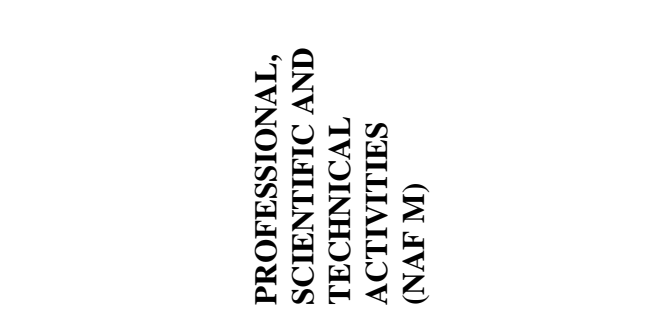 } & \multicolumn{4}{|c|}{ 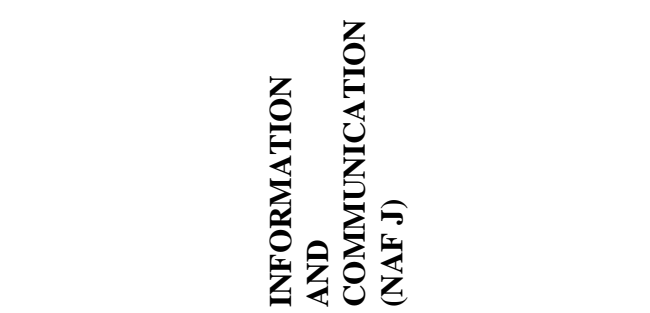 } \\
\hline
\end{tabular}

Source: own calculations, data from official policy-driven cluster website (http://competitivite.gouv.fr)

\footnotetext{
${ }^{187}$ For each policy-driven cluster we had access to the 5 NAF categories that account for the most members. We then calculated following percentage: "NAF category members / Total members of cluster".

${ }^{188}$ Example how to read the table: $50 \%$ of all the members of HealthCluster Paris Region belong to the NAF category "Scientific research and development". The " $\left(1^{\text {st }}\right)$ " (bold number) signifies that this is the NAF category where HealthCluster counts the most members.
} 
Table 37: Five most important ${ }^{187}$ NAF sectors per policy-driven cluster in 2012 (cont.)

\begin{tabular}{|c|c|c|c|c|c|c|c|}
\hline 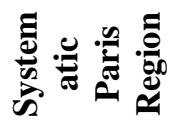 & 次过 & & & & & & \\
\hline है & in & 兽 & & & & & \\
\hline 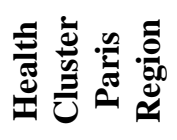 & & & & & 谒过 & 栬圧 & \\
\hline 莺。䓀 & & & & & & & 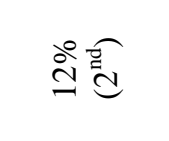 \\
\hline 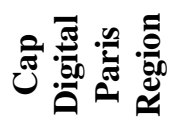 & & & & & & & \\
\hline 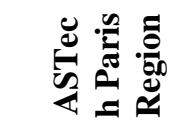 & 斻 & & $\stackrel{\circ 0}{=}$ & $\stackrel{80}{=}=$ & & & \\
\hline 产 & & & & & & \&ீ & \\
\hline 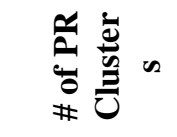 & $m$ & - & - & - & - & $\sim$ & - \\
\hline 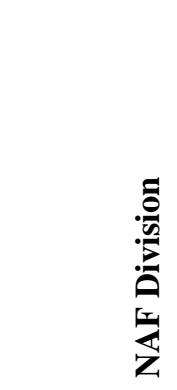 & 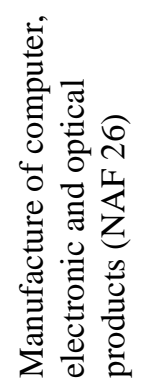 & 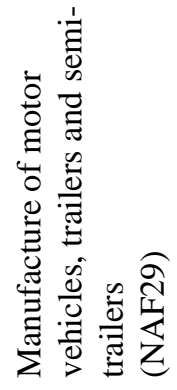 & 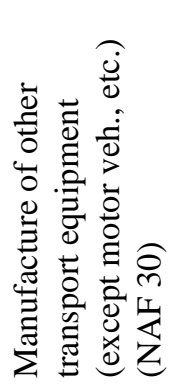 & 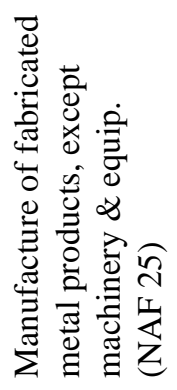 & 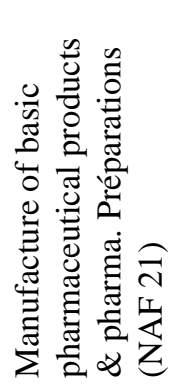 & 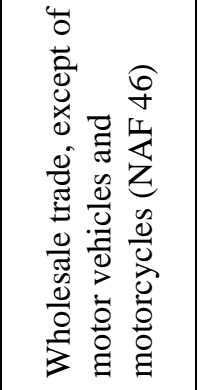 & 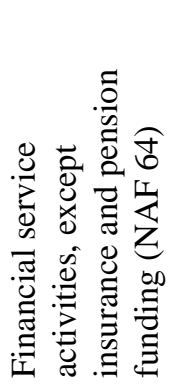 \\
\hline 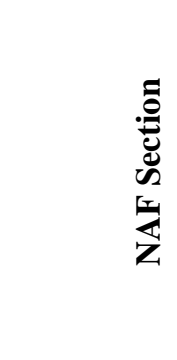 & & & 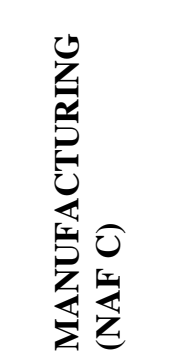 & & & 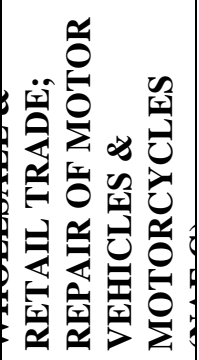 & 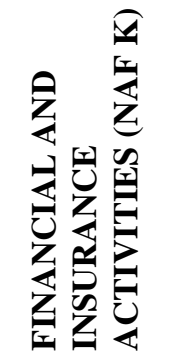 \\
\hline
\end{tabular}

Source: own calculations, data from official policy-driven cluster website (http://competitivite.gouv.fr) 
Table 38: Number of projects funded and project funding sources

\begin{tabular}{|c|c|c|c|c|c|c|c|c|c|c|c|c|c|}
\hline 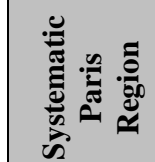 & 흐 & $\begin{array}{l}80 \\
i n\end{array}$ & ळे & ते & $\stackrel{\infty}{\infty}$ & $\stackrel{\circ}{=}$ & $\widehat{\beth}$ & $\frac{\partial 0}{m}$ & $\stackrel{\circ}{\circ}$ & $\sqrt{n}$ & $\stackrel{\circ}{0}$ & $\stackrel{8}{8}$ & $\stackrel{F}{0}$ \\
\hline 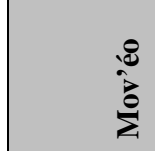 & in & $\stackrel{\triangleright}{\infty}$ & $\begin{array}{l}\stackrel{\circ}{\circ} \\
\stackrel{\infty}{+}\end{array}$ & $\infty$ & in & $\stackrel{\circ}{r}$ & g & $\stackrel{\searrow}{\beth}$ & 字 & $\stackrel{8}{0}$ & $\stackrel{\circ}{\leftrightarrows}$ & छீ & m. \\
\hline 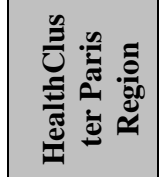 & ల్ల & $\stackrel{\circ}{0}^{\circ}$ & 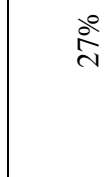 & 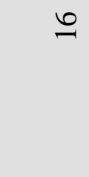 & $\stackrel{\circ}{\circ}$ & $\stackrel{\circ}{\stackrel{0}{2}}$ & t & $\stackrel{\circ 0}{\stackrel{2}{2}}$ & $\begin{array}{l}\text { O̊ } \\
\text { in }\end{array}$ & $\stackrel{ }{\exists}$ & $\stackrel{\circ}{0}$ & $\stackrel{\circ}{\circ}$ & : \\
\hline 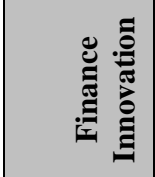 & $a$ & $\stackrel{\circ}{m}$ & $\stackrel{\circ}{m}$ & $\simeq$ & $\stackrel{\circ}{\infty}$ & $\frac{8}{+}$ & 0 & $\stackrel{\circ}{=}$ & $\stackrel{\stackrel{\Im}{\tilde{N}}}{ }$ & $\hat{\imath}$ & $\stackrel{\circ}{m}$ & $\stackrel{8}{8}$ & $\overline{0}$ \\
\hline 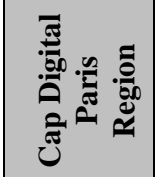 & $\stackrel{\infty}{f}$ & $\stackrel{0}{0}$ & $\check{g}^{\circ}$ & $\underset{\infty}{\ddagger}$ & $\stackrel{80}{\pi}$ & $\stackrel{\circ}{\stackrel{\circ}{m}}$ & $\stackrel{n}{\exists}$ & $\stackrel{\circ}{\stackrel{\infty}{\sim}}$ & $\frac{\stackrel{0}{8}}{8}$ & త্ & 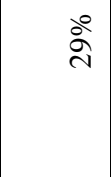 & $\stackrel{80}{\circ}$ & $\stackrel{\text { f }}{0}$ \\
\hline 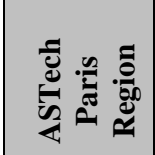 & m & $\stackrel{\circ 0}{=}$ & $\stackrel{8}{0}$ & $m$ & $\stackrel{\circ}{\sim}$ & 80 & $\simeq$ & $\stackrel{\circ}{m}$ & $\begin{array}{l}\stackrel{0}{a} \\
\stackrel{a}{2}\end{array}$ & $\stackrel{\infty}{+}$ & $8^{\circ}$ & $\stackrel{8}{8}$ & กิ \\
\hline 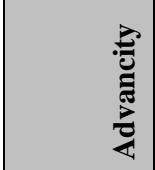 & $\stackrel{\infty}{\sim}$ & $8^{\circ}$ & $\stackrel{ல}{0}^{\circ}$ & $r$ & $\stackrel{\circ}{f}$ & $\stackrel{\circ}{0}^{\circ}$ & $q$ & $\stackrel{8}{0}$ & $\stackrel{\circ}{6}$ & $\stackrel{\infty}{0}$ & $\check{\infty}^{\circ}$ & $\stackrel{\circ}{\circ}$ & ถึ? \\
\hline 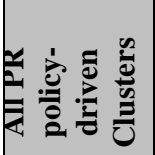 & $\overline{\grave{\lambda}}$ & छ̊ & 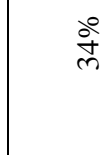 & î & $\stackrel{\circ}{\circ}$ & $\stackrel{\circ}{\triangle}$ & $\frac{6}{7}$ & $\stackrel{\circ}{0}$ & $\stackrel{\stackrel{\circ}{\infty}}{\stackrel{\infty}{+}}$ & : & $\stackrel{\circ}{\circ}$ & ठ̊ & $\stackrel{\infty}{\overbrace{0}^{\infty}}$ \\
\hline 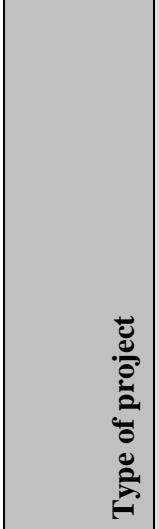 & 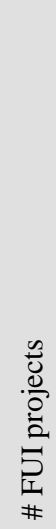 & 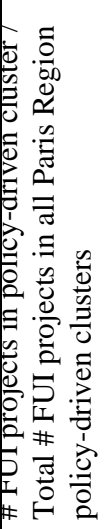 & 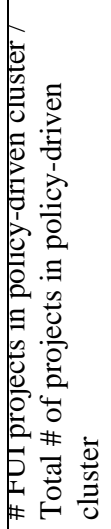 & 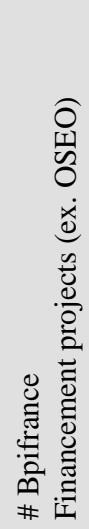 & 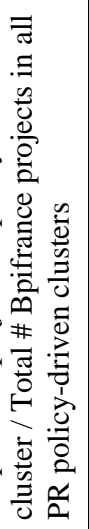 & 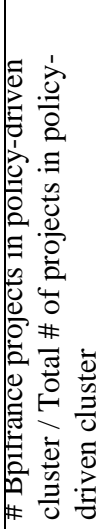 & 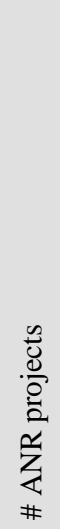 & 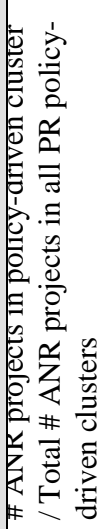 & 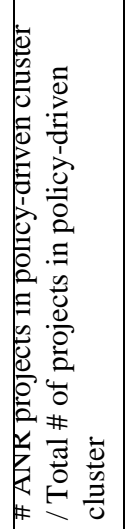 & & 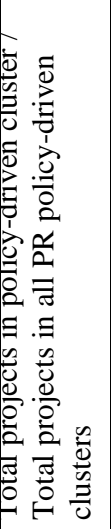 & 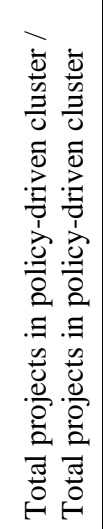 & 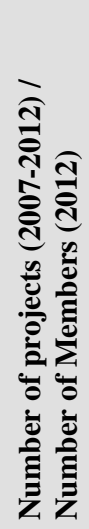 \\
\hline
\end{tabular}

Source: own calculations, data from official policy-driven cluster website (http://competitivite.gouv.fr) 


\section{THIRD PART: EMPIRICAL CASE STUDY - RESULTS \& DISCUSSION}

The results and discussion part is structured in three chapters. Chapter 7 presents HCPR's governance and we discuss the observed dilemmas and developed pathologies. This part is based on our observation period and our follow up interviews with HCPR and two other policy-driven clusters in the Paris Region. Chapter 8 presents the French cluster policy from the collaborative R\&D projects' point of view and analyses which role HCPR plays in the setup process of $R \& D$ projects. This part is based on the interviews we conducted with project leaders, some doctors and additional project consortium partners. Finally, chapter 9 discusses the entanglement of all layers and the observed pathologies. In this last chapter, we not only discuss the observed pathologies, but we also position our findings in the cluster evaluation literature. Finally, we ask the question why HCPR exists, besides all the observed pathologies. An answer might bring the concept "organisation of hypocrisy".

\section{Box 9: Content of third part}

Chapter 7: HCPR's governance: facing dilemmas \& developing pathologies 211

1 Defining objectives, a difficult task: HCPR's performance contract ....................212

2 Managing the ecosystem: A cluster stuck in organisational dilemmas? .224

Chapter 8: Which role does HCPR play in the set-up of R\&D projects? 246

1 Overview of ICT \& Health project leaders and their organisations 248

2 Finding subsidies: Being friend and judge - a schizophrenic situation 258

3 Finding partners: "Las Vegas" weddings thanks to "Meetic" 273

4 Finding ideas: Doctors can't be find at "Meetic" events

Chapter 9: Discussion: how dilemmas drove cluster pathologies in HCPR

1 The identification of HCPR's four side-effect pathologies

2 Existence beyond difficulties: an organisation of hypocrisy?.

3 Enriching the "management model" of cluster policy evaluations. 352 


\section{Chapter 7: HCPR's governance: facing dilemmas \& developing pathologies}

In this chapter we now dig into the French cluster policy through the policy-driven cluster called HealthCluster Paris Region (HCPR). We particularly focus on the functioning and doings of the policy-driven cluster organisation and the dilemmas they face. The chapter presents and discusses the results of our 4-month observational period in HCPR, our follow up interviews with HCPR employees, and all the internal and external documents that we used in order to understand the functioning, actions and challenges of HCPR's governance during the $2^{\text {nd }}$ cluster policy phase (2009-2011, prolonged to 2012).

\section{Box 10: Content of chapter seven}

\section{Defining objectives, a difficult task: HCPR's performance contract .....................212}

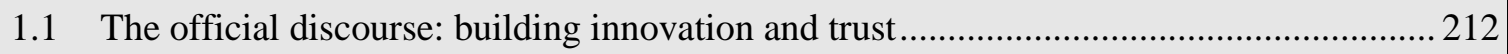

1.2 The content of the performance contract: focalisation on R\&D objectives ....................... 214

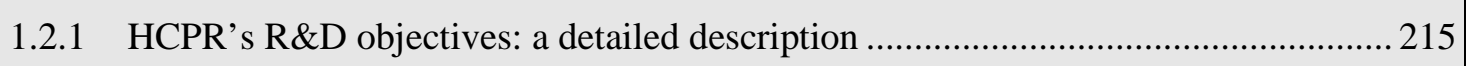

1.2.2 HCPR's animation \& development objectives: a more superficial description.......... 216

1.3 Power games behind the scene: the set-up of the contract and it's visibility ..................... 218

1.3.1 Presentation of HCPR's governance structure: the 4-dimensional matrix system..... 218

1.3.2 The authors of the performance contract: ignoring the operational team .................. 222

1.3.3 The (in)visibility of the performance contract: secretiveness .................................. 223

2 Managing the ecosystem: A cluster stuck in organisational dilemmas? ...............224

2.1 Mapping the Paris Region: who are the "clients"? ....................................................... 225

2.1.1 The inventory: the pride of the development $\&$ animation team ...............................225

2.1.2 Invisibility of the inventory beyond the development $\&$ animation team's office..... 227

2.2 Developing services: torn apart between different objectives.......................................... 231

2.2.1 Asking SMEs of the ecosystem to formulate their needs............................................ 231

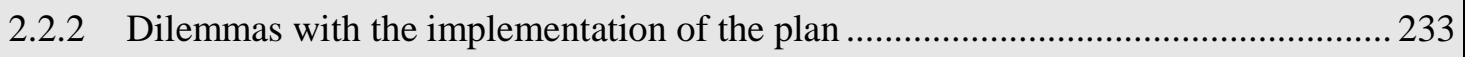

2.3 Developing inter-cluster collaborations: implementation difficulties .............................. 238

2.3.1 Characteristics of the inter-cluster collaboration and set-up difficulties.....................2239

2.3.2 MPRs conflicting relationship with the ICT \& Health initiative ................................. 242

2.3.3 Conclusion: different impacts, depending on policy-driven cluster.......................... 244 


\section{Defining objectives, a difficult task: HCPR's performance contract}

In this section we focus on HCPR's performance contract to understand its set-up and priorities. At the beginning of the $2^{\text {nd }}$ cluster policy phase, every French policy-driven cluster had to sign a binding performance contract with the regional and national authorities that finance the policy. This performance contract stipulates the policy-driven cluster's planned R\&D strategy as well as its animation and development strategy. In this section we show that defining the objectives is already a difficult task. We first present the official discourse that was pronounced during the performance contract signature event, then we dig deeper into the performance contract by looking at the exact content, finally we will discuss the power games that hide behind the set-up of this performance contract. In this section we will be able to start observing dilemmas and pathologies.

\subsection{The official discourse: building innovation and trust}

The performance contract signature ${ }^{189}$ symbolises the official start of the second phase of the cluster policy and represents an important step for every policy-driven cluster. Without signing a performance contract, French policy-driven clusters are theoretically not illegible to participate in the second cluster policy phase (2009-2012). This importance was also symbolised by the location HCPR chose for the official signature ceremony. The performance contract signature took place in the Parisian Trade Exchange building (Bourse de Commerce), the Parisian heart regarding trade and commerce since several centuries.

HCPR chose an important historical building to sign its performance contract in front of journalists, government officials and policy-driven cluster members. The pictures at Figure 22 show that the event was a very formal event with speakers sitting in a straight row facing several tiers of listeners. The event was not conceived to discuss the performance contract or exchange with the audience. During this event, the strategic governance team of HCPR presented its contract, its strategy and its objectives for the $2^{\text {nd }}$ phase of the cluster policy (2009-2012), but also officially signed the performance contract in a ceremonial manner and in the presence of the regional and national authorities. This reinforced the binding character of this new contract. A cocktail followed the official signature of the contract.

$\overline{{ }^{189} \text { Took place on November } 10^{\text {th }}, 2009 .}$ 
In several speeches, HCPR underlined that it positions itself as clearly anchored in the Paris Region ("HealthCluster Paris Region is the cluster that unites major players in the life sciences and healthcare sectors in the Paris Region”, HCPR promotional document, 2009) and that it wishes to become the highest concentration in healthcare in Europe ("The cluster aims at bringing together the highest concentration of expertise and healthcare resources in Europe”, HCPR promotional document, 2009). In order to reach this goal, HCPR focuses on three important cornerstones: Innovation, Partnership and Network (HCPR document, 2009). Emmanuel Canet (the president of HealthCluster Paris Region until 2011) further specified these objectives in a speech he gave at the performance signature event. He particularly insisted on four points that he believes will lead to the success of the HealthCluster Paris Region:

- (1) Creating a cluster spirit and trust: “créer ce réseau d'hommes d'horizons divers, partageant un objectif commun, travaillant dans la confiance. Avec cette volonté d'inscrire leurs actions dans la valorisation et l'innovation. Créer cet esprit cluster avec des hommes qui ont le désir de travailler ensemble."

- (2) Decompartmentalizing the innovation ecosystem: “... décloisonner notre écosystème d'innovation. Faire en sorte que le pôle contribue à rapprocher les différents instituts/organismes de recherche pour accélèrer le transfert de la connaissance, le transfert des technologies dans une volonté d'innovation de technologie, diagnostic, thérapeutique."

- (3) Proposing more and faster financial aid for companies: “... mettre à disposition plus des ressources et des moyens. Des financements à un niveau plus élevé, en particulier, pour les jeunes entreprises. Pour ces entreprises, il faut renforcer le financement, augmenter la rapidité d'accès à ce financement, surtout pour certaines phases de développement"

- (4) Increasing the number of innovative companies: “... augmenter, [...], le nombre des entreprises innovantes, et favoriser la modernisation des grandes entreprises aujourd'hui dédiée à l'innovation thérapeutique."

To sum up, the main objectives of HCPR stay very general and are, typical for clusters, concentrated on creating a "community of people" that trust each other and share the same objectives in order to innovate together. Additionally, more and faster financial resources 
should be provided to the companies to increase regional attractiveness, innovation, jobs, and companies.

Figure 22: Performance contract signature event (November $\left.10^{\text {th }}, 2009\right)$

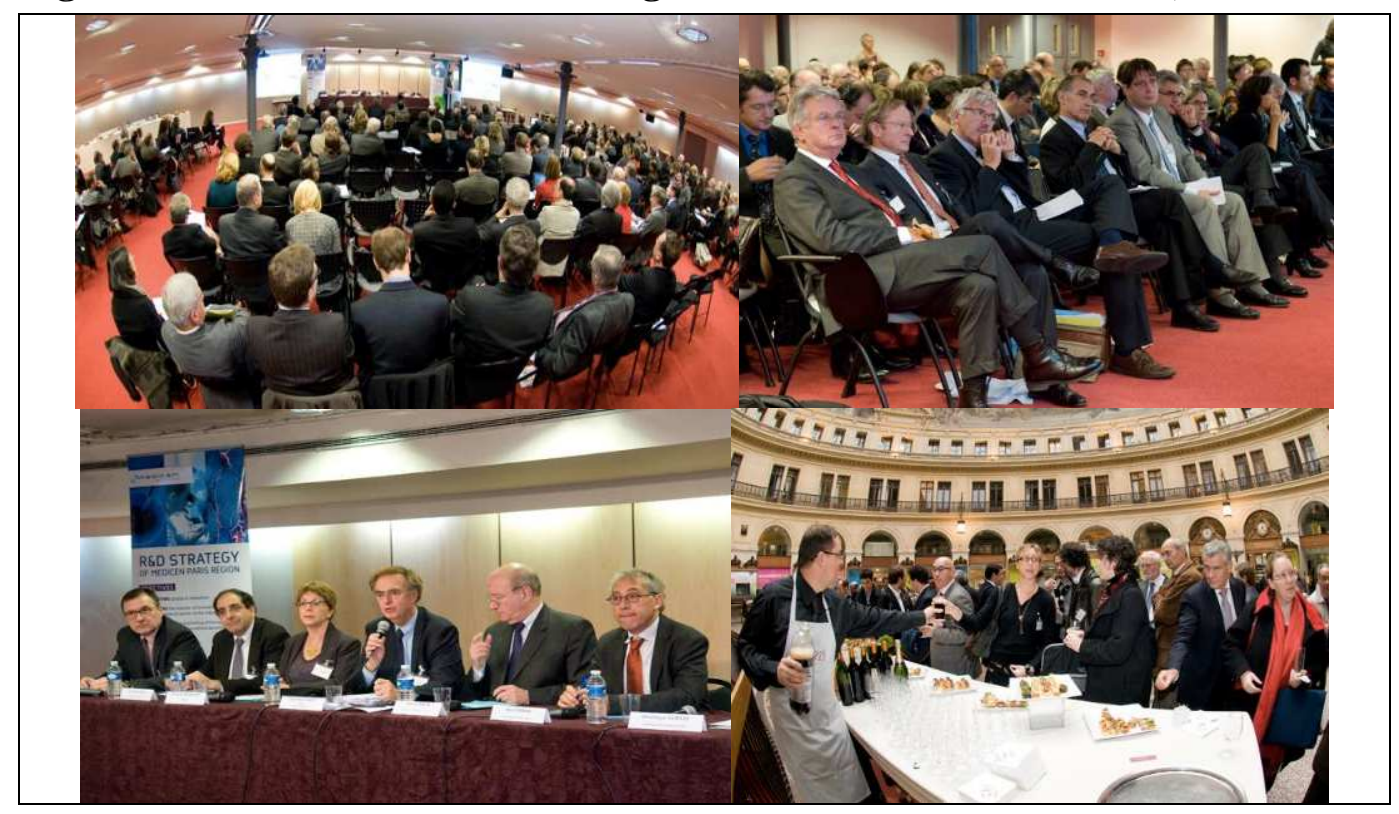

\subsection{The content of the performance contract: focalisation on R\&D objectives}

We now dig into the written performance contract. The written performance contract summarizes exactly the strategy and the different domains that the policy-driven cluster wishes to develop during the $2^{\text {nd }}$ cluster policy phase. The objectives are split into two large domains: (i) technological R\&D objectives (see Annex 9 for the detail) and (ii) animation \& development objectives ${ }^{190}$ (see Annex 10 for the detail). Hereinafter, we present both domains and give examples how the policy-driven cluster has "operationalized" these general domains into concrete impact measures. We will see that the development of the R\&D objectives is more detailed (11 pages) than the animation \& development objectives (6 pages). HCPR exactly knows where it would like to go in research terms, but struggles more to define exactly which type of management should be set-up to support these research objectives.

\footnotetext{
${ }^{190}$ Next to the technological R\&D objectives and the animation \& development objectives, the performance contract also discusses the market objectives (medicinal products market, medical imaging market, biological tools market). However, the market objectives are not discussed with the same detail as the other two main objectives. The market objectives are for example not "operationalized" into concrete actions and outcomes. As we will not focus on these market objectives in our thesis, we decided not discussing them.
} 


\subsubsection{HCPR's R\&D objectives: a detailed description}

HCPR has structured its R\&D strategy around three priorities (see Figure 23). HCPR's three priorities are: translational medicine; biological tools for industrial use and bio-therapeutic products; and biodigital technology (bio-computing, integrating and modelling / e-health / brain-machine interface technology). These R\&D priorities are then further operationalized into programmatic pillars, each programmatic pillar is then further detailed into objectives that are then exactly quantified in terms of challenges, concerned stakeholders, activities ${ }^{191}$, deliverables, deadlines, and impact. We will not detail all the objectives but just give one example in order to grasp the general tenor of the performance contract.

For example, if we look at translational medicine priority, we can distinguish two different programmatic pillars that are associated to this priority: clinical research and medical imaging. The medical imaging programmatic pillar is then further split in three different objectives that HCPR would like to reach until the end of the $2^{\text {nd }}$ cluster policy phase. One of these objectives is for example the creation of "collaborative projects to achieve fundamental breakthroughs in imaging and related technologies". HCPR hopes that "these findings will advance the knowledge of how normal and diseased cell or tissue systems work". For this objective HCPR then further details:

- which actors should be involved in this objective. In this case the involved actors should be the medical imaging working group, including academics from a certain research institute, SMEs, large companies operating in medical imaging and pharmacy. This working group should be supervised from the strategic R\&D committee with the help of HCPR's operational team.

- the different activities that the working group should pursue in order to reach the stipulated objective. The first activity is to "collect the needs of the industrial. [...] in order to structure the programmatic pillar medical imaging and to define a "road map" for biomedical imaging in the Paris Region [...]”, and the second activity is to "design and launch collaborative projects with the objective to generate a technological breakthrough within the framework set by the imaging action plan".

Finally, the performance contract also stipulates measurable deliverables for the objective. In this case they were threefold: (1) action plan for medical imaging, (2) regular update of the

\footnotetext{
${ }^{191}$ Not all the activities listed in the performance contract are actually done by the policy-driven cluster itself. For example, in one case the universities of the region solely carry the proposed activities.
} 
forward looking document (3) start of first collaborative project aimed to generate a technological breakthrough.

To sum up, the technological $R \& D$ objectives are precisely defined in the performance contract and constitute a strategic road map for the $2^{\text {nd }}$ cluster policy phase.

Figure 23: HCPR's R\&D strategy

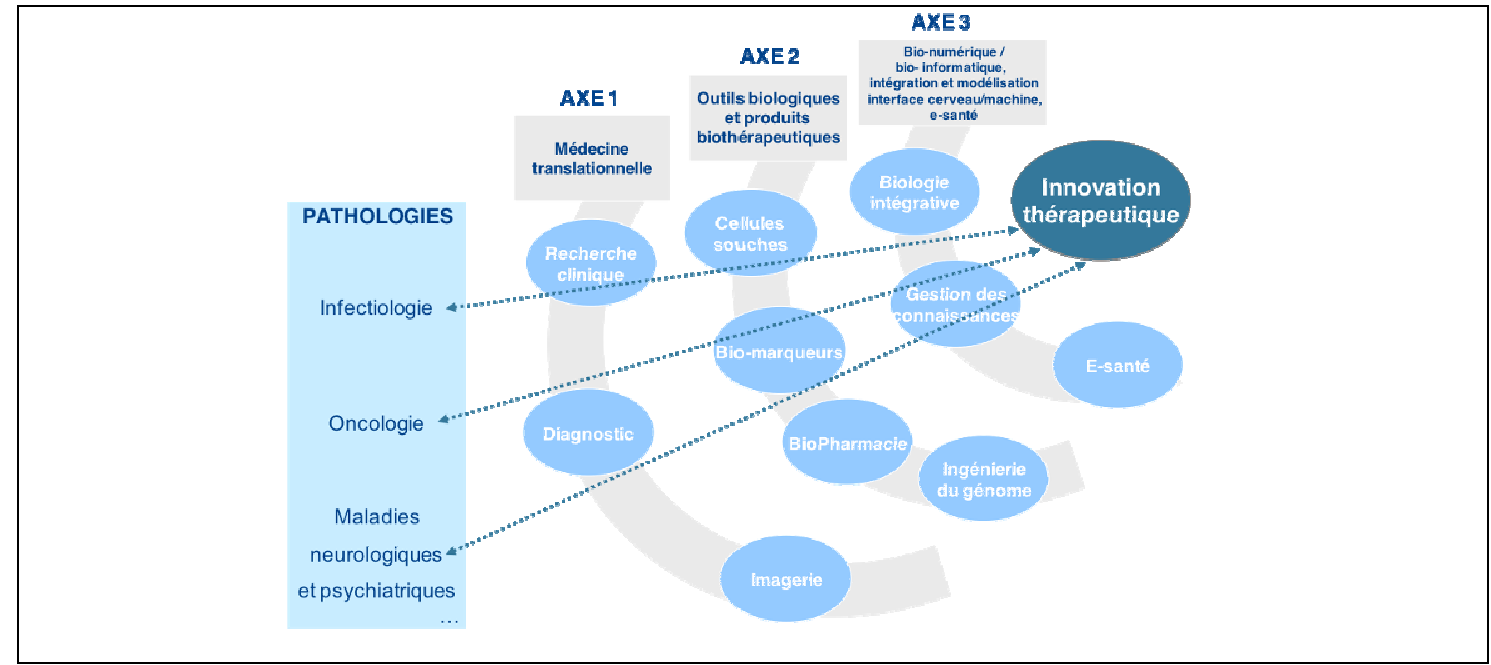

Source: Performance Contract 2009-2012, HealthCluster Paris Region

\subsubsection{HCPR's animation \& development objectives: a more superficial description}

Next to the technological R\&D objectives, the performance contract also details the animation and development objectives for the $2^{\text {nd }}$ policy-driven cluster phase. These objectives are now directly linked to HCPR's operational team that is supposed to implement these objectives. The performance contract stipulates four priorities for the operational team. For every priority of the animation \& development objectives, the performance contract details again the associated challenges, activities \& deliverables, as well as the planned impact. However, the presentation of these priorities is less structured and more confuse than for the R\&D priorities (see Annex 10 for a detailed presentation).

$1^{\text {st }}$ priority - Creating a community of thoughts, objectives and actions: In order to reach this first priority, HCPR particularly underlines that it has to work on the added value of the cluster for its members. The added value is important to motivate local actors to participate in the cluster's activities and to become a member of the cluster. In order to reach this objective, HCPR planned to focus on three different activities: regular exchanges between the members of the cluster (for example round tables, meetings on specific R\&D priority themes); regular 
information sessions organised for the members by the strategic committees; and a complete mapping of its members and potential members. HCPR considers that its actions were successful if it can show an increase of collaborative projects, an increase in members, and an improvement in its image.

$2^{\text {nd }}$ priority - Being the key health actor in the Paris Region: The second priority of HCPR is to become the key health actor of the Paris Region and to harmonise the existent support structure of the region. However, at the same time, this priority also underlines that the financial sustainability of the cluster needs to be looked at and developed. Additionally, HCPR plans to work on the durability of the scientific excellence of the region by developing new trainings and by anticipating future needs.

$3^{\text {rd }}$ priority - Structuring the healthcare sector in the Paris Region: The third priority focuses on how to structure the healthcare sector in the Paris Region. For HCPR the focus lies particularly on identifying who are the SMEs of the region and on understanding the concerns of these SMEs. This should be done by organising regular meetings with the SMEs and by establishing a mapping of all SMEs in the Region. Additionally, HCPR wishes to help the SMEs to better access private and public funding. A success indicator for HCPR is for example the increase of new companies and the increase in jobs offered by these companies.

$4^{\text {th }}$ priority - Developing national and international partnerships: This last priority focuses on the development of national and international partnerships. HCPR assumes that if it wishes to succeed, it has to create partnerships with other national and international clusters. In order to reach this goal, HCPR for example plans to increase its participation in international trade fairs, increase its partnerships with other clusters and organise an important event in the Paris Region. All these activities should help increasing HCPR's notoriety.

To sum up, the different priorities are very large, ranging from creating jobs over establishing contracts with other clusters to mapping the region and organising meetings. This first focus on the performance contract already shows that dilemmas develop around how to actually reach the overall goal of fostering innovation and partnerships in the region. Passing from the general objective (innovation and partnership), announced by HCPR's president during the performance contract signature, to concrete actions, seems to be a difficult task. The different objectives show that HCPR defines a large spectrum of actions to foster innovation 
(exchanges on knowledge, helping in financing, develop trainings, develop various partnerships) (dilemma MD\#2a). Additionally, one particularly interesting objective is that HCPR wishes to become the "key health actor in the Paris Region" by harmonising the existent support structure. However, this ambitious challenge is the first indicator of several structural dilemmas HCPR faces (dilemmas SD\#1, SD\#2, SD\#3). We will still see that realizing such an ambitious objective is not easy in a highly urbanized location where existing support structures are already deeply anchored.

In section 2 of this chapter we will dig deeper into these four priorities of HealthCluster Paris Region and discuss the dilemmas the operational team faces by implementing these ambitious but at the same time vague objectives.

\subsection{Power games behind the scene: the set-up of the contract and it's visibility}

In this sub-section we will now focus on the power games that hide behind the set-up of the performance contract. In order to understand these power games, we first present HCPR's organisational functioning and the different instances that exist within the policy-driven cluster organisation. This is necessary, in order to understand who are the authors that stand behind the performance contract.

\subsubsection{Presentation of HCPR's governance structure: the 4-dimensional matrix system}

HealthCluster Paris Region is a not for profit association (under the French law: "loi 1901") so it is composed out of three official bodies: the assembly general body (AG), the board of directors (CA) and the executive office (BE). All the power of the association cumulates in the executive office (BE) and its president.

The executive office (BE) meets approximately twice a month and is composed out of the president, the vice-presidents, the steering committee presidents, the executive director, and a certain number of representatives of each of the four member panels (i.e. large companies, SME / young innovative companies, research institutes, regional and local authorities) ${ }^{192}$.

\footnotetext{
${ }^{192}$ In a paper we wrote during our thesis (see Annex 20) we analysed how the governance structure has an impact on the resources of policy-driven clusters and we conducted a typology to classify all French policydriven clusters into three different categories. We also analysed all Paris Region policy-driven clusters, except the two policy-driven clusters that were only founded in 2007 (Finance Innovation \& ASTech Paris Region). The results showed that nearly all Paris Region policy-driven clusters (Systematic PR, HealthCluster Paris Region, Cap Digital and Advancity) belong to the same class, which we called "corporate class" (only Mov'éo
} 
In order to prepare the executive office (BE) meetings two regular meetings take place:

- Management committee meeting (CODIR): The management committee meetings have the same members as the executive office (BE) (i.e. president, the vicepresidents, the steering committee presidents, the executive director) with one exception. The representatives of the four panels (i.e. large companies, SME / young innovative companies, research institutes, regional and local authorities) are not participating.

- Operational steering committee meeting (COPIL): The operational steering committee meetings are composed out of the R\&D steering committee president, the development \& animation of the ecosystem steering committee president, and the executive director.

There is one steering committee president for $\mathbf{R} \& D$ and one steering committee president for development $\&$ animation of the ecosystem ${ }^{193}$. Both steering committee presidents are appointed by the respective thematic steering committees. The R\&D steering committee has 36 members, mainly composed out of research institutes and companies. The development \& animation of the ecosystem steering committee has 25 members, mainly composed out of regional \& local authorities and support agencies. These steering committee presidents are the strategic leaders for the respective operational teams and the spokespersons who transform the wishes of the members into thematic groups or activities. For example, the steering committee presidents, with the help of the respective operational teams, transform the performance contract into actions in order to create a "policy-driven cluster ecosystem". Compared to the executive director, who has more a human resource responsibility over the operational

\footnotetext{
belonged to another of the three classes). In the corporate class, groups clearly dominate the supervisory board and the board of directors while SMEs and support entities are rather absent. The corporate class has most of the advantages on its side. First of all, the corporate class has considerably more budget, regardless of the origin, for the animation and the functioning of its policy-driven clusters. Second, it has the highest amount of FTEs (number of full-time equivalents). Finally, its members also receive the highest total amount of public R\&D funding. The good results of the policy-driven clusters of the corporate class might be linked to different characteristics of groups: broad experience in how to obtain research funding, large pool of internal resources (human, financial...), large network of partners which allows forming R\&D consortia in a short period of time, etc. The Paris Region policy-driven clusters were thus clearly belonging to the most "advantageous" policydriven clusters in France.

${ }^{193}$ In September 2010 (when we started our fieldwork), HCPR still had three steering committees (R\&D, Development \& Ecosystem, Animation \& Notoriety). Since then, the Development \& Ecosystem committee absorbed the Animation \& Notoriety committee to form a new committee called "Development and Animation of the Ecosystem" committee. Today, HCPR has only two committees (i.e. R\&D steering committee \& development; animation of the ecosystem steering committee) (see Figure 24 vs. Figure 25).
} 
team $^{194}$, the two steering committee presidents play a major role in the policy-driven cluster. They are responsible for the content of the policy-driven cluster's actions.

The operational team is composed out of 13 permanent full time employees ${ }^{195}$. The two steering committee presidents coordinate all actions with their respective operational teams (one operational team dedicated to $\mathrm{R} \& \mathrm{D}$ and one operation team dedicated to development $\&$ animation of the ecosystem). The operational teams themselves do not have any decision authority. This lack of decision authority is something that the operational teams perceive as very frustrating in their daily work. Just to give an example, we asked the development \& animation of the ecosystem team several times why certain events in the medical domain were not figuring on the HCPR website. They told us that they are not allowed to put any type of information on the website before official validation, a situation that frustrates them a lot. The two operational teams are constantly present in the policy-driven cluster office. This is not necessarily the case for the steering committee presidents. During our fieldwork we were primarily in contact with the operational teams.

The organisational structure of HCPR is complicated or as one of the members of the operational team said, "We are in a 4-dimensional matrix system" ${ }^{\text {"196 }}$. In fact, the actions of the operational team depend on a multitude of actors and committees, who all have a word to say regarding the actions of the operational team. The operational team depends for example on the strategic R\&D committee president and its different members, on the strategic development $\&$ animation of the ecosystem committee president and its different members, on the general cluster president, and on the executive director.

During our fieldwork period we were able to access two different organisational matrixes of HCPR. The two charts are interesting, because they represent two different views of HCPR. The first organisational matrix is an official chart presented during a meeting with HCPR's public funding bodies in October 2010 (see Figure 24). The chart was prepared by one of the operational team members. The operational team considers the steering committees as a mirror image of their own teams.

\footnotetext{
${ }^{194}$ At the moment, the executive director and the development \& animation of the ecosystem steering committee president are one and the same person. However, this was not the case when we started our fieldwork.

${ }_{195}$ This includes the executive director.

196 "On est dans un système matriciel à 4 dimensions."
} 
This mirror image view is not the case if we look at a second organisational matrix (see Figure 25). The second organisational matrix is an official chart presented during an assembly general meeting of HCPR in December 2012. In this chart we see that the executive office (BE) is put in the centre of the whole policy-driven cluster. However, the committees that represent the members (i.e. the four hexagons that are in each corner ${ }^{197}$ and the hexagon representing all members) are the biggest of the chart. However, the operational team nearly vanishes in the chart and is much less visible than in the chart prepared by the operational team itself.

To sum up, the organisational charts and the impression of the 4-dimensional matrix system announce HCPR's leadership dilemma. Several people seem to be in charge of HCPR's actions and strategy. This shows that the cluster tries to represent in an egalitarian manner the different members, but we will still see that this also creates a high conflict potential within the organisation (dilemma MD\#1a).

Figure 24: Official chart presented during a meeting with the public funding bodies

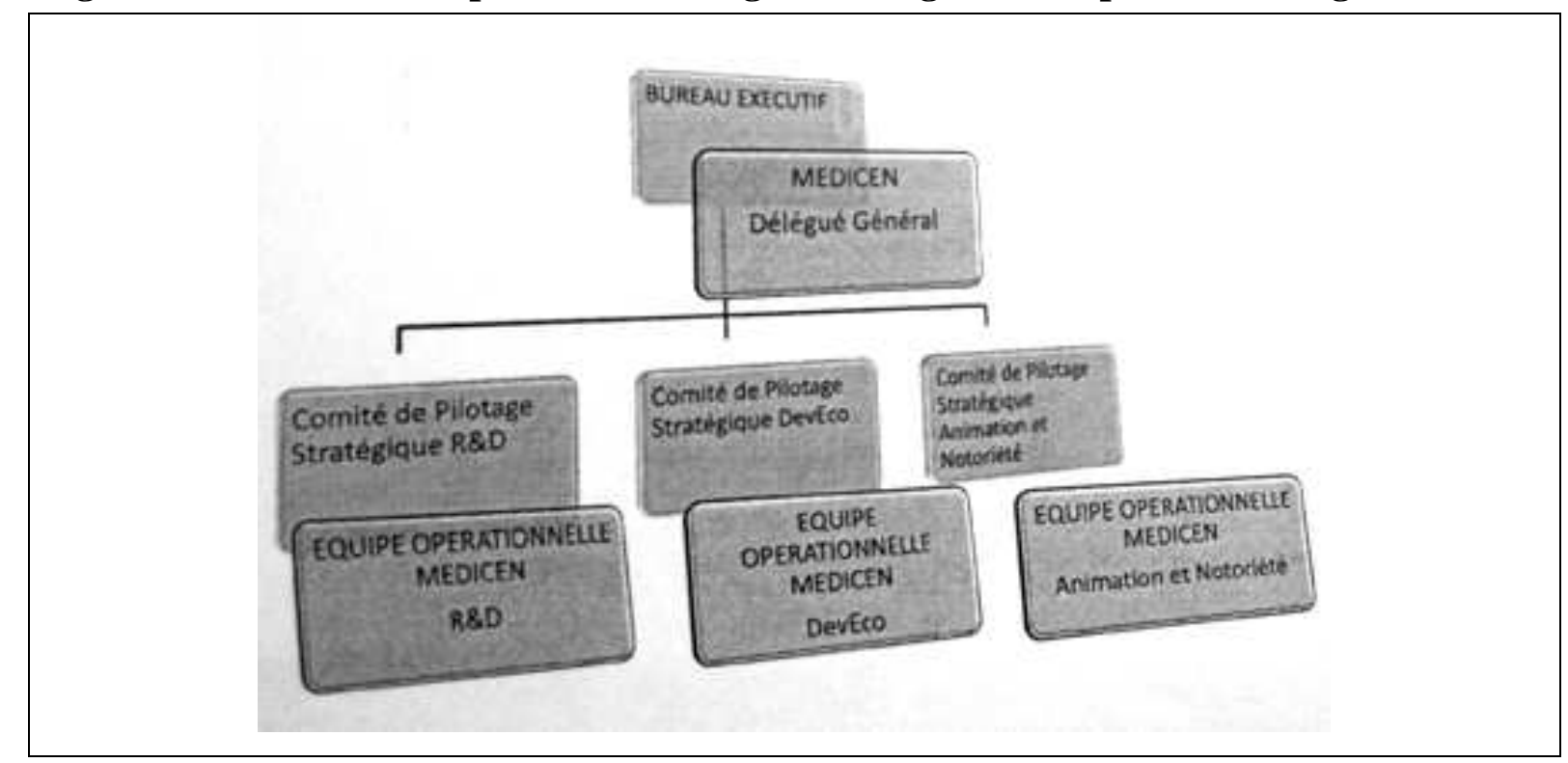

Source: Internal Document HealthCluster Paris Region (01/10/2010)

\footnotetext{
${ }^{197}$ Assembly general body (AG), four member panels (4 collèges), R\&D steering committee (Comité stratégique R\&D), Development \& animation of the ecosystem steering committee (Comité DevEco)
} 
Figure 25: Official chart presented during an assembly general meeting

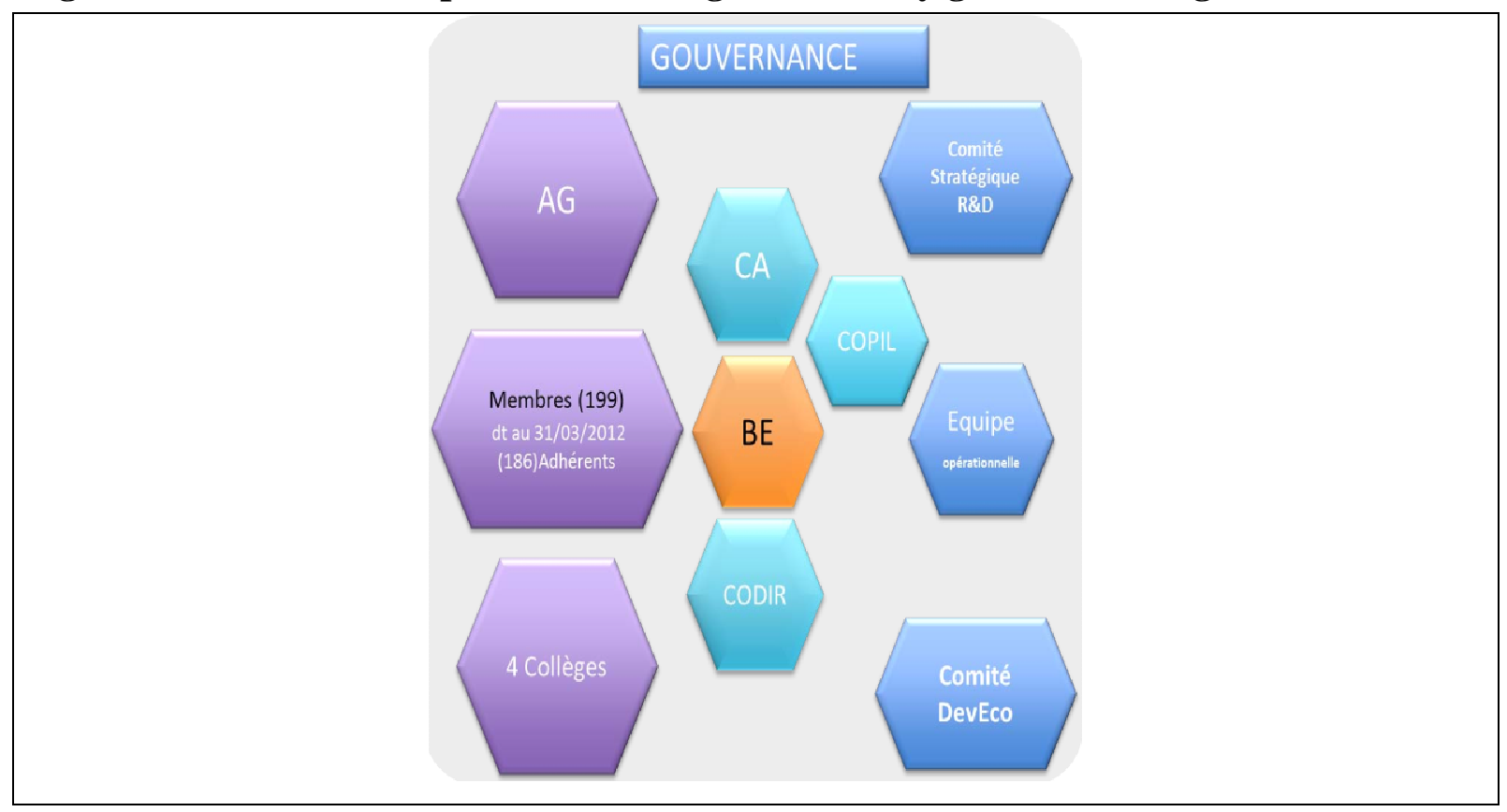

Source: Internal document HealthCluster Paris Region (31/12/2012)

\subsubsection{The authors of the performance contract: ignoring the operational team}

We talked with two members of the operational team in order to understand the set up process of the performance contract:

- The $1^{\text {st }}$ operational team employee told us that the HCPR's members (i.e. large companies, SMEs, research institutes, regional and local authorities) elaborated the performance contract in a collegial manner. The different colleges did several working groups and were assisted in this process by an outside consulting firm. The operational team was not involved.

- The $2^{\text {nd }}$ operational team employee was more critical regarding this process. The employee told us that the governance team does not collaborate with the operational team. They never see each other. The governance team established the performance contract without integrating the operational team. The operational team never saw the performance contract before it was signed and then the governance team just gave the performance contract to the operational team and told them: "Now make what we decided.”

The common denominator of the two comments is that "they" elaborated the performance contract and that the operational team was not included, something that frustrates the operational team because it's them who have to translate the performance contract into 
actions. The operational team sees itself as a crucial element within the policy-driven cluster ecosystem, but whom one does not give enough decision autonomy to animate in a best possible manner the local ecosystem. During our investigation period the operational team told us at several occasions that the animation \& development objectives stipulated in the performance contract are very confuse and that they are dubitative if these objectives will help building a real local ecosystem.

To sum up, we see once again that HCPR's operational team is the entity that seems to have the least amount of power among the different instances. However, it is this operational team that is responsible for animating and building the ecosystem (dilemma MD\#1a). Additionally, the reaction of the $2^{\text {nd }}$ operational team member and the general discussions we had with the operational team already announce a first pathology that we will find at several occasions: distrust. In this case it is a lack of trust between operational team and strategic governance. The operational team, frustrated from the little responsibility they have, stands in conflict and do not trust the strategic governance. The cluster seems to face the dilemma of listening to a range of different members and integrating their various (certainly very valuable) wishes, and listening to the operational team that has maybe more experience in managing networks of different actors.

\subsubsection{The (in)visibility of the performance contract: secretiveness}

The idea of the performance contract is to bring together all policy-driven cluster members behind one common vision that clearly stipulates the research and development objectives and the associated activities. This common vision should allow each member to know exactly where the policy-driven cluster is heading and how each member can participate in order to reach the goal.

However, during our fieldwork period in HCPR's physical office in the 15th district, the different task forces that are responsible for each of the defined objectives in the performance contract were "invisible". The office of HCPR is very small with no dedicated conference rooms ${ }^{198}$. The meetings of the different innovation task forces for the performance contract

\footnotetext{
${ }^{198}$ HCPR moved to another building recently but during the majority of the $2^{\text {nd }}$ policy phase they were in a building with only one small conference room. The room was very small and additionally the printer of the association was positioned in this conference room. Thus during meetings, employees of the association, not participating in a particularly meeting, regularly interrupted meetings in order to get their printings.
} 
did not necessarily take place in the HCPR office but at member locations. The meetings take place outside the daily radar of the operational teams.

Additionally, the actions of these innovation task forces are not visible on the HCPR website. We received the detailed performance contract only after numerous requests from an HCPR representative ${ }^{199}$, otherwise we would not even be aware of the details stipulated in the HCPR's performance contract (i.e. the technological R\&D and animation \& development objectives). It is a closed circle of members that is aware about the detailed innovation objectives of the policy-driven cluster. All others have the general information that can be found on the website or in promotional materials.

To sum up, there is secretiveness around the performance contract. This secretiveness is particularly interesting regarding the managing innovation dilemma (dilemma MD\#2a). Innovation processes can be handled in a more or less open manner. The associated pathology that we deduct from this dilemma is again distrust. This time the lack of trust exists between the members of the policy-driven cluster and the wider ecosystem. The dilemma emerges because of the wish to protect the members and the ideas of the community and the wish to build a cluster where knowledge circulates freely.

\section{Managing the ecosystem: A cluster stuck in organisational dilemmas?}

In this section, we focus on the operationalization of a selection of HCPR's animation \& development objectives that were particularly important during the $2^{\text {nd }}$ cluster policy phase (i.e. mapping the ecosystem, developing services, shifting organisational boundaries). All of the discussed activities are stipulated as objectives in the performance contract signed in November 2009 (see Annex 10). This analysis allows us to gain a deeper understanding about the role of the operational team to structure the local ecosystem and to foster innovation and collaboration among its members. Every sub-section will be structured in the same manner. We first present the activity realized by HCPR's operational team and then we decorticate the different dilemmas and pathologies that emerge by implementing and managing these activities.

\footnotetext{
${ }^{199}$ For anonymity reason, we prefer to stay rather vague.
} 


\subsection{Mapping the Paris Region: who are the "clients"?}

One objective of the performance contract was to conduct an in-depth inventory of all the different biotechnology and health actors that are located in the Paris Region ${ }^{200}$. The result of this in-depth inventory should be summarized in a mapping that should then be made accessible for the wider public through the intranet and the extranet. The inventory and mapping was primarily conducted in 2010 with the help of an external consultancy firm. We first present the set-up and the results of the mapping and then discuss the institutional challenges of rendering the results visible to the ecosystem.

\subsubsection{The inventory: the pride of the development $\&$ animation team}

The mapping of Paris Region's biotechnology and health sector was done in three steps: first counting the actors of the ecosystem, then defining the value chains, and finally positioning the SMEs on the identified value chains.

First step: counting the actors of the ecosystem. The first step of the inventory was to count all actors that are situated in the Paris Region and that are active in the biotechnology and health sector. The perimeter of the biotechnology and health sector was defined by distinguishing three different perimeters (internal document 10/2010): core target, sector, and ecosystem.

- The actors that are in the first perimeter of the policy-driven cluster are called "core target" which includes "all SMEs (less than 250 employees) involved in innovation and value creation in the targeted industry, having more than 50\% of their activity on human health and $a \mathrm{R} \& D$ activity in Ile-de-France”.

- The second perimeter is called "sector". Which of course includes the "core target" population but additionally "economic actors [...] who are directly involved in the research, development and production of drugs, medical devices, diagnostics and analysis, excluding distributors and providers. These players must have over $50 \%$ of their activity in human health and have at least an implantation in Ile-de-France."

- The last perimeter is called "ecosystem" which of course includes all the actors already mentioned but additionally "all organizations that contribute to the advancement of human health, research institutions to health providers, by passing through business, government, the education community and financers."

\footnotetext{
${ }^{200}$ Priority $1 \&$ Priority 3 of the animation \& development objectives in the performance contract, see Annex 10.
} 
HCPR's operational team, together with an external consulting firm, identified all regional actors that belonged to the defined ecosystem. Figure 26 shows the first result of this inventory. In total 2462 entities were identified. These entities included in an ascending order: training institutes (32), financial or innovation support service providers (81), research institutes (83), companies with a related activity to human health and that can be a secondary market for the SMEs of the sector (191), companies with a support activity for human health companies (634), and finally, the largest group, care facilities for patients (1441).

Figure 26: Ecosystem of the Paris Region Biotechnology and Health Sector

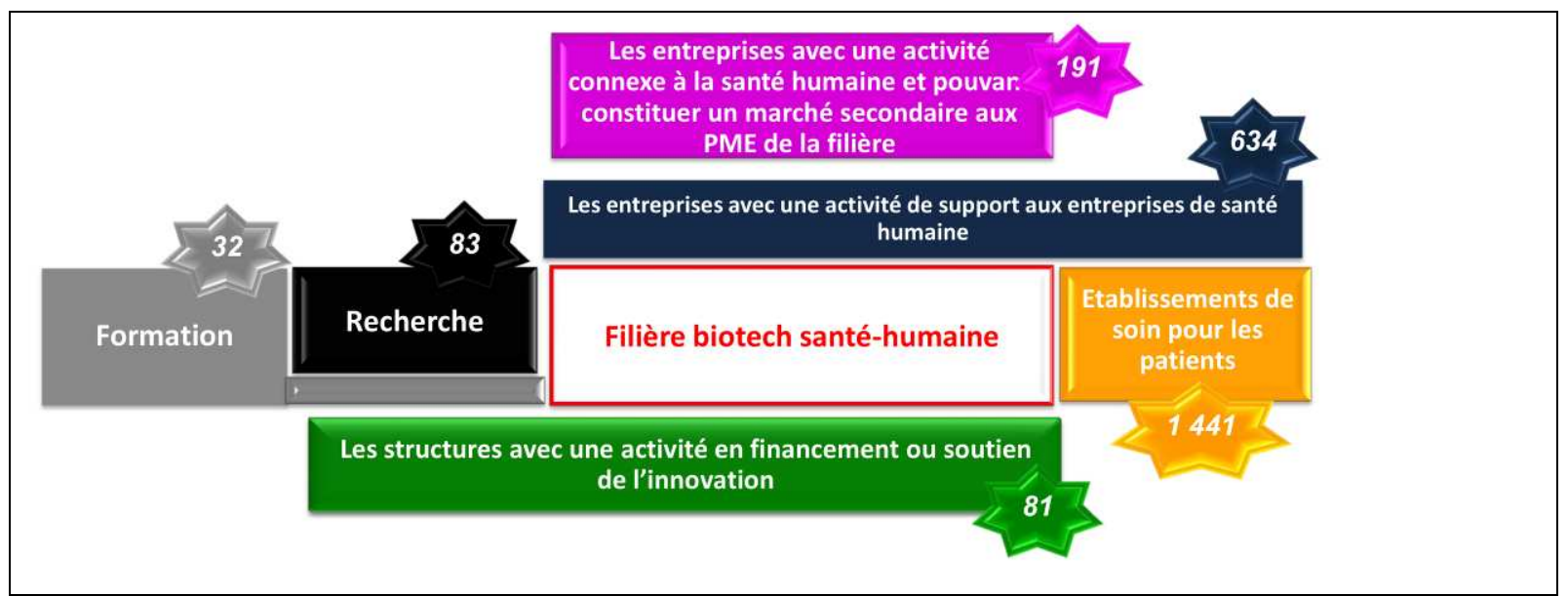

Source: Internal document (10/2010)

Second step: defining the value chain. The second step consisted in defining the exact value chains of the ecosystem. The cluster organisation defines a value chain as: "All consecutive chain elements of a process that allows transforming an idea, an invention or a concept (upstream of the value chain) in economic value (downstream of the value chain) leading to the patient. Within a value chain, several entities are positioned and interact with each other according to their professions, their respective skills and mutual expertises" (internal document 10/2010). ${ }^{201}$ A value chain consists of different chain elements (the actors of the ecosystem) that interact with each other in order to bring an invention to the market. HCPR identified a total of nine different value chains that are important for the biotechnology and health sector in the Paris Region (see Annex 11). These value chains include for example a value chain on "preventive and therapeutic vaccines" (value chain 1) and a value chain on "medical devices" (value chain 7).

201 “Ensemble des maillons constitutifs d'un processus permettant de transformer une idée, une invention ou un concept (amont de la CDV) en valeur économique (aval de la CDV) aboutissant au patient. Au sein d'une chaîne de valeur, plusieurs structures sont positionnées et interagissent les unes avec les autres en fonction de leurs métiers, leurs compétences et expertises respectifs." (internal document 10/2010) 
Third step: positioning the SMEs on the identified value chains. In a third step the operational team then placed the 330 identified SMEs on the 9 value chains (see Annex 11). This revealed that some value chains count a considerable amount of SMEs, as for example the medical devices value chain (value chain 7) with 94 SMEs, while other value chains only count a few, as for example the gene therapy value chain (value chain 2) with only 5 SMEs. Each of these 9 value chains was then split up into distinctive chain links to visualize for each value chain the amount of companies that are close to idea generation or close to the market. (Annex 11 gives an example how such a representation looks like).

To sum up, the final result of this inventory was a global overview of all value chains of the ecosystem and also the identification of the exact geographic position of each actor and value chain (see Annex 11). For example, this analysis showed in which domains the PR has a lot of SMEs (more than half of the SMEs (179 out of 330) are situated in the medical device or service sector) or in which domains the PR has a lot of big and intermediary companies (one third of large or intermediary companies are within the synthetic chemical molecule domain (55 out of 169) but no large or intermediary companies are in the gene and cell therapy domain). With the help of these mappings the operational team hoped to develop tailor-made services for the actors of the ecosystem.

\subsubsection{Invisibility of the inventory beyond the development \& animation team's office}

In 2010 the operational team put a lot of effort into establishing the anatomy of the Paris Region's biotechnology \& health sector. When we started the fieldwork period the operational team had just finished the mapping of the biotechnology \& health sector, talked a lot about it and also displayed it on the wall of their office ${ }^{202}$. The objective of the development $\&$ animation team was now to create services adapted to each value chain and each chain position. Additionally, the operational team planned (as stipulated in the performance contract) to make the mapping accessible to the wider community through an interactive tool on the intranet and extranet. Rendering this mapping accessible had two objectives:

\footnotetext{
${ }^{202}$ The development \& animation team had a separate office from the R\&D team.
} 
- to help everybody who is interested in PR's biotechnology and health sector to gain a detailed picture of the sector. This would for example help companies to find appropriate partners for their collaborative research projects.

- to help the R\&D team. In case a HCPR member calls the R\&D team to find a collaborative $R \& D$ project partner specialised in a certain domain, the $R \& D$ team could then use this inventory to find the best match within HCPR's ecosystem.

However, the mapping stayed largely invisible.

\subsubsection{External and internal (in)visibility}

The results of this mapping were officially presented to HCPR's members during HCPR's annual convention in October 2010. However, since the official presentation of the mapping in October 2010 and up to June 2013, the results of the mapping were never put on the website. The website does not mention the different value chains that were identified. Only somebody who knows that this inventory was done can launch a Google search on value chain and HCPR and then access the official presentation that was presented in October 2010, but nothing else. The mapping stays thus invisible to the ecosystem.

However, it is not only invisible to the ecosystem but also to the $R \& D$ operational team. During our fieldwork observation period 2010/2011 the R\&D team and the development \& ecosystem team hardly communicated with each other. The R\&D team for example did not really know what the development $\&$ ecosystem team was exactly doing, even though their offices were just some meters apart. When we interviewed somebody from the R\&D team in October 2011, so one year after the official presentation of the value chain mapping, the R\&D team still did not use the mapping for the partner finding process, and continued to search for potential partners on the Internet:

"Là aussi il faudrait que [la collaboration entre les deux équipes au sein de HCPR] se fasse mais c'est toujours pas le cas. [..] Donc qu'est ce que je fais? Je vais sur le site de Biotech France, je vais sur internet, et je cherche par mot clé et je regarde. Quand par exemple quelqu'un me demande un partenaire qui fait du diagnostic, je le fais par mes propres moyens. »(October 2011)

Even for us it was difficult to access the value chain mapping. We were able to access a written document that one gave us in the beginning of our fieldwork and the official presentation that was done during the Convention in October 2010. However, we never received the additional documents that were prepared by the external consultancy firm, even though we asked for it several times. There is not only an external visibility problem but also 
an internal visibility problem. In January 2012, an operational team member sent us the officall mapping (see Annex 11: Figure 53 and Figure 54).

\title{
2.1.2.2 Political agendas
}

We do not have an official explanation for the visibility problem as our different interview partners never wanted to address the problem directly. However, the main answer was always: "political agendas". There were two indirect and related explanations that constantly popped up when addressing these difficulties:

The first element that was constantly mentioned by our interview partners from the operational teams is that the prestigious institutes of the Paris Region all have their own political agenda:

\begin{abstract}
"[HealthCluster] n'a pas forcément une belle image à l'extérieur, parce qu'il y a cette composante politique qui est forte, mais c'est aussi très complexe. Les entités sont tellement différentes. La philosophie même. Il y a quand même des institutions d'excellence à Paris. Par exemple si tu prends le pôle Santé à Toulouse ou à Lyon, ils ont moins de difficultés que nous. Parce qu'à Lyon il y a certains gros Bio, mais ils ne sont pas énormes. Ils ont une petite Région. Ils se connaissaient tous, alors à Paris, il y a les grands hôpitaux, il y a les grands professeurs qui ne s'entendent pas forcement. Il y a tout ça. Il y a tout ce microcosme à Paris qui est compliqué, compliqué à gérer. [...] [l'institut de recheche médical] qui est mondialement connu pour [une certaine maladie], [l'université] aussi pourtant ils n'arrivent pas à s'entendre. Alors il y a des spin-offs qui sortent de tout ça mais les gros gros, ils ne s'entendent pas parce qu'ils tirent chacun leur couverture de leur côté, leur notoriété. Et ça n'existe pas dans les autres régions en France. Donc ça aussi ça apporte une difficulté. C'est pour ça que je dis, la composante politique est très très importante dans la Santé à Paris parce qu'après je ne sais pas si dans le numérique à Paris il y a cette composante politique forte. » (October 2011)
\end{abstract}

The comment shows that the different actors in the Paris Region are very prestigious and well known but that they do not get along well together. This problem is apparently not new but historically deeply anchored in their behaviour and in the Region. According to our interview partners these problems are less frequent in policy-driven clusters outside of the capital region.

The second element that was constantly mentioned concerns the strong basic research orientation of HCPR and the attached political agendas. This was another element with which our interview partners tried to justify the difficult and complex situation of HCPR compared to other policy-driven clusters. The Paris Region is a region that has excellent research institutes like for example the CEA, the Pierre and Marie Curie University, or INSERM. All of these institutions are highly respected and successful in emerging research domains. One HCPR manager for example told us: 
« Nous c'est plus des chercheurs, des professeurs. Déjà ils sont dans un intellect, qui n'est pas du tout le même que celui des ingénieurs, qui est beaucoup plus pragmatique, qui doit de toute façon donner un produit, mettre quelque chose sur le marché. Il y a du business. [...] Alors nous, en recherche fondamentale, ce n'est pas grave si ça ne sort pas. [...] On fait de la recherche, on est pharmacien, on est médecin, on est clinicien. Tous ces gens là ils n'ont pas la même vue ou le même objectif qu'un ingénieur qui fait du logiciel, de l'informatique, qui est plus carré. Différents métiers, différents secteurs. 》(Octobre 2011)

HCPR's governance seems mainly driven and motivated by basic research. In the context section we already saw that HCPR has a special position among the policy-driven clusters in the Paris Region as $50 \%$ of its members are operating in research and scientific development, the highest percentage of all policy-driven clusters situated in the Paris Region. Our interview partners confirm this strong research orientation. However, the medical domains discussed in HCPR's performance contract differ to the medical domains of the majority of the companies actually present in the Paris Region. According to the HCPR's value chain mapping, medical device (94) and service SMEs (85) are overrepresented within the HCPR's ecosystem. However, even though number wise these companies are overrepresented, they are not particularly addressed in HCPR's performance contract. In the technological R\&D objectives of the performance contract the word "medical devices" (the value chain that counts most of the SMEs) is only mentioned once. Additionally, there is no chapter only dedicated to the medical service industry, the second biggest value chain. Instead, the performance contract discusses in detail the $R \& D$ objectives of the two smallest value chains, namely gene therapy (5 SMEs and no big companies) and cell therapy (8 SMEs and no big companies). These specialised medical firms are conducting cutting edge research and are particularly concentrated in the world-class bio campuses in the Paris Region (for example Genopole or Cancer campus), but they are not representing the majority of the companies in the ecosystem. The performance contract thus concentrates on cutting edge research domains but is less representing the majority of the local companies.

To sum up, according to our interview partners, "political agendas" are at the root of why the mapping of the biotechnology \& health sector was kept "invisible". HCPR struggles to get things done because of leadership issues (members vs. operational team) (dilemma MD\#1a). HCPR's prestigious members have a strong word on what gets published and what does not get published on the website. In case the political agendas of the members are in danger, the work of the operational team can be blocked. These leadership struggles go hand in hand with the structural characteristics (dilemma SD\#2c and SD\#3b) of the Region. The degree of closeness between the local actors in a dense region such as the Paris Region seems to be 
a particular dilemma for the operational team. The advantage of the HCPR is that it has a lot of prestigious universities, institutes and research parks on its territory. However, all of these structures already existed before the establishment of HCPR and already had a certain manner to function next to each other and with each other. HCPR now tries to put these different well established structures around one table. The operational team seems to be powerless in front of this political complexity. For a policy-driven cluster, having a high amount of prestigious institutes on its territory seems to render the task of building a policy-driven cluster more complicated. Even though a cluster organisation should represent the wishes of its members, the prestigious nature of the members and the regional specificities create also a side effect: the pathology of non-conformity.

\subsection{Developing services: torn apart between different objectives}

A second objective of the development $\&$ animation team was to develop tailor-made services for the companies situated in HCPR's ecosystem. More precisely, the objective was to develop services for the local SMEs according to their position on the value chain mapping. Developing these services was a major cornerstone for the development \& animation team during the $2^{\text {nd }}$ policy phase ${ }^{203}$. Hereinafter, we present the plan and the associated services as well as the institutional dilemmas that emerged during the setup of this plan.

\subsubsection{Asking SMEs of the ecosystem to formulate their needs}

In the beginning of the $2^{\text {nd }}$ policy phase, HCPR did an in-depth diagnosis of its ecosystem. This allowed the operational team of HCPR to set up the value chain mapping but also to get connected to the companies of their region. The HCPR's operational team interviewed the SMEs of its ecosystem in order to understand their needs but also their expectations towards HCPR. The HCPR operational team asked them for the first time "What are actually your needs?" in order to better adapt their services:

"Nous notre question était: "Quel sont vos besoins? "C'était vraiment une phase
d'écoute. [...] C'était assez nouveau [...] [avant c'était eux qui venaient].
[...] [Maintenant] on va les rencontrer en face à face. Et on discute de "Quels sont vos
besoins ». [...] On a interviewé 77 je pense. [...] Soit on le fait au téléphone soit en face à
face. Ca c'est assez nouveau et intéressant. Je pense que c'est une bonne pratique. [...]
D'aller voir les personnes et de discuter avec eux. D'échanger. [...] Il faut qu'on arrête de
se cacher derrière la technique. "(October 2010)

For HCPR's operational team these interviews constituted a considerable change of functioning compared to the $1^{\text {st }}$ cluster policy phase (2005-2008). During the $1^{\text {st }}$ cluster policy

${ }^{203}$ Priority 3 of the animation \& development objectives in the performance contract, see Annex 10. 
phase the operational team was mainly concentrated on "finding subsidies" for R\&D projects and had more a passive attitude, waiting for the companies to contact HCPR. However, in the beginning of the second policy phase, HCPR's operational team really started to reach out to their members and to become more active.

HCPR's operational team started to work on the new services plan in the beginning of 2010 and the interviews with the SMEs took place between May and July 2010. In September 2010, when we started our fieldwork, the operational team had already grouped the different wishes and needs in three domains: a social domain, an economic domain and an environmental domain. In the "social domain" category, the contemplated actions and services were concentrated on the competence development of SMEs. In the "economic domain", the contemplated actions and services were concentrated on enterprise development and in the "environmental domain", the contemplated actions and services were concentrated on innovation development.

Figure 27 shows a photo that we took from a white board that was positioned in the animation $\&$ development team office in October 2010. This chart gives the first overview of the main categories they identified based on their interviews. Every domain was then further declined into different actions. Additionally, partners and indicators had to be defined for every domain. When we integrated the HCPR's operational team, HCPR's operational team just entered into the negotiation phase with a selection of regional partners. Collaborating with these regional partners to develop the new services was necessary, because HCPR was (structural and financial wise) not able to carry the planned services alone. They entered into negotiations $^{204}$ with other regional partners in order to distribute the different tasks and responsibilities of the new contemplated services.

In autumn 2010, the challenge of the HCPR's operational team was thus not only to transform the collected "wishes" and "expectations" into concrete services, tasks, budgets, and indicators ${ }^{205}$, but also to find the right regional partners that could help setting up the new tailor-made services for the local SMEs operating in the biotechnology \& health sector. Table 39 summarizes the roadmap for the development of the new services.

\footnotetext{
${ }^{204} \mathrm{We}$ were able to participate in these meetings.

205 «On raisonne avec les attentes des entreprises et [après] on doit les décliner sur des actions. Et de l'action on doit décliner des taches et des taches on décline des partenaires potentiels. Et après on va définir des budgets et des indicateurs. Ça c'est vraiment l'arbre récent des fiches d'actions »(October 2010)
} 
Figure 27: Défi Biotech Santé Plan - October 2010

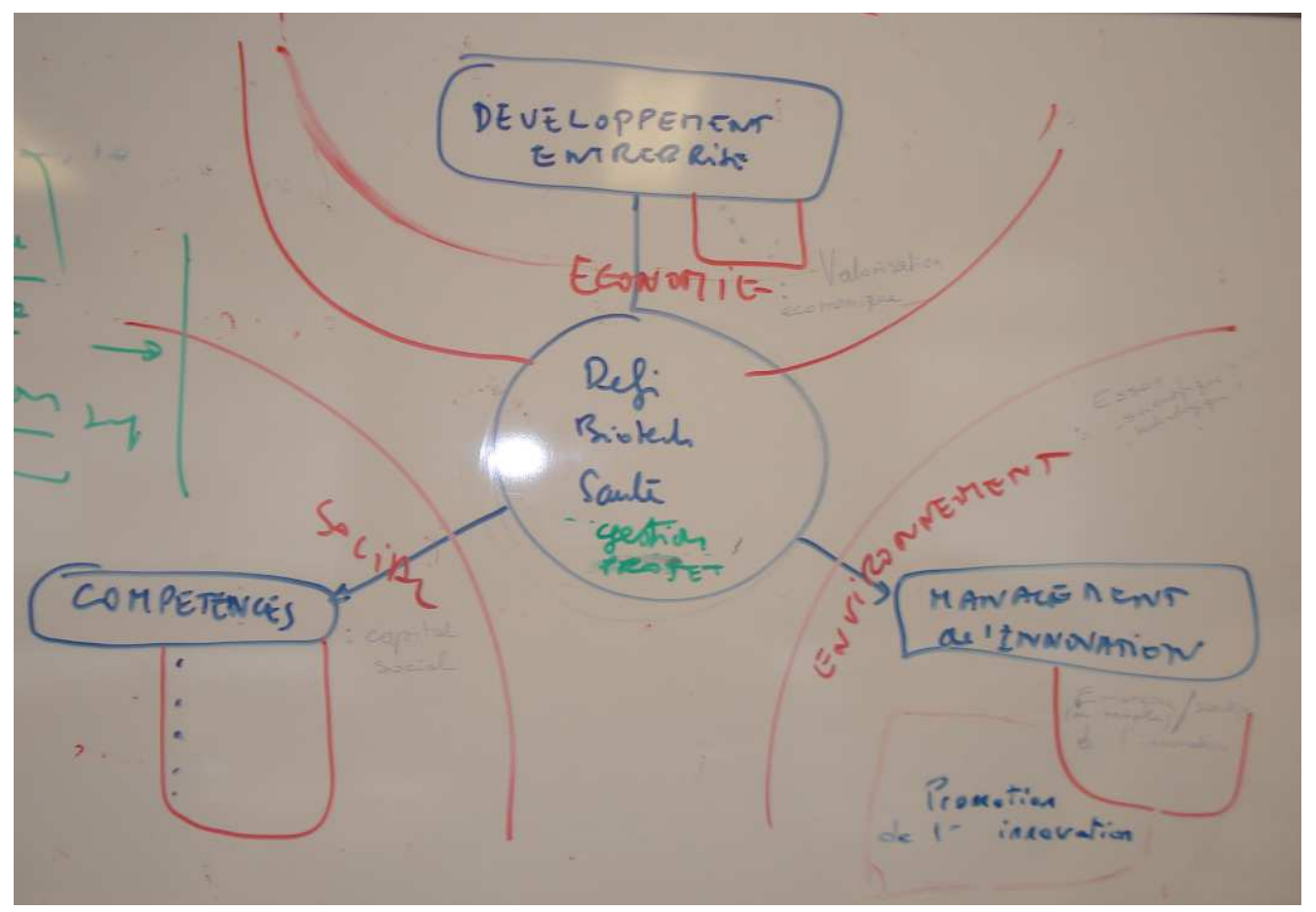

Table 39: Roadmap for the development of the HCPR's services (2010)

\begin{tabular}{|l|l|l|}
\hline Phase & Period & Objective \\
\hline Phase 0 & Jan. - May 2010 & Launch of the Défi Biotech Santé plan \\
\hline Phase 1 & May - July 2010 & $\begin{array}{l}\text { - Selection of the service provider / launch of the study "general diagnostic" } \\
\text { (expectations and needs of the SMEs) } \\
\text { - Identification of potential regional partners with whom HCPR could set up } \\
\text { the Défi Biotech Santé plan } \\
\text { - Benchmark of the partners }\end{array}$ \\
\hline Phase 2/3 & Aug. - Sept. 2010 & $\begin{array}{l}\text { - Definition of the operational objectives } \\
\text { - Engineering of the partners in the ecosystem }\end{array}$ \\
\hline Phase 3 & Sept. - Oct. 2010 & Formalisation of the partners in the ecosystem \\
\hline Phase 4 & Nov. 2010 & $\begin{array}{l}\text { - Final writing of the action plan "Défi Biotech Santé" } \\
\text { (Final hand in of the plan, but each step was delayed) }\end{array}$ \\
\hline
\end{tabular}

\subsubsection{Dilemmas with the implementation of the plan}

However, the implementation of the plan faced again some organisational dilemmas that create pathologies.

\subsubsection{Sharing responsibilities with established actors of the region}

We were able to assist at several meetings between HCPR and its regional partners (for example CCIP, AFNOR, Optics Valley, Polinvest, ADDVDM, UbiFrance...) in order to see if a common ground can be found to establish services for the health and biotech ecosystem in the Paris Region. One of the prerequisites to get a particular service financed from the 
financing bodies (national and regional authorities) that were willing to subsidies HCPR's new services, was that the chosen partner organisation did not already propose a similar service. The services thus had to be new and specifically adapted to the characteristics of HCPR's ecosystem. However, during the meetings, the partner organisations often did not understand this point. During the meetings the potential partner organisations often repeated that they already propose such or such a service (for example UbiFrance for the medical sector). In this case, HCPR always argued that the services have to be adapted to HCPR's ecosystem and thus changed, otherwise they would not get financed.

To sum up, HCPR had difficulties to push forward their plan in the Paris Region because a multitude of support structures exist in the region which also already propose services for the medical sector. This puts HCPR in the delicate situation to defend its existence. First, one could start asking if HCPR exists because of a real intrinsic motivation or just because of a policy prescription (dilemmaPD\#3b)? Second, a one-shop system for the medical industry might be desirable, but at the same time the existing support structures will not stop offering their traditional services. The life-cycle stage of the Paris Region cluster seems already well advanced (dilemma SD\#1a) which makes it challenging for a new entity to establish itself and to regroup existing offers. Again, the policy motivations that are behind the idea of regrouping existing offers are certainly good, but organisations are like human beings: they do not voluntarily decide to die. These dilemmas produce again organisational pathologies, particularly a pathology of nonconformity.

\subsubsection{Representing the members or the ecosystem?}

In January 2011 the animation \& development team under the responsible steering committee president had come up with a first final version of the plan ${ }^{206}$. As we can see in Table 40, the three axes were still the same (i.e. competence development of SMEs, enterprise development, and innovation development). Most of the associated actions are very business oriented as for example "help in business development", "developing international markets", "help in financing", or "human resources planning". The only action that was quite different to the other actions was "Strengthening the Innovation Potential".

\footnotetext{
206 The associated actions or partners to the three axes were constantly adapted between September 2010 and January 2011 but the main axes always stayed the same. As we observed the whole process between September 2010 and January 2011, we could go much more into detail. However, we consider that the most important information for this thesis is the disappearance of the innovation development axes. The collected material though could be explored in another way for additional academic papers.
} 
Table 40: Défi Biotech Santé Plan - January 2011

\begin{tabular}{|c|c|}
\hline Axe & Actions \\
\hline \multirow{4}{*}{$\begin{array}{l}\text { Axe } n^{\circ} 1 \text { : } \\
\text { Développement de } \\
\text { l'entreprise }\end{array}$} & 1. Mise en relation et visibilité des PME au sein de l'écosystème \\
\hline & 2. Accompagner le développement commercial \\
\hline & 3. Développer les affaires à l'international \\
\hline & 4. Financement des entreprises \\
\hline \multirow{4}{*}{$\begin{array}{l}\text { Axe } n^{\circ} 2 \text { : } \\
\text { Développement } \\
\text { des compétecnes }\end{array}$} & 1. Management prévisionnelle des Ressources Humaines ( GPEC) \\
\hline & 2. Ingénierie juridique \\
\hline & 3. Normalisation et risques liés aux marchés et aux réglementations \\
\hline & 4. Appréhender les tendances lourdes \\
\hline \multirow{2}{*}{$\begin{array}{l}\text { Axe n } 3 \text { : Soutien } \\
\text { à l'innovation }\end{array}$} & 1. Veille technologique et intelligence économique \\
\hline & 2. Renforcement du potentiel d'innovation \\
\hline
\end{tabular}

The operational team defined the "strengthening the innovation potential" objective as follows (January 2011): "Strengthening the innovation potential of SMEs in the health sector by helping them to gain a better knowledge and understanding of technologies related to their core business. "207 This objective was a need expressed by the companies that was somehow different compared to the other needs. Box 11 explains the general context of this innovation objective and the needs that were expressed by the companies. The main need that was expressed by the companies concerned the lack of knowledge in other disciplines, particularly technology disciplines, but which are important for the advancement of their own scientific endeavours. The different interviewed companies expressed the need to receive help in accessing knowledge of other domains.

\section{Box 11: Context and expressed needs}

Comment aider les PME de la filière «SANTE »à renforcer leur potentiel d'innovation?
Beaucoup de technologies sont diffusantes et transverses (Electronique, logiciel,...) et les
PME de la filière santé ne sont pas en situation de suivre leur rapide évolution sont peu
connues des PME de la filière. La connaissance des technologies connexes au cour de
métier de la PME de la filière «SANTE » est un accélérateur certain de l'innovation. Il est
nécessaire, voire indispensable pour réduire les cycles de mise sur le marché des produits
ou des services des acteurs de la filière «Santé »
Cet objectif pour être atteint nécessite la mise en réseau des différents pôles et clusters
franciliens porteurs des thématiques qui peuvent servir le domaine de la santé. En effet il
existe un terreau exceptionnel en Ile de France pour répondre à cette action.
Il s'agit de comprendre comment l'interconnexion entre pôles et clusters, les réseaux de
syndicats professionnels d'entreprises existants, se fait ou peut se faire, comment favoriser
un rapprochement entre thématiques (TIC, mécatronique, Développement durable,
robotique, design ...) et mutualiser les connaissances pour favoriser la convergence des
technologies vers des applications santé.
Les actions envisagées sont de nature transverse et concernent toutes les chaines de valeur

207 “Renforcer le potentiel d'innovation des PME de la filière "SANTE » en les aidant à acquérir une meilleure connaissance et une meilleure compréhension des technologies connexes à leur cour de métier.” 
$(C D V)$ identifiées lors de la phase de préparation du Plan Filière "Santé ». Il s'agit de permettre aux PME du domaine des sciences du vivant de mieux connaitre les domaines connexes à leurs problématiques et permettre de mieux incorporer les technologies dans leurs produits ou dans leurs services

However, if we jump now to October 2011 when the new services plan was first presented to HCPR's members (one year later compared to the photo we took in the office of the animation \& development team) the main domains look quite differently (see Figure 28). One main domain has disappeared: the innovation management domain. The new official services plan was now heavily concentrated on actions that target the economic competences of the companies: strategy, financing and management, company development. Why did the plan change?

In January / February 2011, the executive office rejected the services plan elaborated by the animation \& development operational team and the steering committee president. The conflicts around this plan led to the resignation of the animation \& development steering committee president. The newly developed plan (see Figure 28) was officially launched in January 2012 (see Table 41 for the roadmap of the new plan).

Figure 28: Défi Biotech Santé Plan - October 2011

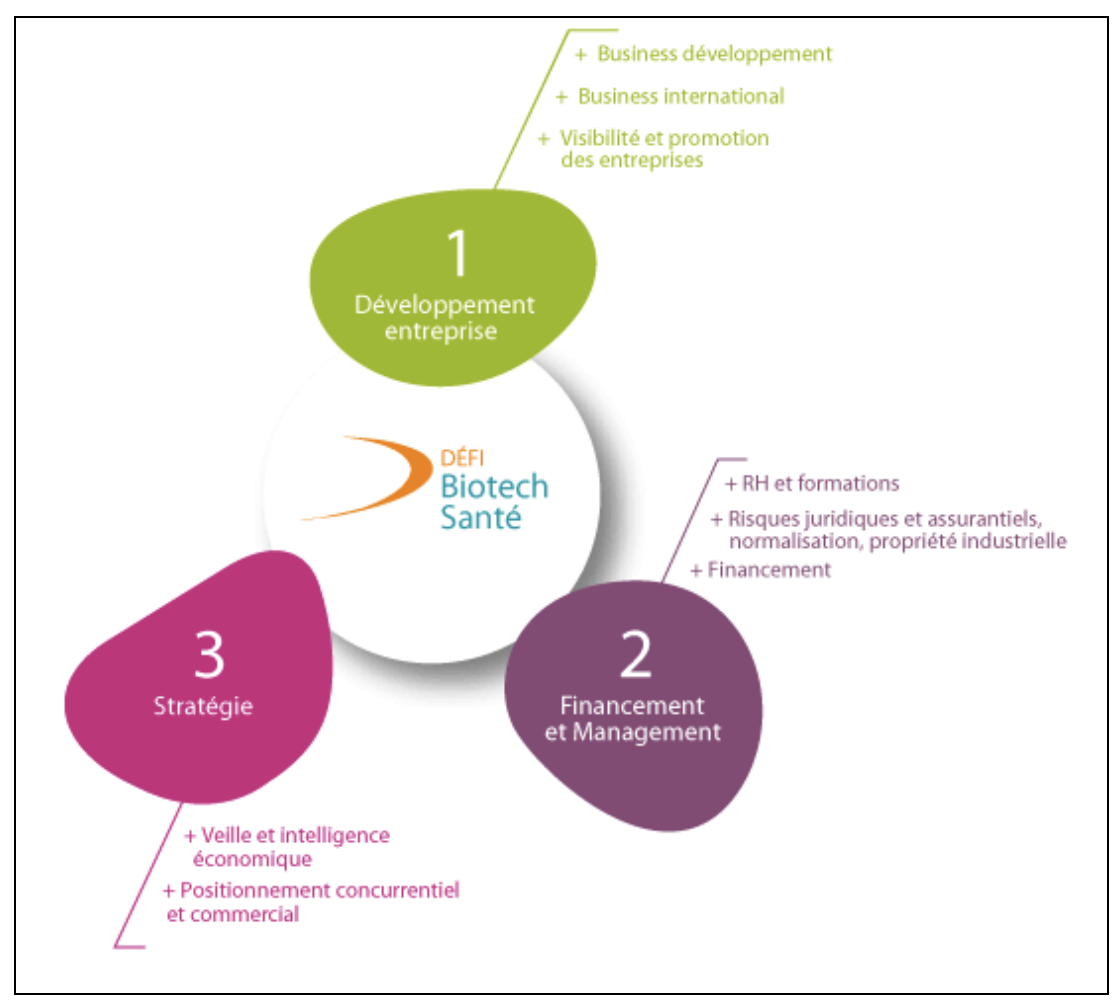


Table 41: Roadmap for the "new" Défi Biotech Santé plan (2011)

\begin{tabular}{|l|l|l|}
\hline Phase & Period & Objective \\
\hline Phase 5 & $\begin{array}{l}\text { Dec 2010 / Jan. } \\
2011\end{array}$ & - Resignation of the animation \& development steering committee president \\
\hline Phase 6 & Jan. / Feb. 2011 & $\begin{array}{l}\text { - Executive office does not validate the Défi Biotech Santé plan } \\
\text { - Back to the start with discussions regarding the content together with the } \\
\text { different representatives of the four panels }\end{array}$ \\
\hline Phase 7 & Spring 2011 & - New set up of the plan, integration of new partners and new budget discussions \\
\hline Phase 8 & Mai / June 2011 & - Submission to the financers \\
\hline Phase 9 & Oct. 2011 & - Presentation of the plan during the HealthCluster Convention \\
\hline Phase 10 & Jan 2012 & - Official Launch \\
\hline
\end{tabular}

What led to the rejection of the plan and the disappearance of the innovation management objective? The services plan was developed by the development \& animation operational team and constantly supervised by the development \& animation steering committee president. However, once the operational team had finalized the plan and was ready to present the final results to HCPR's governance, the Steering Committee President resigned, or as some told us was asked to resign from its position. This incident happened end of 2010. The problem was that the Executive office blocked the already developed plan.

The operational team based their work on the interviews they did with companies from the whole ecosystem. However, the opinions of the companies from the whole ecosystem apparently did not reflect the opinions of the companies that were integrated in the executive office of the policy-driven cluster:

\footnotetext{
«On a poussé, on a poussé, on a poussé pour pouvoir présenter les dossiers et finalement on a commencé à ralentir en disant il faut que ça passe au BE. [...] Le 2 février [2011] on a fait des réunions avec les entreprises avec les PMEs et à partir de là on a pu réécrire les fiches. A partir de ce point là on a fait pratiquement une remise à 0 . Après on a réécrit tout. [...] C'est le BE qui voulait mettre sa patte dedans. [...] [Le nouveau président du steering committee] voulait qu'on réponde à tous les désirs de tout le monde donc on n'était plus dans la même logique. »(October 2011)
}

The members in the executive office considered that HCPR's member companies need help in classic business assistance topics such as accessing finance, development, internationalisation, etc. For the members of the executive office, the innovation part was not a priority. The needs of the companies in the executive office were thus different to the needs of the companies that were interviewed by the operational team during 2010. The operational team interviewed PR companies of the whole biotechnology and health ecosystem and did not only focus on the members of HCPR:

"Ce n'était pas [la] préoccupation [du BE]. Leur préoccupation était vraiment l'histoire du financement, l'histoire d'ouverture du commerce, l'histoire de se développer. [...] Quand tu écoutes les entreprises de l'écosystème [note d'explication: tous les PMEs dans 
la région pas seulement les membres], ils te disent : "C'est [le soutien à l'innovation] qu'on veut. "Quand tu écoutes les gens de notre pôle, c'est [les autres services] qu'ils veulent. [...] [L'année dernière on a fait une enquête auprès les PMEs de l'écosystème], on a vu émerger nos fiches. Quand on retravaille là dessus avec les PMEs de notre pôle, ce n’est pas ça qui les a intéressé. » (October 2011)

The operational team was quite frustrated, not only because they had to start from zero again, but also because they considered that the wishes of the whole ecosystem, and thus also potential new members, were no longer taken into consideration.

To sum up, HCPR faces again different managerial and political dilemmas. The repeating question is who is in charge of this association (members vs. operational team) (dilemma MD\#1a)? The unclear responsibilities drive again the pathology of inefficiency. The executive office decided now that the organisational boundary of HCPR is its members (dilemma PD\#1b), that they are the ones who should be satisfied first, before the wider ecosystem. Additionally, HCPR also takes a clear stance regarding the managing innovation processes dilemma (dilemma MD\#2a). Even though it was not that clear in the performance contract, the executive office now took the decision that the most important services in order to foster the competitiveness of its members is to help them in concrete business issues. However, as innovation is the cornerstone of policy-driven clusters and innovation processes are manifold and difficult to manage, we formulate a new pathology, the pathology of pragmatism and not fostering out-of-the box thinking.

\subsection{Developing inter-cluster collaborations: implementation difficulties}

A third important objective of HCPR's performance contract was to start collaborating with other policy-driven clusters in the Paris Region to create innovation synergies between policydriven cluster members from different sectors ${ }^{208}$. During the first cluster policy phase (20052008), HCPR particularly focused on the basic cluster services (finding partners, finding subsidies and labelling projects). However, the public financers obliged the policy-driven clusters to stipulate in their new performance contracts that they will start collaborating with other local policy-driven clusters in order to stimulate the innovation potential of the associated members. HCPR focused on the intersection between Health and ICT, and together with Cap Digital and Systematic, launched the ICT-Health initiative ("TIC \& Santé") to bridge medical entities (be it hospitals, companies, research institutes, etc) with ICT

\footnotetext{
${ }^{208}$ Priority 2 of the animation \& development objectives in the performance contract, see Annex 10.
} 
companies and research units. For HCPR, this ICT \& Health initiative was one of the first major activities of the operational team during the second cluster policy phase. Additionally, this initiative was considerably different to the basic services HCPR proposed during the first cluster policy phase. Hereinafter, we will first present the characteristics of the ICT \& Health initiative and how the operational teams of the three policy-driven clusters collaborate. In a second step, we turn again to the organisational dilemmas that HCPR faced when implementing this ICT \& Health initiative.

\subsubsection{Characteristics of the inter-cluster collaboration and set-up difficulties}

The inter-cluster initiative was officially launched at the Pasteur Institute in January 2010 (app. 500 participants). The executive director of HCPR introduced the initiative and then different actors from the medical and institutional domain hold speeches on ICT \& Health. In the afternoon session, workshops were organised to define the main ICT \& Health themes the initiative should focus on during the next 3 years. At the end of the day, four priority axes were identified:

- Priority axis 1: Knowledge management, modelling and simulation in biology, pharmacy and medicine

- Priority axis 2: Digital imaging

- Priority axis 3: Medical devices

- Priority axis 4: E-health and telemedicine

For every priority axis a workgroup was created that met three times between February and April 2010 to further detail the four priority axes. Everyone of the local ICT \& Health ecosystem was free to participate in these workgroups. The objective of these workgroups was to establish a detailed roadmap for every priority axis to which future collaborative R\&D projects could apply to. In Mai 2010, the research road maps for the four priority axes were finalised and the objectives for the coming years presented (restitution event: app. 200 participants). The three policy-driven clusters launched the first inter-cluster collaborative R\&D project call in September 2010. All members of the three policy-driven clusters were invited to submit projects that were at the intersection of ICT \& Health and that correspond to one of the priorities described in the research road maps. Since then, there have been several inter-cluster project calls. Every project call follows the same pattern: 
$\mathbf{1}^{\text {st }}$ step - Events: Every inter-cluster project call starts with an event organised jointly by the three policy-driven clusters. These events are generally composed out of a plenary session and a project set-up workshop. The typical plenary session starts with presentations done by for example medical professors, cluster representatives, academics, and government agencies or with round tables on specific relevant ICT \& Health topics. Then there is most of the time also a presentation of already labelled or financed ICT \& Health projects. The third part of every ICT \& Health event is organised in form of workshops. For these workshops the operational teams of the three policy-driven clusters set up standardised power point templates (see Annex 12). Every actor of the region that wishes to present (i) an already started ICT \& Health project but where one or several competences are missing, (ii) just a competence, or (iii) just a need ${ }^{209}$, has to inform, prior to the event, the ICT \& Health policydriven cluster representatives of his/her intention. In case there are too many candidates the priority is given to project presentations (and not need or competences presentation). The priority is particularly given to projects that are already well advanced and which can be finalised within 3 months, the moment where the project has to be handed in for labelling. Every presenter has between 5 minutes (need, competencies) and 10 minutes (projects) for his/her presentation and has to stick to the provided power point templates. The whole process is highly formatted.

$2^{\text {nd }}$ step - Project intention deadline: The $2^{\text {nd }}$ step of the inter-cluster project call initiative is the project intention deadline. Two weeks after an event, the R\&D project consortiums that are interested in submitting a project for the next subsidies call (for example FUI or $\mathrm{ERDF}^{210}$ ), have to send their project intentions ${ }^{211}$ to one centralised ICT \& Health e-mail address $^{212}$. This centralised ICT \& Health submission is then directly forwarded to all three ICT \& Health policy-driven cluster representatives.

\section{$3^{\text {rd }}$ step - Inter-cluster meeting, feedback to project leader, and start of labelling process:}

After the project intention deadline, the three ICT \& Health policy-driven cluster representatives meet to examine the projects (each operational team has appointed an ICT \& Health contact person). This committee is called CLIP (Comité de Liaison Inter Pôles).

\footnotetext{
${ }^{209}$ The need category was only introduced in one of the later project calls and did not exist in the beginning.

${ }^{210}$ ERDF = European Regional Development Fund; in French: FEDER = Fonds européen de développement économique et régional

${ }^{211}$ The project intention is a summary of the project on a few pages.

${ }^{212}$ Also policy-driven cluster members who have not participated in the events can send their intentions.
} 
During these meetings, the ICT \& Health policy-driven cluster representatives first decide which of the submitted projects are allowed to participate in the ICT \& Health initiative, then dispatch the different projects, and then inform the project leaders:

\begin{abstract}
«[Pendant le] CLIP on détermine si les fiches sont plutôt HealthCluster ou Cap Digital ou Systematic. [...] On regarde les verrous technologiques qui sont soulevés. Parce que le truc le plus important dans un projet, c'est quel va être l'innovation. Où elle est l'innovation? C'est le médical, c'est l'application, c'est la numérisation, c'est la vidéo, c'est quoi ? Quand c'est considéré comme étant vraiment du ressort de la médecine, à ce moment là le CLIP décide [que c'est HealthCluster] qui va suivre ce dossier. [...] Après on fait un retour aux porteurs. On leur dit: "Voilà c'est HealthCluster qui [sera responsable pour la labellisation].»(Octobre 2011)
\end{abstract}

At this point the project leader only gets informed that his project was granted (or not granted) the ICT \& Health visa and with which policy-driven cluster he will start the official labelling process. The ICT \& Health visa has mainly a political significance. According to our interview partners, the policy-driven clusters were somehow obliged by the national authorities to start developing inter-cluster initiatives during the $2^{\text {nd }}$ cluster policy phase. The ICT \& Health visa is thus an administrative stamp that proves this inter-cluster collaboration but it does not have any additional value:

"En fait [...] c'est comme si les gens déposaient directement chez HealthCluster. Ils ne
sont pas obligés de passer par TIC \& Santé. En fait on a crée un visa TIC \&Sante. Le visa
TIC \& Santé c'est juste pour dire que les gens rentrent bien dans les critères des trois
pôles. [...] Ça veut dire que le projet rentre bien dans les critères qu'on a signé entre nous,
[c'est la feuille de route]. Mais pour eux [les porteur des projets] ça n'a pas vraiment une
valeur. [...] [Le visa vaut] rien en fin de compte» (Octobre 2011)

As soon as the projects are dispatched into each of the three policy-driven clusters, the collaboration between the three policy-driven clusters stops. Each operational team treats the ICT \& Health projects according to its internal scientific and labelling standards ${ }^{213}$, as if the inter-cluster initiative does not exist. In the beginning the policy-driven cluster organisations wanted to continue the collaboration also during the labelling process, but this was never put into action because it was considered as too complicated. Each policy-driven cluster has its own labelling rules. Setting up an inter-cluster labelling process would have needed new inter-cluster rules:
"Au départ on voulait faire un comité $R \& D$ mixte. C'est à dire des gens de Cap Digital, des gens de Systematic et comme ça on analyse tous les projets TIC \& Santé. Normalement c'est ça qui devrait se faire. En fait ce n'était jamais signé ou accordé. Les gens ont trouvé que : «Non, non, c'était trop compliqué. »Parce que si tu veux, nous on a un processus bien défini pour le label HealthCluster, Cap Digital aussi, et Systematic aussi. Donc si on

\footnotetext{
${ }^{213}$ The labelling standards are not the same in every cluster, some clusters for example only use external evaluators; some only internal evaluators, some have one to one meetings with the cluster actors in order to prepare the labelling, others have pre-examination presentations in front of a jury.
} 
fait un comité mixte il aura fallu redéfinir les règles etc., et ça ils voulaient pas. Personne ne voulait faire cet effort. Alors au départ c'était ça. La philosophie du truc. [...] Du coup le CLIP il fait juste : "Tiens, c'est toi qui va faire ça, c'est toi qui va faire ça. » Et en plus en règle général, s'il y a 10 projets on essaie d'en faire 3-3-4. On essaie d'équilibrer. [...] Je trouve ça très dommageable. [...] On se dispatche [les projets]. Hop on retourne à la maison avec notre petit projet. Et au pôle on fait comme si c'était un truc normal. Et après on les revoit plus, Cap digital et [Systematic]. [...] Ils disent que ça fait double boulot. Ca fait double travail de se taper tous les projets. Par exemple si on a reçu 30 lettres, ils préfèrent faire 10,10,10, plutôt que de se taper les 30. C'est vrai que ça fait beaucoup de travail en plus. Donc c'est comme ça que c'était décidé. Il faut mieux se diviser la tache et on le fait chacun de son côté. »(Octobre 2011)

To sum up, the government authorities responsible for the cluster policy, urged policydriven clusters to set up inter-cluster collaborations to foster the innovation potential of their members (dilemma MD\#1a). Diversity is particularly important for idea generation phase. The cluster organisations manage to join forces and to set up joint events. However, for the labelling process, at the moment where an intersectoral scientific knowledge would be necessary to choose the most promising projects, the policy-driven clusters did not manage to join forces. At that point, the only observation we can make is that the objective stays a policy prescription and is not an intrinsic motivation (dilemma PD\#3b).

\subsubsection{MPRs conflicting relationship with the ICT \& Health initiative}

In the beginning, the ICT \& Health initiative was a novelty for HCPR. We started our fieldwork, just after the $1^{\text {st }}$ project call and the cluster employees often told us about the successful event at the Pasteur Institute, the brainstorming workshops and this first project set up event. They were in a certain manner proud of these events. However, this situation changed rapidly. After the first project call, HCPR's ICT \& Health representative was attributed 4 ICT \& Health projects during the CLIP meeting. However, HCPR's internal labelling committee labelled none of these projects. After the second project call, HCPR's ICT \& Health representative was attributed 3 ICT \& Health projects and HCPR's internal labelling committee labelled all three projects. However, the financial authorities refused to subsidies all of the three projects. So after one year, none of HCPR's ICT \& Health projects actually got financed, even though the operational team invested a considerable amount of time in the initiative. Our interview partners mentioned two main blocking points: the lack in competence in the ICT domain and the non-relevance of ICT for HCPR's research agenda. 


\subsubsection{HCPR's lack in competence in the ICT domain}

As the initiative tries bringing together two different research domains, HCPR encountered difficulties to decide upon the pertinence of the submitted projects:

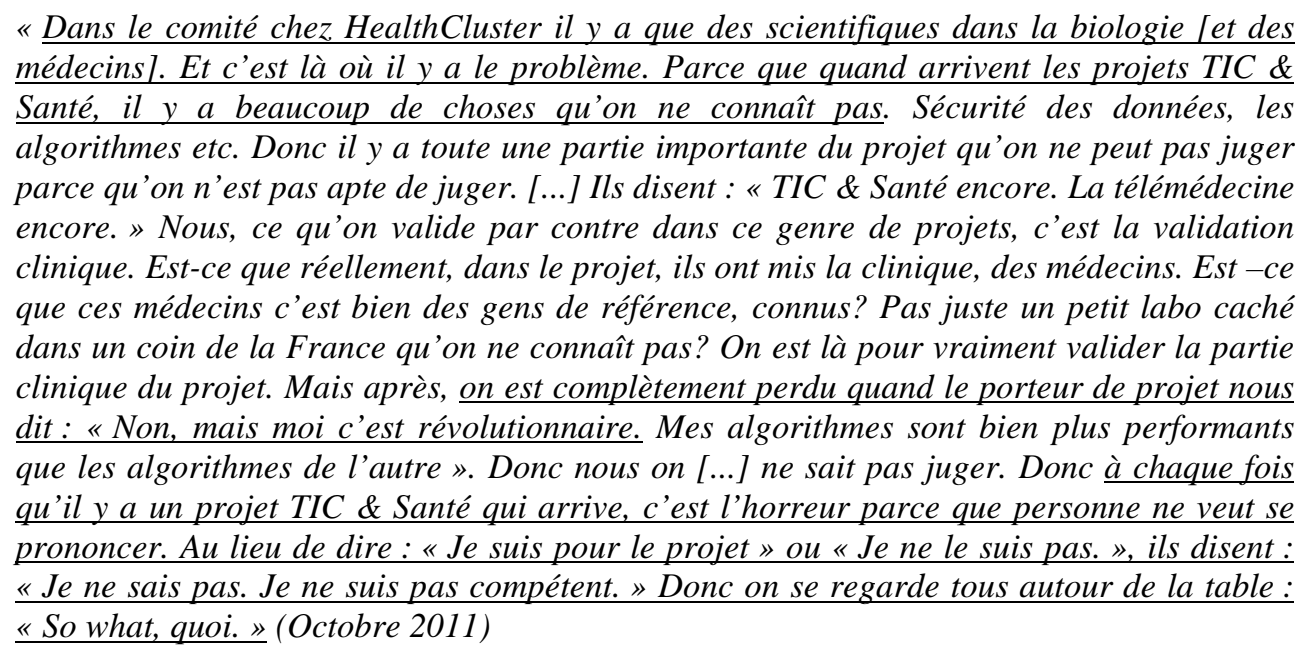

So even though, the policy-driven clusters are pushed to initiate collaborations between their different members, they were not able to collaborate on an organisational level during the labelling process. The lack of competence in ICT, hinders HCPR to pursue the inter-cluster collaboration process with full energy.

\subsubsection{Non-relevance of ICT \& Health projects for HCPR's research agenda}

We already underlined that the performance contract of HCPR particularly concentrates on basic research. Even though HCPR participates in the ICT \& Health inter-cluster collaboration initiative, e-health is not stipulated as a real research priority in the performance contract. The e-health objective in the performance contract is even the only technological R\&D objective that is not explained in detail (absence of a definition of concrete actors, activities or deliverables). For no other research objective this is the case. Additionally, HCPR has neither a dedicated webpage for the ICT \& Health events nor a regular newsletter only dedicated to ICT \& Health. On the contrary, Cap Digital has installed a dedicated webpage on the ICT \& Health subject, where presentations from the last project event sessions can be downloaded. Additionally, Cap Digital sends out regular information e-mails that summarize all-important ICT \& Health events that take place in the Paris Region. Even though HCPR collaborates with the other policy-driven clusters in the region, the ICT \& Health projects are not the research priority of HCPR. Following comment shows that they somehow only do it to please the demands of the government:

«TIC \& Santé au niveau du pôle HealthCluster ce n'est pas très populaire. [...] Ce qui est bon, politiquement parlant, c'est de pouvoir effectivement travailler avec les deux autres 
pôles franciliens. [...] Ca c'est bon sur le papier mais après, dans les faits, on se rend compte que c'est très difficile. [...] Chaque pôle a sa politique. [...] Nous, c'est plutôt médical à fond. Les projets pour le cancer, médicine personnalisée, donc nous, on est vraiment là dedans. [...] et le TIC \& Santé, c'est le truc bâtard, qui fait bien sur le papier parce que c'est du numérique, c'est la télémédecine, c'est l'e-santé. On en parle beaucoup, il y aura de l'argent là dedans mais personne ne s'investit réellement, en tout cas chez HealthCluster, pour ça. [...] [Au niveau] des instances ca ne plait pas. Ils disent que c'est bien mais en fait ils ne nous donnent pas tellement de support. Chaque fois c'est un projet $T I C \&$ Santé au niveau du comité $R \& D$, ils regardent ça un peu .... » (Octobre, 2011)

HCPR's governance seems to know where it wants to go in research terms. However, the policy-driven cluster also has to assure the conformity with the general cluster policy conditions, something they do on the paper but less with full investment.

\title{
2.3.3 Conclusion: different impacts, depending on policy-driven cluster
}

The underlying objective of the ICT \& Health initiative was to create new synergies and new business opportunities between companies of different sectors in the region. This objective seems to be reached for members of Cap Digital. Before the start of the ICT \& Health imitative, the members of Cap Digital were not really aware that they could find business opportunities in the medical and health sector. According to an operational team member of Cap Digital, the initiative changed their perspective:

\begin{abstract}
"L'axe de gestion de connaissance était l'axe qui se rapprochait le plus de nous au départ. Mais en fait on s'est aperçu qu'il y en avait plein d'autres. [...] Au début on pensait qu'on ne rentrait pas dans les thématiques TIC \& Santé, mais après, on s'est rendu compte que c'est faux. [...] [Nos membres] ont compris qu'ils pourront avoir des compétences qui pouvaient être intéressantes dans la santé. [...] Ca on s'en est aperçu au fur et à mesure. [...] C'était un vrai apport. La santé au départ c'était vraiment un domaine sur lequel on n'allait pas. » (January 2011)
\end{abstract}

For Cap Digital the ICT \& Health initiative seems to have brought the planned positive effects. The perspective of the HCPR operational team is quite different to the Cap Digital team. For HCPR this event has also brought a benefit, but they perceive this benefit more from an administrative angle than from a business opportunity or content angle:

\footnotetext{
"Comme les porteurs doivent être absolument des membres de HealthCluster, du coup ils ont du s'inscrire. Ca les a obligé de devenir adhérent. Mais il y a aussi ceux qui, finalement, se disent ; "Vous faites des biomarqueurs. Moi je fais des logiciels. Justement, je veux adhérer à votre pole pour aller dans les groupes de travail du numérique. » On a bénéficié de ça. Alors qu'eux [Cap Digital et Systematic] moins. Parce que finalement ceux qui font des médicaments des molécules [...] ils ne vont pas aller vers la vidéo. Qu'est ce qu'ils vont faire. Donc eux ils n'ont pas bénéficié des nouveaux adhérents d'une nouvelle planète. »(October 2011).
}

HCPR experienced a member increase thanks to ICT companies that were eager to explore new business opportunities in the medical and health sector. However, this was not the case 
the other way round as scientific researchers conducting basic research were not interested in new business opportunities and thus did not join the other policy-driven clusters. One of the French cluster policy objective is to reach a critical mass. This critical mass is measured by numbers of adherent. So from this perspective HCPR profited more from the initiative. However, another objective is to create jobs and business opportunities. From this perspective Cap Digital profited more from the initiative.

To sum up, Cap Digital managed to transform a well-meant policy-description into an intrinsic motivation, while HCPR failed to do so (dilemma PD\#3b). The reason why HCPR seems not to be able to easily integrate and work across different subject areas seems to be HCPR's sector of activity (dilemma SD\#2b). The ICT companies, pursuing more applied research, seem to be better equipped to find new business opportunities across different subject areas than medical companies that pursue basic research. This generates a pathology of non-conformity for HCPR. 


\section{Chapter 8: Which role does HCPR play in the set-up of R\&D projects?}

In this chapter we now investigate the French cluster policy from a collaborative R\&D project point of view. We discuss the results of the structured interviews that we conducted with project leaders and partners participating in the ICT \& Health initiative. Our objective is to understand how the policy-driven cluster actors create collaborative research projects and in which manner the policy-driven clusters help them in this endeavour. We first discuss the profile of our interviewed project leaders and their respective companies and then focus on the collaborative $R \& D$ projects that were submitted to the policy-driven clusters ${ }^{214}$. This allows us to discuss how the project leaders find ideas, partners and subsidies to construct collaborative R\&D projects. A chronological order of presentation would be to start with the idea genesis ${ }^{215}$ of a collaborative $R \& D$ project, followed by a discussion of the partner finding process once the decision that a project should be done was taken, and finally by a discussion about how the subsidies for the project were accessed. However, the policy-driven clusters played their major role in the "finding subsidies" phase. In order to understand the relationship between policy-driven clusters and project leaders, it is thus better to start the discussion with the "finding subsidies" phase (see Figure 29) ${ }^{216}$.

Figure 29: The $R \& D$ collaboration process and the importance of policy-driven clusters

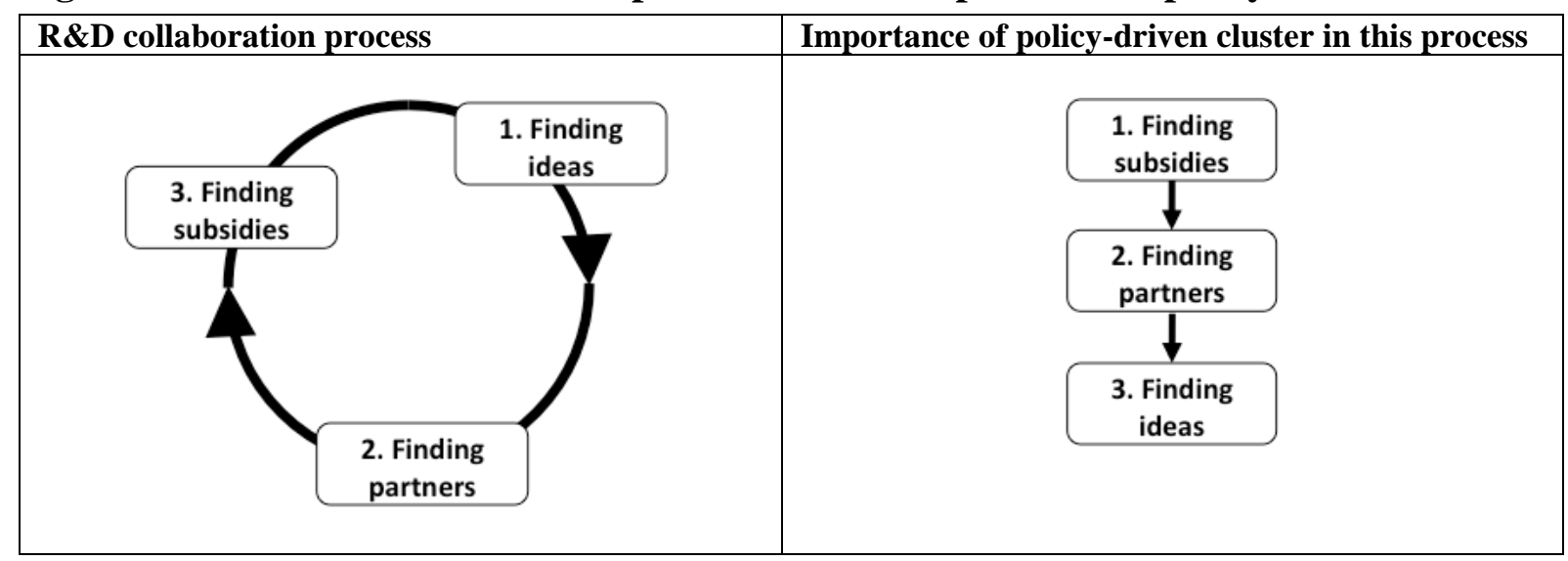

\footnotetext{
214 As already explained in the methodology part, we base our analysis on 19 cases regarding the idea and partner finding process and on 30 cases regarding the subsidies finding process.

${ }^{215}$ By idea genesis we do not mean all the personal mental itineraries a certain project leader might have had prior to the formulation of the idea. By idea genesis we mean the point where the project leader decides that a research project could be done.

${ }^{216}$ We summarized all discussed projects in a project overview table (see Table 45) at the end of this chapter.
} 


\section{Box 12: Content of chapter eight}

\section{Overview of ICT \& Health project leaders and their organisations}

1.1 Presentation of the project leaders' organisations

1.2 Presentation of the project leaders

1.3 Conclusion: the particularities of the R\&D project leaders

2 Finding subsidies: Being friend and judge - a schizophrenic situation 258

2.1 Policy-driven clusters: a super coach 259

2.2 Policy-driven clusters: biased judges and ambiguous objectives

2.2.1 Biased behaviour of the evaluation committee in policy-driven clusters 260

2.2.2 Decision inconsistency: labelling then not labelling 262

2.2.3 FUI: ambiguous objectives and complex set-up 263

2.2.4 Consequence: abandoning policy-driven clusters or intensive lobbying ................... 266

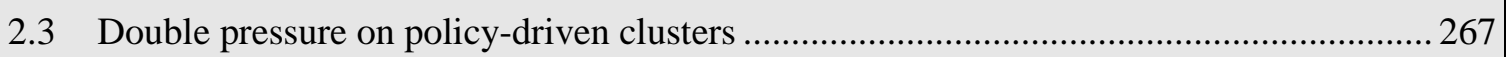

2.3.1 Bottom-up pressure from companies: want to get labelled and financed ................... 268

2.3.2 Top-down pressure from government: performance evaluations.............................. 271

2.4 Conclusion: the finding subsidies' dilemmas of HCPR ................................................ 272

3 Finding partners: "Las Vegas" weddings thanks to "Meetic" .................................2273

3.1 Project leaders learn but have difficulties to find certain partners .................................... 274

3.1.1 Project leaders' learning curve for finding partners ............................................. 275

3.1.2 The difficulty to find medical and industrial partners.......................................... 285

3.1.3 The difficulty to find project partners situated in the same region ............................289

3.2 HCPR's difficult role in the finding partners phase ............................................................ 293

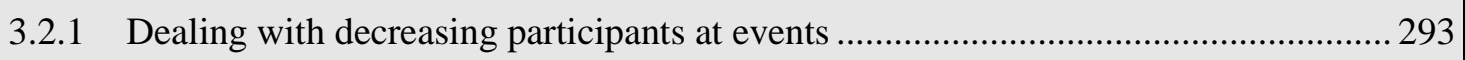

3.2.2 Struggling to integrate medical and industrial partners in events ...............................296

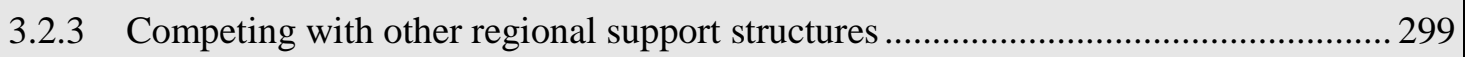

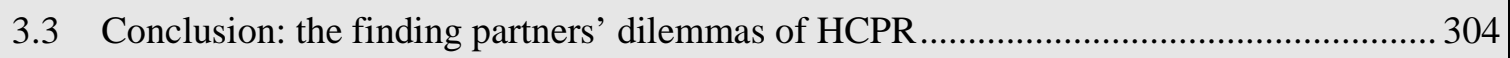

4 Finding ideas: Doctors can't be find at "Meetic" events ...........................................306

4.1 Project leaders' idea generation moments ....................................................................... 306

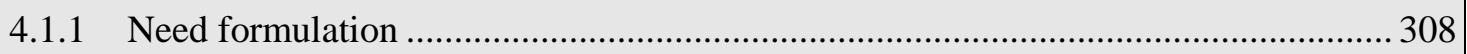

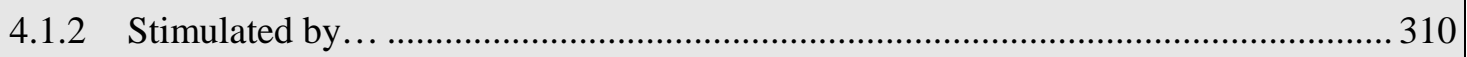

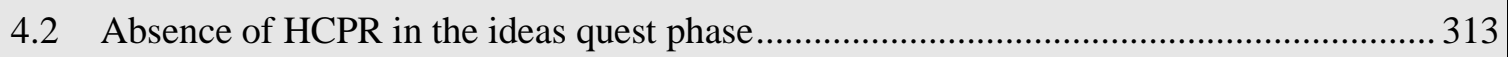

4.2.1 Struggling to attract others than business-driven companies ..................................... 314

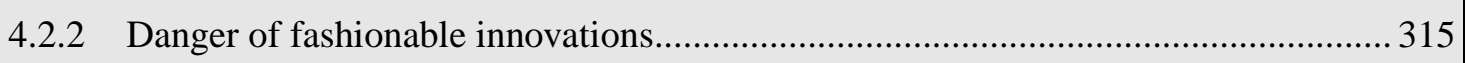

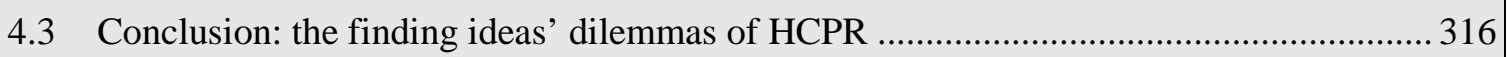




\section{Overview of ICT \& Health project leaders and their organisations}

Before we will discuss how the project leaders find subsidies, partners and ideas, we will present the project leaders and their organisations. All of the interviewed project leaders have submitted at least one ICT \& Health project to the ICT \& Health inter-cluster committee. We first present the project leaders' organisations and then discuss their individual profile. This is not only important for the reliability of our research but also for a better understanding of their behaviour regarding innovation processes in general and investment in the policy-driven clusters in particular.

\subsection{Presentation of the project leaders' organisations}

We start with the presentation of the project leaders' organisations. We particularly focus on the different types of organisations, their sectors of activity, their decades of foundation, the role of medical/health in their business portfolios, their traditions of and their drivers for research collaborations and finally their regional implementation (see Annex 13 for an overview).

\section{Type of organisation}

The majority ( 6 out of 10 ) of the project leaders belong to the SME category ${ }^{217}$. There are two explanations why SMEs are predominant: because they have more net equity than microenterprises and because they are the "flavour of the month" for the governments.

First, in order to profit from the FUI (the main subsidy associated to the French cluster policy), companies need the equivalent of subsidies received as net equity. For example if a company asks for 900000 Euros of subsidies, the company needs at least 900000 Euros of net equity. As the FUI does not finance any projects that need less than 750000 Euros of subsidies, the companies participating in the FUI automatically have a certain financial capacity $^{218}$. Even though the French productive and industrial fabric (see Annex 15 for an overview) is composed out of $95.44 \%$ micro-enterprises ( $<10$ employees) and $4.41 \%$ SMEs $(<250 \text { employees })^{219}$, the micro-enterprises often do not have the financial capacity to be an

\footnotetext{
${ }^{217}$ We did not define any quota regarding the company category of our interviewee partners.

${ }^{218}$ Verbatim: "Une société avec deux - trois ingénieurs [...] où chacun met 5000 euros dans la société, ca fait 15000 euros, donc ca veut dire qu'au maximum, ils peuvent avoir 15000 euros de subvention par an, ce qui n'est rien. [...] Ce qui élimine beaucoup, beaucoup, beaucoup d'acteurs. » (P9)

${ }^{219}$ Source: INSEE (2010)
} 
official project partner. Micro-enterprises are often sub-contracted by one of the main project partners. Even though the sub-contractor companies might significantly participate in a collaborative research project, they do not figure in any official statistics.

Second, in order to help SMEs develop their businesses, the government forces large companies and research institutes to integrate SMEs in their research projects. If a project consortium wants to increase a project chance to be accepted for the FUI, the project leader justifies that SMEs (including Medium sized firms $(\mathrm{MFs})^{220}$ ) are significantly involved in the project, regarding the importance of their work and their economic impact. The SME does not have to be the project leader. However, the majority of project consortiums decide to put the SME at the forefront of their project, to further underpin their integration and to further increase the project's chance of subsidy acceptance. ${ }^{221}$

Besides interviewing six project leaders from SMEs, we also conducted one interview with each of the three remaining company categories: one with a micro-enterprise, one with a medium-sized firm, and one with a large company. Given the weak existence of microenterprises (due to their weak financial capacity), medium-sized firms (due to the strong underrepresentation of this category on the French territory), and large companies (due to the avoidance to put large companies as project leaders), it was precious to be able to also interview project leaders from these three categories. As we will see, the micro-enterprise and the large company have a different behaviour regarding their policy-driven cluster implication than the eight remaining companies.

Finally we also interviewed a project leader working for an association. This was a surprise, as not all types of subsidies allow another entity than a company to be the project leader (for example the FUI). However, before the last project submission for financing (just before the project was finally granted subsidies), the consortium changed the project leader and chose to attribute this role to a micro-enterprise. However, this also reflects the ambiguity of this role. In the official cluster-policy statistics the company referenced as project leader might not be the company that had the idea for the project.

\footnotetext{
${ }^{220}$ Definition of Medium-sized firms (MF) $=<5000$ employees (INSEE, 2010)

${ }^{221}$ Verbatims: "L'air du temps, c'est de tout miser sur les PME » (P7); «Du fait de notre positionnement [grande entreprise], on n'est pas nécessairement coordinateur du projet » $(P 1)$; "On n'a pas beaucoup de PME [dans notre projet], ça ne fait pas bien vis-à-vis des financeurs. Ils cherchent des PME. »(P10)
} 


\section{Sector of activity}

The companies either belong to the service sector or the industrial sector. However, the majority of the companies ( 7 out of 10) belong to the service sector: Four companies exercise "professional, scientific and technical activities" $\left(\mathrm{NAF}^{222}\right.$ category $\left.\mathrm{M}^{223}\right)$, and three companies exercise "information and communication activities" (NAF category $\mathrm{J}^{224}$ ). All of these service companies try to apply their technical expertise to the medical/health domain. Only two of the interviewed companies, at the same time the two oldest companies (founded in the 1940s and 1970s), belong to the industry sector: P1 belongs to the "Electricity, gas, steam and air conditioning supply" sector (NAF category $\mathrm{D}^{225}$ ) and P8 belongs to the “Manufacturing industry" (NAF category $\mathrm{C}^{226}$ ). $\mathrm{P} 8$ produces, among others, devices that can be used in the medical/health sector, while P1 has no obvious link with the medical/health sector but can transfer some of its research activities to the medical/health sector in order to diversify its internal research efforts.

\section{Decade of foundation and Role of medical/health in business portfolio}

The decade of foundation and the role that the medical/health domain plays for the companies' business portfolio varies considerably. The three youngest organisations (founded in the 2000s) are also the only organisations that are solely dedicated to the medical/health sector: the micro-enterprise, the association and one SME. The micro-enterprise and the SME were both incubated by two different business incubators within well-known Parisian medical research institutes. During the interviews, the micro-enterprise (P2) was still linked to the business incubator while the SME (P4) was already outside the incubator. The other companies were founded in the 1990s (three companies), in the 1980s (two companies), in the 1970s (one company), and in the 1940s (one company). For three companies the

\footnotetext{
222 "Nomenclature d'activités française" (NAF): French equivalent to the Standard Industrial Classification (SIC) in the United States.

${ }^{223}$ NAF Category M: "This section includes specialised professional, scientific and technical activities. These activities require a high degree of training, and make specialised knowledge and skills available to users." (INSEE definition, NAF 2008)

${ }^{224}$ NAF Category J: "This section includes the production and distribution of information and cultural products, the provision of the means to transmit or distribute these products, as well as data or communications. The section also includes information technology activities, processing of data service activities and other information service activities." (INSEE definition, NAF 2008)

${ }^{225}$ NAF Category D: "This section includes the activity of providing electric power, natural gas, steam and hot water through a permanent infrastructure (network) of lines, mains and pipes, notably for industrial premises and residential housings. The dimension of the network is not decisive." (INSEE definition, NAF 2008).

${ }^{226}$ NAF Category C: "This section includes the physical or chemical transformation of materials, substances, or components into new products. The materials, substances, or components transformed are raw materials that are products of agriculture, forestry, fishing, mining or quarrying, secondary recycled raw materials as well as products of other manufacturing activities. Substantial alteration, renovation or reconstruction of goods is generally considered to be manufacturing." (INSEE definition, NAF 2008).
} 
medical/health sector represents no business field and for four companies the medical/health sector is one among several business fields. Three companies have no link with the medical/health sector. The reason why these three companies submitted a project to the medical/health sector without actually operating in this field is two-fold:

- Entering the market via a subsidised project: P5 and P7 were both not operating in the medical/health sector prior of submitting a project to a policy-driven cluster. Both companies thought about entering this sector of activity and the project was in a certain manner the potential entry point. P5 did not manage to get its project financed so the organisation abandoned the medical/health sector again. P7 got its project financed and the organisation thinks about creating a medical/health division.

- Research/philanthropic reasons: As already mentioned, P1 has no obvious link with the medical/health sector but can transfer some of its research activities to the medical/health sector to diversify its research effort. For the R\&D project we contacted him for, he said that the company does this out of philanthropic reasons.

\section{Tradition of research collaborations}

We can split the companies in three different levels regarding their research collaboration experiences: (1) high collaborative research tradition (several national \& international experiences); (2) medium collaborative research tradition (some national and/or international experiences); and (3) low collaborative research tradition (just started to enter the collaborative research realm). Nearly all companies (7 out of 10 ) have a high experience in collaborative research projects and accessing financing on a national (e.g. ANR, FUI, ISI OSEO) as well as European (e.g. Eureka, Cost, FP7) level. The remaining three companies have either a medium (P2, P7) or low (P5) experience in collaborative research projects:

- P2 has a medium experience in collaborative research projects as the company has only three research projects going on (whereby two of the three projects were already launched before the spin-off form a large company took place) and one project is just in the starting blocks.

- P7 has a medium experience in collaborative research projects as the company has already participated in collaborative research projects but only as a project partner and not as a project leader. The interviewed project leader was hired by his company to start building and launching collaborative $R \& D$ projects where the company can finally figure as a project leader. 
- P5 has a low experience in collaborative research projects, as the company has never participated in subsidised collaborative research projects before. The project under investigation was the first tentative to enter the collaborative project world. Now they have developed a taste for it and would like to continue.

The interviews with these three companies (P2, P5, P7) were particularly pressures as they allowed us to understand that there is a considerable difference between companies that are already integrated within the policy-driven cluster community and the ones that only start integrating a policy-driven cluster community.

\section{Driver for research collaborations}

We identified three different types of drivers to participate in research collaborations: idea driven, business driven and research/philanthropic driven:

- Business-driven: For the majority of companies (6 out of 10) the driver for participating in research collaborations is to further develop the company's services, technologies or products by applying them to new domains and thus to develop the company's business.

- Idea-driven: Only the association (P6) and the micro-enterprise (P2) are solely idea driven, meaning that they concentrate their efforts on one single mission they believe in. To develop this idea they need money and partners and therefore they initiate research collaborations.

- Intersection between business- and idea-driven: We situate $\mathrm{P} 4{ }^{227}$ between idea driven and business development driven. Like the micro-enterprise (P2), P4 was also situated in an incubator and had one single and clear mission in the beginning of its existence. However, we have the impression that their technology is already well enough developed because they start applying it to several domains within the medical sector (P2 applies its technology to one single domain in the medical sector). This transition between idea driven and business development driven is also reflected in the fact that we were not able to interview the president or vice-president of the company but the chief technical officer. Having a chief technical officer already means that the company has gained a certain size and that the development of the business gets more and more important.

\footnotetext{
${ }^{227} \mathrm{P} 4$ is such like the micro-enterprise and the association only operating in the medical/health sector.
} 
- Research/philanthropic driven: Finally, the driver for P1, the large company, is completely different. P1 has clear internal research objectives to improve internal processes, but sometimes they try to spread their research efforts by applying their internal research to other domains, like for example to the medical/health sector out of philanthropic reasons.

To sum up, we can say that companies (except the large company) are mostly either ideadriven or business-driven. For the remaining analysis of our data, it is important to keep in mind the high experience of the companies in collaborative research projects as well as their mainly business driven attitudes.

\section{Regional implementation of company}

Each of the companies we interviewed submitted at least one project for labelling to the joint ICT \& Health initiative and was then supervised by one of the three Parisian policy-driven clusters (HealthCluster, Cap Digital, Systematic). So it should be no surprise that 7 out of 10 companies are implemented in the Paris Region. It seems actually more surprising that two organisations are not at all implemented (P6 and P8) in the Paris Region, and one company (P2) has only a temporary office in the Paris Region and its main activities in Lower Normandy.

\subsection{Presentation of the project leaders}

After presenting the organisations of the project leaders, we now present the project leaders themselves: who they are, what their objectives are and which liberty they have within their respective organisations (see Annex 13 for an overview). The detailed understanding of the organisations and the project leaders themselves, will allow us to better understand and discuss the services provided by policy-driven clusters in the subsequent sections.

\section{Who are they?}

All project leaders are male, have in average 22.5 (median: 20) years of work experience and at least a Master degree. Nearly all project leaders have an engineering degree, besides P4 who has a PhD in Neuropharmacology and P10 who has a PhD in Geochemistry. Among the eight project leaders who have an engineering degree, five have a double-degree: P5 has an engineering and mathematic degree; P6 has an engineering degree and a PhD in Image 
Processing / Statistics; P7, P8 and P9 have an engineering and management degree. P8 also has a $\mathrm{PhD}$ in Innovation Management.

\section{What is their role in the organisation?}

Nearly all project leaders have a management position. Either they are the President/VicePresident, or they are Innovation Director/Manager or Technical/Research Project Director of the organisation. Only P1 has no management position, as he is "only" a technical expert. However, the responsibilities of the project leaders within their organisations are quite similar. All are responsible for the preparation of collaborative research projects, meaning finding ideas, partners and subsidies. For the companies that are "idea driven" this preparation is concentrated to develop the company's idea. For the large company, the challenge lies in finding new domains to spread the internal research efforts. However, for the companies that are "business driven", the majority of our companies, the challenge lies in finding new or existing domains to apply and further develop the company's technology, service or product:

"J'ai un objectif stratégique qui est d'amener la société, qui n'était pas présente dans le
secteur de la santé, à avoir une notoriété et puis une masse critique d'activité qui va
permettre de créer une division santé. [...] Il faut juste que je ramène (...) j'ai des objectifs
(...) en termes de levée de subventions. [...] La mission principale qui m'a été demandée,
c'est permettre à [nom de l'entreprise] d'apparaître comme chef de file et de lever des
subventions dans ce cadre là. » (P7)

Once the collaborative project gets financed, the majority of the project leaders hand the projects completely over to an operational team within their respective companies. The interviewed project leaders mentioned several reasons why this is done. First of all, project leaders seem to be particularly interested in finding new ideas to apply the company's knowledge but are not interested in the development part of a particular project. They consider that their added value lies in the detection of this idea and their capacity to bring together the most competent people:

\footnotetext{
"Ca ne m'amuse plus trop de m'investir dans le détail des choses. [...l Je n'ai pas envie de faire le travail d'un spécialiste. Je pense que j'ai une capacité à réunir un ensemble de spécialités pour faire un sujet donné... Voilà. » (P10)

"Un projet bien mené, c'est un projet où d'abord les artistes s'expriment pour créer le projet à partir de rien. Quand le projet obtient le financement, en général les artistes passent la main aux gestionnaires qui vont le faire vivre, qui vont l'exécuter. [...] Je ne suis pas bon dans ces choses-là. Je m'ennuie et je déprime. Mon truc, c'est les histoires nouvelles. [...] Mon boulot s'arrête avec la décision de financement ou de non-financement du projet. »(P7)
} 
Once the project gets financed, the project leaders mainly retrieve from the project in order to create a new project. They are in a constant search for new ideas in order to create collaborative research projects. Within their companies, they have operational project leaders who then take the lead of these projects. These internal project leaders have different competences than the project leaders. These internal project leaders (or as one interviewee said the "bulldozers") are actually the ones who work on the research project. However, they already have the general framework of the project, meaning the objective, the budget, the collaboration partners and the deadline:

\begin{abstract}
"On rédige le dossier et, une fois qu'il est financé, on peut le mettre en cuvre. Mais c'est d'autres compétences. C'est d'autres équipes qui vont travailler. Il y a un chef de projet chez [le partenaire], un chef de projet chez nous, qui se mettent en relation mais ce n'est plus forcément nous [les personnes qui ont monté le projet]. On suit ça de loin, mais de très loin, [...] pour moi c'est un dossier parmi d'autres. Donc je passe le truc à la production, après je ne sais même pas (...) j'ai vu les premières images de [nom d'un projet] peut-être un an après le début du projet, comme ça, par hasard, je voulais juste savoir où ils en étaient... »(P9)

"Pour la fonction «gestion de projet», j'ai deux bulldozers chez moi. Ce sont des gens (...) j'arrive avec un projet, je donne ça aux bulldozers, et je dis : 'voilà on a un cadre, c'est ça. Toi tu as ça à faire là-dedans'. On fait une passation. Et après, lui c'est un chef de projet : il organise en interne. Il a l'habitude. Il est apprécié pour sa rigueur. »(P8)
\end{abstract}

Only the project leaders from the micro-enterprise (P2), one SME (P4, the second incubated firm) and the large company (P1) continue being significantly involved in the operational part of a financed project. P5 is also still involved in the operational part of projects but is currently conducting an internal re-organisation in order to stop its implication and to solely concentrate its efforts on the business development part. This handing over of the projects to the internal operational teams also has the consequence that the collaborative most intensive phase of the projects is during the project preparation phase. Once the project is financed, the different actors work on their exactly defined parts:

"On s'arrange pour que les tâches soient séparées, pour ne pas qu'elles recouvrent
vraiment des compétences, et qu'il n'y ait pas de frictions. Chacun chez soi. C'est mieux
pour la bonne collaboration. Sinon, si chacun a des compétences sur les mêmes tâches,
évidemment, il y a des enjeux de pouvoir. " $(P 9)$
"Il y a encore du travail à faire, mais ce n'est plus du tout la même chose. C'est-à-dire
qu'on sera dans un budget donné, dans un planning donné, il faut faire des tâches
techniques données. Il n'y a presque plus aucune incertitude.» $(P 7)$

This shows that the main subsidy associated to the policy-driven clusters is business oriented. Such a strong separation of tasks between project partners and the little risk of uncertainty would not be possible in a basic research project. The collaborative most intensive phase is 
happening during the project set up phase, before the project gets financed. However, even this phase can be very short and is often done per e-mail or telephone.

\section{Which autonomy do they have within the organisation?}

In order to pursue their responsibilities, the interviewed project leaders are very free regarding the organisation of their daily tasks. They can go for example to conferences or seminars and do not need to be in the company location all the time. This is an important element regarding their potential active participation in policy-driven cluster events. Some of them have a complete autonomy and can go wherever they want in order to find ideas, partners and subsidies:

\footnotetext{
"J'ai une totale liberté. Et quand je dis une 'totale liberté, c'est une totale liberté. C'està-dire : je veux aller au Japon, je peux aller au Japon. Je veux aller (...) il y a un mois j'étais au MIT (...) je vais au MIT. Quand je reviens, je reviens avec deux - trois projets, des gens que j'ai croisé et voilà. » (P8)

" Je suis dans les locaux un jour par semaine pour me synchroniser avec les autres collègues, sinon je suis un électron libre. [...] On ne peut pas faire autrement que de laisser les gens libres, parce que c'est trop compliqué de manager. » (P7)
}

Others do not have such a high autonomy for the time being but are planning to change this situation in the near future. They have understood that in order to participate in this collaborative research realm they are not able to do both, the operational part and the collaborative research set-up part:

\begin{tabular}{l} 
"Je suis présent tous les jours, parce que si je ne suis pas là, ça pose des problèmes en \\
interne. En termes de production. Maintenant, j'essaye de me structurer différemment. \\
L'année prochaine, ce que je voudrais, c'est faire beaucoup plus du commercial, et \\
beaucoup plus de marketing, et beaucoup plus de stratégie à long terme, et faire du \\
\hline lobbying. Faire connaitre lnom de l'entrepriseldans les différents cercles. Ca demande du \\
\hline temps et de l'énergie. »(P5)
\end{tabular} Also the project leader from the large company has the liberty to go to conferences but it seems that the general framework within which he is operating is more regulated as he is still involved in the operational part of the project as well:

"On a du temps pour faire un peu ce qu'on veut. [...] On fait plutôt des projets qui durent
de l'ordre de trois ans [...] Et à l'intérieur des projets, les priorités sont refaites un peu
chaque année, et puis après, on a l'année pour atteindre les objectifs, peu importent les
moyens mis en ceuvre. Donc après, ça permet de faire de la veille, d'aller à des
conférences, d'initier des partenariats. " (P1)

To conclude, the project leaders' main responsibility is to find new ideas in order to apply the companies' knowledge to new domains. The majority of the project leaders are not integrated in the operational part of the initiated projects. The tasks of the different projects seem to be exactly defined and clearly distinguished between the different project partners. 


\subsection{Conclusion: the particularities of the $R \& D$ project leaders}

If we want to analyse and discuss cluster policies, a clear understanding of project leaders and their companies that submit projects to the policy-driven clusters is important. The in-depth understanding of who they are and what they strive for allows us to better evaluate their relationship with the policy-driven clusters and the utility of the services they propose. Figure 30 summarizes the most important elements of the interviewed project leaders and their companies. First, most project leaders are SMEs. Second, most of the project leaders' are business driven, only the association and the micro-enterprise are mainly idea driven. Third, nearly all companies (dark grey circles) have a high experience in national and international collaborative research projects. Only three companies (light grey circles) have only national experiences. Either the projects under investigation were their first tries to enter the collaborative project world (P5) or they are just completing their first collaborative research projects (P2 and $\mathrm{P} 7)$.

Figure 30: Overview of the interviewed project leaders and their companies

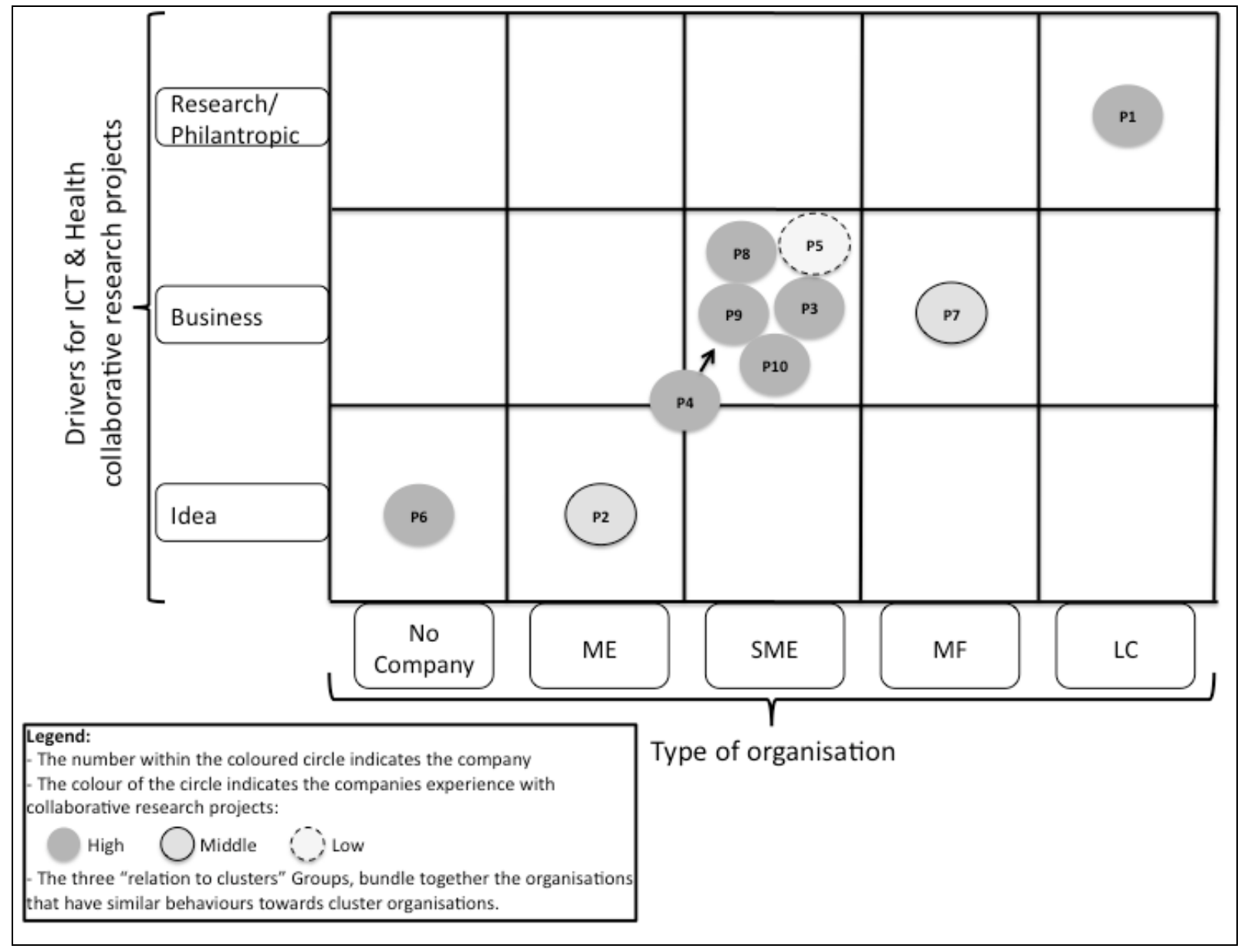




\section{Finding subsidies: Being friend and judge - a schizophrenic situation}

In the second section of this chapter we now focus on the finding subsidies phase of the project leaders. The main subsidy program associated to policy-driven clusters is the FUI. If a project consortium wishes to apply for a FUI subsidy, the project consortium has to submit its project to a policy-driven cluster in order to obtain a policy-driven cluster label. During the labelling process the project leader and the policy-driven cluster are somehow obliged to be in contact with each other. Project leaders are our entry point to the collaborative R\&D project level. This means that all of our interviewees were at least once in contact with a policydriven cluster in order to find subsidies ${ }^{228}$. However, the policy-driven clusters have an ambiguous position in this phase. On the one hand, the policy-driven clusters need to help the project consortiums to develop their projects, but on the other hand the policy-driven clusters also officially label them. They are thus friend and judge at the same time (see Figure 31):

"Dans le cadre du FUI, le pôle est un passage obligatoire et ils sont bizarres parce qu'ils
sont à la fois juge et partie. On est membre du pôle et ils doivent nous développer, mais ils
doivent aussi nous labéliser. Ils nous accompagnent et ils nous labélisent. C'est ambigu
comme position. » (P10)

In this section this ambiguous judge/friend relationship of policy-driven clusters and then focus on the dilemmas policy-driven clusters face regarding this subsidies role.

\section{Figure 31: Policy-driven clusters: A project leader's friend and judge}

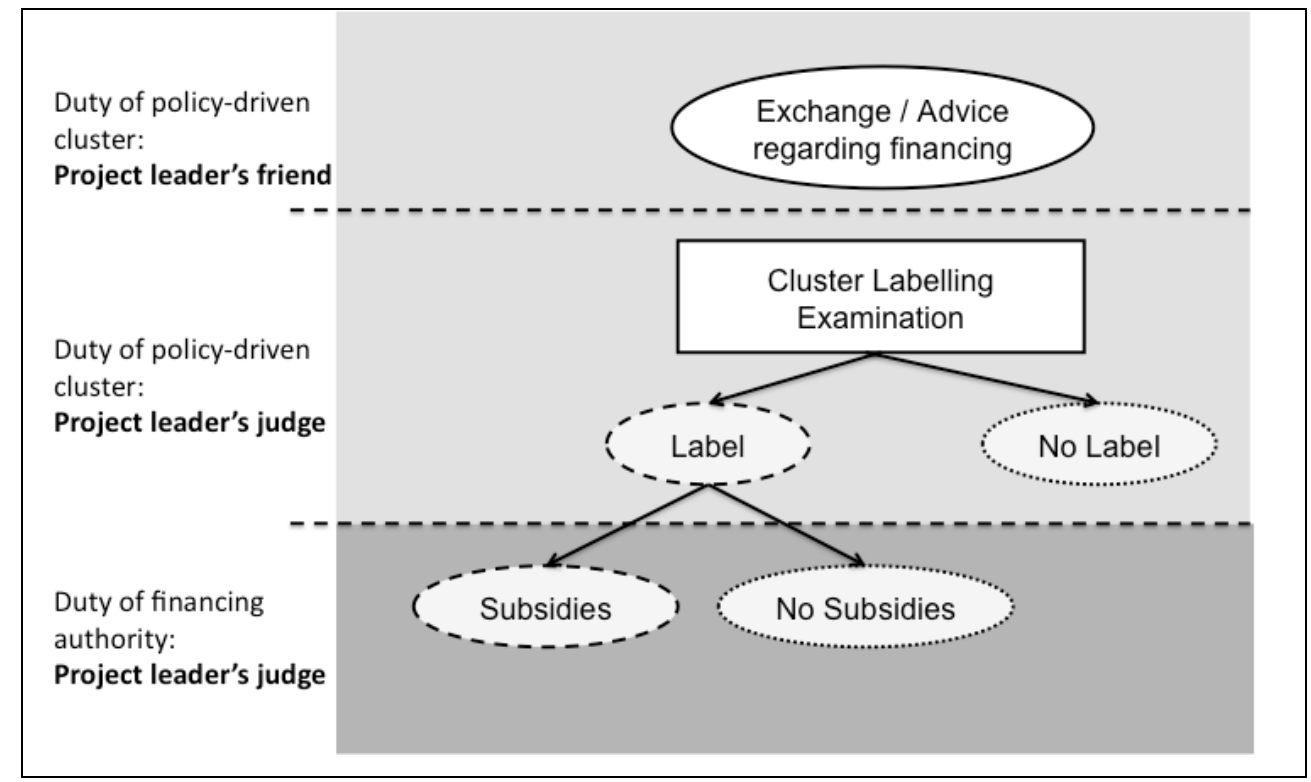

\footnotetext{
${ }^{228}$ For this phase we now have 30 cases (and not 19 cases as in the idea and partner finding phases), because we are entering the administrative realm.
} 


\subsection{Policy-driven clusters: a super coach}

One of the operational teams' objectives is to help the project leaders with their project applications. Very often the project leaders already send a first draft to the policy-driven clusters before the official labelling takes place. The policy-driven clusters examine the project documents and then give recommendations on how to improve the documents so that the projects have a higher probability of being labelled and then financed. The policy-driven cluster acts like a "super coach":

"C'est chez Cap Digital. [Avant la soumission officielle] on présente [le projet], c'est un
service qui est rendu. Ce n'est pas une expertise destructrice, de notation. C'est une
expertise constructive, où on donne des conseils à la personne. La personne vient et dit :
'voilà, j'ai tel ou tel projet. Je voudrais adresser tel marché [...] pour ça, je voudrais ça,
ça, et ça'. Et les mecs dans la salle, il y en a une dizaine en général, dont je fais partie,
[donnent des commentaires]. [...] Leur principale valeur ajoutée, c'est d'orienter les
projets pour qu'ils soient plus innovants, plus éligibles [...] c'est d'augmenter leur chance,
leur taux de succès pour tous les appels à projet, tous les financements. C'est un super
coach qui permet de dire: 'là arrêtez, ça ne sert à rien, vous perdez votre temps, (...) là
oublie, [...] là vas-y, [...] là ca ne va pas, etc.» $(P 9)^{229}$

Besides giving comments regarding the content of the project, the "super coach" also helps the project leaders to find the right subsidy agency for their projects. Something that is highly appreciated by the project leaders:
"[Cap Digital] nous aide vraiment pour tous les projets. Pour savoir où est-ce qu'on trouve du financement. Comment on avance, etc. [...] Parce qu'ils sont très au point de tout ce qui se passe d'un point de vue financement, et donc eux ils peuvent nous orienter un peu sur le meilleur financement pour nous. [...] Je trouve ça très efficace. Ils sont très, très bien documentés. [...] Ils ont très, très bien conseillé sur ces problèmes-là, sur le temps, quand il faut présenter les FUIs, etc.. Ca, c'est une grande aide. » (P6)
"Par exemple, [il y a un projet que] j'ai soumis à l'appel au grand emprunt, et puis le boss de Cap Digital m'appelle et me dit : "Tu l'as déposé mais on n'est pas éligible, dépose-le en FUI. » Je lui dis : " oui mais il reste 4 jours ». Il dit : "Oui, mais bon ». J'ai bossé nuit et jour pour retravailler le projet. [...] Effectivement, il n'était pas du tout éligible à l'appel à projet Igrand empruntl. Si je ne l'avais pas déposé au FUI, il serait tombé à l'eau. Mais parce qu'il m'a appelé, il a senti le truc, il m'a dit: 'dépose le au FUI'. Je n'étais pas forcément au courant qu'il y avait un FUI au même moment, donc le rôle du conseil du coach fait qu'il a apporté à la société 700000 euros de subventions. Donc, c'est beaucoup. Et elle est là, la valeur ajoutée. » $(P 9)^{230}$

Policy-driven clusters play an important role for the project leaders in this exchange and advice phase. However, not all project leaders have used these services and some submit their projects directly for labelling to the policy-driven cluster without a pre-labelling examination. During the subsidies finding phase, the policy-driven cluster can thus be a "friend" of the project leader, because the policy-driven cluster helps in improving the quality of the project,

\footnotetext{
${ }^{229}$ Verbatim: «On a fait une première réunion avant la présentation [officielle]. On nous a dit: 'il y a ça, ça, ça qu'il faut améliorer'. OK, on l'a fait. » (P5)

${ }_{230}$ Verbatim: "Ils aident pour les projets. [...] Ils essayent [...] de nous orienter. Ca, c'est très bien. Ils ont un support administratif qui est très bien. »(P5)
} 
or in orienting the project leader towards the right funding windows. However, the problems emerge when the project leaders start being judged by the policy-driven clusters.

\subsection{Policy-driven clusters: biased judges and ambiguous objectives}

Policy-driven clusters are responsible for labelling projects. This label is necessary, in order to become eligible to apply for the FUI or, until end of 2012, to have a financial pop-up for ANR projects. This labelling process can either be an oral presentation as in the case of Systematic or HCPR, or just a written submission of the projects in the case of Cap Digital. Generally these presentations are very standardized. The presentation at Systematic is for example very short ${ }^{231}$. In 5 minutes the project leader has to present its project with 2 slides and has to answer some questions. In case the project is right away labelled and financed, no problems emerge, but this is nearly never the case. Our data show that it is very seldom that a FUI project gets financed after a first submission (see Table 45 at the end of the chapter):

"C'est très, très rare que, quand on a soumis un projet à un FUI, il soit reçu le premier coup. En général, les gens le re-soumissionnent en retravaillant un peu le projet et en changeant peut-être un partenaire du consortium. » (P9)

When a project gets rejected at the policy-driven cluster level, there is a widespread opinion among project leaders that it is not the quality of their projects that is at cause but political reasons. These impressions might be true or not true but they have an impact on the trust a project leader has in the policy-driven cluster and the willingness of a project leader to participate in the policy-driven clusters' activities.

\subsubsection{Biased behaviour of the evaluation committee in policy-driven clusters}

In case a project leader's project was rejected, a common opinion among project leaders is that the evaluators are impartial and political reasons are at play for labelling or not labelling projects at the policy-driven cluster level. Project leaders get particularly angry if they recognise one of the evaluators as having himself/herself an on-going project on a similar subject. They assume that this evaluator does not want to finance another project that might enter in competition with his plans:

«Après, on a eu une autre personne qui nous a posé la question : «Mais est-ce que vous
vous êtes posé la question vis-à-vis de l'autorité de la sécurité sanitaire »... Pfft... non,
non, non... on ne s'est pas posé la question...cette personne faisait partie du jury...
Morts !.......] Quand je fais la réunion à InVS, à l'institut de veille sanitaire à Saint-
Quentin-en-Yvelines, j’ai eu cette personne en face de moi. Il est venu présenter son projet.
En fait, quand on a une personne dans son jury qui a présenté un projet aussi [...], qui était

\footnotetext{
${ }^{231}$ Verbatim: «Systematic, ils vous invitent, vous avez 5 minutes, vous avez 2 slides, 5 minutes de présentation, 5 minutes de questions. » (P10)
} 
porteur d'un projet $R \& D$, donc on se dit: 'OK, les dés sont pipés, il y a un lobbying, il y a du copinage, c'est bon, on arrête tout' [...] Ils n'auraient jamais dî le mettre dans le jury; on ne peut pas être juge et partie.» (P5)

"J'ai appris que le [spécialiste du domaine technologique du projet], le seul qui était là, c'est quelqu'un qui fait également la [technologie] et il n'a pas forcement intérêt de nous voir arriver là-dessus. C'est quelqu'un que j'apprécie énormément par ailleurs, mais il a jugé le projet, et il ne l'a pas forcement mis en avant. (P8)»

Another cause of frustration among project leaders is when the evaluation committee criticises a project because a certain company, specialist, etc. is not integrated in the consortium. When the evaluation committee criticises the project because an industrial partner is missing, the project leaders understand the utility behind it, even though it seems very difficult for them to find industrials. However, when the criticism turns around why a specific partner is missing, the project leaders have the impression that political reasons are at play and that they have to integrate this actor, otherwise their project will never get financed:
"Ils étaient une demi-douzaine pour soutenir le projet lors de l'audition. Les membres du projet se sont retrouvés face à une trentaine de médecins, tous de l'AP-HP. Ils ont fait un certain nombre de commentaires, si je continue : "On ne comprend pas pourquoi l'AP-HP n'est pas présent dans ce projet. Pourquoi ils ne dirigent pas ce projet? " Ainsi de suite... [...] Donc il y a des partenaires qui ont des visions hégémonistes, qui cherchent à tout contrôler, et ce n'est pas propre à la médecine. La médecine, c'est caractéristique, surtout en région parisienne (...) mais [on trouve la même chose dans] le transport. » $(P 3)^{232}$
"On nous a dit:'on vous finance ce projet là, mais vous mettez cette société dans le consortium, sinon c'est non'. [...] Le financeur, la DGCIS, a des intérêts. Ils avaient beaucoup financé cette entreprise et ils voulaient qu'elle continue. Elle a fait faillite quand même. Ils voulaient capitaliser sur leur investissement. Donc ils continuent à le perfuser, c'est-à-dire mettre de l'argent, en l'imposant à des consortiums dont ils savaient qu'ils allaient les financer. Pour qu'elle continue à reçevoir de l'argent. » (P9)

At the end of the day, project leaders have the impression that it does not count if one has a good project or a bad project, but one just needs to "know" somebody in the evaluation committee:

"Tous les membres du groupe thématique [nom] de Systematic ont un autre projet sur à
peu près la même thématique. Et donc, forcement, quand c'est les membres du groupe
thématique [nom] qui évaluent le projet... [...] Grosso modo, le problème n'est pas d'avoir
un bon projet ou un mauvais projet, c'est qu'il faut avoir des gens qui le portent parmi les
évaluateurs. [...] Grosso modo, on arrive en concurrence des projets du [institution] et on
se fait éliminer pour des raisons politiques. » (P1)

All these little incidents leave the project leaders in the impression that the policy-driven clusters are biased and that lobbying is necessary in order to get the project labelled. This impression is further increased because they already heard that with lobbying at the executive office level, one could change the decisions taken by the evaluation committee. For

\footnotetext{
${ }^{232}$ Verbatim: «Pourquoi la société française de [maladie] n'est pas impliquée ?» (P4)
} 
example, one project leader has heard some rumours that a rejected project was finally labelled thanks to lobbying:

"Ils avaient éliminé les deux, et finalement, apparemment avec du lobbying, [nom d'un projet] était re-labelisé tardivement par Systematic... C'est les infos que j'ai eues. » (P1)

A project leader who is himself heavily integrated in one of the Parisian policy-driven clusters, confirmed that such a behaviour might actually happen:

"Après, il peut y avoir des arbitrages politiques parce qu'il y a un grand groupe qui a ses relations politiques. Donc on fait passer le projet, mais ça c'est autre chose. [...] Il y a une grille de notation. Et ensuite il y a un bureau, qui lui est plus politique chez [pôle, not Systematic as in case P1] qui peut aller repêcher des projets qui ont été mal notés pour des raisons ultra-politiques, genre: 'c'est soutenu par le gouvernement', genre: 'on sait que la boite est en difficulté mais elle veut créer de l'emploi, on a vu la personne avant, on va l'aider', etc. Donc ils remontent les notes. C'est rare qu'ils les baissent, sauf si, dans le comité exécutif, une personne connaît vraiment bien le sujet, et dit qu'ils n'ont pas compris. $»(P 9)$

\subsubsection{Decision inconsistency: labelling then not labelling}

Another point of frustration among project leaders is "decision inconsistency" at the policydriven cluster level. If a project was labelled but gets rejected by the FUI, a project leader can simply start again at the beginning of the process, meaning submitting the project for labelling at a policy-driven cluster and subsequently submitting the project for financing at the financial authorities' level. Three outcomes are possible for the second submission:

- $\quad 1^{\text {st }}$ Case: Receiving cluster label AND subsidies

- $\quad 2^{\text {nd }}$ Case: Receiving cluster label BUT NOT Subsides

- $\quad 3^{\text {rd }}$ Case: Being rejected for cluster label and thus subsidies

In case the project gets labelled this time and financed afterwards, no problem exists and the cluster actor is happy ( $1^{\text {st }}$ case $)$. However, this is not always the case. As the $2^{\text {nd }}$ case shows it is possible that the policy-driven cluster labels the project once again but the financial authorities refuse the subsidies again. This is a frustrating situation for the policy-driven cluster but particularly for the project consortium. Additionally, it undermines the policydriven cluster's utility in this process. However, the worst case for a project consortium is if a project was already labelled by a certain policy-driven cluster in a previous round but refused for financing, and then when the project leader decides to resubmit the project once again, the project is not labelled anymore $\left(3^{\text {rd }}\right.$ case). The reason why a policy-driven cluster might label a project once and then not anymore is because one of the performance indicators of a policydriven cluster is the ratio between labelled projects and financed projects. In case a cluster organisation feels that a project is not getting financed, it might then refuse the label out of 
"self-interest". However, the project leaders do not necessarily have this information. They only see that the project content was evaluated as interesting and good once by the policydriven cluster but then, at the second submission, this was not the case anymore. This creates a high frustration among the project leaders:

\begin{abstract}
"On va le rater au FUI [troisième soumission]. Pourquoi, parce qu'on a trois pôles et le troisième pôle ne veux plus le labéliser. Il y a Systematic qui a refusé de le labéliser alors qu'il l'a labélisé deux fois avant. Et c'est là où je dis qu'il y a un truc qui ne va pas dans ces pôles. » (P8)

«Dans les labellisations, ce qui était un peu étrange, c'est que le projet était labellisé par HealthCluster pour l'ANR TecSan mais refusé ensuite pour le FUI. Et les raisons du refus n'étaient pas mentionnées lors de la première soumission. »(P1)
\end{abstract}

P8 handled his frustration by submitting the project to another Parisian cluster and by turning the back to the policy-driven cluster that refused to label the project a second time. The new policy-driven cluster then labelled the project and the project was finally financed by the FUI.

However, P1 abandoned the project out of great frustration:

"Maintenant, à titre personnel, j'ai plutôt mal vécu l'expérience. Donc en fait, s'il n'y a pas
une demande forte de la hiérarchie, qui va s'impliquer sur un plan politique dans la
labellisation du projet, je considère que c'est perdre mon temps. [...] Ca prend beaucoup de
temps pour un résultat qui n'est pas très intéressant. Sachant qu'on a déjà des projets
européens, FP7 ou ANR qui sont plus intéressants. »(P1)

$\mathrm{P} 1$ is now completely rejecting the FUI and is convinced that without a strong lobbying in place, the projects are not able to get labelled at the policy-driven cluster level. For whom this invest is not worth the outcome and he prefers turning to other types of subsidies where a policy-driven cluster label is not necessary.

\title{
2.2.3 FUI: ambiguous objectives and complex set-up
}

The last two points that we just discussed (behaviour of the evaluation committee and decision inconsistency) where both directly related to the policy-driven clusters. However, policy-driven clusters are also impacted by decisions and situations that lay beyond their perimeter: namely the ambiguous objectives of the FUI itself. Even though the FUI is not the only subsidy linked to policy-driven clusters, it is the only one that can exclusively be accessed through policy-driven clusters and additionally the government often justifies the usefulness of the cluster policy with successful R\&D projects financed by the FUI program. In the head of the project leaders, the FUI program is thus intimately coupled with policydriven clusters. Consequently, having a bad experience with FUI subsidies, can lead project leaders to reject policy-driven clusters all together. The following example perfectly 
summarizes how a project leader was so frustrated from the FUI that he completely refused to apply for the FUI again and to pass through policy-driven clusters:

\begin{abstract}
"Le truc ficelé. On travaille dessus pendant 18 mois. [...] On monte un projet, mais c'était un chef d'œuvre. OK. 3 labellisations. [Pôle 1], [Pôle 2] et encore une autre labellisation. [...] Tout passe devant les experts. Le projet : 'génial'. Favorable. "Super, vraiment vous avez fait un bon boulot ». Pour moi, c'était acquis. On monte même une filiale de deux personnes, une petite boite que j'ai créée [...] parce qu'on sentait le truc important et là : projet non financé! Et là, je ne comprends pas. Donc le mec du [pôle 1] m’appelle, le directeur, il me dit : "Oui mais votre problème est que votre projet supprime de l'emploi. [note : c'était une recherche sur l'automatisation] » Je dis : "Quoi ? Attendez, mais ce n'est pas possible." "Ah oui, mais à la DGCIS ils ont eu des ordres. Tous les projets qui bouffent de l'emploi... » Je dis : "Mais attendez, on l'a adressé sur un axe stratégique. » "Je suis désolé, on peut rien faire, c'est politique, on refuse le projet.» Ahh! Je peux vous dire quand vous êtes une PME, quand vous avez bossé 18 mois là-dessus, vous dites: "Mais qu'est ce que c'est ces appels à projet ? » Voilà, donc du coup j'ai dit: 'FUI, plus jamais'. Et donc j'ai boudé le FUI. [...] Moi ça m'a tellement énervé quand j'étais interviewé par des journalistes, je dis: 'voilà on fait de l'ANR, le FUI n'est pas intéressant'. Jusqu'au moment où les pôles, ça les a un peu énervé, puis il y a le pôle [nom], la directrice est venue me voir, elle me dit : «Pourquoi vous dites ça? » Je lui dis : 'voilà la situation'. Depuis on s'entend très bien, mais j'étais refroidi par ca. Et quand on ne connaît pas et c'est le premier projet, ça fait mal. [...] Ca reste toujours assez politique le FUI, parce que c'est la DGCIS qui tranche. » (P8)
\end{abstract}

The example shows that even though a policy-driven cluster labels a project and thinks that the project has a great potential, the final decision lies beyond its responsibility. However, the refuse to finance the project on the national level has a negative impact on the policy-driven cluster. P8 decided to turn to other subsidies sources (for example ANR, European Programs) and boycotted the FUI and policy-driven clusters because he considers that it is too political.

The example shows that policy-driven clusters are intimately linked to the FUI program. Additionally, the example also shows that policy-driven clusters indirectly suffer from the FUI's ambiguous objectives. Theoretically, the objective of the cluster policy is to promote innovation. This is also anchored in the heads of the project leaders. When project leaders first apply to the FUI, and thus to policy-driven clusters, they often concentrate on the innovation part of their projects. However, little by little they realise that what seems to count more is the business and job creation part of their projects. For example the project P8 was refused because the innovation would have destroyed existing employment. Following comments also show, that the "policy-driven cluster / FUI" objectives are not very clear for the project leaders:

«Je pense qu'ils veulent tout et son contraire. C'est ça le problème. $\underline{\text { Ce qu'ils veulent }}$ fondamentalement, c'est que les projets FUI arrivent à créer des emplois au niveau régional, mais en se basant sur l'innovation et en faisant en sorte que l'innovation ne vienne pas trop des académiques. En limitant quand même l'impact des académiques, parce qu'ils veulent qu'il y ait une aide plus importante sur le tissu industriel. C'est là où on ne sait pas si c'est réaliste ou pas. [...] On a un ratio [entre PME, académique et grands groupes] à respecter [mais] qui est quand même assez dur à respecter, surtout si on veut 
faire de l'innovation. Si je veux faire beaucoup d'innovation, j'ai besoin de beaucoup de contribution des académiques. Ils veulent à la fois un projet innovant et que les académiques contribuent peu. Ca, c'est le déconneur. »(P10)

"Le FUI, c'est hyper-compliqué à avoir, c'est un des plus dur. Pourquoi, parce que ce n'est pas sur un campus scientifique, c'est sur un business model et une opportunité de marché. [...] On a eu Monsieur X qui venait du ministère de l'industrie qui nous a très bien fait sentir qu'il fallait orienter notre projet à l'export avec des modèles économiques viables et surtout avec de la création d'emploi. [...] « Mais attendez! On fait de la $R \& D »$. [...] [En analysant d'autres projets] $O K$, il n'y a pas de $R \& D$ et ils reprennent les technos sur l'étagère. Ca existe, ils les réadaptent. Ils ont le modèle économique qui tient la route. OK nous on a proposé de la $R \& D$. [...] Le problème du FUI? Ce n'est pas fait pour faire de R\&D. [...] Le FUI c'est un modèle économique. C'est de l'innovation technologique, mais avec des retombés économiques très rapides. Donc nous, on s'est trompé. » (P5)

The project leaders seem thus to be confused between the policy-driven clusters' $R \& D$ objectives and FUI's strong job creation and business orientation. Additionally, the project leaders suffer from the impreciseness of the persons that hide between the FUI. The FUI is a common fund of different ministers and different national and regional authorities. The set-up is thus quite complex. This creates a confusion regarding the objectives and preferences of all these entities and thus a blurriness regarding the points to address in the application form:

"Quand vous présentez le projet aux financiers, vous avez un représentant de chaque
département, et puis vous avez des représentants d'OSEO, et puis une personne du pôle ou
des pôles, donc vous ne savez pas qui c'est. On ne sait pas qui ils sont, ce qu'ils veulent, ce
qui les intéresse. On vous demande de faire une présentation stéréotypée, qui ne répond
probablement pas aux questions qu'ils se posent. C'est ça que j'aimerais savoir. C'est
d'avoir une meilleure sensation des questions qu'ils se posent. Ceci dit, les financeurs sont
tellement disparates (...) peut-être il y a un problème de cohérence dans la notion même du
$\underline{F U I »(P 10)}$

This blurriness is particularly strong when looking at ICT \& Health projects. The project leader does not know if he should focus on the medical part to satisfy HealthCluster, the technological part to satisfy Systematic, or the financial part to satisfy the financial authorities:

"Par exemple, pour le projet [P10c], on a rédigé un document à l'attention de Médicen. Dans le projet précédent [P10b], j'ai essayé de faire quelque chose homogène pour Médicen et pour les financeurs. Dans [le projet P10c], les choses ont un peu changé mais je n'étais pas averti. On a du faire une présentation pour Médicen, orientée sur un template Médicen, orientée sur les préoccupations médicales, pour une labellisation Médicen avec un point de vue très particulier qui était assez loin d'en couvrir les intérêts technologiques, par exemple de l'OSEO, et les intérêts des financeurs. Ensuite, on a du faire une présentation Systematic. Systematic s'est posé des questions dans des termes complètements différents. C'est-à-dire [...] ils se posaient des questions sur la qualité des réseaux qu'on allait utiliser, etc. » (P10)

This blurriness of responsibilities that hide behind the FUI also challenges already financed projects. When the project is a success, national and regional financers want to reap the glory. However, the project leaders need to assure that all financial entities that participated in financing the project, be it on the national or regional level, get the same attention: 
« Là, il y aura une conférence de presse dans dix jours [...] en gros au niveau politique, ils veulent justifier l'existence des pôles par un certain nombre de projets, dont celui là, parce qu'aujourd'hui (...) d'après ce que j'ai compris, l'opposition critique les pôles de compétitivité en disant que ça coûte cher etc., et ils veulent garder sous la pédale des projets comme ça pour dire: "Attendez, regardez les emplois». Le problème qu'on a, c'est : 'OK les pôles sont crées par l'Etat qui est de droite, mais nous, nos financeurs pour près de 2 millions d'euros, c'est le conseil régional de [région], qui est de gauche'. Donc nous, on leur a dit clairement: 'on refuse de participer si vous n'intégrez pas [région]'. Parce que je vous ai dit: tout ce qu'on veut, c'est faire avancer la machine. La politique, bon, même si on a des idées, on ne veut pas rentrer là-dedans. » (P8)

However, this blurriness is particularly associated the FUI and not to other subsidies sources:

\begin{abstract}
"Prenons le projet européen. [...] Ils ont un call qui est clair. [...] On demande de développer une instrumentation, un outil pour une problématique de santé et de prouver que le travail effectué va être bénéfique pour l'entreprise. On nous demande que ça. C'est clair. On a un message clair. On a un cadre clair. Après, on est bon ou pas bon. C'est autre chose, mais au moins on a un contexte qui est parfaitement clair. Le FUI pour moi, avec le support des pôles, c'est schizophrénique. Je ne sais jamais ce qu'il faut dire. [...] On finit par tordre le projet. Ce n'est plus un projet. [...] Le programme ISI d'OSEO. Ils ont une problématique qui est claire. Vous y allez. Vous mettez toute votre énergie sur l'axe industrielle. [...] L'ANR est très claire aussi. »(P10)
\end{abstract}

For P10, the complex set-up of the fund (multiple funding parties) and the link to the policydriven clusters (specific objectives as well) renders FUI projects highly complex. At the end, P10 underlines that one nearly does not recognize the project anymore because one has to twist it in all senses so that it corresponds to all the different demands. For P10 this renders the FUI fund together with the policy-driven clusters schizophrenic.

\title{
2.2.4 Consequence: abandoning policy-driven clusters or intensive lobbying
}

The negative impressions a project leader receives from the labelling process and the FUI can push him/her to stop getting involved in policy-driven clusters or the FUI. However, another observed behaviour is that the project leader starts an intensive lobbying process. Getting a project financed is the main objective for a collaborative research consortium. As most of the project leaders consider the FUI to be very political ${ }^{233}$, lobbying is the logical consequence. Two levels of lobbying can be distinguished: on the policy-driven cluster level (responsible for the labelling of projects); and on the financial authorities level (responsible for the granting of the subsidies) and its wider influence sphere.

Lobbying on the policy-driven cluster level: On the policy-driven cluster level, the lobbying passes through, for example, participating at the different meetings, calling the policy-driven cluster or proposing to actively participate in the policy-driven cluster (e.g. as an expert). The objective is to get known among the "fauna and flora" of the policy-driven cluster:

\footnotetext{
${ }^{233}$ Verbatim: «Le FUI, je connaissais en mal. Parce que pour moi, c'était - et c'est toujours - très politique. » (P8)
} 
"Après c'est énormément de lobbying. Si vous n'êtes pas connu, si vous ne prenez pas votre téléphone pour appeler les pôles, pour vous faire connaître des pôles, vous n'êtes pas connu. [...] Mon expérience maintenant, c'est qu'il faut être très, très proche des pôles. Il faut aller aux réunions des pôles, il faut aller voir qui est la faune et la flore des pôles de compétitivité. Pour se faire connaître, parce que c'est très simple. C'est du réseau, si vous êtes connu, on va essayer de vous aider plus que si vous êtes inconnu, parce que quand vous déposez, on ne sait pas qui c'est. C'est comme ça. » $(P 5)^{234}$

The policy-driven cluster environment is strongly associated to a lobbying realm. In order to get a project labelled the project consortium chooses the partner that has the highest experience of lobbying and is well integrated in a policy-driven cluster. This has the consequence that the same project leaders seem to be at the forefront of policy-driven cluster activities: business-driven SMEs that are free electrons with a lot of lobbying potential.

Lobbying on the financial authorities level and its wider influence sphere: In case a policydriven cluster did not label a project, we also observe that a well-connected project leader might directly talk with the national authorities in order to put pressure on the cluster:

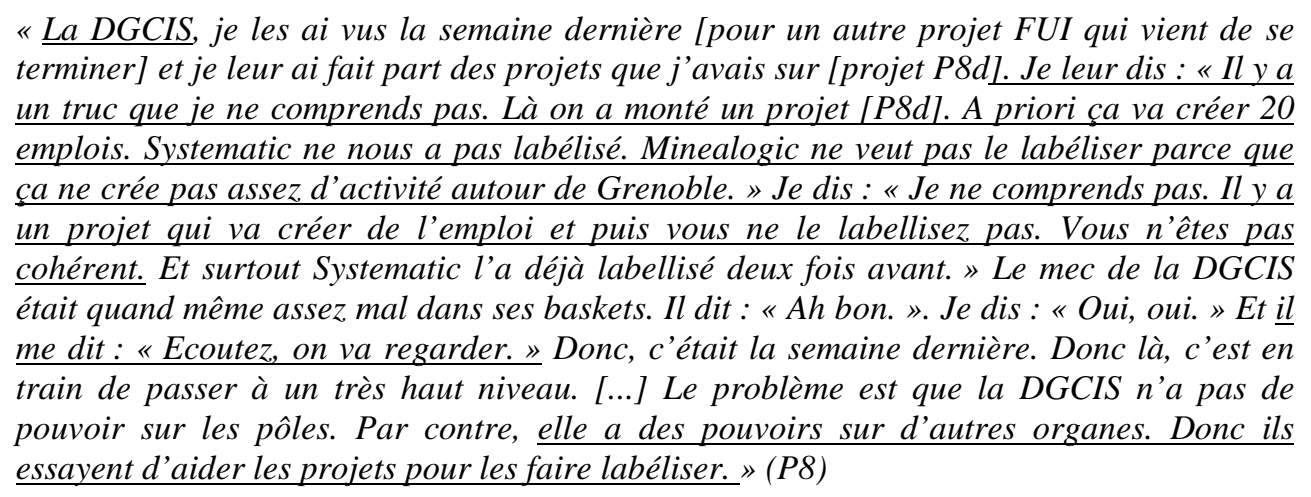

Or talk with other well-connected personalities in the public sphere that can then put pressure on the policy-driven clusters:

"Le directeur du CNR Santé235 nous aide. Là sur le projet [P8d] il est parti faire du lobbying. Parce que je lui ai dit : "Là on ne comprend pas. Il y a des gens intéressés, qui sont prêts à acheter derrière, etc. Nous on paye 1000 euros par an au CNR Santé. On est rentré dedans. Il faut que vous fassiez quelque chose là. » Donc il a dit : «Je m'en occupe. Je vais essayer de voir comment. » Après si ça ne marche pas, ce n'est pas grave. » (P8)

Lobbying is thus a crucial part of the policy-driven cluster realm.

\subsection{Double pressure on policy-driven clusters}

Policy-driven clusters are responsible for helping the companies to access subsidies but at the same time they have to label the projects. This has a considerable impact on policy-driven

\footnotetext{
${ }^{234}$ Verbatim: "C'est un peu notre faute aussi. Il y a [quelqu'un de l'entreprise] qui est au groupe thématique [nom] de Systematic. Il aura pu plus se bouger les fesses sur le plan politique aussi, hein! » (P1)

${ }^{235}$ We will discuss in the next section the difference between CNR Santé and a cluster organisation.
} 
clusters. To summarize, two types of stakeholders put pressure on policy-driven clusters: companies (bottom up pressure) as well as the government (top-down pressure).

\subsubsection{Bottom-up pressure from companies: want to get labelled and financed}

French policy-driven clusters have a double role in the subsidies finding phase: (1) first, a service role, what we call a friendship relationship with the project leader and (2) second, an examination role, what we call a judge relationship with the project leader. In both areas, the different French policy-driven clusters are in competition. For the business-driven project leaders that can easily apply their knowledge to several industries and sectors, cluster organisations are highly exchangeable as all of these comments illustratively show:

"Les pôles de compétitivité sont en compétition entre eux..$(P 9)$

"Surtout, je connais beaucoup de pôles. Je suis dans Cap Digital, mais aussi dans Systematic, plus ou moins. Je suis un proposant chez Images \& Réseaux. Je suis enregistré chez eux, j'ai fait aussi du Mov'eo. Mov'eo, on a abandonné, on est plus dans Advancity. [...] On est vraiment implémenté dans tous les paysages, une grosse partie du paysage national et européen $»^{236}(P 3)$

" J'ai quand même une assez bonne connaissance des 71 pôles français. Je connais à peu près bien... 29. »(P8)

Service role (friend). The Paris Region is a region that counts seven policy-driven clusters on its territory. In order to get the full amount of subsidies, the project leaders absolutely need to get their projects labelled from a local policy-driven cluster. To increase their labelling chances, they wisely chose which policy-driven cluster organisation to contact. The examples hereinafter will particularly display the competition that exists between Cap Digital, HealthCluster and Systematic as the project leaders we interviewed participated in the "ICT \& Health" initiative that is animated by these three clusters ${ }^{237}$. The competition between the policy-driven clusters starts when project leaders first need advices regarding their projects. Most of the interviewed project leaders were in contact with all three Parisian policy-driven clusters (Cap Digital, HealthCluster and Systematic). They acquired a certain image of all three policy-driven clusters:

"Je pense que les pôles sont organisés tous de façon différente. Et Systematic, Cap Digital
et Médicen ne tournent pas du tout de la même manière. [...] Là, par exemple, on s'est
inscrit à Cap Digital. On a une relation qui est beaucoup plus ... Cap Digital, quand
¿'envoie un message, j'ai une réponse à 11 h du soir et des réponses à 6 h du matin. Jamais
plus de $2 \mathrm{~h}$ de décalage, entre le message et sa réponse. [...] [HealthCluster] ce n'est pas la la

${ }^{236}$ Note: Cap Digital, HealthCluster and Systematic are situated in the Paris Region. Image \& Réseaux is situated in Brittany. Mov'eo is situated in the Upper Normandy. The company (P3) is situated in the Paris Region.

${ }^{237}$ Another example of such an inter-cluster collaboration in the Paris Region would be the "ICT \& Sustainable city" initiative, proposed by Cap Digital, Advancity and Systematic. 
même efficacité. HealthCluster a la réputation d'un pôle qui n'est pas bien mis en place et ce n'est pas seulement une réputation. »(P10)

"Pour l'instant, je dirai qu'on est plus en relation avec [noms de cluster managers] chez Cap Digital que chez HealthCluster. Ca ne veut pas dire que ça ne peut pas se développer dans l'avenir. [...] Il y a moins de choses organisées chez HealthCluster. J'ai l'impression. »(P6)

"Systematic, je ne le sens pas bien. Je ne le sens pas bien. [...] J'ai plus d'affinités vers Cap Digital et eux aussi. C'est bizarre, parce qu'on matche bien. Donc j'irai plus facilement sur les présentations de Cap Digital, que sur Systematic. Alors je me trompe peut-être. [...] D'un point de vue humain, Cap Digital est quand même beaucoup plus proche de ses dépositaires. On sent qu'il y a une proximité. [Noms de cluster managers] ont cette inquiétude et cette volonté de faire avancer leur pôle. Systematic...pfff... n'étant pas connu...pfff... voilà... je n'étais pas connu, donc ce n'est pas les mêmes relations. [...] Cap Digital, on commence à se connaître. Je suis allé les voir l'année dernière pour leur re-présenter [le projet P5a]. Parce que on l'a déposé chez Systematic mais on a après essayé de le déposer aussi chez Cap Digital. Ils nous ont reçus. La différence était là. L'autre, c'était au téléphone, là ils m'ont reçu. J'étais chez eux. Le cadre s'y prête. Ils ont essayé de comprendre, de décortiquer.» (P5)

The examples show that the project leaders actively choose where they would like to become a member. Most project leaders point directly to Cap Digital as having the best services. The first reflex would be to say that they are all ICT companies and naturally turn to Cap Digital. However the interpretation has to be more subtle than this:

- First, it is true that P5 is a typical ICT service company and thus is clearly more attracted by a policy-driven cluster like Cap Digital than by HCPR. Additionally, P5 never had a project labelled by HCPR. However, theoretically P5 could be member of Systematic and Cap Digital but has a better "feeling" with Cap Digital than Systematic. One important element that is often mentioned as a difference between Cap Digital and Systematic is that Cap Digital is receiving everybody personally and not only by phone as Systematic does. It just seems a small point, but might be one of the reasons that make a real difference for the project leaders.

- Second, P6 is the association solely specialised in medical issues and having even a president that is a doctor himself. His project P6a was labelled by HCPR and Cap Digital and then financed by an "Investing for the Future" Program. HealthCluster is mentioning this project on its web site as a success for HCPR. As HCPR labelled the project, it will also count in their performance statistic. However, also P6 is more turning to Cap Digital than HealthCluster because the service, in order to find financing, is perceived to be better than at HCPR. Additionally, according to the project leader, Cap Digital seems to organise more events than HCPR.

- Third, P10 is the organisation that has two business fields whereby one is solely specialised in medical issues. For a long time, the president of the company has 
offered services to French doctors so he knows very well this universe. Additionally, all of his collaborative research projects are situated at the intersection between ICT and Health and he always has a strong hospital component in his projects. HCPR, Systematic and Cap Digital labelled one of his projects and the project also figures as a success story on HCPR's web site. However, also this heavily health oriented company is more attracted by the services of Cap Digital than by the services of HCPR.

On the one hand, it seems that Cap Digital is more oriented and open towards SMEs. Cap Digital seems to better understand SMEs' needs and grants a greater participation role to this type of enterprise structure. This is not the case for HCPR:

"Il y a des pôles où c'est difficile quand on est une PME pour pouvoir jouer, de trouver sa
place. Il y en a un où c'est très facile, par exemple : Cap Digital, Image et Réseaux. C'est
de gros intervenants, mais ils laissent à la PME la possibilité de jouer son rôle. Et après il
ya d'autres où c'est très, très difficile. Médecine et transport, c'est très difficile " (P3)

On the other hand, Cap Digital has the advantage to be a service and technology policy-driven cluster, compared to HCPR that is a specialised policy-driven cluster. In technology policydriven clusters like Cap Digital, companies can concentrate on one type of technology and then apply it to other sectors ${ }^{238}$.

Examination role (judge). As we just saw there exists a competition between the policydriven clusters regarding their services. This competition continues when we look at their labelling role. The project leaders turn to the policy-driven clusters they judge as most trustworthy, as following comments show:

\footnotetext{
"[Pour la deuxième soumission] Je n'avais pas confiance au groupe thématique [nom] de Systematic, donc j'ai soumis le projet également dans un autre pôle. [note: HealthCluster] ${ }^{2}\left(P 1,1\right.$ st submission Systematic, $2^{\text {nd }}$ submission Systematic \& HealthCluster, 3rd submission HealthCluster)

"Nous ne sommes pas membres de HealthCluster. Théoriquement, je devrais l'être mais on a eu des aventures [...] Parce que, au premier d'appel d'offre, on a été aidé pour le monter par un chargé de mission et un expert de HealthCluster et au moment de la labellisation la labellisation s'est passée sous la forme d'une audition, ça s'est très mal passé, ça c'est très mal passé. Tout le monde était étonné. Personne n'a compris la réaction du jury lors de cette audition, sachant que le projet était poussé par le bureau de HealthCluster. [...] Maintenant, on le soumet uniquement à Cap Digital. On ne passe plus via HealthCluster. [...] Il y a d'autres pôles médicaux. Je sais qu'il y en a un sur le cancer à Toulouse. On
}

\footnotetext{
${ }^{238}$ Verbatim: «Cap Digital, je pense que c'est plus simple pour moi parce que c'est la techno pure. On met du contenu. »(P5)
} 
peut agir. On peut être amené à agir dans des propositions qui sont gérées par d'autres pôles. » (P3, 1st submission HealthCluster, $2^{\text {nd }}$ and 3 rd submission Cap Digital $)^{239}$

The policy-driven clusters in the Paris Region are in labelling competition with each other particularly. Project leaders, in case they had a negative experience with a certain evaluation committee in a policy-driven cluster, decide to turn to another policy-driven cluster in the Region. Of course, this is again only possible if the project is an interdisciplinary project. Additionally, it is important to mention that project leaders often wait to pay their membership fee until the project is financed:

[Question: S'il est adhérent chez Cap Digital ou Systematic?] « Non, pas encore. J'attends d'avoir un projet pour adhérer, payer mon abonnement. » (P5)

"On utilise les pôles d'une manière abusive et intensive parce qu'on a payé, ou pas, une cotisation au pôle. Mais en général, on ne l'a pas payée, on ne la paye pas au départ, on est labellisé quand même, et si le projet passe, on paye. On paye après coup, globalement. [...] Il y a des grandes entreprises qui ne sont pas OK pour payer d'abord, mais qui sont prêtes à payer après. Comme c'est les grandes entreprises, des grands comptes, etc., on leur dit $O K . »(P 9)$

However, this waiting to pay the membership fee is again an illustrative example that shows that a policy-driven cluster's role seems to be reduced to the subsidies finding phase and omits the role a policy-driven cluster could play in other phases. Additionally, this puts a certain pressure on the policy-driven cluster that in fine is not even controlled by the policydriven clusters themselves.

\title{
2.3.2 Top-down pressure from government: performance evaluations
}

Additionally to this bottom-up pressure, the policy-driven clusters also experience a top-down pressure from the government regarding their performances. The project leaders themselves are aware of this issue and play this fact to their advantage. They know that the clusters are evaluated on their transformation rate of projects (labelled vs. financed projects) and that the clusters are fighting against each other to get the best possible projects:

\begin{abstract}
"Pour moi, les pôles ce sont des organismes qui doivent vivre aussi. Donc il y a un écosystème qu'ils sont obligés de maintenir pour avoir - je dirais - leur existence à eux. Parce qu'on l'a bien vu, les pôles se battent pour récupérer des projets : "Non, vous devriez soumettre chez nous. » [...] Ils sont devenus une administration qui a besoin que les gens déposent des projets pour pouvoir démontrer que : "Regardez! On a eu 50 projets déposées, il y a 10 chez nous qui étaient retenus. » Il y a peut-être deux qui ont été sponsorisés, voilà ça marche. [...] C'est un peu, ça qu'on ressent. [...] C'est une administration comme une autre. On le sent. Ca se sent. On nous dit de déposer des projets. Voilà. «Déposez, déposez, déposez, donnez nous des projets.» Voilà on dépose des projets. On le sent. Ce n'est pas dit. Ce n'est pas direct. On voit bien. [...] C'est des organismes qui étaient mis en place. Ils doivent rendre compte. Parce que : à quoi sert de mettre en place des pôles de compétitivité s'il n'y a pas de résultat? » (P5)
\end{abstract}

\footnotetext{
${ }^{239}$ Verbatim: [Note : Labellisation était refusée chez Systematic] «Non mais Systematic, on l'a oublié. On l'a arrêté. Donc finalement, on est allé à Cap Digital. » (P8, 1st and $2^{\text {nd }}$ submission Systematic, 3rd submission Cap Digital)
} 
Another project-leader, who is in the executive office of a policy-driven cluster, also mentioned this top down pressure. The policy-driven clusters know that they are in competition to each other and that they have to anticipate the number of projects that can potentially get financed, to keep their transformation rate high:

"[Les pôles] ont un intérêt qui n'est pas forcement celui des entreprises. Ils doivent exister, ils doivent se financer. [Nom du pôle] reçoit un certain nombre de projets, on labélise certains, et on regarde l'efficacité du pôle de compétitivité en étudiant le ratio : combien de projets étaient labellisés et combien ont été financés. Ce que [nom du pôle] est en train de faire en ce moment, c'est de travailler sur sa propre évaluation d'efficacité, d'accompagnement des projets. Comme je participe au conseil d'administration, c'est difficile en fait. Leur intérêt est de ne pas trop en labéliser, c'est d'être qualitatif et pas que quantitatif. Pas trop de projets. [...] la DGCIS a seulement une certaine somme d'argent à dispenser. [...] Donc ils sont toujours en train d'essayer de savoir où ils mettent le curseur. [...] En fonction du nombre de projets qu'eux vont estimer possibles. Ils savent combien la DGCIS va financer de projets. S'ils savent que la DGCIS va financer 30 projets cette année, [...] qu'eux présentent 100 projets, ils savent que ce n'est pas bon. Maintenant s'ils n'en présentent que 5, ils savent qu'ils pourront financer plus, pour avoir un taux plus élevé. C'est une question de ne pas se disperser, en fonction de son temps et sa crédibilité. $\underline{V u}$ que les pôles sont en compétition entre eux, ils ont ce taux de succès. »(P9)

The policy-driven clusters are thus put in competition by companies (for services and labelling) but also by the government. On the one hand, for not labelling too much projects, but on the other hand lobbying forces might also intervene when they were too strict. Policydriven clusters are thus in a constant balancing act between different objectives and demands.

\subsection{Conclusion: the finding subsidies' dilemmas of HCPR}

The French policy-driven clusters are structured around R\&D project subsides (direct subsidies). The objective of financing $R \& D$ projects in policy-driven clusters is to create a strong network of actors that innovate together. However, this good subsidy intention (dilemma PD\#2a) also generates a side effect: the pathology of distrust. Policy-driven clusters, at least the one we were able to observe in the Paris Region, are torn apart between their friend role (services) and their judge role (examination) which, according to a project leader, generates a "schizophrenic situation". This ambiguous situation creates a lot of lobbying activities in and around the policy-driven clusters in the Paris Region and negative experiences can push potential cluster members away from the policy-driven clusters. The main direct subsidy type associated to the policy-driven clusters is business oriented. This fact, together with the associated distrust pathology, also lays the ground to push the innovation process of the policy-driven cluster (dilemma MD\#2a) in a certain direction: towards development. Additionally, the subsidies question and the competition that we observe between the different policy-driven clusters in the Paris Region also raise the question of the best organisational boundary (dilemma PD\#1b). The Paris Region counts 7 
cluster organisations. For the time being every cluster organisation is specialised in a certain sector, but our data show that interdisciplinary project leaders go there, were they think they get the best services and where they will get their project financed.

\section{Finding partners: "Las Vegas" weddings thanks to "Meetic"}

In this section we now focus on how and where the project leaders meet their project partners. We started every interview with a very open question: "Please tell me about the genesis of the [name of project] collaboration project? Tell me about the initiation of the project: how did everything begin?". At a later point in the interview we asked the project leaders to tell us how they met every single project partner ${ }^{240}$. However, three important methodology points need to be kept in mind:

- First, being a project leader does not always mean to be the one who initiated the project and who had the idea for the project. The consequence is that the project leader is not always the one who started contacting all remaining project partners. We think that the problem is worth mentioning in case somebody wishes to make a quantitative analysis on the subject in the future. However, the project leader is most of the time the only or the most important contact point with the policy-driven cluster. $^{241}$

- Second, even if the project leader was also the one who initiated the project this does not mean that he knows all the project partners personally. Very often a project has a hard core of two or three partners and then this hard core contacts all the remaining partners. In general, the project leaders trust their partners that they will chose competent partners. In the end, the project leader, though he is at the source of the project idea, has sometimes never met all the project partners personally ${ }^{242}$. The contact is for example only established by e-mail ${ }^{243}$ or by telephone ${ }^{244}$.

\footnotetext{
${ }^{240}$ HCPR gave us an exhaustive list of all project partners for each of the ten initially selected collaborative research projects, so we were able to precisely insist on the different partners. The investigated projects have between 3 and 11 project partners each. In total, the interviewed project leaders mentioned approximately the names of 65 project partners and how they have (more or less) entered into a relationship with them.

${ }^{241}$ In total we discussed 19 project ideas with the 10 interviewed project leaders. For 12 projects the project leader was also the one who had the idea for the collaborative project, in 7 cases the idea came from somebody else.

${ }^{242}$ Verbatim: «Il y a des gens dans mes projets que je n'ai jamais vus. [...] [Par exemple dans ce projet, il y a une université] que je ne connais pas du tout. Ce sont des gens que je n'ai jamais rencontrés. »(P7)

${ }^{243}$ Verbatim: "On a eu le FUI, [le partenaire a] pour 300000 ou 400000 euros de subventions; pourtant je ne les ai jamais rencontrés. Tout par e-mail. » (P9)
} 
- Third, the project leaders create collaborative research collaborations not only with people they rarely know but also extremely fast. One project leader described the consortium construction as a Las Vegas wedding ( $\underline{\text { Au lieu de se marier un peu, c'est }}$ Las Vegas. On trouve quelqu'un dans la rue, on va se marier en un quart d'heure. » (P9)). And another project leader underlined that there is no time to create a real consortium ("La difficulté sur les consortiums, ce que on n'a pas le temps d'un créer un vrai.»(P5)). On the one hand, this might show that they trust each other and believe that nobody will put its reputation at peril because the community is not that big at the end. On the other hand, this also shows that the research collaborations are business oriented.

To sum up, if somebody is solely interested in collaborative research projects financed by the FUI then it is inevitable to talk with all project partners in order to have an in-depth understanding of the consortium. However, we were not solely interested in collaborative research projects but interested in the general influence of policy-driven clusters on partnership creation between local actors. For this analysis, the project leader view is an inevitable angle, as he is often the most active policy-driven cluster participant and also chosen out of this "political" reason by the other project members. We will not discuss every single project consortium separately in this thesis. This could be the object of a separate paper (in Annex 14 we give two visual schemata examples of the relationships between project partners. We hope this helps to get a more concrete idea of the just explained.)

\subsection{Project leaders learn but have difficulties to find certain partners}

In this first sub-section, we discuss the diversity of options project leaders use in order to get in contact with other companies. A learning curve can be observed, as a difference exists between project leaders that are new to the collaborative research community and project leaders that are already integrated. Additionally, we focus on two major types of difficulties for project leaders: (1) the difficulty of finding doctors and industrials, (2) the difficulty of finding project partners that are situated in the same geographical region.

\footnotetext{
${ }^{244}$ Verbatims: «De toute façon, pour le montage du projet, c'était essentiellement par e-mail et puis par téléphone. »(P1); "Quelque fois, je ne les vois pas du tout [les partenaires]. Par exemple, la boîte [nom] je ne l'ai jamais vue. Le projet se monte par téléphone. (P10)
} 


\subsubsection{Project leaders' learning curve for finding partners}

Project leaders can be split in two categories: Those who are new to the research community, and those who are already integrated. Among the interviewed project partners only the microenterprise, the medium-sized firm and one SME were quite new in the collaborative research universe. This was also reflected in their comments regarding the policy-driven cluster ecosystem. For the SME it was clear that in order to be able to participate in this universe they first have to "enter" this world but once they have entered this world they will know with whom to work. The following comment shows very illustrative, the effort a company has to make in order to get accepted by the collaborative research community:

"On a toujours voulu travailler dans le domaine des FUI ou des ANR. Des projets de
recherche. On s'est dit avec mes deux responsables techniques : il faut qu'on y aille. C'est
une source de valeur importante en termes de développement des compétences, du réseau.
Et on sait très bien qu'une fois qu'on est rentré là dedans, on y est. Il faut toujours rentrer.
C'est du réseau, c'est du lobbying avant tout. Il faut faire cet effort pour se faire connaître
[...] il faut être présent, il faut se faire connaître. Il faut aller voir les gens, il faut discuter,
parce que si on n'est pas là, on ne vient pas vous chercher. [...] [Maintenantl j'ai appris le
microcosme des pôles de compétitivité, comment ça marche, avec qui travailler. [...] Parce
que ça marche à travers le réseau. C'est très difficile [.... si on n'est pas adoubé, si on ne
fait pas partie du cercle de connaissances. » $(P 5, S M E)$

The medium-sized firm had a similar discourse as the SME, namely that one has to use the proposed workshops "the tribune" to speak to the community, to show that one exists. Once this is done, and the others know the company, one only has to maintain the positive relationship with the community. One has to cultivate the contacts like any type of relationship:

"Les workshops [TIC \& Santé] n'ont pas donné lieu à des résultats concrets identifiables
comme tels, mais ca a quand même participé à l'idée que [nous sommes] une société qui
arrive en visibilité, qui a la volonté de se placer dans l'écosystème de la santé [...] Les
workshops e-santé ont été les premières tribunes où j'ai pu m'exprimer devant la place,
devant des partenaires potentiels, devant des pôles de compétitivité pour affirmer cette
volonté [...] mais maintenant, je n'en ai plus besoin. C'est-à-dire maintenant, pour le
monde de la santé, ça y est, je suis dans le radar. Peut-être, c'est un premier run
intéressant pour des gens qui ne sont pas du tout connus encore, mais une fois qu'on est
repéré dans les radars de chacun de trois pôles parisiens, bon, on n'a plus besoin de faire
ces étapes préalables. Elles ont jouées leur rôle, et c'est transposable aux prochains appels
à projet. Une fois qu'on est connu, on est connu. Ce n'est pas lié à un appel à projet, c'est
une occasion à se faire connaître, puis après on est connu. Après, il faut l'entretenir. C'est
comme des relations personnelles ou amicales. Il faut entretenir l'amitié. Il faut revoir les
gens périodiquement. Il faut dire «coucou, on est là » pour ne pas qu'on nous oublie. Mais
l'essentiel du travail était fait. Donc juste avant les appels à projets, il faut dire "Hop, on
est là. Il y a peut-être ça qui nous intéresse, pensez à nous si vous voyez un partenaire qui
sera en recherche de telle ou telle compétence. » (P7, medium-sized firm)

However, the micro-enterprise that also participated at an ICT \& Health plenary session did not understand the utility of such a workshop and was even very frustrated from the organisation of this day. The micro-enterprise simply does not have the capacity to do more 
than one project at the time and does not see the necessity to participate in such types of events:

"Chacun venait présenter son projet, mais à partir du moment où les gens ont déjà un projet, ils ne vont pas se manifester vers d'autres projets a priori, sauf si ils sont gros, sauf pour les grosses sociétés. Mais pour être bien on ne peut pas courir 36 projets en parallèle. » $(P 2)$

The medium-sized firm and the SME (P5) are business driven and their objective is to get accepted and known in the collaborative research world in order to find regularly new business and research partners. However, once they are known they prefer investing their limited time somewhere else. The micro-enterprise is still idea driven with one strong objective and limited human capacity. Therefore finding lots of business and research partners is not in their interest. The ICT \& Health events were useful to get to know each other, but once one knows the community and community know the company, the added value of these events decreases ${ }^{245}$.

We summarized the integration of project leaders in the collaborative research community in Figure 32. The integration of partners that are not yet integrated in the collaborative research community often starts by what we call "event fishing". By "event fishing" we mean that potential project leaders participate in events (for example organised by a policy-driven cluster) in order to present the company's competences or the company's ideas for attracting new partners. However, the gathering of partners around one idea for project leaders that are already integrated in the collaborative research world seems to function very differently as we will see hereinafter.

\section{Figure 32: Integration of project leaders in the collaborative research community}

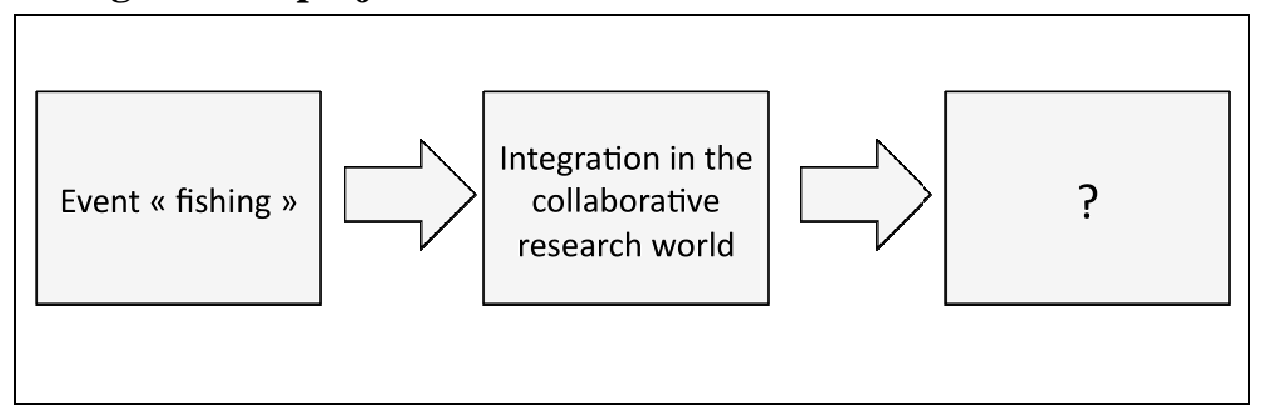

\footnotetext{
${ }^{245}$ Verbatim: "Ces formules là sont très intéressantes, surtout lorsqu'on ne connaît pas les gens, quand on a peu de contacts. [...] C'est un moyen efficace, surtout pour faire rentrer des nouveaux proposants, de nouveaux partenaires. » $(P 3)$
} 


\subsubsection{Project partners, colleagues, and acquaintances $\left(1^{\text {st }}\right.$ step $)$}

The interviewed project leaders who have an idea for a project and who are already well integrated in the collaborative research world do not start building their consortium by going to events. They know how the administrative process of collaborative research projects works and so they do not necessarily need to have a more experienced partner in their consortium. First, they start by mobilising their own, their colleagues and main project partner's acquaintances:
"On a eu un noyau dur qui se connaissait au démarrage du projet. Après, il y a toujours un partenaire qui connaît d'autres partenaires. [...] On a réfléchi à comment monter le projet, qui savait faire quoi, et quelle compétence manquait. Et puis, à travers les différents contacts, on a augmenté le consortium. [...] Il y avait une certaine confiance, dans la mesure où c'était des partenaires de partenaires. » (P1)
"Comme nous on connaissait des partenaires au [centre de recherche], on les appelle: «Vous voulez participer? «

Among this core contacts we would like to point out two specific sub-categories. First, the integrated project leaders have already participated in collaborative research projects. They seem to stay close with these project partners and strongly mobilise all the partners they have met in these projects ${ }^{247}$. This shows the general utility of collaborative R\&D projects and goes in the direction that direct subsidies are useful to create a strong network of potential innovation partners. Second, another category of partners worth mentioning is the category formed by the spin-offs of universities. Several projects had a university spin-off among their collaboration partners ${ }^{248}$.

\subsubsection{Telephone "fishing" (2nd step)}

Once these core contacts are "explored", the project leader starts with its "telephone fishing" phase to find for example a missing competence. By telephone fishing we mean that nobody within the core knows the right person so the project leader starts calling people he knows in order to get the names of other people, and so on, until he finds the right partner:

" Je les ai trouvés par le biais des personnes qui connaissent [nom] qui connaissent [autre noml ... c'est la chaîne. On prend son téléphone, et puis on part à la pêche. On tombe sur

\footnotetext{
${ }^{246}$ Verbatims: «On a eu la chance [...] d'avoir un [...] ingénieur [dans notre entreprise], qui connaît très, très bien [ce professeur qui est] [...] patron d'un laboratoire [dans une Ecole]. » (P5); "Ca fait assez longtemps qu'on se connaît. Moi je [la ] connais très bien [...] parce qu'elle a fait ses recherches à [la même université que moi]. J'ai une relation forte avec elle. » (P6)

247 Verbatims: «Dans un projet précédent [...] c'est là qu'on a fait connaissance avec ces gens-là »(P7); "C'est les gens avec qui on développe ça. [...] Donc on est ensemble dans le projet européen [...] et donc je les ai impliqués dans le projet FUI. » (P10)

${ }^{248}$ Verbatims: "[Cette PME] est issue [d'une université], qui est un des [nos] partenaires [avec qui on travaille]. Ils travaillent en famille, en fait. » (P9); " [Cette PME] est une petite entreprise [...] qui est une spinoff [d'une université]. C'est une spin-off d'un partenaire académique. » (P7); "[Cette PME], c'est un essaimage d'étudiants [d'un de nos partenaires académiques] ». (P1)
} 
quelqu'un qui vous dit qu'il n'est pas concerné, mais qui connaît un tel qui peut être intéressé, etc. » (P7)

"Qu'est-ce que je fais pour ça? J'ai passé un coup de téléphone [à une association] et ils m'ont orienté plutôt sur [une autre technologie] [...]. Donc j'ai pris mon téléphone à nouveau et j'ai appelé une équipe [d'un centre de recherche]. [...] Je ne le connaissais pas mais son nom m'était donné par [l'association]. Et je leur ai proposé de monter un projet. [...] et il me dit OK. [...] Donc je n'ai pas de problème [à contacter des gens]. Je regarde de qui j'ai besoin et je prends mon téléphone et j'appelle. [...] Je passe des coups de fil à tous les gens que je connais pour savoir s'ils connaissaient quelqu'un dans mon domaine. » (P10)

However, in order to be able to start telephone fishing, the project leader has to be deeply integrated in the community with a full address book by his/her side:

«Maintenant, j'ai un carnet d'adresse assez important dans [ce] domaine [...] Par exemple [mon patron] m'appelle il me dit "Il faut que tu me trouves des spécialistes». Deux heures après il avait les trois types en Europe qui sont spécialistes de la problématique, parce que j'appelle le CEA. Le CEA me dit : 'tu appelles un tel de ma part' et voilà. " (P8)

The telephone fishing can also happen by calling a policy-driven cluster. Two interviewed project leaders found a partner for one of their research projects by simply calling (or even emailing) the policy-driven cluster and by asking for a specific competence that was missing in their consortium:

" [PME], je les ai intégrés en un week-end. J'ai commencé les échanges de mail le vendredi soir et le lundi matin, c'était bon. Vendredi après-midi, j’ai envoyé un e-mail à [...] Cap Digital : "Tu n'as pas un partenaire qui fait de la [technologie]?». Donc, leur valeur ajoutée est là. Lui, il a son énorme fichier dans sa tête, 'clac clac'. [...] «Vous connaissez quelqu'un? J'ai besoin de telle compétence. Est-ce que vous connaissez quelqu'un, qui a des fonds propres suffisants et qui a les critères d'éligibilité ? Ca ne peut pas être n'importe qui. » Et le pôle de compétitivité m'a mis en relation avec eux. »(P9b)

"Là, typiquement, c'est HealthCluster qui m'a trouvé [nom du partenaire]. C'est-à-dire que j'ai fait une demande à HealthCluster: "Voilà, j'ai des solutions techniques et je monte un projet qui peut avoir des applications dans le domaine de [maladie]. C'est un monde que je ne connais pas, je compte sur vous pour me proposer des partenaires. » Là. ils ont joué un super rôle qui est: dans leurs annuaires d'adhérents, de faire une recherche, de lancer un appel, un peu à droite et à gauche, pour trouver des gens à qui ça pourrait plaire de participer à un tel projet, et c'est eux qui m'ont proposé [une PME] [...] Ils m'ont proposé [cette PME] en premier contact. Ils se proposaient de continuer la démarche et puis, très rapidement, j'ai pris contact avec [la PME], le courant est si bien passé que je n'ai pas cherché à trouver quelqu'un d'autre. »(P7a)

In both cases the policy-driven cluster was very helpful for the project leaders in order to integrate an additional project partner. The policy-driven cluster was used like a help line. The advantage of "telephone fishing" is that it does not take a lot of time, something most of the project leaders appreciate, even though most of the time they are free to go wherever they want. However, these examples show that once these project leaders are established in a research community they do not have any problems to find the right people by staying in their offices and just using their telephone. 


\subsubsection{Event "fishing" $\left(3^{\text {rd }}\right.$ step $)$}

Project leaders can also use what we call "event fishing". "Event fishing" can be split into active and passive event fishing.

Active event fishing is practiced when there is a need to find (a) key project partner(s) nobody in the consortium knows. During our interviews we observed two cases of active event fishing where the company needed to find a particular doctor and two cases of active event fishing where a university needed to find companies. (Additionally we assisted in official events organised by HCPR (see Figure 33 and Figure 34). Figure 33 shows particularly well the "speed dating" atmosphere that can preveail during such events.)

In the first case of active event fishing, where a company needs to find a doctor, the project leader first contacted doctors he knew in order to identify the name of the best specialist in the medical domain he was interested in. He then looked up when this doctor gave his next conference speech and went to this conference. According to the project leader, he slipped in his "pilgrim clothes" and tracked down the doctor:

\footnotetext{
«Deux médecins [me donnent le nom d'une spécialiste de la maladie dans un hôpital à Paris] [...] : «Elle est professeur. C'est cette femme-là qu'il faut dans le projet. » Donc moi, je prends mon habit de pèlerin. Je vais à une conférence de médecins où elle était, et à la fin, je viens avec un petit schéma, je lui dis : "Voilà, on a imaginé ça. » [...] Elle me dit : "Ah oui, c'est une bonne idée». Je dis : "Mais vous pourriez participer?" Elle me dit: "Oui, venez me voir. » Je vais la voir. [...] Je lui explique. Elle me dit : "Ah oui, c'est génial votre truc » [...] Donc elle participe au projet. » (P8d, project financed by FUI)
}

The second case of active event fishing, where a company needed to find a doctor, is similar to the first case. However, this time the company is less integrated in the research community than the company in the first cited case. Instead of contacting doctors to get the right name, this company did a paid market research study. The market research study identified a list of key opinion leaders that operate in the medical domain they were interested in. Once they were in possession of these names, the cluster actor also participated at a conference where the doctor they were most interested in gave a speech:

\footnotetext{
"On a fait réaliser en amont [...] une enquête, une étude de marché complète par un cabinet spécialisé, qui a permis de dégager une liste de key opinion leaders qui étaient pour la plupart interviewés par ce cabinet. [...] Donc on connaît, on avait déjà un feedback, on savait qui était intéressé potentiellement, qui souhaitait vraiment disposer d'un tel intérêt supplémentaire, qui se posait de vraies questions intéressantes aussi. [...] On a eu un nid de noms. Notamment il y avait le nom [de ce] professeur qui apparaissait dans les interviewés [...] On est rentré en contact avec lui. [...] C'était un de mes collègues qui a fait la prospection. Il l'avait rencontré au cours d'une journée. » (P2a, project financed by FUI)
} 
In this first case, where a university needed to find a company, the university was looking for a certain technical competences but did not know the companies that were operating in this domain. The university first identified the trade fairs of the needed technology, and then went to one of these specialised trade fairs in order to identify and contact the right company:

"Comment on a connu [le project leader] ? Il y a deux salons, des grands salons de [la
technologie qu'on cherchait] en France. [... Ills ont lieu chaque année. Et à cette occasion,
[... on est allé rencontrer les industriels du secteur, et on s'est rendu compte qu'il y a deux
grands industriels en France qui s'occupaient de ce domaine là [...]. [L'entreprise qu'on a
sélectionnée] et une autre. [...] Voilà, donc on a noué des contacts avec [l'entreprise du
project leader] qu'on a trouvé très sympathique et du coup on les a recontacté pour
pouvoir déposer un premier projet, et ça a fonctionné. » (interview with university Partner
of P9a \& P9b project, idea : university, P9a project financed by a special project call, P9b
project financed by FUI)

In the second case, the university needed a certain number of companies for its research project and presented its project idea at a policy-driven cluster event ${ }^{249}$ (ICT \& Health plenary session). The university that was at the source of the project idea was looking for companies to launch its research project. A project leader listened to the presentation, was interested in the idea and then approached the university professor who presented the project idea. However, this case is the only case of the four active event "fishing" cases that was not financed. According to a policy-driven cluster manager, with whom we talked about this project, the project partners were not homogenous enough ${ }^{250}$. In the case where a university does not really know whom to contact and just presents its idea, it seems more difficult to create a homogenous project.

To sum up, we observe that when a person needs to approach a completely different world (a company the medical world or a university the corporate world), the person who had the idea for the project prefers seeing and convincing the missing key partner(s) in person than by phone. In the two cases where the company needed to find a doctor they both identified first the name of the best doctor in the domain in France (either by a market study or by talking with acquaintances), and then the project leader actively looked for an event where the doctor gave a talk. Once this event is identified the project leader goes to this event to talk with the doctor in person about the project. Universities seem to function in a similar manner in case

\footnotetext{
${ }^{249}$ Verbatim: "Lors de la réunion en septembre, c'était en séance plénière, l'objectif était de présenter l'idée du projet et ensuite, donc, il y a eu un break et pendant ce break il était possible, pour les gens qui étaient intéressés par la proposition, d'aller voir les proposants et de leur faire part de son intérêt. [...] C'était [un] professeur [...] qui a présenté et donc ça correspondait aux intérêts qu'on avait, et donc, comme d'autres, je suis allé voir [ce] professeur [...] et j'ai expliqué ce qu'on faisait. Et je disais que ce projet pouvait nous intéresser. » (P3a)

${ }_{250}$ Verbatim: «C'était un peu des briques mais pas une vraie homogénéité entre les partenaires. »(October
} 2011) 
they do not know the right companies. In the first case, the university identified the most important trade fairs and then went there. In the second case, the university presented its project idea at a policy-driven cluster event. However, this more "open” version, meaning just presenting the project idea at a policy-driven cluster event (vs. identifying the key actors of the searched technology / competence) seems to create less homogenous consortiums.

Besides active event fishing, we also observe “passive event fishing”. Passive event fishing is practiced when the company is presenting its competencies without having a concrete project idea. These competence presentations are a standard presentation type during policy-driven cluster project set up events. The company hopes that somebody in the room needs its competencies and will contact it. Passive event fishing is particularly practiced by companies that are new to a certain research community (as already discussed). However, we also sometimes observe that an established company is looking for new project opportunities but does not have a particular project idea. The company then just presents once again the competences of its company to the research community.

Figure 33: One-to-one business meetings during HealthCluster Convention

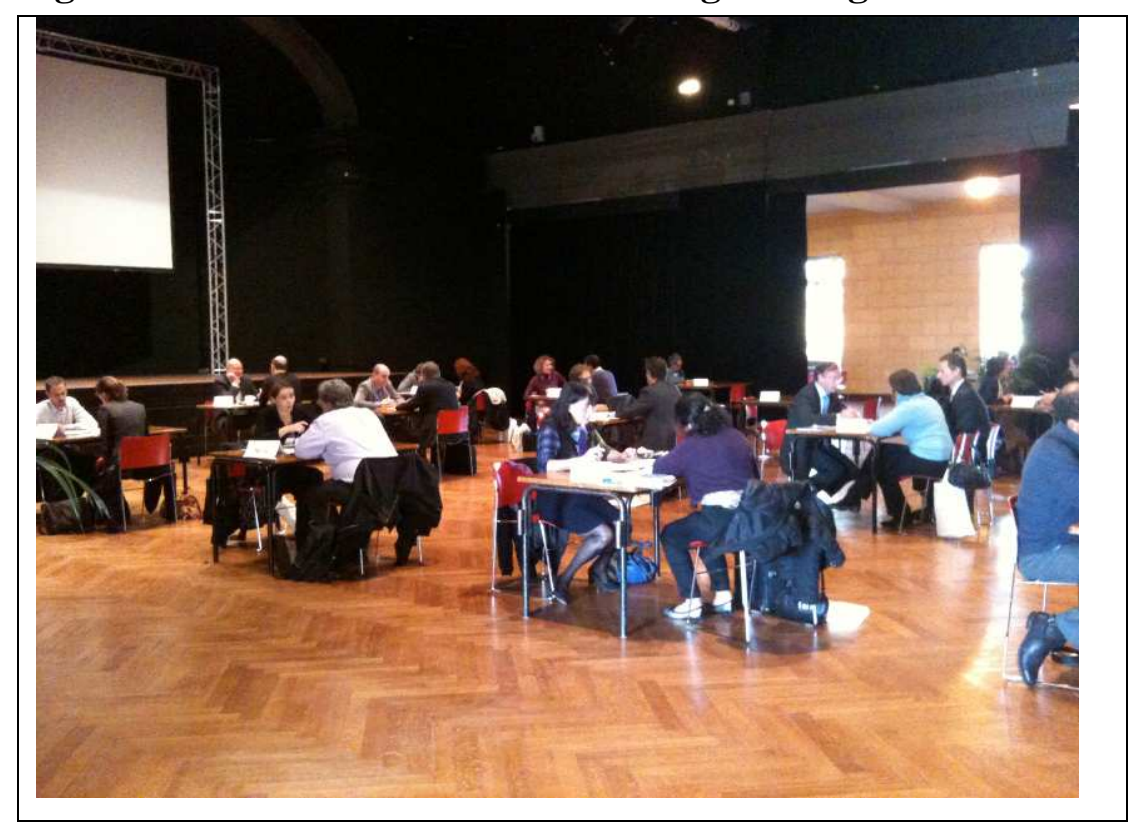


Figure 34: France-Sweden networking event workshop

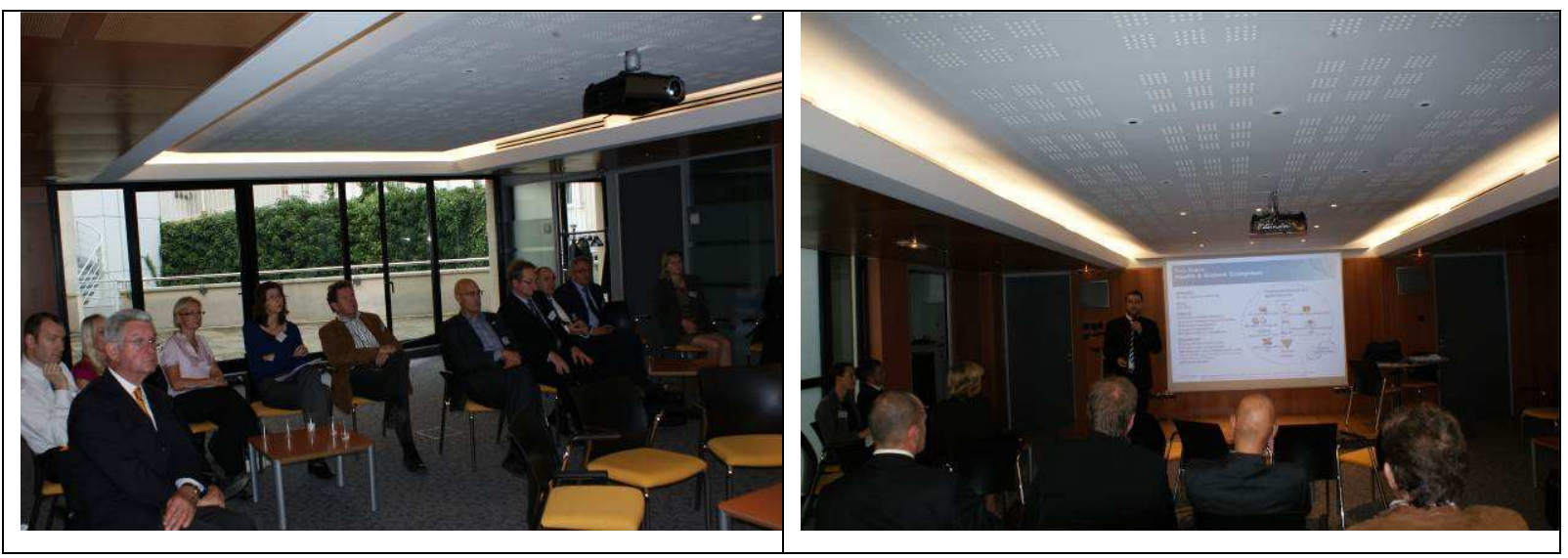

\subsubsection{Maintaining relations $\left(4^{\text {th }}\right.$ step)}

Finally, all project leaders try to maintain their various relations by active partnership management. Either by participating regular at all types of events or by accepting certain responsibilities like for example teaching or being in committees:

- by participating in general events: Project leaders participate in all kinds of events that are organised (e.g. OSEO, ANR, Eureka, FP7, Usine Nouvelle, etc.). However, as it is important for them to maintain a good relationship with a lot of different types of communities, the policy-driven cluster communities only represent one of several communities they need to maintain. Project leaders wish to maintain a close relationship with a lot of different communities in order to stay on the "collaborative research radars" of all of these communities. Participating in a lot of different events allows them to multiply their collaborative research project chances (as we already know, most of the companies are business oriented). The policy-driven cluster organisations are thus in competition with all these other important communities.

- by accepting teaching responsibilities: Besides participating in general events project leaders also try to maintain their relations with universities by accepting teaching responsibilities. When they are setting up new collaborative research projects these teaching "connections" allow them to have a privileged access to the academic world. Additionally, it is well seen by the academic world when a professional is investing time and effort in education. This increases the legitimity of the company and the academic world seems keener to talk with the company ${ }^{251}$.

\footnotetext{
${ }^{251}$ Verbatims: «Je les connaissais parce que j'ai enseigné à l'école là-bas [...] Là encore, je le connais [parce que] j'enseigne aussi à [cette université]. [...] Donc le fait d'enseigner me donne une certaine légitimité. Les gens me respectent et me valorisent parce que je suis un industriel qui prend une partie de son temps libre pour enseigner. Donc je donne. Et ça, quand vous êtes avec des labos du CNRS ... il y a quand même une éthique
} 
- by accepting responsibilities in committees: Project leaders also try to accept responsibilities in committees. For example they accept being the industrial expert in a scientific committee, or they accept being the representative of an association. These efforts give the project leaders access to communities they would otherwise not easily access. Additionally, the integration in these committees gives them a competitive advantage compared to persons who do not accept these types of responsibilities ${ }^{252}$.

- by participating in national competitions: Companies also try to participate in national competitions. We observed for example one relation that was created by the visibility of the project leader thanks to a national competition that made a small company visible to a larger community. From a public policy point of view, attributing prices to the important actors of the local ecosystem seems to be important to keep in mind. ${ }^{253}$

\subsubsection{King of community $\left(5^{\text {th }}\right.$ step)}

Finally, a project leader can also be what we call a "king of community". By "king of community" we mean that the project leader does not have to look actively for research project partners. The project leader is already that well integrated in the research community that the community heavily turns to this type of company, or as one project leader said: "Somewhen we were known" 254 . The big industrial partners are automatically in this category. However, SMEs that are already in the community for a long time can also reach the "king of

fondamentale du don. [...] Le fait de donner autant d'enseignement fait que j'ai des liens beaucoup plus faciles avec les labos. Pourquoi? Parce que tous les labos sont associés à des écoles donc quand j'enseigne à [l'université 1] il y a [le labo 1] derrière, quand j'enseigne à [l'université 2] j'ai [le labo 2] derrière, quand j'enseigne à [l'université 3] j'ai le [le labo 3] derrière, quand j'enseigne à [l'université 4] j'ai le [le labo 4] derrière, etc. » (P8); "De toute façon, je donne aussi des cours à l'ISEP. [...] [J'ai discuté] avec le nouveau [responsable d'option] pas longtemps avant que je monte le projet, donc, du coup, comme on avait des objectifs communs et qu'ils ont fait des choses dans [le domaine] qui nous intéresse, on les a associés. [...] C'était ça qui a fait qu'ils ont rejoint le projet. » (P1)

${ }^{252}$ Verbatims: "Je suis d'ailleurs [dans un groupe thématique] au conseil scientifique du CNRS. [...] [La dernière fois, j'étais juste en train de monter un consortium], j'avais une réunion au CNRS. A cette réunion, je rencontre [un académique]. Donc on rentre ensemble dans le train [...] et à ce moment, on prend un verre au bar. C'est là où je [commence à lui parler du projet]. [...] Il me dit : « Nous, on a le spécialiste là-dessus. »" (P8); "Alors les hôpitaux évidemment [...] je les connais beaucoup moins à l'étranger mais je commence à les connaître parce que je participe pas mal à des réunions internationales. Par exemple, moi, je suis représentant de la France pour [une association], c'est-à-dire là on se trouve avec 18 ou 20 pays qui se réunissent depuis 4 ans régulièrement. $»(P 10)$

${ }^{253}$ Verbatim: "[Cette PME] est rentré en contact avec nous parce qu'ils ont [...] découvert notre nom lorsque nous avons été lauréat du concours « création d'entreprises de technologies innovantes » réalisé par le ministère de la recherche. Il y a une certaine publicité qui se fait autour. [...] puis lorsqu'on a monté le projet [P2a], on s'est dit qu'il faudra quelqu'un qui connait un petit peu les choses et qui travaille dans le domaine de la e-santé, et donc on a vu que [cette PME] se positionnait dans ce domaine, donc naturellement, on les a recontactés. » $(P 2)$

${ }^{254}$ Verbatim: «A un moment, j'étais connu. Donc ils parlaient de moi. Donc les gens venaient me voir : «Le mec du pôle m'a parlé de vous. Ca serait intéressant qu'on se voie. » Donc, je n'ai jamais refusé. »(P8) 
community" status. During the weeks that precede a project call deadline, their telephone does not stop ringing. One project leader compares it to "Meetic" (a partner finding platform):

\begin{abstract}
"Quand il y a des appels à projet [dans notre domaine], on a répondu à 8 appels, on a eu 4 projets financés, mais on a dû avoir 20 sollicitations à peu près. 20 personnes qui ont dit : «Est-ce que vous voulez faire partie de notre consortium? »Si vous êtes sur un site de rencontre, vous avez aussi plein de sollicitations, vous choisissez. Chez nous c'est pareil. Et vous en sélectionnez plusieurs parce que vous allez prendre un verre avec lui, avec lui, avec lui (...) et vous allez voir un peu, initier, laisser tomber, et puis bon, c'est des mariages, c'est pareil. Tout le monde appelle tout le monde. C'est comme sur Meetic. C'est le même mécanisme en fait, d'intérêt, dans un but commun, la mise en relation est assez similaire, sauf que ce n'est pas que à deux, c'est à plusieurs! »(P9)
\end{abstract}

\title{
3.1.1.6 Summary
}

To sum up, the interviewed project leaders that were new to the collaborative research community used the policy-driven cluster services to enter the community. However, once they are established in the community, the policy-driven clusters' utility in finding project partners is strongly reduced. Project leaders then start by looking at their personal and project partner acquaintances, then maybe call a policy-driven cluster, and finally participate in an event to either actively search for a key partner or passively propose their competencies. Project leaders seem to prefer contacting key partners, particularly from the academic and medical domain, personally and not over the phone. These key partners often belong to a world they are not familiar with and so the challenge lies in finding events where the key partners participate (all kinds of events). Finally all project leaders actively maintain a strong relationship with a lot of different communities to multiple their chances to access collaborative research projects. Project leaders can also reach the status of "king of community", meaning that before project call deadlines, they are heavily solicited and do not need to search actively for project partners.

Figure 35 summarizes our results for project leaders that are not yet integrated in the collaborative research community and Figure 36 summarizes the result for project leaders that are integrated in the collaborative research community. 
Figure 35: Not integrated project leaders: Finding partners for projects

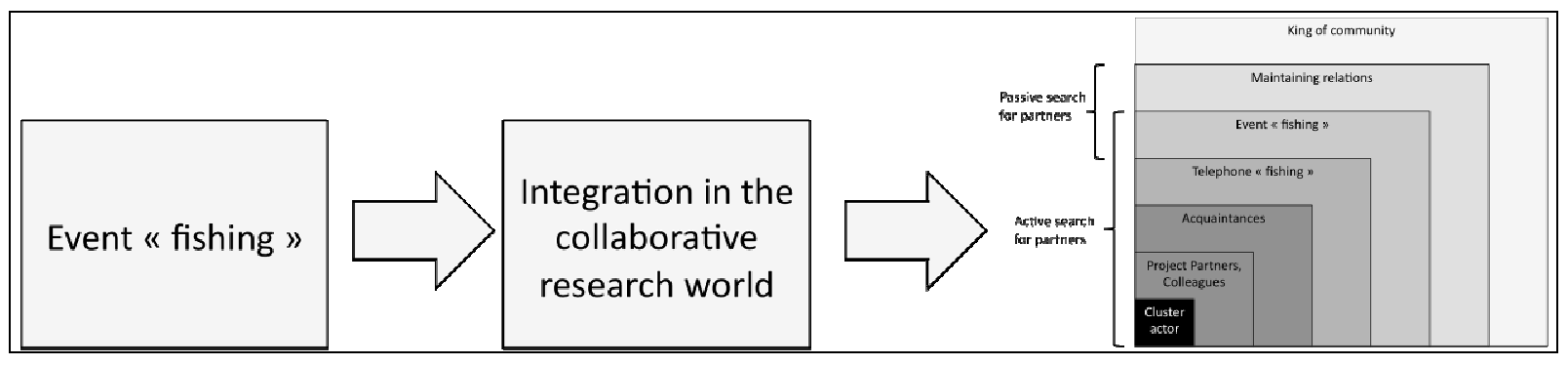

Figure 36: Integrated project leaders: Finding partners for projects

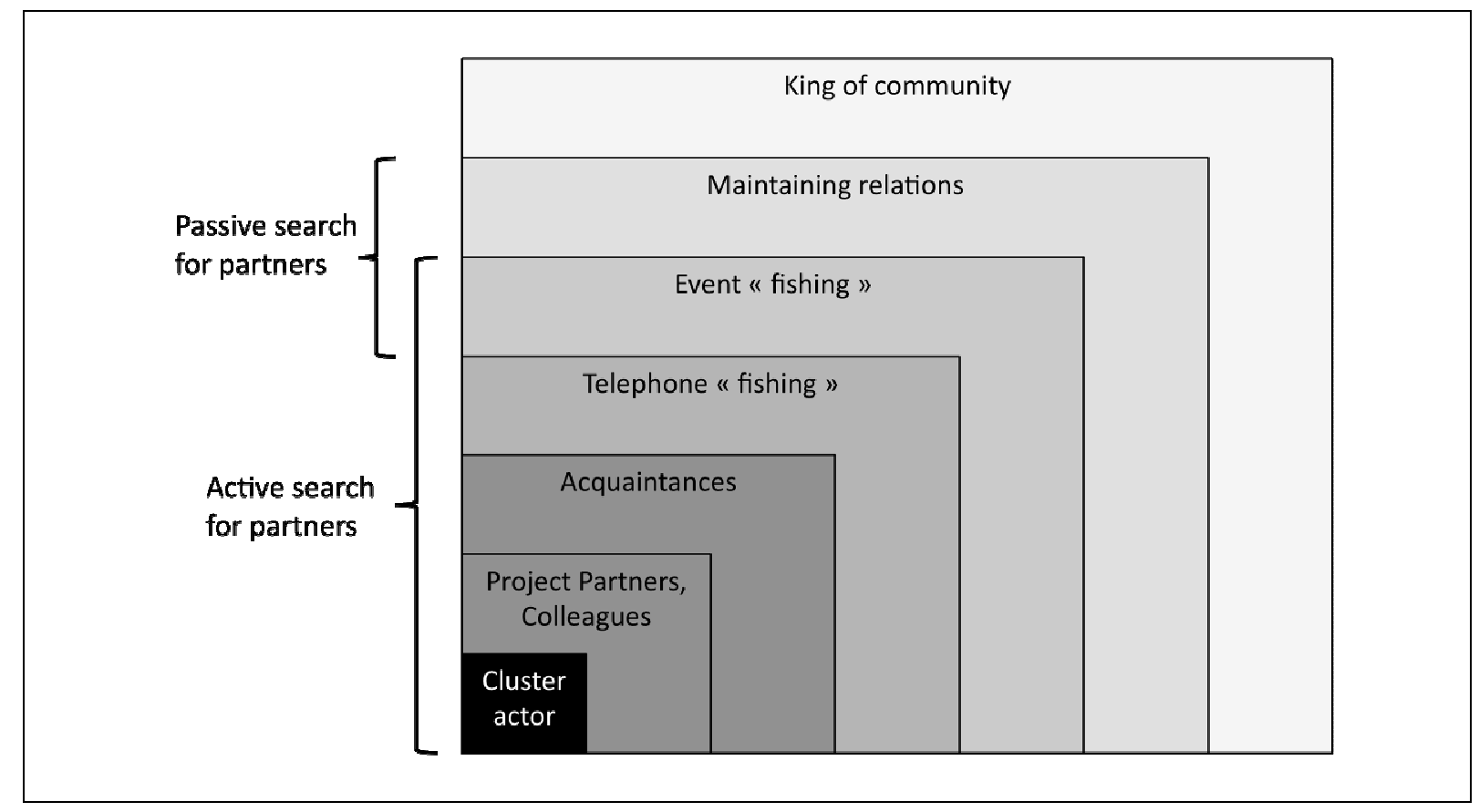

\subsubsection{The difficulty to find medical and industrial partners}

There are two types of partners that are important for every collaborative ICT \& Health project: medical partners and industrials. However, with both partners it is extremely difficult to get in contact for project leaders.

\subsubsection{Medical partners}

As we are studying a policy-driven cluster operating in the medical sector, we consider important to particularly focus on the medical partners. They are not from the same universe as the business driven SMEs and thus have some important particularities. Besides the view of the 10 project leaders on the medical world, we were also able to collect the views of two doctors and two academic partners. 
We start by summarizing the three most important barriers that seem to exist between the corporate world and the medical world:

- Doctors are highly occupied ( $1^{\text {st }}$ barrier). The first important observation is that doctors are highly occupied due to their "place bound" and intensive activities in the hospitals. This stands in very strong contrast to the "free electron" attitude of the business driven project leaders. As already mentioned, the main objective of the project leaders is to set-up collaborative research projects, but doctors also have their "daily work" to do and are not only concentrated in setting up collaborative business projects:

«Le souci est de trouver des trous dans leurs agendas, c'est leur problème majeur. C'est la course contre le temps. La difficulté quand on prépare un projet avec eux, c'est - comme on dit en français - c'est souvent "à l'arrache ». Donc c'est toujours à la dernière minute, parce que bon, ils sont extrêmement sollicités. » (P2)

The challenge for the project leaders is thus not only to find the doctors (as already discussed) but also to find enough time to sufficiently exchange with the doctors regarding their research projects.

- Medical / health projects often have an uncertain business plan ( $2^{\text {nd }}$ barrier). The second important point concerns the business plan on that health/medical projects can build on. Several project leaders mentioned the difficulties they have in finding a viable business model for this sector ${ }^{255}$. Project leaders, as soon as they enter the medical world, have difficulties in finding a business model that allows them to be eligible for the FUI (closer to the market than fundamental research) and that in the end will allow to generate enough business for the company.

- Health sector has a corporatist attitude ( $3^{\text {rd }}$ barrier). The third and last point we would like to mention is the impression that the medical sector has a corporatist attitude. In order to be able to do a collaborative research project, it is not only enough to enter the medical world, but also to collaborate with the "right" professor, who is the specialist of the domain. This seems to be a difficult challenge for a lot of companies: "En plus, le monde médical est un monde quand même très corporatiste où il faut mieux
avoir un médecin dans la boucle. Un vrai médecin diplômé de médecine. L... I Dans le
monde de l'AP-HP, le monde hospitalier, ou dans le monde de médecins libéraux, si vous
n'êtes pas parrainé par un médecin - en plus n'ayant pas une grosse notoriété - vous ne
passez pas. C'est très (...) par cooptation. Il faut que vous soyez recommandé par
quelqu'un qui soit lui-même un médecin, une sommité médicale. Sinon, on ne vous ouvre
pas la porte. »(P7)

${ }^{255}$ Verbatim: «C'est très difficile d'avoir un business plan sur la partie télémédecine pure. »(P6) 
To sum up, all three barriers seem to render the direct interaction between companies and doctors very difficult and also the initiation of medical/health collaborative research projects. Besides these barriers, we have found five types of "brokers" that exists between the medical and corporate world: (i) being in a medical incubator ${ }^{256}$, (ii) the collaboration on a previous project, (iii) through the contacts of a large company, (iv) through an event, or (v) through a university. As these interaction moments are also important in the finding ideas phase, we discuss it in the finding ideas section. At that point, we just underline that most of the time the contact between companies and hospitals seems to be established via a university and less via the policy-driven clusters. The hospital is in contact with a university and the university then contacts the companies. Hospitals seem not to contact companies directly ${ }^{257}$. This might also be explained by the fact that the AP-HP (a French hospital network), often has laboratories that are integrated in universities and thus it kind of seems naturally for the hospitals to contact their university partners first ${ }^{258}$.

\subsubsection{Industrial partners}

Besides the medical world, another world that seems to be very difficult to access for SMEs (including MEs and MFs) is the "industrial" world. The service sector companies, even though they have a lot of business ideas, do not find enough appropriate industrial partners to set up their projects. The FUI and thus the policy-driven clusters privilege subsidising and attributing a label to projects where an industrial company participates. Policy-driven clusters know that these are the projects that have the best chances to get financed by the FUI. As the performance of policy-driven clusters is evaluated regarding their transformation rate (ratio between labelled projects and financed projects) policy-driven clusters are particular vigilant on this point before labelling a project. However, this also means that good ideas might fall in the trap because an industrial is missing. This was for example the case for P5. P5 presented his project to a policy-driven cluster but was criticized for not having an industrial integrated

\footnotetext{
${ }^{256}$ Verbatim: «On a surtout deux collègues qui sont pratiquement le $3 / 4$ de leur temps [dans les locaux de l'incubateur] ce qui permet de recueillir des informations auprès des [médecins] mais aussi de mener à bien les expériences.» (P2)

${ }^{257}$ Verbatims: "[L'université] a eu des infos de l'hôpital [nom de l'hôpital]. Ils se sont rencontrés, puis [l'université] a cherché des gens pour apporter une réponse. » (P5); "[L'Université] était sollicitée par des Médecins du CHU [...] pour essayer de monter un projet. » (P9); " [L'Hôpital] est en relation directe avec [l'Université]. [...] C'était le professeur [de l'Université] qui nous a présenté l'idée. » (P3); "[Quand j'ai travaillé] dans les locaux de l'école Polytechnique [à une époque antérieure] [...] c'est à ce moment là que des médecins sont venu me voir, pour voir ce qu'on faisait » (P10)

${ }^{258}$ Verbatim: «AP-HP [...] [a] souvent des laboratoires mixtes où ils ont une partie clinique et une partie recherche. Donc assez naturellement, ils ont déjà des relations avec des universités. Ils sont déjà affiliés à une université »(P10)
} 
in his project. P5 tried to find an industrial, but did not manage to do so and finally abandoned the project ${ }^{259}$. The next time P5 submitted a project he was vigilant to integrate an industrial right from the start and the project was immediately labelled:

"Ça aide d'avoir un gros industriel derrière. Ça donne du poids. Il y a le côté 'le projet' (...) mais aussi les industriels qui sont derrière. [...] Pour le deuxième FUI, on a eu le label. Mais [nom de l'industriel] est derrière. On le sent. C'est l'intégrateur final. » (P5)

Also P6 had a similar experience as P5. The policy-driven cluster first refused to label P6's project $^{260}$. As soon as P6 found an industrial partner, he resubmitted the project. The project was immediately labelled and financed. Having an industrial in the project consortium is a real boost and functions as a quality stamp in the eyes of the policy-driven cluster.

The few existing industrial partners, particularly the large ones, are extremely solicited for project collaborations. The FUI subsidy requires that the projects have a strong business component (even though this is not always 100\% clear for project leaders, cf. finding subsidies section). The first consequence is that industrials do not see any real use for participating in the policy-driven cluster events, as the companies approach them anyhow. They thus just wait for the ideas:

"Disons que comme on est un industriel, on est plus demandé que ce qu'on peut répondre,
donc c'est plutôt : 'faire un choix parmi les propositions qu'on a, que à moi d'être proactif
à monter des projets' [...] On a plus de propositions que de la ressource qu'on peut mettre
dedans, et à la fin il faut faire des choix. » (P1)
«Indépendamment du projet lui même, [les industriels sont] extrêmement sollicités. Je
m'en suis rendu compte parce que, dès qu'on a su qu'on était dans un projet avec [un
industriel], je ne vous raconte pas le nombre d'entreprises qui sont venues frapper à la
porte. A toutes les portes. » (P10)

The over solicitation of the industrial sector has the dangerous consequence that the industrials get more and more saturated and withdraw from participating in any additional projects. They have the impression to finance projects that should actually be financed by the State:

«[Cet industriel] est énormément sollicité pour ce genre de projet. De partout. [Donc, l'industriell ne voit pas pourquoi, pour quelle raison, il répond plus à un appel à projet qu'à un autre. Il y en a tellement. Ca représente in fine des volumes d'investissement de plusieurs dizaines de millions pour eux. Donc [l'industriel] dit: 'Stop. On arrête tout. On

\footnotetext{
${ }^{259}$ Verbatim: «On a dit : «Si on s'arrête sur la capacité du réseau, on ne fera rien ». Ils ont dit: "Oui mais vous devrez avoir un grand intégrateur, un opérateur». "Oui, on a essayé d'avoir [1 $1^{\text {er }}$ industriel] ou [2 $2^{\text {eme }}$ industriel]. Ils n'ont pas voulu. J'ai demandé à [un $3^{\text {ème }}$ industriel] [mais il] n'était pas intéressé. » 》(P5)

${ }^{260}$ Verbatim: «Les industriels, là on cherche. On est en pleine recherche justement, d'essayer d'attirer un gros industriel dans notre projet. Je suis un peu en contact avec [industriel 1] et [industriel 2]. Je suis en train effectivement de les tenter, de les amener un peu sur notre projet. Pour voir comment on peut développer les choses industriellement. »(P6)
} 
ne participe à aucun projet. Ce n'est pas à nous de financer la recherche pour l'Etat. '” (P10)

However, even if the SME has found a big industrial company for its project, the problems continue. From a legal point of view, the big industrials do not accept the pre-agreements that have to be signed under the FUI subsidies rule. They only accept their own contracts but the set-up of these contracts are generally complicated and take a considerable amount of time. Too long for the short time period of the project calls. SMEs have thus difficulties dealing with this legal rigidity of industrials:

"Pour le FUI [avec le grand industriel] on a eu un gros souci. C'est qu'on a dû mettre un
pré-accord de consortium mais on n'a pas pu en faire parce que les juristes [de grand
industriel] ne veulent pas s'engager n'importe comment. [...] La difficulté, c'est que les
grands groupes industriels ont une armada de juristes qui travaillent sur les contrats. Or
nous, il faut qu'en trois mois, on ait pondu le truc. Et ça ne marche pas, ça ne marche pas.
Les grands groupes ne veulent pas s'engager. Les juristes ont lu le pré-accord de
consortium. Ils ont dit : "D'accord, ce que vous avez écrit ça n'engage à rien. En plus, ça
ne sert à rien les pré-accords de consortium. Ca n'existe pas. Légalement, ça ne sert à rien.
[...] De toute façon, si on met quelque chose en place ça sera [avec notre] contrat ». (P5)

For the SMEs, this situation represents a big risk, but if they wish to work with an industrial and get a project subsidised, they have to take this risk.

To sum up, as soon as an industrial partner pushes the project the project gets most of the time financed. This is related to the fact that the public authorities consider that the chances of viability (in economic terms: job creation, industrialisation) of a project are higher when a big industrial partner takes part in a project. However, on the other hand it seems quite difficult to first get in contact with big industrials, and second to get collaborative projects going. The internal structure of industrials (importance of contracts) does not allow the industrials to engage easily with other partners.

\subsubsection{The difficulty to find project partners situated in the same region}

The government decided to attribute an $R \& D$ zone to every policy-driven cluster. Being situated in a certain R\&D zone brings advantages regarding FUI subsidies. Let's look at our data to understand how the collaborative research projects deal with this rule:

- In the majority of our cases, the partners of the observed collaborative research projects are not concentrated in one and the same region. From 19 observed projects, only 4 consortiums have all partners within the same French region, while 15 consortiums have partners in at least two different French regions. 
- In case the SMEs were situated in different regions, the project leaders submitted their projects for labelling to several policy-driven clusters. This means also to policydriven clusters that are maybe not implemented in the territory of the project leader.

- This is done ${ }^{261}$ so that all SMEs that participate in the consortium will be eligible to the full amount of subsidies. (45\% of subsidies if the SME is in a R\&D zone of a cluster that has labelled the project, $30 \%$ otherwise)

However, this complicated quest to assure the full subsidies amount for all project partners is heavily criticised by the project leaders. They clearly distinguish between the advantages of being occasionally close to each other and the administrative burden of the policy-driven cluster R\&D zone rule.

\subsubsection{Being implemented in the same region is not important}

As already explained, the majority project leaders are all extremely integrated in the collaborative research realm, on a national as well as on an international level. For these companies, collaborating over long distances is in itself no problem. This is nearly the unanimous opinion of all actors we have interviewed. Companies seem to look for the best partners and it is rather incomprehensible for them to understand why they should only chose local actors for their collaborative research projects:

"Par exemple, [un de nos partenaires] est dans la région de Montpellier. On avait besoin
de leur compétence. Ils sont uniques en France à apporter ça. Ils sont presque uniques au
monde, donc on a été les chercher là où ils étaient, il n'y a pas de problème. Pour eux,
c'est un petit handicap parce que ça les finance à $30 \%$ au lieu de $45 \%$, en tant que PME. »
$(P 7)$
"Non, [la proximité géographique] n'a pas d'importance. Pour une société comme [nous],
non. On est à l'international, la plus grande partie de notre chiffre, on le fait à
l'international. On fait peu de choses en France. A peine la moitié de notre chiffre d'affaire
en Europe. Donc la distance n'a pas réellement une importance. Elle a un intérêt politique.
De structuration de l'industrie mais pour une société comme [nous], ça n'a pas
d'importance. " (P3)

For the project leaders, focusing only on the regional territory is foremost a political reason. The FUI, once again, tends to discourage some project leaders to participate in policy-driven clusters. Additionally to the complicated institutional set up (labelling, financing) and the ambiguous objectives, also the regional constraints seem to have an impact on project leaders' perception of policy-driven clusters:

"Le problème est qu'on soumet un projet dans un cadre qui est très régional. [...] J'ai essayé de jouer le jeu, de comprendre comment fonctionne le FUI, de savoir si c'était un

\footnotetext{
${ }^{261}$ We will see that there are also plenty of "political" reasons (according to the cluster actors) to submit a project to several cluster organisations.
} 
bon outil ou pas, mais sur le fond, ce n'est pas terrible parce que vous êtes obligé d'avoir un maximum de partenaire régionaux, ce n'est pas toujours là où vous avez les meilleurs partenaires $\gg(P 10)$

"Après, sur la géographie, j'ai un peu du mal aussi. C'est de dire: 'sur un projet, il faut que les partenaires soient tous dans la même zone géographique'. On envisageait un colabel avec un autre pôle, mais déjà, au sein d'un pôle, c'est politique (pour faire labéliser son projet] (...) Après, entre pôles, ça l'est encore plus.» (P1)

«Si je veux que [notre partenaire] soit financé, il faut qu'on trouve un pôle. Ensuite, pour [un autre partenaire], il nous faut un autre pôle local, et après il faut un pôle... Alors la notion de «territoire » dans les pôles, moi c'est un truc que je n'ai jamais compris. »(P8)

Some project leaders, nevertheless motivated to get financed by the FUI, try to circumvent the rules and to get as many labels as possible. However, this means a higher administrative effort for the companies themselves but also for the policy-driven clusters. Following example illustrates nicely the administrative burden to get one single project labelled that has project partners spread out over several regions. Every policy-driven cluster has specific rules and specific standards. The project leader needs to reformulate and adapt its project application to the standards of each policy-driven cluster he needs a label from. Additionally, he has to travel throughout France to present the projects in the different policy-driven clusters:

\begin{abstract}
«Donc avec Systematic, j'ai eu un entretien téléphonique. Ils me demandent d'envoyer une présentation. J'envoie la présentation que j'avais faite pour l'ANR Isoumission précédente qui n'était pas acceptéel. "Ah non monsieur, ça ne va pas, vous n'êtes pas au format de Systematic ». Je mets au format. Le projet se fait blackboulé par Systematic. Je dis : "Ok, on n'est pas labellisé ». Là je vais voir Cap Digital, recommandé par [un partenaire]. Je vais les voir [...] Ils me disent : "Très bien. Il faut que vous me remettiez le dossier dans 15 jours. » Je dis : "Oui mais le dépôt est seulement dans... " "Ah oui, mais nous il faut qu'on ait le dossier dès qu'on le labelise ». Là, on a 15 jours. Il faut qu'on re-rédige. OK. Donc eux, ils veulent un dossier. On travaille dans la PME pour faire le dossier. Après, Minealogic. Minealogic veut un dossier mais qui est différent au niveau du format des autres, parce qu'eux, ils veulent la valorisation en premier, lalala...etc. Donc on re-rédige un truc. Images et Réseaux, alors eux, c'était facile parce que comme on leur a présenté le dossier pour l'ANR, c'était le même format. [...] Donc vous voyez le boulot qui est derrière. Et ça, eux, ils ne se rendent pas compte. Eux, ils disent: 'mais oui c'est normal'. Alors après, il y a certains pôles où il faut passer des oraux. Et donc Minealogic voulait me faire passer un oral à Grenoble. J'ai dit : "Mais vous n'êtes pas bien. Je suis déjà allé une fois à Systematic. Je suis allé les rencontrer. Je suis allé à Cap Digital à Paris. Je suis allé à Images et Réseaux. Deux oraux Images et Réseaux. Un premier en pré-comité scientifique, un deuxième en comité scientifique la semaine dernière. Voilà. "Ca, c'est la pratique. " (Project P8d, financed by FUI)
\end{abstract}

The project leaders that are new to the collaborative research realm mentioned that choosing actors from the same region is important for them but out of political reasons, in order to get the project financed, and not out of practical reasons. The verbatims show that they want to get accepted in this new community and thus comply with the game: 
" Je choisis national, de préférence régional, parce que les financeurs aiment bien concentrer les efforts financiers. Il est quand même bien vu que ça ne soit pas dans les quatre coins de la France. [...] Pour donner d'avantage de chance au projet, il faut quand même mieux rester territorial. [...] Mais bien sûr, ça n'empêche pas de la chercher. Si la spécialité n'est pas présente sur le territoire, de la chercher ailleurs. » (P7)

\title{
3.1.3.2 Being occasionally close is important
}

However, being occasionally close to each other is important for the project leaders because they have the impression that they cannot exchange all types of information over the phone. This closeness is particularly important during the idea finding phase, but also during the project collaboration phase. Project leaders, though they use new communication technologies to talk with each other, seem to privilege physical meetings to discuss important topics. They need to see each other because information is better shared during face-to-face meetings:

\begin{abstract}
"Pour nous, le face-à-face est indispensable quasiment au départ. La communication par téléphone est très bien pour juste un premier contact. En plus, je pense que pour des gens qui sont dans le médical, c'est extrêmement important. Ils sont beaucoup plus sensibles aux aspects humains que nous on pourrait l'être. »(P2)

"C'est plus simple de se voir, de physiquement se voir, de discuter ensemble, que de tout faire au téléphone. Au téléphone, on arrive à faire beaucoup de choses, mais quelque fois, voir des gens physiquement, c'est mieux. " (P5)

«On a une réunion là, en décembre. On va essayer de faire venir le plus de monde possible. C'est important parce qu'il y a des choses qui se disent plus facilement ou qui émergent plus facilement autour des documents. »(P6)
\end{abstract}

Additionally, project leaders point out that new communication technologies still do not work properly and they are too small to invest in well-equipped videoconference rooms:

\footnotetext{
"On fait des réunions sur Skype ou sur Google, mais les liaisons sont quand même vraiment très pauvres. Il y a souvent des échos ou des trucs comme ça. Donc pour la compréhension, pour partager des documents etc., on sent que la technologie existe, la technologie est là, mais les canaux de circulation ne sont pas encore assez gros pour qu'on puisse vraiment faire des choses propres. Et nous, on n'est pas assez gros pour faire réellement une salle de téléconférence. " (P6)

"Il faut les moyens, il faut être équipé [avec une salle de vidéoconférence], tout le monde ne l'est pas. »(P5)
}

We have to keep in mind that project leaders are extremely mobile. If they need to go to another region or country for a collaborative research project meeting or for an event, they go. Their position in the company allows them to do this. However, locations well connected to other cities are privileged:

\footnotetext{
«Alors, ce qui est sûr, c'est que dans un projet, le fait d'avoir des acteurs qui ne sont pas très loin, c'est important. C'est clair. Là, en ce moment, j'ai des projets avec ClermontFerrand, les raisons pour lesquelles je freine, c'est parce que c'est trop loin. On pourra raconter ce qu'on veut, les visioconférences, etc. mais quand c'est près, à une heure comme Nantes ou deux heures comme Paris, c'est quand même franchement
} 
pratique. [...] Mais par exemple pour [un autre projet], on avait mis une entreprise qui est

à Montpellier. On fait attention, mais ce n'est pas déterminant. » (P8)

The cluster actor is based in Rennes so coming to Nantes or Paris with the train is no problem. However going from Rennes to Clermont-Ferrand lasts approximately 7 hours ${ }^{262}$ and going from Rennes to Montpellier lasts approximately 6 hours and 30 minutes $^{263}$. However, this is a public infrastructure problem of certain cities because a company based in Paris would probably not say the same. For a company based in Paris going to Clermont-Ferrand or Montpellier only lasts approximately 3 hours 30 minutes because direct train connections exist. So being at a geographical well-connected hub opens a lot of collaboration and event participation opportunities. For project leaders, being in a well-connected hub is more important than collaborating with local actors.

\subsection{HCPR's difficult role in the finding partners phase}

The role of HCPR and other policy-driven clusters in the Paris Region is complex. First of all they have to deal with the fact that project leaders get more and more integrated in the collaborative research realm, and thus participate less and less in the proposed events. On the other hand, they seem to struggle themselves to attract key actors such as medical or industrial partners. Finally, policy-driven clusters in the Paris Region are intensively competing with other support structures and thus tend to be put in competition to each other and are sometimes reduced to the FUI.

\subsubsection{Dealing with decreasing participants at events}

In the beginning of this section we saw that project leaders that are integrated in the research community do not necessarily participate at events, only when they are new, need a special partner (for example medical partner) or want to maintain relations. The data we collected on the ICT \& Health initiative (jointly organised by Systematic, Cap Digital and HCPR) show a similar result but from the policy-driven cluster perspective. The cluster managers try to constantly change the format of their events to maintain a certain attendance rate. This is a real challenge for policy-driven clusters, as one of their performance indicators is the number of participants in their events.

\footnotetext{
262 approximate 7 hours between Rennes and Clermont-Ferrand (4 hours 23 minutes from Rennes to Lyon, 10 minutes waiting time, 2 hours 25 minutes from Lyon to Clermont-Ferrand)

263 approximate 6 hours 30 minutes between Rennes and Montpellier ( 2 hours 12 minutes from Rennes to Paris, 52 minutes waiting time, 3 hours 27 minutes from Paris to Montpellier)
} 
As already explained, every inter-cluster ICT \& Health project call starts with an event composed out of a plenary session and a project set-up workshop. The ICT \& Health events took place in engineering universities ( 2 events), in government agencies ( 2 events), on the site of an industrial ( 1 event), or in a medical location (1 event) (see Table 42). We will not discuss once again how a typical plenary and project set-up workshop looks like (for an explanation see Chapter 7 / Section 2.3.1) but focus directly on the main problem: the diminishing participant rate.

Table 42: ICT \& Health inter-cluster plenary sessions and project set-up workshops

\begin{tabular}{|c|c|c|c|c|c|c|}
\hline & Date & Location & $\begin{array}{l}\text { Type of } \\
\text { location }\end{array}$ & $\begin{array}{c}\text { \# of } \\
\text { participants }\end{array}$ & $\begin{array}{l}\text { \# of workshop } \\
\text { presentations }\end{array}$ & $\begin{array}{c}\text { Authorized } \\
\text { workshop } \\
\text { presentations }\end{array}$ \\
\hline \#1 & $\begin{array}{l}09 / 2010 \\
\text { (one day) }\end{array}$ & EFREI & $\begin{array}{l}\text { Engineering } \\
\text { University }\end{array}$ & 200 & 40 & $\begin{array}{l}\text { Projects \& } \\
\text { Competencies }\end{array}$ \\
\hline$\# 2$ & $\begin{array}{l}02 / 2011 \\
\text { (one day) }\end{array}$ & Orange Labs & Industrial & 100 & 12 & Projects \\
\hline \#3 & $\begin{array}{l}\text { 06/2011 } \\
\text { (half day) }\end{array}$ & $\begin{array}{l}\text { Agence de } \\
\text { Développement } \\
\text { du Val-de-Marne }\end{array}$ & $\begin{array}{l}\text { Government } \\
\text { Agency }\end{array}$ & 100 & 8 & Projects \\
\hline \#4 & $\begin{array}{l}01 / 2012 \\
\text { (half day) }\end{array}$ & ENSIIE & $\begin{array}{l}\text { Engineering } \\
\text { University }\end{array}$ & n.a. & n.a. & $\begin{array}{l}\text { Projects \& } \\
\text { Competencies }\end{array}$ \\
\hline \#5 & $\begin{array}{l}\text { 09/2012 } \\
\text { (one day) }\end{array}$ & $\begin{array}{l}\text { Institut du } \\
\text { Cerveau et de la } \\
\text { Moelle épinière } \\
\text { (ICM) à l'Hôpital } \\
\text { de la Pitié } \\
\text { Salpêtrière } \\
\end{array}$ & $\begin{array}{l}\text { Research } \\
\text { Institute of a } \\
\text { Hospital }\end{array}$ & n.a. & n.a. & $\begin{array}{l}\text { Projects \& } \\
\text { Competencies } \\
\& \text { Needs }\end{array}$ \\
\hline \#6 & $\begin{array}{l}01 / 2013 \\
\text { (half day) }\end{array}$ & $\begin{array}{l}\text { Hémicycle du } \\
\text { Conseil régional } \\
\text { d'Ile-de France }\end{array}$ & $\begin{array}{l}\text { Government } \\
\text { Agency }\end{array}$ & n.a. & n.a. & $\begin{array}{l}\text { Projects \& } \\
\text { Competencies } \\
\& \text { Needs }\end{array}$ \\
\hline
\end{tabular}

In order to deal with the diminishing participant rate, policy-driven cluster managers have to constantly "innovate" and propose new "formulas" to attract companies situated in the Paris Region. If we look at the ICT \& Health events, we can see that they were not organised in the same manner since the beginning (see Table 42). The first two events lasted the whole day (morning and afternoon). However, from the third event onwards the ICT \& Health cluster representatives decided to reduce the events to half a day (besides \#5).

After our discussion on how project leaders behave once they are integrated in the collaborative research community, it is no surprise to see that the ICT \& Health events are highly frequented in the beginning but then the participation rate drops drastically. In the beginning the ICT \& Health community was still very "young" and did not know each other. Therefore, a lot of cluster members participated and presented their projects or their 
competences. However, from the second event onwards the number of participants and presentations dropped substantially (200 participants in first event, only 100 participants in second event; 40 presentations in first event, only 12 presentations in second event). Due to the success of the first event, the policy-driven cluster representatives did not really anticipate this drop and also planned a one-day event for the second edition. However, from the second event onwards they knew that the events became "less interesting":

«es gens commencent à s'essouffler. [...] Au premier workshop à Pasteur, il y avait
beaucoup de monde, c'était quelque chose nouveau. Ca excitait beaucoup les gens et au fur
et à mesure on se rendu compte qu'il y avait moins de gens intéressés. C'est la formule qui
est peut-être moins adhérente, excitante. Parce que c'est moins nouveau. Les gens se
lâchent. Il faut peut-être trouver une autre formule. (Octobre 2011)

The natural reaction was to reduce the \#3 event to half a day.

Additionally, between session \#1 and session \#4, cluster members had only the choice between two different types of presentation during the workshop. First, cluster members were able to present projects that they wished to submit to the next project call ${ }^{264}$. In these projects a certain competence was still missing and so the presentation served to find an additional project partner with a certain competence. However, the idea generation phase to the project was already over. Second, cluster actors were also able to present their competences (without an associated project). This is particularly useful in case a certain company is not known in a community but loses its interest as soon as the community knows each other. From the event two onwards, the workshop presentations only concentrated on projects and no longer on competences. However, in the fourth event the ICT \& Health representatives re-introduced the competencies presentations.

The real change took place in the $5^{\text {th }}$ event. Until the edition \#5, the events took place in engineering schools, government agencies or on the site of an industrial with limited participation of medical professionals. However, the fifth event took place in a research institute situated in a hospital. Besides the location, three other elements changed as well: (i) the length of the event, (ii) the content of the event, and (iii) another type of presentation was added to the workshop. First of all the event was again prolonged to cover a whole day instead of half a day. The reason for this is the content of the event. A new element was introduced in order to attract again more cluster actors. The morning of the Session \#5 was in the same format as the previous editions, but the afternoon was organised around three

\footnotetext{
${ }^{264}$ for example FUI or FEDER
} 
workshops that were animated by doctors and academics. Finally, the third change that took place was the introduction of a "need" presentation that allowed for example medical or association representatives to express their needs as well. This need category was also authorized in the \#6 session, but nobody proposed any needs ${ }^{265}$.

To sum up, two points seem important to keep in mind. First, the cluster representatives have not found the ideal formula for their cluster events. They are confronted with the fact that the participation rate, particularly after the first event, drops substantially. This is consistent with our data collected from the project leaders. In order to keep the event going and to continue to attract participants, they have to constantly introduce new elements.

\subsubsection{Struggling to integrate medical and industrial partners in events}

One major difficulty for project leaders is to find medical and industrial partners for their collaborative research projects. However, medical and industrial partners are quite absent from ICT \& Health events. Integrating these actors is a big challenge also for policy-driven cluster managers.

The problem that clinical representatives and industrials are not participating in the ICT \& Health events was already visible during the preparation workshops that took place to prepare the ICT \& Health research roadmap ${ }^{266}$. Both key actors were highly absent in the four different working groups:

- For example in the workshop focusing on “digital imaging”, key actors (like clinical representatives and big industrial groups) who are considered particularly important in order to advance on the topic, were absent. Even though the participants of this workshop underlined this problem ${ }^{267}$ the industrials and clinical staff were also absent during the second workshop. One the one hand, this was a real problem for the companies because they did not know the needs and visions of the medical world is

\footnotetext{
${ }^{265}$ We do not know if there is a link, but our hypothesis is that their exists a link between the venue of location (outside or inside the medical realm) and the absence or presence of the need category.

${ }^{266}$ We did not participate in these workshops between February and April 2010, but HCPR allowed us to access the minutes of the first two workshops of all four groups (in total eight minutes). An external consulting firm animated all workshops and it was also in the office building of this external-consulting firm that all the workshops took place.

${ }^{267}$ HCPR document, internal minutes: «Pour la définition de la feuille de route en imagerie numérique, il sera indispensable d'inclure dans le groupe : (i) des représentants du monde Clinique qui apporteront la vision des besoins et leurs évolutions attendues, et qui seront aussi les testeurs et utilisateurs des futures solutions innovantes mises au point, (ii) des grands industriels (intégrateurs technologiques, imagerie biomédicale, industriels pharmaceutiques). »
} 
meant to use the new devices in the future. This pushed the participating actors to think about alternatives. In order to compensate the fact that the key actors were not participating, they proposed to finance their new solutions by themselves and to present them in a second step to the industrials. They also proposed that they will continue working on project ideas for the ICT \& Health initiative and that they will submit them for validation to clinical representatives in a second step ${ }^{268}$.

- Also the "medical devices" workshops were too one sided regarding their participants. The majority of participants were technicians of the sector. However, this was a problem for this workgroup as the health professionals that should use these devices were absent ${ }^{269}$ and the medical staff who was meant to talk about their needs was absent as well ${ }^{270}$. Again, also for this workgroup, the situation did not improve during the second workshop. Also during the second workshop no medical practitioners were participating in the workshop, only SMEs and academics. The conclusion of this workshop was that they would stay within their community (SMEs, institutional and academics) in order to develop new break-through innovations and to generate business afterwards. ${ }^{271}$

- The workshop focusing on "E-health and Telemedicine" was the biggest workshop group. The majority of the persons participating in the first workshop were industrials of the ICT sector, some academics and institutional representatives as for example from the Ministry of Health or the regional chamber of commerce. However, neither a representative of HCPR nor medical practitioners were present in the workshop. This lead to the same conclusion as for the medical devices axe, namely that the ones that should use the new innovations were absent ${ }^{272}$. The absence of the medical staff posed again a real problem for this workshop. The participants clearly underlined that if one

\footnotetext{
${ }^{268}$ HCPR document, internal minutes: "Question sur la représentativité du groupe liée à l'absence de grands comptes, à une exception près, et de représentants du monde médical : l'hypothèse de travail du groupe sera de rechercher des solutions et de les financer (nouvelle génération de stratégies et produits) pour, dans un second temps, approcher les grands comptes le cas échéant. La présence de professionnels de santé ne permettra pas nécessairement d'atteindre l'objectif final du groupe de travail, à savoir la définition d'un ou plusieurs projets structurants pour cet axe, mais sera recherchée pour valider des concepts acceptables par les professionnels de la santé. "

${ }^{269}$ HCPR document, internal minutes: «l'axe est par définition multidisciplinaire et les usages sont portés par des groupes non représentés (professionnels de santé...) »

${ }^{270}$ HCPR document, internal minutes: « En effet il est ressorti un fort besoin d'identification des besoins par des acteurs non présents mais en même temps la nécessité d'anticiper le futur et d'être imaginatif $\rightarrow$ Création du besoin, identification des innovations de rupture. »

${ }^{271}$ HCPR document, internal minutes: "L'hypothèse de travail du groupe sera de rechercher entre PME, institutionnels et chercheurs des innovations de rupture en vue de générer et de favoriser des projets business. »

${ }^{272}$ HCPR document, internal minutes: "l'axe est par définition multidisciplinaire et les usages sont portés par des groupes non représentés (professionnels de santé...). »
} 
wishes to innovate in certain domains, medical staff has to be present ${ }^{273}$. During the second workshop a representative of HealthCluster Paris Region and from a hospital participated in the meeting, and presented their respective positions on the topic. Even though HealthCluster did not participate in the first workshop organised under the ehealth and telemedicine axe, HealthCluster underlined that e-health is a priority ${ }^{274}$ for HealthCluster. Additionally the hospital, represented by a doctor, presented the hospitals own telemedicine projects.

- Finally, in the workshop focusing on "knowledge management, modelling and simulation" the majority of the participants were from the Biology and Health sector (particularly IT oriented), the others were from the ICT sector. However, two important key players were missing: academics and industrials. In order for the IT specialist to be useful they would have needed the input from the academics and industrials working from a scientific point of view on these research domains ${ }^{275}$.

In the beginning of the ICT \& Health initiative it was already very visible that a big challenge for the policy-driven clusters is to integrate the medical and industrial key-players. This also continued when the official project set up events started. The representative of one policydriven cluster told us that during the \#1 ICT \& Health event, in September 2010, clinical representatives were particularly absent as well. However, the policy-driven clusters tried to improve this situation for the \#2 event that took place in February 2011. They decided to invite clinicians to talk about their needs:

«Il y avait beaucoup qui ont dit qu'il n'y avait pas assez de cliniciens. Des gens qui pouvaient dire on a besoin de ça. Donc, [pour la deuxième plénière] on va faire venir des gens de la clinique qui vont nous dire : "Voilà, on est médecin, on est chef de laboratoire ou chef d'un hôpital, on aura besoin de ça pour avancer. "On a un manque, est-ce que vous pouvez répondre à ce manque? [...] On va essayer de nous améliorer pour répondre à cette attente cette fois-ci. Après il y aura d'autres choses, d'autres questions, on va essayer de répondre chaque fois, à ce que veulent les gens. On est aussi au service des gens [...] c'est à eux de nous donner leurs envies, leurs idées, on essaye d'y répondre au maximum. " (January, 2011)

\footnotetext{
${ }^{273}$ HCPR document, internal minutes: «Si on souhaite impliquer les opérationnels il manque alors des représentants du corps médical, de l'assistance, de la prévoyance, de l'administration (conseil généraux, mairies, gouvernement) et des services à la personne. Selon certains, si on veut innover, la présence des représentants du corps médical sur certains projets est requise.»

${ }^{274}$ HCPR document, internal minutes: particularly «informations et systèmes d'informations centrés sur le patient pour favoriser la médecine translationnelle, c'est-à- dire notamment les échanges de données patient entre la clinique et la recherche. »

${ }^{275}$ HCPR document, internal minutes: «Si la validation des hypothèses formulées à l'aide des modèles fait partie du périmètre de notre action alors il faudra passer de la biologie " sèche » à la biologie " humide », mais dans ce cas se pose la représentativité des contributeurs présents (industriels ou académiques).»
} 
According to the information of one of the policy-driven cluster representatives ${ }^{276}$ (in January 2011) the participants in the ICT \& Health events were approximately $80 \%$ from the ICT domain and $20 \%$ from the health domain.

The discussion just confirmed what we already saw in our data in the finding partners section: industrials and medical partners do not easily participate in events organised by policy-driven clusters. However, one interesting observation is that in the event \#5 more clinical representatives took place. The event \#5 was also the only event situated in a medical location (see Table 42). As doctors are highly occupied, moving the location to a research institute of a hospital might have helped in the endeavour of attracting medical partners.

To sum up, we have already seen that one of the barriers between doctors and companies is the fact that doctors are highly occupied and more place-bound in their hospitals than the business driven project leaders. Additional hospitals have a long tradition in turning towards universities and maybe less in turning towards the corporate world. HCPR somehow struggles to break out of this situation and to connect the doctors with the business driven project leaders situated in the Paris Region; to connect the "place bound electrons" with the "free electrons". None of the new services developed by HCPR seems to address this structural problem.

\subsubsection{Competing with other regional support structures}

At this point we wish to recall that our fieldwork is situated in the Paris Region. The Paris Region is the economic "headquarter" of France and thus the Region proposes a high variety of organised events, a high variety of local associations and of course all ministries are implemented in this Region. Therefore our results might be only representative for Regions that have a similar regional density. We already saw that the main driver of the project leaders is "business". Therefore, the project leaders have the tendency to participate in a lot of different events to increase their possibilities to generate new businesses for their company. Their objective is to create a buzz around them in order to become "known" in the community. For this, they use a multitude of different services:

"Il y a une redondance. Il y a tout un ensemble d'outils [...] alors pour les gens comme moi, c'est d'une richesse énorme. Parce que moi j'en profite à 100\%. [...Pour me retrouver...] j'ai cartographié. [...] Je me suis dit: «Ah lui il fait quoi ? Il appartient à

\footnotetext{
${ }^{276}$ Every cluster organisation appointed one ICT \& Health representative among their operational teams; we interviewed all three representatives in 2010 and the HCPR representative once again in 2011.
} 
qui ?»C'est comme ça que [dans ma région] j'ai compté 66 organismes. [...] En gros il y a les outils des régions et il y a les outils de l'Etat [...] donc nous on joue avec tout le monde. » (P8)

"Moi si je veux exister, il faut que je sois connu. Il faut que tout le monde sache que j'existe. Que je fasse du bruit. [...] Il n'y a pas photo. Il faut faire cet effort pour se faire connaître. »(P5)

"On regarde un peu ce qui se passe dans les différents éléments qui sont organisés dans le Biotech. Même dans l'électronique quand on a besoin d'un partenaire électronique, on regarde qui intervient, qui participe.... $(P 2)$

For example somebody who is interested in ICT \& Health had a vaste choice of events end of Jannuary beginning of February 2011 in the Paris Region: on the $1^{\text {st }}$ of Feburary the Ministry of the Economy, Finance and Industry invited to a ICT \& Health event, on the $4^{\text {th }}$ of February Cap Digital, Systematic and HCPR invited to a ICT \& Health event, and on the the $8^{\text {th }}$ and $9^{\text {th }}$ of February FormaticSanté and Tlécom ParisTech invited to a Tic \& Health event. For the regional actors this choice is great, however organisations like policy-driven clusters who are evaluated according to their participation rate, this vaste choice constitutes also a threat and the operational team members that we interviewed were not very happy that so many parallel events take place at the same time as they organise an ICT \& Health event.

Hereinafter, we will now give a non-exhaustive list of the different "bricks" that our interviewed cluster actors use and considered important to mention during the interviews. The following list is meant to reposition the Parisian policy-driven clusters in a broader context:

- French Ministries. Besides participating in the information events of the cluster organisations the project leaders also heavily participate in the events organised directly by the ministries. ${ }^{277}$

- Other French regional or national platforms. Besides the information sessions organised by the ministries, project leaders also participate in a lot of other regional or national platforms (for example CNR santé, OSEO, ANR, CRITT, ARI, etc.) ${ }^{278}$. All

\footnotetext{
${ }^{277}$ Verbatims: «Là ce matin j'étais au ministère de l'industrie pour, en fait, essayer de voir qui fait quoi. Quelles sont les tendances etc. » (P8); "Il y a quelque chose qui était organisé la semaine dernière par le ministère de la santé. » (P6); "Il y a la liste de diffusion de Patrick Schouller : c'est un titulaire qui est au ministère des finances. En fait, c'est un service du ministère des finances. Grosso modo, ils aident les entreprises. » $(P 1)$

${ }^{278}$ Verbatims: «Plutôt d'utiliser TIC \& Santé des pôles, j'utilise beaucoup le CNR santé. [...] C'est un organe d'Etat. [Le directeur] est un ancien chef d'entreprise. Il a une mission de l'Etat de faire émerger des entreprises dans le domaine du médicale en France. » (P8); "Il y a OSEO qui fait souvent des meetings. [...] On y va. Voilà c'est intéressant. [...] OSEO, j'essaie d'y aller une fois par an. » (P5); "Il y a des journées ANR. On va à des journées ANR pour voir un petit peu les projets passés. On discute avec des gens et donc s'il y a des sujets d'intérêt commun on garde des cartes de visite et on les contacte plus tard. Là c'est plus informel dans ces journées. C'est une fois par an. [...] Les gens discutent entre eux. » (P3); "Je sais quand le CRITT Santé Bretagne fait un truc. » (P8); "Le colloque ingénierie numérique qui était à l'initiative du Conseil Economique,
} 
these public institutions organise events that help project leaders to access ideas, partners and subsidies.

- European Union workshops and networks. The cluster actors also participate in European union workshops or platforms: for example Eureka workshops or the COST network $^{279}$. The European Union initiatives are often perceived as very effective to bring people together around one topic because they allow a very good mix between coffee breaks and poster sessions and little presentations. A lot of time is allocated to exchange:

\begin{abstract}
"Récemment, j'étais à un workshop [Eureka] sur les projets européens en Irlande. J'ai trouvé que l'organisation avait vraiment facilité la mise en relation. [...] Ca s'est passé sur deux jours. Avec une première journée extrêmement officielle, des intervenants de haut niveau etc., de niveau décisionnel assez élevé. Et le soir il y avait un dîner avec des tables rondes de 8 personnes. Il y avait très peu de présentations mais énormément de coffee breaks avec des présentations de posters. C'était très interactif. En fait, d'avoir plutôt des démonstrations, des posters, des pauses cafés assez longues, un dîner....c'est comme ça que se créent des liens. Et les gens discutent. J'ai rencontré des gens que je n'ai jamais pu rencontrer ailleurs.» $(P 2)$
\end{abstract}

- Specialised trade fairs. Specialised trade fairs and their associated associations are another important dispositive for the project leaders ${ }^{280}$. Specialised trade fairs have the advantage that all important key players (be it industrials or academics) participate in these events, something a policy-driven cluster might maybe never be able to do. These specialised trade fairs are the annual meetings of a certain sector or technology.

During these events a lot of discussions are taking place and new projects are created:

"Il y a des salons dans mon métier. Il y a [salon 1] et il y a aussi [salon 2]. [Derrière le
salon 2 il y a une association] dont on fait partie. Ces événements sont des moments dans
l'année où on peut se rencontrer et on mélange des industriels et des académiques. Donc
c'est là où c'est important de faire connaissance. C'est là où on tisse des liens. On vient
discuter et là on tisse des liens et à partir de là, quand on a tissé des liens, c'est plus facile
de rencontrer des gens. Et d'essayer de proposer des projets. [...] Vous pouvez présenter
vos travaux de recherche. On présente nos enterprises, nos projets. [...] Ce sont de grandes
$\underline{\text { assemblées générales. [....] Tout le monde est là. Tout le monde du marché de la }}$

Social et Environnemental. Il y a des grands colloques comme ça. C'est toujours intéressant d'aller les voir, d'aller discuter avec eux. [...] Il y a toutes les grandes sociétés qui viennent, qui présentent. Il faut toujours essayer de venir là pour voir des gens. » (P5); «Il y a [...] la ARI, les agences régionales de l'innovation. »(P8) ${ }^{279}$ Verbatim: «Je travaille dans 2 projets COST. [...] En fait ces projets COST européens visent à développer des réseaux. [...] Grosso modo le COST finance des réunions entre les spécialistes d'un secteur pour proposer des pistes innovantes de recherche collaborative et de développement. [...] Pour participer au groupe de travail, il faut faire valoir ses compétences et sa légitimité. Ca doit être validé d'abord à l'échelle française. Il faut que vous fassiez la preuve que vous pouvez représenter la France parce que vous représentez un pays pour un domaine et vous avez droit à deux représentants par domaine. [...] c'est un mécanisme de réseautage qui n'est pas neutre. [...] Ca permet de développer un réseau. [...] C'est des gens d'une spécialité. Les pôles, c'est beaucoup plus large. Il n'y a pas de réunion technique. [...] Par exemple une de chose qui va résulter de COST: On va écrire un bouquin ensemble sur la [type de télémédecine] en disant voilà ce qu'elle est aujourd'hui. Voilà l'avenir. » (P10)

${ }^{280}$ Verbatim: "Après c'est des relations qui se font durant des salons [plutôt des salons santé]. Moi j'ai rencontré, il y a pas si longtemps que ça, des gens sur un salon ici. Ils sont venus du Canada. [...] On va commencer à créer des choses. » (P6) 
[technologie] est là. Donc les académiques, les industriels, donc on se rencontre tous. On se juge, on voit ce qui est fait. Mais c'est à ce moment là qu'on peut discuter : "Ah en fait on pourra faire ci, on pourra faire ça. », "Tiens je fais ci, je fais ça. », «D'accord. », «Ah bon tu sais faire ça? »C'est là où on se connaît, où on crée des liens. [...] C'est différent [des pôles]. (P5)

- Conferences. Project leaders attend several types of conferences organised by different platforms (for example "Usine nouvelle") or directly by doctors. ${ }^{281}$

- Associations. Project leaders are members of policy-driven clusters but also of many other types of organisations and specialised associations (for example: telemedical society, Opticsvalley, etc. ${ }^{282}$ ).

- Research networks. Another important element is the maintenance of a close relationship with the research sector. Having a close relationship with laboratories and universities opens doors and generates a lot of ideas. Project leaders invest time and effort to get in contact and maintain links with universities ${ }^{283}$.

- Alumni networks. Project leaders use alumni networks to particularly access the large companies $^{284}$.

- “Project set up" days. Finally, project set up events that are organised by different kinds of institutions (policy-driven clusters, FP7 project calls) are also important venues to find partners. However, they are perceived as less "intimate" and more "formal" 285 than other types of workshops. During these project set-up days, content is less discussed. During this set up days one is particularly interested in finding a missing partner. It is like Meetic: «Ces évènements [pôles] c'est «meetic.com». Il y a

\footnotetext{
${ }^{281}$ Verbatim: «Il y a d'autres colloques qui sont fait par Usine nouvelle. » (P5); « Je vais à une conférence des médecins [pour rencontrer des médecins]. » (P8)

${ }^{282}$ Verbatims: "Il y avait la société de la télémédecine [nom] qui fait des choses» (P6); "Il y a des groupes de contacts qui font suivre les événements intéressants. Notamment, il y a un groupe, c'est l'Association des Réservistes du Chiffre et de la Sécurité de l'Information. Là, sur toutes les thématiques sécurité - télécom, il y a pas mal des choses. » (P1)

${ }^{283}$ Verbatim: «Je passe 150 jours de l'année à être dans les labos. »(P8); "C'est énormément la recherche qui lead des choses. Sur la recherche, [nom d'un partenaire très proche] fait des programmes de recherche communs avec McGill. C'est surtout travers ça qu'on monte des choses. [...] La recherche ouvre vraiment énormément de chose. La recherche et la recherche appliquée. » (P6)

${ }^{284}$ Verbatim: «Je connais forcement des gens à cause de mon appartenance, d'ancien de Telecom. On se revoit souvent. Il y a un club des entrepreneurs de Telecom dans le quel je fais partie. Je rencontre des gens là-dedans. [...] On se croise souvent. [...] Beaucoup sont chez Orange, SFR... assez peu chez Bouygues. » (P6)

${ }^{285}$ Verbatim: «Il y a des choses plus formelles. Les organisateurs présentent les appels d'offre. Il y a une partie de ces journées qui est réservée, soit pour des propositions, soit pour présenter l'expertise des candidats pour cibler une participation à une proposition. [...] Par exemple FP7 avec les Info Days [ou TIC \& Santé]. Les clusters Eureka font pareils une fois par an, ils ont des journées montage. [...] Eureka consacre une demi journée à une journée pour laisser le temps aux proposants et candidats de participer, de constituer leur consortium et d'ébaucher leur proposition. [...] Il y a une fiche projet, un résumé qui est présenté, qui est maintenu en ligne pendant un certain temps. Le temps que le consortium puisse se compléter. Puis il y a des dates pour les remises des propositions. Et en général c'est le coordinateur du projet qui anime la rédaction. » (P3)
} 
certains qui proposent. Je propose ça. Et il y a d'autres qui cherchent. Donc voilà, c'est tout. (P9).

Project leaders are extremely mobile and participate in a lot of different events. All of these events are in a certain manner the "competitors" of the policy-driven clusters. For most of the SMEs this high integration in a lot of different events is possible because their company structure allows it and because their objective is per se to create collaborative research projects. However, there are two types of companies that do not participate in these event marathons: the micro-enterprise and the large company. The large company does not need to participate in all these events. They have more project demands than they can accept. The microenterprise is not able to participate in this marathon because they do not have the human capacity to do it:

"On est extrêmement sollicité par des tas de séminaires, conférences, forums etc. et il y en
a beaucoup trop. [...] On est un peu en saturation [...] Si on voulait on pourrait [...]
pratiquement tous les jours [...] participer à un forum à Paris, à Lyon, à Grenoble, à
Toulouse, à Caen, partout en Europe. Donc à la fin ça fait beaucoup et je pense qu'il y a
trop. Mais maintenant je n'ai pas la solution pour que tout le monde se refocalise un peu
sur les choses importantes. [...] Il y a énormément de choses qui se passent et à la fin c'est
un peu trop. [...] Entre nous, il faut quand même faire avancer notre projet. Un vrai projet,
on ne peut pas seulement en discuter. » $(P 2)$

Finally, the last point that is important to mention is the judge/friend role that somehow sticks to the policy-driven clusters, particularly to Systematic and HealthCluster and less to Cap Digital. In this sub-section we have seen that the policy-driven clusters are in direct competition with other support structures. This is particularly intense in Regions such as the Paris Region where plenty of events and institutions exist. The project leaders are looking for "friends" that help them to develop their businesses. For one project leader, this seems for example more the case in associations such as Optics Valley who invite him personally to participate in specific events, than in policy-driven clusters:

[Dans Optics Valley] je trouve un bénéfice plus clair [que dans les pôles]. Ces gens là au moins ils organisent des rencontres. Là par exemple je vais à une rencontre de chefs d'entreprises et peut-être on dîne derrière. [...] On nous invite on dit : 'voilà comment interagir avec la presse'. Presse scientifique et technique. C'est quand même des choses concrètes et intéressantes. [...] Il y a des conférences sur les technologies. [...] Dans les études qui étaient présentées je me suis aperçu que la technologie que j'avais choisi lourdement, c'est actuellement la technologie qui se développe le plus. [...] C'est des choses concrètes. [...] Regardez [sur leur site] vous verrez qu'il y a un très beau reportage [sur nous]. On fait partie de trois PME, et ci et ca. Pour nous c'est quand même important parce que ça a un impact auprès de nos clients. » (P10) 
To sum up, for policy-driven clusters it is not only difficult to keep a stable attendance rate, to attract key actors (medical staff and industrials), but it seems also quite difficult to compete against all the other "competitors" that are situated in the Paris Region. In the performance contract HCPR wrote that a challenge for the second cluster policy phase is to show the local ecosystem the added value of HCPR. In Chapter 7 we already underlined that the partners with whom HCPR negotiated its services had difficulties to understand which new services they should develop. Additionally, when we look now at the data from our interviewed project partners, we see that they are highly volatile and participate in a large range of activities. HCPR's performance contract objective to become the "key health actor" of the region and to structure under one header all the existing support structures seems to be a quite difficult endeavour. In such a tensely-populated region that counts an increasingly high number of support structures, it is quite difficult to establish a policy-driven cluster's "raison d'être", particularly when the sector was already structured before the policy was implemented.

\subsection{Conclusion: the finding partners' dilemmas of HCPR}

One of the objectives of policy-driven clusters is to organise events so that the local ecosystem can get to know each other and start collaborating. This is expected from the government (dilemma MD\#1a and MD\#1b). However, our data has shown that project leaders learn and that they use the events organised by the policy-driven clusters particularly in the beginning when they are new to the community. Once they are established in the community, the policy-driven clusters' utility in finding project partners is strongly reduced, particularly in the Paris Region (dilemma MD\#3b) where plenty of events are constantly organised by different support structures.

The question is thus how collaboration should be fostered (dilemma MD\#3a) in policydriven clusters. In the beginning, when a community does not know each other, organising temporary spaces is important but then, project leaders rely on people and might only call the policy-driven clusters to get necessary contacts. However, they will not regularly participate in the policy-driven cluster "Meetic" events. The project consortiums are formed very fast, like "Las Vegas" weddings, so they only need somebody that knows the right person and that can put them together efficiently via phone or e-mail. So even though the government expects from policy-driven clusters to organise events, little by little policy-driven clusters realize 
that they have to constantly innovate and change the format of these events, otherwise nobody participate. The question is if organising events, just for the sake of organising events to be conform to cluster policy evaluations (dilemma MD\#1a - who is in charge? and MD\#1b - administrative straightjacket), is really necessary and if this does not foster the pathology of inefficiency?

However, there is one key actor that is particularly difficult to integrate in ICT \& Health events: doctors. Doctors belong to a world the project leaders are not familiar with and so the challenge lies in finding events (all kinds of events) where these key partners participate. It is particularly important for the project leaders to meet the doctors in person, so physical spaces are important to exchange with these key actors (dilemma MD\#3a). However, HCPR, at least for the ICT \& Health events, seems to have underestimated this challenge as doctors were highly absent and the cluster managers had difficulties to motivate them to attend.

The Paris Region is a very dense region with a high number of competing events. In the performance contract, HCPR wrote that a challenge for the second cluster policy phase is to show the local ecosystem the added value of HCPR and to become the "key health actor" of the region. Opening the doors to the "doctor" world, might be such an added value and competitive advantage but this also raises the question for whom a policy-driven cluster is working: for its members who might know the "doctor" world or for the wider ecosystem who might not know the doctor world (dilemma PD\#1b). Fostering collaboration is a difficult endeavour and for the time being HCPR seems to be trapped in the pathology of pragmatism, organising the same type of events as their competitors (dilemma MD\#3a), which are though not in the same sector of activity (dilemma SD\#2b). During our observation period in HCPR's operational team, one of the team members told us that one of the new "innovation services" might be to organise hospital visits for member organisations. However, the "innovation services" were finally cancelled to concentrate on more pragmatic services like accessing financing, strategy, etc. which corresponds more to the needs of the members.

Finally, the last point to underline is the difficulty to access industrial partners. As soon as an industrial partner pushes a project, the project gets most of the time financed. This is related to the fact that the public authorities consider that the chances of viability of a project are 
higher when a big industrial partner takes part in a project. However, on the other hand it seems quite difficult to first get in contact with big industrials, and second to get collaborative projects going. The internal structure of industrials (importance of contracts) does not allow the industrials to engage easily with other partners. The SMEs and the big industrials are uneven partners (dilemma MD\#3b).

\section{Finding ideas: Doctors can't be find at "Meetic" events}

In this section we first discuss the idea generation moments for collaborative $R \& D$ projects submitted for financing to one of the three Parisian policy-driven clusters. Second, we will discuss the absence of HCPR in this idea quest phase as none of the analysed projects can directly be linked to HCPR activities.

\subsection{Project leaders' idea generation moments}

We identified five different reasons that explain the emergence of a project idea. Ideas for collaborative research projects are either created out of a specific need or out of a stimulating situation (see Table 43 and Table 44). On the one hand, a company (A) or a university / hospital / health research center $(B)$ can formulate the need to start a collaborative research project in order to improve a certain internal service / product / technology or to create something new. On the other hand, a certain stimulating situation can also generate a collaborative research project that was not initially expected by the actor. We identified three different stimulating situations:

- Interaction between doctor and company $(\boldsymbol{C})$ : thanks to a "serendipitous" interaction between a doctor and a company a project emerges. The need to do the project, prior to the interaction, was neither formulated by the doctor nor by the company. We will see that this interaction is only considered as "serendipitous" at the first glance and that certain repeating patterns can be identified.

- Public project call $(\boldsymbol{D})$ : thanks to a public project call, found by the project leader either by an active or passive search, or

- Previous collaborative research project $(\boldsymbol{E})$ : thanks to the work on another collaborative research project that opened further exploitations of the same initial idea.

Approximately half of the 19 project ideas were created out of a certain "need" while the other half was created thanks to a "stimulating" situation. From a public policy point of view, 
the cases C and D are particularly interesting because they are stimulated (D) or theoretically able to be stimulated (C) by a public policy intervention. Hereinafter, we discuss and illustrate all five reasons to launch a collaborative research project in more detail.

Table 43: Idea to launch a collaborative research project

\begin{tabular}{|c|c|c|c|}
\hline $\begin{array}{c}\text { Company } \\
(\# 10)\end{array}$ & Project & $\begin{array}{c}\text { Idea } \\
(\# 19) \\
\end{array}$ & Financed \\
\hline P1 & P1a & Need of company & No \\
\hline $\mathbf{P 2}$ & P2a & Need of company & Yes \\
\hline $\mathbf{P 3}$ & P3a & Need of university / hospital / health research center & No \\
\hline P4 & P4a & Need of university / hospital / health research center & No \\
\hline \multirow{3}{*}{ P5 } & P5a & Need of university / hospital / health research center & No \\
\hline & P5b & Need of company & yes \\
\hline & P5c & Stimulated by precedent collaborative research project & yes \\
\hline P6 & P6a & Stimulated by interaction between doctor and company & yes \\
\hline \multirow{2}{*}{ P7 } & P7a & Stimulated by public project call & yes \\
\hline & P7b & Stimulated by interaction between doctor and company & yes \\
\hline \multirow{4}{*}{ P8 } & P8a & Stimulated by public project call & No \\
\hline & $\mathbf{P 8 b}$ & Need of company & yes \\
\hline & P8c & Need of company & yes \\
\hline & P8d & Stimulated by interaction between doctor and company & yes \\
\hline \multirow{2}{*}{ P9 } & $\mathbf{P 9 a}$ & Need of university / hospital / health research center & yes \\
\hline & $\mathbf{P 9 b}$ & Need of university / hospital / health research center & yes \\
\hline \multirow{3}{*}{ P10 } & P10a & Stimulated by interaction between doctor and company & yes \\
\hline & P10b & Stimulated by precedent collaborative research project & No \\
\hline & P10c & Need of university / hospital / health research center & yes \\
\hline
\end{tabular}

\section{Table 44: Number of cases per project idea type}

\begin{tabular}{|l|l|c|c|c|}
\hline \multicolumn{2}{|c|}{ Situations } & $\begin{array}{c}\text { Number of } \\
\text { cases }\end{array}$ & Financed & Not financed \\
\hline A & Need of university / hospital / health research center & 6 & 3 & 3 \\
\hline B & Need of company & 5 & 4 & 1 \\
\hline C & Stimulated by interaction between doctor and company & 4 & 4 & 0 \\
\hline D & Stimulated by public project call & 2 & 1 & 1 \\
\hline E & Stimulated by precedent collaborative research project & 2 & 1 & 1 \\
\hline
\end{tabular}




\subsubsection{Need formulation}

One type of idea generation for a project is the need formulated by a university, hospital or health research centre ${ }^{\mathbf{2 8 6}}$. For example the hospital expresses a certain need and then launches the process in order to get the collaborative research project going. In one of our observations, it was the hospital that for example had a certain problem and then invited academics and companies to the hospital. One university was then appointed to set up the project.

Another possibility of idea generation is that the company itself formulates the need for the project. The first case shows how a successful collaborative R\&D project emerged. Successful, because the project created a lot of jobs and consequently the project is often mentioned in order to justify the general cluster policy. However as we will see in this example, the policy-driven cluster was not integrated in the idea-finding phase. The project was "only" financed by a subsidy (FUI) linked to policy-driven clusters. In this case, a large company contacted a SME with a concrete project idea. The company and the SME previously met during a working group meeting of the CNRS (National Scientific Research Council):

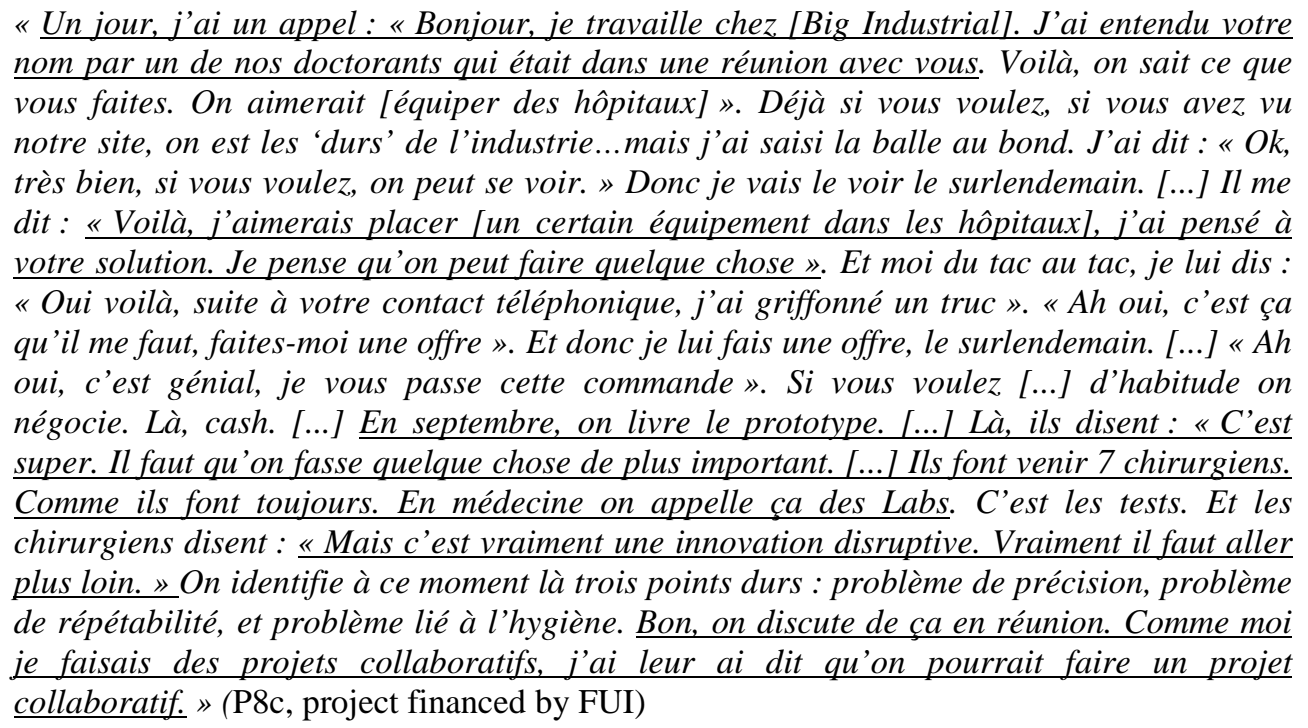

This illustrative example shows that it was the large company that had the idea, contacts the right SME and then brings together the necessary doctors. Two important observations after this first example:

\footnotetext{
${ }^{286}$ Verbatims: «L'idée originale de ce projet, elle vient de [health research center]. » (P4a, project not financed by FUI); «[Nom de l'hôpital] s'est dit qu'on pourra faire des choses.» (P5a, project not financed by FUI); «[L'Université] était sollicitée par des Médecins du CHU pour essayer de monter un projet. » (P9b, project financed by FUI); «L'assistance publique voulait monter un [projet]. » (P10c, project financed by FUI)
} 
- First, the role of the policy-driven cluster is reduced to subsidies finding and the administrative part of the research project.

- Second, the large company was successful in motivating the doctors to look at the device, to identify the main problems of the device and to further specify the points of amelioration. The interaction between the doctors and the companies was crucial in order to define the exact content of the research project.

The second case shows that it seems important for SMEs to stay in regular contact with their big industrial clients. The SME we interviewed decided to present a new internal project to an established client. After this presentation the client proposes the SME to participate in a collaborative research project. It is the pro-active attitude of the SME that allows the SME to participate in a new collaborative research project. However, it was an internal need of the big industrial that initiated the project. The first project was an ANR project. However, the consortium then also proposed the same project, more oriented business, to the FUI. For the FUI project, our interviewee was the project leader. Once again, the policy-driven cluster has not played an active role in the initiation of this project. The policy-driven cluster is once again reduced to a "subsidies finding" function:

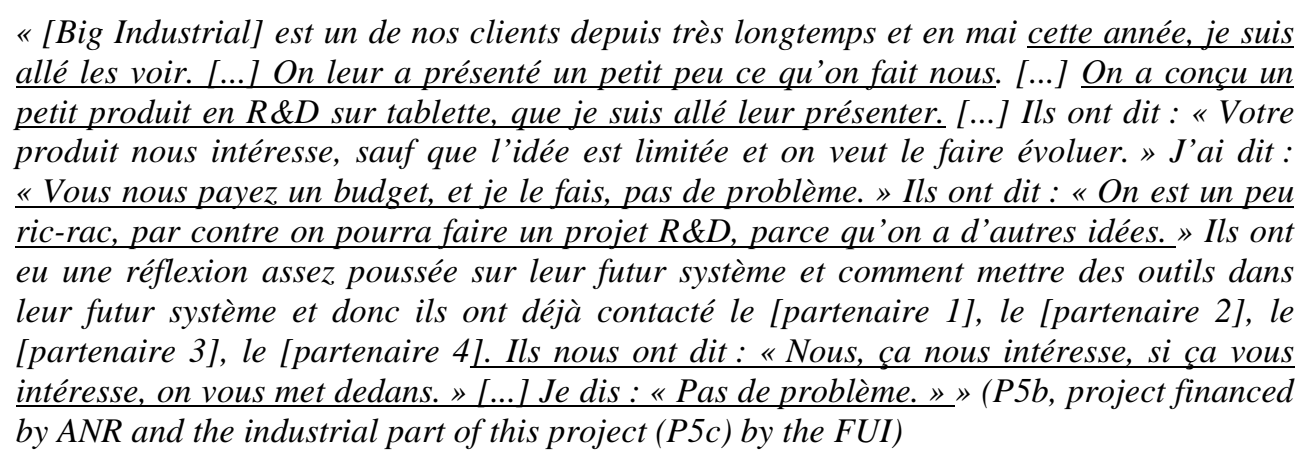

In both cases we have seen that the SME has produced a little prototype that then interests the big industrial to pursue the journey further. Additionally, both examples illustrate that the projects are primarily associated to the cluster policy because they went through a labelling process (thus through an evaluation process) but not because they went through an idea generation process at the policy-driven cluster level. The subsequent examples confirm this tendency. 


\subsubsection{Stimulated by...}

New cluster projects are formulated because of certain needs but also because of certain stimulations as the following examples will show.

\subsubsection{1 ... an interaction between a doctor and a company}

As the majority of our projects are projects situated in the ICT \& Health domain it is no surprise that several projects were stimulated through an interaction between these two worlds. In this section it is a fruitful direct interaction between doctors and companies that created a collaborative research project. The big difference between a need formulation (either by a company (B) or by a hospital / health research centre (A)) and the "serendipitous" discussion between a doctor and a company is that in the latter neither of the two entities has thought about it before. The doctor has not hoped that "something" could improve his/her problem and the company has not thought about that their business could potentially help (in one way or another) the doctors. 4 out of our 19 cases fell into this category and all of these projects were also financed (the only category were all projects were also financed). The difficulties of having these two worlds interact and of bringing both parties together are multisided. However, we think that this category could be one of the most important categories for policy-driven clusters and public policy interventions. However, it was quite a surprise that the policy-driven clusters themselves stimulated none of these interactions. We were able to distinguish three different boundary objects between these the corporate and medical world:

Project: The first possibility is that a doctor and a company already work together on another project and during the work on this project they find out that they could do something else together:

«Ca, c'est une rencontre entre [le médecin] et puis nous. J'ai rencontré [le médecin] quand on était en train de créer un autre projet. [...] On a commencé à réfléchir là-dessus ensemble. " (P6b, project financed by "Investing for the future » program)

" [Cel troisième projet est un dérivé $[. .$.$] ça, on a appris 'en marchant'. On apprend des$ bouches des médecins avec qui on travaille dans les projets collaboratifs. $C^{\prime}$ 'est ça qui est formidable dans les projets collaboratifs, c'est qu'on rencontre des gens qui vous apprennent énormément de choses dans des métiers qui ne sont pas les vôtres. C'est très enrichissant comme métier. Les médecins, en les faisant parler, on s'aperçoit qu'il y a ce besoin-là qui peut représenter beaucoup d'argent pour la France.» (P7b, project financed by « Investing for the future » program)

Particularly the last comment shows that the company highly appreciates to be that close to doctors as it allows the project leader to generate new ideas. This intensive interaction was 
able to get started thanks to a collaborative research project subsidised by the state. However, again, the idea generation for this project had nothing to do with the policy-driven cluster.

Event: The second possibility is that a third party invites the doctor and the company to an event and during this event they find out that they could work together:

"C'est une manifestation qui était organisée [...] par une organisation [...] qui s'appelle la
MEITO, par un monsieur qui s'appelle François ${ }^{28}$. François me connaît bien parce qu'on
avait travaillé l'année d'avant sur un projet. François me dit : «On est en train de lancer,
dans le cadre du mouvement national, un groupe TIC \& Santé. On aimerait bien que tu
viennes ». Quand je dis que je suis libre [de faire ce que je veux], je suis libre, mais je fais
gaffe quand même. C'est-à-dire : je ne vais pas à des trucs trop hors champ. Et il
m'appelle, et il me dit : "Il faut que tu viennes. Il y a le CEA. ». Et je dis : "Ecoute
François. C'est un centre de [maladie]. Je ne vais pas passer ma journée à Orléans. Ca
fait quand même un peu 'touriste'. » Et il dit : « Non. Viens, viens. Tu verras. Viens. ». Bon
voilà. J'y vais, donc. Normalement, a priori, s'il ne m'avait pas poussé, je n’y serai pas
allé. J'y vais. En effet, c'était une journée assez touristique parce qu'à midi on va au bord
de la mer. A Orléans. Et on était à table, 15 personnes, et je me trouve en face d'un
médecin. [Le médecin parle de son problème à l'hôpital]. Alors déclic : mais ça, c'est une
bonne idée! » (P8d, project financed by FUI).

This is a domain where we could have expected a policy-driven cluster to be the initiator of the encounter, but this was not the case. The association that invited the company and the doctor is called MEITO. The MEITO is an association founded in 1984 to stimulate the electronic, informatics and telecommunication sector in the west of France. The MEITO organises events, distributes information, conducts industry specific studies, or proposes help in the setup of projects. Another interesting element is that the MEITO has personally contacted the SME to convince it to participate in the event that was not anywhere near the company's business field. The SME trusted the MEITO and participated in the event.

Business relation: The third possibility is that a doctor and a company know each other because they interact regularly regarding a certain service the company proposes to the doctors. However, at some point the company questions the apparent reality. This situation can only happen if a company does not simply fulfil the immediate need of the doctors but tries to understand the underlying problems of the doctors:

"C'étaient des médecins que je ne connaissais pas, qui me connaissaient plus ou moins
parce qu'on est quand même présent [à cause de son autre activité commerciale]. Ils sont
venus me voir avec des bô̂tes de lames et je leur ai demandé : "Pourquoi vous venez me
demander de numériser ces lames? [...] Donc ils m'ont expliqué [le problème]. Je me suis
dit : "Dit comme ca, c'est intéressant». Parce qu'en général les radiologues, ça sont des
disciplines (...) chacun prétend être capable de prendre en charge tout de son côté.
Quelqu'un qui a l'honnêteté de venir me voir en disant : "Voilà, on coince. On a besoin
d'aller dans un autre domaine, - qui n'est pas le leur - pour mieux interpréter ce qu'on fait

${ }^{287}$ Name changed 
dans le notre... » Je me dis : c'est le bon fil. Donc c'est pour ça que j'ai entamé la réflexion. » (P10a, project financed by ANR).

To sum up, the close interaction between companies and doctors seems to have a high idea generation potential, be it through projects, events or business relations.

\subsubsection{2 ... a public project call}

Another possibility of idea generation is that the company is stimulated by a public project call either by an active search for a public project call or by a passive stimulation of a project call.

Active search: A company can search actively for a public project call because the company wants for example to enter into a certain business domain. However, as we can see in the following comment, project leaders might just follow the research directions given by public authorities, without looking for new cutting edge ideas:

"Ca commence par un travail de prospection où j'essaie de découvrir des besoins et des
appétences. C'est-à-dire: vis-à-vis des guichets qui sont des organismes financeurs,
j'essaie de voir quelles sont les thématiques qui sont dans leur stratégie, car chaque
financeur a ses propres objectifs en termes de choix de dossier. Donc il faut rassembler, il
faut commencer par rassembler, faire un état de lieux et rassembler de l'information...
Mais les attentes changent d'année en année. [...] C'est-à-dire : avant de trouver l'histoire,
il faut déjà se renseigner quelles sont les attentes, parce que ça ne sert à rien de trouver
une histoire qui ne correspond pas à ce que les gens vont vouloir. Donc il y a déjà un
problème de mise à jour par rapport aux attentes des financeurs. » (P7a, project financed
by FUI)

The cluster actor is only looking for ideas that are entering in the "official" direction. This is a reality we were particularly able to observe in the "e-health" project calls, suddenly all the companies in the domain were proposing approximately the same types of projects (at the moment of our interviews the topic was particularly turning around cloud services).

Passive stimulation. On the other hand, a company might be stimulated passively by a public project call. This means the company has already thought about doing something in a particularly domain but never took the final step:

\footnotetext{
«Le président à l'époque - il venait d'être élu - dit: [...] «Il faut qu'on [soit] les plus efficaces de l'Europe à la fin de mon quinquennat [dans ce domaine]». "Ah», je dis: «Bien, enfin on va pouvoir faire quelque chose dans [ce domaine].» Donc je regroupe un consortium hyper-costaud. »(P8a, project not financed by FUI).
}

A project call can thus remotivate a company to finally take action and to invest time in an idea it was already thinking about in the past. 


\subsubsection{3 ... a previous collaborative research project}

Finally, it is also possible that a new collaborative research project is created in extension of an already existing project. This is in a certain manner the "easiest" one as the intrinsic idea stays the same as well as most of the partners:

"En travaillant sur le projet [P5b], on s'est dit: voilà, c'est bizarre, il y a une grosse partie qui est quand même orientée marché, qu'on pourra déployer en FUI. [...] On laisse tomber le côté scientifique du projet [P5b]. » (P5c, project financed by FUI)

"J'ai repris presque les mêmes personnes que dans [projet P10a]. Le projet [P10b] est un projet à vocation principalement industrielle. J'ai mis dans la balance le côté matériel. » (P10b, project not financed by FUI)

Both examples show that a more research-oriented project (in both cases financed by the ANR) can then be transformed in a more development project (in both cases financed by the FUI). This also means that in several cases the real investigation starting point (from an innovation point of view) might actually be the ANR project and not the FUI project. In order to obtain ANR subsidies, the research consortium is not obliged to pass through the labelling process of the policy-driven clusters. However, before 2013, projects that were labelled and then submitted for ANR subsidies received an additional financial pop-up ${ }^{288}$, but the label was not an obligation for the application. ${ }^{289}$

\subsection{Absence of HCPR in the ideas quest phase}

In the majority of idea finding cases a medical entity was involved. In 6 cases the need was formulated by a university, hospital or health research centre (3 financed and 3 not financed) and in 4 cases the idea emerged thanks to a fruitful interaction between a doctor and a company (4 financed and 0 not financed). We see that in the medical domain the interaction with the clinical staff seems extremely important in order to get projects financed. However, we already discussed in the partner finding section that the medical representatives are highly absent in the events and very difficult to grasp for the business driven companies that wish to launch new products. Additionally we have seen that the "innovation" services were cancelled by the executive office and replaced by more business oriented help for the members of HCPR. For the members of HCPR who wish to conduct research in a specific medical domain, this might be understandable. However, as the discussed examples show, for the

\footnotetext{
${ }^{288}$ Before 2012, the financial pop-ups for labelled projects submitted to ANR were: (i) no pop-up if subsidy was $<50000 €$, (ii) $6 \%$ of the subsidy amount if the granted subsidy was situated between $50000 € \square$ and $200000 €$; (iii) $12000 €$ if subsidy was $>200000$

289 Since 2013, the ANR does no longer grant financial pop-ups for policy-driven cluster labels. In case a project consortium decides to go through the policy-driven cluster labelling process and a project gets a policy-driven cluster label, the ANR will now only "take into account" this information.
} 
general ecosystem, the contact between medical staff and other companies seems very important. However, HCPR is completely absent from this domain. Two critical points emerge: On the one hand the strong business and subsidies orientation of HCPR and how it seems to keep away the clinical staff and on the other hand the danger of fashionable innovations.

\subsubsection{Struggling to attract others than business-driven companies}

We observe that the policy-driven cluster members that are most active in as well as attracted by the policy-driven clusters are business driven SMEs and not for example academics, large groups, micro-enterprises or doctors. However, it is them who most of the time had the idea for a new collaborative R\&D project (and not the business-driven SMEs). The policy-driven clusters primarily gather companies that are somehow distant from the initial project idea. Or as one project leader said, SMEs are only the "midwives" who help the ones with the ideas to get their "babies" born"

The most active in the policy-driven clusters we investigated are the business oriented SMEs that also have enough time to lobby for the project among the right decision makers. This might also be the reason why according to P9 (highly integrated in the cluster community, has already been project leader of several FUI projects) most of the technologies and products "die" after the end of the project in case they are not pushed by an academic or other entity that really wants the project to "live":

\begin{tabular}{l} 
"Les consortiums, c'est un peu des mariages forcés. C'est comme à l'époque il y a deux \\
cents ans. [... L'amour dans tout ça n'existait pas. Donc par intérêt, à l'époque politique \\
\hline$\underline{\text { et maintenant financier, on crée des consortiums. [...] Donc là, on a des mariages qui }}$ \\
\hline durent un certain temps. En général 3 ans. Ca va. C'est un mariage à durée déterminé. Le \\
divorce est déjà inscrit dans le contrat du mariage dès le départ. C'est pratique. Et en fait \\
les gens se marient, ils font un bébé, le projet. [...] On leur donne de l'argent pour élever le \\
bébé. Et après le bébé il meurt parce qu'en général c'est assez rare que le bébé vive après. \\
[...] Ca a fait vivre chaque personne pendant un certain temps. Ca aura quand même \\
renforcé leur expérience. [...] Quand je dis « meurt», il ne fait pas une bonne carrière en \\
fait. Dans le cadre des projets, ca ne fonctionne que si c'est le bébé d'un des membres du \\
consortium qui veut vraiment faire du business, qui veut vraiment le développer. » $(P 9)$
\end{tabular}

We will not start a discussion if the State money was spent wisely or not. Even subsidising companies with unsuccessful projects might be better for a Nation than having these

\footnotetext{
${ }^{290}$ Verbatim: "Quand c'est un laboratoire qui cherche des membres de consortium, ce n'est pas un effet d'aubaine. Parce qu'il y a une vraie recherche. Parce que c'est la recherche appliquée, pour qu'il y ait des retombées financières de leurs travaux. En fait, avec les laboratoires c'est facile de collaborer parce que c'est des gens rigoureux. Les projets, c'est leurs bébés en général. Nous on est facilitateurs. On permet la naissance du bébé mais on est plutôt la sage-femme qui permet au bébé de sortir. Mais ce n'est pas notre bébé. [...] Les soumissions sont de meilleure qualité quand le consortium contient un laboratoire. » (P9)
} 
companies go bankrupt where the project members do not gain any additional experience at all. However, we have to ask if the general cluster framework (be it the subsidies rules or the types of events) is adapted to generate new ideas. For the time being, our investigation shows that a certain population of companies is particularly attracted by the policy-driven clusters, where accessing subsidies seems the primary objective:

\begin{abstract}
«Dans le cadre des projets d'innovation, en fait, on se retrouve obligé, pour avoir accès à l'argent public, de créer des consortiums. [...] A la base, on veut juste de l'argent. On ne veut pas être plus compétitif, on veut avoir de l'argent. [...] Sauf qu'en fait au départ, elles s'en foutent de travailler ensemble. Normalement ça les embête. [...] La $R \& D$ sert à financer nos dépenses courantes. [...] C'est d'abord: 'on veut faire de l'argent' et après, 'comment on va faire en sorte que ça soit le plus sexy possible pour l'Etat pour qu'il donne cet argent?' » (P9)

"Comment financer la R\&D sur fonds propres de toutes les boîtes? Mais non, c'est l'envers. Toutes les sociétés vont présenter un ANR ou un FUI pour aller chercher de l'argent. Il faut le savoir, c'est un dispositif où on va chercher de l'argent pour faire un peu de R\&D, mais surtout: on va chercher de l'argent! Il faut le savoir. » (P5)

"On fait de l'innovation pour créer de la valeur, et moi je ne suis pas sûre que tous les gens qui participent aux projets soient là pour créer de la valeur. Je pense qu'il y en a beaucoup qui sont là pour capter de la subvention. " (P8)
\end{abstract}

Our analysis has shown that none of the ideas for the investigated projects was generated thanks to a policy-driven cluster. One reason might be the strong link between subsidies and policy-driven clusters.

\title{
4.2.2 Danger of fashionable innovations
}

Policy-driven clusters are heavily involved in the subsidies finding phase of their members. National and regional innovation financing authorities use policy-driven clusters to pre-select collaborative research projects but also to inform the different policy-driven cluster members about the "topics", "initiatives" or "special calls" of the moment. Financing authorities exploit policy-driven clusters to find the right research consortiums that can bring answers to current national challenges. During our interview phase, a lot of ICT \& Health projects turned around "cloud services", one year later ICT \& Health projects particularly turned around the "silver economy". The policy-driven clusters, know that the chance of a project to be financed increases if it covers one of the "fashionable topics" of the moment:

«Il faut avoir un vrai bon sujet, des vrais bons partenaires. Mais même avec un bon projet et des bons partenaires, non, après il faut aussi être dans l'air du temps. » (P2)

"Je pense qu'il faut être capable de leur raconter une histoire, et si vous avez une histoire qui est dans l'air du temps, qui dans la problématique dans l'air du temps... » (P10)

"Des sujets qui semblent être dans l'air du temps. [...] C'est-à-dire l'ensemble du process qui consiste à, avant de trouver l'histoire, de déjà se renseigner: 'quelles sont les attentes?', parce que ça sert à rien de trouver une histoire qui ne correspond pas à ce que les gens vont vouloir. »(P7) 
A fashionable innovation project can of course create innovation. However, the close relationship between "fashionable topics" and policy-driven clusters might also bear risks. The risk of a general innovation lock-in around certain subjects and pushing all cluster actors to work cannibalize resources on the same topics.

\subsection{Conclusion: the finding ideas' dilemmas of HCPR}

When we started our thesis we were particularly interested in how a policy-driven cluster helps its members to generate new ideas or to find new $R \& D$ partners. However, our data show that none of the 19 investigated project ideas (and therefore the 30 administrative projects) can be particularly linked to one of the policy-driven clusters. Additionally, for only 4 projects a cluster organisation helped finding project partners. Most of the interactions between project leaders and policy-driven clusters took place during the finding subsidies phase but not through events organised by one of the policy-driven clusters.

One of the main dilemmas that emerge after this analysis is what type of innovation process HCPR wishes to foster (dilemma MD\#2a) and which type of collaboration possibilities should be installed to allow this interaction to happen (dilemma MD\#3a)? The interaction between doctors and companies is very important and all of the projects that were born out of a need formulation from a doctor were also financed. However, for the project leaders we interviewed, the ICT \& Health events were somehow not able to generate this fruitful interaction. The "Meetic" format of the organised events doesn't seem to be adapted to involve the doctors, and keep the "free electrons" on the ball. We could also question if the direct subsidies that are linked to the policy-driven clusters hinder a free development of ideas (dilemma PD\#2a). The pathology that emerges is again of pragmatic nature as the current offer doesn't seem to be adapted to the type of the actors (dilemma SD\#2b). 
Table 45: Overview of cases

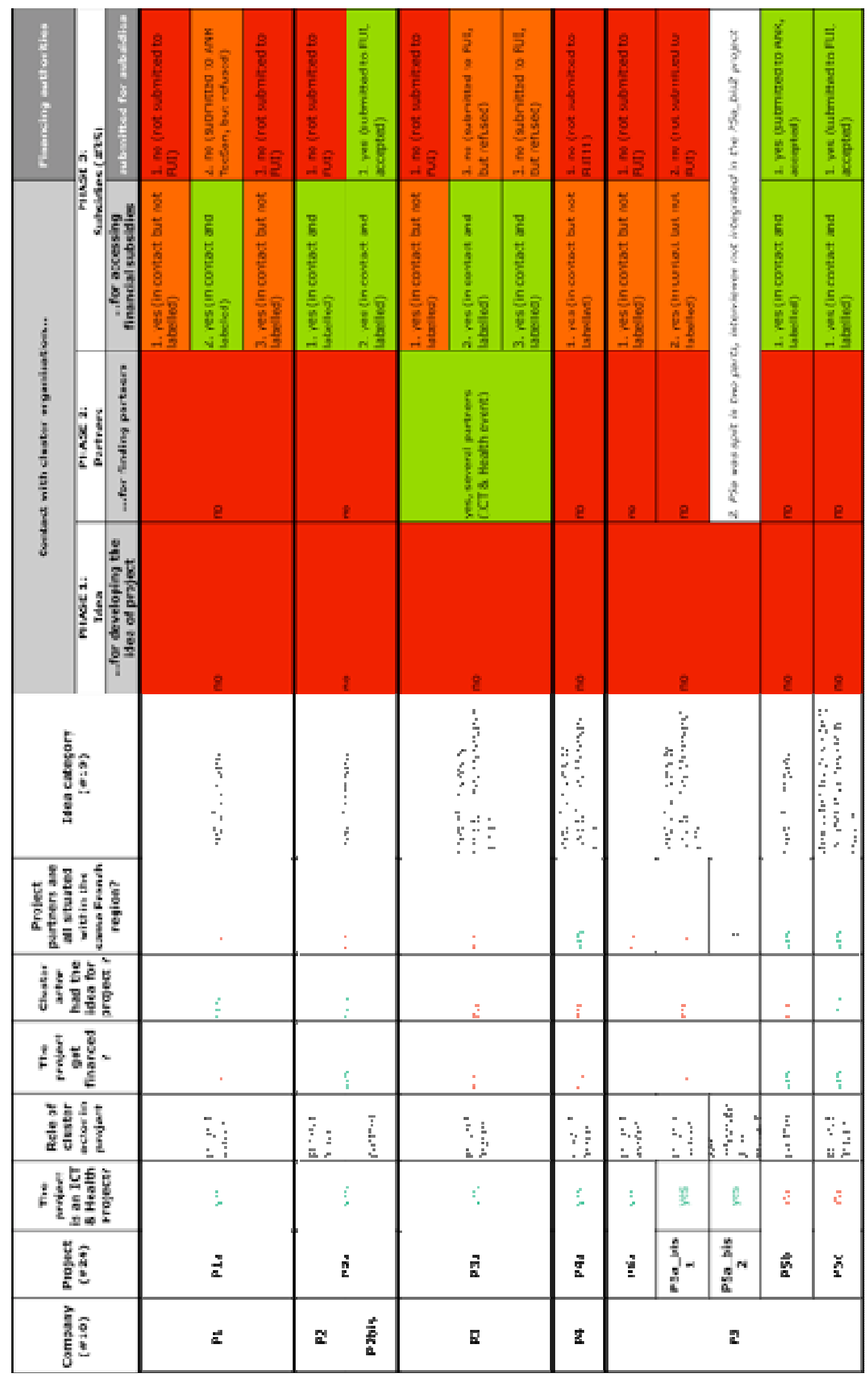


Table 45: Overview of cases (cont.)

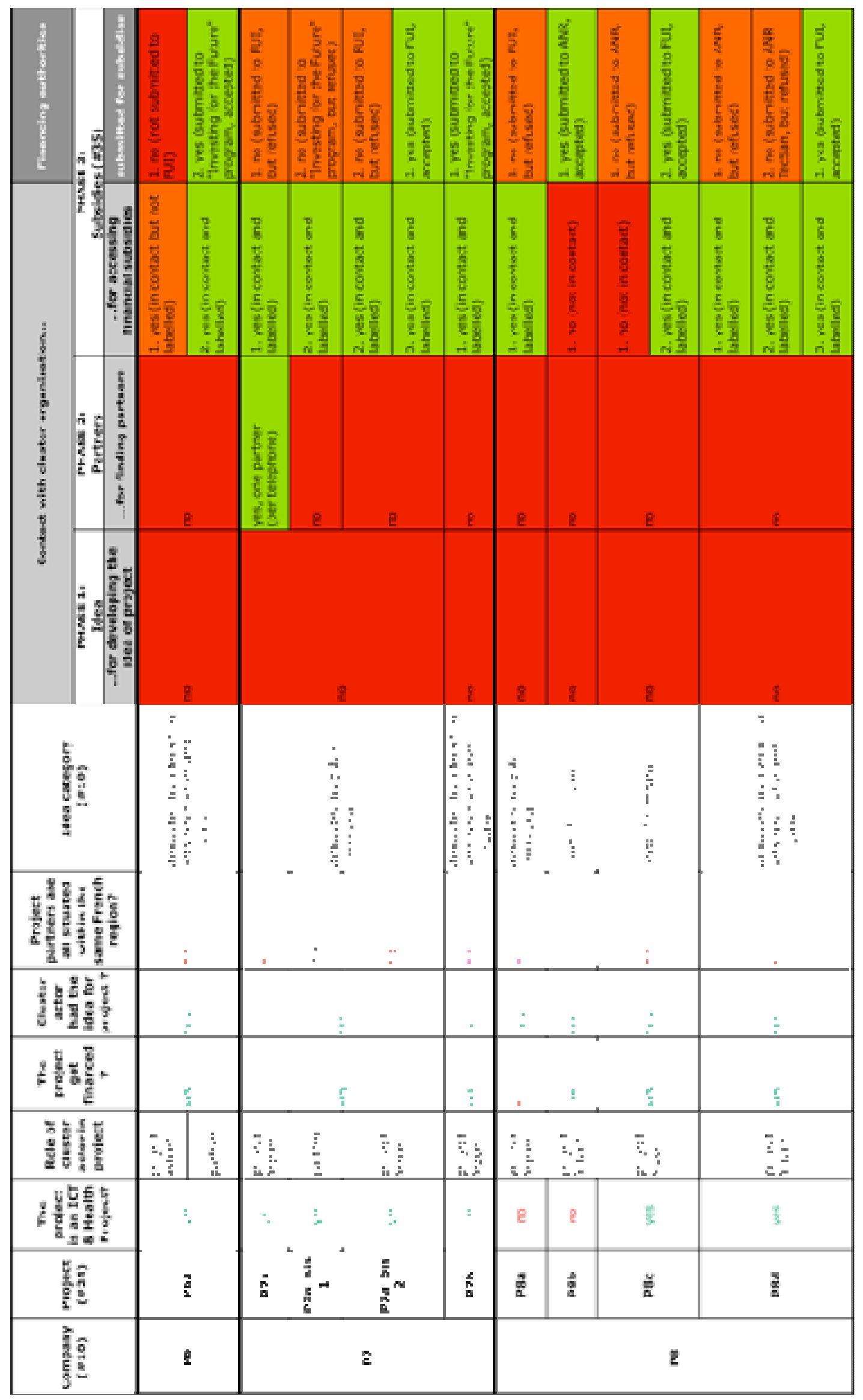


Table 45: Overview of cases (cont.)

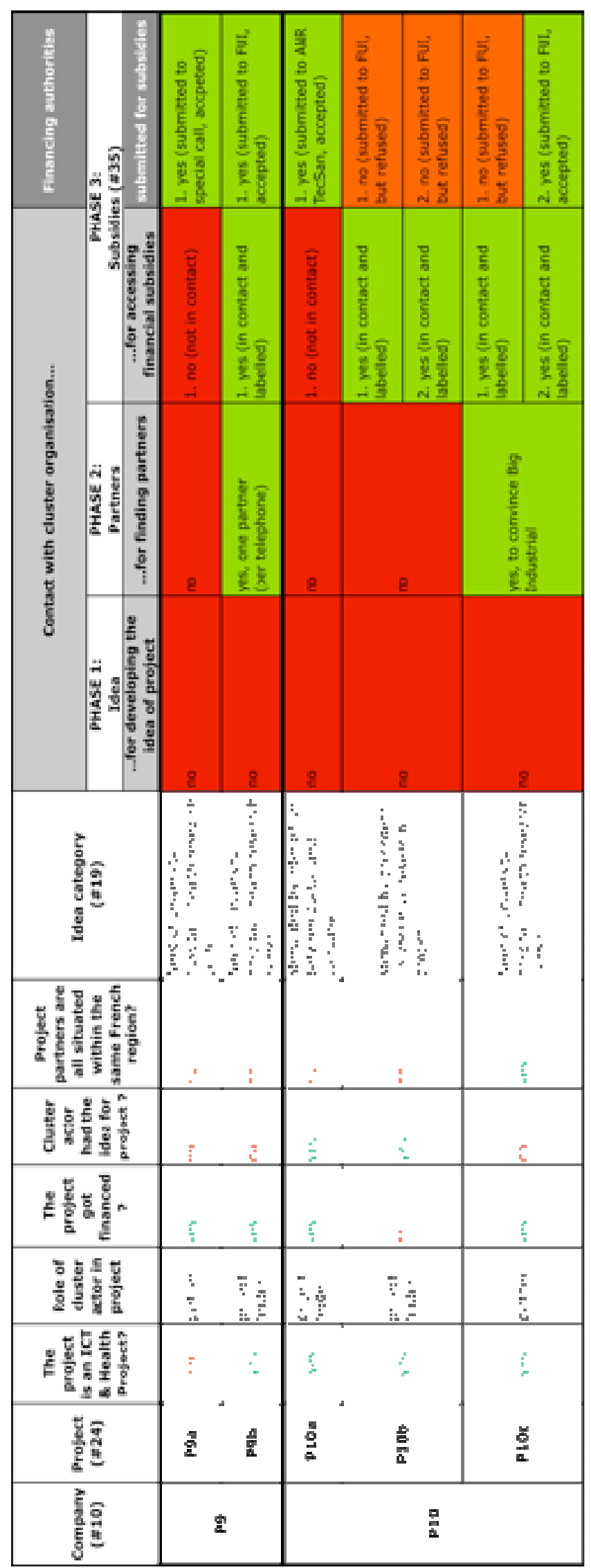




\section{Chapter 9: Discussion: how dilemmas drove cluster pathologies in HCPR}

The thesis that we defend in this document is that implementing cluster policies produce organisational dilemmas (political, managerial and structural dilemmas) that, in turn, generate side-effect pathologies. Figure 37 summarizes the problem statement and the research questions of the thesis, as well as the links that exist between them.

Figure 37: Problem statement and research questions

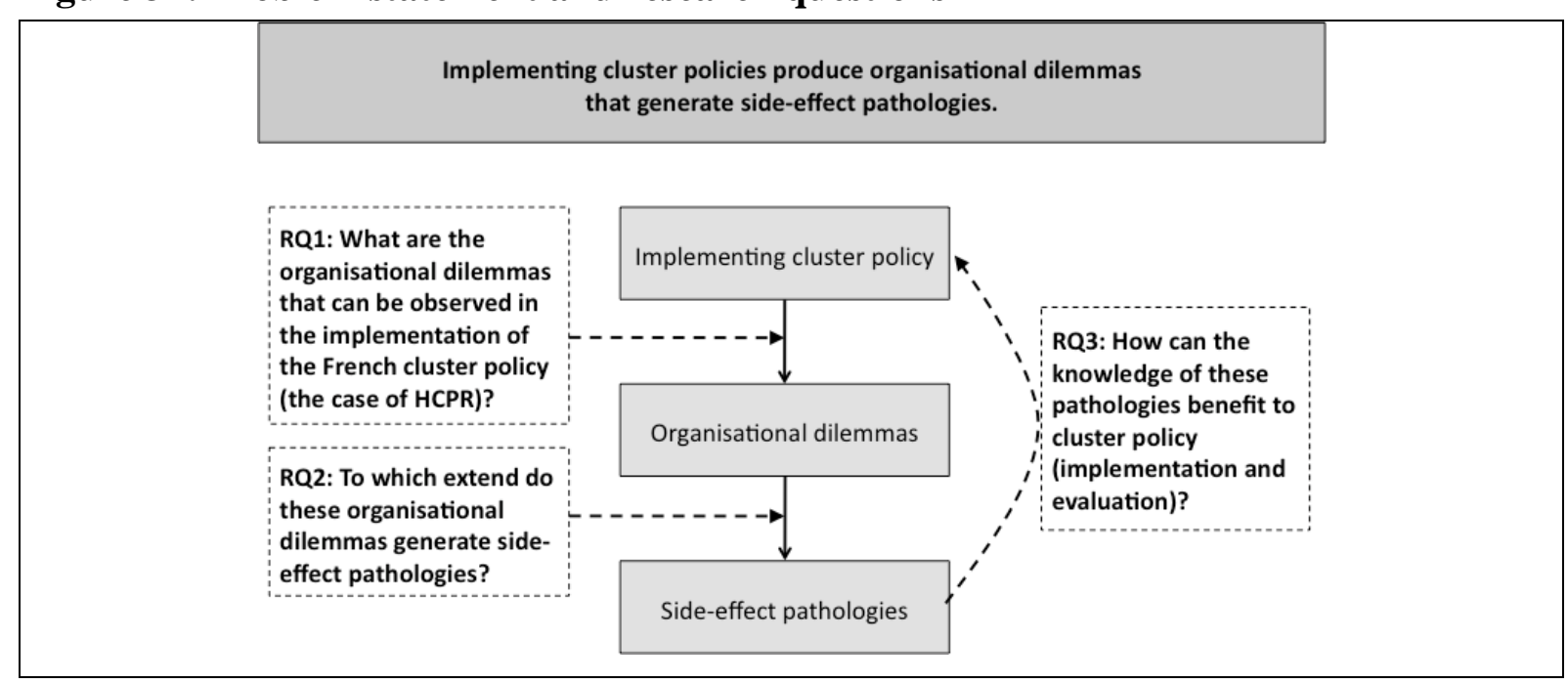

As seen in the first section of this thesis, our systematic literature review has allowed us already to identify a certain amount of dilemmas that policy-driven clusters face and that drive pathologies (see Figure 38)

Figure 38: Studying dilemmas that drive side-effect pathologies in policy-driven clusters

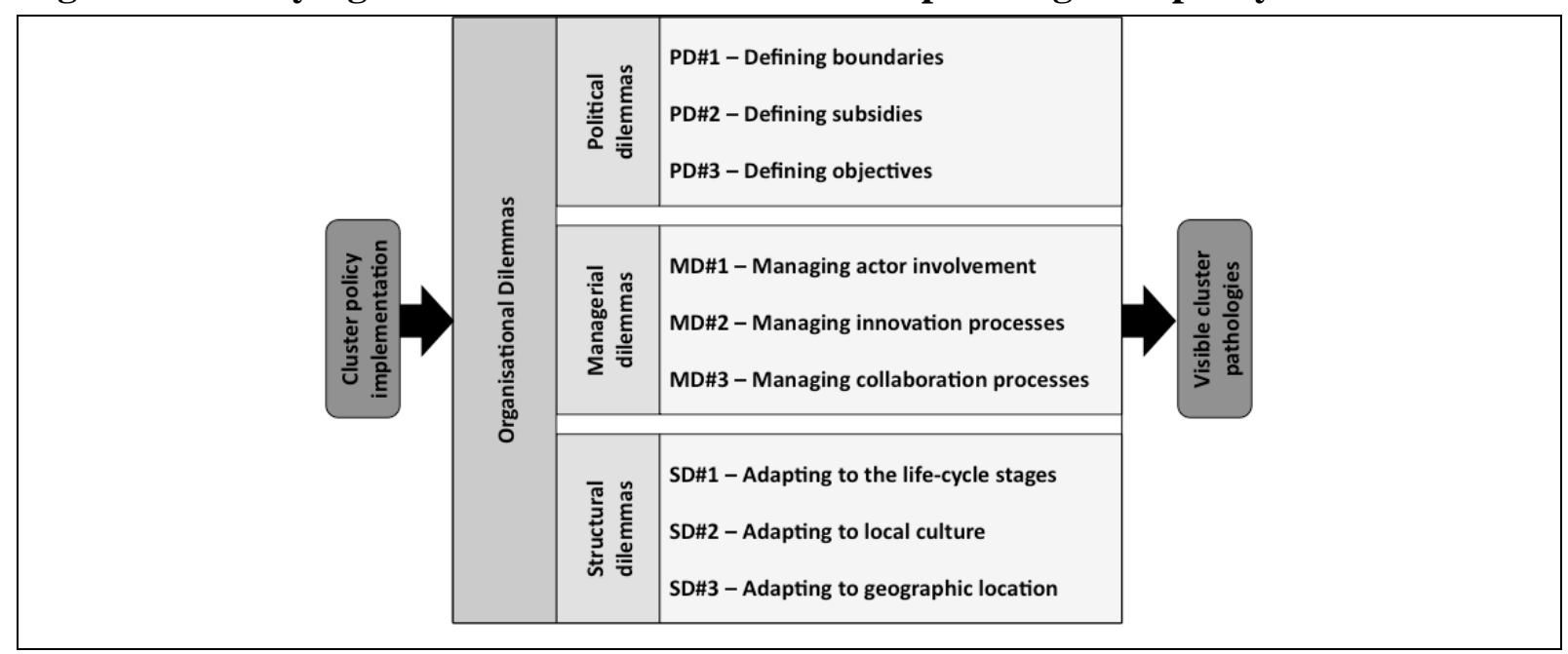


In this final chapter, we will discuss the pathologies that we identified for HCPR and the dilemmas that are at the source of these side-effect pathologies. There is evidence of four side-effect pathologies that are particularly present in the HCPR case: "inefficiency", which is mainly driven by leadership dilemmas; "distrust" mainly driven by subsidies dilemmas; "nonconformity" mainly driven by structural dilemmas; and finally "pragmatism" mainly driven by dilemmas on how to manage innovation and collaboration. Additionally, we will argue that, besides all of these pathologies and the recurrence of rather poor evaluations HCPR received from official evaluators as well as academics (CMI \& BCG, 2008; Erdyn, et al., 2012), and also independent researchers (Bonnafous-Boucher \& Saussois, 2010), HCPR continues to exist as an organization. An empirical phenomenon that we explain thanks to a concept developed by N. Brunsson (1989) and that is called "the organization of hypocrisy". Finally, we discuss how the knowledge of these four side-effect pathologies and the associated dilemmas can help to improve cluster policy implementation and evaluations.

However, before we start discussing the different dilemmas that drove cluster pathologies in HCPR we have to underline once again that HCPR is a "special case" among French policydriven clusters. There are plenty of French policy-driven clusters that are perceived well and obtain great results as for example Minalogic (Retour, 2009b; Therme, 2008), AgriMip (de Rochambeau, Veronese, \& Roché, 2008), I-Trans and Mer PACA (Bidan \& Dherment-Férère, 2009), Lyonbiopole (Retour, 2009a) or Cosmetic Valley (Chabault, 2008). For our purpose, the study of pathologies, HCPR is though an extraordinary case because it allows in a perfect manner to study potential policy-driven cluster pathologies with a magnifying glass. The risks associated with implementing policy-driven clusters are amplified within HCPR, which allows having a close-up of potential pathologies. This needs to be kept in mind. 


\section{Box 13: Content of chapter 9}

1 The identification of HCPR's four side-effect pathologies

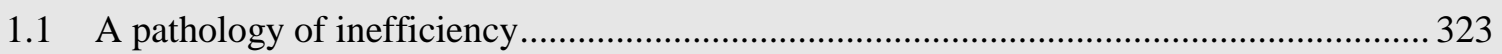

1.1.1 Results: Leadership dilemma contribute to cluster inefficiency ……….................... 323

1.1.2 Discussion: No civic entrepreneur, no external challenge, unitary country.................326

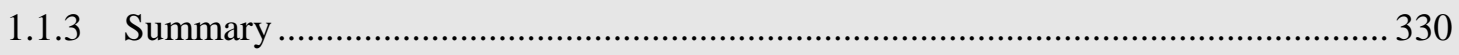

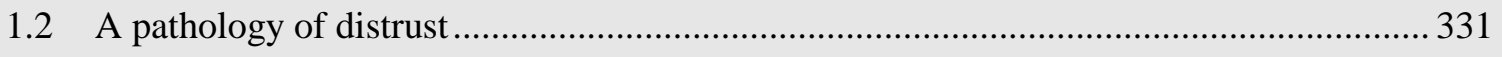

1.2.1 Results: Subsidies dilemma (also) drives cluster distrust ....................................... 331

1.2.2 Discussion: Theoretical "trust facilitator" struggles with trust issues.......................... 334

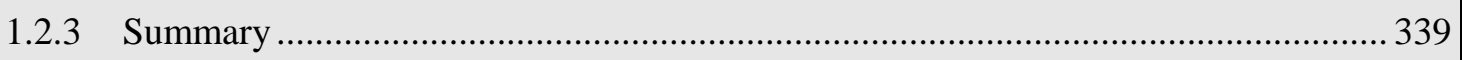

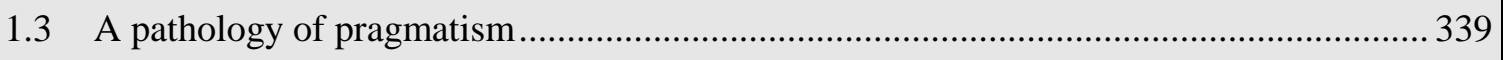

1.3.1 Results: Dilemma on innovation\&collaboration management drives pragmatism.... 340

1.3.2 Discussion: Doctors, a specie difficult to meet? ......................................................... 343

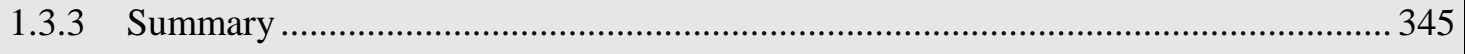

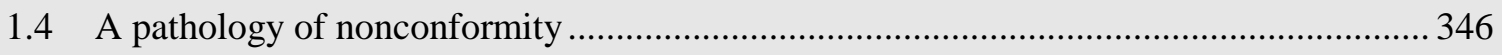

1.4.1 Results: Structural dilemmas drive cluster nonconformity ....................................... 346

1.4.2 Discussion: The challenge of trying to be conform to national cluster policy rules .. 348

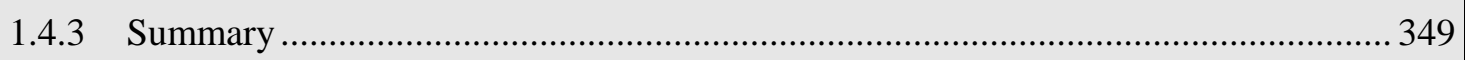

2 Existence beyond difficulties: an organisation of hypocrisy?...............................349

3 Enriching the "management model" of cluster policy evaluations...........................352 


\section{The identification of HCPR's four side-effect pathologies}

In this first section of our discussion, we will now discuss the answers to our first two research questions:

- RQ 1: What are the organisational dilemmas that can be observed in the implementation of the French cluster policy (the case of HCPR)?

- RQ 2: To which extend do these organisational dilemmas generate side-effect pathologies?

Chapter 7 and 8 allowed us to observe several pathologies that are driven by organisational dilemmas. Through the triangulation of different observed situations, we can distinguish four main pathologies, each driven by various dilemmas that HCPR faces. The four main pathologies are: pathology of inefficiency, pathology of distrust, pathology of nonconformity, and pathology of pragmatism.

\subsection{A pathology of inefficiency}

We first summarize the "pathology of inefficiency" results of our fieldwork and then discuss the results in the light of the literature.

\subsubsection{Results: Leadership dilemma contribute to cluster inefficiency}

A main driver for HCPR's inefficiency is the dilemma that no clear leader exists in the association (who is in charge within HCPR? - dilemma MD\#1a). On the one hand, HCPR tries to take into consideration the different opinions of its members and to have an egalitarian approach in the decision making process, but on the other hand the decision process is slow and the operational team has no authority to advance at its rhythm and with its animation priorities. According to an operational team member HCPR's structure is like a "4dimensional matrix", as too many different entities claim to be in charge of the direction that the policy-driven cluster should take (for example executive office, operational team, steering committees, etc.).

This complex leadership situation was for example visible in our data through: the complex organisational set-up (see Figure 39) for the a visual summary organisational set-up of HCPR); the political agendas that hindered the mapping publication; the cooperation and 
knowledge exchange problems between the animation \& development team and the R\&D team; or the conflicts between the executive office and the operational team regarding the content of the proposed services. This last conflict finally lead to the abandoning of some services because the executive office wanted the members to be represented in these services and not the wider ecosystem as wished by the operational team (the organisational boundary is not clear - dilemma PD\#1b). A recurrent theme is thus an operational team that goes in one direction, and an executive office that goes in another direction, consuming a considerable amount of time and resources.

No clear leader also exists among the different policy-driven clusters that try to set up intercluster collaboration projects (who is in charge among the different regional policy-driven clusters? - dilemma MD\#1a). As we have seen, the government has motivated the different regional policy-driven clusters to set up inter-cluster collaboration initiatives to foster interdisciplinary innovations. The three regional policy-driven clusters only manage to cooperate during the event-planning phase but do not manage to cooperate during the project evaluation phase. Homogenizing the different evaluation and labelling rules would have been too time consuming. However, this lead to the situation that HCPR was not able to judge the value of the submitted projects because their knowledge on ICT is limited, which again creates a form of inefficiency. This also raises the question of the best organisational boundaries for policydriven clusters (thematic vs. regional entity? - dilemma PD\#1b).

However, these leadership issues are not only visible within HCPR, and among policy-driven clusters of the Region, but also between HCPR and the government (who is in charge between HCPR and the government? - dilemma MD\#1a). The government imposed on the policy-driven clusters to launch inter-cluster collaboration initiatives during the $2^{\text {nd }}$ policy phase to foster diversity and thus innovation. Even though HCPR submitted itself to the rules, integrated an inter-cluster collaboration objective in its performance contract and started to collaborate with Cap Digital and Systematic, the ICT \& Health events were never a research priority for the executive office. The e-health objective of HCPR's performance contract was for example the only technological R\&D objective that was not explained in detail (absence of a definition of concrete actors, activities or deliverables) and the HCPR's evaluation team had considerable difficulties to judge ICT \& Health projects. While Cap Digital managed to transform a well-meant policy-description into an intrinsic motivation, HCPR failed to do so (intrinsic motivation vs. policy description - dilemma PD\#3b). This policy description thus 
generated inefficiency for HCPR (not for Cap Digital) because HCPR's resources were not used according to the priorities of the association.

Another element that the government expects from policy-driven clusters is to organise events so that the local ecosystem can get to know each other and start collaborating. However, our data has shown that project leaders learn and that they use the events organised by the policydriven clusters particularly in the beginning when they are new to the community. Once they are established in the policy-driven cluster community, the utility of policy-driven cluster events (or "Meetic" events) for finding project partners is strongly reduced. Companies then know the community and can call their acquaintances or use "telephone fishing" to set-up their collaborative R\&D projects. They only need somebody that knows the right person and that can put them together efficiently via phone or e-mail. The collaborative R\&D projects are constructed like "Las Vegas" weddings, so an in-depth knowledge of the project partners is not necessary. The project leaders prefer participating in a wide range of different events and communities to be "on the radar" of a maximum of people. This result might be tempered by the specificities of the HCPR case, a cluster that is particularly related to the Paris Region, where plenty of events are constantly organised by different support structures (degree of urbanisation - dilemma SD\#3b). So even though the government expects from policy-driven clusters to constantly organise events, little by little the investigated policy-driven clusters realized that they have to constantly innovate and change the format of events otherwise nobody participates, particularly in the Paris Region. The question is thus if organising events, just for the sake of organising events to comply with the government's policy expectations is really necessary, or if this just fosters inefficiency? (who is in charge between HCPR and the government? - dilemma MD\#1a; learning capacity vs. administrative straightjacket - dilemma MD\#1b).

Finally, French cluster policy leadership issues are not only visible within HCPR, among regional policy-driven clusters, between HCPR and the government, but also among the different ministries (who is in charge among the different ministries? - dilemma MD\#1a). In the context section, we discussed the set-up process of the French cluster policy and we have seen that conflicting opinions exist between the different ministries (research, industry, and regional development) regarding the objectives of the policy (industrial excellence vs. regional development - dilemma PD\#3a), but also between the different regional authorities regarding the geographical boundaries of the policy-driven clusters (geographical boundary 
- dilemma PD\#1a). The cluster policy set-up already created several dilemmas that pushed the policy to be somehow blurry and ill-defined, as well as situated on geographical entities that might not be the most efficient ones.

Figure 39: Zoom on the multiple actors of HCPR governance level

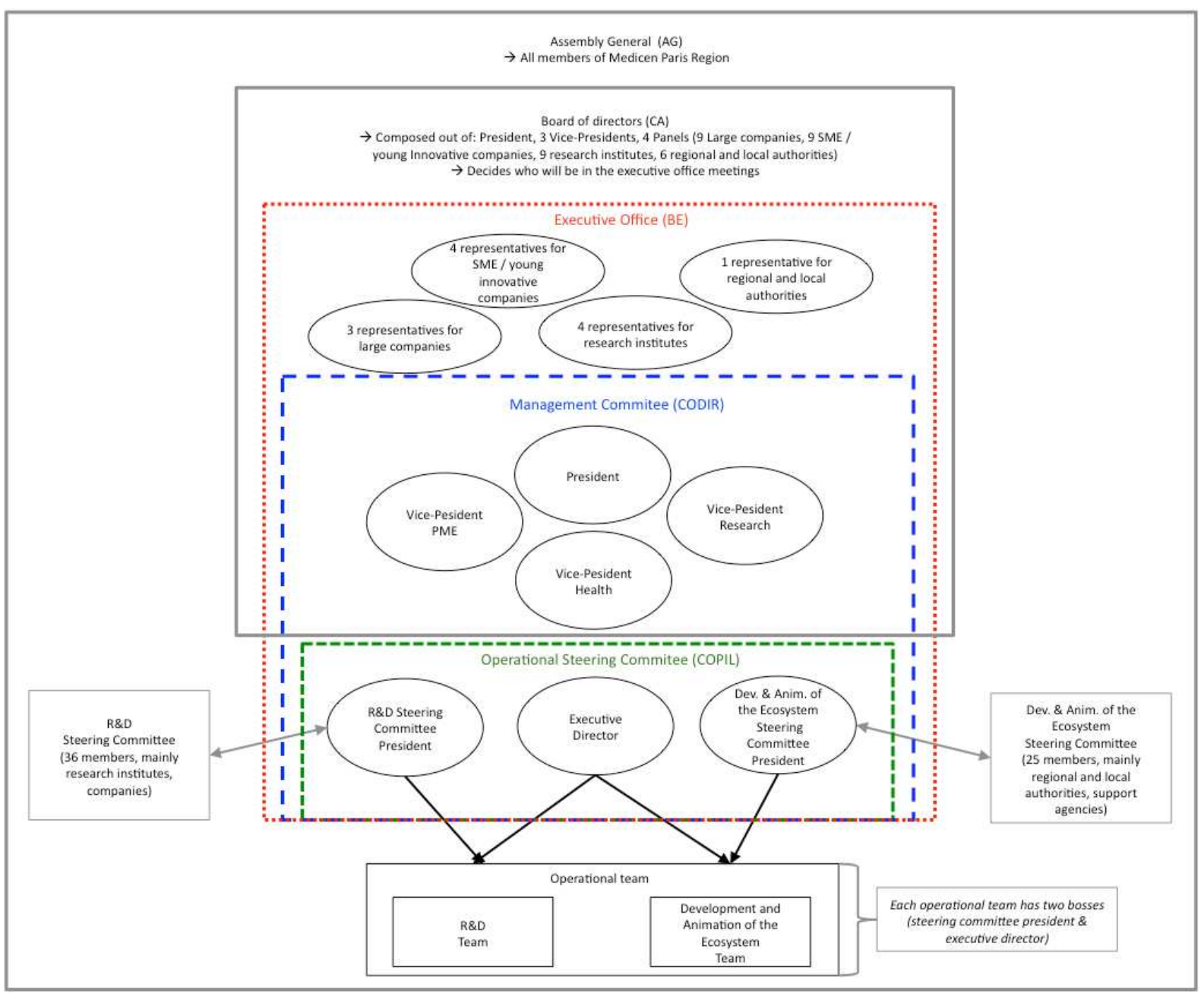

\subsubsection{Discussion: No civic entrepreneur, no external challenge, unitary country}

The French cluster policy, and HCPR in particular, is situated at the intersection of different objectives and wishes that impact HCPR's effective functioning. Leadership issues emerge within HCPR, among regional policy-driven clusters, between HCPR and the government, and among the different ministries regarding the content of the cluster policy. All of these leadership issues create inefficiency. The literature underlines that leadership issues for policy-driven clusters are frequent, as the implementation of cluster policies is very complex. All involved actors have their "own raison d'être, culture, and spatial scale of operation" (MacNeill \& Steiner, 2010, p. 444). In order to overcome this complex situation, the literature 
recommends to appoint one driving cluster force, or civic entrepreneur (Lundequist \& Power, 2002). However, this is not the case in HCPR. HCPR has several leaders for example a president, a managing director, steering committee presidents, one operational team but also a highly involved national and regional government. All of these actors wish to pull the policydriven cluster in a different direction. HCPR does not have one "civic entrepreneur" that clearly decides upon the direction that should be taken and that is then implemented.

The literature shows that the policy-driven clusters in for example Styria (Austria) (MacNeill \& Steiner, 2010) or Bavaria (Germany) (S. Menu, 2012) managed to appoint one driving cluster force, but that this was not the case in policy-driven clusters in Brittany (France) (S. Menu, 2012) and in the West Midlands (UK) (Burfitt \& Macneill, 2008). Our results of the analysis of a policy-driven cluster in the Paris Region (France) point thus in the same direction as the results of Menu (2012) and Burfitt \& Macneill (2008). Menu (2012) and Burfitt \& Macneill (2008) both concluded that leadership of the policy-driven clusters they analysed is weak because of the limited autonomy national governments give to the policydriven clusters. Menu (2012) for example criticizes that everything depends on a central authority. Menu (2012) recommends thus regional umbrella structures such as in Bavaria to overcome the central guidelines and to adapt the policy better to the regional circumstances. In the case of HCPR, the creation of a regional umbrella structure for the Paris Region could have contributed to solve several leadership problems as well:

- First, a regional policy-driven cluster umbrella structure would have solved the ICT \& Health problem and the difficulty to establish a common evaluation team.

- Second, a regional policy-driven cluster umbrella structure might also be more alerted to the specificity of the Paris Region, particularly regarding the high amount of initiatives and events that are organised in the region. The Paris Region policy-driven clusters struggle to keep a high participation rate in their events because too many different events take place at the same time. We even question the usefulness of organising even more events instead of trying to make the already existing ones more visible.

- Third, a regional policy-driven cluster umbrella structure would have also helped to solve the conflict between the operational team and the executive team regarding who should profit from the services developed by HCPR: the members or the regional ecosystem. 
The central guidelines keep HCPR also in a so-called "administrative straightjacket" (Ebbekink \& Lagendijk, 2013). In the case of HCPR this "administrative straightjacket" is particularly visible through the performance contract and the obligation to start inter-cluster collaboration projects, even though HCPR shows little interest in e-health. Ebbekink \& Lagendijk (2013) recommend to have a "collective strategy-building” attitute in order to break out of this "administrative straightjacket" and to establish "an on-going, informal strategic dialogue between "all" cluster stakeholders" which will collectively allow to learn and create action (2013, p. 738). Also MacNeill \& Steiner (2010) recommend a "'postmodern' participative management style" to efficiently manage policy-driven clusters. However, this seems quite utopian and difficult to realize in a policy system like France, that is traditionally organised in a centralist manner and where many different stakeholders (from national to regional level) are involved.

This raises the question of the role of a country's political system ${ }^{291}$ on the leadership style of policy-driven clusters, and if it is possible to establish a "participative management style" system for policy-driven clusters where the national government is highly involved. The interesting fact is that, Menu (2012) and Burfitt \& Macneill (2008) both conducted their research in centralist countries (France and UK respectively) and concluded that the regional policy-driven cluster has "limited autonomy with regard to national government" (Burfitt, et al., 2007, p. 1288). However, the analyses of policy-driven clusters in Bavaria (Germany) (S. Menu, 2012) and Styria (Austria) (MacNeill \& Steiner, 2010) do not show this pathology; both countries are federal countries. In unitary countries "central government is still a significant source of funding for regional development" (OECD, 2010, p. 20)) and thus the decision centre and distance between the central state organ and the actual policy-driven clusters in the regions is longer. Cluster policies, that per se try to foster locally and regionally anchored networks, seem to be particularly pulled apart between regional and national objectives when implemented in unitary countries. Also Salazar \& Holbrook (2007) and Cammett (2007) underline that differences between unitary and federal countries exists and that policies should be adopted accordingly. However, to our knowledge, no targeted research exists on the exact challenges of implementing cluster policies in unitary countries compared to federal countries. The inefficiency of HCPR cannot be exclusively explained because of the fact that it is situated in a unitary country; otherwise Cap Digital would show the same

\footnotetext{
${ }^{291}$ see following report for a discussion of regional policies in different OECD countries (OECD, 2010)
} 
negative results, which is not the case. It is actually the combination of different leadership issues. We have identified four different leadership conflicts that exist in policy-driven clusters and cluster policies more generally and that generate inefficiency:

\subsubsection{Leadership dilemma within the cluster's governance structure}

There exists a leadership issue within HCPR's governance structure, we explained this leadership issue with the absence of a clear "civic entrepreneur", as defined by Lundequist \& Power (2002). This leadership issue is a particular strong problem for HCPR and is also visible in the high turnover of HCPR's presidents and CEOs (see Annex 17). One explanation why HCPR has difficulties to decide upon a "civic entrepreneur" is the absence of a real external "challenger". Our interviews have shown that the operational team is struggling with all the "political agendas" of the highly prestigious research institutes and companies that are situated in the Region. All these entities know that they are situated in one of the most dynamic regions of the world and that they are doing excellent research in the medical domain. They already existed before HCPR was founded and they will also continue to exist in case HCPR dies one day. An external challenger that holds all these entities together and that creates "shared vision" (Himmelman, 2002) is missing. Both regional role models of the 1980s had an external challenger they wanted to surpass: for Silicon Valley the external challenger was Route 128 (Saxenian, 1994) and for Emilia-Romagna the external challenger was the First Italy (Capecchi, 1990). From an organizational theory point of view the "readiness" of organizational members is very important (Armenakis, et al., 1993). Readiness is defined as "the cognitive precursor to the behaviours of either resistance to, or support for, a change effort" (Armenakis, et al., 1993, pp. 681-682). In a policy-driven cluster context, such as in most organisational contexts, policy-driven cluster managers often need to influence their organizational members' "beliefs, attitudes, and intentions regarding the extent to which changes are needed and the organization's capacity to successfully make those changes" (Armenakis, et al., 1993, p. 681). Applied to the Emilia-Romagna Region, we could say that the ruling parties have successfully managed to influence the population's readiness. However, we found no evidence that this is the case for HCPR and it might actually be never the case. To this extent, a civic entrepreneur might thus stay absent. 


\subsubsection{Leadership dilemma among regional policy-driven clusters}

We explained this leadership issue with the absence of a regional umbrella organisations as also already advocated by Menu (2012) for the Brittany region. This would also go in the direction of abandoning maybe cluster policies all together and to focus on an “agglomeration policy” as advocated by Nathan \& Overman (2013, p. 397).

\subsubsection{Leadership dilemma between the cluster and the national government}

We think that this is a leadership issue that is particularly present in unitary countries that try to implement cluster policies (Burfitt, et al., 2007; S. Menu, 2012), but literature on this topic is nearly completely absent and further research is necessary. In the context chapter we asked the question if the French cluster policy is more a top-down or a bottom-up initiative (Fromhold-Eisebith \& Eisebith, 2005). Some argue that the French policy-driven clusters are bottom-up clusters (Fontagné, et al., 2013; Lallemand, 2013), others argue that they are topdown clusters (Berthinier-Poncet, 2012; Gallié, et al., 2013b). The question seems to be more complicated than that, particularly in a unitary country where leadership issues exists between the policy-driven cluster and the national government. Even if regional actors started the initiative (so theoretically a bottom-up initiative), the leadership challenges between the policy-driven cluster and the national government continue to exist. A bottom-up cluster in a federal country does not have the same challenges as a bottom-up cluster in a unitary country.

\subsubsection{Leadership dilemma among the different ministries}

Several authors already discussed that leadership issues in cluster policies emerge because several different ministries try to pull the policy in their direction (Sternberg, et al., 2010; T. Weil \& Fen Chong, 2008; Younès, 2011). However, even though the general cluster policy might be vaguely defined in the beginning and the objectives blurry, this does not seem to impact the policy-driven cluster itself. The analysis of HCPR has shown that this leadership issue at the ministry level is somehow too distant to have a direct impact on the policy-driven cluster. Moreover, the cluster organization has anyhow to "re-intepret" the general objectives in concrete and enunciable management objectives.

\subsubsection{Summary}

Leadership issues in policy-driven clusters drive inefficiency. We identified four sources of leadership dilemmas that drive inefficiency in HCPR: leadership dilemmas within the policy- 
driven cluster's governance structure, among regional policy-driven clusters, between the policy-driven cluster and the national government, and finally among the different ministries (which though has the least direct impact on HCPR). The leadership dilemma within HCPR's governance structure is particularly visible and impact's its performance. No "civic entrepreneur" exists that holds the cluster together and that has identified an external challenge to overcome. On the one hand HCPR wishes to be egalitarian by finding consensus among its very "political" members, on the other hand this situation paralyses all decision processes.

\subsection{A pathology of distrust}

We first summarize the "pathology of distrust" results of our fieldwork and then discuss the results in the light of the literature.

\subsubsection{Results: Subsidies dilemma (also) drives cluster distrust}

A main driver of distrust between HCPR and its members is the dilemma of the subsidies type (direct vs. indirect subsidies - dilemma PD\#2a). The French policy-driven clusters are structured around R\&D project subsides (direct subsidies) and the policy-driven clusters are responsible for labelling the best projects that can then, in a second step, be submitted to a national financing fund. The policy-driven cluster only has a labelling authority and no subsidising authority. Through financing $R \& D$ projects in policy-driven clusters, the government wishes to create a strong local network of actors who know each other and who innovate together. The positive impact of collaborative R\&D projects has been shown in our data: project leaders often find new ideas thanks to partners they have met in collaborative R\&D projects. However, this good intention also generates a side effect: distrust between HCPR and its members. HCPR seems to be torn apart between its role to be a friend for the project leaders (who helps the project leaders with the R\&D project set-up) and its role to be a judge for the submitted R\&D projects. According to the project leaders, this friend/judge role generates a schizophrenic situation.

In Figure 40 we tried to schematize the different conflict zones that are generated because of this subsidies dilemma:

- The zone between the project consortium and the scientific committee, because the project leader considers that the scientific committee is biased, and that it only pushes 
for its own private objectives, refuses projects that might come into their way and is not giving all the projects the same chance.

- The zone between the project consortium and the operational team, because the project leader does not understand the negative outcome of the labelling process. This creates frustration among the operational team and the project consortium. On the governance level we have seen that policy-driven cluster managers have difficulties in managing the negative and aggressive feedback they receive from project leaders once their projects were rejected.

- The zone between the scientific committee and the executive committee, because the executive committee considers that the project has to be labelled and so outruns the decisions previously taken by the scientific committee. In the end, project leaders think that lobbying can overrule the "objective" decisions taken by the evaluation committee, which creates frustration among those that are not yet highly integrated in the policy-driven cluster community.

- The zone between the subsidies level and the project consortium, because the project leader does not understand why his/her project was praised by HCPR but was then refused on the national level.

- Finally, the zone between the national level and the policy-driven cluster, because no clear explanations are given to HCPR as to why a project was eventually refused. 
Figure 40: Trust is challenged when looking at the collaborative R\&D project level

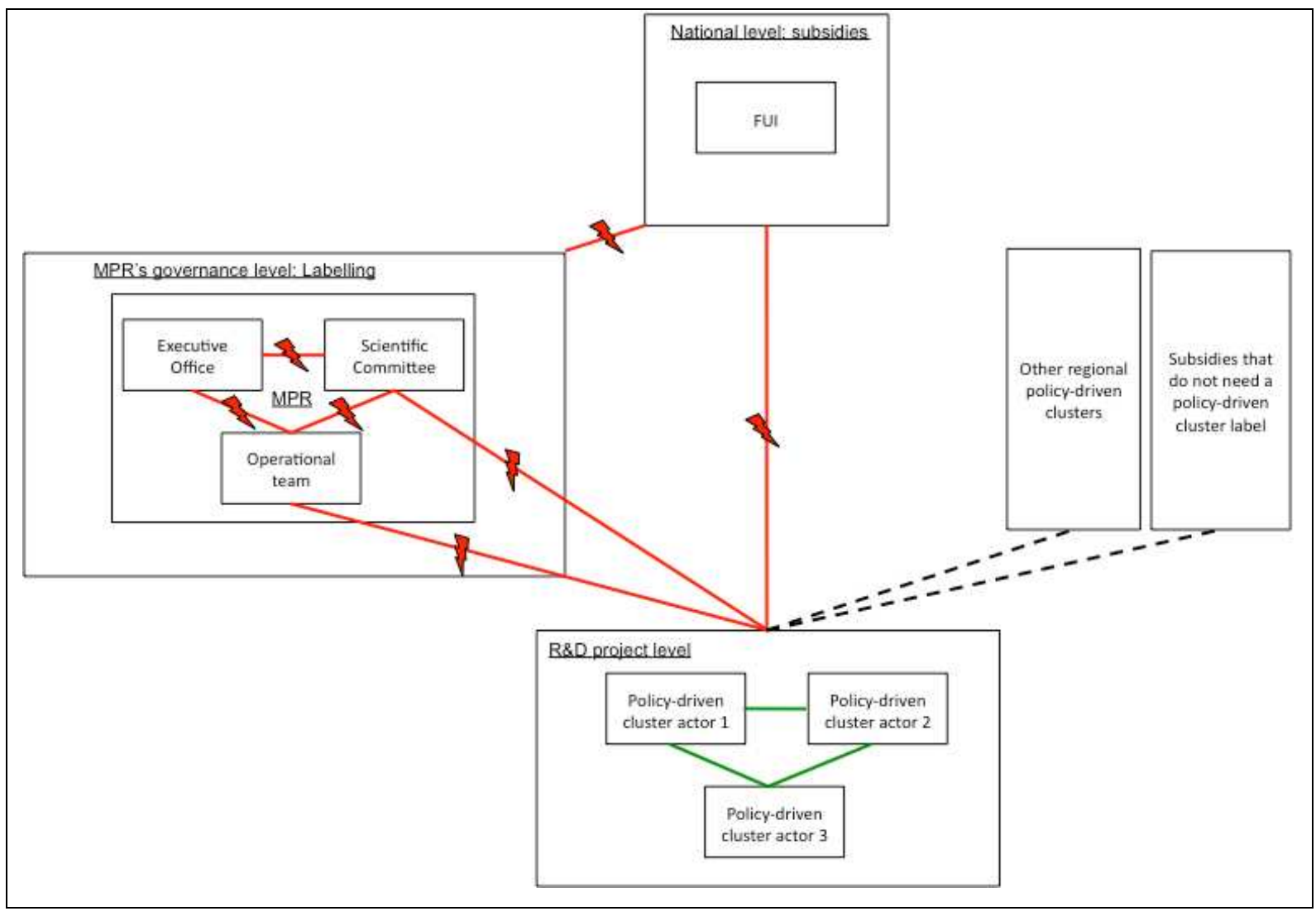

Our examples have shown that if a project is rejected and does not receive a cluster label, this rejection can highly frustrate the project leader (but also HCPR's operational team) and push the project leader away from the policy-driven cluster. In other words, our data show that the project leader may have the tendency to turn away from HCPR and contact another policydriven clusters in the region or stop passing through policy-driven clusters at all, privileging other sources of subsidies not related to policy-driven clusters. Additionally, delegating one part of the direct subsidies' decision to the policy-driven clusters also generates a lot of lobbying activities in and around policy-driven clusters. These lobbying activities are critical seen by some project leaders, because they think that too much effort is needed to submit a project to the policy-driven clusters. This reluctance is intensified because of rumours that for example thanks to lobbying an executive office retrospectively "labels" a project that was not labelled initially. The direct subsidies thus create lobbying behaviour which intensifies the distrust that a project leader might have regarding a policy-driven cluster. The consequence is reluctance to get integrated in the policy-driven cluster community. 


\subsubsection{Discussion: Theoretical "trust facilitator" struggles with trust issues}

A considerable amount of literature exists that investigates and underlines the importance of trust among different actors (e.g. between companies, between companies and universities) located in clusters (Cooke, 1996; Cooke \& Wills, 1999; MacKinnon, et al., 2004; McEvily \& Zaheer, 2004; Mesquita, 2007; Murphy, 2006; Ottati, 1994). A multitude of definitions exists for trust. We will refer to Sabel's (Charles F Sabel, 1993, p. 1133) definition that is often used in the cluster context (Cooke, 1996). According to Sabel (1993, p. 1133), trust is "the mutual confidence that no party to an exchange will exploit the other's vulnerability". The cluster literature emphasises that trust is a crucial element that needs to be created and fostered to improve the knowledge exchange processes between the local actors and to increase the local actor's innovation capacity. However, trust is not only difficult to conceptualise but also difficult to create in "economic space" (Murphy, 2006). A particular role is thus always given to the organisations and managers that are animating the policy-driven clusters. For example, Mesquita (2007) discusses the important role of "trust facilitators" that need to create bridges between normally competing local actors. Also Cooke (1996) or Colletti (2010) allocate a central role to the skills of these cluster or network managers in order to create a "relational glue" (Powell, 1998; Smith-Doerr \& Powell, 2005) between the local actors. The cluster literature focuses on the conflict zone that may exist between economic actors situated in the cluster and the role cluster managers can play to help smoothing this relationship (see Figure 41 for a visual representation of the above situation).

During HCPR's performance contract signature event, HCPR's president announced in his speech that one of HCPR's objectives during the second policy phase would be to "create a cluster spirit and trust between its actors". This discourse uses the official cluster vocabulary also found in the literature. Officially HCPR sees itself as a "trust facilitator", as defined by Mesquita (2007), for the health and medical actors of the Paris Region. However, our observations show that the "trust facilitator" role is challenged. Instead of "just" facilitating trust within the region, the policy-driven cluster managers of HCPR struggle themselves with trust issues (see Figure 41). 
Figure 41: Focus of the cluster literature regarding trust and literature gap

\begin{tabular}{|l|l|l|}
\hline Cluster literature's focus regarding trust & Cluster literature's gap regarding trust \\
\hline $\begin{array}{c}\text { Policy-driven } \\
\text { cluster } \\
\text { manager }\end{array}$ & $\begin{array}{c}\text { Policy-driven } \\
\text { cluster } \\
\text { manager }\end{array}$ \\
\hline $\begin{array}{c}\text { Policy-driven } \\
\text { cluster actor 1 }\end{array}$ & $\begin{array}{c}\text { Policy-driven } \\
\text { cluster actor 2 }\end{array}$ & $\begin{array}{c}\text { Policy-driven } \\
\text { Policy-driven } \\
\text { cluster actor 1 } 1\end{array}$ \\
\hline
\end{tabular}

But what triggers this pathology? The objective of cluster policies is to transform agglomerations into functioning clusters and to find incentives that go in this direction (Chiaroni \& Chiesa, 2006; Mans, et al., 2008; Schmiedeberg, 2010). In some countries (for example France and Japan) one popular method to foster the clustering process between local actors is the use of direct R\&D subsidies (Gallié, et al., 2013b; Kitagawa, 2005; Nishimura \& Okamuro, 2011b). At some point the French government was in front of this subsidies dilemma: putting most of the money into direct subsidies or indirect subsidies. The choice of the French government was to mainly focus on direct subsidies.

The current literature that deals with subsidies and policy-driven clusters focus on two sideeffect pathologies: complexity of the support structure driving inefficiency, and risk aversion of the government driving pragmatic behaviour. The literature generally focuses on criticising the complexity of the support structure or the "bureaucratic" nature support structures can build up and which compromises the dynamism of the regional endeavour (Burfitt \& Macneill, 2008; Enright, 2003; Erdyn, et al., 2012; Guisard, et al., 2010; Lallemand, 2013). We identified one study that goes a little bit further than just discussing the complexity of the cluster policy support system. Nishimura \& Okamuro (2011b) conducted a study on Japanese cluster policies and they identified that direct subsidies (i.e. support for R\&D consortia, R\&D subsidies) might lead to less success than the indirect help (i.e. networking/coordination supports) provided by the government. They mainly argue that direct subsidies in cluster policies lead governments to adopt a risk aversion attitude, mainly financing projects that are already born for success and ignoring the more challenging and thus maybe more radical innovation projects. Our fieldwork allows observing in detail and very close to the ground which type of effects these direct subsidies generate on HCPR. We first discuss our data in 
relation to the two side-effect pathologies related to subsidies and already identified in the literature: complexity and risk aversion. Finally, we turn to the additional side-effect pathology that we identified: "distrust".

\subsubsection{Subsidies dilemma drives inefficiency (complexity of support structure)}

Complexity of the support-structure is often criticised to be a bureaucratic burden for policydriven clusters (Burfitt \& Macneill, 2008; Enright, 2003), which drives inefficiency. On the one hand, our interviewed project leaders are generally real specialists in how to obtain and apply for European and French subsidies. They seem not to be frightened by the high number of support structures. It is their daily job to win subsidies calls for their respective companies and they value the large variety of support structures that exist in the Paris Region. This empirical result goes along with the arguments of Fixari \& Pallez (2014) that complexity always depends on the eye of the beholder. The subsidies system for an outsider seems difficult, but an insider finds its way along and is happy that such a variety exists. However, on the other hand, the project leaders do heavily criticise the complicated nature of the R\&D zones attached to the policy-driven cluster subsidy (the FUI). These R\&D zones create inefficiency. The benefits for companies to build networks with non-local companies are intensively discussed in the literature (Cumbers, et al., 2003; Huggins \& Johnston, 2009; Mans, et al., 2008; Martinez, et al., 2012; McDonald, et al., 2007; Nishimura \& Okamuro, 2011a). However, another body of cluster literature treats the advantages of face-to-face interactions within territories (Gertler, 1995, 2003; Lawson \& Lorenz, 1999; Maskell \& Malmberg, 1999; Storper, 1995; Storper \& Venables, 2004). The underlying assumption is that through face-to-face interactions, people can more easily transfer tacit knowledge (Nonaka, 1991; Polanyi, 1966). The direct subsidies implemented by the French government try to generate face-to-face contact within a defined territory, but again the good intention creates administrative burdens for the companies for whom collaborating only with local actors does not make any sense.

During our interviews, project leaders underlined that indeed face-to-face contact is important in order to get a project going, but it is not necessary that all project partners are located in the same region. Project consortiums do not look for the nearest company to build up a project but look for the most competent national or international company. This result goes along with the results of other authors (Rallet \& Torre, 2005; Torre, 2008), that already underlined that different types of proximity exists and that permanent geographical proximity is not the only type of proximity that counts. We also identified that project leaders are like free 
electrons in their respective organisations, so it is very easy for them to go to a variety of "temporary clusters", as defined by Maskell et al. (2006), to identify new project partners. Geographically bound R\&D subsidies though create a strong administrative burden for project leaders as they try to get the project labelled by several policy-driven clusters in case the project partners are spread out over the whole territory. Since our fieldwork period, the French national authorities have granted policy-driven clusters the possibility to extend their R\&D zones. However, this only means that the geographical boundary dilemma continues to persist, only on another scale. The dilemma of the geographical boundary of a policy-driven cluster is not solved by this measure. To overcome this "subsidy" and related "geographical" problem, a proper agglomeration policy, as advocated by Nathan \& Overman (2013), which would be independent from financial R\&D subsidies, could appear as a better solution.

\subsubsection{Subsidies dilemma favour low-risk projects (risk-aversion of cluster org.)}

Nishimura \& Okamuro (2011b) criticised that direct subsides in policy driven clusters might lead to less success than the indirect help a government can provide by financing policydriven cluster support structures. They mainly argue that direct subsidies in cluster policies lead governments to adopt a risk aversion attitude, mainly financing projects that are born for success. Our results also point in this direction. The Parisian policy-driven clusters are in competition to each other, one indicator used to compare the quality of their work is their transformation rate (labelled projects to financed projects). We have seen as well that it can happen that a policy-driven cluster labels a project but then, during a second submission, does not label the project again. Even though the project idea might appear good, the knowledge that the national authorities will not finance a project prevents the cluster organisation to label it. This raises the question if new radical innovations are able to emerge in policy-driven clusters that face a direct subsidies dilemma. For the government, the advantage of integrating the cluster organisations in the labelling process is to have the experts of a certain field already reunited, but the disadvantage of this process is that the ones that evaluate and label the projects, are themselves evaluated by the state. One project leader perfectly summarized the dilemma: "Policy-driven clusters are organisms that have to live as well".

\subsubsection{Subsidies dilemma drives distrust (policy-driven cluster involved in subsidies)}

Our fieldwork also shows that there exists a third side-effect pathology regarding direct subsidies: distrust. Even though the complexity issue and the risk-aversion issue is treated in 
the cluster policy literature, to our knowledge the distrust issue is not yet fully discussed. One reason might be that it is a specifically French problem, and in the other countries the cluster policies are not directly involved in the labelling process of projects. However, this distrust issue was a central theme in our case study that needs more attention. As already said in the beginning of this sub-section, the cluster literature traditionally underlines the importance of trust so that a cluster can develop successfully, be it a spontaneous or policy-driven cluster (Cooke, 1996; Cooke \& Wills, 1999; MacKinnon, et al., 2004; McEvily \& Zaheer, 2004; Mesquita, 2007; Murphy, 2006; Ottati, 1994). However, the focus of this literature particularly lies on the problem of creating trust between the cluster actors and not on trust problems among those who should actually be the "trust facilitators". Our explorative case study has shown that several types of conflict zones can emerge in policy-driven clusters (see Figure 40 that graphically schematize these conflict zones) because of the direct subsidies labelling decision attached to the policy-driven cluster. These conflict zones create trust issues within the cluster organisation but also between the cluster organisation and the project consortiums and the wider cluster community. This has a negative impact on the development of the policy-driven cluster. Creating "relational glue" (Powell, 1998; Smith-Doerr \& Powell, 2005) in some policy-driven clusters, such as in our case study, seems particularly challenging. However "mutual confidence" (Charles F Sabel, 1993, p. 1133) is important in order to foster innovation. Not only the cluster literature underlines that trust is important for a cluster to develop (Cooke, 1996; Cooke \& Wills, 1999; MacKinnon, et al., 2004; McEvily \& Zaheer, 2004; Mesquita, 2007; Murphy, 2006; Ottati, 1994), also the innovation management literature underlines the importance of trust and positive group climate for creativity and research endeavours (Amabile, 1996, 1998; Bland \& Ruffin, 1992; Chawla \& Singh, 1998; La Porte, 1965; Ryan \& Hurley, 2007). Fostering innovation and being a judge at the same time seems to be a difficult endeavour, at least for HCPR.

We have to recall at this point, that processes leading to innovation are multi-fold. The management literature distinguishes different types of processes that lead to innovation: creativity, research, development and design (Swann, 2009). In order to generate breakthrough innovations all processes are important, but different environments have to be created for each of these processes. The literature for example distinguishes that an evaluation culture or monetary rewards are contra-productive in the creativity process (Amabile, 1996, 1998) but important in the development process (Cooper \& Kleinschmidt, 1995; Ernst, 2002). A recent study on French policy-driven clusters investigated the role of policy-driven clusters in the knowledge identification, acquisition and utilisation phase (Bocquet \& Mothe, 2010). 
Even though Bocquet \& Mothe (2010) do not directly address the role of labelling and direct subsidies for this endeavour, they do underline that the better performing policy-driven cluster under review is a policy-driven cluster that creates incentives, particularly non-financial incentives, for their members to interact.

The HCPR seems to be focus mainly on the labelling part without creating other incentives to participate in the cluster community for knowledge exchange. Our fieldwork shows that these direct subsidies impact the trust relationship between the R\&D consortiums and the theoretical "trust facilitators". The project leaders use the services of HCPR particularly during the subsidies finding phase and less during the partner finding or idea finding phases. During the subsidies finding phase HCPR plays a crucial role as it helps the actors to formalize their R\&D projects and to find the best corresponding subsidies. However, at some point the project leaders submit their projects for labelling to HCPR. This submission creates a "schizophrenic" situation, because HCPR passes from "being a friend to being a judge". In case the final result (be it on the labelling level or the subsidies level) of this submission is negative, distrust emerges.

\subsubsection{Summary}

Governments have to decide how to subsidies policy-driven clusters. They can either privilege indirect subsidies or direct subsidies. In our case study direct subsidies are the main modus operandi. Regional bound direct subsidies have the advantage that they "force" regional actors to get to know each other. However, direct subsidies also create negative sideeffect pathologies. For the time being HCPR struggles to create other types of incentives to participate in its ecosystem to counterbalance the negative side effects that are associated to direct subsidies. Direct subsidies create several pathologies like inefficiency due to the complexity of the support structure or low risk projects due to the risk-aversion of the policydriven cluster (or the government). But direct subsidies also create distrust. This is a side effect that can particularly impact the knowledge exchange capacity, the theoretically heart of every policy-driven cluster, particularly if the modus operandi mainly focuses on direct subsidies.

\subsection{A pathology of pragmatism}

We first summarize the "pathology of pragmatism" results of our fieldwork and then discuss the results in the light of the literature. 


\subsubsection{Results: Dilemma on innovation\&collaboration management drives pragmatism}

Project leaders are extremely active in a variety of different research communities, not only the policy-driven cluster community but also in other communities. Their objective is to maintain good relations with all of these communities. Once they are known they only participate occasionally in events to stay on the radar of the policy-driven cluster and the companies. The result of this is a diminishing number of participants in policy-driven cluster events. This was illustrated through the ICT \& Health events. In case the policy-driven cluster managers do not constantly innovate the concept of the event, the participation number drops.

There are two types of partners that project leaders are very keen on meeting: industrials and doctors. Both parties are necessary for ICT \& Health projects, but extremely difficult to get in contact with. Industrials are the "king of community" and extremely solicited, they don't need to participate in these events, but also doctors are quite difficult to grasp. The ICT \& Health workshops have shown that doctors would have been needed to develop new project ideas, but they were absent. Also the interviews with our project leaders confirmed the fact that doctors are difficult to grasp and that project leaders have to be really inventive in order to track them down. Events were they participate are extremely important. The reasons why doctors are absent of policy-driven cluster events seem different than for industrials.

First of all doctors are highly occupied and often place bound in their hospitals. This stays in strong contrast to the project leaders who are "free agents" that can easily participate in a range of events. Additionally, historically doctors seem to have a privileged relationship with universities and not directly with companies. Finally, once they are in contact with a project leader for a new project, they leave the subsidies lobbying part to the project leaders. As the ICT \& Health events are somehow associated to this lobbying domain doctors seem to stay out of these events.

However, two cases showed that this tendency might be turned around. Each time it was when the companies went to the hospitals. In one case it was the clinicians who invited the universities and companies to the hospital (without a policy-driven cluster involved) and in the other case it was one ICT \& Health event organised by the three Parisian clusters that moved for one occasion to a Research Institute of a Hospital. The event in the research institute of a hospital considerably increased the participation of clinicians as well. This 
exchange with the clinicians seems particularly important in the idea generation phase. Projects that were created out of this interaction seem particularly promising. However, for the time being HCPR seems to have difficulties to integrate doctors.

The different priorities in the performance contract are large, ranging from generating jobs over establishing contracts with other policy-driven clusters to mapping the region and organising meetings. This first impression of the performance contract already shows that dilemmas develop around how to actually reach the overall goal of fostering competitiveness in the region. Passing from the objectives like innovation and becoming the "highest concentration of expertise and healthcare resources in Europe", announced by HCPR's president during the performance contract signature, to concrete actions, that make this vision come true, seems to be a difficult task. In the performance contract, HCPR defines a large spectrum of actions, for example exchanges on knowledge, helping in financing, develop trainings, develop various partnerships. However, at the moment HCPR developed its new services, the executive office took the pragmatic decision that the most important for its members is to help them in concrete business issues (for example help in human resources, business development, financing, etc.), something that is of course advantageous for business development (de Géry, et al., 2013) or training (De Géry, 2010). The wish of the wider ecosystem to have also innovation services, for example hospital visits or other inter-sectoral cooperations, was rejected.

However, as innovation per se is the cornerstone of policy-driven clusters, the access to doctors difficult but a the same time the value of doctor interactions big, this raises the question if this pragmatism, which is certainly profitable for HCPR, is not hindering the development of the whole ecosystem ${ }^{292}$. (recently though (after our fieldwork), HCPR introduced Biomarker workshops to start improving the interaction with clinical staff).

One of the main dilemmas that emerge after this analysis is what type of innovation process HCPR wishes to foster (which stage of innovation? - dilemma MD\#2a) and which type of collaboration possibilities should be installed to allow this interaction to happen (how to foster collaboration - dilemma MD\#3a)? The interviewed project leaders, the ICT \& Health

\footnotetext{
${ }^{292}$ Our data show that none of the 19 investigated project ideas (and therefore the 30 administrative projects) can be particularly linked to one of the policy-driven clusters. Additionally, for only 4 projects a cluster organisation helped finding project partners. Most of the interactions between project leaders and policy-driven clusters took place during the finding subsidies phase but not through events organised by one of the policy-driven clusters.
} 
events were somehow not able to generate this fruitful interaction. The "Meetic" format of the organised events seems to be unadapted to involve the doctors, and keep the "free agents" on the ball. Doctors belong to a world the project leaders are not familiar with and so the challenge lies in finding events (all kinds of events) where these key partners participate. It is particularly important for the project leaders to meet the doctors in person, so physical spaces are important to exchange with these key actors. However, HCPR, at least for the ICT \& Health events, seems to have underestimated this challenge as doctors were highly absent and the cluster managers had difficulties to motivate them to attend. Additionally, we could ask if the lobbying activities and direct subsidies that are linked to the policy-driven clusters hinder a free development of ideas and attract only business driven SMEs instead of idea driven actors.

The Paris Region is a very dense region with a high number of competing events. In the performance contract, HCPR wrote that a challenge for the second cluster policy phase is to show the local ecosystem the added value of HCPR. Opening the doors to the "doctor" world, might be seen as a source of added value and competitive advantage, but it also inevitably raises the following question: for whom a policy-driven cluster is working? Is it mainly for its members who might know the "doctor" world, or rather for the wider ecosystem who might not know the doctor world (organisational boundary - dilemma PD\#1b)? Fostering collaboration is a difficult endeavour and for the time being HCPR seems to be draped in the pathology of pragmatism, focusing on the needs of its members and staying in a businessoriented approach. This fact, together with the associated distrust pathology, also lays the ground to push the innovation process of the policy-driven cluster in a certain direction: towards development and away from creativity.

The project leaders seem to be particularly attracted by the subsidies function of the policydriven cluster and less by finding new ideas. Our data showed that the idea generation process has always taken place outside HCPR's boundary. HCPR's operational team seems to be strongly business oriented and mainly focuses on the development and commercialisation process of innovation. This strong focus on the development process is visible through different observations:

- The main subsidy associated to the policy-driven clusters is the FUI. The FUI is concentrated on the development phase of innovation. 
- The types of events HCPR organises are situated at a very advanced stage of the project consortium formation process. At the ICT \& Health events the project consortium presents its project with the objective to attract maybe one additional missing project partner or to just lobby for its project. However, the idea finding process is already over.

- During these events, ICT \& Health managers privilege projects that are already well formulated, set-up and which have the potential to be submitted for labelling and financing in a very short period of time.

- The tasks of the different project consortium partners are well separated. The project leader does not necessarily know all the partners personally. Sometimes he has only talked by phone with a partner and all project consortium partners do not know each other. The project consortium is not a close group of people that tries to develop a ground-breaking innovation together. Once the project is financed, each project partner works on its defined task.

- The collaborative research projects need to integrate an industrial partner even though this seems quite difficult to do.

- HCPR has not further pursued services concentrated on innovation management but privileges economic development services for its members.

\subsubsection{Discussion: Doctors, a specie difficult to meet?}

The events and services that we were able to observe at HCPR are more oriented towards the development phase of innovation (Cooper \& Kleinschmidt, 1995; Ernst, 2002) than the creativity phase of innovation (Amabile, 1996; Amabile, et al., 1996). While this is of course an acceptable decision, several cluster policy authors underline the risk of clusters to lock themselves in into a certain innovation path (Agogué, 2012; Eklinder-Frick, et al., 2012; Hermans, et al., 2012; Visser, 2009). This leads to diminishing returns in the longue run (Visser, 2009). Some authors thus argue that the creativity of the members has to be stimulated actively (Agogué, 2012; Lefebvre, 2013) by dedicated workshops to motivate members to think out of the box. However, HCPR does little to organise dedicated innovation workshops and the proposed services were cancelled.

Additionally, a variety of "boundary objects" can foster knowledge exchange and potential collaborations between different partners: for example people (J. S. Brown \& Duguid, 1998; 
Lester \& Piore, 2006; McEvily \& Zaheer, 2004) or physical meeting places (Allen, 1977; Allen \& Henn, 2007; Morris, 2002; Nonaka \& Konno, 1998). In policy-driven clusters this role is particularly incarnated by the policy-driven cluster managers (Bellandi \& Caloffi, 2010a), by organised temporary clusters (Guisard, et al., 2010; Lefebvre, 2013; Maskell, et al., 2006) and sometimes also by permanent locations (Le Barzic \& Distinguin, 2010). Our case study showed that particularly policy-driven cluster managers (the operational team) and to a far lesser extent temporary clusters (e.g. ICT \& Health events) play a role in HCPR's ecosystem. However, no permanent location exists where cluster members can freely meet. As we have seen, HCPR's office was even that small, that no proper conference room existed, which lead to the externalisation of many meetings to scattered member locations. HCPR counts on its policy-driven cluster managers and temporary clusters to get their actors of their ecosystem connected. However, for the time being HCPR seems to have difficulties to integrate doctors, who are quite place bound in hospitals. Our hypothesis is that the current event format is not adapted to the needs of the clinicians. This would also mean that for the time being the HCPR has not yet been able to be the perfect translator (J. S. Brown \& Duguid, 1998) between the company and the medical world.

Finally, our data has shown Project leaders that wish to participate in the policy-driven cluster research community go through different phases (see Figure 42). When the project leaders are new to the community, they actively participate in different events, or so called temporary clusters (Maskell, et al., 2006), organised by the policy-driven cluster. However, in parallel, they also participate in a range of other events (e.g. events organised by the ministries, other associations, etc.). Already Cooke (1996) underlined that a lively ecosystem is necessary for regional innovation system to prosper, however for HCPR, that wishes to establish itself in the region as the key actor of the health care sector, this lively ecosystem also represents a danger. The policy-driven cluster events and parallel events allow the project leaders to get to know the different communities. However, this changes, once they know the community and the community knows them. Once this happens, the project leaders prefer contacting their acquaintances or the policy-driven cluster managers by phone instead of participating in events. This also confirms the research stream on proximity and that permanent geographical proximity is not the only type of proximity that counts (Rallet \& Torre, 2005; Torre, 2008).

Our data has also shown that most of the projects need several rounds of presentations and lobbying, labelling submissions and subsidies submissions before getting finally financed. 
During this itinerary, national but also international competitors that have enough financial capacity, can easily get started to develop the newly proposed ideas. A fear expressed by several project leaders. Guisard et al (2010) underline that one big problem of policy-driven clusters is the fear of speaking freely and share information during meetings. However, this problem seems to be even amplified, once the idea is finally formalised and starts the labelling and submission process.

Figure 42: R\&D consortium construction process

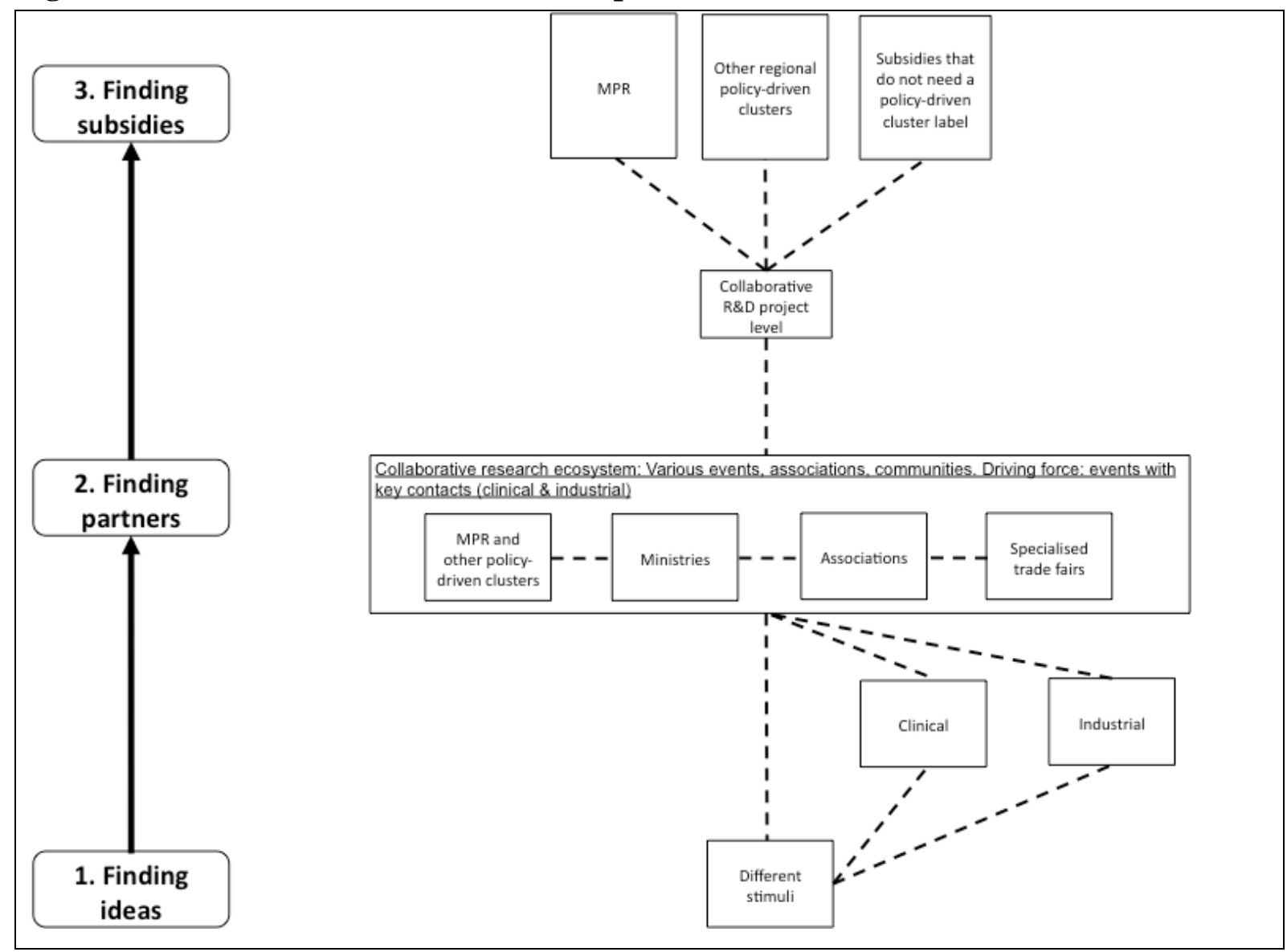

\subsubsection{Summary}

In this sub-section we have looked at the pathology of pragmatism. For the time being, HCPR proposes very pragmatic animation services mainly concentrated on fostering the business aspects of its members. However this raises the question if other opportunities (such as the links with doctors which are currently little explored) or potential dangers (such as the regional innovation lock-in) are not important to keep in mind and a purely pragmatic focus might be dangerous as well. 


\subsection{A pathology of nonconformity}

We first summarize the "pathology of nonconformity" results of our fieldwork and then discuss the results in the light of the literature.

\subsubsection{Results: Structural dilemmas drive cluster nonconformity}

HCPR has the advantage (and disadvantage) to be situated in the Paris Region, a highly dense urban agglomeration (degree of urbanisation - dilemma SD\#3b). On the one hand, the region has the highest concentration of hospitals in Europe and world-class research universities, institutes, and research parks. On the other hand, the region was already highly structured and dynamic before the cluster policy was launched. The degree of closeness but also potential hostilities between the local actors are already deeply anchored in the Region's DNA (degree of closeness between regional actors - dilemma SD\#2c). Additionally, also HCPR's DNA is different compared to other policy-driven clusters of the region. HCPR is more radical innovation oriented compared to Cap Digital or Systematic that are more incremental innovation oriented (type and sector of activity of policy-driven cluster actors - dilemma SD\#2b). This puts HCPR in a difficult position, regarding the added value it can bring to its members based on what is expected from it under a standardised cluster policy. There are two main structural dilemmas: the Region's DNA and HCPR's DNA.

\section{Region's DNA (degree of urbanisation - dilemma SD\#3b; degree of closeness between} regional actors - dilemma SD\#2c). The dilemma emerges between what is theoretically expected from a French policy-driven cluster and the local reality the policy-driven cluster is facing: on the one hand regarding the already existing support structures, and on the other hand regarding the already existing relationships between the members of the ecosystem.

- Existing support structure. HCPR announced in its performance contract that it wishes to become the "key health actor in the Paris Region" by harmonising the existing support structure. Somehow one could say that HCPR takes its cluster role at heart and wishes to become the central organ of the local ecosystem. During our observation period in HCPR we participated in the negotiations HCPR had with other support structures of the region to develop new services tailor-made for the medical sector. However, HCPR had difficulties to push forward its ideas because multitudes of support structures exist in the region that also already propose services for the medical sector. This puts HCPR in the delicate situation to defend its existence but at 
the same time comply with the policy demands. A one-shop system for the medical industry might be desirable, but at the same time the existing support structures will not stop offering their services. The life-cycle stage of the Paris Region cluster seems already well advanced which makes it challenging for a new entity to establish itself and to regroup existing offers. Again, the policy motivations that are behind the idea of regrouping existing offers are certainly good, but organisations are like human beings: they do not voluntarily decide to die. Pursuing such an ambitious objective is difficult in a highly urbanized location where existing support structures are deeply anchored.

- Existing relationships between the members of the ecosystem. Another important element concerns the already existing degree of closeness between the local actors at the start of the cluster policy. The operational team seems to face a particular challenge in a dense Region such as the Paris Region with a lot of prestigious institutions that at the same time have a lot of "political" diverging objectives. This was particularly visible during our observation period in the policy-driven cluster: how the operational team talked about all the different personalities of the ecosystem, but also how there was a constant battle about what should actually be done (see mapping discussion or services). All of the prestigious structures already existed before the establishment of HCPR and already had a certain manner to function next to each other and with each other. The operational team of HCPR now tries to put these different well-established structures around one table. The operational team seems to be powerless in front of this political complexity. Even though a cluster organisation should represent the wishes of its members, the prestigious nature of the members and the regional specificities create considerable side effects.

\section{HCPR's DNA (type and sector of activity of policy-driven cluster actors - dilemma}

SD\#2b). Besides these structural challenges of bringing members and other support structures around one table, HCPR is less interested, compared to Cap Digital for example, in working across thematic boarders (for example less interested in ICT \& Health, not interested in proposing new inter-cluster innovation services). This seems to be related to HCPR's sector of activity. Cap Digital managed to transform a well-meant policy-description into an intrinsic motivation, while HCPR failed to do so. The ICT companies, pursuing more applied research, seem to be better equipped to find new business opportunities across thematic boundaries than medical companies that pursue basic research. 


\subsubsection{Discussion: The challenge of trying to be conform to national cluster policy rules}

A large range of studies underline that cluster policies should be adapted to the local culture and circumstances (Ebbekink \& Lagendijk, 2013; Hospers, 2005; G.-J. Hospers \& S. Beugelsdijk, 2002; Martinez, et al., 2012; Santisteban, 2006). However, even though the policy-driven cluster literature discusses this topic in a constant manner, multiple case studies on policy-driven clusters show that governments continue to use a best practice approach (G.J. Hospers, et al., 2009), believing in a universal “cluster credo" (Ebbekink \& Lagendijk, 2013) without taking the local circumstances into account. Also in our case study, the difficult nature of HCPR's local structure has not been taken into account prior the launch of the policy, be it the prestigious institutes or the already existing medical support structure. There was no prior assessment, as for example recommended by Hospers \& Beugelsdijk (2002), to analyse the existing structure of the medical and health sector of the Paris Region, to understand the exact needs and challenges of the local actors, and then to adapt the policy accordingly. Starting a policy-driven cluster without really understanding the local structure bears several risks as some studies have already shown. Eklinder-Frick et al (2014, p. 10) for example observed that "despite the aim and effort to generate innovation, the network failed to do so" because the social structure of the local network has not been analysed enough in the beginning which hinders innovation initiatives to be correctly implemented. Also Ciravagna (2012), analysing Costa Rican ICT clusters, have shown that deeply rooted hostilities existed between local universities and the local private sector. They concluded that without addressing and talking about these "social obstacles", any kind of proposed help fails to carry its fruits (Ciravegna, 2012).

HCPR was the lowest rated policy-driven cluster in the Paris Region, during the first (2008) and second (2012) cluster policy evaluation (CMI \& BCG, 2008; Erdyn, et al., 2012). This means that HCPR, since the beginning, is the policy-driven cluster of the Paris Region that has most of the problems with complying with the national cluster policy objectives. One possible reason of HCPR's bad performance might be related to the nonconformity to the regional DNA, as just discussed. Another reason of HCPR's bad performance might be related to its type of actors and sector of activity. According to the literature, policy-driven clusters with a more analytical approach (radical innovation) for example need another type of support structure than policy-driven clusters with a more synthetic approach (incremental innovation) (Asheim \& Gertler, 2005; Coletti, 2010). If we look at the Paris Region clusters 
and particularly the ICT \& Health policy-driven clusters, HCPR's ecosystem is much different to the other policy-driven clusters. 50\% of HCPR's members are scientific research and development companies (NAF 72). No other policy-driven cluster in the Paris region has such a high percentage of NAF 72 members. HCPR has to find a common ground with companies, hospitals and researchers and tries to do basic research, something that seems more difficult to do than Cap Digital, that is very SME and incremental innovation centred. HCPR is also different compared to nearly all other French policy-driven clusters operating in the biotechnology / health sector (the average among the medical clusters, excluding Lyon Biopôle and HealthCluster, is 35\%). However, there is one exception: Lyon Biopôle. Lyon Biopôle has even more NAF 72 companies as members (58\%) and was rated as an excellent performing cluster during the 2012 evaluation (Erdyn, et al., 2012). In a future study it would thus be highly interesting to compare HCPR and Lyon Biopôle to get a deeper insight in how Lyon Biopôle manages this basic research endeavour under the common cluster policy in order to have such an excellent performance compared to HCPR.

\subsubsection{Summary}

According to the national cluster policy evaluations, HCPR's performance compared to other policy-driven clusters in the Paris Region is bad. However, our hypothesis is that this pathology of nonconformity could be solved by more closely looking at the region's DNA, be it the conflicts or closeness of actors of the region or the already existing support structures. In a certain manner, HCPR needs to find its added value with the local reality. This added value might lie at places it has not thought about yet, as for example opining the doors of the doctors to the wider ecosystem of the region.

\section{Existence beyond difficulties: an organisation of hypocrisy?}

When looking at the pitfalls experienced by HCPR, the multitude of organisational dilemmas and pathologies it faces, one could legitimately wonder why - and how - this organization still exists today. In fact, not only was HCPR quite poorly evaluated during the first and second official cluster evaluation compared to the other policy-driven clusters of the Paris Region (CMI \& BCG, 2008; Erdyn, et al., 2012), but also independent researchers judged HCPR's organisational quality as being much lower than in the Systematic cluster (Bonnafous-Boucher \& Saussois, 2010). Finally, our results also show that HCPR faces 
important pathologies such as inefficiency, distrust, non-conformity and pragmatism. In other words, HCPR seems to struggle to get going since now nearly 10 years.

However, instead of stopping this "hypocrisy", the French State continues financing HCPR. One theoretical concept that could be helpful in order to explain this phenomenon is the concept of “organization of hypocrisy” (Brunsson, 2002 (1989), 2007). Hypocrisy at a first glance has a negative connotation, but for Brunsson (2002 (1989), p. xi) an organisational theorist, hypocrisy is "a solution rather than a problem", particularly in political organizations. Political organisations, compared to action organisations, are organisations that are situated in environments where diverging opinions and values prevail.

Brunsson (2002 (1989)) identified that political organisations use three types of instruments for "winning legitimacy and support from the environment": talk, decisions and actions (products) (Brunsson, 2002 (1989), p. 27). When we look at action organizations, the three different instruments are consistent and in harmony with each other. Talks and decisions lead to certain actions, which then lead to an outcome (product). However, when looking at political organizations, the reality seems to be different and the three instruments "talk, decisions and actions" are not connected with each other in a logical manner: "hypocrisy is a fundamental type of behaviour in the political organization: to talk in a way that satisfies one demand, to decide in a way that satisfies another, and to supply products in a way that satisfies a third” (Brunsson, 2002 (1989), p. 27). HCPR and the French cluster policy more general can be interpreted with Brunsson's concept (see Table 46).

The French government evaluated for the first time all policy-driven clusters and their performances in 2008 (CMI \& BCG, 2008) and then a second time in 2012 (Erdyn, et al., 2012). This was done to justify the high investment and to take the necessary actions, theoretical to stop the policy, if needed. The decision was thus taken that the government ordered an evaluation. However, the actions were somehow not in coherence with the announced talk. The decision to extend the policy was already taken before the cluster evaluation was published (Gallié, et al., 2012).

Only after a two years period, some clusters were delabelled. For HCPR, a delabelling seems though nearly impossible. In both cluster evaluations HCPR was rated the lowest policydriven cluster in the Paris Region, but besides alerts, no consequences have followed. 
Somehow, it seems impossible to stop financing HCPR. Our hypothesis is the following: objectively, there is a high concentration of medical actors in the PR, a cluster exists and has a political value for the Paris region location. HCPR from a traditional geographical point of view can be considered as a cluster. The density of hospitals in the Paris Region is the highest in Europe ${ }^{293}$ and additionally one of the most renowned medical universities and research institutes are situated in the region. According to the typology of Markusen (1996), HCPR might have the greatest resemblance with the state-anchored industrial districts, where the local hospitals and universities are the core of the cluster. Having a medical cluster in the Paris Region brings international prestige and even though evaluations are conducted, and the policy-driven cluster functions badly, a delabelling might not be possible from a political point of view. This is different for policy-driven clusters that have been delabelled and that were situated in less prestigious regions and treating less prestigious sectors.

Besides this general reflection on HCPR's existence, we can also observe a more content "talk-decision-action" incoherence when digging into HCPR's functioning. The official cluster discourse is that innovation has to be created. We not only see it at the political level when the policy is defined, but also in the language and discourse employed by HCPR's president. On a political level, the decision is thus taken to launch policy-driven clusters to foster innovation and a collaborative R\&D project subsidy system is put in place. However, if we look at the concrete actions that are proposed by the policy-driven clusters we realise that little help is provided in actually fostering innovation. The policy-driven cluster focuses more on business services and feels the pressure to create jobs in the region. So besides the omnipresent discourse that "innovation" has to be fostered in policy-driven clusters, the real actions on the ground are much more business oriented (see for example the services proposed) than innovation oriented.

We think, that discussing HCPR's existence and content in the light of Brunsson's (2002 (1989)) "organization of hypocrisies" concept is particularly valuable to put things in a broader context. This allows thinking "out of the box" and to not miss-interpret hastily certain incomprehension why organisations continue to exist that look very instable. Such as Fixari \& Pallez (2014) who argue that the complexity of the system needs to be looked at from different angles, we also think that the incomprehension that we observed at HCPR have to be

\footnotetext{
${ }^{293}$ Source: http://www.paris-region.com/decouvrir-lile-de-france/des-filieres-economiques-dexcellence/sante-etsciences-du-vivant $(01 / 09 / 2014)$
} 
analysed from different angles. Even though the cluster is evaluated badly, having a labelled cluster appears to be crucial for the Paris Region. Due to the highly systemic nature of policydriven clusters, their might always be levels of conflict and diverging opinions, but at the end somehow this organisation of hypocrisy continue to function and to work because some people do take advantage of its existence.

Table 46: Interpretation of results in the spirit of Brunsson: talk, decision and actions

\begin{tabular}{|c|c|c|c|c|}
\hline & Talk & Decision & Actions & Interpretation \\
\hline $\begin{array}{l}\text { Cluster policy } \\
\text { evaluations }\end{array}$ & $\begin{array}{l}\text { Public } \\
\text { authorities } \\
\text { announce to } \\
\text { evaluate all } \\
\text { policy-driven } \\
\text { clusters and } \\
\text { their } \\
\text { performance, } \\
\text { to justify the } \\
\text { high } \\
\text { investment and } \\
\text { take the } \\
\text { necessary } \\
\text { actions if } \\
\text { needed }\end{array}$ & $\begin{array}{l}\text { Public authorities } \\
\text { ask private/public } \\
\text { organisations to } \\
\text { conduct a national } \\
\text { evaluation of all } \\
\text { policy-driven } \\
\text { clusters }\end{array}$ & $\begin{array}{l}\text { No: } \\
\text { - The decision to } \\
\text { continue the policy } \\
\text { was already taken } \\
\text { before the cluster } \\
\text { evaluation was } \\
\text { published. } \\
\text { - Critics regarding the } \\
\text { organisation of } \\
\text { HCPR, etc. but no } \\
\text { consequences } \\
\text { (already twice) }\end{array}$ & $\begin{array}{l}\text { It seems impossible to stop } \\
\text { financing HCPR because } \\
\text { objectively, there is a high } \\
\text { concentration of medical } \\
\text { actors in the PR, a cluster } \\
\text { exists and has a political } \\
\text { value for the Paris region } \\
\text { location }\end{array}$ \\
\hline $\begin{array}{l}\text { Cluster } \\
\text { objective: } \\
\text { Innovation vs. } \\
\text { Business }\end{array}$ & $\begin{array}{l}\text { Policy-driven } \\
\text { clusters will } \\
\text { foster } \\
\text { innovation }\end{array}$ & $\begin{array}{l}\text { Launch of a } \\
\text { policy-driven } \\
\text { cluster call, set up } \\
\text { of policy-driven } \\
\text { clusters, financing } \\
\text { of collaborative } \\
\text { R\&D projects }\end{array}$ & $\begin{array}{l}\text { No/(Yes): } \\
\text { Project ideas are } \\
\text { created outside of } \\
\text { HCPR's realm, } \\
\text { HCPR focuses on } \\
\text { business services and } \\
\text { not innovation } \\
\text { services per se }\end{array}$ & $\begin{array}{l}\text { Even though innovation is } \\
\text { always put forward as the } \\
\text { main raison d'être other } \\
\text { more pragmatic elements } \\
\text { seem more important: the } \\
\text { business support and job } \\
\text { creation. }\end{array}$ \\
\hline
\end{tabular}

\section{Enriching the "management model" of cluster policy evaluations}

In this last section of our discussion we will now "close the loop" of our research and address our last research question: "How can the knowledge of these pathologies benefit to cluster policy (implementation and evaluation)?”(RQ3).

Governments invest a substantial amount of money (Boekholt \& Thuriaux, 1999; Cooke, 2002; Fromhold-Eisebith \& Eisebith, 2005) to create clusters. Due to the high amount of money that governments spend for cluster policies, and the need to justify the use of such public funds (Desautels, 1997), we currently witness a multiplication of policy-driven cluster evaluation reports. All countries face the same challenges regarding evaluations: the systemic nature of clusters and its multiple actors involved make clusters an extremely difficult object to evaluate. Reflections on cluster or regional innovation policy evaluations (Arthurs, et al., 
2009; Bellandi \& Caloffi, 2010b; Learmonth, et al., 2003; Russo \& Rossi, 2009; Schmiedeberg, 2010) are still in the fledgling stages and governments still have to develop precise measurements and frameworks (Diez, 2001). Bellandi and Caloffi (2010a, p. 70) summarize very well the particularity of cluster evaluations, which need a "careful combination of the languages and tools of different study fields: the evaluation of public policies and the analysis of innovation and development processes."

Although cluster policies differ from country to country (OECD, 2005, 2007, 2009), cluster evaluations generally have the objective to improve, reorient, or justify the policy and the invested money (Diez, 2001; Jakoby, 2006; Shapira \& Kuhlmann, 2003). Beyond these general objectives, evaluators face challenges in designing the evaluation itself. In fact, as there is no available and general "recipe" for a solid cluster policy evaluation, governments and evaluators have to choose among a large variety of evaluation design parameters and performance criteria. In two of our published articles we exactly address this issue by focusing on the design of policy-driven cluster evaluations and their usage.

In our first article we analysed in detail the first French cluster policy evaluation conducted in 2008 (Gallié, et al., 2012) (see Annex 18). We first developed an evaluation analysis framework (see Figure 43) (that we then further specified in Gallié et al. (2014, p. 106)) which allowed us to look in a structured manner on all the important components to understand the nature and the scope of the evaluation. This policy-driven cluster analysis framework is composed out of three components: Objects of evaluation and causality schema, approach and methodology, and effects and uses. Particularly, through the analysis of how the results of the evaluation are used, we show that the first French cluster policy evaluation takes part of a progressive construction of doctrine on what a cluster is and how it should be managed. Even though the direct impact of the evaluation on the reconfiguration of the policy was relatively small, we can however make the hypotheses that the evaluation process in itself has matured certain ideas, particularly the objectives of the policy, which are generally very vague in the beginning (Benzerafa, Garcin, Gibert, \& Gueugnon, 2011) ${ }^{294}$. Additionally, the

\footnotetext{
${ }^{294}$ Wolman (1981, p. 436) explains this vagueness problem regarding the objectives as follows: "policy agendas usually reflect the mobilization of political demands rather than a rational process of evaluating needs, values, and objectives" and therefore rhetoric is frequently "substituted for adequate conceptualization, resulting in vagueness and lack of direction." The advantage of this vagueness is that the policy can easily be changed and adapted without major political discussions, but this flexibility also implies a major disadvantage, namely that no clear evaluation criteria are defined at the beginning of the policy life cycle. Due to this vagueness of definition,
} 
evaluation had an impact on the policy-driven clusters and the government by generating a reflective process. Following the policy-driven cluster evaluation the missions of the clusters were enlarged and the lack of a clear strategy triggered the government to set up individual cluster performance contracts during the second policy phase. The first French cluster policy evaluation is thus closer to the "in the action" approach than the "of the action" approach (Chanut, 2009). The evaluation process in itself becomes one part of the steering device for the policy-driven clusters. We can conclude that the evaluation process is somehow desacralised and becomes just a device amongst others.

Figure 43: The three components of a policy-driven cluster evaluation

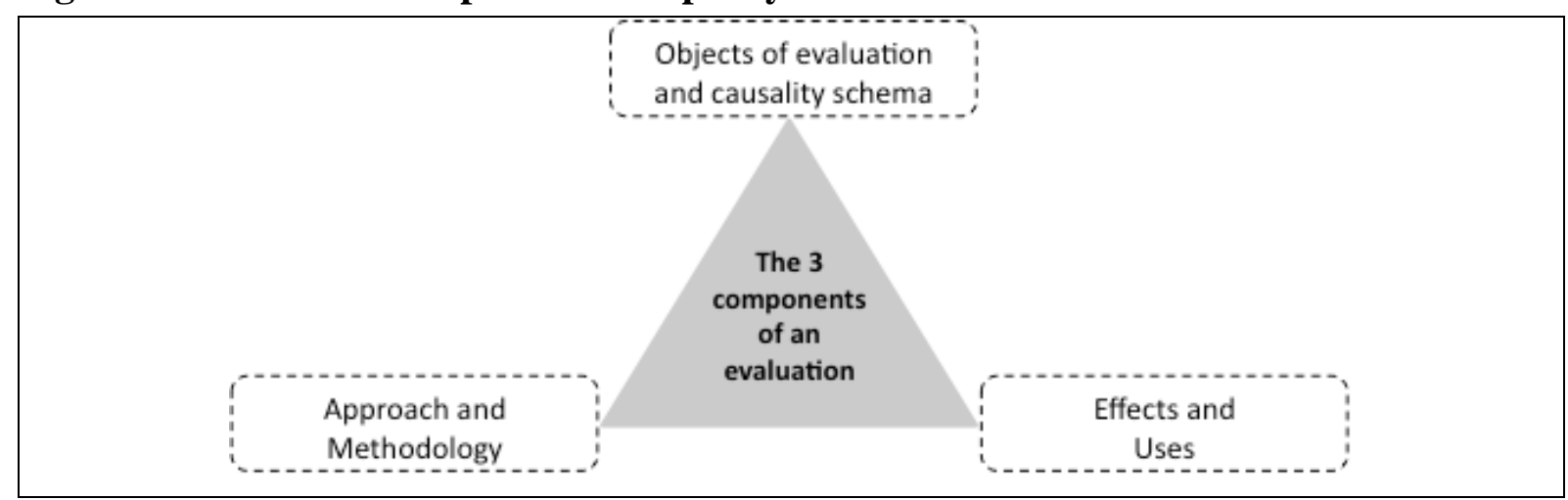

Source: English translation of the figure we developed in Gallié et al. (2014, p. 106)

In our second article we compared the French cluster policy evaluation with three other European cluster policy evaluations (in Germany, Austria and Belgium) (Gallié, et al., 2014) (see Annex 19). This was particularly important because we were able to put the French results in a more European context to find evaluation communalities and differences. The major question we asked in this second article was if it is possible to identify one or several cluster policy evaluation models, which might eventually spare governments, or other cluster policy sponsors, to "reinvent" a new evaluation device each time (Gallié, et al., 2014). In the end we were able to identify two different evaluation model archetypes: an "economist" model (Germany) and a "management" model (France and Austria) ${ }^{295}$, which can again be related to the general notions "of the action" evaluation and "in the action" evaluation (Chanut, 2009):

- The "economist" model, primarily uses an ex post assessment of the policy in terms of its economic impacts. For that the evaluation relied on quantitative and comparative

policy might alter considerably between the implementation of the policy and the end of the policy making it difficult for evaluators to set the "right" indicators and references.

${ }^{295}$ Belgium was used a hybrid model. 
approaches. The results of this type of evaluation, in appearance at least, have greater “objectification” (Gallié, et al., 2014).

- The "management" model, emphasizes the assisting role of evaluation in the piloting process of policy-driven clusters. Therefore, this model seeks to qualify on-going interim results and explore patterns of causality on which the policy is based to test and possibly redirect the policy. This type of approach, without neglecting the interest of quantitative indicators, is based on qualitative methods and goes "into the black box" of the functioning of the policy-driven clusters. The independence of the evaluation process is not specifically sought; the "actionable" character of the evaluation is privileged often in close proximity to decision-makers. (Gallié, et al., 2014)

Even though the "management" model is more oriented towards actionable knowledge, both models have the virtue to oblige the evaluator to look at the problem of what is actually evaluated, which object. One major problem of every evaluation is what Sölvell (2008) calls the "ruler problem" or Hertting \& Vedung (2012) call the "evaluative merit criteria". Every evaluation should at some point translate the policy objectives in criteria that measure the benefit, merit, value or quality of the policy under appraisal. Evaluators can refer in their evaluations to criteria measured at different moments of the policy life cycle. Ideally every evaluation should be carried out in view of cluster policy criteria that were clearly defined and measured already at the beginning of the policy life cycle. In reality though ex ante evaluations are seldom conducted and most policies are solely evaluated by ex post evaluations that do not dispose of criteria that are comparable to similar criteria measured before or at the implementation stage of the policy. The main difficulty of ex post evaluations is thus already to define what the evaluators should actually evaluate or the "object" of evaluation.

In Figure 44, based on the works of BIPE (2007) and Sölvell (2008) we summarized the different evaluation objects. The evaluation either concentrates on the cluster itself (white rectangles) or the evaluation can concentrate on the global effectiveness of the cluster policy or the inherited characteristics of each clusters (light grey rectangles). Finally the cluster evaluation can also focus on exogenous factors such as fiscal, legal or social environment (dark grey rectangle). The schema also shows the distinction that can be made between evaluating the cluster policy (light grey rectangle on the left side) or the cluster in itself (white 
rectangles). While the first also needs the evaluation of the second, the second can also be evaluated independently. Additionally, when we only focus on the cluster itself (white rectangles) we can distinguish three different objects to evaluate (from the bottom to the top): The impact of the clusters on their territories or on the involved actors, the actions and intermediary results of the clusters, or finally the effectiveness of the cluster organization in terms of resources, governance and management. Additionally, all these objects are not independent from each other. The different objects are generally related through a causality schema on which the policy is based.

Each of the different objects has different types of indicators. An evaluation can for example focus on the impact of clusters on their territories or on their members (level 1 in Figure 44). The chosen indicators are thus economic indicators such as turnover, job creation, size of business, new company formation, etc. An evaluation can also focus on the action and intermediary results of clusters with the assumption that these evaluation criteria are reliable intermediary results to evaluate the later impact. These intermediary results are for example number of projects, the amount of funding dedicated to $R \& D$ projects, number of patents, number of networking events, participation rates of members in collective activities, etc. (level 2 in Figure 44). Finally, an evaluation can also focus on the effectiveness of the cluster organization by evaluating its organizational structure, the quality of its strategy, skill and competence of cluster managers, animation budget, etc. (level 3 in Figure 44).

The literature dealing with cluster policy evaluations underlines the need to combine different approaches and methodologies to better grasp the systemic and multi-dimensional nature of the object evaluated (Diez, 2001; Kuhlmann, 2003), but also to improve or to develop new indicators "that would enable innovation activities and policies to be evaluated" in a better way (Zabala-Iturriagagoitia, Voigt, Gutiérrez-Gracia, \& Jiménez-Saez, 2007, p. 1157). There are several articles focusing on the exact methodologies and measurement issues of policy driven clusters (Colgan \& Baker, 2003; Learmonth, et al., 2003; Schmiedeberg, 2010). However, all these articles have the tendency to focus on level 1 and level 2 indicators but not on how one could conduct a structured analysis of level 3, the effectiveness of the cluster organisation (and indirectly the effectiveness of its implementation). In this thesis we tried to fill this gap by proposing a new manner to think about the effectiveness of the cluster organisation, in line with the recent urge of some scholars to start studying cluster policies as a policy challenge (Burfitt, et al., 2007; Ebbekink \& Lagendijk, 2013). In Figure 45 we 
schematically show on which level we situate our thesis and propose an evaluation framework to improve level 3 object evaluations. We argue that implementing cluster policies produce organisational dilemmas that generate side-effect pathologies. In order to help governments and policy-driven cluster organisations to make more deliberate decisions we have to start observing the policy-driven clusters' pathologies (e.g. distrust, inefficiency, etc.). This will then lead us to the associated dilemmas that are at the source of these pathologies. A dilemma always implies two or more options, by knowing which dilemma has driven a certain pathology we can then re-evaluate if another choice is better or if we just have to "cure" the pathology. Knowing its source is though necessary to start its treatment. We thus urge cluster policy scholars to pass from studying the "anatomy of clusters" (Porter, 1998c) to studying the "pathology of clusters".

Figure 44: The different objects of a cluster evaluation

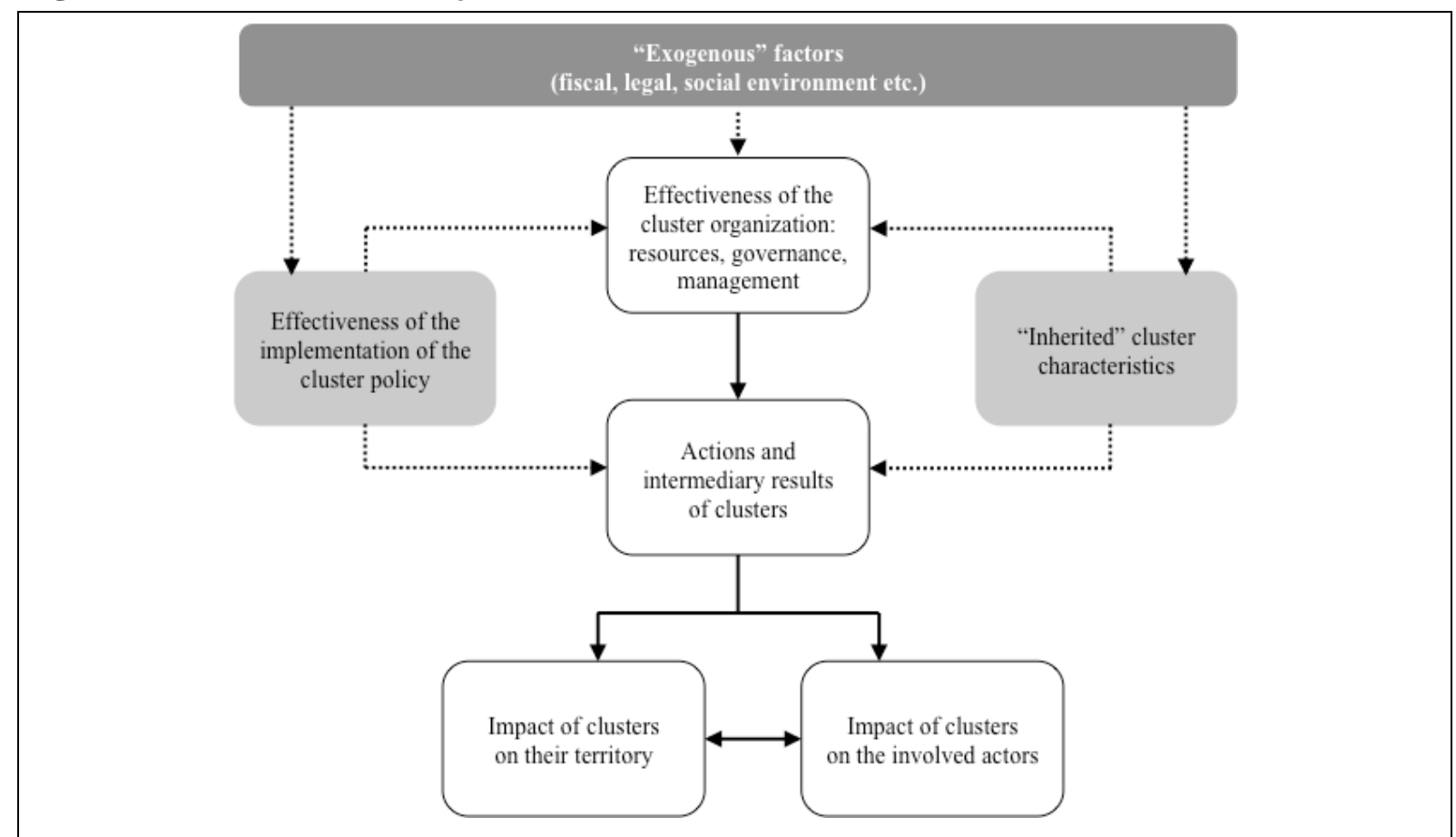

Source: English translation of the figure we developed in Gallié et al. (2014, p. 93) 
Figure 45: Proposition of an evaluation framework to improve level 3 object evaluations

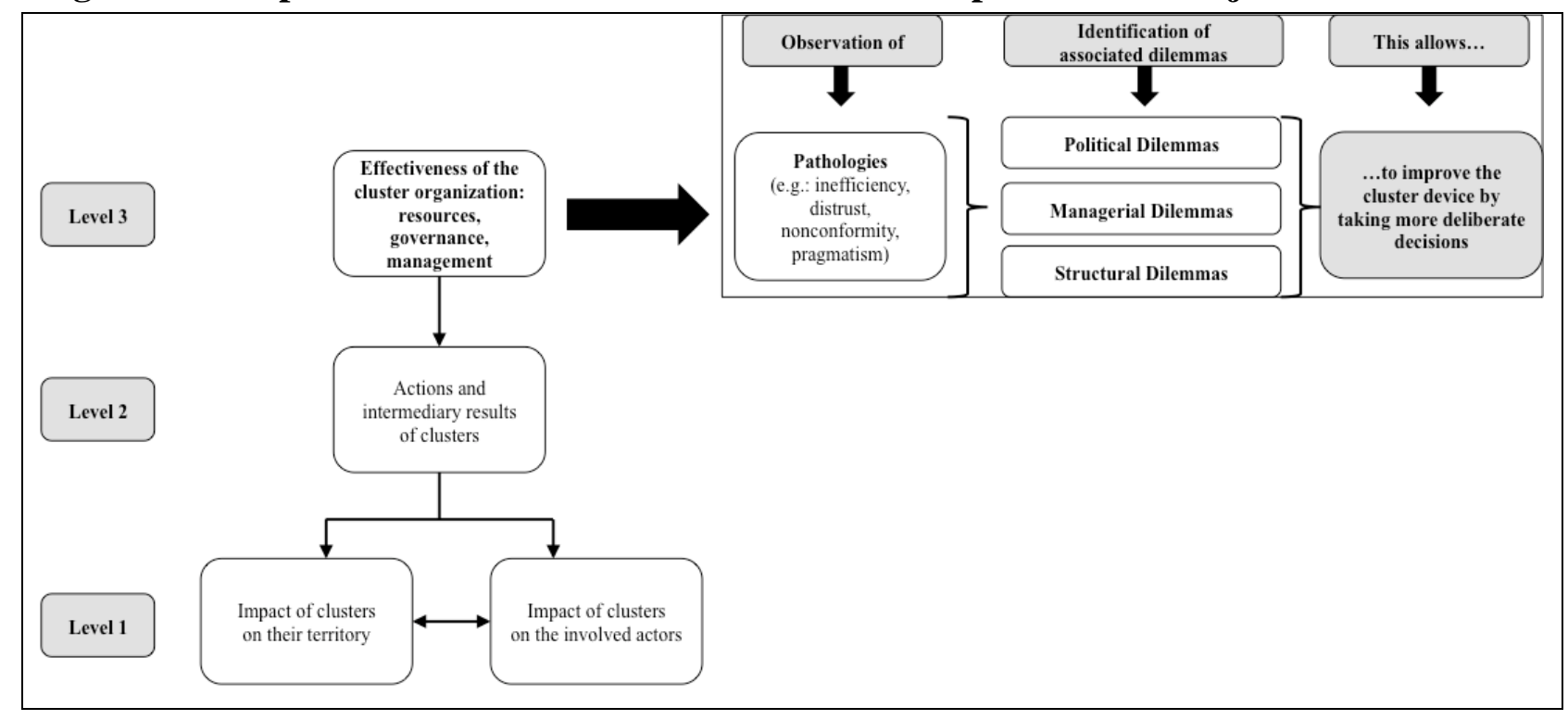




\section{GENERAL CONCLUSION}

At the end of this doctoral work on the implementation of cluster policy and the related organisational dilemmas and pathologies that it generates within policy-driven clusters, it appears possible to synthesize its main results and to detail its contributions, at theoretical, methodological as well as empirical levels (section 1). Our work comprises necessarily a certain number of limitations, especially those related to the single case study methodology that was used and the empirical setting of the HCPR case (section 2). Finally, we conclude on the perspectives for further research that this thesis opens (section 3 ).

\section{Theoretical, methodological and managerial contributions}

In the introduction of the thesis, we have highlighted the particular place that policy-driven clusters occupy in today's policy realm to foster innovation and competitiveness. We have also underlined the numerous difficulties, critics and crises that these organisations are currently facing. Some authors criticise for example the best practice attitude (Hospers, 2005), others the closed system view (Shearmur, 2011a) or the increasing relevance gap between academics and practitioners (Kiese \& Wrobel, 2011). In regard to the profound transformation of the empirical landscape of the cluster research field (shifting away from economic objects towards political and organisational objects), the rise of organisational and managerial issues appears today as a major set of challenges that these "organisations" face (Burfitt \& Macneill, 2008). This new turn in cluster research has founded an important stream of new academic research, dedicated to the study of managerial practices (Lefebvre, 2013), of implementation practices (Burfitt, et al., 2007) and cluster policy evaluation (Gallié, et al., 2014). The main thesis developed in this doctoral work is that implementing cluster policies tends to produce organisational dilemmas at cluster level that generate side-effect pathologies. In Chapter 9 we have addressed each of our three research questions, hereinafter we will now highlight our contributions.

\subsection{Theoretical contributions}

During the 1990s, Porter (1998c, p. 78) scrutinized in detail a multitude of "healthy regions" in the United States, established mappings of these healthy regions, and called it the "anatomy" of clusters governments could strive for. In this thesis, we have shown that it is 
necessary to pass from studying the "anatomy of clusters" to studying the "pathology of clusters" to help practitioners with their operational challenges to create "healthy regions". We have defined "pathology" in a cluster setting as the visible managerial symptoms that policy-driven clusters may endure. We have demonstrated how some of these pathologies are directly generated by "organizational dilemmas", i.e. a set of decisions and choices for which there is no "one best choice". By privileging one direction over another in such dilemmas, side-effect pathologies can emerge. The challenge in cluster policy study is to pinpoint these side-effect pathologies and their associated dilemmas in order to improve cluster policy implementation and to better adapt the cluster policy to the local settings.

Important theoretical contribution was made to the cluster policy literature (Burfitt \& Macneill, 2008; Champenois, 2012; Ebbekink \& Lagendijk, 2013; Engel, et al., 2013; Ketels, 2013; S. Menu, 2012; Nishimura \& Okamuro, 2011a, 2011b; Swords, 2013; Younès, 2012) especially with the establishment of a taxonomy of cluster policy dilemmas based on a systematic literature review (Denyer \& Neely, 2004; Pittaway, et al., 2004; Tranfield, et al., 2003). We grouped the identified organisational dilemmas in three main categories (political dilemmas, managerial dilemmas and structural dilemmas) and established a framework (see Figure 46). For every type of dilemma category we then identified a certain set of subdilemmas (see Figure 47).

Figure 46: A framework for the study of pathology in policy-driven clusters

\begin{tabular}{|c|c|c|c|c|}
\hline \multirow{3}{*}{ 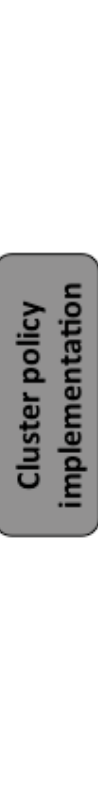 } & \multirow{3}{*}{ 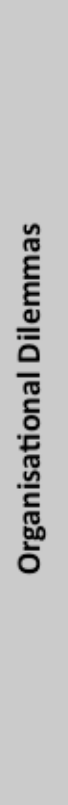 } & 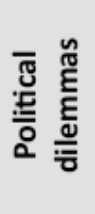 & $\begin{array}{l}\text { PD\#1 - Defining boundaries } \\
\text { PD\#2 - Defining subsidies } \\
\text { PD\#3 - Defining objectives }\end{array}$ & \multirow{3}{*}{ 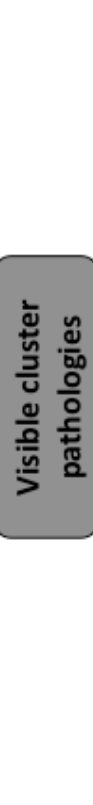 } \\
\hline & & 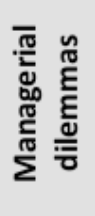 & $\begin{array}{l}\text { MD\#1 - Managing actor involvement } \\
\text { MD\#2 - Managing innovation processes } \\
\text { MD\#3 - Managing collaboration processes }\end{array}$ & \\
\hline & & 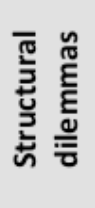 & $\begin{array}{l}\text { SD\#1 - Adapting to the life-cycle stages } \\
\text { SD\#2 - Adapting to local culture } \\
\text { SD\#3 - Adapting to geographic location }\end{array}$ & \\
\hline
\end{tabular}


Figure 47: Reminder of the different dilemmas developed in the literature review

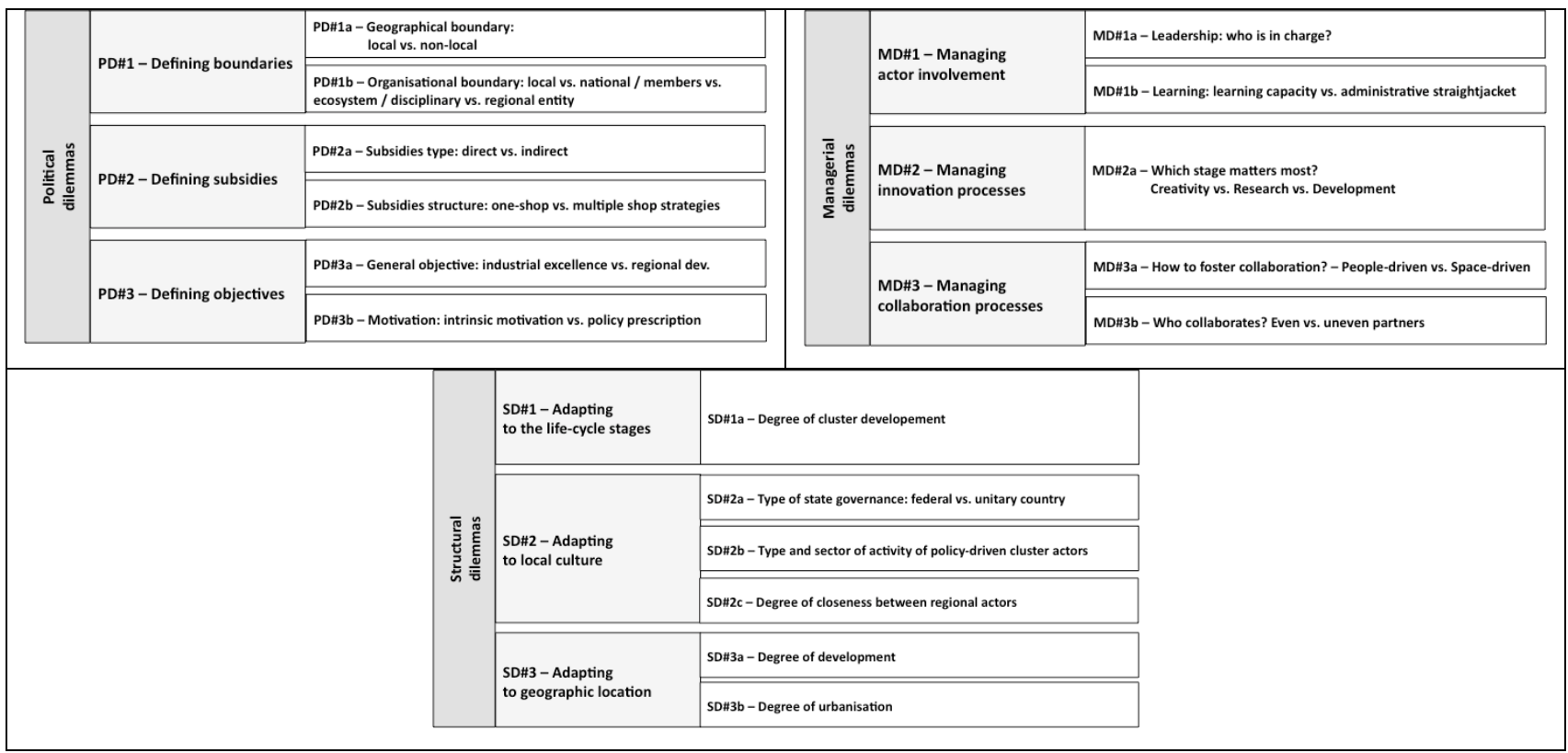

Another theoretical contribution to the cluster policy literature is the study an empricial cluster policy case and additionally of a "pathological" case, the HCPR case, that represents an extreme case (Eisenhardt, 1989; Flyvbjerg, 2006) in the cluster landscape. First, it was underlined that "few empirical studies with micro data have been conducted [...] on the effects of cluster policies” (Nishimura \& Okamuro, 2011b, p. 715), our research tries to contribute to this gap. Second, during our empirical fieldwork, we were able to study a policy-driven cluster that consecutively received a low performance evaluation, from national cluster policy evaluators (CMI \& BCG, 2008; Erdyn, et al., 2012) but also from academics (Bonnafous-Boucher \& Saussois, 2010). HCPR is thus an ideal policy-driven cluster to show the academic community a pathologic case. This pathologic case allows, in a Popperian falsification tradition, to look at a "black swan" and to start a new critical reflection process (Flyvbjerg, 2006, p. 228; Popper, 1959) on how a policy-driven cluster works. Even though there are numerous policy-driven clusters in France that seem to encounter much less difficulties (the "white swans") (see for example (Bidan \& Dherment-Férère, 2009; Chabault, 2008; Retour, 2009b; Therme, 2008)), the knowledge we gained from our extreme case study will help rethinking how a policy-driven cluster works, can be better implemented and evaluated. It is the studies of "black swans" that are particularly important to get new scientific conversations going (Flyvbjerg, 2006). 
A third theoretical contribution is the establishment, based on our empirical observation, of a first list of pathologies that are mainly driven by certain dilemmas. The identified pathologies and associated dilemmas, discussed in detail in Chapter 9, are summarized in Figure 48:

- "Inefficiency" pathology: A first major pathology that we observed in HCPR is inefficiency. We identified four sources of leadership dilemmas that drive inefficiency in HCPR: leadership dilemmas within the policy-driven cluster's governance structure, among regional policy-driven clusters, between the policy-driven cluster and the national government, and finally among the different ministries (which though has the least direct impact on HCPR). Additionally, no "civic entrepreneur" exists that holds the cluster together and that has identified an external challenge to overcome. On the one hand HCPR wishes to be egalitarian by finding consensus among its very "political" members, on the other hand this situation paralyses all decision processes.

- "Distrust" pathology: Governments have to decide how to subsidies policy-driven clusters (direct subsidies vs. indirect subsidies). In our case study direct subsidies are the main modus operandi. Regional bound direct subsidies have the advantage that they "force" regional actors to get to know each other. However, direct subsidies also create negative side-effect pathologies. Our empirical case has shown that direct subsidies create several pathologies like inefficiency due to the complexity of the support structure ( $R \& D$ zones) or low risk projects due to the risk-aversion of the policy-driven cluster (evaluated on transformation rate: labelled vs. financed projects). Additionally, direct subsidies also create distrust. This is a side effect that can particularly impact the knowledge exchange capacity, the theoretically heart of every policy-driven cluster.

- "Nonconformity": According to the national cluster policy evaluations, HCPR's performance compared to other policy-driven clusters in the Paris Region is bad. However, our hypothesis is that there exists pathology of nonconformity problem. This could be solved by more closely looking at the region's DNA, be it the conflicts or closeness of actors of the region (strong political actors that have difficulties to collaborate with each other) or the already existing support structures (highly dense region with already plenty of existing support structures). In a certain manner, HCPR needs to find its added value with the local reality.

- "Pragmatism": For the time being, HCPR proposes very pragmatic animation services mainly concentrated on fostering the business aspects of its members. However this raises the question if other opportunities (such as the links with doctors 
which are currently little explored) or potential dangers (such as the regional innovation lock-in) are not important to keep in mind as well and if a pure pragmatic focus might be dangerous.

Figure 48: Summary of identified pathologies driven by associated dilemmas

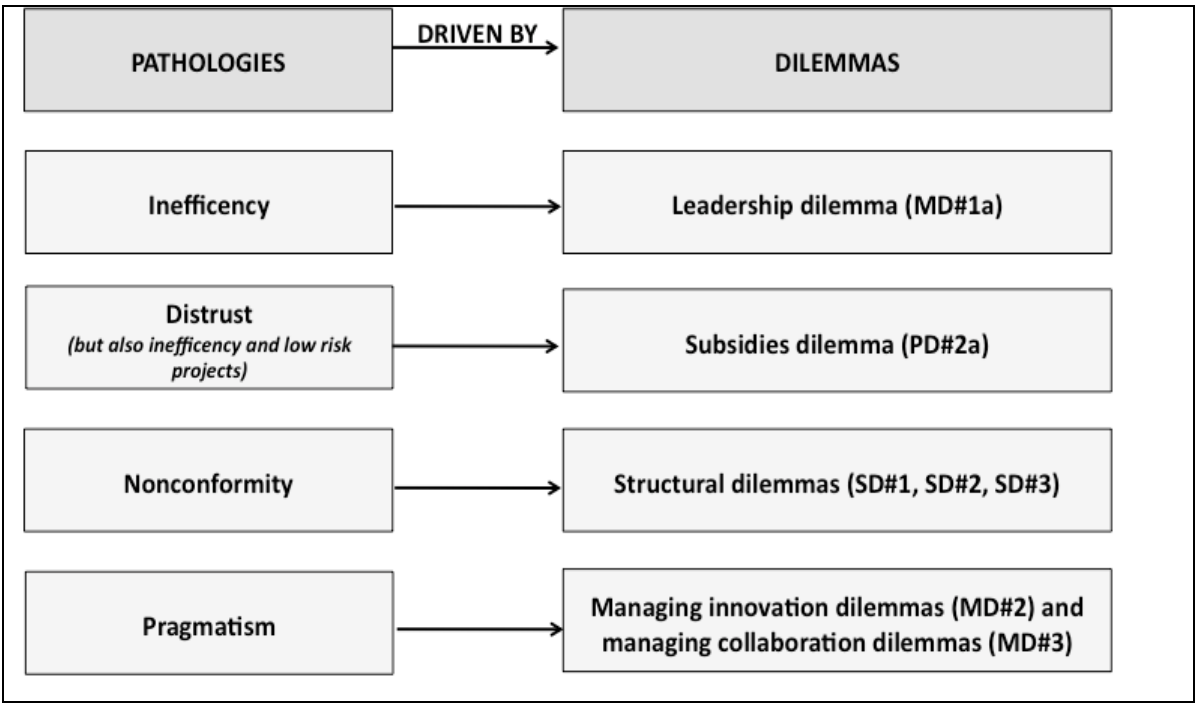

Finally, we wish to highlight once again the fact that the empirical setting in this doctoral dissertation drove us to study in depth a "policy-driven cluster". These policy-driven clusters are of course very different in their purpose and functioning compared to "spontaneous clusters" (Chiaroni \& Chiesa, 2006).

\subsection{Methodological contributions}

Along with previous research that demonstrated the entanglement of different actors (T. Weil \& Fen Chong, 2009) as well as competing strategic objectives (Brachert, et al., 2011; Kiese \& Wrobel, 2011; Sellar, et al., 2011; Steinle, et al., 2007) our thesis has shown that policydriven clusters are indeed highly "multilevel", "entangled" and "systemic" organisational objects. Such a complexity is a consequence of the cluster policy itself that aims at gathering different actors (companies, research labs, universities, political institutions...) with various objectives. However, the fact that these objects are complex does not necessarily mean that some "confusion" must prevail. Our study has shown that a research methodology and design simultaneously pointed at different levels (cluster policy, policy-driven cluster organisation, policy-driven cluster members) could allow to "dis-entangle" the analysis to in fine address cross-level organisational dilemmas (political, managerial and structural). One has to first thoroughly decompose the general view and identify the different pathologies before it is 
possible to go "up-stream" again (towards the dilemma) and give sense to the whole. This endeavour is indeed ambitious and difficult, but it was one of the main objectives of this thesis.

Additionally, we also want to underline that the systematic literature review (SLR) methodology (Denyer \& Neely, 2004; Pittaway, et al., 2004; Tranfield, et al., 2003) that was used in this thesis is a powerful tool for framing the literature of a nascent field, like for example the challenges associated to cluster policy implementation. The SLR methodology was only recently adapted from the medical realm to the management realm (Mulrow, 1994; Thorpe, et al., 2005) and for the time being it is particularly used in the entrepreneurship field. As policy implementation needs a very inter-disciplinary view (Schofield, 2001), the SLR constitutes a great possibility to dig into several domains that already treat the topic in a dispersed manner to then synthesize the main issues.

\subsection{Managerial contributions}

Our first managerial contribution lies in the cluster policy evaluation field (Colgan \& Baker, 2003; Gallié, et al., 2012; Gallié, et al., 2014; Learmonth, et al., 2003; Schmiedeberg, 2010). In the beginning of our thesis we started working with the cluster policy evaluation data that was used during the first French cluster policy evaluation in 2008 (see Annex 8 and (Gallié, et al., 2013b) or (A. Glaser, et al., 2012)). The collected indicators were for example: the "transformation rate" (labelled projects vs. financed projects), diversity of R\&D project teams, number of members and their diversity, diversity of the supervisor board, budget of the cluster organisation, etc. These indicators try to measure the actions and intermediary results (level 2 in Figure 45) but also cluster organisation effectiveness (level 1 in Figure 45) (Gallié, et al., 2014).

Our research has shown that also other types of indicators need to be taken into account if one wishes to improve the organisational effectiveness and to take an "in the action" evaluation approach (Chanut, 2009) that tries helping policy-driven clusters identifying their specific inherent pathologies that need to be addressed and overcome. Ideally, it would seem necessary to propose additional indicators that particularly focus on identifying pathologies (such as number of leadership conflicts, types of leadership conflicts, number of trust issues, 
types of trust issues, etc.) to then help the evaluated policy-driven clusters to overcome certain dilemmas that might be very different in each policy-driven cluster setting.

However, the "new public management" approach, less state and more performance management, increasingly used in OECD member states, and also in France, goes more in the direction of "enhancing control and 'upwards accountability", instead of "promoting learning and improvement" (Sanderson, 2001, p. 297). During our fieldwork we saw that HCPR is reluctant about sharing too much information and at the same time suffering from the review system in place. The cluster policy-evaluation was not seen as a learning procedure but as a performance evaluation procedure. However, in order to achieve "Best Value" of an evaluation, the underlying culture needs be changed (Sanderson, 2001, p. 297). In order to improve the functioning of policy-driven clusters, governments need to take into account organisational learning and avoid "accountability myopia” (Ebrahim, 2005). All the more as we have already seen that organisational learning is possible in policy-driven clusters (Lundequist \& Power, 2002; Sotarauta, 2012; T. Weil \& Fen Chong, 2009). Such as MacNeill \& Steiner (2010), who analysed policy-driven clusters in Austria, we also think that a more “"post-modern' participative management style” (Gibney, et al., 2009) is necessary in order for policy-driven clusters to reap their full potential. However, one question that remains is in which manner such a participative management style is possible in a centralised country like France where the policy-driven cluster policy is steered from the national level and the distance to the local policy-driven clusters is longue.

Our second managerial contribution lies in the cluster policy implementation field (Burfitt, et al., 2007; Foray, et al., 2011; Nauwelaers, 2001). We have seen that the implementation of policy-driven cluster generates a range of organisational dilemmas that policy-driven cluster managers and governments have to face. In this doctoral thesis we tried to summarize the different implementation dilemmas that will help the ones who implement policy-driven clusters to structure their reflections in a more systematic manner. This will also help to overcome the current best practice focus of governments (Hospers, 2005), and increase the adaptability of cluster policies to the national characteristics and local circumstances. 


\section{Limitations}

Like most research, this doctoral dissertation counts several limitations.

First, we have not done a $360^{\circ}$ investigation of HCPR, the policy-driven cluster under review. In order to improve our results, it would be necessary to also interview the state and local government, the funding partners, the regional development agency, the strategic governance of the policy-driven cluster, etc. The problem with policy-driven clusters is that they are a very systemic object and thus difficult to analyse by one research alone in a limited period of time. For the time being we have "only" observed the view of the project leaders that submitted projects to the ICT \& Health imitative and their partners (for example doctors and academics), the view from two other policy-driven clusters in the region, the view from HCPR's operational team, the view form one of HCPR's steering committee presidents, the view from official evaluations and other analysis that were already done on HCPR. This is a first start to get an overview of pathologies and associated dilemmas of a policy-driven cluster. However, further investigations are necessary to test the already obtained results among other stakeholders.

Second, we had the great opportunity to analyse a difficult case because it allowed a Popperian falsification process to get started (Flyvbjerg, 2006; Popper, 1959) (for example that cluster policies automatically create trust among actors). We deeply believe that finding and analysing "black swans" is an extremely important element of research. However, digging and trying to analyse "black swans" and extreme cases (Eisenhardt, 1989; Flyvbjerg, 2006) can also go along with methodological difficulties. First of all the access to data is hard because political issues prevent a proper investigation to take place. Actors that were already evaluated badly by official cluster evaluations fear about their own legitimization when they open the door to researchers. Even though, it was extremely difficult to get access to certain data and some data were either never send to us or only send to us "secretly" or one year after we first asked for them. Additionally, a difficult access to data also means more time that is needed to investigate the study object. This leads to a second methodological difficulty, namely that we only had the time to do one single case study in one region. It would now be necessary to study pathologies and dilemmas in other policy-driven clusters, for example in a "white swan" and in another "black swan" setting. 
Finally, mature research fields have already established constructs and measures on which they heavily rely (Edmondson \& McManus, 2007). However, cluster policy research and the study of its implementation challenges is new (Burfitt \& Macneill, 2008; Ebbekink \& Lagendijk, 2013). In nascent research endeavours few formal measures exist and evidence of construct still needs to be established (Edmondson \& McManus, 2007). Our theoretical framework was only developed after our fieldwork took place because it was the fieldwork that allowed us to see the existent literature in another way. Our theoretical framework is thus also part of our results. However, this also bears the high risk that the theoretical framework is not stable yet and that further research is necessary to confront and test it in other settings.

\section{$3 \quad$ Research perspectives}

There are also some interrogations that remain open at the end of this thesis, which allows defining avenues and opportunities for further research.

First, as Swords (2013) developed, we think that a massive amount of research exists on clusters but that, in a paradoxical manner, we know little about how to actually implement cluster policies on the field. We therefore need to start studying cluster policies as a policy challenge (Ebbekink \& Lagendijk, 2013) and establish new avenues of research that allow addressing these difficulties. In this doctoral thesis we started this new endeavour by proposing to see policy-driven cluster challenges as pathologies that are driven by dilemmas. We proposed to identify pathologies, the problems that are encountered and talked about on the field, to then go "upstream" to relate them to a set of specific dilemmas. In our case for example the observed inefficiencies were strongly related to the difficult leadership issue that existed in the policy-driven cluster, but also between the policy-driven clusters of the region, and between the policy-driven cluster and the national government. The analysis in terms of organisational dilemmas and related pathologies seems powerful not only to identify the sources of clusters' managerial difficulties, but also to enlighten possible solutions (or cures). It would be necessary, through other case studies, to evaluate the efficiency of classic remedies that are currently used to build policy-driven clusters and to identify new remedies that target the pathogen factor. Furthermore, starting with the pathologies and then going upstream allows overcoming the difficulty to study such a systemic object called "cluster". 
Second, analysing pathologies and dilemmas also allows to outbreak from the intensive study of innovation and collaboration topics in the cluster literature and to focus on new important issues that need to be addressed with the same intensity. We thus advocate, in a "Krugmanian" manner (Krugman, 1991 (1993), p. 54), to be aware of the current " "megatrends' style of thought[s]" and to embrace the whole range of challenges that policy driven clusters face. For example:

- Which type of subsidies should be used to build policy-driven clusters? Direct vs. indirect subsidies? What are the advantages and disadvantages of each type in order to create a "cluster spirit"?

- Which type of organisational boundary should be drawn around a policy-driven cluster? Regional boundary, thematic boundary, national boundary, etc.? What is the ideal organisational size for an effective functioning?

- Which type of set up according to which region? Regions with a plenty of existing support structures and events might need another type of policy-driven cluster help than regions that are weakly structured?

- What differences exist between the implementation of policy-driven clusters in unitary countries and in federal countries? Does the distance between local policy-driven clusters and national authorities cause additional challenges?

Third, new avenues of research need also be started in the cluster policy evaluation field. The classical cluster evaluations heavily concentrate on impact assessment, be it on the territory or on the local actors, by using for example econometric methods, I/O-analysis, or Network analysis (Schmiedeberg, 2010). However, the managerialisation of clusters also raises the question of how to evaluate intermediary results and organisational efficiency (Gallié, et al., 2014). Evaluating these intermediary results and organisational efficiency needs further research. Focusing on pathologies and dilemmas could be a new approach to further develop an “in the action" evaluation approach (Chanut, 2009).

To sum up, we hope that more scholars in the cluster and cluster policy field will start shifting from studying the "anatomy of clusters" to studying the "pathology of clusters". We believe that this will further contribute to closing the relevance gap that is currently observed in the cluster literature and assist practitioners in considering their actions from a renewed perspective. 


\section{ANNEXES}

Annex 1: American's Commission on Industrial Competitiveness ....................................... 370

Annex 2: First appearances of the word "policy" in academic literature............................... 372

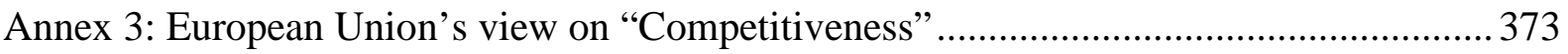

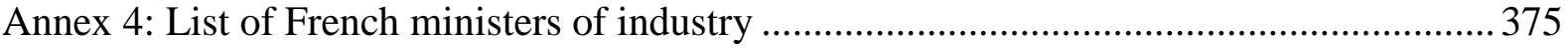

Annex 5: Focus on French "local productive systems" (SPL) ............................................. 376

Annex 6: E-mail template for contacting project leaders................................................... 377

Annex 7: General interview guide for interviewing project leaders ..................................... 378

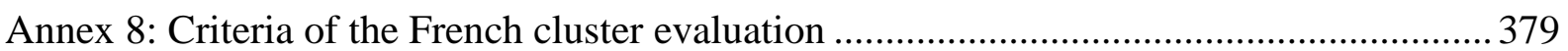

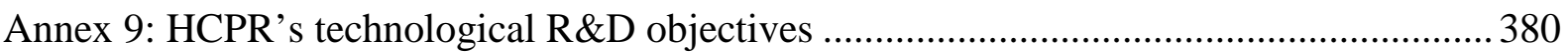

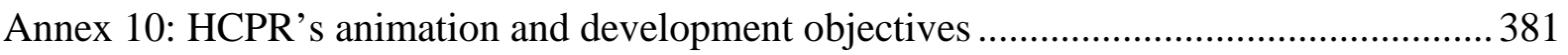

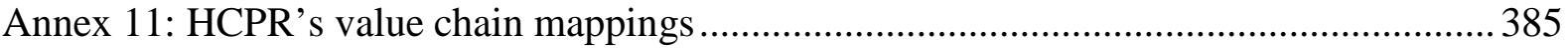

Annex 12: Project, competences \& needs presentation templates ........................................ 389

Annex 13: Characteristics of project leaders \& their organisations ....................................... 391

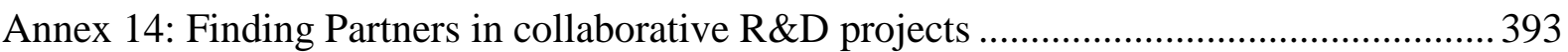

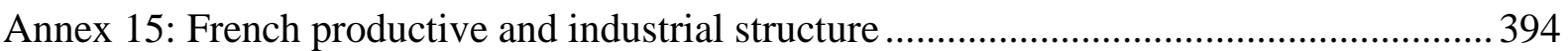

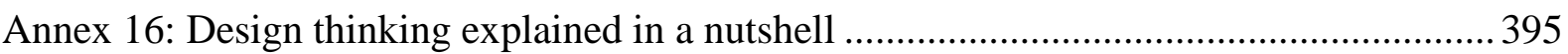

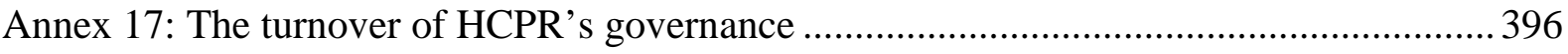

Annex 18: Article on the French cluster policy evaluation (2012) ..................................... 397

Annex 19: Article on European cluster policies evaluations (2014) ..................................... 412

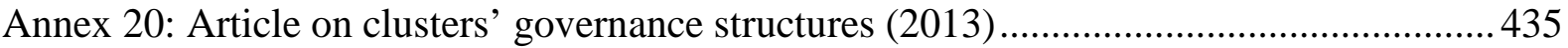




\section{ANNEX 1: AMERICAN'S COMMISSION ON INDUSTRIAL COMPETITIVENESS}

The Box 14 and Box 15 display some excerpts from discourses of Ronald Reagan regarding the American "Commission on Industrial Competitiveness" which was installed in 1983. These excerpts are particularly interesting because they reflect very well the increasing strive for competitiveness during the 1980s and the fear of the nations to fall behind in the global competition race. At the same time they also reflect a certain different stance compared to the European counterpart.

\section{Box 14: President's Commission on Industrial Competitiveness (Executive Order 12428)}

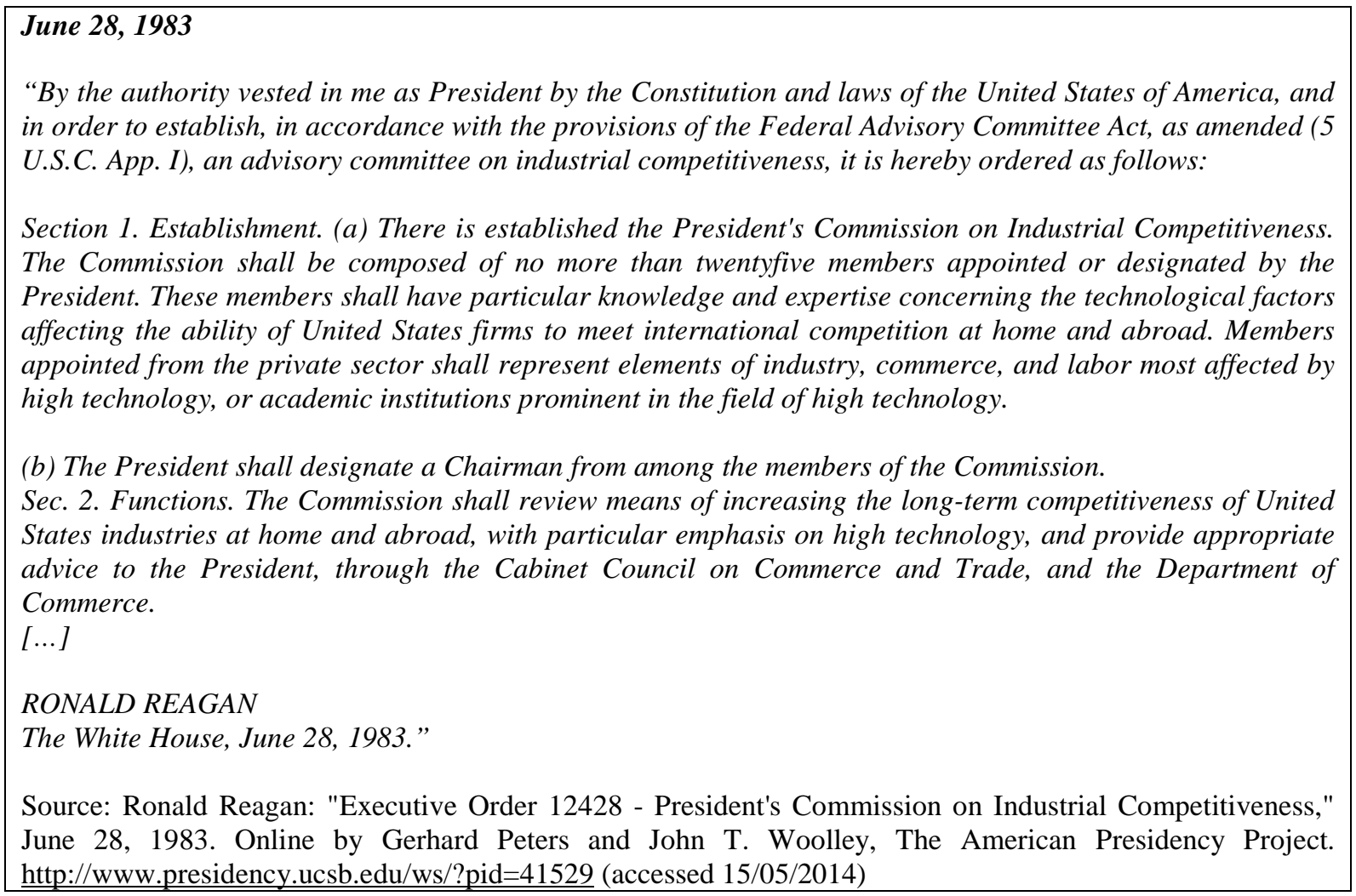




\title{
Box 15: Establishment of the President's Commission on Industrial Competitiveness
}

\author{
August 4, 1983 \\ "On June 28 I signed an Executive order establishing a Commission on Industrial Competitiveness. I charged \\ the Commission with advising me and my administration on ways to strengthen the competitiveness of U.S. \\ industry.
}

This nation's greatest competitive advantage in the past were ideas that helped America grow. We need to put the power of ideas to use again, for the good of our future. America needs her best minds to create technologies that will enhance America's economic leadership in the 1980's. To sustain high rates of real economic growth, we must continue to create new "miracles" of high technology-miracles both for innovation and for modernization of the major areas of our economy in manufacturing, agriculture, and services.

The Commission members I am appointing today are distinguished leaders from large and small businesses, from labor, and from academia. They are ideally suited to lead us in a national dialog-a discussion of the kinds of actions required by the public and private sectors to make U.S. industries more competitive in domestic and foreign markets. The Commission will be chaired by John A. Young, president of the HewlettPackard Co.

The Commission will focus its attention on government and private sector actions, specifically:

- Identifying the problems and opportunities for the private sector to transform new knowledge and innovations into commercial products, services, and manufacturing processes.

- Recommending policy changes at all levels of government to improve the private sector's ability to compete in the international marketplace and to maintain and create opportunities for American workers.

The Commission will report to me and work closely with the Department of Commerce, the Office of Policy Development, and the Office of Science and Technology Policy.

The increasingly rapid pace of technological advancement assures us that our economy will change constantly in the future. New developments in information processing, biology, and materials science are spawning sunrise industries. They are improving our quality of life and standard of living in ways few could have foreseen. These technologies are transforming all sectors of our economy and even our lifestyles. Not only can information processing capabilities improve the way farmers manage their livestock, provide the "brains" in a flexible manufacturing system, and keep track of the paper flow in an office; they will also change the way we live.

Now some believe that the Government should try to read these trends to determine which products, services, and industries have a place in our future and which do not. They would have government planners divert resources away from traditional industries and channel them into new fields. But the history of progress in America proves that millions of individuals making decisions in their own legitimate self-interest cannot be outperformed by any bureaucratic planners.

Government's legitimate role is not to dictate detailed plans or solutions to problems for particular companies or industries. No, government serves us best by protecting and maintaining the marketplace, by ensuring that the rules of free and fair trade, both at home and abroad, are properly observed, and by safeguarding the freedoms of individual participants.

$[\ldots] "$

Source: Ronald Reagan: "Statement on Establishment of the President's Commission on Industrial Competitiveness", August 4, 1983. Online by Gerhard Peters and John T. Woolley, The American Presidency Project. http://www.presidency.ucsb.edu/ws/?pid=41678 (accessed 15/05/2014) 


\section{ANNEX 2: FIRST APPEARANCES OF THE WORD "POLICY" IN ACADEMIC LITERATURE}

Table 47 lists for each policy when it was first mentioned in the literature. The date corresponds to the first mention of the policy in the title, abstract or keyword of an article referenced in the academic article database Scopus. This implies that the policy might have already been discussed in the corpus of a text ${ }^{296}$.

Table 47: Genealogy of "policy" appearances in academic research

\begin{tabular}{|l|l|l|}
\hline $\begin{array}{l}\text { Year of first } \\
\text { appearance }\end{array}$ & Type of policy & Reference \\
\hline 1947 & Science Policy & $\begin{array}{l}\text { Study Group - Washington Association of Scientists. (1947). Toward } \\
\text { a National Science Policy? Science, 106(2756), 385-387. }\end{array}$ \\
\hline 1953 & Research Policy & $\begin{array}{l}\text { Kidd, C. V. (1953). Research Planning and Research Policy } \\
\text { Scientists and Administrators. Science, 118(3058), 147-152. }\end{array}$ \\
\hline 1967 & Regional Policy & $\begin{array}{l}\text { Fisher, J. L. (1967). Reflections on the formulation of regional } \\
\text { policy. Papers in Regional Science, 18(1), 67-74. }\end{array}$ \\
\hline 1971 & Industrial Policy & $\begin{array}{l}\text { Balassa, B. (1971). Industrial policies in Taiwan and Korea. } \\
\text { Weltwirtschaftliches Archiv 106(1), 55-77. }\end{array}$ \\
\hline 1972 & Technology Policy & $\begin{array}{l}\text { Dobrov, G. M., \& Smirnov, L. P. (1972). Forecasting as a means for } \\
\text { scientific and technological policy control. Technological } \\
\text { Forecasting and Social Change, 4(1), 5-18. }\end{array}$ \\
\hline 1975 & Structural Policy & $\begin{array}{l}\text { Kern, H. (1973). The need for a policy of regionalisation. } \\
\text { Intereconomics, 8(3), 91-94. }\end{array}$ \\
\hline 1999 & $\begin{array}{l}\text { Uhlmann, L. (1975). Innovation in industry: a discussion of the state- } \\
\text { of-art and the results of innovation research in german-speaking } \\
\text { countries. Research Policy, 4(3), 312-327. }\end{array}$ \\
\hline
\end{tabular}

\footnotetext{
${ }^{296}$ Date: 01/04/13; Database: Scopus; Search Criteria: Search for "[x] policy" OR "[x] policies" in "Article Title, Abstract, Keywords“; $[\mathrm{x}]$ = Science, Research, Regional, Structural, Industrial, Technology, Innovation or Cluster; Data Range: "all years to present"; Document Type: Article; Subject Areas: "Social Sciences \& Humanities" AND "Physical Sciences"
} 


\section{ANNEX 3: EUROPEAN UNION'S VIEW ON “COMPETITIVENESS”}

The following two boxes are excerpts of documents regarding the European Union stands towards competitiveness and the economic challenges ahead. Box 16 contains an excerpt of a European Commission White Paper on competitiveness published in 1993. Box 17 contains an excerpt of the European Lisbon Strategy decided upon in 2000.

\section{Box 16: European Commission on growth, competitiveness and employment in 1993}

1993: The following excerpt contains the opening words of the European Commission's White Paper entitled "Growth, competitiveness, employment. The challenges and ways forward into the $21^{\text {st }}$ century":

"This White Paper sets out to foster debate and to assist decision-making - at decentralized national of Community level - so as to lay the foundations for sustainable development of the European economies, thereby enabling them to withstand international competition while creating the millions of jobs that are needed.

We are convinced that the European economies have a future. Looking at the traditional bases of property and competitiveness, Europe has preserved its chances. It possesses assets which it has only to exploit - assets such as its abundant non-physical capital (education, skills, capacity for innovation, traditions), the availability of financial capital and highly efficient banking institutions, the soundness of its social model, and the virtues of cooperation between the two sides of industry.

Given the scale of the needs that have to be met, both in the European Union and elsewhere in the world, recovery must be achieved by developing work and employment and not by endorsing basically Malthusian solutions. Yes, we can create jobs, and we must do so if we want to safeguard the future - the future of our children, who must be able to find hope and motivation in the prospect of participating in economic and social activity and of being involved in the society in which they live, and the future of our social protection systems, which are threatened in the short term by inadequate growth and in the long term by the deterioration in the ratio of the people in jobs to those not in employment.

In other words, we are faced with the immense responsibility, while remaining faithful to the ideals which have come to characterize and represent Europe, of finding a new synthesis of the aims pursued by society (work as a factor of social integration, equality of opportunity) and the requirements of the economy (competitiveness and job creation). [...]" (Commission of the European Communities, 1993, p. 3) 


\section{Box 17: European Lisbon Strategy 2000}

The following passage is an excerpt of the "European Council" presidency conclusion, held on the $23^{\text {rd }}$ and $24^{\text {th }}$ March 2000

\section{“A STRATEGIC GOAL FOR THE NEXT DECADE}

\section{The new challenge}

1. The European Union is confronted with a quantum shift resulting from globalisation and the challenges of a new knowledge-driven economy. These changes are affecting every aspect of people's lives and require a radical transformation of the European economy. The Union must shape these changes in a manner consistent with its values and concepts of society and also with a view to the forthcoming enlargement.

2. The rapid and accelerating pace of change means it is urgent for the Union to act now to harness the full benefits of the opportunities presented. Hence the need for the Union to set a clear strategic goal and agree a challenging programme for building knowledge infrastructures, enhancing innovation and economic reform, and modernising social welfare and education systems.

$[\ldots]$

\section{The way forward}

5. The Union has today set itself a new strategic goal for the next decade: to become the most competitive and dynamic knowledge-based economy in the world, capable of sustainable economic growth with more and better jobs and greater social cohesion. Achieving this goal requires an overall strategy aimed at:

- preparing the transition to a knowledge-based economy and society by better policies for the information society and $R \& D$, as well as by stepping up the process of structural reform for competitiveness and innovation and by completing the internal market;

- modernising the European social model, investing in people and combating social exclusion;

- sustaining the healthy economic outlook and favourable growth prospects by applying an appropriate macro-economic policy mix."

(Source: http://www.europarl.europa.eu/summits/lis1_en.htm, accessed 15/05/2014) 


\section{ANNEX 4: LIST OF FRENCH MINISTERS OF INDUSTRY}

Table 48 lists the titles of all French industrial ministers since the beginning of the $5^{\text {th }}$ Republic (since 1958). The list displays the slow diseaperance of the word industry in the title of the French minister who is ment to be responsible for the French industry.

Table 48: French Ministers of Industry since the beginning of the $5^{\text {th }}$ Republic

\begin{tabular}{|c|c|}
\hline Start & Title \\
\hline $01 / 1959$ & Ministre de l'industrie et du Commerce \\
\hline $11 / 1959$ & Ministre de l'industrie \\
\hline $06 / 1969$ & Ministre du Développement industriel et scientifique \\
\hline $02 / 1974$ & Ministre de l'industrie, du commerce et de l'artisanat \\
\hline $05 / 1974$ & Ministre de l'industrie et de la Recherche \\
\hline 03/1977 & Ministre de l'Industrie, du Commerce et de l'Artisanat \\
\hline 04/1978 & Ministre de l'industrie \\
\hline $03 / 1983$ & Ministre de l'industrie et de la recherche \\
\hline $07 / 1984$ & Ministre du Redéploiement industriel et du Commerce extérieur \\
\hline 03/1986 & Ministre de l'Industrie, des Postes et Télécommunications et du Tourisme \\
\hline $05 / 1988$ & Ministre de l'industrie, du commerce extérieur et de l'aménagement du territoire \\
\hline 06/1988 & Ministre de l'industrie et de l'aménagement du territoire \\
\hline $05 / 1991$ & Ministre d'État, ministre de l'Economie, des Finances et du budget \\
\hline 04/1992 & Ministre de l'industrie et du Commerce extérieur \\
\hline 03/1993 & Ministre de l'industrie, des postes et télécommunications et du commerce extérieur \\
\hline 05/1995 & Ministre de l'industrie \\
\hline $11 / 1995$ & Ministre de l'industrie, de la Poste et des Télécommunications \\
\hline $06 / 1997$ & Ministre de l'Économie, des Finances et de l'Industrie \\
\hline $03 / 2004$ & Ministre d'État, ministre de l'Économie, des Finances et de l'Industrie \\
\hline $06 / 2005$ & Ministre de l'Économie, des Finances et de l'Industrie \\
\hline $05 / 2007$ & Ministre de l'Économie, des Finances et de l'Emploi \\
\hline $11 / 2010$ & Ministre de l'Économie, des Finances et de l'Industrie \\
\hline $05 / 2012$ & Ministre du Redressement productif \\
\hline $04 / 2014$ & Ministre de l'Économie, du Redressement productif et du Numérique \\
\hline
\end{tabular}

Own compilation, source: http://www.gouvernement.fr/institutions/les-gouvernements-de-la-ve-republique\# \& http://fr.wikipedia.org/wiki/Liste_des_ministres_français_de_l'Industrie (accessed 9/6/2014) 


\section{ANNEX 5: FOCUS ON FRENCH “LOCAL PRODUCTIVE SYSTEMS” (SPL)}

The main dispositive that preceded the competitiveness cluster policy was the "local productive systems" ("systèmes productifs locaux" or SPL) initiative. This initiative, launched in 1998, was the first large-scale cluster-planning project in France. The initiative mainly covered only two policy areas: regional policy and industrial enterprise policy but not science \& technology policy (Fen Chong, 2009). The SPL policy was initiated according to the already explained French tradition: by the national government via an open call for tender. ${ }^{297}$ The different SPL projects were rather heterogeneous (Vibert \& Dupont, 2008). Chaubault (2009), summarizes that they are either (1) structured around traditional and craft based companies to foster complementarities (like industrial districts (Becattini, 1989)); or (2) structured around the scientific competences of the local actors thus technology oriented (like clusters (Porter, 1998c)), or (3) structured around big companies which had externalised their activities to local actors (like hub-and-spoke districts (Markusen, 1996)), or (4) just emerging around an external animator to start stimulating collaboration between the local actors. The SPL initiative launched a dynamic and allowed the actors to meet, to get to know each other and start working together (Carluer, 2006). However, not a lot of technology-oriented clusters emerged (Pommier \& Boilève, 2002), as the slected SPLs were more oriented towards the local development of SMEs (Duranton, et al., 2008). Additionally, the major industrial locations of the French territory were not applying for the official State label and so the collaboration between the most performing industrials and researchers stayed weak. In 2004, some of these SPLs were the incubators of today's French competitiveness clusters. However, it would be inaccurate to believe that these competitiveness clusters are only a continuity of the SPLs. The competitiveness clusters marked in reality a new departure in relation to the SPLs, and signal an unprecedented political era of French territory development. Despite their definitions, which might look similar, the local productive systems and competitiveness clusters differ in a certain number of elements (Perrat, 2007):

- Profile of the companies: the SPLs are predominantly based on the development of cooperation between SMEs, whereas the competitiveness clusters are predominantly based on large companies (Ernst \& Young, 2005);

- Relation to innovation: in the SPLs, the aim is to obtain an increasing yield related to a sectorial specialisation, whereas in the competitiveness cluster, the aim is to produce in a recurrent way - new products (Gaffard, 2005);

- Relation to space: the SPLs are based on proximity, whereas the competitiveness clusters have the vocation to go beyond the regional space to participate in the globalised market. This tendency could even increase with the rapprochement and collaboration of some competitiveness clusters;

- Relation to time: if the SPLs aim a middle- and long-term development, the competitiveness clusters work within a project temporality;

- Relation to employment: in the SPLs, the logic is to hire employees with local roots, whereas these considerations on social relations are still very weak in the competiveness clusters.

\footnotetext{
${ }^{297}$ The French government labelled the first projects in 1999 (124 applicants / 60 selections) and due to the great success immediately launched a second tender to label an additional 36 projects in 2000 (79 applicants) (Vibert $\&$ Dupont, 2008). Even though the first two calls for tender were the biggest ones, every year some additional SPLs were added (Vibert \& Dupont, 2008). In 2008 the SPLs were evaluated and the evaluation report (Vibert \& Dupont, 2008) stipulates that in the period between 1999 and 2007, 161 projects were labelled and the global budget accounted for 5.7 million Euros. However, from these 161 labelled SPLs only around hundred are still active because some stopped the project or were transformed into "competitiveness clusters" or other initiatives.
} 
ANNEX 6: E-MAIL TEMPLATE FOR CONTACTING PROJECT LEADERS

Betreff: Demande d'entretien : projet $[\ldots]$

Bonjour $[\ldots]$,

Je me permets de vous contacter au sujet de votre projet collaboratif [...] que vous avez soumis pour labellisation chez [...HealthCluster/Cap Digital/Systematic...] l'année dernière. J'aimerais, si bien sûr vous avez un moment à me consacrer, pouvoir m'entretenir avec vous.

Je mène actuellement une recherche de doctorat en gestion à l'ESCP Europe et à l'Observatoire des Pôles de Compétitivité (OPC) de Mines ParisTech. Mes recherches portent plus particulièrement sur la manière dont les pôles soutiennent (ou ne soutiennent pas) les projets collaboratifs de R\&D menés par les entreprises. Dans le cadre de cette recherche, je serai très intéressée d'avoir votre analyse sur les workshops TIC \& Santé organisés par HealthCluster, Cap Digital et Systematic l'année dernière et sur le soutien que vous avez reçu en amont, avant de soumettre votre projet [...] à la labellisation.

Cet entretien me permettrait de mieux comprendre les modalités et dispositifs de soutien des pôles, mais aussi leurs limites pour les projets d'innovation des entreprises. Cet entretien, effectué indépendamment de [...HealthCluster/Cap Digital/Systematic...], restera bien sûr anonyme.

Dans l'espoir que vous répondrez favorablement à ma demande d'entretien, je suis à votre disposition pour une interview dans les prochaines semaines. Je reste aussi à votre disposition pour tout renseignement complémentaire.

Merci beaucoup par avance pour votre aide dans mes recherches,

Bien cordialement,

Anna Glaser

Anna GLASER

Doctorante / $\mathrm{PhD}$ candidate

ESCP Europe (anna.glaser@escpeurope.eu)

Mines ParisTech (anna.glaser@mines-paristech.fr)

www.observatoirepc.org 
ANNEX 7: GENERAL INTERVIEW GUIDE FOR INTERVIEWING PROJECT

\section{LEADERS}

\section{Introduction:}

- $\quad$ Tell me about you, your professional background.

- I would like to talk with you about the [...name...] project. Could you tell me, in very simple words, what was the objective of the project? What is your companies responsibility / role in this project? What importance does this project have for your company?

\section{Project:}

- More particularly, please tell me about the genesis of the collaboration project? The story how everything began? (Who came up with the idea of the project?)

- How did you first meet your project partners? (Maybe without knowing you will collaborate with them one day, where, when, introduced / not introduced)

- Who initiated the idea to collaborate (Have you looked for potential partners or been approached by a partner?)

- With whom of these partners do you think you will do another project in the future?

- What is your experience in collaborative R\&D projects?

\section{Cluster membership:}

- How do the policy-driven clusters help you? Which importance do they have for you? When do you contact them?

\section{General:}

- Please tell me about the integration of your company in your sector's community? (participation in associations, meetings, conferences, etc.)

- Do you discuss your projects publicly during these activities? Why/Why not?

- What is the work culture within your company? (Are you allowed to participate in conferences, meetings during your work-time or is it something you have to do after work?)

- Do you prefer collaborating with actors, which are situated within the Paris region? Why? / Why not? 


\section{ANNEX 8: CRITERIA OF THE FRENCH CLUSTER EVALUATION}

Box 18 summarizes a range of key indicators that were collected by the evaluators in 2008 to evaluate the performance of the different policy-driven clusters situated in France.

\section{Box 18: Selection of key criteria used for the French cluster evaluation in 2008}

I. Indicators regarding the "transformation rate" of $R \& D$ projects (from planned to financed):

I.1. How many projects were submitted to the cluster for examination?

I.2. How many projects were submitted to the cluster for labelling?

I.3. How many projects were labelled by the cluster?

I.4. How many projects were submitted to financers?

I.5. How many projects were financed?

I.6. How much money was generated?

I.6.1. How much money was generated for 'SME < 250', 'SME > 250', 'Large firm > 2000', or 'Research and/or Training Institutes'?

II. Indicators regarding the diversity and the leadership of $R \& D$ project teams:

II.1. How many 'Young Innovative Companies', 'SME < 250', 'SME > 250', 'Large firm > 2000', or 'Research and/or Training Institutes' have been project leaders of collaborative R\&D projects?

II.2. How many 'Young Innovative Companies', 'SME < 250', 'SME > 250', 'Large firm > 2000', or 'Research and/or Training Institutes' participated in collaborative R\&D projects?

II.3. How many 'new project partners' (i.e. they have never been in a cluster project before) participated in collaborative R\&D projects?

II.3.1. Who (i.e. SME < 250, SME > 250) are the new project partners?

III. Indicators regarding the general diversity of the cluster

III.1. How many cluster members does the cluster count?

III.1.1. Who (i.e 'SME < 250', 'SME > 250', 'Large firm > 2000', or 'Research and/or Training Institutes') are these cluster members?

IV. Indicators regarding the leadership/supervision of the cluster

IV.1. How many cluster members are in the management board of the cluster?

IV.1.1. Who (i.e 'SME < 250', 'SME > 250', 'Large firm > 2000', or 'Research and/or Training Institutes') are these cluster members?

IV.2. How many cluster members are in the supervisory board of the cluster?

IV.2.1. Who (i.e 'SME < 250', 'SME > 250', 'Large firm > 2000', or 'Research and/or Training Institutes') are these cluster members?

IV.3. How many cluster members are in the labelling committee of the cluster?

IV.3.1. Who (i.e 'SME < 250', 'SME > 250', 'Large firm > 2000', or 'Research and/or Training Institutes') are these cluster members?

V. Indicators regarding the management of the cluster (operational team)

V.1. How many full time equivalents are working for the cluster?

V.2. What is the time repartition between following tasks:

V.2.1. Help in the detection, planning and supervision of $R \& D$ projects

V.2.2. Communication, promotion, recruitment of members

V.2.3. Cluster life (committees, meetings, seminars, etc.)

V.2.4. Internationalisation

V.2.5. Administrative tasks

V.2.6. Other

VI. Indicators regarding the budget of the cluster organisation

VI.1. How much money does the cluster organisation have?

VI.1.1. Who (i.e. the State, national agencies, the Region, regional agencies, other local authorities, cluster members, Research and/or Training Institutes') provided the money?

VI.1.2. For what was the money spent?

VI.1.2.1.Employee salaries

VI.1.2.2.Functioning (rent, furniture, etc.)

VI.1.2.3.Specific actions (communication campaign, international visibility, etc.)

VI.1.2.4.Specific survey or expertise (market research, set up of intranet, etc.) 


\section{ANNEX 9: HCPR'S TECHNOLOGICAL R\&D OBJECTIVES}

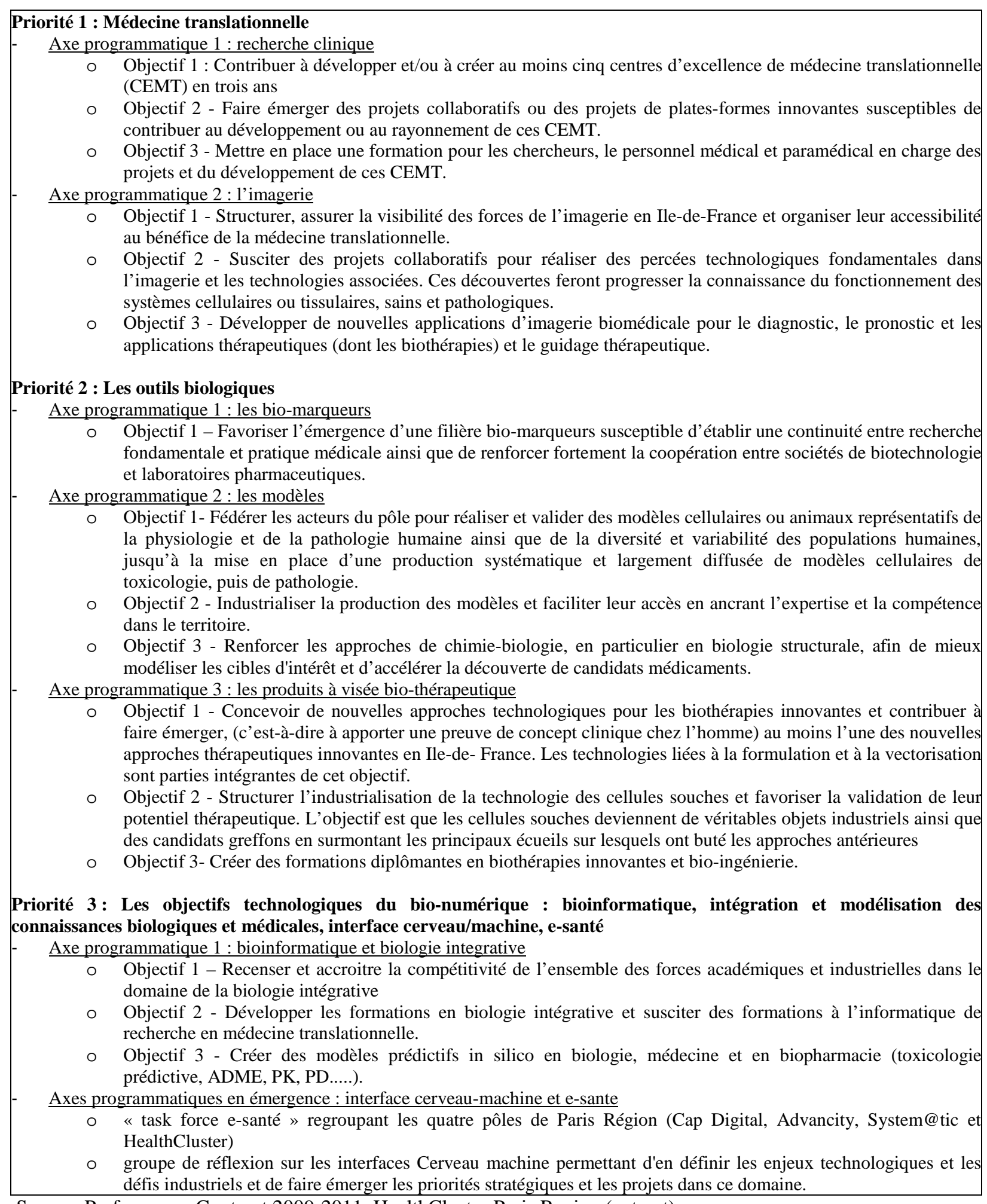

Source: Performance Contract 2009-2011, HealthCluster Paris Region (extract) 


\section{ANNEX 10: HCPR'S ANIMATION AND DEVELOPMENT OBJECTIVES}

The following tables (Table 49 to Table 52) summarize the four priorities of HealthCluster Paris Region for the $2^{\text {nd }}$ cluster phase (2009 to 2011, and then extended to 2012). These priorities were part of the performance contract HCPR signed with the State and the regional authorities.

Table 49: Priority 1: Creating a community of thoughts, objectives and actions

\begin{tabular}{|c|c|c|c|}
\hline & Challenges & Activities (\& Deliverables) & \\
\hline Objective & $\begin{array}{l}\text { - Valeur ajoutée du pôle } \\
\text { pour ses membres. } \\
\text { - Développer } \\
\text { l'écosystème du pôle et } \\
\text { les filières qui s'y } \\
\text { rattachent. } \\
\text { - Créer une communauté } \\
\text { exemplaire qui donne } \\
\text { envie d'adhérer au pôle, } \\
\text { renforcer la connaissance } \\
\text { réciproque des membres, } \\
\text { consolider lesprit } \\
\text { dee appartenance et } \\
\text { favoriser les initiatives } \\
\text { communes. }\end{array}$ & $\begin{array}{l}\text { Action } 1 \text { : etats de lieux complet } \\
\text { - Identifier les données à collecter et les outils et } \\
\text { cartographie des membres du pôle. } \\
\text { - Elaborer la cartographie des acteurs franciliens } \\
\text { concernés par les priorités stratégiques du pôle / } \\
\text { cartographie interactive complète des compétences } \\
\text { disponibles sur l'intranet et extranet. } \\
\text { Action } 2 \text { : échanges réguliers entres les acteurs du pôle } \\
\text { - Organiser des tables rondes / rencontres sur des } \\
\text { thématiques ciblées sur chacune des priorités du pôle / } \\
\text { Lancement d'appel à projets / " } n \text { " projets soumis et } \\
\text { labellisés } \\
\text { Action } 3 \text { : information régulière des membres } \\
\text { - Mettre en place une nouvelle gouvernance. } \\
\text { - Organiser des réunions régulières entre les } \\
\text { responsables des comités stratégiques et le délégué } \\
\text { général / animation des comités stratégiques } \\
\text { - Animer les collèges (par les vice-présidents). }\end{array}$ & $\begin{array}{l}\text { - Augmentation du } \\
\text { nombre de projets } \\
\text { collaboratifs. } \\
\text { - Renforcement de } \\
\text { la vie du cluster et } \\
\text { de l'image de } \\
\text { HealthCluster. } \\
\text { - Augmentation du } \\
\text { nombre } \\
\text { d'adhérents. }\end{array}$ \\
\hline
\end{tabular}

Source : Performance Contract 2009-2011, HealthCluster Paris Region (extraits) 
Table 50: Priority 2: Being the key health actor in the Paris Region

\begin{tabular}{|c|c|c|c|}
\hline & Challenges & Activities (\& Deliverables) & Impact \\
\hline $\begin{array}{l}\text { Objectif } 1 \text { : } \\
\text { Développer les } \\
\text { ressources } \\
\text { financières du } \\
\text { pôle. }\end{array}$ & $\begin{array}{l}\text { Assurer la pérennité } \\
\text { financière du pôle. }\end{array}$ & $\begin{array}{l}\text { Action } 1 \text { : maintenir des relations régulières } \\
\text { avec les financeurs publics. } \\
\text { - Signature annuelle des conventions avec les } \\
\text { financeurs publics } \\
\text { Action } 2 \text { \& } 3 \text { : diversifier les ressources } \\
\text { financières nécessaires au pôle et lancer une } \\
\text { réflexion et identifier les actions permettant de } \\
\text { développer les ressources propres du pôle. }\end{array}$ & $\begin{array}{l}\text { Conforter l'existence du } \\
\text { pôle HealthCluster, } \\
\text { réalisation de ses } \\
\text { objectifs }\end{array}$ \\
\hline $\begin{array}{l}\text { Objectif } 2 \text { : } \\
\text { Proposer aux } \\
\text { partenaires } \\
\text { publics du pôle } \\
\text { des initiatives } \\
\text { et des actions } \\
\text { pertinentes, en } \\
\text { cohérence avec } \\
\text { ses priorités } \\
\text { stratégiques et } \\
\text { développer les } \\
\text { partenariats } \\
\text { régionaux. }\end{array}$ & $\begin{array}{l}\text { Harmonisation et } \\
\text { coordination des } \\
\text { structures du secteur de } \\
\text { la santé en IdF. Effet } \\
\text { cluster. }\end{array}$ & $\begin{array}{l}\text { Action 1: proposer des actions et des choix } \\
\text { dans le cadre des projets d'aménagement du } \\
\text { territoire et des documents d'orientation } \\
\text { technique et économique locale, régionale } \\
\text { (CPER). } \\
\text { - Contribution à la réflexion sur la place des } \\
\text { sciences de la vie et de la santé sur le campus } \\
\text { Saclay. } \\
\text { Action } 2 \text { : développer des partenariats entre } \\
\text { membres du pôle et avec d'autres acteurs de la } \\
\text { Région, dont les pôles de compétitivité } \\
\text { - Réunions périodiques entre les responsables } \\
\text { des incubateurs et des parcs biotechnologiques } \\
\text { - signature d'un accord de partenariat avec } \\
\text { System @ tic, Advancity et Cap Digital. } \\
\text { - signature d'un accord de partenariat avec } \\
\text { d'autres pôles. }\end{array}$ & $\begin{array}{l}\text { Contribution à la } \\
\text { structuration territoriale } \\
\text { de la Région et du } \\
\text { secteur santé francilien } \\
\text { en renforçant les sites } \\
\text { qui peuvent acquérir ou } \\
\text { augmenter leur visibilité } \\
\text { internationale. }\end{array}$ \\
\hline $\begin{array}{l}\text { Objective } 3 \text { : } \\
\text { Développer les } \\
\text { formations et } \\
\text { les } \\
\text { enseignements } \\
\text { qui répondent } \\
\text { aux besoins } \\
\text { actuels et } \\
\text { futurs des } \\
\text { entreprises et } \\
\text { des organismes } \\
\text { de recherche et } \\
\text { renforcer } \\
\text { l'attractivité } \\
\text { des universités }\end{array}$ & $\begin{array}{l}\text { - Attractivité de la } \\
\text { région IdF. } \\
\text { - Pérennité de } \\
\text { l'excellence scientifique } \\
\text { et médicale de l'IdF. } \\
\text { - Développement des } \\
\text { échanges scientifiques. } \\
\end{array}$ & $\begin{array}{l}\text { Action } 1 \text { : créer un groupe de travail pour } \\
\text { identifier et anticiper les besoins en } \\
\text { compétences des entreprises et des laboratoires } \\
\text { en matière d'enseignement supérieur et de } \\
\text { formation continue pour que les universités et } \\
\text { les Ecoles puissent mettre en place les } \\
\text { nouveaux enseignements et cursus adaptés. } \\
\text { - Rapport sur les besoins exprimés en } \\
\text { formation } \\
\text { Action } 2 \text { : labelliser et favoriser des formations } \\
\text { ou des modalités de formation dans les } \\
\text { domaines de la médecine translationnelle, des } \\
\text { biotechnologies et de la bio-informatique } \\
\text { répondant aux critères définis par le pôle . } \\
\text { Action } 3 \text { : favoriser la mise en place de stages, } \\
\text { la réalisation de formations mixtes ou } \\
\text { l'utilisation de plates-formes technologiques } \\
\text { pour les formations et participer ainsi à } \\
\text { l'attractivité des universités et des écoles. }\end{array}$ & $\begin{array}{l}\text { - Accès facilité des } \\
\text { étudiants aux lieux } \\
\text { d'excellence, de haute } \\
\text { technicité (plates- } \\
\text { formes), ainsi qu'aux } \\
\text { centres industriels dans } \\
\text { le cadre normal de leur } \\
\text { cursus ; } \\
\text { - Capacité de concevoir } \\
\text { et de mettre en place des } \\
\text { formations nouvelles } \\
\text { nécessaires aux métiers } \\
\text { de demain comme la } \\
\text { mise en place des } \\
\text { filières d'enseignements } \\
\text { pluridisciplinaires. } \\
\text { - Attractivité renforcée } \\
\text { des établissements qui } \\
\text { dispensent des } \\
\text { formations et des } \\
\text { enseignements dans les } \\
\text { sciences de la vie et de } \\
\text { la santé. }\end{array}$ \\
\hline
\end{tabular}

Source : Performance Contract 2009-2011, HealthCluster Paris Region (extraits) 
Table 51: Priority 3: Structuring the healthcare sector in the Paris Region

\begin{tabular}{|c|c|c|c|}
\hline & Challenges & Activities (\& Deliverables) & Impact \\
\hline $\begin{array}{l}\text { Objectif } 1 \text { : } \\
\text { Organiser la } \\
\text { structuration des } \\
\text { PME santé de la } \\
\text { région en filières, } \\
\text { par offre } \\
\text { technologique ou } \\
\text { par finalité } \\
\text { thérapeutique, dans } \\
\text { le cadre du plan } \\
\text { filière Ile-de- } \\
\text { France }\end{array}$ & $\begin{array}{l}\text { Le renforcement } \\
\text { du tissu des PME } \\
\text { santé en Ile-de- } \\
\text { France est } \\
\text { indispensable } \\
\text { pour développer } \\
\text { l'emploi et } \\
\text { accroître } \\
\text { l'attractivité de la } \\
\text { Région. }\end{array}$ & $\begin{array}{l}\text { Action 1: établir une typologie des PME (offre, } \\
\text { besoin, domaine deactivité) à partir de la cartographie } \\
\text { établie dans la Priorité } 1 . \\
\text { - Cartographie complète des filières PME dans le } \\
\text { cadre de la cartographie des membres } \\
\text { Action } 2 \text { : organiser des visites et des entretiens } \\
\text { réguliers avec les PME. } \\
\text { Action } 3 \text { : prospecter activement le tissu des biotechs } \\
\text { et des PME de la Région dont les activités s'inscrivent } \\
\text { dans les axes prioritaires des thématiques ou en soutien } \\
\text { technologiques pour qu'elles bénéficient de la } \\
\text { dynamique du Pôle. } \\
\text { Action } 4 \text { : établir le plan filière PME biotechnologies } \\
\text { en Ile-de-France. }\end{array}$ & $\begin{array}{l}\text { (pas renseigné } \\
\text { dans le contrat de } \\
\text { performance) }\end{array}$ \\
\hline $\begin{array}{l}\text { Objectif } \mathbf{2} \text { : } \\
\text { Optimiser l'accès } \\
\text { des PME aux } \\
\text { financements privés } \\
\text { et publics } \\
\text { (régionaux, } \\
\text { nationaux, } \\
\text { européens) et } \\
\text { favoriser le } \\
\text { développement de } \\
\text { leur activité (R\&D } \\
\text { et chiffre } \\
\text { d'affaires) }\end{array}$ & $\begin{array}{l}\text { Le pôle doit créer } \\
\text { les conditions } \\
\text { favorables à la } \\
\text { pérennité et au } \\
\text { développement } \\
\text { des PME/JEI } \\
\text { existantes et à la } \\
\text { naissance de } \\
\text { nouvelles } \\
\text { entreprises. }\end{array}$ & $\begin{array}{l}\text { Action 1: travailler à améliorer la compréhension de la } \\
\text { diversité auprès d'une base large d'investisseurs pour } \\
\text { adapter les financements à chaque type de société et à } \\
\text { un stade de maturation défini } \\
\text { Action } 2 \text { : faciliter l'accès au fonds d'investissement } \\
\text { dédié aux biotechnologies (...), à l'investissement } \\
\text { privé, aux marchés de capitaux, et à une offre } \\
\text { diversifiée de financement ; (...) le développement des } \\
\text { partenariats avec les grands acteurs industriels, (...) la } \\
\text { connaissance des sociétés de service, notamment les } \\
\text { prestataires de R\&D contribuant à l'offre } \\
\text { technologique de la région. } \\
\text { Action } 3 \text { : soutenir le développement du chiffre } \\
\text { d'affaires des PME et réduire leurs coûts de } \\
\text { fonctionnement par le soutien de la "première } \\
\text { commande" des jeunes sociétés innovantes en liaison } \\
\text { avec les incubateurs du pôle ; par une action proactive } \\
\text { du pôle auprès des PME et des grands groupes ; par le } \\
\text { rapprochement de PME complémentaires pour passer } \\
\text { de l'offre technologique individuelle à la construction } \\
\text { de solutions intégrées innovantes qui répondent aux } \\
\text { attentes des grands comptes ; par la mise en place de } \\
\text { structures mutualisées qui prennent en compte les } \\
\text { compétences spécifiques des PME. } \\
\text { Action } 4 \text { : faciliter l'identification et l'accès des PME } \\
\text { innovantes aux programmes européens, en utilisant la } \\
\text { base de données qui sera constituée par le pôle ou en } \\
\text { s'appuyant sur les structures d'accompagnement } \\
\text { régionales et nationales } \\
\text { - Création d'un club des investisseurs. } \\
\text { - Collaboration à organiser avec le pôle de } \\
\text { compétitivité Innovation Finance } \\
\text { - Constitution d'un premier consortium pour répondre } \\
\text { à un appel à projets européen \& Participer aux grands } \\
\text { projets européens }\end{array}$ & $\begin{array}{l}\text { le } \\
\\
\text { - Renforcement } \\
\text { du tissu des PME } \\
\text { santé en Ile-de- } \\
\text { France. } \\
\text { - Augmentation } \\
\text { du nombre } \\
\text { d'emplois. } \\
\end{array}$ \\
\hline
\end{tabular}

Source: Performance Contract 2009-2011, HealthCluster Paris Region (extraits) 
Table 52: Priority 4: Development of national and international partnerships

\begin{tabular}{|c|c|c|c|}
\hline & Challenges & Activities (\& Deliverables) & Impact \\
\hline Objectif & $\begin{array}{l}\text { La réussite du pôle } \\
\text { repose sur sa notoriété } \\
\text { et sur sa capacité à } \\
\text { susciter des partenariats } \\
\text { en son sein, ainsi } \\
\text { queavec des pôles } \\
\text { partenaires nationaux et } \\
\text { internationaux } \\
\text { complémentaires. }\end{array}$ & $\begin{array}{l}\text { Action 1: développer le pôle et accroître la } \\
\text { dynamique du pôle au travers des partenariats } \\
\text { avec les clusters bio-santé nationaux (autres que } \\
\text { les franciliens) et internationaux complémentaires } \\
\text { pour donner aux membres accès à des ressources } \\
\text { et opportunités non disponibles en Ile-de-France. } \\
\text { - établissement d'une stratégie } \\
\text { communication/notoriété et d'un plan de } \\
\text { communication. } \\
\text { - signature d'au moins deux accords avec des } \\
\text { pôles nationaux et internationaux. } \\
\text { Action } 2 \text { : promouvoir le pôle et ses membres (i) } \\
\text { l'offre technologique et académique du pôle ; (ii) } \\
\text { ses spécificités et ses actions emblématiques pour } \\
\text { attirer et accueillir des investisseurs } \\
\text { ou des laboratoires R\&D de grands groupes } \\
\text { internationaux ; (iii) ses acteurs, notamment, les } \\
\text { PME, qui seront soutenues à travers des actions } \\
\text { ciblées ou collectives, dans leur prospection } \\
\text { internationale ou lors de leur participation à des } \\
\text { grands événements professionnels dans le monde. } \\
\text { - Mise en æeuvre des actions en particulier la } \\
\text { présence aux manifestations internationales (par } \\
\text { exemple : Salon BioMed Israel, Salon } \\
\text { EuroBioLille, Bio Japan et mission collective en } \\
\text { Corée) } \\
\text { - organisation d'un événement fédérateur } \\
\text { HealthCluster } \\
\text { - organisation du premier grand événement } \\
\text { récurrent et de dimension } \\
\text { internationale, en Ile-de-France, pour valoriser } \\
\text { les forces du pôle au niveau mondial et asseoir sa } \\
\text { légitimité dans le domaine. }\end{array}$ & $\begin{array}{l}\text { Potoriété et } \\
\text { attractivité de } \\
\text { HealthCluster et } \\
\text { de son } \\
\text { écosystème. } \\
\\
\\
\\
\end{array}$ \\
\hline
\end{tabular}

Source: Performance Contract 2009-2011, HealthCluster Paris Region (extraits) 


\section{ANNEX 11: HCPR'S VALUE CHAIN MAPPINGS}

Figure 49 to Figure 54 present the different cluster mapping results of HCPR's operational team.

Figure 49: The value chain (CDV) of the biotechnology \& health sector in the PR

\begin{tabular}{|c|c|c|c|}
\hline & & Intitulé & Détails \\
\hline CDV 1 & Vac & $\begin{array}{c}\text { Vaccins } \\
\text { préventifs et } \\
\text { thérapeutiques }\end{array}$ & $\begin{array}{l}\text { Médicaments immunologiques contenant des virus, bactéries, } \\
\text { parasites, fragments de microbes ou substances visant à conduire } \\
\text { au développement d'une réponse immunitaire spécifique }\end{array}$ \\
\hline CDV 2 & TG & $\begin{array}{l}\text { Thérapie } \\
\text { génique }\end{array}$ & $\begin{array}{c}\text { Ensemble des médicaments obtenus parun ensemble de procédés } \\
\text { de fabrication visant au transfert d'un gène chez l'homme et son } \\
\text { expression consécutive in vivo }\end{array}$ \\
\hline CDV 3 & TC & $\begin{array}{l}\text { Thérapie } \\
\text { cellulaire }\end{array}$ & $\begin{array}{c}\text { Cellules humaines utilisées à des fins thérapeutiques quel que soit } \\
\text { le niveau de transformation, y compris leurs dérivés }\end{array}$ \\
\hline CDV 4 & PT & $\begin{array}{l}\text { Protéines } \\
\text { thérapeutiques }\end{array}$ & Biomédicaments polypeptidiques \\
\hline CDV 5 & MCS & $\begin{array}{l}\text { Molécule } \\
\text { chimique de } \\
\text { synthèse }\end{array}$ & $\begin{array}{l}\text { Ensemble des moléculeschimiques à visée thérapeutiqueou } \\
\text { diagnostic hors produits biologiques thérapeutiques }\end{array}$ \\
\hline CDV 6 & DIVit & $\begin{array}{l}\text { Diagnostic in } \\
\text { vitro }\end{array}$ & $\begin{array}{l}\text { Ensemble des produits utilisés surdes échantillons de tissus ou } \\
\text { des fluides biologiques du patient dans un but de diagnostic }\end{array}$ \\
\hline CDV 7 & DM & $\begin{array}{l}\text { Dispositifs } \\
\text { médicaux }\end{array}$ & $\begin{array}{l}\text { Tout instrument, appareil, équipement, matière, produit, à } \\
\text { l'exceptiondes produits d'origine humaine, destiné à être utilisé } \\
\text { chez l'homme à des fins médicales }\end{array}$ \\
\hline CDV 8 & TS & E santé & $\begin{array}{l}\text { Ensemble des ressources contribuant à la santé via les TIC et } \\
\text { englobant la télé-médecine, la télé-assistance et la télé-chirurgie }\end{array}$ \\
\hline CDV 9 & Service & Service & Toutes PME avec une activité de service dans la santé humaine \\
\hline
\end{tabular}

Source: Internal document (10/2010)

Figure 50: Number of SMEs in every value chain

\begin{tabular}{|c|c|c|c|c|c|}
\hline & & Intitulé & $\begin{array}{c}\text { PRODUIT } \\
\text { Nombre de PME (19 PME sont sur } \\
\text { plusieurs CDV) }\end{array}$ & $\begin{array}{l}\text { CDV } 9 \text { SERVICE } \\
\text { Nombre de PME }\end{array}$ & $\begin{array}{l}\text { Outils pour la } \\
\text { recherche }\end{array}$ \\
\hline CDV 1 & Vac & $\begin{array}{l}\text { Vaccins préventifs et } \\
\text { thérapeutiques }\end{array}$ & 13 & \multirow{8}{*}{$\begin{array}{c}85 \text { PME avec une } \\
\text { activité de service } \\
\text { pouvant être spécifique } \\
\text { à une CDV ou transverse } \\
\text { à plusieurs CDV }\end{array}$} & \multirow{8}{*}{$\begin{array}{c}29 \text { PME } \\
\text { développant des } \\
\text { outils pour la } \\
\text { recherche avec } \\
\text { un } \\
\text { positionnement } \\
\text { transverse aux } 9 \\
\text { CDV identifiées }\end{array}$} \\
\hline $\operatorname{CDV} 2$ & TG & Thérapie génique & 5 & & \\
\hline CDV 3 & TC & Thérapie cellulaire & 8 & & \\
\hline CDV 4 & PT & $\begin{array}{l}\text { Protéines } \\
\text { thérapeutiques }\end{array}$ & 13 & & \\
\hline CDV 5 & MCS & $\begin{array}{l}\text { Molécule chimique de } \\
\text { synthèse }\end{array}$ & 49 & & \\
\hline CDV 6 & DIV & Diagnostic in vitro & 30 & & \\
\hline CDV 7 & DM & Dispositifs médicaux & $\begin{array}{c}94 \text { dont } 25 \text { PME dédiées à l'imagerie de } \\
\text { I'homme ou de l'animal, } 7 \text { à la radiothérapie et } \\
2 \text { au dossier patient }\end{array}$ & & \\
\hline CDV 8 & TS & E-santé & 27 & & \\
\hline
\end{tabular}

Source: Internal document (10/2010) 
Figure 51: Focus on the value chain of medical imagery companies

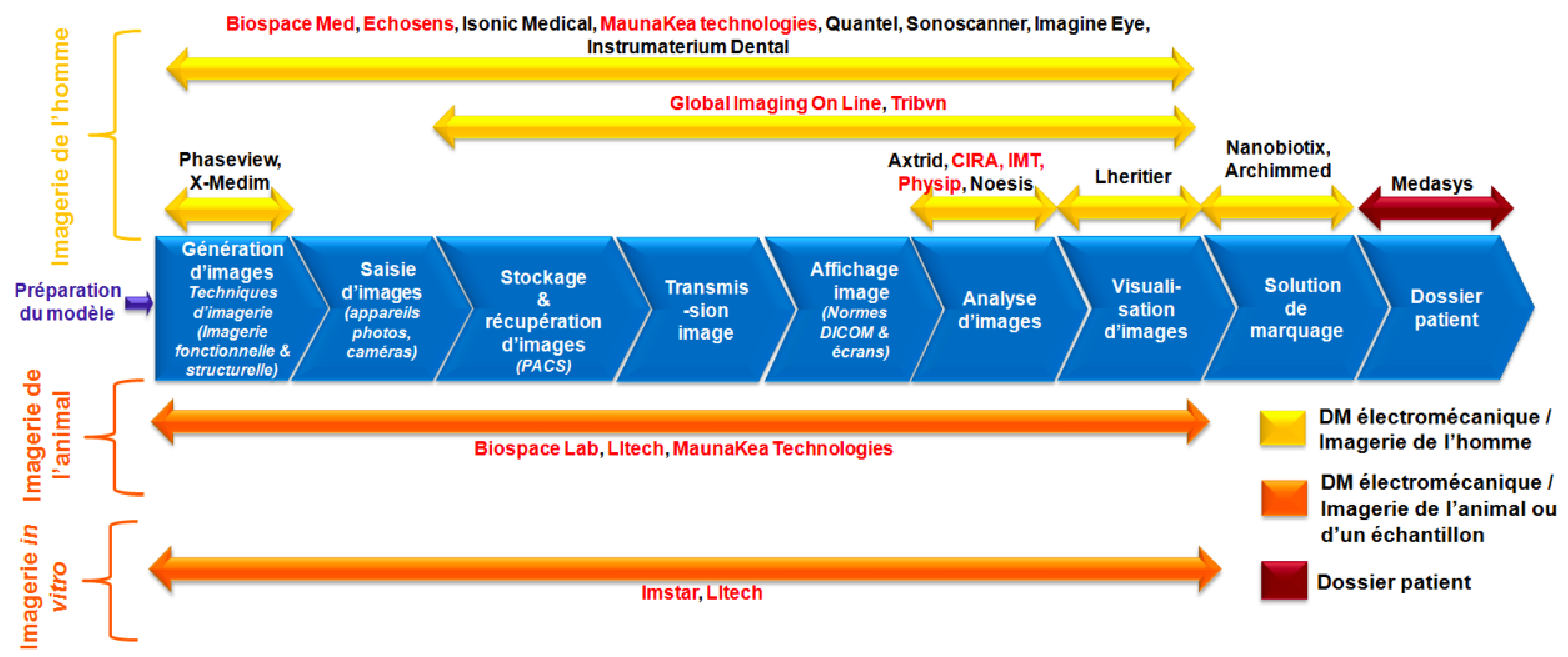

Source: Internal document (10/2010)

Figure 52: Comparison between SMEs and Large groups

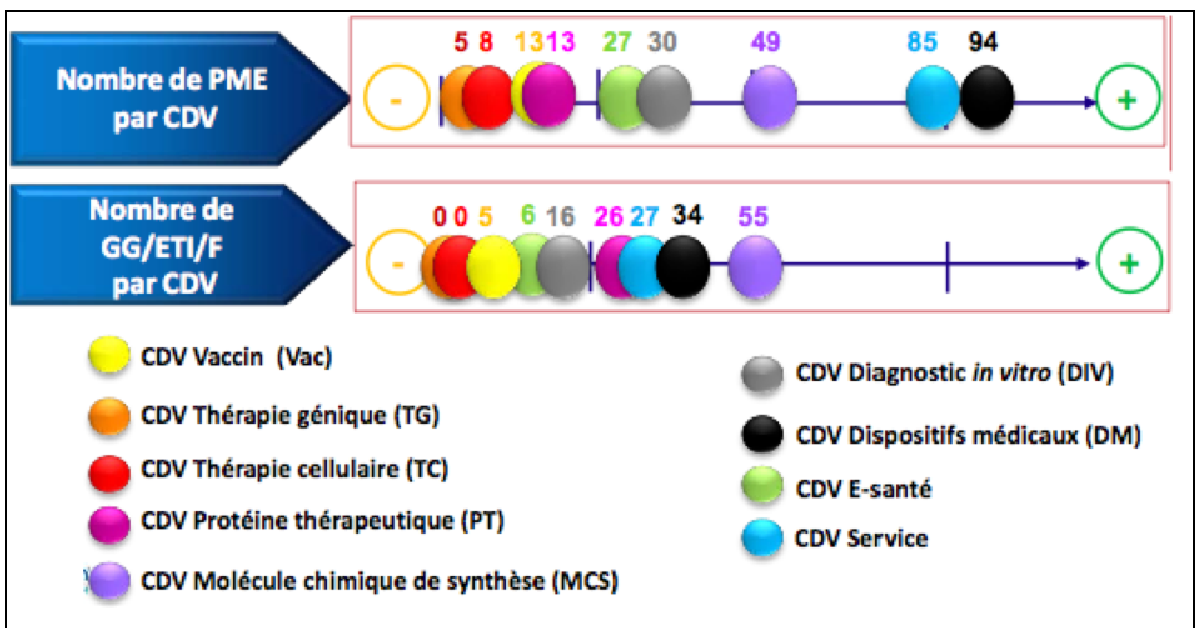

Source: internal document of HCPR (10/2010) 
Figure 53: All value chains of the biotechnology and health sector in the Paris Region

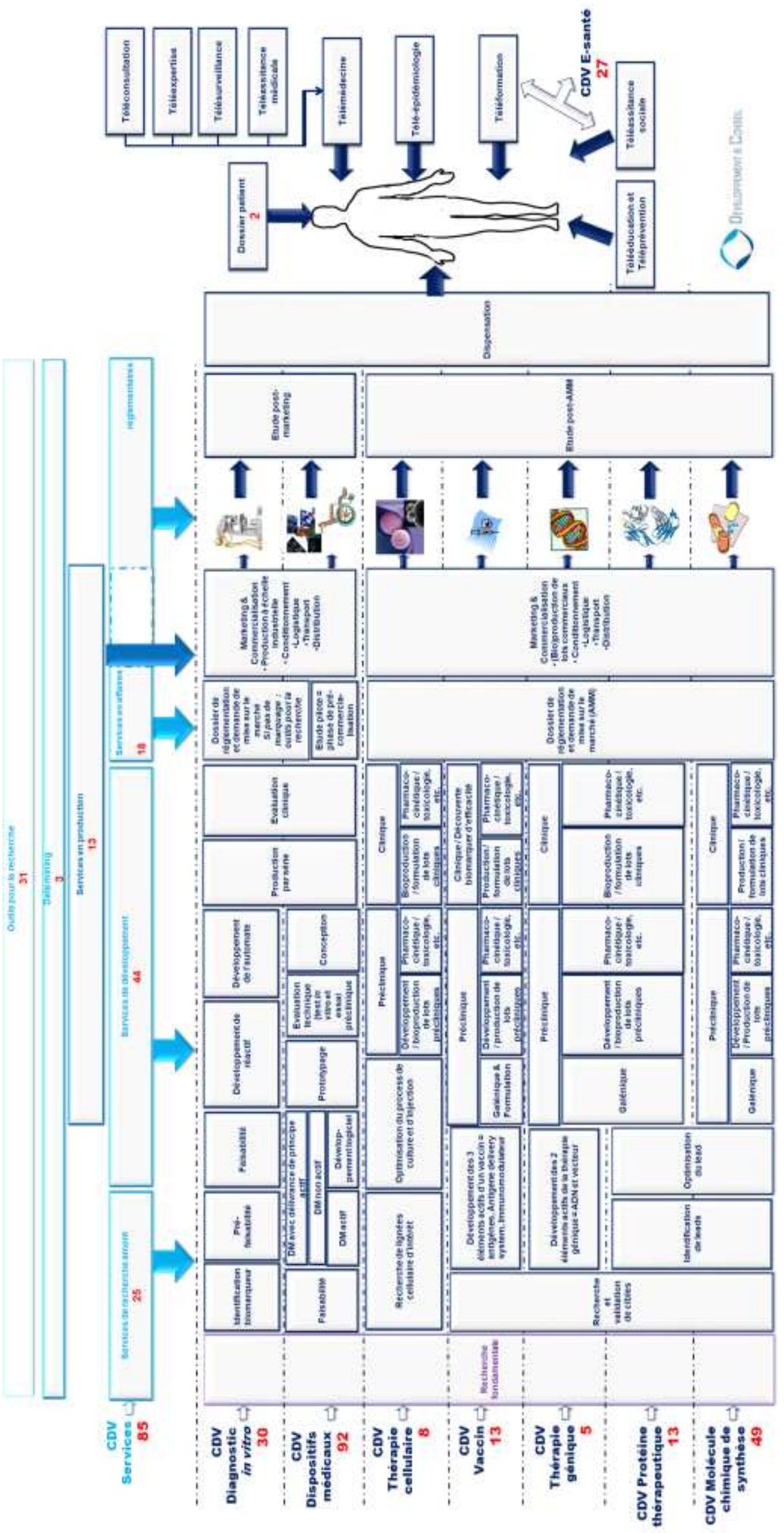

Source: internal document of HCPR (10/2010) 
Figure 54: Cartography of the biotechnology and health sector of the Paris Region

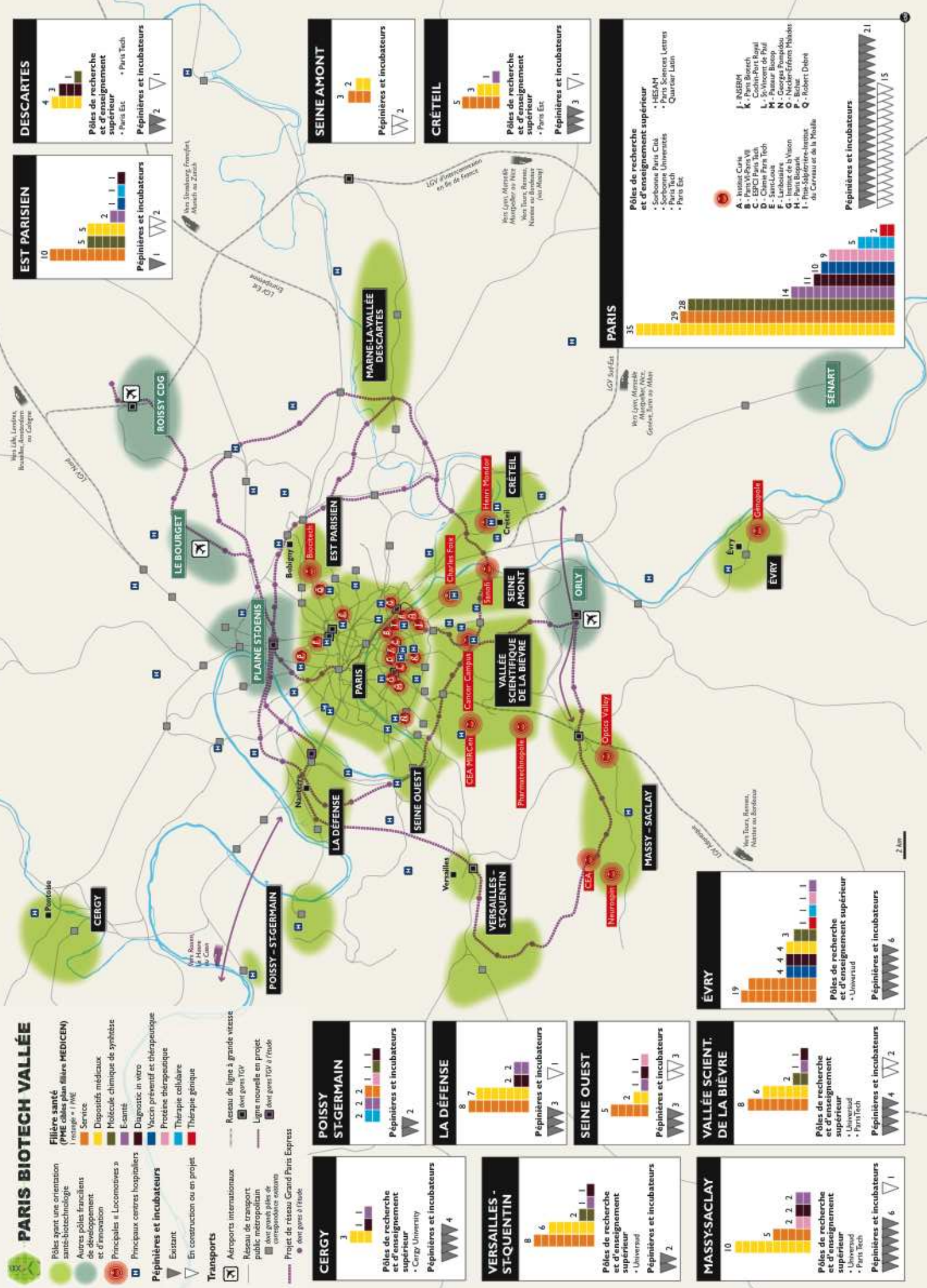

Source: internal document of HCPR (01/2012) 


\section{ANNEX 12: PROJECT, COMPETENCES \& NEEDS PRESENTATION TEMPLATES}

Figure 55 and Figure 56 show the different presentation templates that have to be used during ICT \& Health events.

Figure 55: Project presentation template

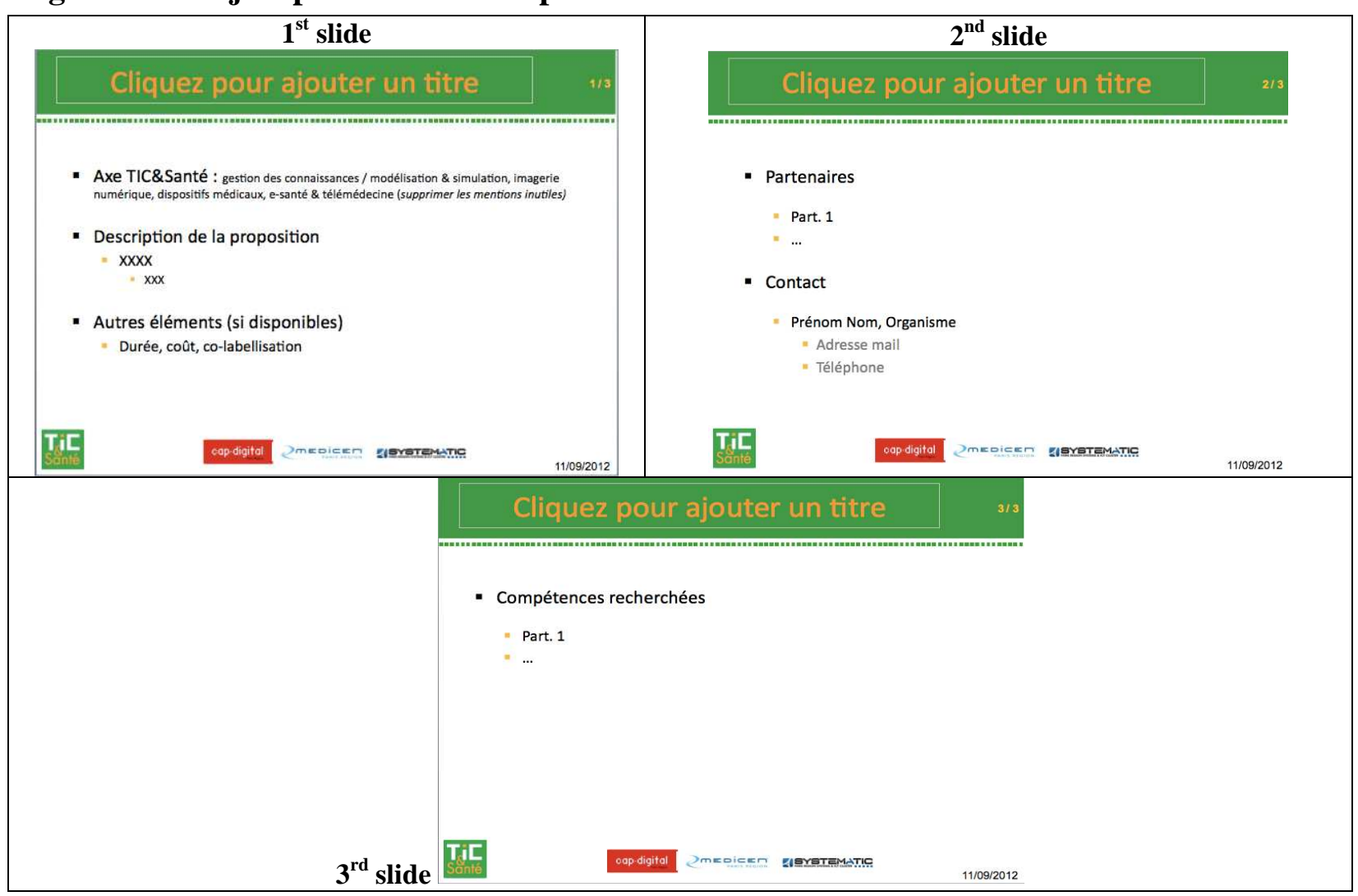

Source: Cap Digital Website (04/2013) 
Figure 56: Competences and need presentation template

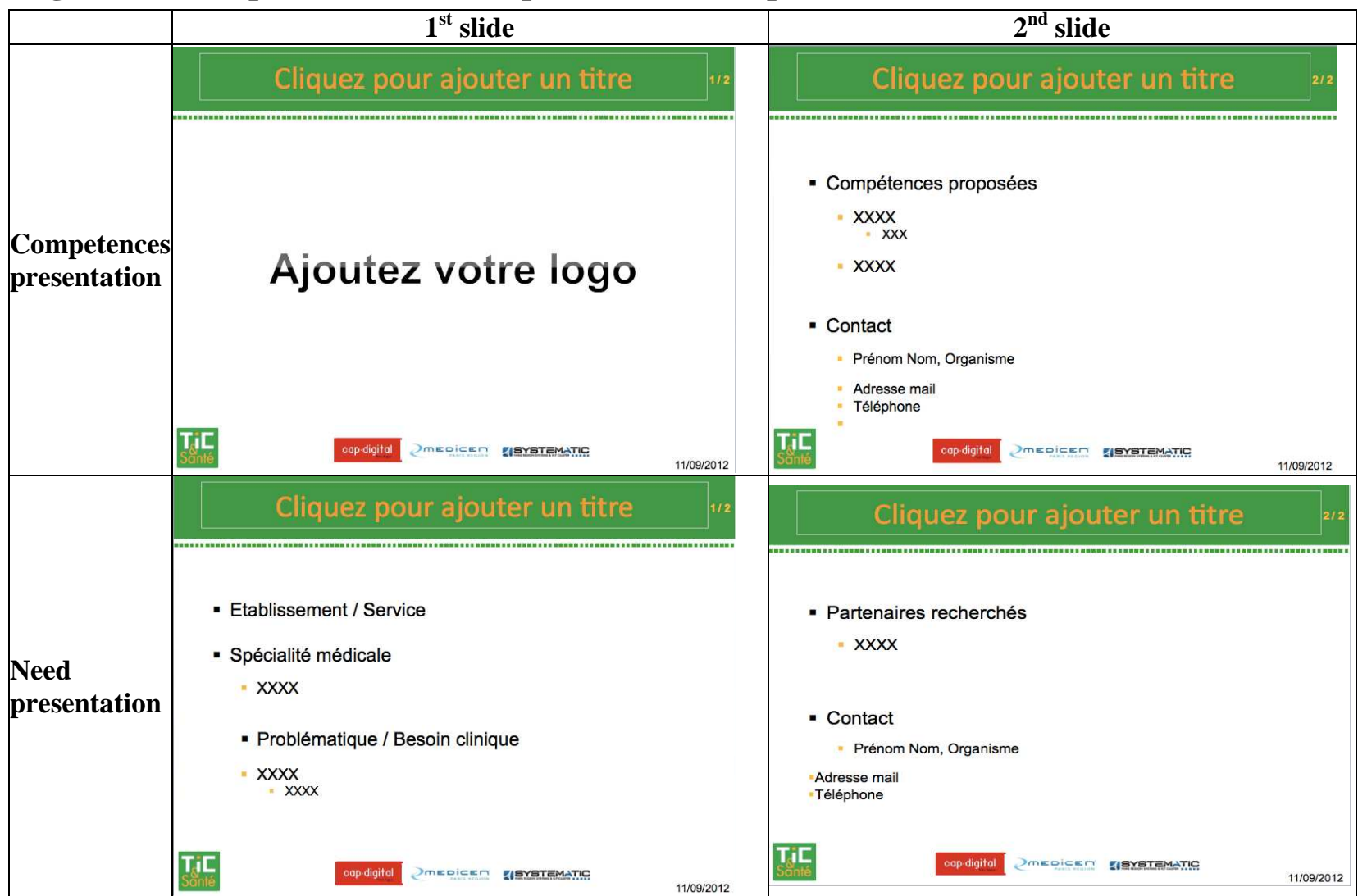

Source: Cap Digital Website (04/2013) 


\section{ANNEX 13: CHARACTERISTICS OF PROJECT LEADERS \& THEIR}

\section{ORGANISATIONS}

Table 53 \& Table 54: overview of the interviewed project leaders and their organsiations.

Table 53: Characteristics of the investigated cluster actors

\begin{tabular}{|c|c|c|c|c|c|c|c|}
\hline$\#$ & $\begin{array}{l}\text { Gend } \\
\text { er }\end{array}$ & Education & $\begin{array}{l}\text { Professi } \\
\text { onal } \\
\text { experien } \\
\text { ce (app.) }\end{array}$ & Job Title & $\begin{array}{l}\text { Interviewee's } \\
\text { responsibility in } \\
\text { company }\end{array}$ & $\begin{array}{l}\text { Once a project } \\
\text { gets financed... }\end{array}$ & $\begin{array}{l}\text { Free } \\
\text { electro } \\
\text { ns / } \\
\text { Libert } \\
\text { y }\end{array}$ \\
\hline P1 & Male & $\begin{array}{l}\text { - } \\
\text { Engineering } \\
\text { Degree }\end{array}$ & 10 years & $\begin{array}{l}\text { Technical } \\
\text { Expert }\end{array}$ & $\begin{array}{l}\text { - Finding domains to } \\
\text { spread the internal } \\
\text { research efforts } \\
\text { - Preparation of projects }\end{array}$ & $\begin{array}{l}\text { Still involved in } \\
\text { the operational } \\
\text { part }\end{array}$ & low \\
\hline P2 & Male & $\begin{array}{l}\text { - } \\
\text { Engineering } \\
\text { Degree }\end{array}$ & 30 years & $\begin{array}{l}\text { Founder } \\
\text { \& Vice- } \\
\text { President }\end{array}$ & $\begin{array}{l}\text { - Finding money \& partners } \\
\text { to develop the company's } \\
\text { idea } \\
\text { - Preparation of projects }\end{array}$ & $\begin{array}{l}\text { Still involved in } \\
\text { the operational } \\
\text { part }\end{array}$ & high \\
\hline P3 & Male & $\begin{array}{l}\text { - } \\
\text { Engineering } \\
\text { Degree }\end{array}$ & 35 years & $\begin{array}{l}\text { Research } \\
\text { Projects } \\
\text { Director }\end{array}$ & $\begin{array}{l}\text { - Finding domains to apply } \\
\text { and further develop the } \\
\text { company's technology } \\
\text { - Preparation of projects }\end{array}$ & $\begin{array}{l}\text { Handover to } \\
\text { operational team } \\
\text { within company }\end{array}$ & middle \\
\hline P4 & Male & $\begin{array}{l}\text { - PhD in } \\
\text { Neuropharm } \\
\text { acology }\end{array}$ & 20 years & $\begin{array}{l}\text { Chief } \\
\text { Technical } \\
\text { Officer }\end{array}$ & $\begin{array}{l}\text { - Finding domains to apply } \\
\text { and further develop the } \\
\text { company's technology } \\
\text { - Preparation of projects }\end{array}$ & $\begin{array}{l}\text { Handover to } \\
\text { operational team } \\
\text { within company } \\
\text { but still close } \\
\text { supervision }\end{array}$ & low \\
\hline P5 & Male & $\begin{array}{l}\text { - } \\
\text { Engineering } \\
\text { Degree } \\
\text { - Mathematic } \\
\text { Degree }\end{array}$ & 15 years & $\begin{array}{l}\text { Innovatio } \\
\text { n } \\
\text { Director }\end{array}$ & $\begin{array}{l}\text { - Finding domains to apply } \\
\text { and further develop the } \\
\text { company's } \\
\text { services/technology } \\
\text { - Preparation of projects }\end{array}$ & $\begin{array}{l}\text { Still involved in } \\
\text { the operational } \\
\text { part } \\
\text { (but will soon } \\
\text { stop it) }\end{array}$ & $\begin{array}{l}\text { low } \\
\text { (but } \\
\text { soon } \\
\text { more) }\end{array}$ \\
\hline P6 & Male & $\begin{array}{l}\text { Engineering } \\
\text { Degree } \\
\text { - PhD in } \\
\text { Image } \\
\text { Processing / } \\
\text { Statistics }\end{array}$ & 20 years & $\begin{array}{l}\text { Business } \\
\text { Develop } \\
\text { ment \& } \\
\text { Vice- } \\
\text { President }\end{array}$ & $\begin{array}{l}\text { - Finding money \& partners } \\
\text { to develop the } \\
\text { association's idea } \\
\text { - Preparation of projects }\end{array}$ & $\begin{array}{l}\text { Handover to } \\
\text { operational team } \\
\text { within } \\
\text { association }\end{array}$ & high \\
\hline P7 & Male & $\begin{array}{l}\text { - } \\
\text { Engineering } \\
\text { Degree } \\
\text { - MBA } \\
\text { - Patent Law } \\
\text { Degree } \\
\end{array}$ & 25 years & $\begin{array}{l}\text { Innovatio } \\
\mathrm{n} \& \\
\text { Intellectu } \\
\text { al } \\
\text { Property } \\
\text { Director }\end{array}$ & $\begin{array}{l}\text { - Finding domains to apply } \\
\text { and further develop the } \\
\text { company's } \\
\text { services/technology } \\
\text { - Preparation of projects }\end{array}$ & $\begin{array}{l}\text { Handover to } \\
\text { operational team } \\
\text { within company }\end{array}$ & high \\
\hline P8 & Male & $\begin{array}{l}\text { - } \\
\text { Engineering } \\
\text { Degree } \\
\text { - PhD in } \\
\text { Innovation } \\
\text { Management }\end{array}$ & 15 years & $\begin{array}{l}\text { Innovatio } \\
\mathrm{n} \\
\text { Manager }\end{array}$ & $\begin{array}{l}\text { - Finding domains to apply } \\
\text { and further develop the } \\
\text { company's product } \\
\text { - Preparation of projects }\end{array}$ & $\begin{array}{l}\text { Handover to } \\
\text { operational team } \\
\text { within company }\end{array}$ & high \\
\hline P9 & Male & $\begin{array}{l}\text { Engineering } \\
\text { Degree } \\
\text { - MBA }\end{array}$ & 20 years & $\begin{array}{l}\text { Chief } \\
\text { Innovatio } \\
\text { n Officer }\end{array}$ & $\begin{array}{l}\text { - Finding domains to apply } \\
\text { and further develop the } \\
\text { company's technology } \\
\text { - Preparation of projects }\end{array}$ & $\begin{array}{l}\text { Handover to } \\
\text { operational team } \\
\text { within company }\end{array}$ & middle \\
\hline $\begin{array}{l}\text { P1 } \\
0\end{array}$ & Male & $\begin{array}{l}\text { - PhD in } \\
\text { Geochemistr } \\
\text { y }\end{array}$ & 35 years & $\begin{array}{l}\text { Founder } \\
\& \\
\text { President }\end{array}$ & $\begin{array}{l}\text { - Finding domains to apply } \\
\text { and further develop the } \\
\text { company's technology } \\
\text { - Preparation of projects }\end{array}$ & $\begin{array}{l}\text { Handover to } \\
\text { operational team } \\
\text { within company }\end{array}$ & high \\
\hline
\end{tabular}


Table 54: Characteristics of the cluster actors' organisations

\begin{tabular}{|c|c|c|c|c|c|c|c|}
\hline$\#$ & $\begin{array}{l}\text { Orga } \\
\text { nisati } \\
\text { on } \\
\text { Type }\end{array}$ & $\begin{array}{l}\text { Code NAF } 2008 \\
\text { Level } 1\end{array}$ & $\begin{array}{l}\text { Decad } \\
\text { e of } \\
\text { Found } \\
\text { ation \& } \\
\text { implem } \\
\text { entatio } \\
n\end{array}$ & $\begin{array}{l}\text { Role of } \\
\text { medical/health: } \\
\text { "The medical/health } \\
\text { sector is [.....] of the } \\
\text { company (or } \\
\text { association)" }\end{array}$ & $\begin{array}{l}\text { Collaborat } \\
\text { ive } \\
\text { Research } \\
\text { Tradition }\end{array}$ & $\begin{array}{l}\text { Examples } \\
\text { subsidies } \\
\text { (received } \\
\text { applied for) }\end{array}$ & $\begin{array}{l}\text { Company's } \\
\text { driver for } \\
\text { participating } \\
\text { in } \\
\text { collaborative } \\
\text { projects }\end{array}$ \\
\hline $\mathbf{P 1}$ & $\begin{array}{l}\text { Large } \\
\text { comp } \\
\text { any }\end{array}$ & $\begin{array}{l}\text { Electricity, gas, } \\
\text { steam and air } \\
\text { conditioning } \\
\text { supply (NAF: D) }\end{array}$ & $\begin{array}{l}\text { 1940s, } \\
\text { in Paris } \\
\text { Region }\end{array}$ & $\begin{array}{l}\text { no business field } \\
\text { (a very small number } \\
\text { of projects contain a } \\
\text { health part, } \\
\text { philanthropy reasons) }\end{array}$ & $\begin{array}{l}\text { High } \\
\text { (National \& } \\
\text { Internation } \\
\text { al) }\end{array}$ & $\begin{array}{l}\text { FP7, ANR, FUI, } \\
\text { industry specific } \\
\text { private programs }\end{array}$ & $\begin{array}{l}\text { Spreading } \\
\text { research effort }\end{array}$ \\
\hline P2 & $\begin{array}{l}\text { Micro } \\
- \\
\text { enter } \\
\text { prise }\end{array}$ & $\begin{array}{l}\text { Professional, } \\
\text { scientific and } \\
\text { technical } \\
\text { activities (NAF: } \\
\text { M) }\end{array}$ & $\begin{array}{l}2000 s, \\
\text { not in } \\
\text { Paris } \\
\text { Region }\end{array}$ & $\begin{array}{l}\text { the only business } \\
\text { field }\end{array}$ & $\begin{array}{l}\text { Medium } \\
\text { (National \& } \\
\text { Internation } \\
\text { al) }\end{array}$ & $\begin{array}{l}\text { ANR, FUI, Eureka } \\
\text { (Just tries to get its } \\
\text { first } \\
\text { financed) }\end{array}$ & $\begin{array}{l}\text { Idea (raison } \\
\text { d'être of the } \\
\text { company) }\end{array}$ \\
\hline P3 & SME & $\begin{array}{l}\text { Professional, } \\
\text { scientific and } \\
\text { technical } \\
\text { activities (NAF: } \\
\text { M) }\end{array}$ & $\begin{array}{l}\text { 1980s, } \\
\text { Paris } \\
\text { Region }\end{array}$ & $\begin{array}{l}\text { one of several } \\
\text { business fields }\end{array}$ & $\begin{array}{l}\text { High } \\
\text { (National \& } \\
\text { Internation } \\
\text { al) }\end{array}$ & $\begin{array}{l}\text { FP7, Eureka, ANR, } \\
\text { FUI, PREDIT }\end{array}$ & $\begin{array}{l}\text { Business } \\
\text { development }\end{array}$ \\
\hline P4 & SME & $\begin{array}{l}\text { Professional, } \\
\text { scientific and } \\
\text { technical } \\
\text { activities (NAF: } \\
\text { M) }\end{array}$ & $\begin{array}{l}\text { 2000s, } \\
\text { Paris } \\
\text { Region }\end{array}$ & $\begin{array}{l}\text { the only business } \\
\text { field }\end{array}$ & $\begin{array}{l}\text { High } \\
\text { (National \& } \\
\text { Internation } \\
\text { al) }\end{array}$ & $\begin{array}{l}\text { FUI, ISI - OSEO, } \\
\text { "Investing for the } \\
\text { Future" } \\
\text { FP7 }\end{array}$ & $\begin{array}{l}\text { Between idea } \\
\text { (raison d'être } \\
\text { of } \quad \text { the } \\
\text { company) \& } \\
\text { Business } \\
\text { development }\end{array}$ \\
\hline P5 & SME & $\begin{array}{l}\text { Information and } \\
\text { communication } \\
\text { (NAF: J) }\end{array}$ & $\begin{array}{l}\text { 1980s, } \\
\text { Paris } \\
\text { Region }\end{array}$ & $\begin{array}{l}\text { no business field } \\
\text { (project under } \\
\text { investigation was the } \\
\text { first try to enter the } \\
\text { health sector; try was } \\
\text { not successful, thus } \\
\text { abandoned) }\end{array}$ & $\begin{array}{l}\text { Low } \\
\text { (National) }\end{array}$ & $\begin{array}{lr}\text { ANR, } & \text { FUI } \\
\text { (Started with the } \\
\text { project } \\
\text { investigation) }\end{array}$ & $\begin{array}{l}\text { Business } \\
\text { development }\end{array}$ \\
\hline P6 & $\begin{array}{l}\text { Asso } \\
\text { ciatio } \\
\mathrm{n}\end{array}$ & n.a. & $\begin{array}{l}2000 s, \\
\text { not in } \\
\text { Paris } \\
\text { Region }\end{array}$ & $\begin{array}{l}\text { the only business } \\
\text { field }\end{array}$ & $\begin{array}{l}\text { High } \\
\text { (National \& } \\
\text { Internation } \\
\text { al) }\end{array}$ & $\begin{array}{l}\text { FP7, ANR, FUI, } \\
\text { "Investing for the } \\
\text { Future" Program }\end{array}$ & $\begin{array}{l}\text { Idea (raison } \\
\text { d'être of the } \\
\text { association) }\end{array}$ \\
\hline P7 & $\begin{array}{l}\text { Medi } \\
\text { um- } \\
\text { sized } \\
\text { firm }\end{array}$ & $\begin{array}{l}\text { Information and } \\
\text { communication } \\
\text { (NAF: J) }\end{array}$ & $\begin{array}{l}\text { 1990s, } \\
\text { Paris } \\
\text { Region }\end{array}$ & $\begin{array}{l}\text { no business field (yet) } \\
\text { (project under } \\
\text { investigation was the } \\
\text { first try to enter the } \\
\text { health sector; try was } \\
\text { successful) }\end{array}$ & $\begin{array}{l}\text { Medium } \\
\text { (National) }\end{array}$ & $\begin{array}{l}\text { ANR, FUI, "Investing } \\
\text { for the Future" } \\
\text { Program, ISI - } \\
\text { OSEO } \\
\text { (Plans to get also } \\
\text { European funding) }\end{array}$ & $\begin{array}{l}\text { Business } \\
\text { development }\end{array}$ \\
\hline P8 & SME & $\begin{array}{l}\text { Manufacturing } \\
\text { industry (NAF: } \\
\text { C) }\end{array}$ & $\begin{array}{l}\text { 1970s, } \\
\text { not in } \\
\text { Paris } \\
\text { Region }\end{array}$ & $\begin{array}{lr}\text { one of } & \text { several } \\
\text { business } & \text { fields } \\
\text { (but very new, } & \text { since } \\
2009 \text { ) } & \end{array}$ & $\begin{array}{l}\text { High } \\
\text { (National \& } \\
\text { Internation } \\
\text { al) }\end{array}$ & $\begin{array}{l}\text { FP7, ANR, FUI, } \\
\text { Feder, } \\
\text { subsidies, OSEO }\end{array}$ & $\begin{array}{l}\text { Business } \\
\text { development }\end{array}$ \\
\hline P9 & SME & $\begin{array}{l}\text { Professional, } \\
\text { scientific and } \\
\text { technical } \\
\text { activities (NAF: } \\
\text { M) }\end{array}$ & $\begin{array}{l}\text { 1990s, } \\
\text { Paris } \\
\text { Region }\end{array}$ & $\begin{array}{l}\text { one of several } \\
\text { business fields }\end{array}$ & $\begin{array}{l}\text { High } \\
\text { (National \& } \\
\text { Internation } \\
\text { al) }\end{array}$ & $\begin{array}{l}\text { FUI, ANR, "Investing } \\
\text { for the } \quad \text { Future" } \\
\text { Program, Regional } \\
\text { subsidies, FP7 }\end{array}$ & $\begin{array}{l}\text { Business } \\
\text { development }\end{array}$ \\
\hline P10 & SME & $\begin{array}{l}\text { Information and } \\
\text { communication } \\
\text { (NAF: J) }\end{array}$ & $\begin{array}{l}\text { 1990s, } \\
\text { Paris } \\
\text { Region }\end{array}$ & $\begin{array}{l}\text { one of two business } \\
\text { fields }\end{array}$ & $\begin{array}{l}\text { High } \\
\text { (National \& } \\
\text { Internation } \\
\text { al) }\end{array}$ & $\begin{array}{l}\text { FP7, FUI, ANR, ISI - } \\
\text { OSEO, COST }\end{array}$ & $\begin{array}{l}\text { Business } \\
\text { development }\end{array}$ \\
\hline
\end{tabular}




\section{ANNEX 14: FINDING PARTNERS IN COLLABORATIVE R\&D PROJECTS}

Figure 57 and Figure 58 give two visual schemata examples of the relationships between project partners. We hope this helps to get a more concrete idea of how collaborative R\&D projects, that are submitted to policy-driven clusters can look like.

\section{Figure 57: Project P1a networks of actors}

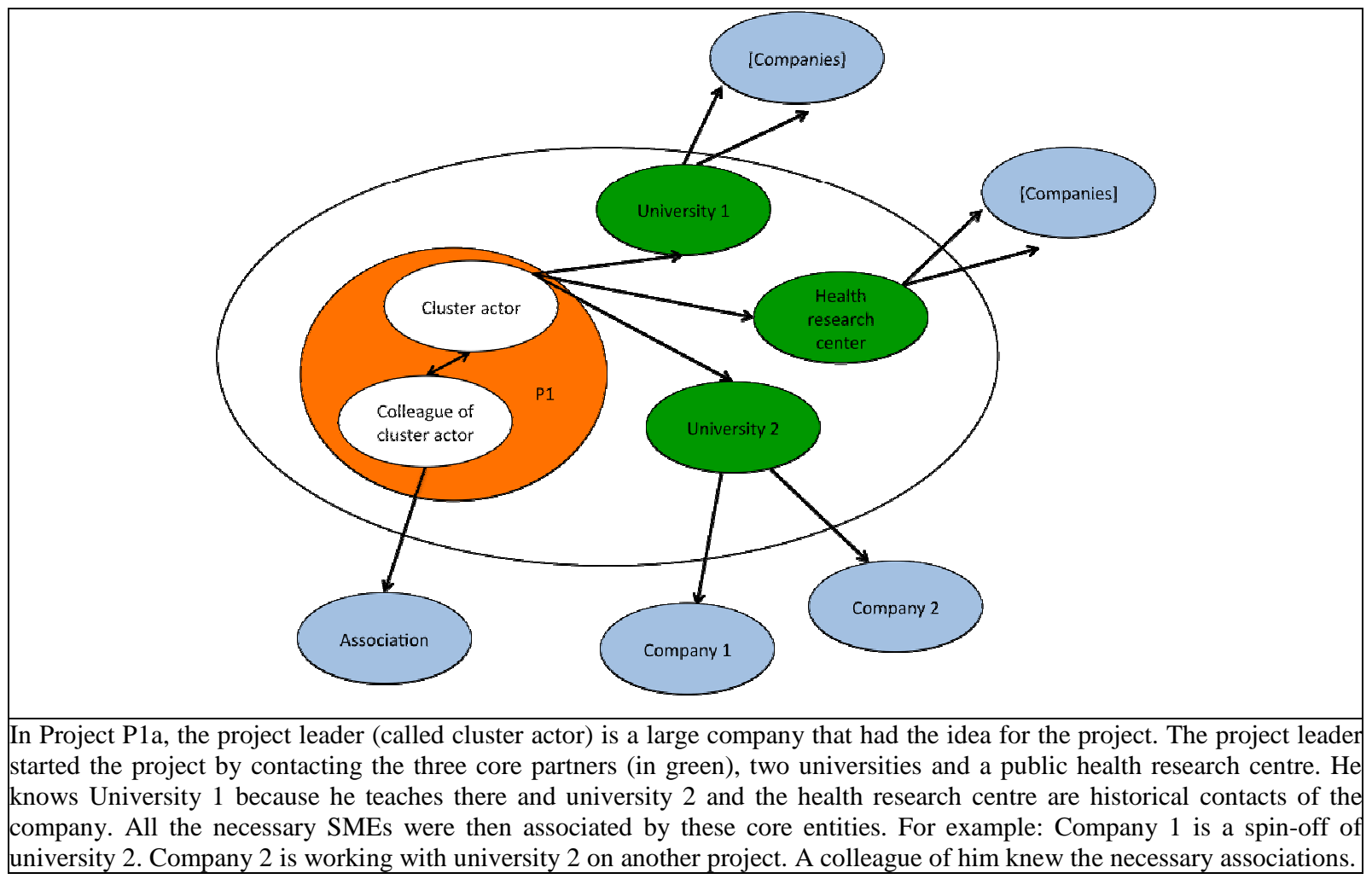

\section{Figure 58: Project P5a network of actors}

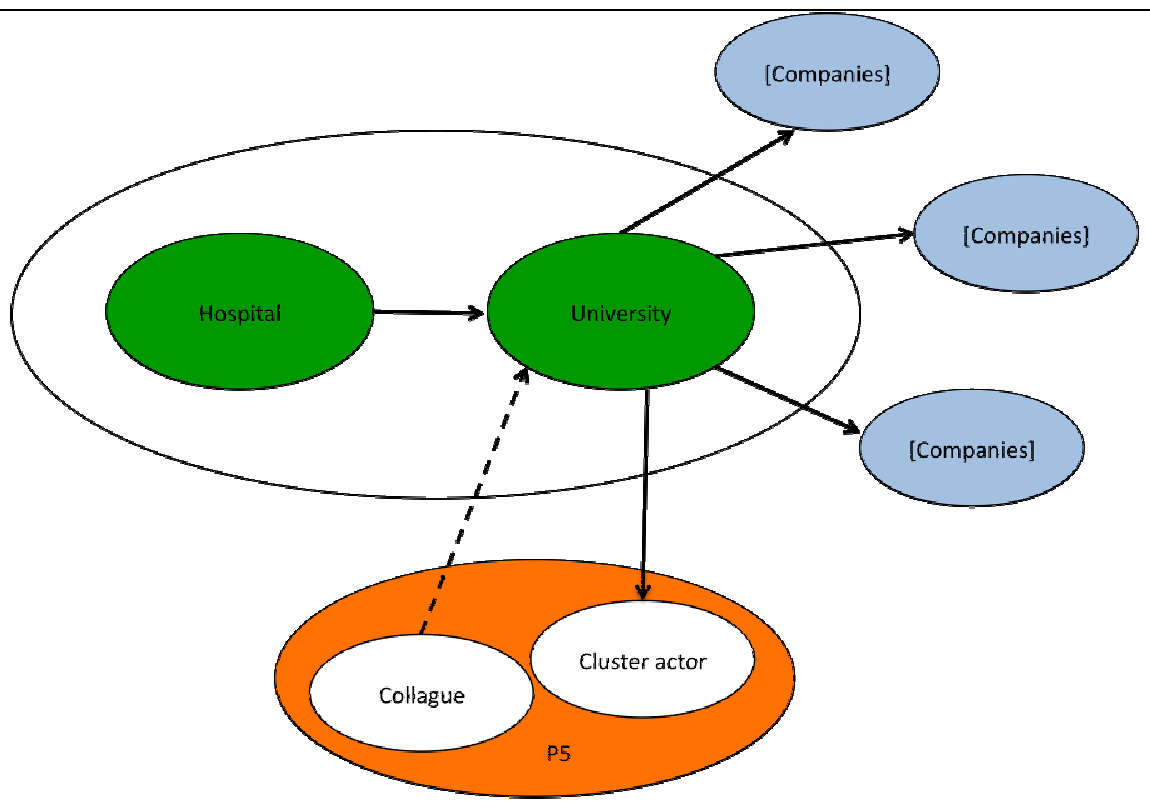

In Project P5a, the project leader (called cluster actor) is a SME that did not have the idea for the project. The idea was formulated by the hospital that contacted the university and then the university contacted all the remaining partners. The project leader knew the university thanks to an employee who knows well the professor of the university. 


\section{ANNEX 15: FRENCH PRODUCTIVE AND INDUSTRIAL STRUCTURE}

The French national institute of economic and statistical information (INSEE) divides the French productive and industrial structure into four enterprise categories (see Table 55): Micro-enterprises (ME), Small and medium enterprises (SME), Medium-sized firms (MF), and large companies. Nearly all companies belong either to the micro-enterprise $(95.44 \%)$ or SME $(4.41 \%)$ category. Only $0.16 \%$ of all companies belong to the medium-sized $(0.15 \%)$ or large company $(0.01 \%)$ category.

Table 55: Definition and overview of French enterprise categories

\begin{tabular}{|l|l|l|l|c|}
\hline & \multicolumn{3}{|c|}{ Definition } & $\begin{array}{c}\text { Percentage } \\
\text { (Number) }\end{array}$ \\
\hline & Employees & Annual Sales & $\begin{array}{c}\text { Balance sheet } \\
\text { total }\end{array}$ & 2010 \\
\hline Micro-enterprises (ME) & $<10$ & $\leq 2$ million $€$ & $\leq 2$ million $€$ & $\begin{array}{c}95.44 \% \\
(2941117)\end{array}$ \\
\hline $\begin{array}{l}\text { Small and medium } \\
\text { enterprises (SME) }\end{array}$ & $<250$ & $\leq 50$ million $€$ & $\leq 43$ million $€$ & $4.41 \%$ \\
\hline Medium-sized firms (MF) & $<5000$ & $\leq 1500$ million $€$ & $\leq 2000$ million $€$ & $0.15 \%$ \\
$(4623)$
\end{tabular}

Source: INSEE $(2010)^{298}$

\footnotetext{
${ }^{298}$ Definition of categories: http://www.insee.fr/fr/themes/document.asp?ref id=ip1321 (12/05/2013)

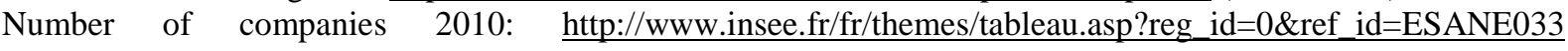
$(12 / 05 / 2013)$
} 


\section{ANNEX 16: DESIGN THINKING EXPLAINED IN A NUTSHELL}

Design thinking (T. Brown, 2009; T. Brown \& Katz, 2011) has recently become an important element when talking about innovation. The core idea of design thinking is converting need into want through observation. Brown \& Katz (2011, p. 382) argue that the design approach to innovation passes through insight, "one of the key sources of design thinking". They further explain: "the only way we can get to know [everyday people] is to seek them out where they live, work, and play. Accordingly, almost every project we undertake involves an intensive period of observation. We watch what people do (and do not do) and listen to what they say (and do not say)." However, such as Verganti (2011), Brown \& Katz (2011) draw a clear line between observing consumers vs. exchanging with consumers (as for example advocated by the open innovation approach (Chesbrough, 2003)), as they believe that the latter does not necessarily lead to anything really new as consumers do not know what they really need. It is the designer's responsibility to detect the new needs. The modus operandi of design thinking also gets clear through this statement: "in contrast to our academic colleagues, we are not trying to generate new knowledge, test a theory, or validate a scientific hypothesis. The mission of design thinking is to translate observations into insights, and insights into the products and services that will improve lives" (T. Brown \& Katz, 2011, p. 382). Due to the relative young age of integrating design thinking into the innovation process, literature is still very scarce. The most important elements of design thinking are (T. Brown, 2009, pp. 68-69): divergent and convergent phases during the design thinking process ${ }^{299}$ and certain mental capabilities of the design thinkers (i.e. being both analytical and synthetic) ${ }^{300}$. Additionally, the design thinking process moves through three spaces: inspiration space, ideation space and implementation space ${ }^{301}$.

\footnotetext{
299 Divergent and convergent phases: Two different phases are necessary in the design thinking process: divergent and convergent phases. "The process of the design thinker, [...], looks like a rhythmic exchange between the divergent and convergent phases, which each subsequent iteration less broad and more detailed than the previous ones. In the divergent phase, new options emerge. In the convergent phase [...] it's time to eliminate options an make choices" (T. Brown, 2009, p. 68).

${ }^{300}$ The mental capabilities of design thinkers: Designers use analytical and synthetic tools in their work, both are necessary for the innovation process. It is not possible to be only analytical or only creative. They "use analytical tools to break apart complex problems to understand them better" and then the "creative process" starts that "relies on synthesis, the collective act of putting pieces together to create whole ideas" (T. Brown, 2009, p. 69).

${ }^{301}$ The operational element of design thinking: The designer and the design team are the operational element of design-oriented companies. The design team might be an external design agency or an internal design agency. The design team moves through three spaces: Inspiration space: "in which insights are gathered from every possible source" (T. Brown, 2009, p. 64), Ideation Space: "insights are translated into ideas" (T. Brown, 2009, p. 64), Implementation space: "the best ideas are developed into a concrete, fully conceived plan of action" ( $\mathrm{T}$. Brown, 2009, p. 64).
} 


\section{ANNEX 17: THE TURNOVER OF HCPR'S GOVERNANCE}

In order to better grasp the particularity of HCPR, we compared HCPR with Cap Digital and Systematic Paris Region, two other policy-driven clusters of the Paris Region (see Table 56 and Table 57). The turnover of HCPR's presidents and CEOs is much higher than the turnover of Cap Digital's or Systematic's presidents and CEOs. Since the beginning of the French cluster policy HCPR already counts five different CEOs while Cap Digital only counts one and Systematic two different CEOs.

Table 56: Number of presidents: HCPR, Cap Digital \& Systematic

\begin{tabular}{|l|c|l|c|l|l|}
\hline $\begin{array}{l}\text { Policy-driven } \\
\text { cluster name }\end{array}$ & $\#$ & Period & Years & Name & Company \\
\hline HealthCluster PR & & & & & \\
\hline & 1 & $2005-2009$ & $<4$ years & Jean-Claude Muller & Sanofi-Aventis \\
\hline & 2 & $2009-09 / 2011$ & $<2$ years & Emmanuel Canet & Servier \\
\hline & 3 & $09 / 2011-03 / 2012$ & $<1$ year & David Sourdive & Cellectis Sa \\
\hline Cap Digital & 4 & since $03 / 2012$ & $<3$ years & Arnaud Gobet & INNOTHERA \\
\hline & & & & & Lagardère \\
\hline & 1 & $01 / 2006-2008$ & $<2$ years & Jean-Pierre Cottet & MFG Labs \\
\hline & 2 & $2008-01 / 2013$ & $<5$ years & Henri Verdier & Fabernovel \\
\hline Systematic PR & 3 & since $01 / 2013$ & $<2$ years & Stéphane Distinguin & \\
\hline & & & & & Thales \\
\hline & 1 & $2005-06 / 2011$ & $<6$ years & Dominique Vernay & Alcatel Lucent \\
\hline
\end{tabular}

Sources: divers (fieldwork discussions and newspaper articles)

Table 57: Number of chief executive officers: HCPR, Cap Digital \& Systematic

\begin{tabular}{|l|c|l|c|l|}
\hline $\begin{array}{l}\text { Policy-driven } \\
\text { cluster name }\end{array}$ & $\#$ & Period & Years & Nom \\
\hline $\begin{array}{l}\text { HealthCluster } \\
\text { PR }\end{array}$ & & & & \\
\hline & 1 & $01 / 2006-08 / 2007$ & $<2$ years & Bernard Brigonnet \\
\hline & 2 & $01 / 2008-2009$ & $<$ years & Michel Vieillefosse \\
\hline & 3 & $09 / 2009-2010$ & $<1$ year & Jean Deregnaucourt \\
\hline & 4 & $01 / 2011-07 / 2013$ & $<3$ years & François Chevillard \\
\hline & 5 & since $09 / 2013$ & $<1$ year & Jean-Roch Meunier \\
\hline Cap Digital & & & & \\
\hline & 1 & since $04 / 2006$ & $<$ years & Patrick Coquet \\
\hline Systematic PR & & & & \\
\hline & 1 & $2005-10 / 2011$ & $<$ years & Sylvain Dorschner \\
\hline & 2 & since $10 / 2011$ & $<3$ years & François Cuny \\
\hline
\end{tabular}

Sources: divers (fieldwork discussions and newspaper articles) 


\title{
ANNEX 18: ARTICLE ON THE FRENCH CLUSTER POLICY EVALUATION (2012)
}

\author{
Evaluation moderne, évaluation modeste ? \\ Le cas des pôles de compétitivité français \\ (What should be expected from a public policy evaluation? \\ The case of the French cluster policy)
}

(Published in 2012, in Politiques et management public 29 (4):573-590)

Emilie-Pauline GALLIE, IMRI, Paris Dauphine, emilie-pauline.gallié@ dauphine.fr IMRI, Université Paris-Dauphine, Pl. Maréchal de Lattre de Tassigny, 75775 Paris Cedex 16

Anna GLASER, ESCP Europe \& Mines ParisTech, anna.glaser@escpeurope.eu CRDMP, ESCP Europe, 79 avenue de la République, 75543 Paris Cedex 11

Philippe LEFEBVRE, Mines ParisTech, philippe.lefebvre@mines-paristech.fr CGS, Mines ParisTech, 60 Boulevard Saint-Michel, 75272 Paris Cedex 06

Frédérique PALLEZ, Mines ParisTech, frederique.pallez@mines-paristech.fr CGS, Mines ParisTech, 60 Boulevard Saint-Michel, 75272 Paris Cedex 06

\section{Résumé :}

L'évaluation des politiques publiques est un thème récurrent pour les praticiens et chercheurs travaillant sur l'action publique. Mais au-delà de l'accord sur le principe, il n'y a pas stabilisation de la doctrine et de ses pratiques. Différents modèles coexistent ou se succèdent, selon les pays ou les époques. En nous appuyant sur le cas de l'évaluation de la politique française des pôles de compétitivité en 2008, nous montrons les principales difficultés de la démarche, liées au caractère systémique, multi-acteurs et hétérogène de l'objet «cluster ». A travers l'analyse des utilisations de l'évaluation, nous mettons ensuite en évidence que cette évaluation participe à la constitution progressive et simultanée d'une doctrine des clusters et de leur pilotage. En conclusion, nous traçons les bases d'un modèle de démarche évaluative, qui la désacralise et l'intègre à un dispositif plus large de pilotage des politiques publiques.

Mots clés : Politique publique, évaluation, pôle de compétitivité, cluster

\begin{abstract}
:
Public policy evaluations constitute a current topic among practitioners and academics working on public action. However, beyond a mutual agreement on the principles of evaluation, there is hardly any stabilisation of evaluation doctrines and practices. Different models coexist, according to the country and the period. Basing our analysis on the evaluation of the French cluster policy in 2008, we highlight the main difficulties of the evaluation process, which are linked to the systemic, multi-actor and heterogeneous character of a "cluster". Through the analysis of how the results of the evaluation are used, we then show that this evaluation takes part of a progressive construction of doctrine on what a cluster is and how it should be managed. In conclusion, we build the basis of an evaluation framework, in which evaluation is integrated in a larger public policy management process.
\end{abstract}

Keywords: Public policy, evaluation, competitiveness pole, cluster 


\section{Introduction}

L'évaluation des politiques publiques est, comme la réforme de l'Etat, une des thématiques récurrentes en France depuis plus de 30 ans dans les débats des praticiens et des chercheurs intéressés par le management public (Trosa, 2009). Chacun appelle de ses vœux l'expansion d'une «culture de l'évaluation ». L'évaluation est devenue un «badge de modernité » selon l'expression de Pollitt (citée par (Perret, 2001)). Le principe de l'évaluation des politiques publiques est maintenant d'autant moins contesté qu'il est inscrit dans la Constitution depuis juillet 2008 (article 47-2). L'Assemblée nationale devrait même consacrer en principe une semaine par mois au contrôle et à l'évaluation des activités gouvernementales ou des politiques publiques. Néanmoins, les divergences et les doutes apparaissent dès que l'on essaie de préciser les conceptions qui président à l'évaluation, les méthodes mises en œuvre, et les impacts qu'elle peut avoir sur les décisions (Perret, 2001; Bernard Perret, 2008; Stame, 2009; Thoenig, 2002).

Une occasion d'analyser une évaluation de politique publique «en actes » s'est présentée récemment. En effet, le gouvernement français a lancé en 2005 une politique ambitieuse de clusters, appelés «pôles de compétitivité » ${ }^{302}$. Cette politique est destinée à « renforcer la compétitivité de l'économie française et développer la croissance et l'emploi sur des marchés porteurs ${ }^{303}$ principalement à travers le soutien financier à des projets de R\&D innovants et collaboratifs entre entreprises et laboratoires de recherche. Dans ce cadre, 71 pôles de compétitivité, répartis sur tout le territoire français, ont été labellisés en 2005. Derrière ce mot de «pôles de compétitivité » se cachent donc des structures regroupant des entreprises et des laboratoires sur des territoires, avec une organisation et une gouvernance dédiées pour susciter les projets et animer l'action collective. Tous ces pôles de compétitivité ont été évalués en 2008 (soit trois ans après leur démarrage) dans le cadre d'une opération d'envergure commanditée par les pouvoirs publics en charge de leur tutelle.

Travaillant depuis 2007 sur les pôles de compétitivité au sein d'une équipe de recherche pluridisciplinaire ${ }^{304}$, nous avons suivi avec attention le déroulement, les résultats et les effets de l'évaluation nationale réalisée en 2008 sur cette politique. Par ailleurs, nous avons pu avoir accès à une partie du matériau brut rassemblé par les évaluateurs, et recueillir les opinions de différents acteurs (notamment dirigeants de pôles) sur cette démarche d'évaluation. A travers ce cas particulier, il est intéressant de remettre en perspective le processus et les résultats de cette évaluation par rapport aux débats contemporains sur l'évaluation, et de tracer, au moins pour les politiques de clusters, les lignes de force des évaluations à venir. En quelque sorte, faire l'évaluation de l'évaluation.

Après avoir rappelé succinctement les grandes problématiques de l'évaluation des politiques publiques, telles qu'elles apparaissent dans une abondante littérature, nous nous focalisons sur la manière dont cette question se décline en pratique sur les politiques de clusters. Suite à cette revue de la littérature, nous analysons les principes et les résultats de l'évaluation des pôles de compétitivité, clusters «à la française ». Nous abordons ensuite les effets de cette évaluation et sa place dans le dispositif de pilotage, pour finalement proposer des pistes sur la manière dont on peut continuer à apprendre de cette opération pour améliorer ses prochaines

\footnotetext{
302 dont la logique, en tant que politique industrielle, est analysée dans (Menu, 2011).

303 Pour plus d'information sur les pôles de compétitivité, on peut visiter le site officiel : http://competitivite.gouv.fr/

${ }^{304}$ Les auteurs appartiennent à une équipe de chercheurs en gestion et en économie qui ont lancé un programme de recherche pluriannuel sur les clusters, financé par l'ANR.
} 
moutures $^{305}$. En conclusion, nous réinterrogeons la relation entre évaluation et politique publique.

\section{L'évaluation de politiques publiques dans la littérature: un changement de paradigme?}

\subsection{Des pratiques d'évaluation nationales}

Il n'est pas dans notre propos de refaire de manière détaillée un panorama de l'histoire de l'évaluation de politiques publiques en France (cf. Thoenig, 2002), ni une discussion des présupposés théoriques qui président aux diverses conceptions de l'évaluation (Chanut, 2009; Stame, 2009). On se contentera de noter qu'en France, après une importation des pratiques américaines par des chercheurs dans les années 70, l'évaluation se développe timidement, avant d'être institutionnalisée en 1990 par un décret qui n'en assure pas, pour autant, l'assise définitive. Après une refonte du système institutionnel en 1998, et une nouvelle mise en sommeil, l'entrée récente du principe dans la Constitution (article 47-2, juillet 2008) pourrait marquer une nouvelle phase de cette institutionnalisation, qui, en France, est considérée comme la clé d'un développement de la pratique évaluative.

Chaque pays a des traditions propres en matière d'évaluation (Bachtler \& Wren, 2006). Ainsi, on sait que dans les pays anglo-saxons, où le rôle de l'Etat est moins marqué, et où n'existe pas de tradition d'expertise étatique liée à la présence des grands corps techniques, l'évaluation repose davantage sur l'existence d'un corps de professionnels autonomes (Perret 2003). En France, alors que la pratique de l'évaluation de politiques publiques s'est bien établie au niveau régional (grâce par exemple aux évaluations des politiques ou des «programmes » de développement régional de la Commission Européenne), elle peine à se routiniser et se banaliser au niveau étatique. Même si un certain nombre d'évaluations ont d'ores et déjà été effectuées ${ }^{306}$, de nombreux observateurs sont néanmoins critiques sur l'ampleur et la portée de cette pratique. Il est vrai que toute démarche évaluative se heurte à des problèmes génériques qui dépassent les spécificités nationales.

\subsection{Les difficultés intrinsèques de l'évaluation des politiques publiques}

L'évaluation d'une politique publique consiste à "apprécier son efficacité en comparant ses résultats aux objectifs assignés et aux moyens mis en œuvre» (décret du 18/11/1998). Audelà de cette définition, apparemment claire, apparaissent au moins trois séries de difficultés, ou de dilemmes, largement connus, que nous nous contentons de rappeler, et qui nous donneront une grille d'analyse de notre cas :

- La formulation des objectifs est difficile. Le travail des évaluateurs consiste souvent à énoncer eux-mêmes les questionnements pertinents sur une politique. Les « résultats », quant à eux, à supposer qu'ils puissent être mesurés ou appréciés,

\footnotetext{
305 Une deuxième évaluation nationale des pôles de compétitivité vient de se dérouler, en 2012.

306 Des dizaines d'évaluations ont été réalisées depuis 1990, dans le cadre des processus institutionnels mentionnés plus haut, par exemple : les politiques de contractualisation avec les universités, de sécurité routière, de la ville... Par ailleurs, un séminaire commun au cercle de la Réforme de l'Etat et à la Société Française d'évaluation, démarré début 2010, passe en revue toute une série de démarches évaluatives récentes, qui montrent que cette pratique est assez répandue, quoi qu'on en dise, même si elle est réalisée dans des cadres institutionnels variés. C'est ainsi que la Cour des Comptes a publié en mai 2010 son évaluation de la politique éducative.
} 
doivent ensuite être intégrés dans une «théorie de l'action » qui en permette l'interprétation (Gibert, 2003). Cependant, la «théorie de l'action » est elle-même objet de débat dans une évaluation, d'autant qu'elle n'a pas nécessairement été formulée lors de la conception de la politique. Certains auteurs (Pawson, 2006 ; (Weiss, 1997), s'appuyant sur le paradigme de la rationalité limitée, sont même allés jusqu'à contester cette vision, qui présuppose la validité de la notion même de « résultats», et doutent que l'on puisse faire autre chose que d'identifier les mécanismes de fonctionnement de systèmes complexes, partiellement autonomes par rapport aux intentions des politiques.

- Les choix méthodologiques de la démarche sont problématiques. Parmi les plus structurantes, trois catégories de questions peuvent être isolées :

- Le moment : Les évaluations peuvent être effectuées à différents moments du déroulement d'une politique, - ex ante, ex post, ex itinere -, ce qui en modifie considérablement le statut et l'usage possible, voire la pertinence (Gibert, 2003). Implicitement, derrière ces options, sont présents des choix et des contraintes variés, en particulier politiques.

- La méthode: Les méthodes utilisées, pour rigoureuses qu'elles cherchent à être, ne peuvent se limiter à des approches purement quantitatives, fondées sur un positivisme étroit. Elles puisent donc dans les méthodes et les grilles des sciences sociales, au prix d'une fragilité apparente plus grande des conclusions. Quel équilibre trouver entre méthodes quantitatives et qualitatives ?

- Les participants : La participation des diverses parties prenantes, notamment les usagers ou les bénéficiaires finaux, est toujours source de connaissance. Cependant, l'évaluation ne peut, pour autant, du moins dans l'optique actuelle des pouvoirs publics français, se transformer en instance de négociation, et les conclusions être l'expression des compromis qui en résulteraient. Comment concilier les deux objectifs? D'autant que cette vision encore restrictive de l'intervention des parties prenantes est actuellement dépassée ${ }^{307}$ par les partisans d'une évaluation «de $4{ }^{\text {ème }}$ génération » (Guba \& Lincoln, 1989), voire «de $5^{\text {ème }}$ génération», ou d'une évaluation «émancipatrice » (« empowerment evaluation ») (Fetterman, Kaftarian, \& Wandersman, 1995), permettant à des groupes de citoyens de s'exprimer et d'intervenir directement sur la construction des politiques, donc source de démocratie.

- L'interaction entre une évaluation et les suites qui y sont données par les "décideurs » est un phénomène complexe. Après une période d'attente déçue de la part des tenants de la démarche évaluative, force a été de constater qu'on ne pouvait la considérer, loin de là, comme seule source de la décision politique ou administrative (Lacasse, 1995). De fait, on observe peu d'infléchissements d'une politique liés à un processus évaluatif, et ses effets, sans être inexistants, sont plus diffus et indirects. En effet, au-delà du rôle d'aide à la décision et au pilotage des systèmes de gestion que peuvent jouer les évaluations, ont été mis en évidence des effets d'apprentissage ou de mobilisation des acteurs, ainsi que de déplacement et de partage de représentations. Ces derniers effets se révèlent essentiels dans un contexte où les politiques publiques reposent sur des partenariats entre de nombreux acteurs, et où «la production des

\footnotetext{
${ }^{307}$ Evolution plus spécifiquement anglo-saxonne, qui n'est pas directement transposable au contexte français, pour les raisons évoquées en 2.1
} 
normes de l'action publique est partiellement déléguée aux acteurs et parties prenantes » (Bernard Perret, 2008).

\subsection{L'évaluation des politiques de clusters : des modèles qui se cherchent}

Ces difficultés d'évaluation des politiques publiques se retrouvent amplifiées en matière d'évaluation des politiques de clusters et de politiques d'innovation en général, alors même qu'est soulignée l'importance de l'évaluation pour l'apprentissage et la transmission du savoir (Potter, 2005). De nombreux travaux existent, tant en France qu'à l'étranger, sur les politiques de clusters, mais bien peu de travaux ont été menés sur l'évaluation de ces politiques (Sölvell, 2008). Les auteurs qui s'y sont intéressés (Bellandi \& Caloffi, 2010b; Diez, 2001; Russo \& Rossi, 2009; Zabala-Iturriagagoitia, et al., 2007) soulignent en particulier la difficulté à spécifier des objectifs souvent impalpables (comme les processus d'apprentissage collectif), la complexité des modèles de causalité, le caractère systémique et dynamique de l'objet à évaluer. La plupart en déduisent la nécessité d'approches nouvelles (sans forcément les spécifier), et mettent l'accent en particulier sur deux points : la nécessité d'affirmer le caractère processuel de l'évaluation, l'intérêt d'approches plus participatives.

Derrière ces débats, qu'il s'agisse de textes généraux sur l'évaluation des politiques publiques ou plus spécifiquement de l'évaluation des politiques de clusters, se joue en fait le renoncement à un modèle souvent critiqué, que certains ont qualifié de «balistique » (Padioleau, 1982) ou d' «épidémiologique» (Stame, 2009). Ce modèle voyait dans l'évaluation le dernier maillon d'un processus d'action publique conçu comme séquentiel et linéaire : selon cette conception, la chaîne objectifs-moyens-résultats serait suivie d'une phase de correction, permise par un processus d'évaluation objectif et rigoureux. Mais le modèle qui pourrait s'y substituer se constitue par tâtonnements et les doctrines sont loin d'être stabilisées.

En France, selon certains auteurs, on serait davantage actuellement dans un paradigme de l'évaluation «dans l'action » que d'évaluation «de l'action», pour reprendre les termes de Chanut (2009). L'évaluation «dans l'action» fait de l'évaluation un processus quasi-continu, et non spécifiquement ex post. Cette évolution, si elle est avérée, brouille donc les frontières entre évaluation et management ou contrôle de gestion, et contribue à déplacer la charge de l'évaluation des «experts » vers les managers eux-mêmes. Cette assertion est-elle vérifiée dans le cas de l'évaluation des politiques de pôles de compétitivité ? C'est ce que nous examinerons dans la suite, en présentant les modalités de cette évaluation et ses usages. Mais auparavant, nous allons préciser les principales questions que pose en pratique l'évaluation des politiques de clusters.

\section{L'évaluation des politiques de clusters en pratiques}

\subsection{Une exigence contemporaine}

La multiplication des politiques de clusters, dans un grand nombre de pays, s'explique assez bien: schématiquement, dans un contexte où la mondialisation exacerbe la compétition internationale, et où les pays développés voient avec inquiétude leurs capacités de production, puis de R\&D, délocalisées vers les pays émergents, le constat du succès économique de certains clusters spontanés (dont l'exemple emblématique est la Silicon Valley (Weil, 2010)), a conduit la puissance publique à tenter de soutenir, de manière volontariste, l'émergence et le 
développement de clusters (Rosenberg, 2002). Ces politiques, s'appuyant sur un certain nombre de travaux théoriques (cf. revues de littérature dans FenChong, 2009 ou Cruz \& Teixeira 2009), ont pour point commun de consacrer des ressources publiques notables (subventions, incitations fiscales, etc.) au développement de ces clusters. Le souci de rendre compte de l'utilisation de ces fonds et des effets de ces politiques («accountability»), la volonté d'améliorer ces politiques ou de les réorienter, mais aussi des doutes persistants sur les effets des clusters sur la croissance et ses mécanismes (Martin \& Sunley, 2003 ; Potter \& Miranda, 2009 ; Torre, 2008) ainsi que sur la capacités des politiques à contribuer à la création et à la dynamique des clusters, sont à l'origine de la multiplication des évaluations, commanditées par les pouvoirs publics dans différents pays. La France, après le lancement de sa politique de pôles de compétitivité, n'a pas échappé à la règle. Ce besoin d'évaluation étant posé, qu'évalue-t-on en pratique et comment ${ }^{308}$ ?

\subsection{Que faut-il évaluer? Les objectifs de l'évaluation et la question de l'imputabilité}

Une des difficultés classiques de l'évaluation de politiques publiques est en effet la variété des angles d'attaque qui peuvent se dissimuler sous l'unique vocable «évaluation». En ce qui concerne les politiques de clusters, différents niveaux d'évaluation, qui renvoient souvent à des acteurs aux intérêts différents, peuvent être distingués :

- d'abord, l'évaluation des politiques de clusters, c'est-à-dire des modalités de mise en œuvre et de l'efficacité de ces politiques, prises au niveau national, par opposition à l'évaluation individuelle des clusters ;

- ensuite, si l'on s'intéresse à l'évaluation d'un cluster, on pourra distinguer: l'efficacité de son organisation (structuration, gouvernance, pilotage, etc.), ses résultats par rapport aux objectifs visés (par exemple le nombre de projets collaboratifs qu'il a suscités), son impact sur le territoire et sa dynamique économique (en termes de richesse, d'emplois, d'entreprises créées, etc.), son impact sur les acteurs (entreprises, organismes de recherche, collectivités territoriales).

Ces différents éléments ne sont évidemment pas indépendants, comme l'illustre le graphique ci-dessous. Ce schéma met bien en évidence la différence entre évaluation d'une politique de clusters et évaluation des clusters eux-mêmes. Malgré son caractère simplificateur, le schéma montre également les déterminants potentiels des résultats atteints par un cluster, qui peuvent être liés à la politique publique en cause, à l'organisation interne du cluster, à des facteurs externes nationaux, mais aussi à des éléments de contexte propres à chaque cluster, comme ses caractéristiques « héritées ». Par ce terme, nous entendons notamment la configuration des acteurs concernés, les ressources, et les liens qu'entretiennent entre eux, et avec le territoire, ces différents acteurs, avant même la création institutionnelle du cluster (FenChong 2009).

\footnotetext{
${ }^{308}$ Nous nous appuyons sur un travail bibliographique comparatif réalisé sur les démarches d'évaluation de politiques de clusters : voir Lefebvre, P., \& Pallez, F. 2009. Evaluation de la performance des pôles - Approches comparées. Mines ParisTech - Centre de gestion scientifique, rapport commandité par Advancia-Negocia et financé par la Chaire Entreprenariat CCIP.
} 


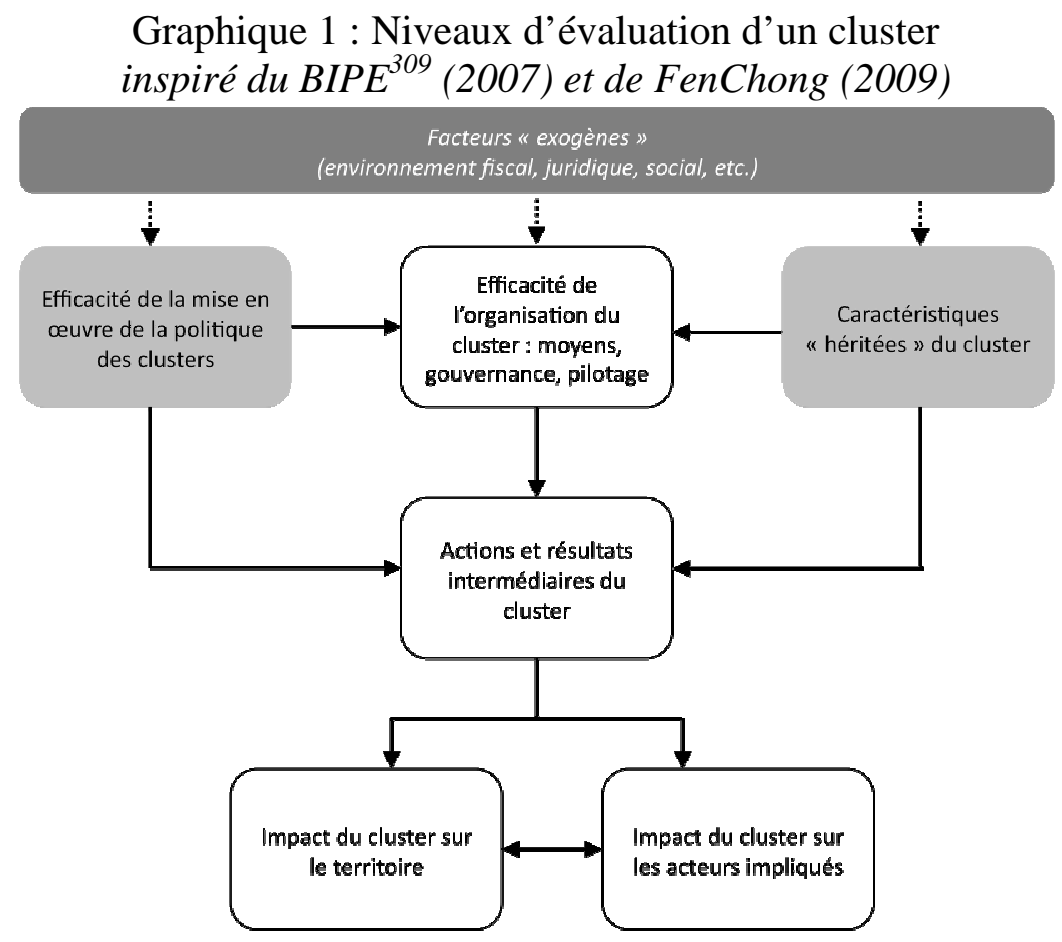

Ces différentes remarques permettent de comprendre la relative variété des démarches d'évaluation des clusters à travers le monde, au-delà d'une diversité liée à des traditions nationales. Ce schéma permet aussi de comprendre que l'évaluation de l'efficacité de l'organisation d'un cluster, sur laquelle il est souvent mis l'accent, n'est qu'une des composantes de l'évaluation d'une politique de cluster. Enfin, il met en évidence le caractère systémique dont nous avons déjà parlé, source d'un problème d'imputabilité des résultats observés à une politique donnée. En effet :

- en théorie, l'évaluation devrait être conduite par rapport à des objectifs définis ex ante, et sur la base d'une comparaison avec une situation de référence elle-même définie et caractérisée avant le lancement de la politique.

- en pratique, on observe en général que les réseaux d'acteurs rassemblés au sein du cluster pré-existaient, que la dynamique de développement était déjà en germe, que les objectifs que se fixe le cluster évoluent au fil du temps et que différents facteurs exogènes peuvent avoir joué sur les résultats observés. Ces constats rendent délicate toute évaluation, et notamment tout jugement, en termes d' «additionnalité » de la politique, au sens de la Commission Européenne.

\subsection{Démarche et méthodologie}

\section{Qui commandite l'évaluation et à quel moment?}

Les évaluations sont toujours effectuées à la demande d'un acteur particulier, à un instant donné. Ces deux variables (origine et moment de la demande) influent sur la nature des questions posées, différente selon le type d'acteurs et selon la phase de développement du cluster. En l'occurrence, la plupart des évaluations de politiques de clusters sont faites à l'initiative des acteurs publics concepteurs et financeurs de la politique. En outre, dans le cas français, mais cela est vrai aussi pour beaucoup d'autres pays, l'évaluation est faite dans une phase relativement précoce du développement de la politique ( 3 ans après son lancement).

\footnotetext{
309 Cabinet ayant réalisé un benchmark international des démarches d'évaluation de politiques de clusters, préparatoire à l'évaluation des pôles de compétitivité en 2008 (BIPE 2007)
} 


\section{Quels indicateurs?}

Les critères pour évaluer les clusters découlent des «objets » que l'on a choisi d'évaluer, euxmêmes choisis en fonction du moment de l'évaluation et des intérêts du commanditaire. Ces indicateurs concernent en général aussi bien l'organisation du cluster que ses résultats, de toute nature ${ }^{310}$. Par exemple la qualité de l'animation sera jugée par des indicateurs comme le nombre et le coût des actions soutenues. On trouve des indicateurs de résultats « intermédiaires » qui qualifient l'action du cluster comme par exemple le montant consacré aux projets de R\&D ou le montant des investissements réalisés (plateformes de recherche, etc.). La performance scientifique et technique sera estimée par le nombre de brevets et licences. Quant aux impacts «finaux» du cluster, ils sont qualifiés en général par des indicateurs économiques très classiques comme des indicateurs de croissance et de santé des entreprises (chiffre d'affaires, valeur ajoutée, taux d'exportation, etc.), mais également, pour apprécier l'impact sur le territoire, par des indicateurs de création d'emplois, de création d'entreprises, ou d'investissements directs sur ledit territoire.

\subsection{Usages et effets des évaluations}

Sans étude empirique détaillée, il est assez difficile d'appréhender les effets, directs et indirects des évaluations commanditées par les pouvoirs publics et même les usages que ceuxci en font. En effet, les liens entre recommandations des évaluateurs et décision politique n’ont rien de mécanique.

A travers les quelques cas que nous avons pu étudier à l'étranger, et qui ne seront pas développés ici (Gallié, Glaser, \& Pallez, 2010, 2011), nous nous contenterons de noter que les différentes évaluations ont toutes conduit à une reconduction des politiques de cluster, en suggérant des améliorations des dispositifs dans différents domaines (pilotage, financement...). Dans tous les cas, l'évaluation est considérée comme un outil pour réfléchir à la suite de la politique, et non comme un couperet qui déterminerait à lui seul de la poursuite ou non de la politique. Quant à l'évaluation des clusters eux-mêmes, elle a pu, dans certains cas, conduire à des arrêts du soutien public, comme par exemple dans la région wallonne (arrêt du financement de deux clusters) (cf. Lepage, 2009) ou en France (délabellisation de six pôles de compétitivité).

Après avoir donné cet aperçu général des pratiques d'évaluation des politiques de clusters, nous allons présenter plus en détail un cas particulier, le cas français.

\section{L'évaluation, composante de la politique française des pôles de compétitivité}

En France, la politique des pôles, par contraste avec nombre de politiques antérieures, s'est construite en intégrant dès l'origine la question de l'évaluation. Dès le lancement de la politique des pôles, l'Etat avait prévu de l'évaluer au bout de trois ans et d'utiliser les résultats pour réorienter éventuellement la doctrine initiale. Sans être totalement nouvelle ${ }^{311}$, cette particularité est suffisamment notable pour que nous la signalions. Naturellement nous

\footnotetext{
310 Toutefois, certains pays, comme l'Allemagne, disposant de plus de recul temporel, ont choisi de centrer leur évaluation des programmes BioRegio et Bioprofile sur les impacts économiques sur les territoires (10 ans après le lancement des programmes).

311 On se rappelle que, dès 1988, le lancement du RMI s'était accompagné d'un engagement de procéder à une évaluation.
} 
distinguons cette démarche d'évaluation institutionnelle des travaux de chercheurs, qui, selon des méthodes diverses, se sont intéressés à la performance des pôles français (voir par exemple Chalaye \& Massard, 2009 ; Duranton, Martin, Mayer \& Mayneris, 2008 ; Bocquet \& Mothe, 2009).

Pour présenter les caractéristiques de la démarche d'évaluation menée en France, nous procéderons en deux temps :

- dans un premier temps, nous décrirons factuellement la conception de la démarche en reprenant les rubriques générales que nous venons de présenter succinctement : objectifs et type de résultats évalués, méthodologie et démarche adoptées. Nous commenterons brièvement au passage les choix qui ont été faits par rapport aux questionnements généraux évoqués ci-avant ;

- puis nous analyserons plus en détail la manière dont cette évaluation a été utilisée, et montrerons qu'elle est conçue comme un outil de pilotage.

Nous nous appuierons pour ce faire sur un matériau constitué

- des textes publics de synthèse produits par les évaluateurs en 2008, mais aussi d'un certain nombre de rapports d'évaluation confidentiels fournis par des pôles avec qui nous étions en contact

- des séances de l'Observatoire des Pôles de Compétitivité ${ }^{312}$, séminaire mensuel au cours duquel dialoguent des chercheurs et des acteurs impliqués dans la politique des pôles (dirigeants de pôles, représentants de l'Etat et des collectivités territoriales, responsables d'entreprises ou d'établissements d'enseignement supérieur et de recherche, consultants...). L'une de ces séances, notamment, a été consacrée à l'évaluation de 2008

- d'entretiens avec les évaluateurs ainsi qu'avec divers responsables de pôles (une quinzaine) et des représentants de l'Administration (DGCIS), pendant et après la phase d'évaluation.

\subsection{La démarche d'évaluation des pôles : objectifs, méthodes, résultats}

Après avoir établi un cahier des charges s'appuyant sur le cadrage fourni par le BIPE, la DIACT (Délégation Interministérielle à l'Aménagement et à la Compétitivité des Territoires) ${ }^{313}$ lança un appel d'offres en 2007, qui fut remporté par deux cabinets de conseil, CM International (CMI) et Boston Consulting Group (BCG). Sur la base du cahier des charges, les cabinets précisèrent les objectifs et la méthodologie.

\section{Les objectifs de l'évaluation}

La mission consistait à mener de front l'analyse de l'orientation stratégique et des modalités d'intervention de la politique nationale et celle de la cohérence et de l'efficacité du dispositif, pôle par pôle, donc de manière exhaustive. On notera en cela l'ambition de la démarche, mais aussi l'idée, pertinente, de notre point de vue, que l'évaluation de la politique nationale devait s'alimenter de la connaissance fine des dispositifs qu'elle avait créés, à savoir les pôles.

L'évaluation de la politique s'intéressait à trois grands thèmes : sa pertinence/cohérence, sa mise en œuvre et ses premiers effets; les évaluateurs avaient en effet jugé peu pertinent, compte tenu de la jeunesse de la politique, de détecter des impacts économiques. Quant à

\footnotetext{
312 http://observatoirepc.org/

${ }^{313}$ Qui a repris, depuis, le nom de DATAR
} 
l'évaluation des 71 pôles, structures légères de statut associatif, dotées de quelques permanents financés par des fonds publics, elle portait surtout sur l'efficacité de ces organisations, et sur leurs premières actions. Elle reposait donc sur l'analyse de trois axes : la dynamique des pôles, leur structuration et leurs projets de R\&D. Sur chaque axe ont été définis les résultats qui seraient considérés comme satisfaisants, moyens ou insuffisants.

Par rapport au graphique 1, on en restait donc à l'évaluation de l'organisation (de sa dynamique) et de résultats intermédiaires (comme les financements obtenus) à l'exclusion de la mesure de tout «impact» final. Quant à la délicate question de l'imputabilité de la politique, elle n'était pas traitée explicitement, les évaluateurs ayant probablement conscience de sa difficulté dans un contexte aussi systémique. En effet, la causalité supposée R\&D $\rightarrow$ innovation $\rightarrow$ compétitivité, qui est à la base de la politique des pôles, n'est pas déterministe. Ainsi des projets de recherche collaboratifs peuvent avoir des impacts très divers, parfois immédiatement visibles s'ils débouchent sur une innovation rencontrant un succès commercial, parfois plus indirects s'ils contribuent seulement à la constitution d'un réseau entre acteurs complémentaires. En outre, il peut s'agir de coalitions opportunistes d'acteurs désireux de trouver des financements complémentaires pour des actions qu'ils souhaitaient engager de toute façon. En France, les évaluateurs ont d'ailleurs remarqué, dans les débuts de la vie des pôles, un effet de «déstockage » de projets de R\&D existants, qui ont pu trouver ainsi un financement.

On notera toutefois que l'évaluation a cherché à analyser la «vie antérieure » des pôles et a donc pris en compte, de manière implicite, le fait que les caractéristiques « héritées » d'un pôle (la nature des partenaires et leurs liens antérieurs, leurs modalités historiques de coopération et d'innovation, etc.) pouvaient expliquer une partie des résultats constatés.

\section{La méthodologie et le pilotage de l'évaluation}

La méthodologie utilisait l'analyse documentaire, les entretiens et réunions avec les acteurs et organismes concernés, ainsi qu'une enquête qualitative et quantitative par questionnaire envoyé aux pôles préalablement aux entretiens, ceux-ci étant réalisés selon une procédure formalisée pour garantir la comparabilité et le caractère normé de l'évaluation. Au total, plus de mille personnes furent interrogées, dont 720 au niveau des pôles, soit dix par pôle en moyenne. Une phase de test sur quatre pôles «pilotes » avait par ailleurs permis de mettre au point le questionnaire, de manière à ce qu'il prenne en compte au mieux la diversité des pôles. L'opération fut pilotée de manière rapprochée par les commanditaires : une rencontre par semaine avec la DIACT, des contacts fréquents également avec la Direction générale des Entreprises, un comité interministériel par mois, un comité de pilotage tous les deux ou trois mois... Les résultats globaux de l'évaluation furent présentés au comité de pilotage en juin 2008, et furent suivis d'une communication gouvernementale. Mais seuls les documents de synthèse furent publiés sur le web, les évaluations «individuelles» des pôles restant strictement confidentielles. Des retours furent par ailleurs effectués vers chacun des pôles classés en $3^{\text {ème }}$ catégorie par les évaluateurs (voir 4.1.3), sous forme $d$ ' «entretiens contradictoires » en présence des différentes parties prenantes (tutelle, gouvernance des pôles, évaluateurs, collectivités territoriales concernées, etc.).

S'appuyant aussi bien sur des analyses qualitatives que quantitatives, l'évaluation a donc utilisé différentes approches méthodologiques, dans un cadre néanmoins très formalisé, qui assurait en particulier une «égalité de traitement » entre les pôles. Mais, même si la démarche semblait emprunter certains de ses traits à l'audit, il s'agissait bien d'explorer des fonctionnements et des dynamiques non pré-déterminés par des standards (Fouquet, 2009). En 
revanche, il ne s'agit pas, à l'évidence, d'une évaluation participative, les commanditaires tenant à maîtriser le processus et ses résultats de bout en bout.

\section{Les résultats de l'évaluation}

La conclusion principale de CMI et BCG fut que le «dispositif des pôles de compétitivité semble suffisamment prometteur pour être maintenu dans ses grands principes ». Elle était assortie de diverses recommandations d'amélioration, sur lesquelles nous reviendrons.

Quant à l'évaluation des pôles de compétitivité, pris isolément, elle conduisit à un classement en trois catégories, proposé par les évaluateurs sur la base de trois axes-clés (stratégie du pôle, gouvernance, capacité à monter des projets de R\&D) :

- Les pôles (39) qui « ont atteint les objectifs de la politique des pôles »

- Les pôles (19) qui «ont atteint partiellement les objectifs de la politique des pôles et qui doivent travailler à l'amélioration de certaines dimensions de leur action »

- Les pôles (13) qui « pourraient tirer parti d'une reconfiguration en profondeur ».

Mais, au-delà de ce classement, l'évaluation permit aussi le renvoi à chaque pôle - c'est-à-dire à sa gouvernance - d'une image de son fonctionnement, à travers une «fiche » assez fouillée d'une quinzaine de pages.

A la suite de ces conclusions, le gouvernement annonça un certain nombre de décisions ${ }^{314}$ qui constituent ce que l'on a appelé «la politique 2.0 » des pôles, et sur lesquelles nous reviendrons ci-dessous. D'ores et déjà, notons le lien fort qui a été fait entre les résultats de l'évaluation et l'annonce de la deuxième phase de la politique.

\section{Quel usage a-t-on fait de l'évaluation ?}

Il est souvent reproché à l'Etat français de peu évaluer ses politiques et dans tous les cas, de donner peu de suite à ses évaluations (Duranton, Martin, Mayer \& Mayneris, 2008). Quels ont donc été les effets et les usages de l'évaluation par les différentes parties prenantes? Nous nous interrogeons d'abord sur l'appropriation des résultats de l'évaluation par l'Etat, puis sur les effets possibles de cette dernière sur les pôles, pour terminer par les apprentissages pour l'évaluation suivante.

\subsection{Une évaluation pour réorienter la politique et améliorer le pilotage}

Nous avons déjà noté que cette démarche évaluative s'inscrit dans un mouvement très général, qui fait de l'obligation de « rendre compte » une exigence maintenant naturelle de la vie économique (Dumez, 2008) et, quand il s'agit de politiques publiques, de la vie démocratique. Cela dit, même si la communication politique sur les résultats de la politique des pôles en était évidemment un objectif important, la démarche d'évaluation était aussi explicitement conçue comme un élément du dispositif de pilotage. Nous allons indiquer comment cela s'est traduit en pratique.

Le principe de la reconduction de la politique des pôles avait été annoncé par le chef de l'Etat dès juin 2007, soit un an plus tôt. Néanmoins, l'évaluation a permis de montrer la pertinence du dispositif en termes de structuration des acteurs et de réflexion stratégique territoriale, et a

\footnotetext{
${ }^{314}$ Pour une synthèse, on pourra se reporter au compte rendu de la séance du 21 octobre 2008 du séminaire de l'Observatoire des pôles de compétitivité (http://observatoirepc.org/) auquel participèrent le CMI, le BCG et la DIACT.
} 
conduit l'Etat à réaffirmer la prorogation de sa politique sur les trois ans à suivre (actuellement prolongée jusqu'en 2012), en renouvelant le budget initial dans les mêmes conditions à savoir 1,5 milliard d'euros.

Plus que la décision même de reconduire la politique nationale des pôles de compétitivité, que l'on ne peut imputer à l'évaluation, la nouvelle politique 2.0 peut lui être reliée. Il y a eu, bien sûr, avant l'évaluation, de nombreuses occasions d'interactions entre les pôles et les représentants de leur tutelle. Mais il est indéniable que certains des nouveaux dispositifs exploitent directement les résultats et puisent dans les nombreuses préconisations issues de l'évaluation. Nous commentons ci-dessous deux de ces dispositifs qui nous semblent parmi les plus significatifs.

\section{Une formalisation accrue de la stratégie}

Ainsi, l'évaluation met en avant la faiblesse des pôles en matière d'élaboration et de formalisation de leur stratégie. Il semble que la conséquence de ce résultat a été, à la demande de l'Etat, la rédaction de «feuilles de route technologiques » par les pôles et la signature d'un «contrat de performance » pluriannuel entre l'Etat, les collectivités territoriales et chaque pôle. Dans ce contrat, signé par le président du pôle, celui-ci s'engage sur un programme d'actions, assorti d'un calendrier de réalisation. La tutelle montre donc un désir de formalisation accrue de la relation entre l'Etat et les pôles, avec des objectifs pour chaque pôle mieux définis.

\section{La mise en place d'indicateurs de suivi des résultats}

Dans la logique du contrat de performance, la tutelle impose maintenant à chaque pôle la mise en place d'indicateurs. L'insistance sur la construction d'indicateurs est particulièrement intéressante, car elle montre dès à présent la préoccupation de l'Etat pour l'évaluation future de l'action du pôle. Une première série d'environ 70 indicateurs sont communs à tous (création d'entreprises, nombre de projets de R\&D retenus pour un financement public, nombre de brevets, etc.). Ces indicateurs doivent faciliter la comparaison entre les pôles. Mais l'Etat a également pris en compte la diversité des pôles, en demandant à chacun de produire des indicateurs spécifiques.

Même si, en apparence, ces évolutions paraissent relativement attendues, on peut y déceler des éléments plus originaux, que l'on peut interpréter comme le résultat d'un apprentissage de la tutelle, obtenu notamment à travers le processus d'évaluation. Ce nouveau savoir pourrait être sommairement qualifié comme suit : affirmation du lien entre la dynamique de développement et la formulation détaillée d'une stratégie (y compris en termes technologiques), que les pôles sont dès lors encouragés à établir par un formalisme contractuel ; reconnaissance de l'existence de schémas de développement diversifiés des pôles, au-delà d'un socle d'indicateurs communs à tous.

\subsection{Une évaluation pour mobiliser les pôles}

L'évaluation peut aussi avoir des effets directs sur les pôles. En effet, à travers la connaissance «pôle par pôle » qu'elle apporte, les comparaisons qu'elle autorise, et surtout, la légitimité qu'apporte une expertise extérieure aux décisions étatiques, l'évaluation peut permettre de piloter ou de mobiliser les pôles, voire de les sanctionner. Il est intéressant d'analyser les choix de l'Etat en la matière. 
L'effet le plus visible de l'évaluation pour les pôles a été leur classement en trois catégories. Un tel classement récompense symboliquement les «bons élèves ». Mais les 13 pôles classés en catégorie 3 l'ont vécu comme une sanction. Certains des pôles mal classés se sont interrogés sur la pertinence même des critères utilisés. On peut en effet défendre l'idée que la compétitivité de certains pôles reposerait moins sur des innovations technologiques radicales que sur des innovations par l'usage (exemple du pôle Enfant, construit autour d'un marché $\left.{ }^{315}\right)$; ou sur la disponibilité d'une main d'œuvre formée à des compétences spécialisées et l'organisation d'une filière industrielle (exemple du Pôle Nucléaire de Bourgogne (Fen Chong \& Pallez, 2008)). Or ces critères ont été peu pris en compte par les évaluateurs. Ces pôles ont pu alors considérer qu'ils n'avaient pas été évalués à l'aune de leurs spécificités.

Pour la tutelle, diverses attitudes étaient envisageables à l'issue de l'évaluation : sanctionner immédiatement en délabellisant les «mauvais» pôles pour se focaliser sur les plus performants, se rapprochant ainsi d'un schéma plus «élitiste » que certains avaient défendu lors du lancement de la politique ; ou conserver pour l'instant le statu quo, en espérant que la remobilisation soit forte d'elle-même.

L'Etat a opté pour une position intermédiaire, en proposant aux pôles mal classés une phase transitoire de réorganisation/restructuration, qui devait durer un an, mais s'est en fait prolongée presque deux ans. Des décisions de délabellisation, qui ont touché finalement six des treize pôles classés en catégorie 3, n'ont en effet été prises qu'en mai 2010.

Cette position a eu des effets notables puisque l'on a pu observer une motivation certaine des pôles mal classés à travailler sur des réorientations de leur stratégie et de leur fonctionnement. En outre, l'électrochoc lié à l'évaluation a conduit à une forte mobilisation des partenaires territoriaux de ces pôles en leur faveur, parfois à un haut niveau politique (députés, sénateurs, présidents de conseils régionaux, dont certains anciens ministres). Cette mobilisation était évidemment liée à la menace crédible d'une délabellisation qui constituait une sanction symbolique lourde, risquant de plus d'entraîner des conséquences importantes sur le pôle (perte de visibilité, tarissement de certains financements publics, etc.) et sur son territoire (risques accrus de délocalisation, démobilisation des acteurs privés, recentrage des chercheurs sur une recherche plus académique, etc.). On notera que le poids important accordé aux « labels » est probablement une caractéristique profonde de la culture nationale française, attachée aux marques d'excellence attribuées par l'Etat.

Ce faisant, la tutelle a utilisé l'effet de «sunshine regulation », jouant sur la publication (et donc la comparaison) des résultats. Mais elle l'assortissait aussi d'une procédure plus directive : injonction pour certains pôles à la «remise en ordre » et deuxième évaluation (effectuée pendant le deuxième semestre 2009 par les mêmes évaluateurs et avec la même grille que la première évaluation), avec une échéance et une «menace ». Plus généralement, même pour les pôles mieux classés, le regard extérieur porté par des évaluateurs et la publicité donnée aux résultats ont constitué un incitatif à la réflexion interne et à la remise en cause de certains fonctionnements. D'autant que l'évaluation de 2012 s'appuiera nécessairement sur les résultats de l'évaluation de 2008.

\footnotetext{
315 Voir l'audition du Pôle Enfant par la Mission d'évaluation et de contrôle de l'Assemblée Nationale : http://www.assemblee-nationale.fr/13/cr-mec/08-09/c0809045.asp
} 


\subsection{Des pistes d'apprentissage pour une évaluation future?}

Peut-on aussi tirer de cette expérience des enseignements pour la prochaine évaluation? Il nous semble que l'expérience qui vient de se dérouler en France peut modifier sensiblement les choses sur deux points : l'objectivation des jugements portés par les évaluateurs et la prise en compte de la diversité des pôles.

\section{$\underline{\text { L'objectivation des jugements }}$}

En matière d'objectivation des données et de rigueur de la méthode, l'élaboration des feuilles de routes et des contrats de performance devrait contribuer à faciliter la prochaine évaluation puisque les objectifs auront été plus clairement formulés, et que des indicateurs normalisés ont été fixés. En outre, grâce à la première évaluation, une situation de référence aura été définie, permettant ainsi d'objectiver la notion de trajectoire.

Quant à la question de la fiabilité des données, on pourrait craindre qu'elle reste sujette à caution, les évalués étant pour partie les fournisseurs de ces données. Même si le risque n'est pas nul, il nous semble qu'il doit être mis en balance des cercles vertueux enclenchés dans les pôles par cette obligation (incitation à l'autoévaluation). En outre, la confrontation de données quantitatives aux points de vue des acteurs, qui du coup devrait être systématisée par la tutelle pour permettre de contrôler la fiabilité, peut être en soi source de connaissance, notamment pour mettre en évidence les schémas de causalité expliquant la performance. Mais, ce faisant, on accepte une conception moins positiviste de la vérité, en se contentant de vérités «non invraisemblables » (GRETU, 1980).

\section{Une meilleure prise en compte de la diversité des pôles?}

Par ailleurs, on l'a dit, un des enjeux futurs réside dans la prise en compte de la diversité des pôles dans les évaluations à venir. Il s'agirait en effet de mener les comparaisons au sein de catégories au sein desquelles la comparabilité entre pôles, en termes de trajectoires de développement et de performance attendue, soit avérée. Mais sur quelles bases construire cette typologie?

Les différences sectorielles sont classiquement une première explication pour justifier la diversité. Par exemple Colgan et Baker (2003) proposent de regrouper les clusters du Maine, qu'ils étudient, en trois groupes. Cette classification, basée sur la nature des ressources mobilisées (technologie, ressources naturelles, autres), doit permettre, selon eux, de différencier les clusters, et donc d'en améliorer le pilotage par les autorités publiques. Mais la richesse des données rassemblées lors de la première évaluation par le CMI et le BCG, et de celles que les différents organismes publics concernés accumulent actuellement, permet maintenant de dépasser ces typologies simples et intuitives (Bonnafous-Boucher \& Saussois, 2010 ; Caillou et al., 2012; Glaser, Gallié, Mérindol, \& Weil, 2010 ; Hussler, Muller, \& Ronde, 2010 ). Sur cette base, on pourra ainsi travailler simultanément sur la question de l'imputabilité des résultats et sur la différenciation des trajectoires et des performances des pôles.

A travers ce passage en revue des effets de l'évaluation, on retrouve les grandes catégories d'usages déjà identifiées dans la littérature : aide à la décision et au pilotage, mobilisation des acteurs et construction de visions partagées, apprentissage (tutelle autant que gouvernance des pôles). Si l'effet direct de l'évaluation (au sens de ses résultats finaux) sur la reconfiguration de la politique a été relativement modéré, on peut en revanche faire l'hypothèse que le processus même de l'évaluation a fait mûrir certaines idées (par exemple élargissement des 
missions des pôles, ou lancement d'une politique de «grappes » d'entreprises ${ }^{316}$ ) et a contribué à un processus réflexif pour tous les acteurs concernés.

\section{Conclusion : Evaluation moderne, évaluation modeste}

Cette exploration de l'évaluation des pôles de compétitivité nous incite, en conclusion, à nous demander comment caractériser le modèle d'évaluation qui ressort de cette expérience et s'il est par ailleurs conforté par d'autres exemples dans d'autres secteurs.

Sur le premier point, il nous semble que la démarche que nous avons analysée, critiquable à certains égards, porte néanmoins en germe un nouveau modèle de l'évaluation,

- qui abandonne l'ambition d'être la seule source des décisions stratégiques ;

- qui renonce à une vision positiviste en laissant place à des approches plus qualitatives,

- qui, par la mobilisation qu'elle suscite, accélère la construction des collectifs et des référentiels communs que la politique des pôles elle-même souhaitait encourager ;

- qui, finalement, par les apprentissages qu'elle induit, participe à la production simultanée d'une politique publique et de sa doctrine de pilotage.

Ces différents éléments nous semblent en faire une démarche qui rejoint le modèle de l'évaluation «dans l'action» selon la terminologie de Chanut (2009). Une évaluation «de l'action» (ou ex post) viserait en effet à mesurer les résultats des actions au regard des objectifs d'une politique parvenue à maturité afin d'en tirer les enseignements rétrospectifs. Or, étant donné la temporalité du processus de développement, cette conception n'est pas soutenable. Et pourtant, compte tenu des sommes allouées, l'évaluation à trois ans résulte d'une exigence démocratique, qui oblige à s'interroger sur la pertinence et la réorientation au plus juste de la politique. Le schéma de l'évaluation «dans l'action » tel que nous avons essayé de le caractériser, permet de dépasser cette contradiction.

Retrouve-t-on ces caractéristiques dans les dernières évaluations de politiques publiques réalisées en France ? Répondre à cette question nécessiterait une analyse systématique qui dépasse le propos de cet article. Mais sur l'exemple de l'évaluation récemment réalisée par la Cour des Comptes sur la politique éducative on peut déjà remarquer que, malgré les nombreuses différences des deux démarches, il existe un point commun dans la philosophie de l'évaluation, telle qu'elle est présentée par Jean Picq, président de la troisième chambre de la Cour des comptes : la volonté d'ouvrir des questionnements plus que de clore les débats par des réponses, l'exigence d'humilité qui découle des imperfections de toute évaluation, l'évaluation vue comme élément d'un processus qui se déroule sur le temps long.

Pour conclure, il faut prendre conscience que ce positionnement de l'évaluation comme une des composantes du dispositif de pilotage, lui confère en même temps un statut plus modeste: l'évaluation devient un outil «parmi d'autres », autant à la disposition des responsables qui conduisent une politique, que des acteurs évalués. Elle s'éloigne de ce fait d'un modèle de production de connaissance objective, incontestable, indépendante, dictant ses décisions au décideur, modèle qui a longtemps constitué l'ultima ratio de l'évaluation. Une évaluation plus modeste mais plus utile, n'est-ce pas la voie de l'évaluation moderne ?

\footnotetext{
${ }^{316}$ Des grappes d'entreprises sont des clusters d'orientation moins technologique et plus petits que les pôles.
} 


\section{ANNEX 19: ARTICLE ON EUROPEAN CLUSTER POLICIES EVALUATIONS}

(2014)

\section{Une analyse comparative des évaluation de politiques de clusters en Europe: vers deux modèles idéal-typiques \\ (A comparative analysis of cluster policy evaluations in Europe: Towards two ideal-typical models)}

(Published in 2014, in Politiques et management public 31 (1):87-111)

Emilie-Pauline GALLIE, Observatoire des sciences et des techniques (OST) OST, 21 boulevard Pasteur, 75015 Paris

Anna GLASER, Novancia Business School

Novancia Business School, 3 rue Armand Moisant, 75015 Paris

Frédérique PALLEZ, Mines ParisTech

CGS, Mines ParisTech, 60 Boulevard Saint-Michel, 75272 Paris Cedex 06

Résumé : Dans ce volet de nos recherches sur l'évaluation des clusters (cf. Gallié, et al., 2012, qui analyse le cas de l'évaluation de la politique française des pôles de compétitivité), nous comparons quatre cas européens d'évaluation de clusters : Wallonie, Allemagne, BasseAutriche et France. Nous développons d'abord une grille de lecture avec laquelle nous analysons ensuite ces différentes évaluations. Cette grille de lecture nous aide surtout à souligner les différences entre ces évaluations sur trois dimensions : les objets de l'évaluation et l'imputabilité des résultats, la démarche et la méthodologie des évaluations, et les effets et usages des évaluations. En conclusion, à partir de ces cas empiriques, nous proposons de distinguer deux modèles idéal-typiques d'évaluation, qui combinent ces différentes caractéristiques de manière cohérente et renvoient à des usages contrastés des évaluations : un modèle « économiste » et un modèle « gestionnaire ».

Mots clés : Politique publique, évaluation, pôle de compétitivité, cluster, politique de cluster

Abstract: In this article, part of our research programme on cluster evaluations (cf. Gallié, Glaser, Lefebvre, \& Pallez, 2012, which is an in-depth analyzes of the evaluation of the French policy of competitiveness clusters), we compare four European cluster evaluations: Wallonia, Germany, Lower Austria and France. We first develop a framework with which we then analyze these evaluations. This framework particularly helps us to underline the differences of these evaluations on three dimensions: the objects of the evaluations and the accountability of results, the approach and methodology of the evaluations, and finally the effects and uses of the evaluations. In conclusion, based on these empirical cases, we propose to distinguish two ideal-typical evaluation models that combine these different characteristics in a consistent manner and that point to two contrasted evaluation uses: an "economist" model and a "management model".

Keywords: Public policy, evaluation, competitiveness cluster, cluster, cluster policy 


\section{INTRODUCTION}

Le succès de la Silicon Valley et d'autres clusters spontanés (Saxenian, 1994) ainsi que les travaux de Porter (1990 (1998), 1998c) sur l'avantage concurrentiel des entreprises situées dans des clusters, ont entraîné la multiplication, dans le monde entier, de politiques de clusters. Ces politiques s'inspirent de ces modèles pour essayer de faire émerger des clusters ou d'amplifier la dynamique de clusters spontanés (OECD, 2007; D. Rosenberg, 2002). Parallèlement, de nombreuses recherches ont tenté de théoriser les composantes de ces politiques et, en amont, d'analyser les mécanismes vertueux produisant, dans un cluster, des effets bénéfiques sur l'efficacité économique des firmes et des territoires sur lesquels elles sont implantées (cf. Cruz \& Teixeira, 2009 pour un résumé de la littérature sur les clusters).

Pourtant, certains chercheurs académiques émettent des doutes sur les effets des clusters. Martin \& Sunley (2007) écrivent par exemple qu' «il n'existe pas d'étude ayant cherché à tester l'hypothèse clé de Porter, à savoir l'impact positif de l'appartenance à un cluster sur la compétitivité des entreprises » (traduit et cité par Bocquet \& Mothe (2009, p. 106)). D'autres, comme Duranton, Martin, \& Mayer (2008), doutent également du bien-fondé des politiques cherchant à encourager ou accélérer la naissance de clusters.

Les pouvoirs publics ne sont pas insensibles à ces critiques, et par ailleurs, même s'ils sont convaincus de l'efficacité des clusters et des politiques de clusters, particulièrement en Europe, ils ont besoin de justifier l'emploi des fonds publics qui leur ont été consacrés. C'est pourquoi on assiste également à une multiplication de rapports d'évaluation commandités par les instigateurs de ces politiques (par exemple CMI \& BCG, 2008; Jakoby, 2006; Staehler, Dohse, \& Cooke, 2007), avec un double objectif : améliorer et éventuellement réorienter les politiques, ne serait-ce qu'à la marge, et rendre compte de l'utilisation des fonds publics.

Malgré ces objectifs assez communément partagés, au vu des évaluations réalisées et publiées dans divers pays occidentaux, on constate assez vite la grande variété des démarches, et des critères d'évaluation adoptés. Au-delà de cette diversité, nous nous sommes demandé s'il était malgré tout possible d'identifier un ou plusieurs modèles d'évaluation des politiques de clusters, ce qui permettrait de se dispenser de réinventer chaque fois tout un dispositif d'évaluation. Nous verrons que nous sommes amenées à distinguer deux grands modèles idéal-typiques en matière d'évaluation des politiques de clusters et essaierons de les caractériser en les reliant notamment aux usages faits des évaluations réalisées. Cet article est volontairement centré sur les questions liées à l'évaluation des politiques de clusters mais comme nous le verrons, il s'inscrit dans des problématiques plus générales liées à l'évaluation des politiques publiques, problématiques que nous avons déjà traitées plus spécifiquement dans d'autres publications (Gallié, et al., 2012) et que nous ne reprendrons donc pas ici dans le détail.

\section{METHODOLOGIE}

Notre recherche, qui s'inscrit dans le courant de pensée de la recherche qualitative (ou compréhensive) défendant l'intérêt des études de cas (Dumez, 2013; Eisenhardt, 1989; Flyvbjerg, 2006), s'appuie sur différents travaux, bibliographiques et empiriques, réalisés depuis 2009, sur la question de l'évaluation de la performance des clusters et des politiques de clusters. Nous avons particulièrement travaillé sur l'évaluation des pôles de compétitivité français réalisée en 2008. Pour ceux-ci, nous avons eu accès aux sources les plus nombreuses 
puisque, outre la synthèse publique de l'évaluation, nous avons pu disposer de matériau brut et interagir à la fois avec les commanditaires, les évaluateurs et un certain nombre des « évalués ». Nous renvoyons à l'article que nous en avons tiré, déjà cité (Gallié, et al., 2012). Nous avons aussi travaillé sur des expériences d'évaluation des politiques de clusters à l'étranger, de façon directe pour certains (accès aux rapports d'évaluation, entretiens avec les acteurs concernés), ou à travers une littérature secondaire. En Basse Autriche par exemple, un certain nombre d'entretiens ont également pu être réalisés : directeurs de cluster, responsables de l'agence Ecoplus et de la politique de cluster au gouvernement régional. Ces rencontres ont permis d'accéder au rapport d'évaluation. En revanche, en Wallonie et en Allemagne, nous n'avons pu disposer que de textes publics, qui étaient néanmoins suffisamment documentés pour apporter un contrepoint intéressant à nos deux premiers cas. Les investigations sont donc « de profondeur différente », ce qui est une limite pour certaines de nos analyses, comme on le verra. Au total, nous disposons donc de quatre cas : la France, la Wallonie (une des régions belges), l’Allemagne, la Basse Autriche (une des régions autrichiennes).

Précisons enfin que cette recherche a été menée pour l'essentiel en 2010, avant la deuxième évaluation des pôles de compétitivité français menée en 2012, et également avant certaines évaluations qui, dans les pays sélectionnés, ont pu prolonger celles que nous avons analysées.

\section{Données}

Le tableau 1 ci-dessous résume les documents primaires, c'est à dire les rapports d'évaluation sur lesquels nous avons travaillé pour chacun des quatre pays. Le tableau 2 présenté ensuite résume les principaux documents et sources secondaires que nous avons mobilisés pour mieux comprendre et analyser nos quatre rapports d'évaluation. Les documents secondaires consultés pour chaque pays nous ont notamment permis de compléter mais aussi de trianguler nos informations, pour ensuite alimenter notre grille d'analyse, et pour enfin construire des cas comparables. Cependant il n'y a pas d'homogénéité entre les différents documents secondaires consultés pour chacun des pays.

\begin{tabular}{|l|l|l|}
\hline Pays & Contenu du rapport d'évaluation & Référence \\
\hline \multirow{3}{*}{ France } & $\begin{array}{l}\text { Évaluation intermédiaire des 71 clusters français lancés en } \\
\text { 2005. Les administrations nationales responsables de cette } \\
\text { nouvelle politique ont demandé une évaluation en 2008. }\end{array}$ & $\begin{array}{l}\text { CM } \\
\text { International \& } \\
\text { BCG, 2008 }\end{array}$ \\
\hline Allemagne & $\begin{array}{l}\text { Evaluation ex-post de la compétition BioRegio, qui a eu lieu en } \\
\text { 1996. Le ministre de l'éducation et de la recherche allemand a } \\
\text { demandé cette évaluation, qui a été réalisée entre 2005 et 2007. }\end{array}$ & $\begin{array}{l}\text { Staehler, et al., } \\
2007\end{array}$ \\
\hline \multirow{3}{*}{$\begin{array}{l}\text { Basse } \\
\text { Autriche }\end{array}$} & $\begin{array}{l}\text { Evaluation intermédiaire de quatre clusters (lancés en 2001) de } \\
\text { la région Basse Autriche. EcoPlus a demandé cette évaluation } \\
\text { en 2004. EcoPlus est l'agence économique de la région Basse } \\
\text { Autriche qui est responsable des clusters locaux. }\end{array}$ & $\begin{array}{l}\text { Kalcher, et al., } \\
2004\end{array}$ \\
\hline \multirow{2}{*}{ Wallonie } & $\begin{array}{l}\text { Évaluation intermédiaire de quatre clusters pilotes, sélectionnés } \\
\text { en 2001. Le conseil économique et social de la région wallonne } \\
\text { a demandé une évaluation en 2004. }\end{array}$ & $\begin{array}{l}\text { Nauwelares \& } \\
\text { Pellegrin, 2004 }\end{array}$ \\
\hline
\end{tabular}

Tableau 1 - Documents primaires 


\begin{tabular}{|l|l|}
\hline Pays & Documents et sources secondaires \\
\hline France & $\begin{array}{l}\text { Article académique sur l'évaluation de la politique des clusters (Gallié, et al., } \\
\text { 2012); séminaires de l'observatoire des pôles de compétitivité à Mines ParisTech } \\
\text { (Blivet, Ezvan, \& Moulet, 2008; Gallié, Glaser, \& Pallez, 2011); communiqués de } \\
\text { presse et circulaires du gouvernement; site internet officiel de la politique } \\
\text { (http://competitivite.gouv.fr/); accès aux données brutes de l'évaluation de la } \\
\text { politique en 2008; discussions avec les responsables de la mise en oeuvre de la } \\
\text { politique et de son évaluation, ainsi qu'avec de nombreux responsables de pôles } \\
\text { de compétitivité, lors des séminaires et workshops organisés à Mines ParisTech; } \\
\text { participation à une étude préparatoire à l'évaluation 2012, pour la DATAR. }\end{array}$ \\
\hline Allemagne & $\begin{array}{l}\text { Articles académiques et documents de travail des évaluateurs de la politique des } \\
\text { clusters (Dohse, 2000, 2007); séminaires de l'observatoire des pôles de } \\
\text { compétitivité à Mines ParisTech (Champenois, 2008; Muller, 2011); rapport de } \\
\text { mission sur la politique de clusters allemande (Lefebvre \& Masson, 2011); site } \\
\text { internet officiel de la politique (http://www.go-cluster.de/) } 317 \text {; rapport ministériel } \\
\text { annuel 2010/2011 de la politique }\end{array}$ \\
\hline $\begin{array}{l}\text { Basse } \\
\text { Autriche }\end{array}$ & $\begin{array}{l}\text { Site internet officiel de la politique (http://www.ecoplus.at/); rapport annuel 2004 } \\
\text { d'Ecoplus ; communiqué officiel sur l'évaluation 2004 d'Ecoplus ; rapports } \\
\text { commandités par le gouvernement sur les clusters en Autriche (Clement \& } \\
\text { Welbich-Macek, 2007); entretiens avec un des clusters managers de la Basse } \\
\text { Autriche ainsi qu'un responsable d'Ecoplus }\end{array}$ \\
\hline Wallonie & $\begin{array}{l}\text { Articles académiques sur l'évaluation et la politique des clusters (Lepage, 2009); } \\
\text { conférence de presse sur le premier bilan de la politique ; rapports de clôture de la } \\
\text { politique (Vaessen, 2010); site internet officiel de la politique } \\
\text { (http://clusters.wallonie.be/) }\end{array}$ \\
\hline
\end{tabular}

Tableau 2 - Documents et sources secondaires

\section{Plan de l'article}

Dans un premier temps, nous présenterons la grille d'analyse que nous avons utilisée pour étudier les quatre cas sélectionnés. Cette grille permet de structurer l'essentiel des problématiques présentes dans la littérature sur l'évaluation des politiques de clusters et d'effectuer ensuite l'analyse comparative visée. Dans un deuxième temps, après avoir succinctement présenté les politiques de clusters dans les quatre pays choisis, et les modalités de leur évaluation, nous tenterons d'analyser, sur la base de cette grille, quelques traits marquants de ces évaluations, en travaillant sur un mode comparatif. Enfin, nous montrerons, en conclusion, comment ces éléments nous semblent renvoyer à deux modèles idéal-typiques d'évaluation, que nous essaierons de caractériser et dont la validation empirique constituerait une perspective de recherche future.

\section{EVALUATION DE POLITIQUES DE CLUSTERS : CONSTRUCTION D'UNE GRILLE D'ANALYSE A PARTIR DES PROBLEMATIQUES RECURRENTES}

Bien que les politiques de clusters diffèrent d'un pays à l'autre (OECD, 2005, 2007, 2009), tous les pays font face aux mêmes difficultés en matière d'évaluation de ces politiques : le caractère systémique des clusters et la multiplicité des parties prenantes en sont à l'origine. Les réflexions sur l'évaluation des politiques de clusters ou d'innovation en sont encore à leurs balbutiements (Diez, 2001; Learmonth, et al., 2003). Bellandi et Caloffi (2010a, p. 70)

\footnotetext{
317 Jusqu'à juillet 2012 la politique allemande de clusters était appelée «Kompetenznetze » (réseaux des compétences), depuis juillet 2012 la politique s'appelle « go-cluster ».
} 
résument les difficultés en montrant que ces évaluations demandent "une combinaison pertinente des langages et des outils de domaines d'étude différents : l'évaluation des politiques publiques et l'analyse des processus d'innovation et de développement ».

La Commission européenne a cherché à surmonter ces difficultés à travers deux initiatives différentes qui illustrent bien la variété des approches possibles : le European Cluster Observatory (ECO), mis en place en 2007, et le programme European Cluster Excellence Initiative (ECEI), lancé en septembre 2009. Chacun de ces deux programmes cible un aspect particulier de l'évaluation des politiques de clusters :

- Le projet ECO cherche à rassembler de l'information sur les conditions de la compétitivité régionale. En conséquence, le cadre d'analyse est construit à partir des indicateurs économiques classiques (taux de chômage, valeur ajoutée, taux d'exportation, croissance des firmes, etc).

- De son côté, l'ECEI a pour objectif « de créer un processus objectif de mesure et d'évaluation de la qualité de management d'un cluster » et "de développer un ensemble modulaire d'indicateurs de qualité ${ }^{318}$. Il s'agit donc de se centrer sur l'évaluation de la qualité du management des clusters, à un niveau beaucoup plus «micro ».

Pour caractériser et comparer des évaluations de politiques de clusters, il était donc nécessaire de construire une grille d'analyse qui rende compte de la variété des approches tout en structurant les principales questions. Sur la base d'une revue de la littérature académique, ainsi que deux rapports importants en la matière, celui du BIPE (2007) et le «Redbook» de Sölvell $(2008)^{319}$, nous avons identifié trois grandes dimensions, classiques en matière d'évaluation des politiques publiques, qui constitueront la structure de notre grille d'analyse, grille très proche de celle que nous avons déjà utilisée pour analyser le cas français (Gallié, et al., 2012) :

- d'abord la question des «objets » évalués, et du schéma de causalité, souvent implicite, qui les relie. Comment ces objets d'évaluation sont-ils déterminés ? En quoi diffèrent-ils d'un pays à l'autre ?

- ensuite, les questions de méthodologie : peut-on caractériser les démarches et les outils des différents processus évaluatifs observés?

- enfin, la dernière thématique concerne la question de l'interaction entre les évaluations et les décisions politiques qui les suivent, en d'autres termes celle des effets et des usages des évaluations.

Nous ne développerons pas en tant que telles ces questions qui concernent toute évaluation de politique publique et qui ont été abondamment traitées dans la littérature (Chanut, 2009; Gibert, 2003; B Perret, 2008; Thoenig, 2002). Nous allons seulement revenir rapidement sur chacun de ces trois items pour les expliciter et montrer le type de problématiques que ces questions génèrent, dans le cas des politiques de clusters, sans qu'il y ait, à l'heure actuelle, dans la littérature, de réponse univoque. Cela permettra de mettre en perspective, ensuite, les choix opérés dans les quatre pays étudiés.

\footnotetext{
${ }^{318}$ Source : http://www.cluster-excellence.eu/

${ }^{319}$ Le BIPE est un cabinet de conseil français qui était mandaté par la DIACT (Délégation Interministérielle à l'Aménagement et à la Compétitivité des Territoires) pour élaborer un travail de synthèse sur l'évaluation des clusters, préparatoire à l'évaluation de la politique de clusters française. Örjan Sölvell est professeur à la Stockholm School of Economics et publie régulièrement des rapports sur les clusters.
} 


\subsection{Objets de l'évaluation et schéma de causalité}

\section{Le problème des objets de l'évaluation}

Théoriquement, une évaluation de politique devrait s'appuyer sur la connaissance des objectifs de cette politique, qu'on suppose clairement définis ex ante. De nombreux auteurs, comme par exemple Perret (2008), ont toutefois mis en évidence le caractère largement irréaliste d'une telle position dans toute évaluation de politique publique, problème particulièrement visible dans le cas des politiques de clusters :

- Les objectifs des politiques de clusters sont souvent formulés de manière vague (compétitivité et visibilité d'un territoire, performance économique des entreprises...) qui autorise de multiples interprétations. Ceci n'a rien d'étonnant : la logique politique s'accommode mieux du confort de l'ambigüité que des contraintes de la précision (Benzerafa, et al., 2011).

- La nature systémique des clusters et les multiples acteurs impliqués rendent la définition de la performance problématique et donc les processus d'évaluation compliqués (Diez, 2001; Zabala-Iturriagagoitia, et al., 2007). En effet, les acteurs peuvent avoir des intérêts et des buts variés. Par exemple, on peut s'interroger sur l'identité des bénéficiaires d'une politique de cluster : s'agit-il des entreprises ou de la « collectivité » (région, nation) ? En outre, les clusters eux-mêmes peuvent avoir des objectifs différents selon leur maturité, leur secteur d'activité, etc. Comment intégrer cette diversité dans une évaluation standardisée?

- Enfin, à supposer qu'on puisse les identifier à un instant donné, les objectifs sont euxmêmes évolutifs, en fonction des changements de personne ou des évolutions de la politique.

Il n'est donc pas étonnant que beaucoup d'évaluations de politiques de clusters mettent surtout en évidence des «objets »d'évaluation, qui sont reliés aux objectifs supposés de la politique par une rhétorique parfois assez lâche. Il faut donc avant tout prêter attention à ces objets, qui, de notre point de vue, discriminent fortement les différentes démarches d'évaluation et sont, eux, parfaitement observables quand on analyse a posteriori des démarches d'évaluation. Pour les définir de manière un peu systématique, nous nous appuyons sur les auteurs, déjà cités (BIPE, 2007; Sölvell, 2008), qui ont cherché à modéliser les processus d'évaluation de politiques de clusters, ainsi que sur nos connaissances empiriques concernant le cas français (Fen Chong, 2009; Gallié, et al., 2012).

La figure 1 tente de représenter les grandes catégories d'objets évalués quand on cherche à évaluer une politique de clusters. Les objets d'évaluation peuvent se focaliser sur les clusters eux-mêmes (rectangles blancs), mais ils peuvent concerner globalement la politique de clusters ou, pour chaque cluster, les conditions historiques de son émergence (rectangles gris clair). Tous les objets sont en permanence influencés par les facteurs « exogènes » du cluster comme par exemple l'environnement fiscal, juridique, ou social (rectangle gris foncé). 


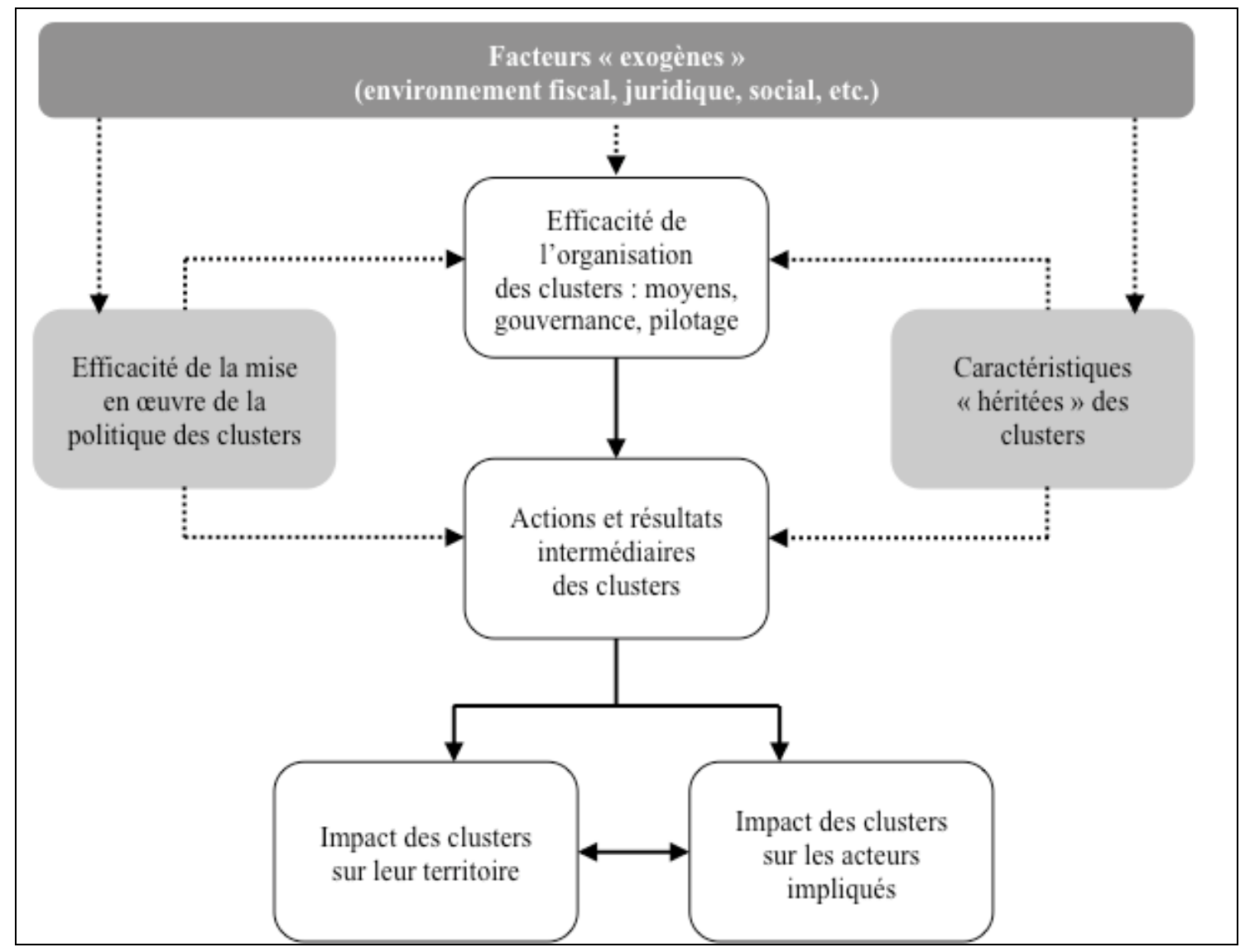

Figure 1 - Les objets d'évaluation d'un cluster

Ce schéma met d'abord en évidence la différence entre l'évaluation d'une politique de cluster (rectangle gris clair, côté gauche) et l'évaluation d'un cluster (rectangles blanc). En effet, si la première nécessite l'évaluation des seconds, la réciproque n'est pas vraie et l'évaluation d'un cluster peut tout-à-fait être faite isolément.

Il montre surtout que, concernant l'évaluation des clusters, les « objets » évalués, regroupés dans les rectangles blancs, peuvent se situer, schématiquement, à trois niveaux différents (de bas en haut) : celui des impacts finaux, celui des actions et résultats intermédiaires, ou celui de l'organisation du cluster.

Les impacts finaux sur le territoire, ou sur les acteurs impliqués dans le cluster (représentés sur le niveau du bas du schéma) semblent mesurer l'atteinte des objectifs de la politique (par exemple compétitivité accrue des entreprises, attractivité des territoires) et sont donc a priori les plus pertinents.

Cependant, outre le fait que ces impacts ne sont pas évidents à objectiver (quels impacts, économiques, sociaux, environnementaux etc. identifier, et comment les mesurer ?), les effets réels de la politique ne peuvent être décelés qu'au bout d'un certain temps en termes d'impacts finaux. Faute de ce recul temporel, on est donc souvent conduit à évaluer d'autres objets, à un niveau intermédiaire, à savoir des résultats intermédiaires de l'action de chaque cluster, ainsi que les actions menées par ces clusters. Il s'agira par exemple d'évaluer les succès des clusters en matière de financement de projets collaboratifs, ou la nature des actions menées en matière de mise en réseau des entreprises, d'aide au montage de projets, de soutien au développement international, de communication, etc. Ces actions et résultats intermédiaires pouvant être eux-mêmes difficiles à appréhender et à objectiver, on peut 
finalement souhaiter se centrer sur des objets qui caractérisent l'efficacité de l'organisation et du pilotage des clusters (comme le fait l'ECEI évoquée plus haut), en faisant l'hypothèse que cette efficacité sera source de résultats pour le cluster. On examinera alors les modalités d'animation mises en place, l'organisation de la structure de gouvernance, les compétences des dirigeants, etc. On est ainsi amené à «remonter» le schéma de bas en haut pour appréhender des objets possibles à évaluer.

Nous percevons maintenant mieux la variété des démarches évaluatives en matière de clusters : elles peuvent ainsi se focaliser sur la politique de clusters ou sur les clusters euxmêmes ; sur les impacts économiques ou sur l'efficacité organisationnelle, sur les territoires ou sur les entreprises, etc. Chaque démarche évaluative est caractérisée par un choix spécifique des objets qui sont soumis à évaluation.

Mais ces différents objets ne sont pas indépendants les uns des autres. Ils sont en général reliés par un schéma de causalité, sur lequel s'appuie plus ou moins explicitement la politique publique et son évaluation. Dans ce schéma interviennent d'ailleurs aussi, comme on l'a dit, des facteurs exogènes (environnement fiscal par exemple), ou les caractéristiques « héritées » du cluster comme les ressources du territoire ou l'histoire des coopérations entre acteurs (Crespo, 2010; Fen Chong, 2009; St. John \& Pouder, 2006). Ce schéma de causalité est à notre sens le deuxième élément important qui caractérise telle ou telle démarche évaluative. Nous allons donc examiner ce point dans ce qui suit.

\section{Le problème de l'imputabilité des résultats et du schéma de causalité}

La question centrale pour juger des effets d'une politique de clusters est : que se serait-il passé en l'absence de cette politique, c'est-à-dire sans soutien volontariste à la création et au développement de clusters?

On peut tenter de mesurer des résultats par rapport à une situation de référence. Mais, même quand cela est possible, si l'on veut imputer ces résultats à la politique menée, il est nécessaire, dans le processus évaluatif, d'explorer le schéma de causalité, pas toujours explicité, qui est sous-jacent à cette politique, d'autant que d'une politique à l'autre, ces schémas peuvent être sensiblement différents. En effet, les jugements portés par les évaluateurs s'appuieront sur les liens de cause à effet qu'ils supposent entre les objets évalués.

Ainsi, certaines politiques de clusters comme la politique française s'emploient à inciter les entreprises à développer des projets de R\&D collaboratifs en supposant que ces collaborations stimuleront leurs capacités d'innovation, ce qui sera source d'impacts économiques positifs pour elles et leur territoire d'implantation. Pourtant, on peut se demander si les projets coopératifs accélèrent toujours l'innovation, certains pensant que «la mauvaise collaboration est pire que son absence » (Hansen, 2009, p. 1). Mais, si la politique est construite sur l'hypothèse du rôle majeur des projets collaboratifs, la démarche évaluative devra identifier des critères qui permettent de tester cette hypothèse.

En d'autres termes, une politique publique met toujours en œuvre une «théorie de l'action » (Gibert, 2003), même si celle-ci n'est pas toujours explicite, et ce n'est autre que le schéma de causalité qui relie les différents objets du schéma précédent. Ce sont donc ces liens logiques supposés qu'il s'agit d'explorer dans le processus évaluatif, et dont la caractérisation distingue les différents processus d'évaluation. 


\subsection{Démarche et méthodologie de l'évaluation}

Le processus institutionnel et les choix de méthode propres au processus évaluatif constituent une deuxième grande catégorie de variables qui interviendront dans notre analyse comparative.

Concernant ce processus, la palette des possibilités est large, sans qu'une doctrine dominante se dégage (Stame, 2009) et les modèles institutionnels nationaux sont assez variés en ce domaine. Différents paramètres sont à considérer, qui influent fortement sur la nature des résultats obtenus dans le processus évaluatif, mais également sur sa légitimité et son insertion dans l'action (Chanut, 2002) : nature du commanditaire, de l'évaluateur, des parties prenantes impliquées, et de leurs relations, qui renvoient au thème de l'indépendance de l'évaluation ; caractère plus ou moins participatif de la démarche ${ }^{320}$; moment où se déroule l'évaluation par rapport au déroulement de la politique publique; moyens qui y sont affectés, qui peut en affecter la «profondeur », etc.

Les choix méthodologiques constituent également une autre source importante de variété. Ils doivent donc être caractérisés précisément. La méthodologie suppose en général un choix entre démarche qualitative ou quantitative, ou une combinaison entre ces deux approches. Mais, dans tous les processus d'évaluation, l'idée est d'objectiver les jugements, et donc de rechercher au maximum à quantifier les phénomènes analysés, par exemple l'impact économique de la politique. D'où l'importance du choix des indicateurs.

Le choix des indicateurs est largement dépendant des objets d'évaluation que le commanditaire et les évaluateurs ont choisis. Nous en donnons quelques exemples dans le schéma déjà utilisé ci-avant, que nous reprenons ci-dessous. Ces choix sont néanmoins fortement contraints par la disponibilité et la fiabilité des données recherchées.

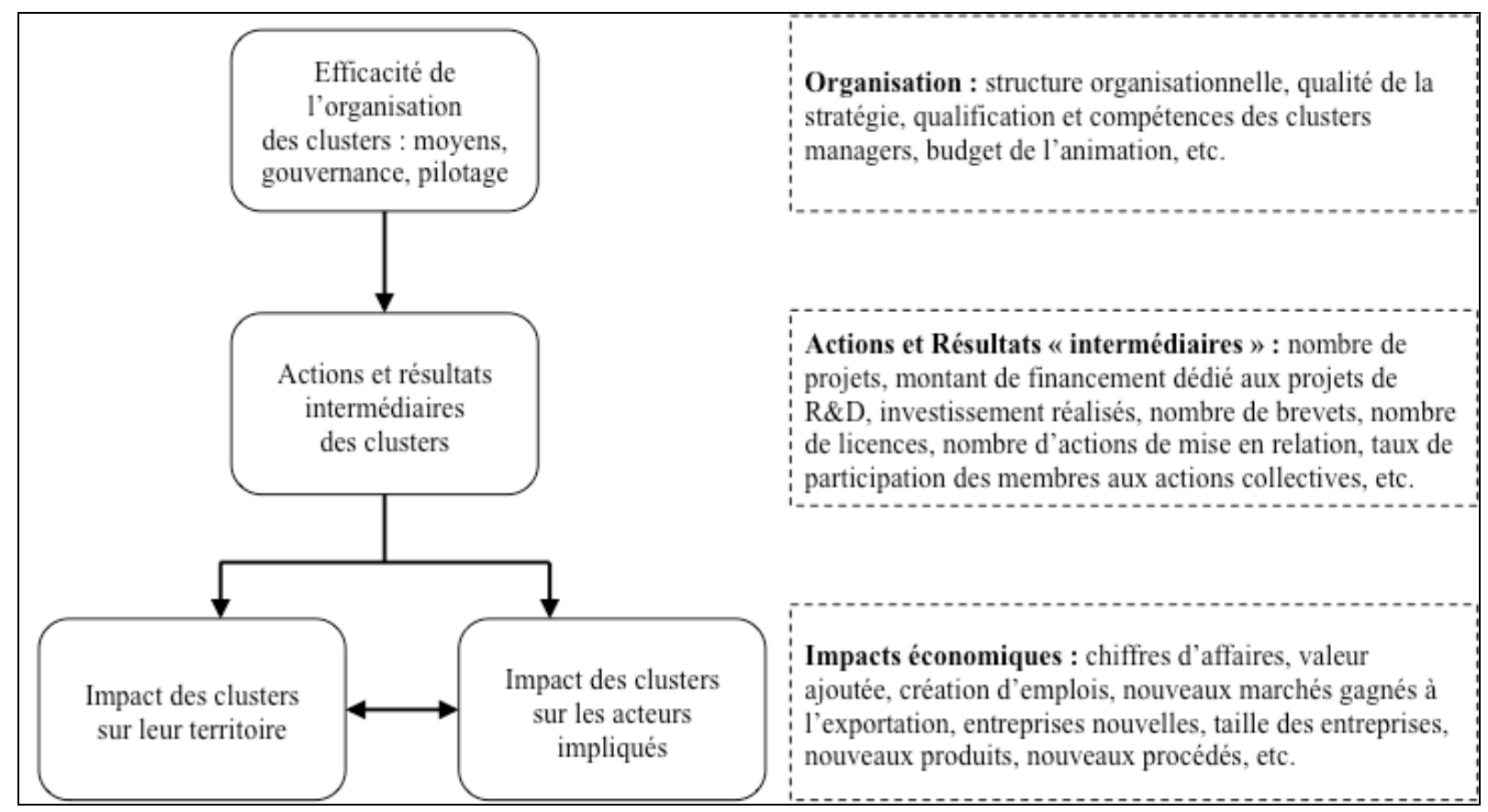

Figure 2 - Exemples d'indicateurs sur les différents objets évalués

${ }^{320}$ Les démarches d'évaluation «participatives » connaissent en particulier un fort développement (Diez, 2001; Plottu \& Plottu, 2009). 
Cependant, certains des phénomènes que l'on cherche à appréhender ainsi que la pertinence même des schémas de causalité qui ont été explicités ne peuvent être finement compris que si l'on utilise des méthodes qualitatives, fondées sur des entretiens avec les acteurs. Exemples : la collaboration, la qualité du management et de l'animation, les liens préexistants à la création du cluster, la progression des mises en relation, etc. Il faudra donc caractériser le « mix » méthodologique choisi dans chaque cas étudié.

\subsection{Effets et usages de l'évaluation}

Dernier volet de notre grille d'analyse : l'interaction entre les résultats de l'évaluation et les décisions politiques, en d'autres termes les effets et usages du processus d'évaluation.

Un processus d'évaluation de politique publique a en effet, on le sait, des objectifs affichés qui sont en général de deux ordres :

- rendre compte de l'usage des fonds publics

- réorienter la politique et améliorer son pilotage par les pouvoirs publics

Sur le premier volet, on peut voir dans l'évaluation, plus cyniquement, l'occasion, pour les acteurs décisionnaires, de communiquer sur le bien-fondé et les résultats de leurs politiques. Sur le deuxième, on sait que les résultats des évaluations sont diversement utilisés par les décideurs, et qu'ils peuvent aussi servir à légitimer des décisions déjà prises.

Il faut donc se départir d'une vision utopique où «... l'évaluation est vue comme un processus linéaire dans lequel les résultats scientifiques corroborés, basés sur les meilleurs moyens de mesure, sont transmis à une machine de prise de décision bien huilée, où les résultats sont reçus, adoptés et mis en æuvre par les responsables publics. »(Vedung, 2009, p. 267). La réalité est tout autre.

Une évaluation a aussi des effets collatéraux importants, recherchés ou non. Une évaluation peut avoir pour effet de mobiliser les différents acteurs de clusters, de forger des représentations communes, d'accroître les connaissances des acteurs, notamment les pouvoirs publics, sur le fonctionnement des clusters et les pratiques d'évaluation efficaces (effet d'apprentissage).

Nous essaierons donc, autant que possible, dans nos quatre cas, de caractériser ces différents effets et usages. Cependant, il s'agit là des éléments les plus difficiles à appréhender quand on n'a accès qu'à des sources secondaires, car leur compréhension nécessite en général une étude empirique fine auprès des principales parties prenantes de la politique. Nos analyses sur ce troisième volet seront donc nécessairement succinctes.

A l'aide de la grille en trois points que nous venons de présenter, nous allons maintenant analyser les démarches d'évaluation des politiques de clusters menées dans les quatre pays (ou les quatre régions) ${ }^{321}$ choisis, après avoir présenté succinctement au préalable ces politiques.

\footnotetext{
${ }^{321}$ En France et en Allemagne, les politiques de clusters sont conçues à un niveau national alors qu'en Autriche et en Belgique, elles le sont à un niveau régional.
} 


\section{L'EMERGENCE DE POLITIQUES DE CLUSTERS DANS QUATRE PAYS EUROPEENS ET LEURS EVALUATIONS}

France. En 2005, le gouvernement français lançait une politique de clusters (appelés pôles de compétitivité) sur l'ensemble de son territoire. Cette politique nationale devait stimuler l'innovation des entreprises, et donc la compétitivité des territoires grâce à un dispositif de subventions à des projets de R\&D faisant collaborer entreprises, petites et grandes, et laboratoires de recherche publics. Entre 2005 et 2008, le gouvernement français consacra une enveloppe de 1,5 milliards d'euros à cette politique, et la reconduisit pour 3 ans en 2008, à la même hauteur. A noter qu'une petite partie des fonds (3.3\%) était consacrée, non pas au financement des projets collectifs, mais au financement de l'animation des clusters, et que par ailleurs, les collectivités territoriales (notamment les Régions) participèrent également au financement des pôles labellisés nationalement.

Allemagne. Au milieu des années 90, l'Allemagne, comme d'autres, se lançait dans une politique industrielle fondée sur la notion de clusters (Dohse, 2007), notamment en organisant en 1996 un processus de sélection national (BioRegio), destiné à soutenir des clusters de pointe dans le domaine des biotechnologies. Des processus analogues suivirent dans d'autres secteurs. L'objectif était de devenir le leader européen dans ce domaine en stimulant la croissance des entreprises. Sur la base de dossiers, un jury choisit trois régions qui reçurent chacune 50 millions de marks (environ 26 millions d'euros), charge à elles d'aider les acteurs concernés à atteindre les objectifs fixés en cinq ans (Staehler, et al., 2007). A la différence de la France, le gouvernement fédéral allemand joua uniquement un rôle de "catalyseur et de facilitateur »(Dohse, 2007, p. 90), laissant aux Länder la liberté du pilotage de la politique.

Basse Autriche. En Autriche, la responsabilité des politiques de clusters incombe aux régions (même si, récemment, le gouvernement autrichien a commencé à mettre l'accent sur la question de la coordination des initiatives régionales). En 1995, la Styrie, bientôt suivie par les autres, fut la première région autrichienne à développer une politique dans ce domaine. Le principe en est un soutien financier destiné à encourager la structuration de clusters et à développer les services aux entreprises qu'ils proposent. En revanche, ces subsides publics n'ont pas pour but de financer des projets de recherche, qui continuent à émarger aux sources traditionnelles de financement. La Basse Autriche, qui créa quatre clusters entre 2001 et 2004, date de la première évaluation, est la région que nous avons étudiée. En Basse Autriche, la structure de management de chaque cluster est abritée par l'agence économique régionale, EcoPlus. Deux des objectifs majeurs de la politique sont de stimuler la compétitivité des PME locales et de les aider à accéder à de nouveaux marchés (par le biais de projets coopératifs au niveau national et international).

Wallonie. Comme en Autriche, les politiques de clusters en Belgique sont régionales. En Wallonie, elles ont démarré en 2000, le gouvernement régional ayant décidé d'encourager la naissance de réseaux d'entreprises (Lepage, 2009). De 2001 à 2006, quatre clusters expérimentaux furent mis en place. Les subventions publiques avaient pour but le soutien à l'émergence de ces regroupements, en prenant en charge les frais de fonctionnement au début du processus : pendant les trois premières années, un budget annuel de $480 \mathrm{k} €$ était garanti aux clusters, budget qui fut ensuite réduit progressivement.

Le tableau 3 ci-dessous résume les principales caractéristiques de ces politiques. 


\begin{tabular}{|c|c|c|c|c|}
\hline & France & Allemagne & Basse Autriche & Wallonie \\
\hline Début & 2005 & 1996 & 2001 & 2001 \\
\hline Echelle & Nationale & Nationale & Régionale & Régionale \\
\hline Etendue & $\begin{array}{l}\text { - Multisectoriel } \\
\text { - } 71 \text { pôles de } \\
\text { compétitivité }\end{array}$ & $\begin{array}{l}\text { - Monosectoriel } \\
\text { - BioRegio : } 3 \\
\text { régions }\end{array}$ & $\begin{array}{l}\text { - Multisectoriel } \\
\text { - } 4 \text { clusters }\end{array}$ & $\begin{array}{l}\text { - Multisectoriel } \\
\text { - } 4 \text { clusters pilotes }\end{array}$ \\
\hline Objectifs & $\begin{array}{l}\text { - Renforcer la } \\
\text { compétitivité } \\
\\
\text { - Stimuler } \\
\text { l'innovation par } \\
\text { l'encouragement à } \\
\text { la R\&D } \\
\text { collaborative }\end{array}$ & $\begin{array}{l}\text { - Faire de } \\
\text { l'Allemagne le } n^{\circ} 1 \\
\text { européen des } \\
\text { biotechnologies } \\
\text { - Stimuler } \\
\text { l'entrepreneuriat }\end{array}$ & $\begin{array}{l}\text { - Renforcer la } \\
\text { compétitivité } \\
\\
\text { - Mise en relation } \\
\text { des membres et } \\
\text { prestation de } \\
\text { services }\end{array}$ & $\begin{array}{l}\text { - Encourager le } \\
\text { développement des } \\
\text { entreprises } \\
\\
\text { - Faciliter les } \\
\text { interactions entre } \\
\text { les entreprises }\end{array}$ \\
\hline $\begin{array}{l}\text { Orientation } \\
\text { du } \\
\text { financement }\end{array}$ & $\begin{array}{l}\text { Projets de } R \& D \text { et } \\
\text { animation }\end{array}$ & $\begin{array}{l}\text { Enveloppe globale } \\
\text { affectée }\end{array}$ & Animation & Animation \\
\hline
\end{tabular}

Tableau 3 - Quatre politiques de clusters

\section{QUATRE PROCESSUS EVALUATIFS : UN REGARD COMPARATIF}

Après cet aperçu rapide des quatre politiques développées dans les quatre pays européens choisis, nous nous intéressons aux évaluations réalisées dans les quatre cas.

Nous allons maintenant, en nous aidant de la grille d'analyse présentée plus haut, sur les trois dimensions choisies, mettre en évidence un certain nombre de rapprochements ou de différences observés en comparant nos quatre cas.

\subsection{Objets des évaluations et schémas de causalité}

\section{Les objets des évaluations}

Nous résumons d'abord, pour les quatre pays étudiés, la nature des objets d'évaluation choisis dans chacun des processus évaluatifs.

L'évaluation des pôles français s'est centrée sur trois grandes catégories d'objets, à l'exception des impacts économiques, qu'il semblait prématuré de regarder. L'évaluation française a d'abord investigué la politique publique en termes de cohérence, pertinence, et implémentation. Ensuite, elle s'est concentrée sur la gouvernance et l'organisation des pôles (structuration des organes de gouvernance, budgets et moyens humains, mise en place...). Enfin, elle a également regardé les actions menées et leurs résultats intermédiaires (subventions obtenues, projets labellisés...). Les éléments quantifiés, fournis par les tutelles et les pôles, et qui ont permis de nourrir ces investigations, ont été complétés par des entretiens avec les responsables de clusters et de la politique. Le point de vue des membres des pôles n'a pas été sollicité de manière systématique. 
L'évaluation autrichienne a considéré trois objets. D'abord, la politique de cluster, et son insertion dans la politique industrielle de la Basse Autriche (sur la base d'indicateurs généraux de structure et de budget). Ensuite, le management de l'agence économique Ecoplus qui coiffe les quatre clusters. Enfin, la satisfaction des entreprises membres concernant le fonctionnement du cluster, ses moyens et ses actions, les projets coopératifs menés. Comme en France, aucune analyse d'impact n'a été réalisée.

En Wallonie, l'évaluation a abordé de nombreux thèmes. Schématiquement, après avoir caractérisé chaque cluster en termes de composition, de poids économique, de nature du management interne, les évaluateurs ont réalisé une étude de leur activité et de leurs résultats (nombre d'actions collectives, taux de participation, nombre de projets $\mathrm{R} \& \mathrm{D}$, etc.) et ont tenté, au cours des entretiens, de qualifier leur impact sur deux niveaux: (i) les entreprises situées dans le cluster (nouveaux produits, taux de création de nouvelles entreprises, etc.); (ii) le territoire dans son ensemble (développement d'exportations, offres d'emploi, etc). Ils ont parallèlement analysé la pertinence et la cohérence de la politique, ainsi que la qualité du pilotage gouvernemental.

Enfin, en Allemagne, l'évaluation s'est centrée sur la question de la valeur ajoutée économique du programme, de sa place par rapport aux autres politiques, et surtout sur l'analyse de ses résultats macroéconomiques (développement du nombre d'entreprises, du marché du travail, mobilisation du capital risque, résultats technologiques en termes de brevets et licences...). Cette analyse quantitative et comparative par rapport à des régions non retenues dans les programmes a été complétée par des analyses qualitatives sur les effets de la politique, le rôle des clusters, le développement de la coopération, la structuration du secteur des biotechnologies, en interrogeant l'ensemble des entreprises, les instituts de recherche et des «experts». Enfin, une comparaison avec des clusters britanniques leaders en biotechnologies a été effectuée, sur la base d'indicateurs quantitatifs (caractéristiques du cluster, de sa composition, et des produits scientifiques et économiques de son activité).

Finalement, trois points nous semblent discriminants dans le choix des objets d'évaluation :

- l'évaluation explore ou non, selon les cas, les impacts économiques finaux

- ces impacts finaux sont ciblés selon les cas sur les entreprises, ou la collectivité

- les évaluations s'attachent plus ou moins à l'analyse des organisations (des clusters ou des pouvoirs publics en charge de la politique)

On retrouve le fait que les objets d'évaluation choisis dans les quatre pays ne sont pas les mêmes, malgré des recouvrements: l'évaluation allemande se concentre sur les impacts économiques finaux, alors que l'évaluation française ne traite pas cet aspect, mais cherche à caractériser à la fois l'efficacité du management et les résultats intermédiaires obtenus (par exemple en termes d'obtention de subventions ou de nombre de projets labellisés). L'évaluation autrichienne est également centrée sur l'efficacité du management des clusters et les résultats obtenus notamment en termes de services offerts aux entreprises, mais, outre une analyse interne, elle utilise une évaluation de la satisfaction des entreprises membres des clusters pour apprécier cette efficacité.

En termes de bénéficiaires, il est notable que la Wallonie et l'Allemagne, bien qu'attentives aux effets de la politique sur les entreprises, cherchent à caractériser, plus généralement, l'impact sur la collectivité, au moins au niveau du territoire, en analysant par exemple les investissements de R\&D, l'évolution de l'emploi, la création d'entreprises. La Basse 
Autriche, par contraste, met davantage l'accent sur la satisfaction des entreprises qui apparaissent comme les bénéficiaires essentiels.

Il est à noter enfin que, contrairement à l'Allemagne, les évaluations wallonne et autrichienne s'intéressent apparemment d'assez près au pilotage public de la politique: en Autriche, l'organisme qui pilote et gère les clusters, Ecoplus, est évalué (en termes de stratégie, de système de reporting, de développement du know-how), mais l'insertion de la politique de clusters dans la politique industrielle de Basse Autriche est également examiné.

En Wallonie, les évaluateurs se sont penchés sur la gestion de la politique par l'administration wallonne, notamment sur le processus de sélection, mais également sur l'organisation de l'administration, et ont participé aux «comités d'accompagnement» réunissant les représentants des clusters et de la région.

L'évaluation française a également, dans une moindre mesure, analysé le pilotage public de la politique des pôles de compétitivité, essentiellement sous l'angle des procédures de financement et de reporting, mais sans rentrer dans les modes d'organisation des pouvoirs publics.

Dans le tableau 4, nous reprenons les catégories d'objets d'évaluation présentées dans la figure 1 pour résumer d'une manière synthétique la palette d'objets évalués par chacune des évaluations analysées. Cette synthèse illustre que l'évaluation wallonne est la plus complète car elle a essayé de couvrir la totalité des objets répertoriés pour évaluer une politique de cluster tandis que les autres pays se sont focalisés sur une partie de ces objets. Toutes les quatre ont essayé d'investiguer les actions et résultats intermédiaires. Mais l'évaluation allemande, typique d'une évaluation ex post se concentre surtout sur les impacts économiques. Les évaluations intermédiaires réalisées en France et en Basse Autriche, quant à elles, se concentrent surtout sur la mise en œuvre de la politique et l'efficacité de l'organisation des clusters.

Nous verrons plus loin que le choix de ces objets d'évaluation n'est pas sans lien avec les usages qui ont été faits des évaluations. 


\begin{tabular}{|c|c|c|c|c|c|}
\hline $\begin{array}{c}\text { Catégorie } \\
\text { d'objet }\end{array}$ & $\begin{array}{c}\text { Les objets d'évaluation } \\
\text { concentrés sur... }\end{array}$ & France & Allemagne & $\begin{array}{c}\text { Basse } \\
\text { Autriche }\end{array}$ & Wallonie \\
\hline \multirow{2}{*}{$\begin{array}{l}\text { L'environnemen } \\
\text { t historique ou } \\
\text { politique des } \\
\text { clusters }\end{array}$} & $\begin{array}{l}\text {...les caractéristiques } \\
\text { « héritées » des clusters }\end{array}$ & $(X)^{322}$ & & & $X$ \\
\hline & $\begin{array}{l}\text {...la mise en ouvre de la } \\
\text { politique de clusters }\end{array}$ & $X$ & & $\mathrm{X}$ & $X$ \\
\hline \multirow{4}{*}{$\begin{array}{l}\text { Les clusters } \\
\text { eux-mêmes }\end{array}$} & $\begin{array}{l}\text {...l'efficacité de } \\
\text { l’organisation des } \\
\text { clusters : moyens, } \\
\text { gouvernance, pilotage }\end{array}$ & $X$ & & $X$ & $X$ \\
\hline & $\begin{array}{c}\text {...les actions et résultats } \\
\text { intermédiaires des } \\
\text { clusters }\end{array}$ & $X$ & $X$ & $\mathrm{X}$ & $X$ \\
\hline & $\begin{array}{l}\text {...l'impact des clusters } \\
\text { sur les acteurs impliqués }\end{array}$ & & $X$ & & $(X)^{323}$ \\
\hline & $\begin{array}{l}. . l \text { 'impact des clusters } \\
\text { sur leur territoire }\end{array}$ & & $X$ & & $(\mathrm{X})$ \\
\hline
\end{tabular}

Tableau 4 - les objets d'évaluation dans les quatre pays

\section{Les schémas de causalité}

Les schémas de causalité ont été reconstitués à partir des documents d'évaluation et des exposés de la politique. Comme on l'a dit, le schéma de causalité sous-jacent à la politique française fait le lien entre projets collaboratifs de R\&D, innovation, et compétitivité des entreprises et du territoire concernés. Pour les autres pays étudiés, la situation est assez contrastée :

- la Basse Autriche fait l'hypothèse que la qualité des services offerts par le cluster aux entreprises, alliée à ses actions de mise en réseau, va augmenter la coopération des entreprises et donc les rendre plus compétitives ;

- l'Allemagne, quant à elle, ne détaille pas de schéma de causalité de sa politique, ce qui est cohérent avec le fait que l'Etat laisse les Länder libres de l'utilisation des fonds qui leur sont attribués à l'issue du concours. Les schémas de causalité sont donc en fait construits par les Länder, éventuellement différemment les uns des autres, et l'Etat ne cherche pas à les tester : ce sont essentiellement les résultats macro-économiques de la politique qui sont examinés ;

\footnotetext{
${ }^{322}$ En France, une seule question (à savoir « une structure similaire à un cluster était-elle déjà en place avant le lancement de la politique ?») était posée concernant les caractéristiques « héritées » des clusters, c'est pourquoi nous l'indiquons dans le tableau mais préférons le mettre en parenthèse.

${ }^{323}$ L'impact final des clusters sur les acteurs ou sur le territoire a simplement été approché par les appréciations qualitatives qu'en ont données certains de leurs membres dans les entretiens.
} 
- enfin, dans le cas de la Wallonie, le schéma de causalité sous-jacent à la politique est peu apparent, les actions encouragées dans le cadre de la politique de clusters étant diverses (R\&D, formation, investissements). Sur ce point, ce cas se rapproche du cas autrichien par la transmission de la responsabilité des modalités d'action aux managers des clusters, et du cas allemand par l'absence d'explicitation des modalités d'action à mettre en œuvre...

\begin{tabular}{|l|l|l|l|}
\hline \multicolumn{1}{|c|}{ France } & \multicolumn{1}{c|}{ Allemagne } & \multicolumn{1}{c|}{ Basse Autriche } & \multicolumn{1}{c|}{ Wallonie } \\
\hline $\begin{array}{l}\text { Le soutien à des projets } \\
\text { collaboratifs de R\&D } \\
\text { va stimuler les } \\
\text { innovations et donc la } \\
\text { compétitivité des } \\
\text { entreprises et la } \\
\text { croissance économique } \\
\text { du territoire }\end{array}$ & $\begin{array}{l}\text { Le soutien à quelques } \\
\text { régions sélectionnées } \\
\text { va stimuler leur } \\
\text { croissance économique }\end{array}$ & $\begin{array}{l}\text { Le haut niveau de } \\
\text { service apporté aux } \\
\text { entreprises par le } \\
\text { cluster va accroître } \\
\text { leurs coopérations et les } \\
\text { rendre plus } \\
\text { compétitives }\end{array}$ & $\begin{array}{l}\text { diverses actions (R\&D, } \\
\text { formation, } \\
\text { investissements), } \\
\text { soutenues par la } \\
\text { politique de clusters, } \\
\text { contribue à la } \\
\text { compétitivité des } \\
\text { entreprises et à la } \\
\text { croissance économique }\end{array}$ \\
\hline
\end{tabular}

Tableau 5 - Les schémas de causalité dans les quatre processus évaluatifs

Ces situations contrastées permettent d'éclairer le choix des objets d'évaluation qui ont été identifiés, dans chacun des quatre pays : en particulier, on comprend pourquoi l'évaluation allemande se centre sur les effets et impacts économiques des clusters ; alors que l'Autriche se préoccupe de l'évaluation du management des clusters, tournés vers les entreprises.

A travers cette comparaison, on peut aussi d'ores et déjà noter que c'est le schéma de la politique française qui est le plus explicite, ce qui devrait permettre d'évaluer la pertinence même de la politique, si, à plus long terme, tous les maillons de la chaîne de causalité deviennent observables (en particulier les impacts économiques, mais aussi les caractéristiques héritées des pôles). Une telle observation n'est guère surprenante quand on sait que, en France, l'Etat pilote lui-même de près un certain nombre de politiques publiques. A l'inverse, l'Etat allemand, qui finance et conçoit une politique, mais en délègue la mise en œuvre aux Länder, peut difficilement s'intéresser à sa mise en œuvre détaillée sans mettre en cause le partage des rôles institué entre les deux niveaux institutionnels.

\subsection{Démarche et méthodologie des évaluations}

\section{Démarche}

A l'exception de l'Allemagne, les évaluations ont toutes été lancées trois ou quatre ans après le lancement de la politique; elles peuvent donc être considérées comme des évaluations intermédiaires.

Dans les quatre cas, les évaluations ont été déclenchées par les commanditaires des politiques de clusters ou des entités publiques qui leur étaient proches, mais les évaluateurs avaient des profils assez différents selon les cas (consultants plus ou moins internationaux, universitaires d'autres pays, experts internationaux...). Ces choix donnent des indications sur la question de l'indépendance de l'évaluation, qui peut jouer un rôle dans les idéaux-types d'évaluation que nous tentons de mettre en lumière en conclusion. 


\begin{tabular}{|c|c|c|c|c|}
\hline & France & Allemagne & Basse Autriche & Wallonie \\
\hline $\begin{array}{l}\text { Période } \\
\text { évaluée }\end{array}$ & $2005-2007$ & $\begin{array}{l}\text { BioRegio: } 1996 \\
\text { BioProfile: } 1999\end{array}$ & $2000-2003$ & 2001-2004 \\
\hline $\begin{array}{l}\text { Date de } \\
\text { l'évaluation }\end{array}$ & 2008 (après 3 ans) & $\begin{array}{l}2005-2007 \text { (après } \\
10 \text { ans) }\end{array}$ & 2004 (après 4 ans) & 2004 (après 4 ans) \\
\hline $\begin{array}{l}\text { Type } \\
\text { d'évaluation }\end{array}$ & Intermédiaire & Ex post & Intermédiaire & Intermédiaire \\
\hline $\begin{array}{l}\text { Qui a } \\
\text { commandité } \\
\text { l'évaluation? }\end{array}$ & $\begin{array}{l}\text { DATAR et DGCIS } \\
\text { (administrations en } \\
\text { charge de la } \\
\text { politique nationale) }\end{array}$ & $\begin{array}{l}\text { Ministre de } \\
\text { l'éducation et de la } \\
\text { recherche }\end{array}$ & $\begin{array}{l}\text { Eco Plus: agence } \\
\text { économique de la } \\
\text { Basse Autriche }\end{array}$ & $\begin{array}{l}\text { Conseil } \\
\text { Economique et } \\
\text { Social de la Région } \\
\text { wallonne }\end{array}$ \\
\hline $\begin{array}{l}\text { Qui sont les } \\
\text { évaluateurs? }\end{array}$ & $\begin{array}{l}\text { - Boston } \\
\text { Consulting Group } \\
\text { (grand cabinet de } \\
\text { conseil } \\
\text { international) } \\
\\
\text { - CMI (cabinet de } \\
\text { conseil français) }\end{array}$ & $\begin{array}{l}\text { - Un professeur de } \\
\text { l'université Kiel en } \\
\text { Allemagne (Dohse) } \\
\text { - Un professeur de } \\
\text { l'université Cardiff } \\
\text { Pays de Galles, } \\
\text { spécialiste internat. } \\
\text { (Cooke) } \\
\text { - Un expert } \\
\text { freelance }\end{array}$ & $\begin{array}{l}\text {-Trigon (entreprise } \\
\text { autrichienne, } \\
\text { conseil régional) } \\
\text {-Joanneum } \\
\text { Research } \\
\text { (entreprise semi- } \\
\text { publique, détenue à } \\
90 \% \text { par une autre } \\
\text { région } \\
\text { autrichienne, la } \\
\text { région Styria) }\end{array}$ & $\begin{array}{l}\text { Université de } \\
\text { Maastricht } \\
\text { (MERIT) }\end{array}$ \\
\hline
\end{tabular}

Tableau 6 - Les quatre processus évaluatifs

\section{Méthodologie}

Si l'on s'intéresse maintenant aux choix méthodologiques mis en œuvre dans les quatre pays, on constate que, même si des points communs existent, une certaine diversité des approches se manifeste, notamment

- dans la volonté de mettre en évidence des impacts économiques par des mesures objectives

- dans l'accent mis sur la comparaison avec des entités "témoin"

- dans l'équilibre choisi entre approches quantitative et qualitative,

- dans le croisement des points de vue, et en particulier l'importance accordée aux jugements des membres des clusters (notamment les entreprises) sur les dispositifs

Les évaluateurs allemands optèrent pour une approche analytique la plus scientifique possible, en réalisant une comparaison statistique entre les régions distinguées par les programmes gouvernementaux et d'autres régions «témoins ». Pour ce faire, toutes les entreprises qui, début 2006, en Allemagne, avaient pour activité principale les biotechnologies (630 entreprises) ont été contactées, alors que 98 d'entre elles seulement (soit moins de 20\%) avaient bénéficié des subventions liées aux programmes BioRegio et BioProfile ; ces enquêtes ont cherché à savoir par exemple si les programmes avaient amélioré la réputation internationale de l'Allemagne en tant que site économique dans les biotechnologies, si, grâce aux programmes, des coopérations avaient été réalisées qui sans ceux-ci n'auraient pas débuté, ou si les coopérations étaient fructueuses et durables. On notera que le recul temporel de l'évaluation allemande permettait d'évaluer la progression de certains indicateurs économiques (valeur ajoutée par exemple). Par ailleurs, la comparaison s'effectuant au sein 
d'un même secteur (les biotechnologies), elle s'affranchissait des critiques portant sur la nonpertinence des comparaisons multisectorielles. Enfin, une comparaison des principales caractéristiques de la structure, de l'activité et du financement des clusters a été effectuée (pour les clusters leaders) avec des clusters britanniques majeurs, manifestant à nouveau le souci de trouver des entités témoin, auxquelles comparer les clusters allemands. Cela dit, des éléments en partie qualitatifs ont également été recueillis auprès des entreprises et des institutions de recherche pour caractériser l'action et les résultats des clusters.

A l'inverse, la France, la Basse Autriche, et la Wallonie optèrent pour des approches plus descriptives et qualitatives, imposées de toute façon par la faible durée d'existence de leurs clusters. C'est une des raisons qui explique qu'en France, mais aussi en Wallonie et en Autriche, une partie importante de l'évaluation s'attache à spécifier, par quelques indicateurs quantitatifs (nombre de membres des clusters, nombre de salariés concernés, nombre de projets, volume des subventions accordées...), mais surtout qualitativement, par des entretiens, la qualité de management des clusters et les résultats de leur activité.

Enfin, il est intéressant de caractériser la manière dont la variété des parties prenantes a été prise en compte dans les différentes évaluations. Dans toutes les démarches sont interviewés des acteurs impliqués dans la politique, des responsables de clusters, et à un moindre degré, des représentants d'institutions de recherche. Toutefois, deux spécificités notables apparaissent :

- dans l'évaluation allemande, 19 interviews d'“experts" sont réalisées dans les 10 régions concernées par le secteur Biotechnologie.

- dans deux des quatre pays étudiés (l'Allemagne et la Basse-Autriche), un questionnaire est adressé à toutes les entreprises concernées ( $\mathrm{y}$ compris, pour l'Allemagne, des entreprises du secteur, mais dans des régions non lauréates). Ces questionnaires, destinés entre autres, à recueillir de l'information économique dans le cas allemand, sont centrés, en Autriche, sur l'appréciation de la compréhension et de la satisfaction des entreprises vis-à-vis de la politique et de l'action des clusters qui les concernent. 


\begin{tabular}{|c|c|c|c|}
\hline $\begin{array}{l}\text { France } \\
\text { (exhaustif : } 71 \text { pôles) }\end{array}$ & $\begin{array}{l}\text { Allemagne } \\
\text { (sectoriel : Bio) }\end{array}$ & $\begin{array}{l}\text { Basse Autriche } \\
(4 \text { clusters })\end{array}$ & $\begin{array}{l}\text { Wallonie } \\
\text { (4 clusters pilotes) }\end{array}$ \\
\hline $\begin{array}{l}\text { - entretiens avec des } \\
\text { acteurs nationaux, des } \\
\text { responsables clusters } \\
\text { et un échantillon de } \\
\text { membres }\end{array}$ & $\begin{array}{l}\text { - entretiens avec des } \\
\text { experts dans les } \\
\text { différentes régions }\end{array}$ & $\begin{array}{l}\text { - entretiens et } \\
\text { workshops avec les } \\
\text { acteurs de la politique, } \\
\text { (cluster managers) }\end{array}$ & $\begin{array}{l}\text { - entretiens avec les } \\
\text { gestionnaires des } \\
\text { clusters, un } \\
\text { échantillon des } \\
\text { membres, et } \\
\text { observation } \\
\text { participante }\end{array}$ \\
\hline - pas d'enquête & $\begin{array}{l}\text { - enquête auprès des } \\
\text { instituts de recherche } \\
\text { et toutes les } \\
\text { entreprises du secteur } \\
\text { des biotechnologies }\end{array}$ & $\begin{array}{l}\text { - enquête de } \\
\text { satisfaction auprès des } \\
\text { membres }\end{array}$ & - pas d'enquête \\
\hline $\begin{array}{l}\text { - indicateurs d'activité } \\
\text { des clusters mais pas } \\
\text { d'indicateur } \\
\text { économique }\end{array}$ & $\begin{array}{l}\text { - indicateurs micro et } \\
\text { macroéconomiques, } \\
\text { comparaison avec } \\
\text { régions témoins }\end{array}$ & $\begin{array}{l}\text { - indicateurs d'activité } \\
\text { mais pas d'indicateur } \\
\text { économique }\end{array}$ & $\begin{array}{l}\text { - indicateurs } \\
\text { microéconomiques sur } \\
\text { les entreprises }\end{array}$ \\
\hline $\begin{array}{l}\text { - pas de comparaison } \\
\text { internationale }\end{array}$ & $\begin{array}{l}\text { - comparaison } \\
\text { quantitative avec } \\
\text { clusters anglais }\end{array}$ & $\begin{array}{l}\text { - pas de comparaison } \\
\text { internationale }\end{array}$ & $\begin{array}{l}\text { - pas de comparaison } \\
\text { internationale }\end{array}$ \\
\hline
\end{tabular}

Tableau 7 - Sources des données et éléments de méthodologie

Au total, au-delà de difficultés classiques rencontrées par tous les évaluateurs en matière de collecte de données fiables, ou de définition de périmètres pertinents, problèmes que nous ne détaillerons pas ici, on constate surtout que toutes les évaluations essaient de multiplier les approches en termes d'angles d'attaque et de méthode.

Cela dit, dans le "mix" méthodologique ainsi défini, on remarque le contraste notable entre l'approche allemande, beaucoup plus centrée sur les résultats économiques de la politique, appréciés par rapport à des points de référence, et l'approche autrichienne, orientée vers la mesure détaillée de la satisfaction des entreprises par rapport aux services apportés par les clusters. Les approches française, et surtout wallonne, sont plus hybrides.

\subsection{Effets et usages des évaluations}

Dans les sections précédentes nous venons d'analyser en profondeur les quatre rapports d'évaluation présentés dans le tableau 1. Dans cette dernière section, nous abordons maintenant, sur la base d'autres types de sources (entretiens, communiqués publics, presse...) présentées dans le tableau 2, les effets et usages des évaluations analysées. Mais sur ce point, compte tenu de la différence de profondeur de nos investigations selon les pays, nous ne pourrons donner que quelques aperçus succincts portant sur les usages faits par les pouvoirs publics des évaluations réalisées.

D'abord, la publicité des évaluations n'a pas été la même dans les quatre pays. En France par exemple, la synthèse de l'évaluation a été largement diffusée et le gouvernement a utilisé cette évaluation pour confirmer sa politique et son investissement. En Autriche, une partie de l'information sur l'évaluation (les recommandations des évaluateurs, les résultats les plus 
importants de l'enquête de satisfaction) a aussi été diffusée sur le site web de l'agence responsable des clusters et dans le rapport annuel de l'agence. En revanche, dans ces deux cas, l'information sur les résultats de l'évaluation de chaque cluster a été réservée aux responsables du cluster. En Wallonie, en revanche, le rapport fait par les universitaires a été intégralement mis en ligne, alors qu'il comportait des analyses détaillées concernant chaque cluster. Quant au rapport d'évaluation allemand, il est également accessible intégralement par internet $^{324}$.

Ensuite, en ce qui concerne l'intervention sur le pilotage des clusters eux-mêmes et la mobilisation de leurs acteurs par le risque de sanction liée à l'évaluation, elle a été différente selon les pays. En Wallonie, deux des quatre clusters pilotes ont été délabellisés immédiatement, avec les conséquences concomitantes en termes de soutien financier (Lepage, 2009). Suite à cette phase pilote et son évaluation, qui ont donc permis à la Wallonie d'apprendre d'abord à petite échelle sur l'utilité et les effets de la politique, le «vrai » programme de cluster a été lancé en Wallonie. En France, où il n'y a pas eu de phase pilote, les 71 clusters ont été évalués. Pour treize d'entre eux, les évaluateurs ont recommandé de procéder à une «reconfiguration en profondeur », recommandation qui a été une incitation à restructurer et à clarifier leur politique et qui a fortement mobilisé les clusters concernés et leurs soutiens politiques régionaux. Presque deux ans plus tard (en mai 2010) six des treize pôles «mal évalués » lors de l'évaluation (publiée en juin 2008) se sont vu retirer leur label, avec les subventions associées. Contrairement à la Wallonie, l'effet sanction, en France, n'a joué qu'in fine, après avoir laissé les pôles apprendre de l'évaluation.

Enfin, en ce qui concerne la réorientation de la politique, en France, une politique 2.0 est partiellement issue des préconisations des évaluateurs (par exemple obligation pour chaque cluster de développer un plan stratégique et ensuite de signer un contrat de performance avec la tutelle nationale et les régions; plus grande ouverture vers les financements européens). Cependant, il faut se garder de toute forme d'angélisme et remarquer qu' un certain nombre de décisions ont été prises en amont, avant l'achèvement formel de l'évaluation. On sait plus généralement que l'évaluation d'une politique publique ne peut être considérée comme seule source de la décision politique ou administrative (Lacasse, 1995). En Allemagne, l'évaluation, effectuée ex post, ne pouvait avoir de conséquences sur un programme à durée déterminée. Cependant, l'évaluation positive du programme a influencé la réplication de celui-ci sur d'autres secteurs.

Les usages de l'évaluation en terme de pilotage par les décisionnaires publics semblent donc plus manifestes dans les cas français et wallon que dans le cas allemand. Dans le cas autrichien, malgré l'absence de décision spectaculaire comme une délabellisation, nous ne pouvons émettre de jugement étayé sur ce point. Nous pouvons seulement faire l'hypothèse, par analogie avec des situations semblables, que le renvoi aux clusters des jugements portés par les entreprises a pu constituer un stimulant à l'amélioration du management, et donc un outil de pilotage.

\footnotetext{
${ }^{324}$ sur le site de l'EFI (Expertenkommission Forschung und Innovation ), organisme qui joue le rôle conseil scientifique sur la recherche et l'innovation du gouvernement allemand.
} 


\section{CONCLUSION : AU-DELA DE LA DIVERSITE, DEUX MODELES CONTRASTES D'EVALUATION?}

Au-delà de la variété des démarches évaluatives constatée dans les quatre pays étudiés, peuton repérer quelques invariants et, au moins, trouver des explications à la diversité ? La première observation qui peut être faite, est que, dans chaque pays, nous décelons une certaine cohérence entre les trois grandes catégories de caractéristiques de notre grille d'analyse. Les objets d'évaluation et le schéma de causalité qui les relie, la méthodologie utilisée, les usages faits de l'évaluation ne sont pas indépendants les uns des autres.

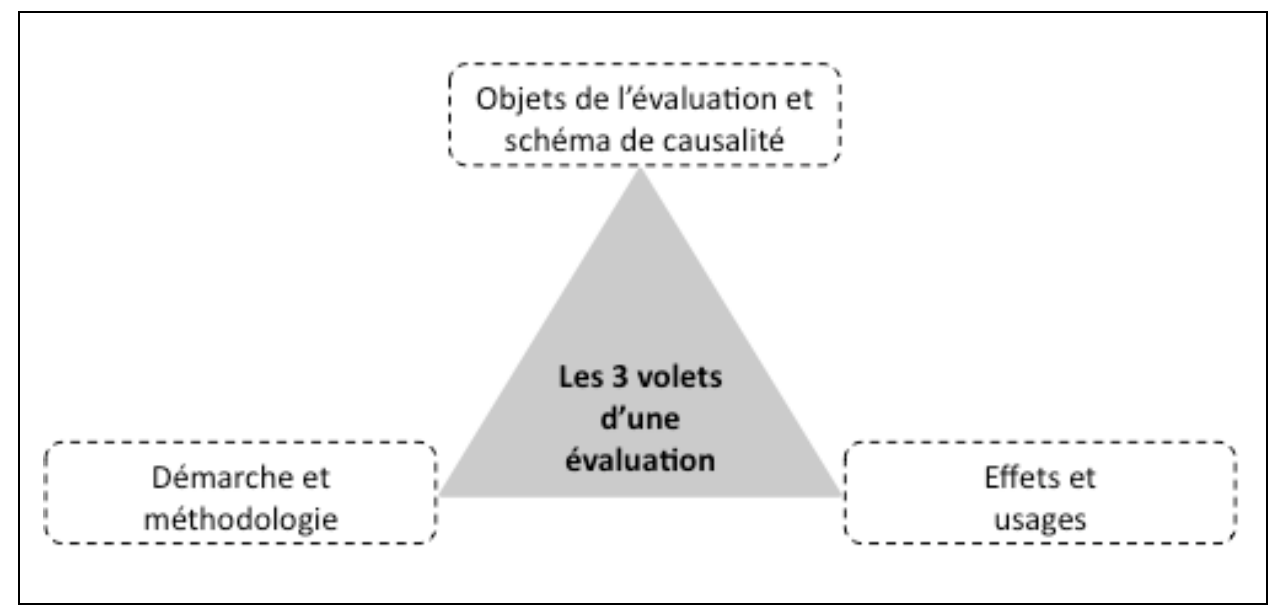

Figure 3 - Résumé : Les trois volets d'une évaluation

Ainsi, en Allemagne,

- les objets d'évaluation sont centrés sur la question de l'impact économique, et aucun schéma de causalité n'est explicité

- la méthodologie est essentiellement quantitative et l'évaluation s'appuie sur des universitaires et un expert international

- il n'y a pas d'usage direct des résultats (publics) de l'évaluation pour piloter la politique, (autre que le lancement ultérieur d'autres programmes analogues dans des secteurs différents)

Par contraste, en France,

- les objets d'évaluation sont des résultats intermédiaires (des projets de R\&D financés) et des modes d'organisation, mais pas les impacts finaux

- la méthodologie a une forte composante qualitative et les évaluateurs sont des cabinets de consultants pilotés par les administrations qui exercent la tutelle des pôles

- les résultats de l'évaluation, en partie publics seulement, sont utilisés à des fins de mobilisation des acteurs, de pilotage et de réorientation de la politique (Politique 2.0.)

Le cas wallon, plus hybride en termes d'objets et de méthodologie, se rapproche toutefois davantage du cas français, en ce que l'évaluation est directement utilisée pour piloter la politique.

Quant à l'Autriche, elle se rapproche du cas français, en termes d'objets et de méthodologie mais semble viser essentiellement, en termes d'usages, un pilotage des clusters via la mobilisation des managers, plus qu'une réorientation ou amélioration de la politique ellemême. 
Nous synthétisons ces constats dans le tableau ci-dessous.

\begin{tabular}{|c|c|c|c|c|c|}
\hline & France & Allemagne & Basse Autriche & Wallonie \\
\hline \multicolumn{2}{|c|}{ Effets et usages } & $\begin{array}{l}\text { «Mieux piloter »: } \\
\text { infléchir la } 2^{\text {eme }} \\
\text { phase de la } \\
\text { politique et } \\
\text { mobiliser les } \\
\text { clusters }\end{array}$ & $\begin{array}{l}\text { "Rendre compte » } \\
\text { et disposer d'un } \\
\text { bilan pour répliquer } \\
\text { la politique sur } \\
\text { d'autres secteurs }\end{array}$ & $\begin{array}{l}\text { «Mieux piloter » : } \\
\text { mobiliser les } \\
\text { clusters managers }\end{array}$ & $\begin{array}{l}\text { «Rendre compte» } \\
\text { et « Mieux } \\
\text { piloter »: infléchir la } \\
\text { politique et } \\
\text { mobiliser les } \\
\text { clusters }\end{array}$ \\
\hline \multirow{3}{*}{$\begin{array}{l}\text { Démarche } \\
\text { et } \\
\text { méthodol } \\
\text { ogie }\end{array}$} & $\begin{array}{l}\text { Type de } \\
\text { l'évaluation }\end{array}$ & intermédiaire & finale & intermédiaire & intermédiaire \\
\hline & $\begin{array}{l}\text { Indépendance } \\
\text { supposée }{ }^{325} \text { de } \\
\text { l'évaluation }\end{array}$ & moyenne & forte & moyenne & forte \\
\hline & $\begin{array}{l}\text { Spécificités } \\
\text { des données et } \\
\text { d'analyse }\end{array}$ & & $\begin{array}{l}\text { Forte composante } \\
\text { quantitative } \\
\text { (indicateurs } \\
\text { d'impact } \\
\text { macroéconomique) } \\
\text { et comparative }\end{array}$ & $\begin{array}{l}\text { Enquête de } \\
\text { satisfaction des } \\
\text { entreprises }\end{array}$ & \\
\hline \multicolumn{2}{|c|}{$\begin{array}{l}\text { Objets de l'évaluation et } \\
\text { schéma de causalité }\end{array}$} & $\begin{array}{l}\text { Objets : résultats } \\
\text { intermédiaires } \\
\text { (activités, projets } \\
\text { R\&D) et } \\
\text { organisation des } \\
\text { clusters } \\
\text { Schéma de } \\
\text { causalité explicite }\end{array}$ & $\begin{array}{l}\text { Objets : Impacts } \\
\text { économiques } \\
\text { Pas de schéma de } \\
\text { causalité }\end{array}$ & $\begin{array}{l}\text { Objets: } \\
\text { organisation et } \\
\text { activités des } \\
\text { clusters } \\
\text { Schéma de } \\
\text { causalité explicite }\end{array}$ & $\begin{array}{l}\text { Objets: } \\
\text { organisation et } \\
\text { activités des } \\
\text { clusters, } \\
\text { caractéristiques } \\
\text { économiques des } \\
\text { clusters } \\
\text { Pas de schéma de } \\
\text { causalité }\end{array}$ \\
\hline \multicolumn{2}{|l|}{ Modèle } & $\begin{array}{l}\text { Modèle } \\
\text { «gestionnaire » }\end{array}$ & $\begin{array}{l}\text { Modèle } \\
\text { " économiste " }\end{array}$ & $\begin{array}{l}\text { Modèle } \\
\text { «gestionnaire » }\end{array}$ & $\begin{array}{l}\text { Modèle } \\
\text { « hybride» }\end{array}$ \\
\hline
\end{tabular}

Tableau 8 - Résumé : Les deux modèles d'évaluation

A titre d'hypothèse heuristique, qui demanderait à être testée de manière plus approfondie et sur de plus nombreux exemples, on pourrait avancer que deux modèles idéal-typiques sont sous-jacents à ces différences, caractérisés notamment par des usages contrastés des évaluations :

- un modèle "économiste », qui s'intéresse prioritairement au bilan ex post de la politique, fait en termes d'impacts économiques, et qui, pour cela s'appuie nécessairement sur des approches quantitative et comparative, qui permettent, en apparence au moins, une «objectivation» plus grande des résultats, et dont la légitimité est renforcée par les caractéristiques des évaluateurs

- un modèle "gestionnaire» qui met en exergue le rôle d'aide au pilotage d'une démarche évaluative, et qui, à ce titre, cherche à qualifier in itinere des résultats intermédiaires, et à explorer des schémas de causalité explicites, sous-jacents à la politique, pour les tester et éventuellement réorienter la politique. A ce titre, ce type de démarche, qui, sans négliger l'intérêt d'indicateurs quantitatifs, s'appuie sur des méthodes qualitatives, pour «rentrer dans la boîte noire »du fonctionnement des clusters, ne revendique pas, en général, les mêmes caractéristiques de scientificité que la précédente. Un signe en est que l'indépendance de la démarche évaluative n'y est pas spécifiquement recherchée, le caractère «actionnable» de la démarche, souvent corollaire de la proximité aux décideurs, y étant en revanche privilégié.

\footnotetext{
${ }^{325}$ Comme indiqué en 2.2, l'indépendance de l'évaluation est supposée liée au design institutionnel du processus (nature du commanditaire et des évaluateurs et de leurs relations, implication des parties prenantes, etc)
} 
On retrouvera là une dualité qui renvoie, de manière plus générale, à l'opposition, classique en évaluation des politiques publiques (EPP), entre «évaluation de l'action » et «évaluation dans l'action » (Chanut, 2009).

Comment, alors, les différents pays se déterminent-ils par rapport à ces deux idéaux-types ?

Bien sûr, on sait que les modèles d'évaluation des politiques publiques sont largement nationaux, modelés par l'histoire institutionnelle et socio-politique de chaque pays (Barbier \& Matyjasik, 2010; Lacouette-Fougère \& Lascoumes, 2013). Mais, pour ce qui concerne le champ des politiques de clusters, le choix d'une démarche évaluative renvoyant à l'un ou l'autre de ces modèles nous semble orienté par au moins deux considérations complémentaires :

- d'une part, la maturité de la politique de clusters, car, on l'a vu, le modèle « économiste » demande un recul temporel qui n'est pas exigé par l'autre ;

- d'autre part, la légitimité des modes d'intervention des pouvoirs publics. En effet, les systèmes politico-économiques des différents pays et leur culture nationale, ne permettent pas toujours aux pouvoirs publics d'intervenir directement dans des processus gérés par d'autres acteurs, même si des soutiens financiers sont accordés via la politique de clusters : ainsi, en Allemagne, l'état fédéral n'est pas légitime à intervenir dans des programmes gérés par les Länder, alors que la tradition interventionniste de l'Etat français lui permet de demander des comptes sur les processus de gestion internes des pôles de compétitivité.

Par ailleurs, on observera que ces deux modèles, également légitimes, ne sont bien sûr pas exclusifs l'un de l'autre. Ils apportent des points de vue complémentaires sur une politique et peuvent donc se combiner, ou se succéder au fil du temps. Ces choix dépendront des commanditaires des évaluations et des usages qu'ils souhaitent en faire. Mais la mise en évidence de ces deux modèles peut permettre aux instigateurs des évaluations de construire des démarches évaluatives plus cohérentes.

Enfin, même si le modèle «gestionnaire» semble a priori plus tourné vers la production de connaissances actionnables, source d'apprentissage pour les acteurs opérationnels (responsables de clusters autant que décideurs politiques), on fera observer que, dans les deux cas, la démarche évaluative a une vertu qui n'est pas souvent mise en exergue : elle oblige l'évaluateur (en commun avec le commanditaire), en se posant le problème du choix des objets d'évaluation, à révéler les objectifs de la politique menée, qui ne sont pas nécessairement très explicites. A travers ce processus, les acteurs impliqués commencent alors à faire rétrospectivement sens de leurs actions déjà menées. Cette "interaction entre action et interprétation » (Weick, Sutcliffe, \& Obstfeld, 2005, p. 409) ajoute à l'évaluation cette vertu souvent oubliée : la clarification des objectifs sous-jacents de la politique. Cette clarification permet donc d'améliorer potentiellement l'orientation des politiques et des actions futures. 


\title{
ANNEX 20: ARTICLE ON CLUSTERS' GOVERNANCE STRUCTURES (2013)
}

\section{Governance Structures as Determinants of Resource Attraction? Evidence from French Clusters}

( ${ }^{\text {st }}$ revise \& resubmit in Entrepreneurship \& Regional Development)

Anna GLASER, ESCP Europe \& Mines ParisTech, anna.glaser@escpeurope.eu ESCP Europe, 79 avenue de la République, 75543 Paris Cedex 11 Mines ParisTech, 60 Boulevard Saint-Michel, 75272 Paris Cedex 06

Emilie-Pauline GALLIE, IMRI, Paris Dauphine, emilie-pauline.gallié@ dauphine.fr IMRI, Université Paris-Dauphine, Pl. Maréchal de Lattre de Tassigny, 75775 Paris Cedex 16

Thierry WEIL, Mines ParisTech, thierry.weil@ensmp.fr CERNA, Mines ParisTech, 60 Boulevard Saint-Michel, 75272 Paris Cedex 06

\begin{abstract}
The objective of this article is to explore reasons for the resource variations between clusters, which were triggered under the same public policy. More precisely, we investigate the relationship between a cluster's governance and its ability to attract resources. We approach this question by taking a resource based and a resource dependence view of clusters. The resource based view helps to define the set of resources that explain performance differences between clusters. The resource dependence view then allows us to discuss the role of a cluster's governance to attract important resources. Our methodology differs from most case-study-based examinations of clusters as we have access to data on 66 French clusters accredited by the French government. We are thus able to use a quantitative approach in our analysis. The results of our analysis show that we can categorise French clusters in three broad categories (support, scientist and corporate class) and that one of these categories (corporate class) possesses more resources than the other two categories. Finally, we discuss the results in the light of the resource dependence theory, highlight possible implications for cluster evaluations and propose avenues for further research.
\end{abstract}

Keywords: Cluster; Governance; Resources; Categorisation

\section{Introduction}

The objective of this article is to explore possible reasons for the resource variations between clusters (Porter, 2008), which were triggered under the same public policy (Chiaroni \& Chiesa, 2006). More precisely, we investigate the following question: is there a relationship between a cluster's governance and its ability to attract resources?

Several scholars discuss clusters' resources and capabilities, for example de Oliveira Wilk \& Fensterseifer (2003) analyse the resources of a wine cluster in Brazil, Hervas-Oliver \& 
Albors-Garrigos (2007) compare the resources of a Spanish and an Italian ceramic cluster, or St. John \& Pouder (2006) highlight the differences between the resources of technology and industry clusters. The spectrum of investigated resources is very large, ranging from natural resources to external linkages, social interactions, skilled workers, researchers, entrepreneurs, service providers, etc. However, one resource element that we consider important is to our knowledge always missing, a cluster's governance. The objective of this article is to investigate the role of this rarely studied resource in the cluster literature. Therefore we first define what we understand by cluster governance and then discuss its influence on other available cluster resources.

Our analysis is based on a resource based view (Barney, 1991, 2001; Wernerfelt, 1984) and a resource dependence view (Hillman \& Dalziel, 2003; Pfeffer \& Salancik, 2003 (1978)), two well-known strategic management theories, which are often used to frame research on firms, but rarely used to frame research on clusters (De Oliveira Wilk \& Fensterseifer, 2003; Hervas-Oliver \& Albors-Garrigos, 2007; St. John \& Pouder, 2006; Wu, Geng, Li, \& Zhang, 2010). By taking a resource based view, which derives from economics (Popp, Toms, \& Wilson, 2006), we define the set of resources that explain differences between clusters. By taking a resource dependence view, which derives from sociology (Popp, et al., 2006), we discuss the role of a cluster's governance to attract important resources (financial, human, etc.) to the cluster. According to Popp et al. (2006) both perspectives are needed to understand the resource differences between clusters.

Our methodological approach differs from most case-study-based examinations of clusters in that we have access to data on 66 French cluster governances, accredited by the French government in 2005 and 2006. The variables we use stem from two data sources, the 2008 French clusters evaluation and from the General Directorate for Competitiveness, Industry and Services (DGCIS). Using an exploratory data analysis (Hierarchical Cluster Analysis, One-Way ANOVA, Post-Hoc Test) we contribute with this article to the cluster policy literature and more precisely to the understanding of clusters' governances. Additionally, we provide a categorisation based on governance structures, which according to Reinau \& Dalum (2008) is still a missing element in cluster typologies (Iammarino \& McCann, 2006; Markusen, 1996; Paniccia, 2006).

The article is organised as follow. Firstly, we give a presentation of the resource based and resource dependence view and discuss their roles in a cluster context. Secondly, we establish cluster categories by focusing on the composition of their governance. We group the clusters into homogenous categories based on the weight of the actors (groups, small and medium enterprises, research and/or training institutes, support entities) in the supervisory board and the board of directors. Thirdly, we take a closer look at these categories to highlight the differences in resources they possess (i.e. budget for the animation and the functioning of the cluster, amount of public R\&D funding, number of full time equivalents working for the cluster organisation) depending on which governance category they belong to. Finally, we discuss the results in the light of the resource dependence theory, highlight possible implications for cluster evaluations and propose avenues for further research. 


\section{Clusters in the light of two resource perspectives}

\section{A resource based view of clusters}

The resource based view (Barney, 1991, 2001; Wernerfelt, 1984) of the firm is a wellestablished research stream in strategic management. According to this view, every firm has a unique set of resources and capabilities that explain performance differences between firms. For Wernerfelt (1984, p. 172) for example, a resource is "anything which could be thought of as a strength or weakness of a given firm" and can thus be either tangible or intangible (e.g. brand names, in-house knowledge of technology, employment of skilled personnel, trade contacts, machinery, efficient procedures, capital, etc.). More generally, according to Barney (1991), "all firms are different because they do not have the same history, the same experiences, the same organisational culture or the same assets and abilities" (De Oliveira Wilk \& Fensterseifer, 2003, p. 996).

Clusters, such as firms, also differ from each other due to their unique history, culture or resources. However, due to the fact that the cluster concept itself still lacks a clear definition (Enright, 2003; Gordon \& McCann, 2000; R. Martin \& Sunley, 2003), the general resources of a cluster are not yet as well conceptualised as firm resources. Guinet (2003, p. 154) for example highlights that it is difficult to compare clusters as "a clusters is always a singularity in the economic space. Cluster is a universal concept that materialises always as an economic sub-system with unique properties regarding the respective role of main actors, and knowledge flows between them. Clusters are inherently different between countries (or regions), between technological areas and ultimately between individual clusters themselves."

Despite these problems, scholars recently started to apply the resource based theory to clusters (De Oliveira Wilk \& Fensterseifer, 2003) to highlight for example the competitive advantage of certain clusters compared to other clusters (Hervas-Oliver \& Albors-Garrigos, 2007; St. John \& Pouder, 2006) or to analyse the impact of cluster resources on firm performance (Wu, et al., 2010). However, due to the fuzziness of the cluster concept, scholars mobilise a variety of terms ( $\mathrm{Wu}$, et al., 2010), each trying in its own way to resume the spectrum of unique cluster resources (factor conditions (Porter, 1990 (1998)), higher-order capabilities (Foss, 1996), shared resources (Molina-Morales \& Martinez-Fernandez, 2003), research capabilities (St. John \& Pouder, 2006), cluster capabilities (Hervas-Oliver \& AlborsGarrigos, 2007), etc.). Due to the lack of a commonly accepted definition of cluster resources, we tried to summarise the main cluster resources (more or less important dependent on the cluster type) found in the literature (see Table 1). Additionally we grouped the resources into two broad categories ${ }^{326}$ : component capitals (natural, human, educational, business, financial and animation resources), which can be seen as the bricks of a cluster, and architectural capitals (social, reputation, network and governance resources), which can be seen as the cement of a cluster, holding the bricks together. For every resource we give illustrative examples in Table 1. In this article, as already underlined, we focus on the rarely studied governance resource that we consider as an important part of a cluster's cement. We thus question which type of governance resource (or type of governance structure) best allows attracting or complementing existent bricks, in particular animation and financial resources. To answer this question we refer to the resource dependence view, explained hereinafter.

\footnotetext{
${ }^{326}$ Inspired by Tallman et al. (2004) who distinguish clusters' component and architectural knowledge.
} 
Table 1. Illustrations of the main cluster resource categories

\begin{tabular}{|c|c|}
\hline \multicolumn{2}{|c|}{ COMPONENT CAPITALS: } \\
\hline Natural & $\begin{array}{l}\text { - Rosenfeld (2005): "the roots of clusters can be found...in access to critical natural resources } \\
\text { or infrastructure" (p. 9) } \\
\text { - Audretsch \& Feldman (1996): "a high dependence on natural resources tends to result in a } \\
\text { greater geographic concentration of production" (p. 268) }\end{array}$ \\
\hline Human & $\begin{array}{l}\text { - Porter (1990): "highly educated personnel such as graduate engineers and computer } \\
\text { scientists" (p. 77) } \\
\text { - St. John \& Pouder (2006): "researchers or inventors conducting basic research in a new } \\
\text { technology area" (p. 153) }\end{array}$ \\
\hline Educational & $\begin{array}{l}\text { - St. John \& Pouder (2006): "knowledge and research from universities and national } \\
\text { laboratories are often essential resources that serve as the attractors to and anchors in the } \\
\text { region" (p. 147) } \\
\text { - Hervas-Oliver \& Albors-Garrigos (2007): "Educational and training cluster's programmes } \\
\text { contribute...to renovate and upgrade the community of people and thus extending the } \\
\text { cluster's knowledge platform." (p. 118) }\end{array}$ \\
\hline Business & $\begin{array}{l}\text { - Hervas-Oliver \& Albors-Garrigos (2007): "Business sophistication.... way to describe } \\
\text { firm's strategies as contributions for upgrading competitiveness in certain regions and } \\
\text { countries...it implies activities such as enhancing marketing, distribution or in-house R\&D" } \\
\text { (p. 118) }\end{array}$ \\
\hline Financial & $\begin{array}{l}\text { - Chiaroni \& Chiesa (2006): "Diffusion of innovative funding mechanisms, which means that } \\
\text { there are funding schemes in place (especially related to seed and venture capital) tailored to } \\
\text { and appropriate for high-tech new ventures" (p. 1073) or/and "Governmental funds dedicated } \\
\text { to support the creation of industrial spin-offs for new companies." (p. 1074) }\end{array}$ \\
\hline & - Rosenfeld (2005): "[cluster]organisations became the symbol of a cluster's very existence; \\
\hline
\end{tabular}

\begin{tabular}{ll}
\hline ARCHITECTURAL CAPITALS: \\
\hline Social & - Hervas-Oliver \& Albors-Garrigos (2007): "trust, common language, objectives and \\
& assumptions, local vocabulary and mutual understandings, similar values, expectations, etc." \\
& (p. 116), "social capital enables network effectiveness and facilitates knowledge absorption \\
& and dissemination by the community of people" (p. 117) \\
\hline Reputational & $\begin{array}{l}\text { - Molina-Morales \& Martinez-Fernandez (2003): "within the industrial district there is an } \\
\text { image of itself that is independent of the individual firms...The industrial district...enjoys a } \\
\text { collective reputation" (p. 158) }\end{array}$ \\
\hline Network & $\begin{array}{l}\text { - Hervas-Oliver \& Albors-Garrigos (2007): "continuous interactions outside the workplace, } \\
\text { especially frequent face-to-face relationships... are associated with high-quality information } \\
\text { flows and tacit knowledge held by workers and managers available in the area" (p. 116-117); } \\
\text { "linkages can be either internal, if they occur just within cluster located members, or external } \\
\text { when connectivity is provided between the cluster and outside agents" (p. 118), both are } \\
\text { important }\end{array}$ \\
\hline Governance & $\begin{array}{l}\text { - Molina-Morales \& Martinez-Fernandez (2003): "as intermediaries, local institutions } \\
\text { facilitate net value for firms by compiling and disseminating knowledge, and by reducing } \\
\text { search costs" (p. 161) }\end{array}$ \\
\hline
\end{tabular}




\section{A resource dependence view of clusters}

Instead of seeing a firm as an accumulation of a unique set of resources and capabilities, a firm can also be seen as a coalition of interests (March, 1962; Pfeffer \& Salancik, 2003 (1978)) that depends on external resources to survive. The theory that illustrates very well this behaviour is called resource dependence theory, which has its theoretical origin in organisational theory and sociology (Zahra \& Pearce, 1989), and mainly draws from the works of Pfeffer (1972, 1973) and Pfeffer \& Salancik (2003 (1978)), who investigated the impact of a board's size and composition on the ability of a company to attract important external resources. Pfeffer (1972, p. 226) concludes "that the board size and composition are not random or independent factors, but are, rather, rational organisational responses to the conditions of the external environment".

Since then, many scholars (e.g. Lynall, Golden, \& Hillman, 2003; Peng, 2004; Provan, 1980), have built on the work of Pfeffer \& Salancik and continue to investigate the link between an organisation's board and its resources (for an extensive review, see Hillman, Withers, \& Collins, 2009). Hillman \& Dalziel (2003) for example consider the board as a provider of resources (e.g., legitimacy, advice and counsel, links to other organisations, etc.). Boyd (1990) on the other hand particularly underlines the importance of 'resource-rich' individuals in boards. Hillman \& Dalziel (2003, p. 383) call this the board capital, which can consist of two types of capital: human capital (experience, expertise, reputation) and relational capital (network of ties to other firms and external contingencies). In other words, the boards "are a cooptative mechanism to extract resources vital to company performance", "serve a boundary spanning role" and "enhance organizational legitimacy" (Zahra \& Pearce, 1989, p. 293). What does this mean exactly in the context of a cluster?

The academic literature on cluster governance bodies is still very scarce, even though Europe already counts 1205 cluster organisations ${ }^{327}$. Cluster organisations can be defined as "intermediate bodies employing people in charge of animating clusters" (Coletti, 2010, p. 679). In order to enlarge this minimalistic definition, cluster organisations are here taken as organisations, composed of different governance bodies, that on the one hand develop strategic plans for a defined geographic area in a specific sector and, that, on the other hand, through a variety of tasks (e.g. networking events, place marketing, aid in accessing venture capital or other research subsidies), try to improve the area's competitiveness. Literature that investigates the governance of clusters started to emerge approximately ten years ago in Italy and Spain (Ahedo, 2004; Alberti, 2001; Mistri, 1999) and has recently been growing in France following the competitiveness cluster policy ${ }^{328}$ introduction in 2005 (Bocquet, Mendez, Mothe, \& Bardet, 2009; Bocquet \& Mothe, 2009; Ehlinger, Perret, \& Chabaud, 2007; Gomez, 2009). Mendel \& Bardet (2009) for example question in their article what role the governance structure plays in the development of cooperation between companies for knowledge accumulation and diffusion. Bocquet et al. (2009) on the other hand state that the implication of a cluster's governance is a key element for the collective and individual performance. Others try to question what kind of governance are adapted for territorial networks (Ehlinger, et al., 2007) or try to find the right theoretical angle to analyse these new organisational artefacts (Gomez, 2009). A few studies adopt a theoretical approach to these

\footnotetext{
${ }^{327}$ www.clusterobservatory.eu (2010)

${ }^{328}$ In France, the policy dedicated to develop clusters is called "competitiveness cluster policy" ("Politique des pôles de compétitivité"). Every French cluster has a dedicated cluster organisation, and thus governance, which is responsible for the cluster's management and strategic orientation. We will explain the particularities of this policy in the next section.
} 
questions (Ehlinger, et al., 2007; Gomez, 2009), but most of the literature dealing with the governance of French clusters focuses on empirical case studies (Bocquet, et al., 2009; Bocquet \& Mothe, 2009; Mendel \& Bardet, 2009). None of these studies tries to develop a general picture of clusters and their governance.

In France, clusters are largely dependent on the subsidies provided by public authorities and try to maximise the resources they can obtain. Indeed, French clusters were created ex nihilo in 2005 and were thus almost entirely financed by the public authority. If a cluster received the official cluster label from the national government, the cluster could profit from the three billion euros that the public authorities reserved for the cluster policy between 2005 and 2011. In contrast to other European cluster policies, only a small part (3.3\%) was used for the functioning of the cluster organisation and its animation ${ }^{329}$. The majority of this money was dedicated to concrete projects $(96.7 \%)$, i.e. R\&D projects, innovation platforms or other thematic collective actions. It is important to underline that the subsidies for the projects are most of the time distributed through public tenders, which means that the distribution of this money between the clusters is not even but related to their success in the tender process. This means that cluster governance structures, which for example are very experienced in tendering processes or have an influential political network, might have a competitive advantage compared to inexperienced or more isolated governance structures.

According to the theory of Pfeffer (1972) we expect thus the following hypothesis: The member composition of the supervisory board and the board of directors impact the capacity to acquire necessary resources for the clusters survival. Moreover, we wonder whether the structure of the cluster organisation influences the capability of receiving resources. Our analysis should try to highlight if a well-balanced mixture of different types of actors or the representation of only one specific actor in the governance structure of a cluster influences a cluster's ability to acquire important financial (R\&D subsidies) and animation resources (operating budget, employees).

Even though several quantitative studies exist that investigate the link between board composition and firm resources (e.g. Dalton, Daily, Johnson, \& Ellstrand, 1999; Hillman, Cannella, \& Paetzold, 2000), to our knowledge no such study exists on the link between cluster governance composition and cluster resources. The current literature on cluster governance mainly focuses on empirical case studies (Bocquet, et al., 2009; Bocquet \& Mothe, 2009; Mendel \& Bardet, 2009), but does not try to establish a more systematic view on this subject. Also Provan et al. (2007, p. 507) highlight that governance structures have "implicitly been considered in many of the network-level studies" but "it is important to explicitly consider network governance" and to study them accordingly. In this perspective we wish to contribute to this gap in the literature by proposing an analysis on a cluster's governance composition and its associated resources.

\section{A categorisation of French clusters according to their governance}

\section{Cluster categorisation in the literature}

Several cluster categorisations have already been suggested to allow a more distinctive look at this fuzzy concept (Iammarino \& McCann, 2006; Markusen, 1996; Paniccia, 2006). The typologies focus on the density of relationships between members and exchanges of knowledge (Eisingerich, Bell, \& Tracey, 2010), the different modes of formal and informal

\footnotetext{
329 Additionally to these $3.3 \%$, the cluster organisations receive money for their functioning and cluster animation activities from local authorities and their members.
} 
intervention from local and national authorities (Fromhold-Eisebith \& Eisebith, 2005) and sector characteristics, like the strength of links between science and industry (Marcon, 2008; C. Saublens, et al., 2007). Recently, two studies developed categorisations for French clusters: one typology characterises the economic structure of the companies that make up clusters and then attempts to study their entrepreneurial dynamics (Bonnafous-Boucher \& Saussois, 2010); the other one tries to link the pre-existing regional R\&D activities to the performance of the clusters (Gallié, Glaser, Mérindol, \& Weil, 2011).

All these categorisations try to grasp the different aspects of a cluster's reality and they tend to show that there is no unique concept and therefore few reasons to take a uniform look at the role played by clusters in the performance of companies or territories. Despite the variety of approaches, it appears that cluster governance structures have rarely been the subject of categorisations (Reinau \& Dalum, 2008). Additionally, only few authors integrate in their analysis the members" composition of the clusters (Carpinetti, Gerolamo, \& Galdámez, 2007). For instance, Markusen (1996) identifies four types of clusters: the Marshallian industrial district structured by a large and exclusive number of SME; the huband-spoke industrial cluster, revolving around one or more dominant, externally oriented firms; a satellite platform, an assemblage of unconnected branch plants embedded in external organisation links; and the state-anchored district focused on one or more public-sector institutions. From this literature, we expect that our categorisation will include a SME, a large group and finally a research-oriented class. We wonder if some categories can be characterised by the mix of the members in their governance structure.

In this section, we provide thus a categorisation of French cluster organisations based on their governance structure. This categorisation ultimately allows us to look in a more distinctive manner at the characteristics of these governance classes and to better apprehend their particularities. By doing this we strive for what Rosch (1999) calls the ultimate situation, i.e. creating categories with the highest amount of information but that need the least cognitive effort. This situation can either be achieved by defining or redefining attributes "to render a given set of categories appropriately structured" or by mapping "categories to given attribute structures" (Rosch, 1999, p. 190). We chose to stick to the second approach as we first define our classes, and then once we have obtained our different cluster governance categories, we attribute specific characteristics (i.e. resources) to these categories.

\section{Context}

The French competitiveness cluster policy, launched in 2005, is based on national programmes and initiatives with the objective to foster the competitiveness of the French territory through economic and employment growth in future oriented industry sectors (Blanc, 2004). France would like to reach this objective by increasing its innovation capacity, by reinforcing or creating activities of high technology content and by improving its attractiveness through better international visibility ${ }^{330}$. Instead of focusing on key sectors or key regions, the French policy opted to focus on a wide range of different sectors and to implement one or several clusters in nearly all of its 27 regions. A cluster, which receives the official "competitiveness cluster label" from the French government, is allowed to apply for specific subsidies, most of which are distributed through public tenders. ${ }^{331}$

\footnotetext{
${ }^{330}$ For more information, visit the official French cluster webpage: http://competitivite.gouv.fr/ (2012)

331 The number of clusters has fluctuated since the introduction of the policy as new clusters were labelled and existing clusters lost their accreditation. In March 2012, France officially counts 71 labelled clusters (and thus cluster organisations) spread over the whole French territory.
} 
French clusters are characterised by a certain number of common characteristics, e.g. the modalities to apply for public subsidies or the formalised governance structure imposed by the French government. Thus, most of the French clusters registered as an association whose aim is to stimulate and to promote the innovation capacities inside the cluster (Ehlinger, et al., 2007). The governance structure of a French cluster can be split into two broad categories: strategic governance (comprising the supervisory board and the board of directors) and operational governance (comprising the management committee) (Bocquet \& Mothe, 2009).

In this article we focus on the strategic governance, which is composed of the (1) supervisory board and (2) board of directors. The supervisory board normally consists of different colleges (i.e. SMEs, large groups, research and/or training institutes or support entities), which meet a few times a year. The objectives of the supervisory board range from deciding on the general orientation of the cluster and nominating and supervising the board of directors to establishing links with the larger environment of the cluster (e.g. other clusters, institutions). On the other hand, the board of directors, which is composed of representatives of the supervisory board and the management committee, watches if the general cluster orientation defined by the supervisory board is correctly implemented by the management committee, or for example raises new future oriented questions for the well functioning and development of the association. So each of the 71 French clusters is steered by a different proportion of small and large companies, research and/or training institutes as well as support entities (e.g. local development agencies). Figure 1 summarises the hierarchical relations of the different cluster governing bodies.

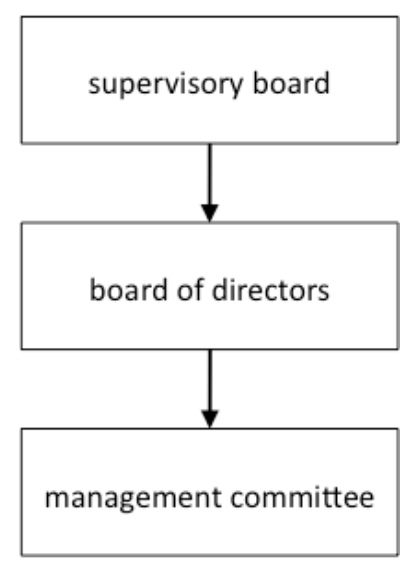

Figure 1. Hierarchical relations of the governing bodies of a French cluster

\section{Data Source}

The data for the cluster categorisation stems from the consortium CM International (CMI) \& Boston Consulting Group (BCG) (CMI-BCG hereafter), two consulting firms, which were responsible for the French cluster evaluation in 2008. The mission of this evaluation was twofold. The first objective was to analyse the strategic orientation of the intervention modalities of the national policy, and the second objective was to investigate the coherency and the efficiency of the plan, cluster by cluster, in an exhaustive manner. The evaluators analysed the period between July 2005 (launch of the French cluster policy) and December 2007. In December 2007, a total of 71 clusters were already officially labelled. However, our analysis only takes into account the 66 clusters that disposed of an official competitiveness label since 2005 and 2006, as more data is available for those clusters. Appendix 1 lists all 66 clusters taken into account in our study. For the evaluation, CMI-BCG sent an online 
questionnaire to all French cluster organisations in January 2008. Through the questionnaire, CMI-BCG collected data regarding the dynamic of the clusters (e.g. members, implication in projects) and the structure of the cluster organisations (e.g. strategy, governance, management of $R \& D$ projects). The report of this evaluation is publicly available (CMI \& BCG, 2008) but we were able to access the raw data of this study thanks to CMI .

\section{Variables}

The CMI-BCG survey had one section dedicated to the governance of the clusters. In this section, CMI-BCG collected the number of members per type for each of the two governance bodies (supervisory board and board of directors) at the end of 2007. We choose these variables relating to the composition of the boards, as they constitute a proxy of the governance structures.

We first looked at the correlation between the member structure and the governance structure to rule out that the two are the same. According to the Pearson Correlation Coefficient, no correlation $(\alpha>0.05)$ exists between the proportion of SMEs (or RTIs) within the members and the proportion of SMEs (or RTIs) within the board of directors. However a correlation exists between the proportion of SMEs (or RTIs) within the members and the proportion of SMEs (or RTIs) within the supervisory board. The number of groups among the members significantly correlates $(\alpha<0.05)$ with the number of groups in the board of directors and the supervisory board. The governance structure of a cluster is thus not exactly the same as the member structure of a cluster, which justifies the choice of our variables.

We distinguished four different types of members per governance body, which means that in total we have eight variables. However, to avoid a size effect (big vs. small governance structures) we decided to conduct our analysis with relative data (e.g. Board_SME + Board_Group + Board_RTI + Board_Support $=100 \%)$, which leaves us with only six independent variables (to avoid collinearity). Table 2 summarises the variables used in the governance categorisation. The different types of members per governance body are (1) small and medium enterprises with less than 2000 employees (SME), (2) firms with more than 2000 employees (groups), (3) research and/or training institutes (RTI), and (4) support entities, which combines different kinds of agencies, such as professional associations, local authorities, regional chambers of industry and trade unions (support entities). This homogenous dataset on the strategic governance structure of 66 clusters allows us to group the clusters in more homogenous classes. 
Table 2. Description of the variables used for the governance categorisation

\begin{tabular}{lll}
\hline Category & Name & Description \\
\hline Board_SME & $\begin{array}{l}\text { The relative number of small and medium enterprises (SME }<2000 \\
\text { employees) within the supervisory board. }\end{array}$
\end{tabular}

\begin{tabular}{|c|c|c|}
\hline $\begin{array}{l}\text { Number of } \\
\text { members ner }\end{array}$ & Board_Group & $\begin{array}{l}\text { The relative number of groups (>2000 employees) within th } \\
\text { supervisory board. }\end{array}$ \\
\hline $\begin{array}{l}\text { type in the } \\
\text { supervisory } \\
\text { board at the }\end{array}$ & Board_RTI & $\begin{array}{l}\text { The relative number of research and/or training institutes } \\
\text { vithin the supervisory board. }\end{array}$ \\
\hline
\end{tabular}

end of 2007

Board_Support The relative number of support entities (e.g. professional associations, local authorities, regional chambers of industry, trade unions) within the supervisory board.

Executive_SME

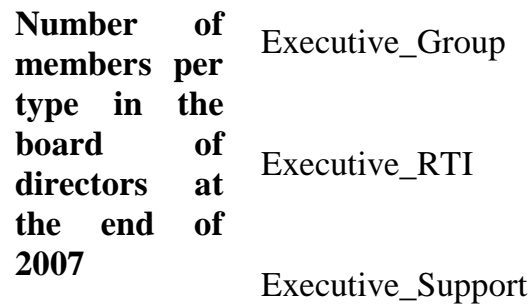

The relative number of small and medium enterprises (SME $<2000$ employees) within the board of directors.

The relative number of groups (>2000 employees) within the board of directors.

The relative number of research and/or training institutes (RTIs) within the board of directors.

The relative number of support entities (e.g. professional associations, local authorities, regional chambers of industry, trade unions) within the board of directors.

Regarding the data quality, five clusters ${ }^{332}$ did not reply to all of the governance questions in the questionnaire administrated by CMI-BCG. To avoid losing clusters already in the categorisation, we decided to use a common method in organisational studies, which is the mean substitution method (Schwab, 2005) and which replaces the missing values by the average of the variable. The disadvantage of the method is for example that the standard error is biased downwards, but if only a few missing values exist, which is the case, then the method only leads to minor errors (Outhwaite \& Turner, 2007) and preserves all observations.

Another point we would like to highlight is the reason why we choose SME $<2000$ employees. In the CMI-BCG survey, they distinguished between SME < 250 and SME $>250$ employees. However, we decided to merge SME < 250 and SME > 250 employees because we discovered that the respondents found it hard to distinguish between the two categories.

\section{Methodology}

We conducted a Hierarchical Cluster Analysis (HCA) to group the 66 clusters in relatively homogeneous groups of similar strategic governance structures. The HCA "starts with each case as a separate cluster [...] and then combines the clusters sequentially, reducing the number of clusters at each step until only one cluster is left. The clustering method uses the dissimilarities or distances between objects when forming the clusters" (Burns \& Burns, 2008 , p. 555). For the cluster method (rules for cluster formation), we used Ward's method, which uses an analysis of variance approach to evaluate the distances between clusters. The

\footnotetext{
${ }^{332}$ Data was missing for the clusters Xylofutur (XYL) and Q@LI-MEDéditerranée (QMED) in the variable "Supervisory board" and for the clusters Atlantic Biothérapies (ATL), Minalogic (MIN) and Imaginove (IMAG) in the variable "Board of directors".
} 
recommended interval measure for the Ward's method is the squared Euclidean distance measure (Kaufman \& Rousseeuw, 2005).

In order to verify the significance between the groups and in order to obtain the characteristics of the groups defined through the HCA we first conducted a One-Way ANOVA and then a post-hoc test. The analysis of variance, or ANOVA, is "a nondirectional procedure that tests the equality among two or more population means" (Weinberg \& Abramowitz, 2002, p. 339). Compared to a simple T-test, which can only compare the means of two groups, the ANOVA allows the comparison of the means of several groups with a single test. We calculated the $\mathrm{F}$ ratio, in order to determine if the mean values (in our case the relative number of members per type) vary significantly between groups.

The ANOVA tells us if the mean of a specific variable differs significantly between at least two groups of our sample, but it does not indicate which of the groups significantly differ. To compare the means of every group with every other group, we conducted a post-hoc test. For a pairwise comparison between means, one appropriate test is the Tukey Honestly Significant Difference (or Tukey HSD) test (Weinberg \& Abramowitz, 2002).

\section{Results}

Before presenting the results of the hierarchical cluster analysis and subsequently the results of the ANOVA and the post-hoc test, we first propose a descriptive analysis of the variables used:

- Supervisory board: The RTIs (average participation: 29\%) are slightly more present in the supervisory board than groups (average participation: 22\%). The participation of RTIs also tends to be more homogenous across clusters (Standard Deviation of 0.10) than the participation of other types of members (e.g. Standard Deviation: 0.18 for support entities, 0.15 for SMEs). Finally, there are also some clusters, which have a strong representation of only one type of member in their supervisory board. For example: Imaginove's (IMAG, dedicated to video games, cinema, audiovisual, animation, and interactive multimedia) supervisory board consists of 67\% SMEs; or Filière équine's (EQU, dedicated to the horse industry) supervisory board consists of 90\% support entities).

- Board of directors: support entities (average participation: 21\%) are slightly less represented within the board of directors than the other three member types (average participation: 26\% SME, 25\% Group, 27\% RTI). In general, the results for the board of directors are less homogenous across clusters (higher standard deviations) than for the supervisory board. Finally, there are again some clusters, which have a strong representation of only one type of member in their board of directors as for example Génie Civil Ecoconstruction's (GCO, dedicated to civil engineering and ecoconstruction), whose board of directors consists only of SMEs, or LyonBioPole (LYB, dedicated to biotechnology and health), whose board of directors is made up $80 \%$ of groups.

Table 3 summarises the descriptive statistics for the relative number of members per type in the supervisory board and board of directors. 
Table 3. Descriptive statistic of the governance data

\begin{tabular}{llcccc}
\hline & N & Minimum (\%) & Maximum (\%) & Mean (\%) & Std. Deviation \\
\hline Board_SME & 66 & 0 & 67 & 25 & .15 \\
Board_Group & 66 & 0 & 50 & 22 & .14 \\
Board_RTI & 66 & 10 & 55 & 29 & .10 \\
Board_Support & 66 & 0 & 90 & 24 & .18 \\
\hline Executive_SME & 66 & 0 & 100 & 26 & .17 \\
Executive_Group & 66 & 0 & 80 & 25 & .20 \\
Executive_RTI & 66 & 0 & 57 & 27 & .14 \\
Executive_Support & 66 & 0 & 67 & 21 & .20 \\
\hline
\end{tabular}

The HCA allows us to retain 3 classes. Appendix 1 indicates for every cluster to which class the cluster belongs. In order to verify if the variables are significantly different between the groups defined in the HCA we conducted a One-Way ANOVA, which revealed a significant difference $(\alpha<0.05)$ between the groups for every variable (see Table 4$)$. This means that for every variable at least two classes of our total three governance classes are significantly different.

Table 4. ANOVA with the governance classes as independent variable

\begin{tabular}{|c|c|c|c|c|c|c|}
\hline \multirow{3}{*}{ Board_SME } & \multirow{2}{*}{\multicolumn{2}{|c|}{ Sum of Squares }} & \multicolumn{3}{|c|}{ Mean } & \multirow[b]{2}{*}{ Sig. } \\
\hline & & & df & Square & $\mathbf{F}$ & \\
\hline & Between Groups & .282 & 2 & .141 & 8.081 & .001 \\
\hline & Within Groups & 1.098 & 63 & .017 & & \\
\hline & Total & 1.380 & 65 & & & \\
\hline \multirow[t]{3}{*}{ Board_Group } & Between Groups & .783 & 2 & .391 & 47.768 & .000 \\
\hline & Within Groups & .516 & 63 & .008 & & \\
\hline & Total & 1.299 & 65 & & & \\
\hline \multirow[t]{3}{*}{ Board_RTI } & Between Groups & .174 & 2 & .087 & 12.002 & .000 \\
\hline & Within Groups & .456 & 63 & .007 & & \\
\hline & Total & .629 & 65 & & & \\
\hline \multirow[t]{3}{*}{ Board_Support } & Between Groups & .313 & 2 & .157 & 5.626 & .006 \\
\hline & Within Groups & 1.754 & 63 & .028 & & \\
\hline & Total & 2.067 & 65 & & & \\
\hline \multirow[t]{3}{*}{ Executive_SME } & Between Groups & .411 & 2 & .205 & 8.489 & .001 \\
\hline & Within Groups & 1.525 & 63 & .024 & & \\
\hline & Total & 1.936 & 65 & & & \\
\hline \multirow[t]{3}{*}{ Executive_Group } & Between Groups & 1.325 & 2 & .663 & 33.668 & .000 \\
\hline & Within Groups & 1.240 & 63 & .020 & & \\
\hline & Total & 2.565 & 65 & & & \\
\hline \multirow[t]{3}{*}{ Executive_RTI } & Between Groups & .387 & 2 & .194 & 12.718 & .000 \\
\hline & Within Groups & .959 & 63 & .015 & & \\
\hline & Total & 1.346 & 65 & & & \\
\hline \multirow[t]{3}{*}{ Executive_Support } & Between Groups & 1.020 & 2 & .510 & 20.244 & .000 \\
\hline & Within Groups & 1.587 & 63 & .025 & & \\
\hline & Total & 2.607 & 65 & & & \\
\hline
\end{tabular}

However we do not know yet which exact groups significantly differ for every variable. Therefore we conducted a Tukey HSD test. The Tukey HSD test allowed us to compare the means of every group and thus to highlight the distinctiveness of each of the three classes. According to the predominance of one of the four member types (i.e. SMEs, groups, RTIs or support entities) within the governance structure we attributed a specific name to the class. The 3 categories can be defined as follow and are summarised in Table 5: 
- Class 1 - The scientist class (31.8\% of the sample): research and/or training institutes clearly dominate boards of directors and to a lesser extent the supervisory board. Another particularity of the scientist class is that groups are almost absent from the governance structure.

- Class 2 - The support class (25.8\% of the sample): support entities (e.g. professional associations, local authorities, regional chambers of industry, trade unions), which dominate this class, are entities which have a supporting role but do not conduct research or create competitiveness themselves. Most of the time the support entities are structures that existed in the region or industry sector before the introduction of the competitiveness cluster policy. These support entities clearly dominate the board of directors and to a lesser extent the supervisory board in the support class. On the supervisory board, the support entities seem to share responsibilities with SMEs. Another particularity of the support class is that groups and even more so RTIs are almost absent from the governance structure.

- Class 3 - The corporate class (42.4\% of the sample): This class is the most distinctive class. Groups clearly dominate the supervisory board and the board of directors while SMEs and support entities are rather absent.

Table 5. Summary of the significant differences between the three classes

\begin{tabular}{|c|c|c|c|c|}
\hline & \multicolumn{2}{|c|}{ Board of directors } & \multicolumn{2}{|c|}{ Supervisory board } \\
\hline & sig. positive & sig. negative & sig. positive & sig. negative \\
\hline $\begin{array}{ll}\text { Class 1: } & \text { The } \\
\text { scientist class } & \end{array}$ & $\begin{array}{l}\text { RTI* } \\
S M E^{3}\end{array}$ & $\begin{array}{l}\text { Groups }^{3} \\
\text { Support entities }^{2}\end{array}$ & $R T I^{2}$ & Groups $^{3}$ \\
\hline $\begin{array}{ll}\text { Class 2: The } \\
\text { support class }\end{array}$ & Support entities* & $\begin{array}{l}\text { RTI }^{1} \\
\text { Groups }^{3}\end{array}$ & $\begin{array}{l}\text { Support entities } \\
S M E^{3}\end{array}$ & $\begin{array}{l}\text { RTI* } \\
\text { Groups }^{3}\end{array}$ \\
\hline $\begin{array}{l}\text { Class 3: The } \\
\text { corporate class }\end{array}$ & Groups* & $\begin{array}{l}\text { Support entities } \\
S^{2} \\
R T E^{l}\end{array}$ & $\begin{array}{l}\text { Groups* } \\
R T I^{2}\end{array}$ & $\begin{array}{l}\text { Support entities } \\
\text { SME }^{2}\end{array}$ \\
\hline
\end{tabular}

* significant difference vs. the remaining two classes $(\alpha<0.05)$

1 significant difference only vs. class $1(\alpha<0.05)$

2 significant difference only vs. class $2(\alpha<0.05)$

${ }^{3}$ significant difference only vs. class $3(\alpha<0.05)$

In each of the three classes, one type of actor dominates the governance structure. After establishing these three classes of cluster organisations we now turn to the attributes that might distinguish these classes.

\section{Governance categories and their ability to attract resources}

In this section we investigate the capability of clusters to obtain different kinds of resources. We examine how the structure of the strategic governance might be correlated with the resources available to the cluster.

\section{Data Source}

The data for the analysis of the obtained classes of cluster organisations draws from two different data sets. One part of the data was derived from the CMI-BCG survey as already described; the other part came from the General Directorate for Competitiveness, Industry and Services (DGCIS). The DGCIS' mission is to develop the competitiveness and the growth of 
the French industry and service enterprises and to this end collects structural data on French clusters. All of the French clusters as well as all the financing institutions of the clusters have to report statistical indicators to the DGCIS every year. All these indicators (i.e. member, financial indicators, etc.) are assembled by the DGCIS and published in the form of charts and tables on the official French cluster web site ${ }^{333}$.

\section{Variables}

We chose financial and animation resource indicators to analyse the differences between the three cluster governance categories. Table 6 summarises the variables.

\section{Financial resources}

Cluster members need a sufficient amount of financial resources in order to develop their full potential. Sölvell (2008, p. 107) for example discusses in his report the evaluation of "Uppsala Bio" (a Swedish government initiative to promote the local life science cluster) and highlights that during this evaluation, "the lack of financial support was identified as the biggest barrier to starting a new company...[and that] financing is an important area that requires more attention". One respondent to the "Uppsala Bio" evaluation for example stated: "Promoting inflow of venture capital is by far the most important activity for the long term survival of a cluster like Uppsala. Without money no new companies can emerge, it is that simple! All other activities are just glazing the cake!". Additionally also Chiaroni \& Chiesa (2006) underline in their article that crucial components of clusters are either the "diffusion of innovative funding mechanisms, which means that there are funding schemes in place (especially related to seed and venture capital) tailored to and appropriate for high-tech new ventures (p. 1073)" or, depending on the type of cluster, "governmental funds dedicated to support the creation of industrial spin-offs for new companies (p. 1074)". Based on this literature, we thus assume that the amount of financial resources available to cluster members constitute an important indicator to differentiation clusters from each other.

Therefore, to differentiate the financial resources of the French clusters under scrutiny, we use "public $R \& D$ funding" distributed by French government agencies to cluster members. In total we distinguish three main public financing institutions in France, i.e. the French National Research Agency (ANR), the Unique Interministerial Fund (FUI) and OSEO:

(1) The French National Research Agency (ANR) finances research projects based on partnerships between public and private actors, or just between public laboratories. The aim of the ANR is to fund exploratory research projects that focus on developing new knowledge. ANR selects projects based on criteria of scientific excellence and then grants a "cluster bonus" to the projects selected that have been accredited by a cluster, indicating that the project is in line with the cluster's strategy. The total funding granted to cluster projects is counted (not just the bonus).

(2) The Unique Interministerial Fund (FUI) grants funding to joint research projects coming exclusively from cluster projects. The fund brings together contributions from all ministries. To be eligible, projects must involve at least a minimum of two companies and a research laboratory. The projects financed must relate to innovations relatively close to the market. Local authorities can co-fund joint research projects funded by the FUI.

(3) OSEO funding supports innovation and economic development within French SMEs, whether they are members of a cluster or not. There are various types of aid for SMEs

\footnotetext{
${ }^{333}$ http://competitivite.gouv.fr/ (2012)
} 
(e.g. technological transfer, funding for commercialising a new product). We make use of data relating to OSEO funding granted to SMEs that are members of clusters.

The financial amounts distributed to cluster members by these three institutions were made available to us by the DGCIS. As public R\&D funding can vary strongly from one year to another we decided to use the average amount of 2006, 2007 and 2008.

\section{Animation resources}

But not only cluster members also cluster organisations need a sufficient amount of resources (financial and human) in order to best support the local cluster members. Rosenfeld (2005, p. 10) splits cluster strategies into two waves: the fist wave of cluster strategies was fuelled by the ideas of Porter (1990) and "emphasised the basic non-specialised conditions for growth and the factors that could be influenced by the public sector - but without appreciably changing the structure of the public sector." The second wave was influenced by the ideas of Putnam (1993), emphasising the "value of relationships, networking and strategies targeting cluster organisations." European countries currently invest a high amount of money into cluster policies ${ }^{334}$ and create cluster organisations to manage these clusters. Rosenfeld (2005, p. 10) even argues that "[cluster]organisations became the symbol of a cluster's very existence; the growth of the association or its resources a proxy for success of the cluster." In cluster evaluations, the resources of these cluster organisations are thus taken as an important proxy for analysing the health and development of the general cluster.

Therefore, to differentiate the animation resources of the French clusters under scrutiny, we use two types of indicators: the "budget for the animation and the functioning" and the "number of full-time equivalents (FTE)" of the cluster organisation.

The first type of indicator, the "budget for the animation and the functioning of the cluster", was derived from the CMI-BCG online survey. This budget includes the cash and in-kind contributions (expressed in monetary terms) received from the national government, national agencies, regional government, regional agencies, local authorities, companies and research and/or training institutes (RTIs). We looked at each of these indicators separately, but we also analysed the total budget (financial resources and in-kind contributions transformed in monetary values) available to each cluster organisation for their animation and functioning. The term "functioning" corresponds to all indirect costs (e.g. salaries, energy, rent) and the term "animation" corresponds to all direct costs (e.g. workshops, leaflets, company visits). The year under scrutiny for every variable was the average budget of 2006 and 2007.

The second type of indicator deals with the number of full time equivalents (FTE) dedicated to the cluster for its animation and functioning. This indicator was also derived from the CMI-BCG survey. The number of FTEs is split in three variables according to the origin of the FTE: hired by the cluster itself, made available by a company or private organisation or made available by a local authority or public organisation. We also took into consideration the total number of full time equivalents (FTE) dedicated to the cluster regardless of the origin. All variables indicate the situation of FTEs at the end of 2007.

\footnotetext{
${ }^{334}$ E.g. the French government invested 3 billion euros between 2005 and 2011, the Walloon government plans to invest 618 million Euros between 2006 and 2014.
} 
Table 6. Description of the variables used for the governance classes analysis

\begin{tabular}{|c|c|c|c|c|c|}
\hline Category & Name & Description & $\begin{array}{c}\text { Unit } \\
\text { (Variable } \\
\text { Type) }\end{array}$ & Year & Source \\
\hline \multicolumn{6}{|c|}{ ANIMATION RESSOURCE INDICATORS: } \\
\hline \multirow{6}{*}{$\begin{array}{l}\text { Budget for } \\
\text { the } \\
\text { animation } \\
\text { and the } \\
\text { functioning } \\
\text { of the } \\
\text { cluster }\end{array}$} & Budget_National & $\begin{array}{l}\text { Financial resources received from } \\
\text { the national government or } \\
\text { national agencies }\end{array}$ & \multirow{6}{*}{$\begin{array}{l}€ \text { in } 000 \text { 's } \\
\quad \text { (scale) }\end{array}$} & \multirow{6}{*}{$\begin{array}{l}\{2006 \\
2007\}\end{array}$} & \multirow{6}{*}{$\begin{array}{l}\text { CMI- } \\
\text { BCG }\end{array}$} \\
\hline & Budget_Regional & $\begin{array}{l}\text { Financial resources received from } \\
\text { the regional government, regional } \\
\text { agencies, local authorities }\end{array}$ & & & \\
\hline & Budget_Company & $\begin{array}{l}\text { Financial resources received from } \\
\text { companies }\end{array}$ & & & \\
\hline & Budget_RTI & $\begin{array}{l}\text { Financial resources received from } \\
\text { research and/or training institutes } \\
\text { (RTIs) }\end{array}$ & & & \\
\hline & Budget_Inkind & $\begin{array}{l}\text { Total in-kind contributions } \\
\text { transformed in monetary values } \\
\text { received from the national } \\
\text { government, national agencies, } \\
\text { regional government, regional } \\
\text { agencies, local authorities, } \\
\text { companies, RTIs, support entities }\end{array}$ & & & \\
\hline & Budget_Total & $\begin{array}{l}\text { Total budget (financial resources } \\
\text { and in-kind contributions } \\
\text { transformed in monetary values) } \\
\text { received from the national } \\
\text { government, national agencies, } \\
\text { regional government, regional } \\
\text { agencies, local authorities, } \\
\text { companies, RTIs, support entities }\end{array}$ & & & \\
\hline \multirow{4}{*}{$\begin{array}{l}\text { Number of } \\
\text { Full time } \\
\text { equivalents } \\
\text { (FTE) }\end{array}$} & FTE_Own & $\begin{array}{l}\text { Number of FTEs dedicated to the } \\
\text { cluster and hired by the cluster } \\
\text { itself }\end{array}$ & \multirow{4}{*}{$\begin{array}{c}\# \\
(\text { scale })\end{array}$} & \multirow{4}{*}{2007} & \multirow{4}{*}{$\begin{array}{l}\text { CMI- } \\
\text { BCG }\end{array}$} \\
\hline & FTE_Privat & $\begin{array}{l}\text { Number of FTEs dedicated to the } \\
\text { cluster and made available by a } \\
\text { company or private organisation }\end{array}$ & & & \\
\hline & FTE_Public & $\begin{array}{l}\text { Number of FTEs dedicated to the } \\
\text { cluster and made available by a } \\
\text { local authority or public } \\
\text { organisation }\end{array}$ & & & \\
\hline & FTE_Total & $\begin{array}{l}\text { Total number of FTEs dedicated } \\
\text { to the cluster }\end{array}$ & & & \\
\hline \multicolumn{6}{|c|}{ FINANCIAL RESSOURCE INDICATORS: } \\
\hline \multirow{4}{*}{$\begin{array}{l}\text { Public R\&D } \\
\text { funding }\end{array}$} & ANR & $\begin{array}{l}\text { Funding received from the } \\
\text { National Research Agency (ANR) }\end{array}$ & \multirow{4}{*}{$\begin{array}{l}€ \text { in } 000 \text { 's } \\
\quad \text { (scale) }\end{array}$} & \multirow{4}{*}{$\begin{array}{l}\{2006 \\
2007 \\
2008\}\end{array}$} & \multirow{4}{*}{ DGCIS } \\
\hline & FUI & $\begin{array}{l}\text { Funding received from the Single } \\
\text { Interministerial Fund (FUI) }\end{array}$ & & & \\
\hline & OSEO & Funding received from OSEO & & & \\
\hline & Funding_Total & $\begin{array}{l}\text { Total funding received from } \\
\text { OSEO and ANR and FUI }\end{array}$ & & & \\
\hline
\end{tabular}

\section{Methodology}

We used the same methodology as described in the previous section. We first verified with the help of the One-Way ANOVA if a significant difference exists between the groups and then, to highlight the specific characteristics of every group, we used the Tukey HSD test. 


\section{Results}

Before presenting the characteristics of the governance classes we shortly present a descriptive analyses of the variables used:

(1) Budget for the animation and the functioning of the cluster: on average $(2006,2007)$ every cluster had 730,000 euros at its disposal to finance the functioning of its cluster organisation and its animation activities. The regional governments, regional agencies and local authorities are on average the highest contributors $(32.9 \%)$, followed by national governments and national agencies (29.2\%). Companies (11.8\%) and RTIs (1.6\%) contribute less to the budget. As a side note, $19.8 \%$ of the total budget is provided in kind.

(2) Number of full time equivalents (FTE): on average (2007) every cluster had 5.2 FTEs at its disposal. The majority (67\%) of FTEs are hired directly by the cluster itself whereas the others are made available as "in-kind contributions" either by a private or public entity.

(3) Public R\&D funding: on average (2006, 2007, 2008), each cluster received $€ 10.9$ million in total from FUI, OSEO or ANR. This amount stems very equally from the three financing institutes: FUI (35.11\%), OSEO (35.45\%) and ANR (29.44\%). However, the amount of public $\mathrm{R} \& \mathrm{D}$ funding is very dispersed as one cluster only received $€ 14,000$ and another cluster $€ 68.9$ million.

Table 7 summarises the results for budget, FTE and public R\&D funding variables.

Table 7. Description of the scale variables used to characterise the governance classes

\begin{tabular}{|c|c|c|c|c|c|c|}
\hline & $\mathbf{N}$ & Minimum & Maximum & Mean & Percentage & $\begin{array}{r}\text { Std. } \\
\text { Deviation }\end{array}$ \\
\hline Members & 66 & 15.00 & 502.00 & 115.77 & - & 90.43 \\
\hline Budget_National ( $€$ in 000’s) & 66 & 30.00 & 825.00 & 213.64 & 29.2 & 164.69 \\
\hline Budget_Regional (€ in 000’s) & 66 & 15.00 & 861.00 & 240.09 & 32.9 & 173.69 \\
\hline Budget_Companies ( $€$ in 000's) & 66 & .00 & 403.00 & 86.24 & 11.8 & 91.73 \\
\hline Budget_RTI (€ in 000’s) & 66 & .00 & 89.00 & 11.29 & 1.6 & 18.55 \\
\hline Budget_Inkind ( $€$ in 000's & 66 & .00 & 700.00 & 144.59 & 19.8 & 180.96 \\
\hline Budget_Total (€ in 000’s) & 66 & 134.50 & 2021.50 & 730.60 & 100.0 & 463.83 \\
\hline FTE_own & 66 & .00 & 10.80 & 3.53 & 68.3 & 2.62 \\
\hline FTE_privat & 66 & .00 & 5.00 & .72 & 13.9 & 1.09 \\
\hline FTE_public & 66 & .00 & 4.70 & .93 & 18.0 & 1.25 \\
\hline FTE_Total & 66 & 1.00 & 12.80 & 5.17 & 100.0 & 2.73 \\
\hline FUI (€ in 000’s) & 66 & .00 & 32626.00 & 3832.27 & 35.1 & 6343.58 \\
\hline OSEO ( $€$ in 000's) & 66 & 10.00 & 24782.00 & 3868.69 & 35.5 & 6342.32 \\
\hline ANR (€ in 000’s) & 66 & .00 & 18772.67 & 3213.52 & 29.4 & 3737.21 \\
\hline Total_funding ( $€$ in 000 's) & 66 & 14.33 & 68870.67 & 10914.48 & 100.0 & 12991.38 \\
\hline
\end{tabular}

We will now point out the differences of the three governance classes according to these variables (summarised in Table 8):

(1) The analysis of the budget for the animation and the functioning of the cluster reveals that the corporate class disposes of a significantly higher total budget than the scientist and support classes. The corporate class is particularly strong in obtaining money from the national government and national agencies compared to the other two classes. The scientist class, on the other hand, is particularly weak in obtaining money from the 
regional government, regional agencies or local authorities compared to the corporate class. Finally, the support class is particularly weak in obtaining money from companies and research and/or training institutes compared to the corporate class. There is no significant difference between the three classes regarding the in-kind donations. Finally, we wonder if this result means that in order to obtain for example funds from companies or RTIs, clusters should place in their governance structures actors from these organisations.

(2) The analysis of the number of full time equivalents within the management committee shows that the corporate class has the highest while the scientist class has the lowest number of FTEs. While no significant difference exists between the three classes regarding the number of FTEs made available by a company / private organisation or by a local authority / public organisation, the scientist class stands out by the very low number of FTEs hired by the cluster itself. Does this mean that clusters from the scientist class are less able to attract or to finance FTEs, or does this mean that these clusters have another perception of a cluster's development, where the number of FTEs for example is not that important?

(3) The analysis of the public $R \& D$ funding shows that in total the corporate class receives significantly more public R\&D funding than the support class. However, when looking at each financing body separately (ANR, FUI, OSEO), we do not observe a significant difference between the three classes. Only the difference of the total sum of the three institutions is significant. These results are interesting in two ways: first, the absence of difference between the financing bodies could mean that clusters manage to support every type of actor even if the funding is dedicated to actors not present in the governance (for example OSEO is particularly dedicated to SMEs). Second, the difference of the total sum could be linked to the fact that groups are maybe more able to manage more or bigger projects than small companies or RTIs. 
Table 8. Results of the governance classes analysis (significant if $\alpha<0.05$ )*

\begin{tabular}{|c|c|c|c|c|}
\hline Category & Name & $\begin{array}{c}\text { Class 1: } \\
\text { Scientist class }\end{array}$ & $\begin{array}{c}\text { Class 2: } \\
\text { Support class }\end{array}$ & $\begin{array}{c}\text { Class 3: } \\
\text { Corporate class }\end{array}$ \\
\hline \multirow{9}{*}{$\begin{array}{l}\text { Budget for the } \\
\text { animation and } \\
\text { the functioning } \\
\text { of the cluster }\end{array}$} & Budget_National & sig. negative & sig. negative & sig. positive \\
\hline & Dunget_National & vs. class 3 & vs. class 3 & vs. class $1 \& 2$ \\
\hline & Budget Regional & sig. negative & & sig. positive \\
\hline & & vs. class 3 & & vs. class 1 \\
\hline & Budget Company & & sig. negative & sig. positive \\
\hline & & & vs. class 3 & vs. class 2 \\
\hline & Budget_RTI & & sig. negative & sig. positive \\
\hline & Budget_Inkind & & no significant differences & V.s. Chass 2 \\
\hline & Budget_Total & $\begin{array}{c}\text { sig. negative } \\
\text { vs. class } 3\end{array}$ & $\begin{array}{l}\text { sig. negative } \\
\text { vs. class } 3\end{array}$ & $\begin{array}{c}\text { sig. positive } \\
\text { vs. class } 1 \& 2\end{array}$ \\
\hline \multirow{3}{*}{$\begin{array}{l}\text { Number of Full } \\
\text { time equivalents } \\
\text { (FTE) }\end{array}$} & FTE_Own & $\begin{array}{l}\text { sig. negative } \\
\text { vs. class } 3\end{array}$ & \multirow{3}{*}{ no significant differences } & $\begin{array}{l}\text { sig. positive } \\
\text { vs. class } 1\end{array}$ \\
\hline & $\begin{array}{l}\text { FTE_Privat } \\
\text { FTE_Public }\end{array}$ & & & \\
\hline & FTE_Total & $\begin{array}{l}\text { sig. negative } \\
\text { vs. class } 3\end{array}$ & & $\begin{array}{l}\text { sig. positive } \\
\text { vs. class } 1\end{array}$ \\
\hline \multirow{4}{*}{$\begin{array}{l}\text { Public } \\
\text { funding }\end{array}$} & ANR & & \multirow{3}{*}{ no significant differences } & \\
\hline & FUI & & & \\
\hline & OSEO & & & \\
\hline & Funding_Total & & $\begin{array}{c}\text { sig. negative } \\
\text { vs. class } 3\end{array}$ & $\begin{array}{l}\text { sig. positive } \\
\text { vs. class } 2\end{array}$ \\
\hline
\end{tabular}

To conclude, the HCA and the subsequent ANOVA revealed that French clusters could be categorised into three categories according to the weight of the different members in their strategic governance structure:

(1) In the clusters of the scientist class (class 1), research and/or training institutes clearly dominate the board of directors, while groups are quite absent of the governance structure. The clusters of this class have problems obtaining budget from the national government and national agencies as well as from the regional government, regional agencies or local authorities for the animation and the functioning of its clusters. Possible reasons of these results could be that in 2007 RTIs were not yet really aware of the importance of developing science-industry relations or of how to obtain public funding. As already mentioned, another characteristic of the clusters of the scientist class is that they have the fewest number of FTEs. The scientist class is particularly lagging behind in the number of FTEs directly hired by the cluster. One possible explanation might be that for RTIs sending some of their staff on temporary assignments to cluster organisations might be easier than for groups.

(2) In the clusters of the support class (class 2), support entities dominate the board of directors, while RTIs are particularly absent from the governance structure. This class has difficulties in obtaining public R\&D funding for their members. Additionally, the clusters of this class have smaller budgets allocated by the national government, national agencies, RTIs and companies to use for animation and functioning. An interpretation of this result might be that support entities are very competent in helping regional actors in their economic development but not so competent in helping regional actors in their scientific development. Support entities might have to enlarge their competences and also propose more scientific oriented help, as for example how to write an $R \& D$ project application to attract public $R \& D$ funding. 
(3) In the clusters of the corporate class (class 3), groups clearly dominate the supervisory board and the board of directors while SMEs and support entities are rather absent. The corporate class has most of the advantages on its side. First of all, the corporate class has considerably more budget, regardless of the origin, for the animation and the functioning of its clusters. Second, it has the highest amount of FTEs. Finally, its members also receive the highest total amount of public R\&D funding. The good results of the clusters of the corporate class might be linked to different characteristics of groups: broad experience in how to obtain research funding, large pool of internal resources (human, financial...), large network of partners which allows forming R\&D consortia in a short period of time, etc.

\section{Conclusion}

This study tries to fill a gap in the cluster literature by focusing particularly on cluster governance structures. Firstly, we show that the repartition of the different actors inside governance structures is very heterogeneous between clusters and that in each governance class one dominant type of actor exists. We are nevertheless quite surprised that SMEs play a minor role in the governance structures and that no SME cluster class emerges from our statistical analysis. Secondly, we put in evidence that a linkage between certain types of governance structures and their ability to attract resources (and in particular public resources) might exist. Our results advocate for a resource dependence view of cluster organisations and highlight possible implications for cluster performance evaluations.

\section{A resource dependence view of clusters}

Our analysis identifies that the corporate class is very strong in its ability to obtain resources such as animation and functioning budget, public R\&D funding and FTEs. Governance could thus be seen as a part of the cement of a cluster in order to attract resources. However, this result does not necessarily mean that all clusters should have a governance structure consisting predominantly of groups with more than 2000 employees. Our analysis is a descriptive analysis and does not allow drawing direct cause-effect conclusions between the governance structure and the resources we analysed. Other structural variables, not analysed, such as historic relationships between local actors, firms' stock of R\&D resources, decision processes, might also play an important role in explaining these results. Additionally we do not know if these resources (i.e. animation and functioning budget, public R\&D funding, FTEs) are decisive for the long-term success of a cluster.

However, our analysis does show that some cluster governance categories have to operate with fewer resources than other categories and that this is particularly the case if groups are absent from the governance structure. Using the vocabulary of the resource dependence theory (Hillman, et al., 2009; Pfeffer, 1972, 1973; Pfeffer \& Salancik, 2003 (1978)), we could say that the clusters of the corporate category have governance structures that best suit the external environment. So if we think that attracting more of our defined resources is better (however we do not know which are the resources really needed to build successful clusters (Rosenfeld, 2005)), then the composition of the governance of these clusters is better adapted to the challenges of their environment or in other words, they manage better their resource dependency to the public authorities. However, the other side of the coin is that the structural disadvantaged classes (in our case the scientist and support category) not only have more difficulties to access these resources but additionally might also 
be more severely punished if the national government decides to delete or redirect the public subsidies to other national priorities.

Why are clusters where groups dominate the governance structure more "successful", than clusters where groups are absent? Are groups what Boyd (1990) calls "resource-rich individuals"? Why are some clusters not placing groups in their governance structure? We draw several interpretations that of course need to be investigated further.

(1) Some regional stakeholders, particularly SMEs (OECD, 2001), might lack crucial skills compared to large groups. According to Zahra \& Pearce (1989) a board should scan the environment, represent the cluster in the community and secure valuable resources. In order to do this, the board needs human and relational capital (Hillman \& Dalziel, 2003). In the light of our results, we might ask if groups have more of this relational and human capital than less experienced regional actors (i.e. PMEs and support entities). Groups might have a broader established professional network and they might also be more used to organise $R \& D$ projects and thus subsequently be more successful in applying for subsidies than these less experienced and smaller actors.

(2) As mentioned in the literature review, according to the theory of Pfeffer (1972), we could expect that clusters place actors in their supervisory board and board of directors, which are best suited to acquire the necessary resources for survival. In this perspective, it seems illogical that not all clusters place large groups in their governance structure, which, according to our results, might be the most capable entities to do so. Firstly, we are not allowed to forget that clusters are regionally embedded and that their pool of members and thus representatives in their governance structures is geographical limited. There are several clusters that simply do not have large groups on their territories and which thus cannot mobilise their aid in the governance structure. Secondly, some sectors are mainly developed by SMEs as for example the digital service sector. Finally, political issues might also play a role when nominating certain cluster members in the governance structures.

\section{Possible implications for cluster evaluations}

This article also identifies possible implications for cluster performance evaluations. The present study shows that evaluators have to be very careful when comparing clusters directly with each other. This is particularly the case if resource indicators such as operational budget or R\&D subsidies are taken as measures in evaluations that try to inspect the performance of clusters. Mceldowney (1997) for example distinguishes two goals of evaluations (1) "assess the value for money" of the policy (control model), and (2) "providing feedback on the policy" (helping model). In the helping model the main goal is a learning process for all actors and thus there is no punishment in case the goal is not reached, while in the control model sanctions or budget cuts could be the consequent of a bad performance. Being aware of the structural disadvantages of clusters having no groups in their governance structure might be particularly important in cluster evaluations that correspond to the control model. Traditionally, cluster evaluations do not take into account the influence of cluster governance structures on clusters performance (e.g. Learmonth, et al., 2003; Schmiedeberg, 2010), however our results encourage to complete cluster evaluations by testing possible links between governance and resources attraction.

Indeed, when French clusters are evaluated (and thus compared among one another) by the national government, evaluators should bear in mind that a "bad performance" in 
resource attraction could be linked to the absence of large companies in their governance structure. Enlarging thus the spectrum of investigations in cluster evaluations would lead to improve the usefulness but also the impact of evaluations on clusters. Maybe it could be stated that some clusters (support and scientist class) lack the needed governance resources to advance as fast as the corporate class. However, we still do not know if more resources automatically result in better performance. The question remains whether more budget and FTEs automatically triggers a better cluster performance or if clusters possessing less (support and scientist class) simply manage better their limited resources and obtain the same or even better results in the long term. For public policy conception, the question is then posed: Does public policy have to adapt their tools according to the governance structure of the cluster? In other words, do governments need to address a special aid and help to these clusters, which are structurally disadvantaged by the absence of large groups? Indeed, these clusters possess less board capital (Hillman \& Dalziel, 2003) than other clusters for an efficient resource attraction. Further research is needed on this topic.

Finally, we thus retain from our research that governance structures contribute to explain some differences between the resources clusters manage to attract. This can have important implications for the creation of clusters. If one objective of a new cluster is to obtain a lot of resources, then placing large groups in its governance structure might be better than support entities. Moreover, our work suggests that beyond evaluation, policy makers could propose different kind of aids to corporate clusters, scientist clusters and support clusters. However, our research has also some limitations. First, it would be interesting to have more variables to define the governance structure. Secondly, it would be worthwhile to verify if the link between governance structure and resources is stable with other types of resources. Thirdly, further research should investigate the causality link between governanceresource-performance.

We think that our study serves as an interpretive lens, which helps shed light on the existing diversity of cluster governance structures. We hope that this first quantitative study on cluster governance will prompt scholars to further investigate this topic in a theoretical and also empirical manner, to build more insight into this relatively new type of cluster resource. Researchers interested in cluster governance issues could for example try to verify if our results can be generalised to other European and Non-European clusters, to technology and industry clusters, to spontaneous or policy driven clusters, to bottom-up and top-down clusters, etc. 
Appendix 1. Cluster acronyms, cluster names and corresponding HCA class

\begin{tabular}{|c|c|c|c|c|c|}
\hline Acro. & Name & Class & Acro. & Name & Class \\
\hline AERO & Aerospace Valley & 1 & TES & $\begin{array}{l}\text { Transactions } \\
\text { Electroniques Sécurisées }\end{array}$ & 2 \\
\hline ATL & Atlantic Biothérapies & 1 & TRI & Trimatec & 2 \\
\hline CBS & Cancer-Bio-Santé & 1 & UPT & Up-tex & 2 \\
\hline CEN & Capénergies & 1 & VAL & $\begin{array}{l}\text { Valorial-L'aliment de } \\
\text { demain }\end{array}$ & 2 \\
\hline DERB & Derbi & 1 & VEG & Végépolys & 2 \\
\hline EUBM & EuroBioMed & 1 & $\mathrm{ADV}$ & Advancity & 3 \\
\hline $\mathrm{F} \& \mathrm{~L}$ & Innovation fruits et légumes & 1 & AUTO & $\begin{array}{l}\text { Automobile Haut de } \\
\text { Gamme }\end{array}$ & 3 \\
\hline FGE & Fibres Grand Est & 1 & AXEL & Axelera & 3 \\
\hline GCO & Génie Civil Ecoconstruction & 1 & $\mathrm{CD}$ & Cap Digital & 3 \\
\hline INV & InnoViandes & 1 & CERQ & Céramique & 3 \\
\hline MAUD & Maud & 1 & CERV & Céréales Vallée & 3 \\
\hline MOV & Mov'eo & 1 & COSV & Cosmetic Valley & 3 \\
\hline OPT & Optitec & 1 & EMC2 & EMC2 & 3 \\
\hline PLA & Plastipolis & 1 & $\mathrm{I} \& \mathrm{R}$ & Images et Réseaux & 3 \\
\hline PROD & Prod'Innov & 1 & IAR & $\begin{array}{l}\text { Industries et } \quad \text { Agro- } \\
\text { Ressources }\end{array}$ & 3 \\
\hline QMED & Q@LI-MEDéditerranée & 1 & IC & Industries du commerce & 3 \\
\hline RLAS & Route des lasers & 1 & ITR & I-Trans & 3 \\
\hline S2E2 & $S^{2} E^{2}$ & 1 & LYB & LyonBioPole & 3 \\
\hline SPOR & Sporaltec & 1 & LYUT & $\begin{array}{l}\text { Lyon Urban Truck, Bus } \\
2015\end{array}$ & 3 \\
\hline TEC & Techtera & 1 & MED & $\begin{array}{l}\text { HealthCluster } \quad \text { Paris } \\
\text { Region }\end{array}$ & 3 \\
\hline VIAM & Viaméca & 1 & MERB & Pole Mer Bretagne & 3 \\
\hline ALBV & Alsace Biovalley & 2 & MERP & Mer Paca & 3 \\
\hline AQUA & Aquatiques & 2 & MIN & Minalogic & 3 \\
\hline ARV & Arve-Industries & 2 & MTA & $\begin{array}{l}\text { Mobilité et transports } \\
\text { avancés }\end{array}$ & 3 \\
\hline ELOP & Elopsys & 2 & NOV & Novalog & 3 \\
\hline ENF & Pôle Enfant & 2 & NUC & Pôle Nucléaire Bourgogne & 3 \\
\hline EQU & Filière équine & 2 & NUT & Nutrition Santé Longévité & 3 \\
\hline IMAG & Imaginove & 2 & SCS & SCS & 3 \\
\hline MAT & Mateleria & 2 & SYS & Systematic & 3 \\
\hline MIC & Microtechnique & 2 & TEN & Tenerrdis & 3 \\
\hline PASS & Pass & 2 & VF & Véhicule du futur & 3 \\
\hline QTRO & Qualitropic & 2 & VITA & Vitagora & 3 \\
\hline RISQ & Gestion des risques & 2 & XYL & Xylofutur & 3 \\
\hline
\end{tabular}




\section{LIST OF FIGURES}

Figure 1: Problem statement and Research Questions .................................................... 9

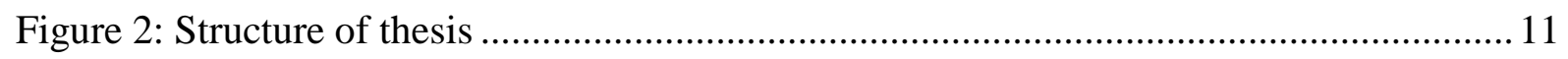

Figure 3: Evolution of the articles published on 'clusters' (1962-2007) ................................. 14

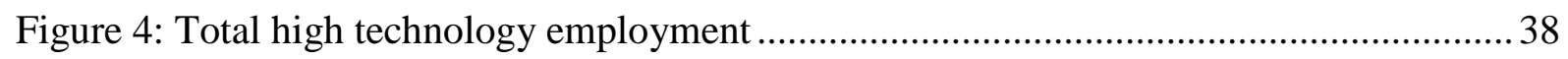

Figure 5: Employment in electronic components and semiconductor firms ........................... 38

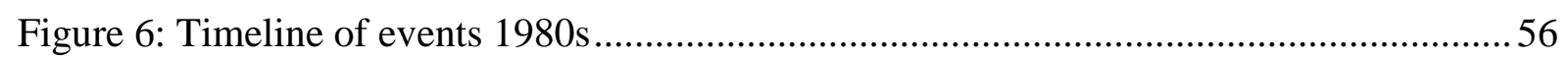

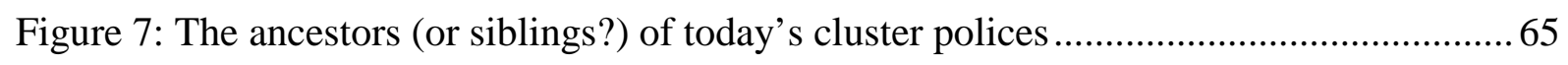

Figure 8: Cluster Policy vs. Science, Research, Technology and Innovation Policy ..............65

Figure 9: Cluster Policy vs. Industrial, Regional and Structural Policy ................................. 66

Figure 10: A framework for the study of pathology in policy-driven clusters ........................ 80

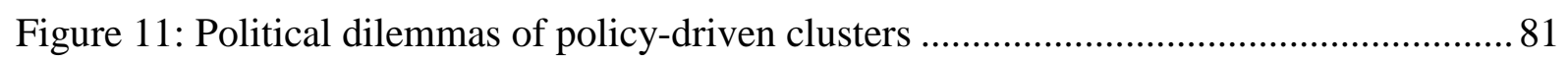

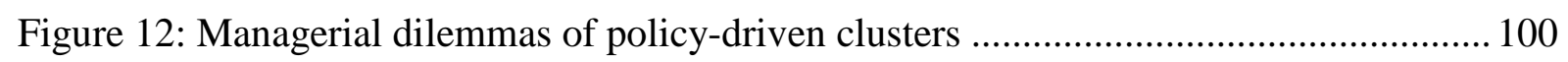

Figure 13: Processes and intermediary results leading to innovation .................................. 108

Figure 14: Structural characteristics of policy-driven clusters........................................... 123

Figure 15: Problem statement and research questions ...................................................... 138

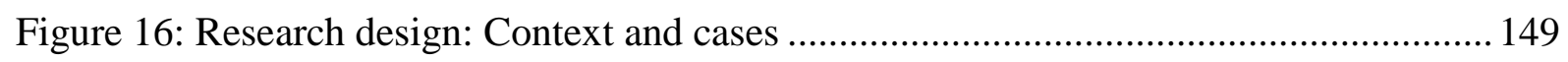

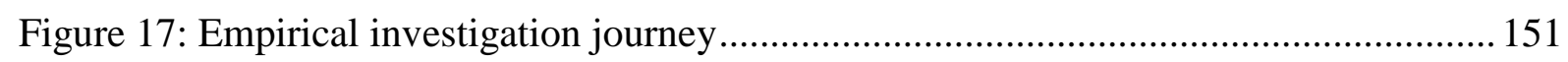

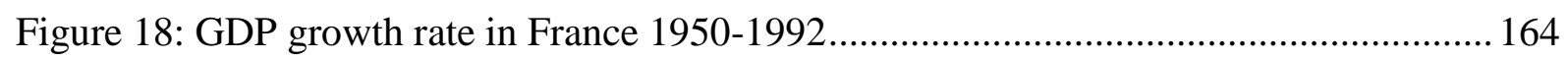

Figure 19: Contribution to global growth per country and decade $(\%)$................................. 164

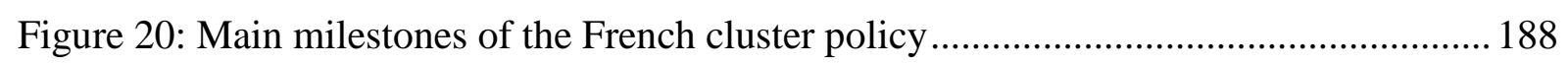

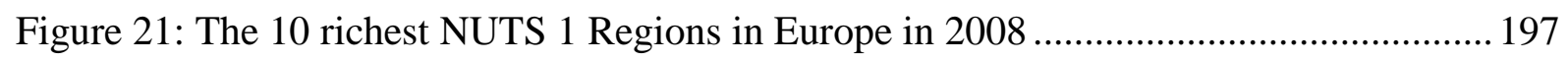

Figure 22: Performance contract signature event (November $\left.10^{\text {th }}, 2009\right)$.............................. 214

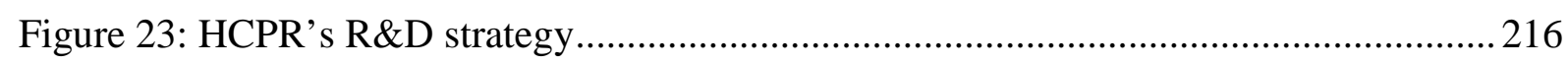

Figure 24: Official chart presented during a meeting with the public funding bodies...........221

Figure 25: Official chart presented during an assembly general meeting............................ 222

Figure 26: Ecosystem of the Paris Region Biotechnology and Health Sector ....................... 226

Figure 27: Défi Biotech Santé Plan - October 2010......................................................... 233

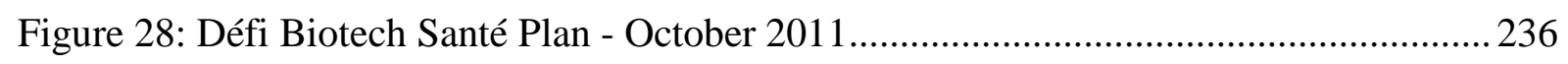

Figure 29: The R\&D collaboration process and the importance of policy-driven clusters.... 246

Figure 30: Overview of the interviewed project leaders and their companies .257 


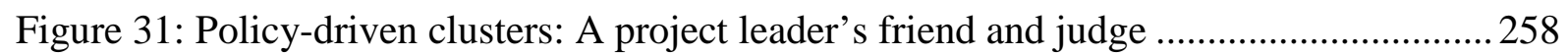

Figure 32: Integration of project leaders in the collaborative research community ...............276

Figure 33: One-to-one business meetings during HealthCluster Convention........................ 281

Figure 34: France-Sweden networking event workshop.................................................... 282

Figure 35: Not integrated project leaders: Finding partners for projects ............................. 285

Figure 36: Integrated project leaders: Finding partners for projects ................................... 285

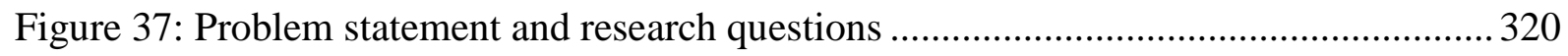

Figure 38: Studying dilemmas that drive side-effect pathologies in policy-driven clusters .. 320

Figure 39: Zoom on the multiple actors of HCPR governance level .................................... 326

Figure 40: Trust is challenged when looking at the collaborative R\&D project level........... 333

Figure 41: Focus of the cluster literature regarding trust and literature gap .......................... 335

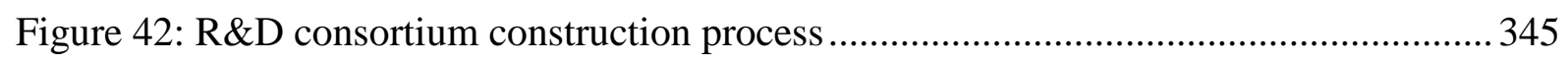

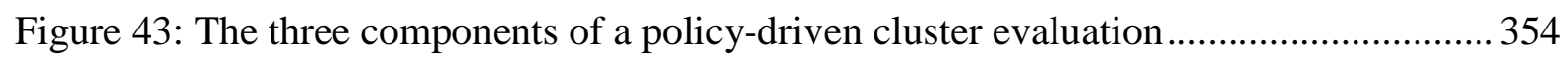

Figure 44: The different objects of a cluster evaluation.................................................... 357

Figure 45: Proposition of an evaluation framework to improve level 3 object evaluations ... 358

Figure 46: A framework for the study of pathology in policy-driven clusters ....................... 360

Figure 47: Reminder of the different dilemmas developed in the literature review ...............361

Figure 48: Summary of identified pathologies driven by associated dilemmas .................... 363

Figure 49: The value chain (CDV) of the biotechnology \& health sector in the PR ............. 385

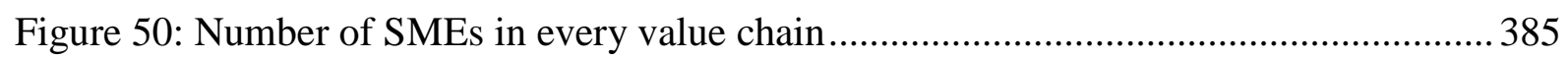

Figure 51: Focus on the value chain of medical imagery companies .................................. 386

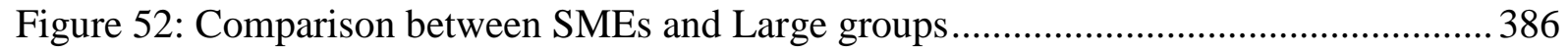

Figure 53: All value chains of the biotechnology and health sector in the Paris Region........ 387

Figure 54: Cartography of the biotechnology and health sector of the Paris Region ............. 388

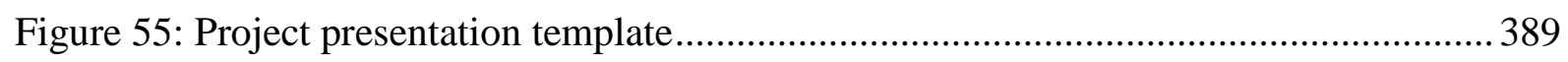

Figure 56: Competences and need presentation template ................................................. 390

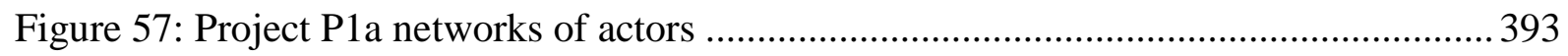

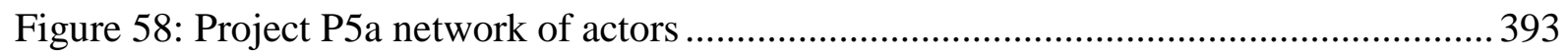




\section{LIST OF TABLES}

Table 1: Comparison of my master and PhD theses supervisors' environments ......................

Table 2: Co-location: main advantages and reasons according to Marshall ............................25

Table 3: Differences and similarities between Silicon Valley and Emilia-Romagna .............. 40

Table 4: Evolution of Porter's ideas on competition............................................................... 43

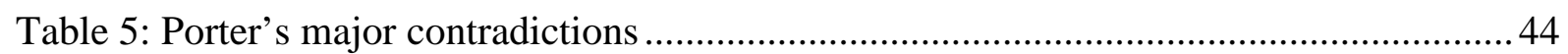

Table 6: Porter's stages of development intersected with his sources of competitiveness ...... 49

Table 7: Top ten most innovative companies and regions in Europe ....................................53

Table 8: Summary of research shifts during the 1980s ........................................................57

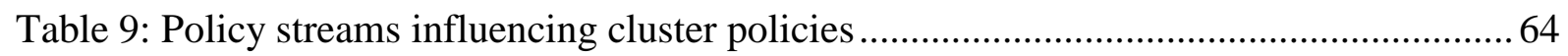

Table 10: Articles dealing with cluster policy, management, promotion, etc.......................... 77

Table 11: Examples of cluster policy articles per country (European countries) .....................78

Table 12: Examples of cluster policy articles per country (Not European countries) ............. 79

Table 13: Advantages and disadvantages of local vs. national support structures ..................89

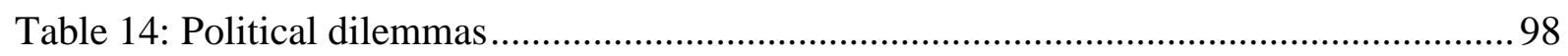

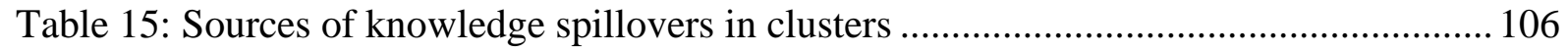

Table 16: Factors that influence the processes leading to innovation.................................... 115

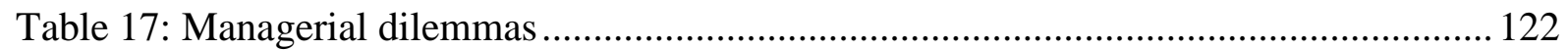

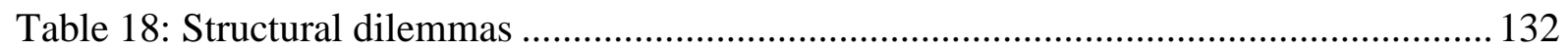

Table 19: Overview of organisational dilemmas in the cluster policy literature ................... 134

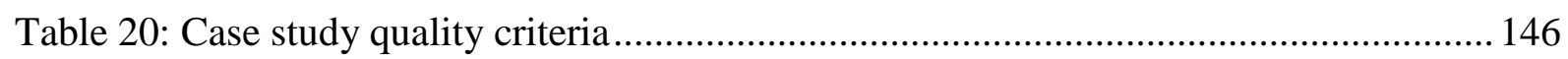

Table 21: Source of evidence: Observations of events and meetings ................................... 152

Table 22: Source of evidence: Interviews with Policy-driven cluster/other support entity ... 154

Table 23: Source of evidence: Documentations and Archival records ................................... 154

Table 24: Source of evidence: Interviews with R\&D project leaders and their partners ....... 156

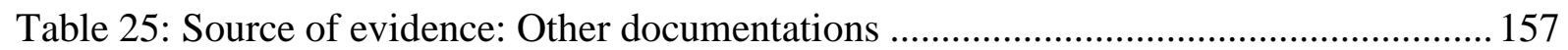

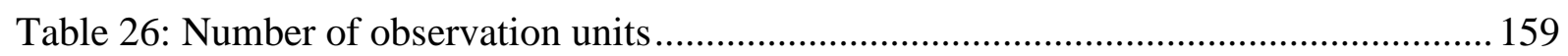

Table 27: Examples of policies supporting "regional systems" in France........................... 179

Table 28: Two opposing views: the conflicting base of the French cluster policy ................. 183

Table 29: Three different ministries: the basis for conflicting interests .............................. 184

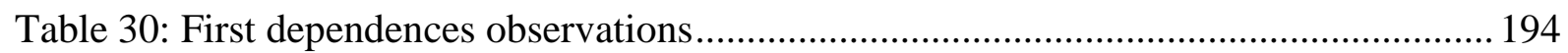


Table 31: Paris Region's key figures and the share it accounts for in France ....................... 196

Table 32: Paris Region's position compared to other core European regions ........................ 198

Table 33: The Paris Region: "Stuck in the middle" in an European context .......................... 200

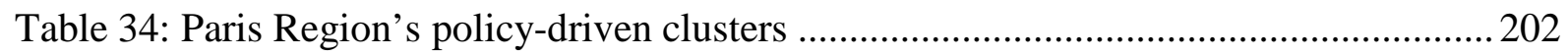

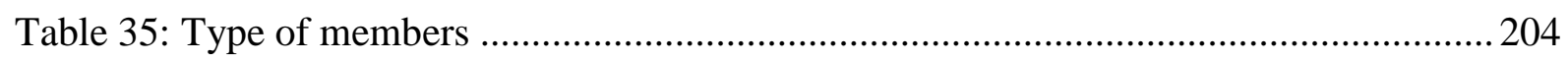

Table 36: Five most important NAF sectors per policy-driven cluster in 2012 .................... 207

Table 37: Five most important NAF sectors per policy-driven cluster in 2012 (cont.) ......... 208

Table 38: Number of projects funded and project funding sources ...................................... 209

Table 39: Roadmap for the development of the HCPR's services (2010) ............................. 233

Table 40: Défi Biotech Santé Plan - January 2011 ................................................................ 235

Table 41: Roadmap for the "new" Défi Biotech Santé plan (2011).....................................237

Table 42: ICT \& Health inter-cluster plenary sessions and project set-up workshops .......... 294

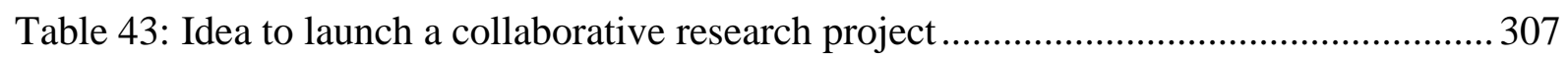

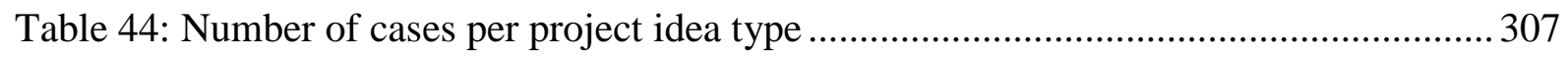

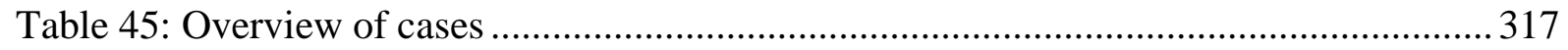

Table 46: Interpretation of results in the spirit of Brunsson: talk, decision and actions ........ 352

Table 47: Genealogy of "policy” appearances in academic research .................................... 372

Table 48: French Ministers of Industry since the beginning of the $5^{\text {th }}$ Republic ................... 375

Table 49: Priority 1: Creating a community of thoughts, objectives and actions ................... 381

Table 50: Priority 2: Being the key health actor in the Paris Region .................................... 382

Table 51: Priority 3: Structuring the healthcare sector in the Paris Region ............................ 383

Table 52: Priority 4: Development of national and international partnerships ....................... 384

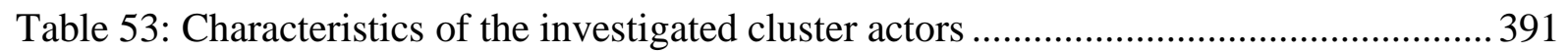

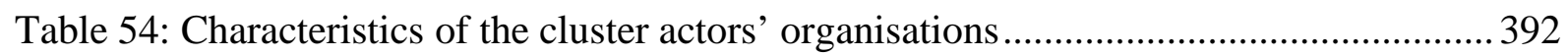

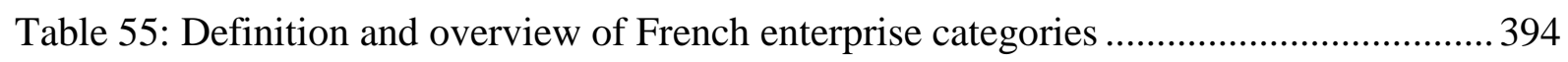

Table 56: Number of presidents: HCPR, Cap Digital \& Systematic ..................................... 396

Table 57: Number of chief executive officers: HCPR, Cap Digital \& Systematic ................. 396 


\section{LIST OF BOXES}

Box 1: Henry's adventure and thoughts ............................................................................. viii

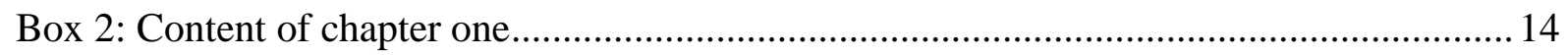

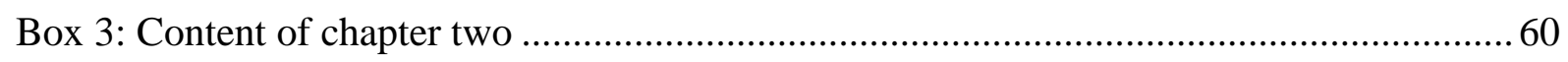

Box 4: Government intervention in the name of scientific progress - a recurrent theme ........ 63

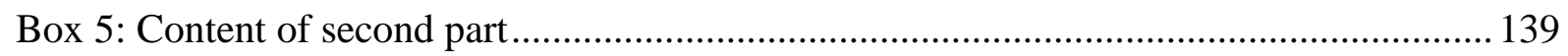

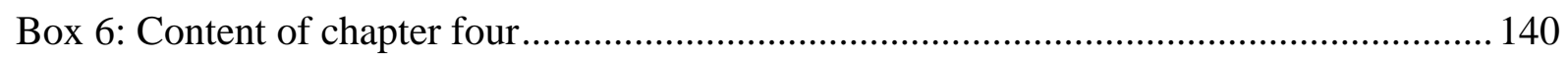

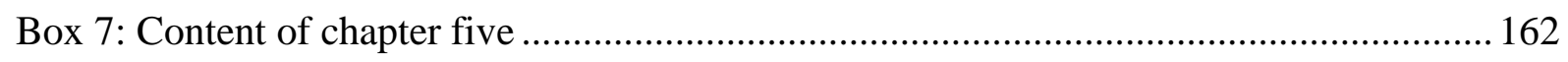

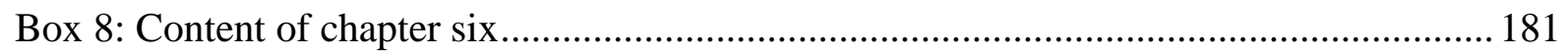

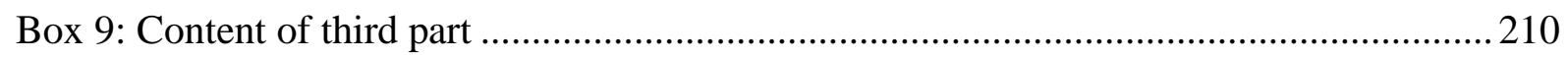

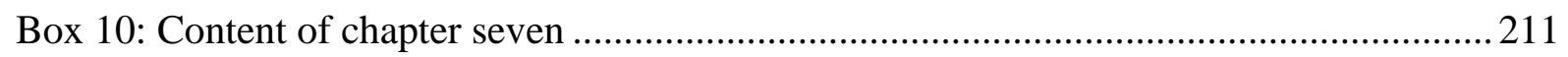

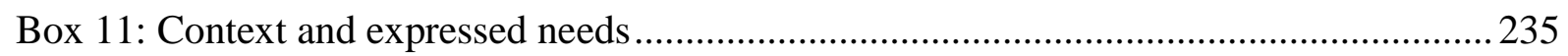

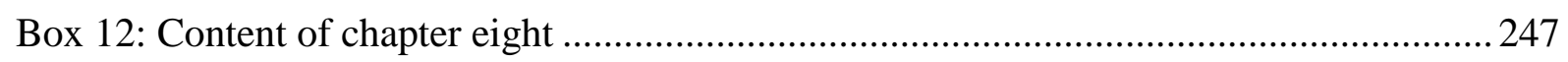

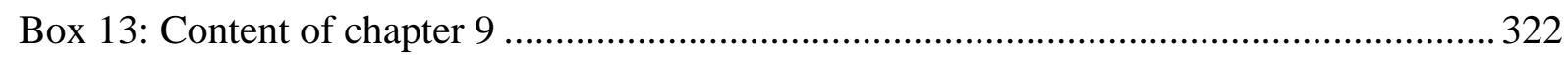

Box 14: President's Commission on Industrial Competitiveness (Executive Order 12428) .. 370

Box 15: Establishment of the President's Commission on Industrial Competitiveness .......... 371

Box 16: European Commission on growth, competitiveness and employment in 1993........ 373

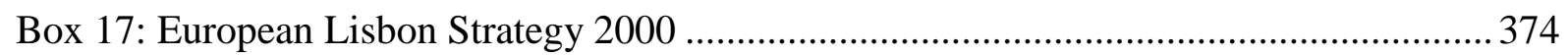

Box 18: Selection of key criteria used for the French cluster evaluation in 2008 ................. 379 


\section{REFERENCES}

Aggeri, F., \& Pallez, F. (2005). Restructurations, délocalisations: les nouvelles formes de l'action territoriale. La Revue de l'IRES(1), 235-256.

Aghion, P., \& Durlauf, S. N. (Eds.). (2005). Handbook of economic growth (Vol. 1). Oxford: Elsevier.

Aghion, P., \& Durlauf, S. N. (Eds.). (2014). Handbook of economic growth (Vol. 2). Oxford: Elsevier.

Agogué, M. (2012). Modeling the impact of cognitive biases on industrial dynamics - Orphan innovation and architect of the unknown. Mines ParisTech, Paris.

Ahedo, M. (2004). Cluster policy in the Basque country (1991-2002): constructing 'industrygovernment' collaboration through cluster-associations. European Planning Studies, 12(8), 1097-1113.

Aiginger, K. (2007). Industrial policy: A dying breed or a re-emerging phoenix. Journal of Industry, Competition and Trade, 7(3-4), 297-323.

Aktouf, O., Chennoufi, M., \& Holford, W. D. (2011). The strategic management framework: a methodological and epistemological examination. In R. Huggins \& H. Izushi (Eds.), Competition, competitive advantage, and clusters: the ideas of Michael Porter (pp. 75-92). Oxford: Oxford University Press.

Alberti, F. (2001). The governance of industrial districts: a theoretical footing proposal. Paper presented at the Liuc papers $n^{\circ} 82$, Serie Piccola e Media Impresa 5.

Allen, T. J. (1977). Managing the Flow of Technology: Technology Transfer and the Dissemination of Technological Information Within the $R \& D$ Organization. Cambridge, MA: MIT Press.

Allen, T. J., \& Henn, G. W. (2007). The Organization and Architecture of Innovation Managing the Flow of Technology. Oxford: Elsevier.

Altenburg, T., \& Meyer-Stamer, J. (1999). How to promote clusters: policy experiences from Latin America. World development, 27(9), 1693-1713.

Amabile, T. M. (1996). Creativity and innovation in organizations. Harvard Business School.

Amabile, T. M. (1998). How to kill creativity. Harvard Business Review, 76(5), 76-87.

Amabile, T. M., Conti, R., Coon, H., Lazenby, J., \& Herron, M. (1996). Assessing the work environment for creativity. Academy of Management Journal, 39(5), 1154-1184.

Andersson, S., Colovic, A., \& Lamotte, O. (2014). The role of formal industry clusters in the internationalization of new ventures. European Business Review, 26(5), 449-470.

Andersson, T., Schwaag-Serger, S., Sörvik, J., \& Hansson, E. W. (2004). The Cluster Policies Whitebook. Malmö: IKED - International Organisation for Knowledge Economy and Enterprise Development.

Angel, D. P. (1991). High-technology agglomeration and the labor market: the case of Silicon Valley. Environment and Planning A, 23(10), 1501-1516.

Antonelli, C. (2000). Collective Knowledge Communication and Innovation: The Evidence of Technological Districts. Regional Studies, 34(6), 535-547.

Argyris, C., \& Schön, D. (1978). Organizational Learning: A theory of action perspective. Reading: Addison-Wesley.

Arikan, A. T. (2009). Interfirm Knowledge Exchanges and the Knowledge Creation Capability of Clusters. Academy of Management Review, 34(4), 658-676.

Armenakis, A. A., Harris, S. G., \& Mossholder, K. W. (1993). Creating readiness for organizational change. Human Relations, 46(6), 681-703. 
Arrow, K. J. (1962). The economic implications of learning by doing. The Review of Economic Studies, 155-173.

Arthurs, D., Cassidy, E., Davis, C. H., \& Wolfe, D. (2009). Indicators to support innovation cluster policy. International Journal of Technology Management, 46(3), 263-279.

Asheim, B. T. (1996). Industrial districts as 'learning regions': A condition for prosperity. European Planning Studies, 4(4), 379-400.

Asheim, B. T., \& Gertler, M. S. (2005). The geography of innovation: Regional Innovation Systems. In J. Fagerberg, D. C. Mowery \& R. R. Nelson (Eds.), The Oxford Handbook of Innovation (pp. 291-317). Oxford: Oxford University Press.

Asheim, B. T., \& Isaksen, A. (1997). Location, agglomeration and innovation: towards regional innovation systems in Norway? European Planning Studies, 5(3), 299-330.

Asheim, B. T., Smith, H. L., \& Oughton, C. (2011). Regional innovation systems: theory, empirics and policy. Regional Studies, 45(7), 875-891.

Audretsch, D. B., \& Feldman, M. P. (1996). Innovative Clusters and the Industry Life Cycle. Review of Industrial Organization, 11(2), 253-273.

Aydalot, P. (1986). Milieux Innovateurs en Europe. Paris: GREMI (excerpt: http://wwwa.unine.ch/irer/Gremi/Gremi\%201.pdf ; accessed 20/05/2014).

Aydalot, P., \& Keeble, D. (1988). High technology industry and innovative environments: the European experience. London: Routledge.

Aziz, K. A., \& Norhashim, M. (2008). Cluster-based policy making: Assessing performance and sustaining competitiveness. Review of Policy Research, 25(4), 349-375.

Bachtler, J., \& Wren, C. (2006). Evaluation of European Union Cohesion Policy: Research Questions and Policy Challenges. Regional Studies, 40(2), 143-153.

Bagnasco, A. (1977). Tre Italie : la problematica territoriale dello sviluppo italiano. Bologna: Il Mulino.

Balassa, B. (1971). Industrial policies in Taiwan and Korea. Weltwirtschaftliches Archiv, 106(1), 55-77.

Barbier, J.-C., \& Matyjasik, N. (2010). Evaluation des politiques publiques et quantification en France: des relations ambiguës et contradictoires entre disciplines. Revue française de socio-Economie, 1(5), 123-140.

Bardet, M. (2011). Quelles logiques d'insertion dans les pôles de compétitivité ? Une analyse par les ressources recherchées et les liens mobilisés Les cas des pôles Mer PACA et PASS ( 2006-2008). Université Aix-Marseille, Aix-Marseille.

Barney, J. B. (1986). Strategic factor markets: expectations, luck, and business strategy. Management science, 32(10), 1231-1241.

Barney, J. B. (1991). Firm Resources and Sustained Competitive Advantage. Journal of Management, 17(1), 99-120.

Barney, J. B. (2001). Resource-based theories of competitive advantage: A ten-year retrospective on the resource-based view. Journal of Management, 27(6), 643-650.

Barro, R. J., \& Sala-i-Martin, X. (2003). Economic growth (2 ed.). Boston: MIT Press.

Bathelt, H., \& Dewald, U. (2008). Relational aspects of regional economics support and cluster policy. Ansatzpunkte einer relationalen Regionalpolitik und Clusterförderung, 52(2-3), 163-179.

Bathelt, H., Malmberg, A., \& Maskell, P. (2004). Clusters and knowledge: local buzz, global pipelines and the process of knowledge creation. Progress in Human Geography, 28(1), 31-56.

Bathelt, H., \& Zeng, G. (2005). From resource-dependent, isolated industrial firms to industrial clusters? The example of Nanning, Southern China. Zeitschrift für Wirtschaftsgeographie, 49(1), 1-22. 
Bayenet, B., \& Wunderle, M. (2009). Les pôles de compétitivité wallons. Bruxelles: Courrier hebdomadaire du CRISP.

Beaudry, C., \& Schiffauerova, A. (2009). Who's right, Marshall or Jacobs? The localization versus urbanization debate. Research Policy, 38(2), 318-337.

Becattini, G. (1979). Dal 'settore' industriale al 'distretto' industriale. Alcune considerazioni sull'unità di indagine dell'economia industriale. Rivista di Economia e politica industriale, 5(1), 7-21.

Becattini, G. (1989). Sectors and/or Districts: Some Remark on the Conceptual Foundation of Industrial Economics. In E. Goodman \& J. Bamford (Eds.), Small Firms and Industrial Districts in Italy. London: Routledge.

Becattini, G. (1990). The Marshallian industrial district as a socio-economic notion. In F. Pyke, G. Becattini \& W. Sengenberger (Eds.), Industrial districts and inter-firm cooperation in Italy (pp. 37-51). Geneva: International Institute for Labour Studies.

Becattini, G. (2002). From Marshall's to the Italian "Industrial Districts". A Brief Critical Reconstruction. In A. Curzio \& M. Fortis (Eds.), Complexity and Industrial Clusters (pp. 83-106). Heidelberg: Physica-Verlag (Springer).

Bellandi, M., \& Caloffi, A. (2010a). An Analysis of Regional Policies Promoting Networks for Innovation. European Planning Studies, 18(1), 67-82.

Bellandi, M., \& Caloffi, A. (2010b). Towards a framework for the evaluation of policies of cluster upgrading and innovation. Revue d'économie industrielle (129-130), 259-276.

Benko, G. B. (1989). Géographie des mutations industrielles: Le phénoméne des pépiniéres d'entreprises. Annales de Géographie(550), 628-645.

Benzerafa, M., Garcin, L., Gibert, P., \& Gueugnon, j.-F. (2011). Le management par objectifs met-il fin à l'ambiguïté dans la gestion publique ? Poltiques et management public, 28(3), 353-389.

Bergman, E. M. (2008). Cluster life-cycles: An emerging synthesis. In C. Karlsson (Ed.), Handbook of research on cluster theory (Vol. 1, pp. 114-132). Cheltenham: Edward Elgar Publishing.

Bergman, E. M., \& Feser, E. J. (1999a). Industrial and regional clusters: concepts and comparative applications. Web Book in Regional Science.

Bergman, E. M., \& Feser, E. J. (1999b). Industry clusters: a methodology and framework for regional development policy in the United States. In OECD (Ed.), Boosting Innovation: The Cluster Approach (pp. 243-268). Paris: OECD Publishing.

Berthinier-Poncet, A. (2012). Gouvernance et innovation dans les clusters à la française. Une approche par les pratiques institutionnelles. Université de Grenoble, Grenoble.

Bidan, M., \& Dherment-Férère, I. (2009). Les pôles de compétitivité comme leviers cognitifs de création de valeur: cas de I-TRANS et MER PACA. Management \& Avenir(5), 245-266.

BIPE. (2007). Méthodes et outils d'évaluation des clusters appliqués aux pôles de compétitivité. Paris: BIPE.

Blanc, C. (2004). Pour un écosystème de la croissance. Paris: Assemblée Nationale.

Bland, C. J., \& Ruffin, M. T. (1992). Characteristics of a productive research environment: literature review. Academic Medicine, 67(6), 385-397.

Blivet, L., Ezvan, C., \& Moulet, A. (2008). Retour sur l'évaluation nationale des pôles de compétitivité. Paris: Séminaire de l'Observatoire des pôles de compétitivité, Mines ParisTech.

Bocquet, R., Mendez, A., Mothe, C., \& Bardet, M. (2009). Pôles de compétitivité constitués de PME : quelle gouvernance pour quelle performance ? Management \& Avenir, $5(25), 227-244$. 
Bocquet, R., \& Mothe, C. (2009). Gouvernance et performance des pôles de PME. Revue française de gestion (190), 101-122.

Bocquet, R., \& Mothe, C. (2010). Knowledge governance within clusters: the case of small firms. Knowledge Management Research \& Practice, 8(3), 229-239.

Boekholt, P., \& Thuriaux, B. (1999). Public policies to facilitate clusters: Background, rationale and policy practices in international perspective. In OECD (Ed.), Boosting Innovation - The Cluster Approach (pp. 381-412). Paris: OECD.

Boer, H., \& During, W. E. (2001). Innovation, what innovation? A comparison between product, process and organisational innovation. International Journal of Technology Management, 22(1), 83-107.

Bonnafous-Boucher, M., \& Saussois, J.-M. (2010). La dynamique entrepreneuriale dans les pôles de compétitivité. Paris: CCIP (Advancia-Negocia, ESCP Europe).

Boschma, R. A. (1998). The industrial rise of the Third Italy: open window of locational opportunity? Paper presented at the 38th Congress of the European Regional Science Association.

Boschma, R. A., \& Ter Wal, A. L. (2007). Knowledge networks and innovative performance in an industrial district: the case of a footwear district in the South of Italy. Industry and Innovation, 14(2), 177-199.

Bourdieu, P. (1982). Ce que parler veut dire: l'économie des échanges linguistiques. Paris: Fayard.

Boyd, B. (1990). Corporate linkages and organizational environment: A test of the resource dependence model. Strategic Management Journal, 11(6), 419-430.

Brachert, M., Titze, M., \& Kubis, A. (2011). Identifying industrial clusters from a multidimensional perspective: Methodical aspects with an application to Germany. Papers in Regional Science, 90(2), 419-439.

Bresnahan, T., \& Gambardella, A. (2004). Building High-Tech Clusters: Silicon Valley and Beyond. Cambridge: Cambridge University Press.

Brette, O., \& Chappoz, Y. (2007). The French competitiveness clusters: toward a new public policy for innovation and research? Journal of Economic Issues, 41(2), 391-398.

Brown, J. S., \& Duguid, P. (1998). Organizing Knowledge. California Management Review, 40(3), 90-111.

Brown, T. (2009). Change by design: How Design Thinking Transforms Organizations and Inspires Innovation. New York: Harper Collins.

Brown, T., \& Katz, B. (2011). Change by design. Journal of Product Innovation Management, 28(3), 381-383.

Brunsson, N. (1989). The Organization of Hypocrisy: Talk, Decisions, and Actions in Organizations. Chichester: John Wiley \& Sons Ltd.

Brunsson, N. (2002 (1989)). The Organization of Hypocrisy: Talk, Decisions and Actions in Organizations (2 ed.). Copenhagen: Copenhagen Business School Press.

Brunsson, N. (2007). The Consequences of Decision-Making. Oxford: Oxford University Press.

Brusco, S. (1982). The Emilian model: productive decentralisation and social integration. Cambridge journal of economics, 6(2), 167-184.

Brusco, S. (1990). The idea of the industrial district: its genesis. In F. Pyke, G. Becattini \& W. Sengenberger (Eds.), Industrial districts and inter-firm co-operation in Italy (pp. 1019). Geneva: International Institute for Labour Studies.

Burfitt, A., \& Macneill, S. (2008). The challenges of pursuing cluster policy in the congested state. International Journal of Urban and Regional Research, 32(2), 492-505. 
Burfitt, A., Macneill, S., \& Gibney, J. (2007). The dilemmas of operationalizing cluster policy: The medical technology cluster in the West Midlands. European Planning Studies, 15(9), 1273-1290.

Burnier, M., \& Lacroix, J. (1996). Les technopoles. Paris: Presses universitaires de France.

Burns, R. B., \& Burns, R. A. (2008). Business Research Methods and Statistics Using SPSS. London: SAGE Publications Ltd.

Burt, R. S. (1992). Structural Holes: The Structure of Competition. Cambridge, MA: Harvard University Press.

Bush, V. (1945). Science: The endless frontier. Transactions of the Kansas Academy of Science (1903-), 48(3), 231-264.

Camagni, R. (1991). Innovation Networks: Spatial Perspectives. London: Belhaven-Pinter.

Cammett, M. (2007). Business-government relations and industrial change: The politics of upgrading in Morocco and Tunisia. World development, 35(11), 1889-1903.

Capecchi, V. (1990). A history of flexible specialization and industrial districts in EmiliaRomagna. In F. Pyke, G. Becattini \& W. Sengenberger (Eds.), Industrial districts and inter-firm co-operation in Italy (pp. 20-36). Geneva: International Institute for Labour Studies.

Capron, H. (2011). Esquisse du positionnement européen des pôles de compétitivité belges. Reflets et perspectives de la vie économique(3), 107-131.

Caraça, J., Lundvall, B.- $\AA$., \& Mendonça, S. (2009). The changing role of science in the innovation process: From Queen to Cinderella? Technological Forecasting and Social Change, 76(6), 861-867.

Carluer, F. (2006). Réseaux d'entreprises et dynamiques territoriales: une analyse stratégique. Géographie, économie, société, 8(2), 193-214.

Carpinetti, L. C. R., Gerolamo, M. C., \& Galdámez, E. V. C. (2007). Continuous innovation and performance management of SME clusters. Creativity and Innovation Management, 16(4), 376-385.

Carré, D., Lefebvre, G., \& Madeuf, B. (2008). Les pôles de compétitivité, territoires d'innovation. Hermès, La Revue(1), 39-46.

Chabaud, D., Messeghem, K., \& Sammut, S. (2011). Vers de nouvelles formes d'accompagnement? Revue de l'Entrepreneuriat, 9(2), 1-5.

Chabault, D. (2008). L'intégration d'une stratégie de développement durable dans les pôles de compétitivité: l'exemple de la Cosmetic Valley. Réalités industrielles(2), 50-54.

Chabault, D. (2009). Gouvernance et trajectoire des réseaux territoriaux d'organisations : une application aux pôles de compétitivité., Université de Tours, Tours.

Champenois, C. (2008). Action publique, réseaux locaux de soutien et entreprenariat : Le cas des «BioRegio » allemandes. Paris: Séminaire de l'Observatoire des pôles de compétitivité, Mines ParisTech.

Champenois, C. (2012). How can a cluster policy enhance entrepreneurship? Evidence from the German 'BioRegio' case. Environment and Planning C: Government and Policy, 30(5), 796-815.

Chanut, V. (2002). L'évaluation: affaire d'Etat ou question d'organisation? Politiques et management public, 20(4), 1-32.

Chanut, V. (2009). Pour une nouvelle geste évaluative. In S. Trosa (Ed.), Evaluer les politiques publiques pour améliorer l'action publique - Une perspective internationale. (pp. pp. 171-202). Paris: Comité pour l'histoire économique et financière de la France.

Chappoz, Y., \& Poisat, J. (2000). Procédures contractuelles de développement local et gestion de l'héritage industriel. Les cas de l'Ondaine et du Roannais (France). Revue de géographie alpine, 88(1), 75-92. 
Chaskin, R. J. (2001). Organizational infrastructure and community capacity: The role of broker organizations. In T. I. K. Youn (Ed.), The Organizational Response to Social Problems (Research in Social Problems and Public Policy) (Vol. 8, pp. 143-166). United Kingdom: Emerald Group Publishing Limited.

Chautard, G., \& Zuindeau, B. (2001). L'enjeu d'une reconversion durable des territoires de tradition industrielle: l'exemple du bassin minier du Nord-Pas-de-Calais. Espace, populations, sociétés, 19(3), 325-339.

Chawla, A., \& Singh, J. (1998). Organizational environment and performance of research groups - A typological analysis. Scientometrics, 43(3), 373-391.

Chesbrough, H. W. (2003). Open innovation: The new imperative for creating and profiting from technology. Boston: Harvard Business Press.

Chesbrough, H. W. (2007). Business model innovation: it's not just about technology anymore. Strategy \& Leadership, 35(6), 12-17.

Chiaroni, D., \& Chiesa, V. (2006). Forms of creation of industrial clusters in biotechnology. Technovation, 26(9), 1064-1076.

Child, J., \& Faulkner, D. (1998). Strategies of cooperation: Managing alliances, networks, and joint ventures. New York: Oxford University Press.

Chiu, Y. T. H. (2009). How network competence and network location influence innovation performance. Journal of Business \& Industrial Marketing, 24(1), 46-55.

Christensen, C. (1997). The innovator's dilemma: when new technologies cause great firms to fail. Boston: Harvard Business School Press.

Christopherson, S., \& Storper, M. (1986). The city as studio; the world as back lot: The impact of vertical disintegration on the location of the motion picture industry. Environment and Planning D: Society and Space, 4(3), 305-320.

Christopherson, S., \& Storper, M. (1989). The effects of flexible specialization on industrial politics and the labor market: The motion picture industry. Industrial and Labor Relations Review, 42(3), 331-347.

CIADT. (2004). Pour une nouvelle politique industrielle: la stratégie des pôles de compétitivité. Paris: Comité interministériel d'aménagement et de développement du territoire.

Ciravegna, L. (2012). Linkages in the new ICT clusters of Latin America: Evidence from Costa Rica. Journal of Latin American Studies, 44(3), 553-580.

Clement, W., \& Welbich-Macek, S. (2007). Erfolgsgeschichte: 15 Jahre Clusterinitiativen in Österreich. Wien: Bundesministerium für Wirtschaft und Arbeit.

CLOE. (2006). Cluster Management Guide - Guidelines for the Development and Management of Cluster Initiatives Clusterforum.

Cluster Navigators Ltd. (2001). Cluster Building: A Toolkit. A Manual for Starting and Developing Local Clusters in New Zealand. . Wellington: Cluster Navigators Ltd.

CMI, \& BCG. (2008). L'évaluation des pôles de compétitivité 2005-2008 - Evaluation réalisée par CM International en association avec BCG. Paris: La Documentation française.

Coase, R. H. (1937). The nature of the firm. Economica, 4(16), 386-405.

Coase, R. H. (1988). The Nature of the Firm: Influence. Journal of Law, Economics, \& Organization, 4(1), 33-47.

Cohen, E. (2007). Industrial policies in France: the old and the new. Journal of Industry, Competition and Trade, 7(3-4), 213-227.

Coletti, M. (2010). Technology and industrial clusters: how different are they to manage? Science and Public Policy, 37(9), 679-688.

Colgan, C. S., \& Baker, C. (2003). A Framework for Assessing Cluster Development. Economic Development Quarterly, 17(4), 352-366. 
Colovic, A. (2013). Le rôle des pôles de compétitivité dans l'internationalisation des PME: une étude exploratoire. Management international/International Management/Gestiòn Internacional, 18(1), 138-152.

Colovic, A., \& Mayrhofer, U. (2011). Optimizing the location of R\&D and production activities: trends in the automotive industry. European Planning Studies, 19(8), 14811498 .

Commission of the European Communities. (1993). Growth, competitiveness, employment. The challenges and ways forward into the 21 st century.

Commons, J. R. (1931). Institutional economics. The American Economic Review, 21(4), 648657.

Cooke, P. (1992). Regional innovation systems: competitive regulation in the new Europe. Geoforum, 23(3), 365-382.

Cooke, P. (1996). The new wave of regional innovation networks: Analysis, characteristics and strategy. Small Business Economics, 8(2), 159-171.

Cooke, P. (2001). From technopoles to regional innovation systems: the evolution of localised technology development policy. Canadian Journal of Regional Science, 24(1), 21-40.

Cooke, P. (2002). Biotechnology clusters as regional, sectoral innovation systems. International Regional Science Review, 25(1), 8.

Cooke, P., Uranga, M. G., \& Etxebarria, G. (1998). Regional systems of innovation: an evolutionary perspective. Environment and Planning A, 30(9), 1563-1584.

Cooke, P., \& Wills, D. (1999). Small Firms, Social Capital and the Enhancement of Business Performance Through Innovation Programmes. Small Business Economics, 13(3), 219-234.

Cooper, R. G., \& Kleinschmidt, E. J. (1995). Benchmarking the firm's critical success factors in new product development. Journal of Product Innovation Management, 12(5), 374391.

Costanza, R., Hart, M., Talberth, J., \& Posner, S. (2009). Beyond GDP: The need for new measures of progress. Boston: Boston University.

Crafts, N., \& Toniolo, G. (1996). Economic growth in Europe since 1945. Cambridge: Cambridge University Press.

Crespo, J. (2010). How emergence conditions of technological clusters affect their viability? Theoretical perspectives on cluster lifecycles. Utrecht University, Section of Economic Geography.

CROCIS. (2011). Les Cahiers du CROCIS: L'Ile-de-France parmi les régions européennes. Paris: Chambre de commerce et d'industrie de Paris.

Crocombe, G. T., Enright, M. J., Porter, M. E., \& Caughey, T. (1991). Upgrading New Zealand's competitive advantage. Auckland: Oxford University Press Auckland.

Crozier, M. (1964 (2010)). The bureaucratic phenomenon (Vol. 280). New Brunswick, New Jersey: Transaction Publishers.

Cruz, S. C. S., \& Teixeira, A. A. C. (2009). The Evolution of the Cluster Literature: Shedding Light on the Regional Studies-Regional Science Debate Regional Studies, 44(9), 1263-1288.

Cumbers, A., Mackinnon, D., \& Chapman, K. (2003). Innovation, collaboration, and learning in regional clusters: A study of SMEs in the Aberdeen oil complex. Environment and Planning A, 35(9), 1689-1706.

Dalton, D., Daily, C., Johnson, J., \& Ellstrand, A. (1999). Number of directors and financial performance: A meta-analysis. Academy of Management Journal, 42(6), 674-686.

Dang, R. J. (2011). L'intégration des PME au sein des dynamiques territoriales d'innovation: une approche fondée sur les connaissances. Le cas de deux clusters du Pôle de Compétitivité SCS. Université de Nice - Sophia Antipolis, Nice. 
DATAR. (2004). France, puissance industrielle: une nouvelle politique industrielle par les territoires. Paris: La Documentation française.

DATAR. (2010). Première promotion de l'appel à projets "Grappes d'entreprises". Paris: DATAR

DATAR. (2011). Deuxième promotion de l'appel à projets Grappes d'entreprises". Paris: DATAR

Davies, H., \& Ellis, P. (2000). Porter's competitive advantage of nations: time for the final judgement? Journal of Management Studies, 37(8), 1189-1214.

Dayasindhu, N. (2002). Embeddedness, knowledge transfer, industry clusters and global competitiveness: a case study of the Indian software industry. Technovation, 22(9), 551-560.

De Géry, C. (2010). Le pôle PASS : un cluster historique à la croisée d'une régulation sectorielle et d'une régulation territoriale de la relation formation / emploi. Paper presented at the AISRe-ASRDLF.

de Géry, C., Laviolette, E. M., \& Bonnafous-Boucher, M. (2013). Le développement des compétences entrepreneuriales au service de la performance entrepreneuriale des pôles de compétitivité. Le cas des pôles Médicen et System@tic. In D. Chabault, A. Hulin, D. Leroy \& R. Soparnot (Eds.), La gestion des ressources humaines au service des réseaux d'innovation (pp. 21-41). Paris: L'Harmattan.

De Oliveira Wilk, E., \& Fensterseifer, J. E. (2003). Use of resource-based view in industrial cluster strategic analysis. International Journal of Operations \& Production Management, 23(9), 995-1009.

De Propris, L. (2007). Reconciling cohesion and competitiveness through EU cluster policies? Policy studies, 28(4), 327-345.

de Rochambeau, H., Veronese, T., \& Roché, P. (2008). Un exemple d'écoconception dans les filières agricoles, agroalimentaires et agro-industrielles: le pôle de compétitivité "AgriMip Innovation" en région Midi-Pyrénées. Réalités industrielles(4), 72-77.

De Tocqueville, A. (1856 (1988)). L'ancien régime et la révolution. Paris: Flammarion.

DeBresson, C. (1989). Breeding innovation clusters: a source of dynamic development. World development, 17(1), 1-16.

Delaplace, M. (2011). La politique des pôles de compétitivité: la question de l'articulation entre compétitivité des entreprises et compétitivité des territoires. Géographie, économie, société, 13(3), 255-271.

Denyer, D., \& Neely, A. (2004). Introduction to special issue: innovation and productivity performance in the UK. International Journal of Management Reviews, 5(3, Äê4), 131-135.

Desautels, D. (1997). Evaluation as an Essential Component of "Value-for-Money". In E. Chelimsky \& W. R. Shadish (Eds.), Evaluation for the 21st Century: A Handbook (pp. 72-79). Thousand Oaks, California: Sage Publications, Inc.

Desmarteau, R. H., \& Saives, A.-L. (2003). Modéliser une grappe industrielle de compétences: le cas des entreprises de biotechnologie de la région de Montréal. Gestion, 28(1), 75-87.

Diez, M. A. (2001). The Evaluation of Regional Innovation and Cluster Policies: Towards a Participatory Approach. European Planning Studies, 9(7), 907-923.

DiMaggio, P. J., \& Powell, W. W. (1983). The iron cage revisited: Institutional isomorphism and collective rationality in organizational fields. American sociological review, 48(2), 147-160.

Dobrov, G. M., \& Smirnov, L. P. (1972). Forecasting as a means for scientific and technological policy control. Technological Forecasting and Social Change, 4(1), 518. 
Dohse, D. (2000). Technology policy and the regions - the case of the BioRegio contest. Research Policy, 29(9), 1111-1133.

Dohse, D. (2007). Cluster-Based Technology Policy - The German Experience. Industry and Innovation, 14(1), 69-94.

Doloreux, D., \& Shearmur, R. (2009). Maritime clusters in diverse regional contexts: The case of Canada. Marine Policy, 33(3), 520-527.

Domdey, H., \& Hazouard, S. (2008). Le pôle biotech de Munich: une "culture de l'innovation". Regards sur l'économie allemande. Bulletin économique du CIRAC.(86), 19-24.

Dorfman, N. S. (1983). Route 128: the development of a regional high technology economy. Research Policy, 12(6), 299-316.

DTI. (2004). A Practical Guide to Cluster Development. London: A Report to the Department of Trade and Industry and the English Regional Developement Agencies by Ecotec Research \& Consulting.

Dubois, A., \& Gadde, L.-E. (2002). Systematic combining: an abductive approach to case research. Journal of Business Research, 55(7), 553-560.

Duffin, J. (2010). History of medicine: a scandalously short introduction. Toronto: University of Toronto Press.

Duiker, W. J. (2009). Contemporary World History (5th ed.). Boston: Wadsworth, Cengage Learning.

Dumez, H. (2013). Méthodologie de la recherche qualitative. Paris: Vuibert.

Dunning, J. H. (1993). Internationalizing Porter's diamond. MIR: Management International Review, 33(2), 7-15.

Duranton, G., Martin, P., \& Mayer, T. (2008). Les pôles de compétitivité. Que peut-on en attendre ? Paris: CEPREMAP.

Ebbekink, M., \& Lagendijk, A. (2013). What's Next in Researching Cluster Policy: PlaceBased Governance for Effective Cluster Policy. European Planning Studies, 21(5), 735-753.

Ebrahim, A. (2005). Accountability myopia: Losing sight of organizational learning. Nonprofit and voluntary sector quarterly, 34(1), 56-87.

Eckstein, H. (1975). Case study and theory in political science. In F. J. Greenstein \& N. W. Polsby (Eds.), Handbook of political science (Vol. 7, pp. 79-137). Reading, MA: Addison-Wesley.

Edmondson, A. C., \& McManus, S. E. (2007). Methodological fit in management field research. Academy of Management Review, 32(4), 1246-1264.

Edquist, C. (2001). The Systems of Innovation Approach and Innovation Policy: An account of the state of the art. Paper presented at the DRUID Conference, Aalborg.

Edquist, C. (2005). Systems of Innovation. In J. Fagerberg, D. C. Mowery \& R. R. Nelson (Eds.), The Oxford Handbook of Innovation (pp. 181-208). Oxford: Oxford University Press Oxford.

Ehlinger, S., Perret, V., \& Chabaud, D. (2007). Quelle gouvernance pour les réseaux territorialisés d'organisations ? Revue française de gestion (170), 155-171.

Eisenhardt, K. M. (1989). Building theories from case study research. Academy of Management Review, 14(4), 532-550.

Eisenhardt, K. M., \& Graebner, M. E. (2007). Theory building from cases: opportunities and challenges. Academy of Management Journal, 50(1), 25-32.

Eisingerich, A. B., Bell, S. J., \& Tracey, P. (2010). How can clusters sustain performance? The role of network strength, network openness, and environmental uncertainty. Research Policy, 39(2), 239-253. 
Eklinder-Frick, J., Eriksson, L. T., \& Hallén, L. (2014). Multidimensional social capital as a boost or a bar to innovativeness. Industrial Marketing Management, in press.

Eklinder-Frick, J., Eriksson, L. T., \& Hallén, L. (2012). Effects of social capital on processes in a regional strategic network. Industrial Marketing Management, 41(5), 800-806.

Engel, D., Mitze, T., Patuelli, R., \& Reinkowski, J. (2013). Does Cluster Policy Trigger R\&D Activity? Evidence from German Biotech Contests. European Planning Studies, 21(11), 1735-1759.

Enright, M. J. (2003). Regional Clusters: What we know and what we should know. In J. Bröcker, D. Dohse \& R. Soltwedel (Eds.), Innovation clusters and interregional competition (pp. 99-129). Berlin: Springer.

Erdyn, Technopolis, \& BearingPoint. (2012). Etude portant sur l'évaluation des pôles de compétitivite. Paris.

Ernst \& Young. (2005). Etude relative à l'implication des PME et des SPL dans les pôles de compétitivité: DATAR.

Ernst, H. (2002). Success factors of new product development: a review of the empirical literature. International Journal of Management Reviews, 4(1), 1-40.

Etzkowitz, H., \& Leydesdorff, L. (1997). Universities and the global knowledge economy: a triple helix of university-industry-government relations. London: Pinter.

Etzkowitz, H., \& Leydesdorff, L. (2000). The dynamics of innovation: from National Systems and "Mode 2" to a Triple Helix of university-industry-government relations. Research Policy, 29(2), 109-123.

European Commission. (1995). Green Paper on Innovation.

European Commission. (2002). Regional clusters in Europe. Luxembourg.

Putting knowledge into practice: A broad-based innovation strategy for the EU (2006).

European Commission. (2007). Innovation Clusters in Europe: A statistical analysis and overview of current policy support.

Falck, O., Heblich, S., \& Kipar, S. (2010). Industrial innovation: Direct evidence from a cluster-oriented policy. Regional Science and Urban Economics, 40(6), 574-582.

Feldman, M. P., \& Francis, J. L. (2003). Fortune favours the prepared region: The case of entrepreneurship and the capitol region biotechnology cluster. European Planning Studies, 11(7), 765-788.

Felzensztein, C., Gimmon, E., \& Aqueveque, C. (2012). Clusters or un-clustered industries? Where inter-firm marketing cooperation matters. Journal of Business and Industrial Marketing, 27(5), 392-402.

Fen Chong, S. (2009). Le pilotage chemin faisant : Emergence des modes de gouvernance et de pilotage des pôles des compétitivité. Université Paris-Dauphine, Paris.

Fen Chong, S., \& Pallez, F. (2008). Le Pôle Nucléaire de Bourgogne, ou l'art du décalage. Réalités industrielles (2).

Feser, E. J. (2008). On building clusters versus leveraging synergies in the design of innovation policy for developing economies. In U. Blien \& G. Maier (Eds.), The Economics of Regional Clusters: Networks, Technology and Policy (pp. 191-213). Cheltenham: Edward Elgar.

Feser, E. J., \& Bergman, E. M. (2000). National industry cluster templates: a framework for applied regional cluster analysis. Regional Studies, 34(1), 1-19.

Feser, E. J., Renski, H., \& Goldstein, H. (2008). Clusters and economic development outcomes an analysis of the link between clustering and industry growth. Economic Development Quarterly, 22(4), 324-344.

Fetterman, D. M., Kaftarian, S. J., \& Wandersman, A. (1995). Empowerment evaluation: Knowledge and tools for self-assessment and accountability. Thousand Oaks, CA: Sage Publications. 
Fisher, J. L. (1967). Reflections on the formulation of regional policy. Papers in Regional Science, 18(1), 67-74.

Fixari, D., \& Pallez, F. (2014). Bonnes et mauvaises complexités: des illusions d'optique? Le cas des écosystémes d'innovation. Gérer et comprendre(2), 17-29.

Fleck, L. (1935 (1980)). Entstehung und Entwicklung einer wissenschaftlichen Tatsache: Einführung in die Lehre vom Denkstil und Denkkollektiv. Frankfurt: Suhrkamp.

Florida, R. (1995). Toward the learning region. Futures, 27(5), 527-536.

Flyvbjerg, B. (1998). Rationality and power: Democracy in practice. Chicago: University of Chicago Press.

Flyvbjerg, B. (2006). Five misunderstandings about case-study research. Qualitative Inquiry, 12(2), 219-245.

Fontagné, L., Koenig, P., Mayneris, F., \& Poncet, S. (2013). Cluster policies and firm selection: Evidence from France. Journal of Regional Science, 53(5), 897-922.

Foray, D., David, P. A., \& Hall, B. (2011). Smart specialization. From academic idea to political instrument, the surprising career of a concept and the difficulties involved in its implementation. Management of Technology \& Entrepreneurship Institute, Ecole Polytechnique Fédérale de Lausanne.

Foss, N. J. (1996). Higher-order industrial capabilities and competitive advantage. Journal of Industry Studies, 3(1), 1-20.

Foucault, M. (1966 (1994)). The order of things: An archaeology of the human sciences. New York: Vintage, Random House.

Fromhold-Eisebith, M., \& Eisebith, G. (2005). How to institutionalize innovative clusters? Comparing explicit top-down and implicit bottom-up approaches. Research Policy, 34(8), 1250-1268.

Gadille, M., Méhaut, P., \& Courault, B. (2013). Compétences et régulation des marchés du travail dans les pôles de compétitivité: le cas du pôle Pégase. Revue d'économie Régionale \& Urbaine(2), 339-361.

Gaffard, J.-L. (2005). Développement local et globalisation. Nouveaux regards sur la croissance, le bien-être, les inégalités interrégionales et l'attractivité des territoires. Revue de l'OFCE, 3(94).

Gaffard, J.-L. (2008). Localisation, globalisation, et action publique. Revue de l'OFCE(104), 271-290.

Gallié, E.-P. (2008). Attractivité R\&D des territoires : Politiques nationales et régionales de recherche et d'innovation en France. Paris: Institut pour le Management de la Recherche et de l'Innovation (IMRI), Université Paris-Dauphine.

Gallié, E.-P. (2009). Is geographical proximity necessary for knowledge spillovers within a cooperative technological network? The case of the French biotechnology sector. Regional Studies, 43(1), 33-42.

Gallié, E.-P., Glaser, A., Lefebvre, P., \& Pallez, F. (2012). Evaluation moderne, évaluation modeste ? Le cas des pôles de compétitivité français. Politiques et management public, 29(4), 573-590.

Gallié, E.-P., Glaser, A., Mérindol, V., \& Weil, T. (2011). How do pre-existing R\&D activities in a region influence the performance of cluster initiatives? The case of French competitiveness clusters. European Planning Studies (Forthcoming).

Gallié, E.-P., Glaser, A., Mérindol, V., \& Weil, T. (2013a). How Do Pre-existing R\&D Activities in a Region Influence the Performance of Cluster Initiatives? The Case of French Competitiveness Clusters. European Planning Studies, 21(10), 1653-1675.

Gallié, E.-P., Glaser, A., Mérindol, V., \& Weil, T. (2013b). How do pre-existing R\&D activities in a region influence the performance of cluster initiatives? The case of French competitiveness clusters. European Planning Studies, 21(10), 1653-1675. 
Gallié, E.-P., Glaser, A., \& Pallez, F. (2010). Public policy and evaluation, a new process in construction - The case of the French cluster evaluation. Paper presented at the Regional Science Association International - British and Irish Section; 25th - 27th August.

Gallié, E.-P., Glaser, A., \& Pallez, F. (2011). Evaluer la politique des pôles de compétitivité, quels principes, quels usages ? Paris: Séminaire de l'Observatoire des pôles de compétitivité, Mines ParisTech.

Gallié, E.-P., Glaser, A., \& Pallez, F. (2014). Une analyse comparative des évaluations de politiques de clusters en Europe : vers deux modèles ideal-typiques. Politiques et management public, 31(1), 87-111.

Gallié, E.-P., \& Guichard, R. (2005). Do collaboratories mean the end of face-to-face interactions? An evidence from the ISEE project. Economics of Innovation and New Technology, 14(6), 517-532.

Garsten, C. (Ed.). (2013). Organisational Anthropology: Doing Ethnography in and Among Complex Organisations. London: Pluto Press.

Gausdal, A. H. (2008). Developing regional communities of practice by network reflection: the case of the Norwegian electronics industry. Entrepreneurship and Regional Development, 20(3), 209-235.

Gertler, M. S. (1988). The limits of flexibility: comments on the post-Fordist vision of production and its geography. Transactions of the Institute of British Geographers, 419-432.

Gertler, M. S. (1995). "Being There": Proximity, Organization, and Culture in the Development and Adoption of Advanced Manufacturing Technologies. Economic Geography, 71(1), 1-26.

Gertler, M. S. (2003). Tacit knowledge and the economic geography of context, or The undefinable tacitness of being (there). Journal of Economic Geography, 3(1).

Gévart, P. (2006). Comprendre les enjeux de la décentralisation (Vol. 16). Paris: Editions l'Etudiant.

Gibbert, M., Ruigrok, W., \& Wicki, B. (2008). What passes as a rigorous case study? Strategic Management Journal, 29(13), 1465-1474.

Gibert, P. (2003). L'évaluation de politique : contrôle externe de la gestion publique ? Revue française de gestion (147), 258-273.

Gibney, J., Copeland, S., \& Murie, A. (2009). Toward a 'new' strategic leadership of place for the knowledge-based economy. Leadership, 5(1), 5-23.

Gilpin, R. (2001). Global Political Economy - Understanding the International Economic Order. Princeton: Princeton University Press.

Girin, J. (1989). L'opportunisme méthodique dans les recherches sur la gestion des organisations. Paper presented at the Communication à la journée d'étude la recherche-action en action et en question, AFCET, Collège de systémique.

Giuliani, E. (2007). The selective nature of knowledge networks in clusters: evidence from the wine industry. Journal of Economic Geography, 7(2), 139-168.

Giuliani, E. (2013). Network dynamics in regional clusters: Evidence from Chile. Research Policy, 42(8), 1406-1419.

Glaeser, E. L., Kallal, H. D., Scheinkman, J. A., \& Shleifer, A. (1992). Growth in Cities. Journal of Political Economy, 100(6), 1126-1152.

Glaser, A. (2007). The Impact of Mergers on Regional Systems - The Case of North Carolina. Vienna University of Economics and Business, Vienna.

Glaser, A. (2011). Les clusters et la politique de clusters en Autriche : Le cas de " Clusterland Oberösterreich ». Paris: Research note, part of the preparation for the 
French cluster policy evaluation; directed by Mines ParisTech and Kurt Salmon, commissioned by the DATAR and the DGCIS.

Glaser, A. (2012a). Constructing collaborative $R \& D$ projects: An empirical exploration of the role played by public cluster organizations in the Paris Region. Paper presented at the Academy of Management (AOM), PNP Doctoral Student Professional Development Consortium.

Glaser, A. (2012b). Fostering inter-sectoral collaborative $R \& D$ projects by increasing proximity between regional actors. The case of the ICT \& Health clusters in the Paris Region. Paper presented at the Proximity Days (MOSAIC, HEC Montréal).

Glaser, A. (2013a). Richard Sennett: Adopting a more human approach to systems of innovation. Paper presented at the Danish Research Unit for Industrial Dynamics (DRUID) (accepted but not attended).

Glaser, A. (2013b). The role of cluster organisations in the construction of collaborative $R \& D$ projects: The case of the ICT \& Health Clusters in the Paris Region. Paper presented at the Danish Research Unit for Industrial Dynamics (DRUID) (accepted but not attended).

Glaser, A., Gallié, E.-P., Mérindol, V., \& Weil, T. (2010). The link between a Cluster's Governance and its Capability to get Collaborative Research Projects funded: An investigation of French clusters. Paper presented at the 4ème Atelier "Stratégies, Espaces et Territoires" de l'Association Internationale de Management Stratégique (AIMS) organisé conjointement avec l'Association de Science Régionale de Langue Française (ASRLF).

Glaser, A., Gallié, E.-P., \& Weil, T. (2012). Governance Structures as Determinants of Resource Attraction? Evidence from French Clusters. Mines ParisTech \& ESCP Europe.

Glaser, B. G., \& Strauss, A. L. (1967 (2009)). The discovery of grounded theory: Strategies for qualitative research. Piscataway, New Jersey: Transaction Publishers.

Godet, M. (Ed.). (2010). Créativité et innovation dans les territoires. Paris: Conseil d'analyse économique (CAE), Délégation interministérielle à l'aménagement du territoire et à l'attractivité régionale (Datar), l'Académie des technologies.

Gomez, P.-Y. (2009). La gouvernance des pôles de compétitivité. Impasses théoriques et reformulation de la spécificité des pôles. Revue française de gestion (190), 197-209.

Gordon, I. R., \& McCann, P. (2000). Industrial Clusters: Complexes, Agglomeration and/or Social Networks? Urban Studies, 37(3), 513-532.

Gouldner, A. W. (1954 (1964)). Patterns of industrial bureaucracy. New York: Free Press.

Granovetter, M. (1973). The strength of weak ties. American Journal of Sociology, 78(6), 1360-1380.

Granovetter, M. (1985). Economic Action and Social Structure: The Problem of Embeddedness. American Journal of Sociology, 91(3).

Granovetter, M. (1990). The old and the new economic sociology: A history and an agenda. In R. O. Friedland \& A. F. Robertson (Eds.), Beyond the marketplace: Rethinking economy and society (pp. 89-112). New York: Aldine de Gruyter.

Gray, B. (1985). Conditions facilitating interorganizational collaboration. Human Relations, 38(10), 911-936.

Greckhamer, T., Koro-Ljungberg, M., Cilesiz, S., \& Hayes, S. (2008). Demystifying interdisciplinary qualitative research. Qualitative Inquiry, 14(2), 307-331.

Grossetti, M. (2004). Concentration d'entreprises et innovation: esquisse d'une typologie des systémes productifs locaux. Géographie, économie, société, 6(2), 163-177.

GTZ. (2007a). Cluster Management - A Practical Guide. Part A: Overview

GTZ. (2007b). Cluster Management - A Practical Guide. Part B: Tools. 
Guillaume, R. (2008). Des systémes productifs locaux aux pôles de compétitivité: approches conceptuelles et figures territoriales du développement. Géographie, économie, société, 10(3), 295-309.

Guinet, J. (2003). Drivers of Economic Growth: The Role of Innovative Clusters. In J. Bröcker, D. Dohse \& R. Soltwedel (Eds.), Innovation clusters and interregional competition (pp. 150-160). Berlin: Springer.

Guinot, F. (2010). Les instituts Carnot, un dispositif original de recherche partenariale. In M. Godet (Ed.), Créativité et innovation dans les territoires. Paris: Conseil d'analyse économique (CAE), Délégation interministérielle à l'aménagement du territoire et à l'attractivité régionale (Datar), l'Académie des technologies.

Guisard, D., Le Bas, C., \& Nief, P. (2010). The French regional industrial clusters policy: Lessons from the Lyon urban trucks and bus cluster. Local Economy, 25(8), 668-677.

Hallencreutz, D., \& Lundequist, P. (2003). Spatial clustering and the potential for policy practice: Experiences from cluster-building processes in Sweden. European Planning Studies, 11(5), 533-547.

Hannan, M. T., \& Freeman, J. (1977). The Population Ecology of Organizations. American Journal of Sociology, 82(5), 929-964.

Hannan, M. T., \& Freeman, J. (1989 (1993)). Organizational ecology. Cambridge, Massachusetts: Harvard University Press.

Hansen, M. T. (2009). Collaboration: How leaders avoid the traps, create unity, and reap big results. Boston, Massachusetts: Harvard Business Press.

Hargadon, A. B. (1998). Firms as Knowledge Brokers: Lessons in Pursuing Continous Innovation. California Management Review, 40(3), 209-227.

Harrison, R. T., Cooper, S. Y., \& Mason, C. M. (2004). Entrepreneurial activity and the dynamics of technology-based cluster development: the case of Ottawa. Urban Studies, 41(5-6), 1045-1070.

Harzing, A.-W. (2013). Journal quality list. available at: http://www.harzing.com/jql.htm (accessed December 26, 2013).

Helpman, E. (2004). The Mystery of Economic Growth. Cambridge: Harvard University Press.

Henderson, R. M., \& Clark, K. B. (1990). Architectural innovation: the reconfiguration of existing product technologies and the failure of established firms. Administrative Science Quarterly, 35(1), 9-30.

Hermans, J., Castiaux, A., Dejardin, M., \& Lucas, S. (2012). Configuration in the flesh: Challenges in publicly promoted clusters. Journal of Technology Transfer, 37(5), 609630.

Hertting, N., \& Vedung, E. (2012). Purposes and criteria in network governance evaluation: How far does standard evaluation vocabulary takes us? Evaluation, 18(1), 27-46.

Hervas-Oliver, J. L., \& Albors-Garrigos, J. (2007). Do clusters capabilities matter? An empirical application of the resource-based view in clusters. Entrepreneurship and Regional Development, 19(2), 113-136.

Hillman, A. J., Cannella, A. A., \& Paetzold, R. L. (2000). The resource dependence role of corporate directors: Strategic adaptation of board composition in response to environmental change. Journal of Management Studies, 37(2), 235-256.

Hillman, A. J., \& Dalziel, T. (2003). Boards of directors and firm performance: Integrating agency and resource dependence perspectives. Academy of Management Review, 28(3), 383-396.

Hillman, A. J., Withers, M. C., \& Collins, B. J. (2009). Resource dependence theory: A review. Journal of Management, 35(6), 1404-1427. 
Himmelman, A. T. (1996). On the theory and practice of transformational collaboration: Collaboration as a bridge from social service to social justice. Creating Collaborative Advantage. London: Sage Publishers.

Himmelman, A. T. (2001). On coalitions and the transformation of power relations: Collaborative betterment and collaborative empowerment. American Journal of Community Psychology, 29(2), 277-284.

Himmelman, A. T. (2002). Collaboration for a change: Definitions, Decision-making models, Roles, and Collaboration Process Guide. Himmelman Consulting.

Hofstadter, D. R. (1979 (1999)). Gödel, Escher, Bach: an Eternal Golden Braid. New York: Basic Books.

Holford, W. D., Ebrahimi, M., Aktouf, O., \& Simon, L. (2008). Viewing Boundary 'Objects' as Boundary Constructions. Paper presented at the 41st Hawaii International Conference on System Sciences, Waikoloa, Big Island, Hawaii.

Hollanders, H. (2006). European Regional Innovation Scoreboard (2006 RIS). Maastricht: MERIT (Maastricht Economic and social Research and training centre on Innovation and Technology).

Hospers, G.-J. (2005). 'Best practices' and the dilemma of regional cluster policy in Europe. Tijdschrift voor economische en sociale geografie, 96(4), 452-457.

Hospers, G.-J., \& Beugelsdijk, S. (2002). Regional cluster policies: learning by comparing? Kyklos, 55(3), 381-402.

Hospers, G.-J., Desrochers, P., \& Sautet, F. (2009). The next Silicon Valley? On the relationship between geographical clustering and public policy. International Entrepreneurship and Management Journal, 5(3), 285-299.

Hospers, G. J., \& Beugelsdijk, S. (2002). Regional cluster policies: Learning by comparing? Kyklos, 55(3), 381-402.

Hospers, G. J., Desrochers, P., \& Sautet, F. (2009). The next Silicon Valley? On the relationship between geographical clustering and public policy. International Entrepreneurship and Management Journal, 5(3), 285-299.

Hudson, R. (1989). New Industrial Spaces: Flexible Production Organization and Regional Development in North America and Western Europe by Allen J. Scott. Economic Geography, 65(2), 168-171.

Huggins, R., \& Izushi, H. (Eds.). (2011). Competition, competitive advantage, and clusters: the ideas of Michael Porter. New York: Oxford University Press.

Huggins, R., \& Johnston, A. (2009). Knowledge networks in an uncompetitive region: SME innovation and growth. Growth and Change, 40(2), 227-259.

Huggins, R., \& Johnston, A. (2010). Knowledge flow and inter-firm networks: The influence of network resources, spatial proximity and firm size. Entrepreneurship \& Regional Development, 22(5), 457-484.

Huxham, C., \& Vangen, S. E. (2005). Managing to collaborate: The theory and practice of collaborative advantage. London: Routledge Taylor \& Francis Group.

Iammarino, S., \& McCann, P. (2006). The structure and evolution of industrial clusters: transactions, technology and knowledge spillovers. Research Policy, 35(7), 10181036.

Ingstrup, M. B. (2010). The role of cluster facilitators. International Journal of Globalisation and Small Business, 4(1), 25-40.

Innovation America. (2007). Governor's Guide to Cluster-Based Strategies for Growing State Economies. Washington, DC: National Governors Association \& Council on Competitiveness.

Jacobs, J. (1961). The death and life of great American cities (1993 ed.). New York: Radnom House, Inc. 
Jacobs, J. (1969). The economy of cities (1970 ed.). New York: Vintage.

Jacquet, N., \& Darmon, D. (2005). Les pôles de compétitivité: le modèle français (Vol. 5225). Paris: La documentation française.

Jaffe, A. B. (1986). Technological Opportunity and Spillovers of R\&D: Evidence from Firms' Patents, Profits, and Market Value. American Economic Review, 76(5), 984-1001.

Jakoby, H. (2006). Evaluation as Part of the Regional Policy Life Cycle: The Example of North Rhine-Westphalia, Germany. Regional Studies, 40(2), 281-284.

James, A. (2005). Demystifying the role of culture in innovative regional economies. Regional Studies, 39(9), 1197-1216.

Jankowski, J. E. (2001). A brief data-informed history of science and technology policy. In M. P. Feldman \& A. N. Link (Eds.), Innovation Policy in the Knowledge-Based Economy (pp. 5-36). Norwell: Kluwer Academic Publishers.

Jones, G. (2007). Globalization. In G. Jones \& J. Zeitlin (Eds.), The Oxford Handbook of Business History (pp. 141-168). Oxford: Oxford University Press.

Kaiser, R. (2003). Multi-level Science Policy and Regional Innovation: The Case of the Munich Cluster for Pharmaceutical Biotechnology. European Planning Studies, 11(17).

Kalcher, T., Piber, H., \& Gruber, M. (2004). Management Summary: Evaluierung Clusterland Niederösterreich. Wien: EcoPlus.

Karaev, A., Koh, S. C. L., \& Szamosi, L. T. (2007). The cluster approach and SME competitiveness: A review. Journal of Manufacturing Technology Management, 18(7), 818-835.

Kaufman, L., \& Rousseeuw, P. J. (2005). Finding Groups In Data: An Introduction To Cluster Analysis. Hoboken, New Jersey: John Wiley \& Sons Inc.

Kern, H. (1973). The need for a policy of regionalisation. Intereconomics, 8(3), 91-94.

Ketels, C. (2013). Cluster Policy: A Guide to the State of the Debate. In P. Meusburger, J. Glückler \& M. Meskioui (Eds.), Knowledge and the Economy (Vol. 5, pp. 249-269). Amsterdam: Springer.

Ketels, C., \& Sölvell, Ö. (2006). Clusters in the EU-10 new member countries.

Kidd, C. V. (1953). Research Planning and Research Policy Scientists and Administrators. Science, 118(3058), 147-152.

Kiese, M. (2008). Mind the gap: Regional cluster policies between science, politics and practice from public choice perspective. Zeitschrift für Wirtschaftsgeographie, 52(23), 129-145.

Kiese, M., \& Wrobel, M. (2011). A Public Choice Perspective on Regional Cluster and Network Promotion in Germany. European Planning Studies, 19(10), 1691-1712.

Kitagawa, F. (2005). Regionalization of innovation policies: the case of Japan. European Planning Studies, 13(4), 601-618.

Kitagawa, F. (2007). The regionalization of science and innovation governance in Japan? Regional Studies, 41(8), 1099-1114.

Klein Woolthuis, R., Lankhuizen, M., \& Gilsing, V. (2005). A system failure framework for innovation policy design. Technovation, 25(6), 609-619.

Kline, S. J., \& Rosenberg, N. (1986). An overview of innovation. In R. Landau \& N. Rosenberg (Eds.), The positive sum strategy: Harnessing technology for economic growth (pp. 275-306). Washington, D.C.: National Academy Press.

Koberg, C. S., Detienne, D. R., \& Heppard, K. A. (2003). An empirical test of environmental, organizational, and process factors affecting incremental and radical innovation. The Journal of High Technology Management Research, 14(1), 21-45.

Komninos, N. (2002). Intelligent cities: innovation, knowledge systems and digital spaces. London: Routledge. 
Kreiner, K., \& Schultz, M. (1993). Informal collaboration in R \& D. The formation of networks across organizations. Organization Studies, 14(2), 189-209.

Krugman, P. R. (1991 (1993)). Geography and trade. Cambridge, MA: MIT Press.

Krugman, P. R. (1994). Competitiveness: a dangerous obsession. Foreign affairs, 37(2), 2844.

Kuhlmann, S. (2003). Evaluation of research and innovation policies: a discussion of trends with examples from Germany. International Journal of Technology Management, 26(2), 131-149.

La Porte, T. R. (1965). Conditions of strain and accommodation in industrial research organizations. Administrative Science Quarterly, 10(1), 21-38.

Lacasse, F. (1995). Mythes, savoirs et décisions politiques. Paris: PUF.

Lacouette-Fougère, C., \& Lascoumes, P. (2013). Les scènes multiples de l'évaluation - les problèmes récurrents de son institutionnalisation. SciencesPo, LIEPP.

Lallemand, A.-S. (2013). L'évaluation de la performance des réseaux territorialisés d'organisations : le cas des pôles de compétitivité français. Université PanthéonAssas, Paris.

Larsen, H. (2005). Foreign policy and discourse analysis: France, Britain and Europe. London: Routledge.

Lawson, C., \& Lorenz, E. (1999). Collective Learning, Tacit Knowledge and Regional Innovative Capacity. Regional Studies, 33(4), 305-317.

Le Barzic, M.-V., \& Distinguin, S. (2010). La Cantine : Un espace de rencontres physiques au coeur de l'économie virtuelle. Séminaire de l'Ecole de Paris du management.

Learmonth, D., Munro, A., \& Swales, J. K. (2003). Multi-sectoral Cluster Modelling: The Evaluation of Scottish Enterprise Cluster Policy. European Planning Studies, 11(5), 567-584.

Lechner, C., \& Dowling, M. (2003). Firm networks: external relationships as sources for the growth and competitiveness of entrepreneurial firms. Entrepreneurship \& Regional Development, 15(1), 1-26.

Lefebvre, P. (2008). Pôles de compétitivité et Centres de transfert: comment les articuler? Réalités industrielles(2), 88-94.

Lefebvre, P. (2013). Organising deliberate innovation in knowledge clusters: from accidental brokering to purposeful brokering processes. International Journal of Technology Management, 63(3), 212-243.

Lefebvre, P., \& Masson, A. (2011). Regards sur les politiques de clusters en Allemagne. Paris: Mines ParisTech \& Ministère de l'Enseignement supérieur et de la Recherche.

Leonard-Barton, D. (1990). A dual methodology for case studies: synergistic use of a longitudinal single site with replicated multiple sites. Organization Science, 1(3), 248266.

Lepage, V. (2009). L'évaluation externe comme outil de pilotage de la politique de clustering : Leçons tirées de 5 années de pratique en région Walonne. Paper presented at the conference: Pôles de compétitivité et développement économique régional.

Lequiller, F., \& Blades, D. (2006). Understanding National Accounts. Paris: OECD.

Leseure, M. J., Bauer, J., Birdi, K., Neely, A., \& Denyer, D. (2004a). Adoption of promising practices: a systematic review of the evidence. International Journal of Management Reviews, 5(3, Ӓê4), 169-190.

Leseure, M. J., Bauer, J., Birdi, K., Neely, A., \& Denyer, D. (2004b). Adoption of promising practices: a systematic review of the evidence. International Journal of Management Reviews, 5(3-4), 169-190.

Lester, R. K., \& Piore, M. J. (2006). Innovation - The Missing Dimension. Cambridge, MA: Harvard University Press. 
Leydesdorff, L. (2000). The triple helix: an evolutionary model of innovations. Research Policy, 29(2), 243-255.

Li, J., \& Geng, S. (2012). Industrial clusters, shared resources and firm performance. Entrepreneurship and Regional Development, 24(5-6), 357-381.

Lissoni, F. (2001). Knowledge codification and the geography of innovation: the case of Brescia mechanical cluster. Research Policy, 30(9), 1479-1500.

Liyanage, S. (1995). Breeding innovation clusters through collaborative research networks. Technovation, 15(9), 553-567.

Longhi, C. (1999). Networks, collective learning and technology development in innovative high technology regions: the case of Sophia-Antipolis. Regional Studies, 33(4), 333342 .

Longhi, C., \& Quéré, M. (1993). Innovative networks and the technopolis phenomenon: the case of Sophia Antipolis. Environment and Planning C, 11, 317-317.

Lucas, R. E. (1988). On the mechanics of economic development. Journal of monetary economics, 22(1), 3-42.

Lundequist, P., \& Power, D. (2002). Putting porter into practice? Practices of regional cluster building: Evidence from Sweden. European Planning Studies, 10(6), 685-704.

Lundvall, B.-А̊. (Ed.). (1992). National Systems of Innovation: Towards a Theory of Innovation and Interactive Learning. London: Pinter.

Lynall, M. D., Golden, B. R., \& Hillman, A. J. (2003). Board composition from adolescence to maturity: A multitheoretic view. Academy of Management Review, 28(3), 416-431.

MacKinnon, D., Chapman, K., \& Cumbers, A. (2004). Networking, trust and embeddedness amongst SMEs in the Aberdeen oil complex. Entrepreneurship \& Regional Development, 16(2), 87-106.

MacNeill, S., \& Steiner, M. (2010). Leadership of Cluster policy: lessons from the Austrian province of Styria. Policy studies, 31(4), 441-455.

Maguire, K., \& Davies, A. (2007). Competitive regional clusters: national policy approaches: OECD - Organisation for Economic Co-operation and Development.

Maier, G., \& Tödtling, F. (2002). Regional- und Stadtökonomik 2: Regionalentwicklung und Regionalpolitik (2 ed.). Wien - New York: Springer.

Maillat, D., \& Lecoq, B. (1992). New technologies and transformation of regional structures in Europe: the role of the milieu. Entrepreneurship \& Regional Development, 4(1), 120.

Maillat, D., Lecoq, B., Nemeti, F., \& Pfister, M. (1995). Technology district and innovation: the case of the Swiss Jura Arc. Regional Studies, 29(3), 251-263.

Maillat, D., \& Perrin, J.-C. (Eds.). (1992). La relation des entreprises innovatrices avec leur milieu. Neuchâtel: Université de Neuchâtel.

Maillat, D., Quévit, M., \& Senn, L. (Eds.). (1993). Réseaux d'innovation et milieux innovateurs: un pari pour le développement régional. Neuchâtel: Université de Neuchâtel.

Malaterre-Vaille, L. (2010). Les pôles d'éxcellence comme facteur de compétitivité et d'attractivité des territoires: l'éexemple de la métropole lilloise. EchoGéo.

Mans, P., Alkemade, F., Van der Valk, T., \& Hekkert, M. P. (2008). Is cluster policy useful for the energy sector? Assessing self-declared hydrogen clusters in the Netherlands. Energy policy, 36(4), 1375-1385.

March, J. G. (1962). The business firm as a political coalition. The Journal of Politics, 24(04), 662-678.

March, J. G. (1991). Exploration and exploitation in organizational learning. Organization Science, 2(1), 71-87. 
March, J. G., \& Olsen, J. P. (1984). The new institutionalism: organizational factors in political life. The American Political Science Review, 78(3), 734-749.

Marcon, A. (2008). Les pôles de compétitivité: faire converger performance et dynamique territoriale. Paris: Conseil économique et social.

Markusen, A. (1996). Sticky places in slippery spaces: A typology of industrial districts. Economic Geography, 72(3), 293-313.

Markusen, A. (2003). Fuzzy Concepts, Scanty Evidence, Policy Distance: The Case for Rigour and Policy Relevance in Critical Regional Studies. Regional Studies, 37(6\&7), 701-717.

Marshall, A. (1890 (1920)). Principles of economics (8th ed.). London: Macmillan and Co., Ltd. (online version: http://www.econlib.org/library/Marshall/marPCover.html ; accessed 02/10/2010).

Martin, P., Mayer, T., \& Mayneris, F. (2011). Public support to clusters A firm level study of French "Local Productive Systems". Regional Science and Urban Economics, 41(2), 108-123.

Martin, R., \& Sunley, P. (2003). Deconstructing clusters: chaotic concept or policy panacea? Journal of Economic Geography, 3(1), 5-35.

Martin, R., \& Sunley, P. (2007). Complexity thinking and evolutionary economic geography. Journal of Economic Geography, 7(5), 573-601.

Martinez, A., Belso-Martinez, J. A., \& Mas-Verdu, F. (2012). Industrial clusters in Mexico and Spain: Comparing inter-organizational structures within context of change. Journal of Organizational Change Management, 25(5), 657-681.

Maskell, P., Bathelt, H., \& Malmberg, A. (2006). Building Global Knowledge Pipelines: The Role of Temporary Clusters. European Planning Studies, 14(8), 997 - 1013.

Maskell, P., \& Malmberg, A. (1999). Localised learning and industrial competitiveness. Cambridge journal of economics, 23(2), 167-185.

Matteaccioli, A., \& Tabariés, M. (2006). Historique du GREMI - Les apports du GREMI à l'analyse territoriale de l'innovation. In R. Camagni \& D. Maillat (Eds.), Milieux innovateurs - Théorie et politiques (pp. 3-19). Paris: Economica.

Matthews, R. C. O. (1986). The Economics of Institutions and the Sources of Growth. The Economic Journal, 96(384), 903-918.

McDonald, F., Huang, Q., Tsagdis, D., \& Tüselmann, H. J. (2007). Is there evidence to support Porter-type cluster policies? Regional Studies, 41(1), 39-49.

Mceldowney, J. J. (1997). Policy evaluation and the concepts of deadweight and additionality. A Commentary. Evaluation, 3(2), 175-188.

McEvily, B., \& Zaheer, A. (2004). Arichtects of Trust: The Role of Network Facilitators in Geographical Clusters. In R. M. Kramer \& K. S. Cook (Eds.), Trust and distrust in organizations: Dilemmas and approaches. New York: Russell Sage Foundation Publications.

Mendel, A., \& Bardet, M. (2009). Quelle gouvernance pour les pôles de compétitivité constitués de PME. Revue française de gestion (190), 123-142.

Menu, S. (2010). La ressource identitaire territoriale des partenariats publics- privés et des clusters: Usages et rôles en Bavière, en Bretagne et dans le Nord-Est de l'Angleterre depuis 1980. Revue Internationale de Politique Comparée, 17(3), 157-174.

Menu, S. (2011). Les pôles de compétitivité, un nouveau pilotage de la politique industrielle? Bilan en Ile-de-France. Politiques et management public, 28(1), 105-121.

Menu, S. (2012). The role of cluster policy on leadership: Evidence from two Pôles de compétitivité. Environment and Planning C: Government and Policy, 30(5), 816-834.

Menzel, M.-P., \& Fornahl, D. (2010). Cluster life cycles--dimensions and rationales of cluster evolution. Industrial and Corporate Change, 19(1), 205-238. 
Mérindol, V., Gallié, E.-P., Glaser, A., Lefebvre, P., Pallez, F., \& Weil, T. (2010). Comment mesurer la performance des pôles de compétitivité français ? Paper presented at the European Localized Innovation Observatory Conference (EUROLIO).

Merlin, J.-C. (2003). Rapport du Comité de coordination des plates-formes de Réseaux de recherche et d'innovation technologique. Paris: Ministère des Finances.

Mesny, A., \& Mailhot, C. (2012). Control and traceability of research impact on practice: reframing the 'relevance gap' debate in management.M@n@gement, 15(2), 181-207.

Mesquita, L. F. (2007). Starting over when the bickering never ends: Rebuilding aggregate trust among clustered firms through trust facilitators. Academy of Management Review, 32(1), 72-91.

Meyer, J. W., \& Rowan, B. (1977). Institutionalized organizations: Formal structure as myth and ceremony. American Journal of Sociology, 83(2), 340-363.

Miller, R., \& Cote, M. (1985). Growing the Next Silicon Valley. Harvard Business Review, 63(4), 114-123.

Ministère. (2002). Les Réseaux de recherche et d'innovation technologiques. Bilan au 31 décembre 2002. Paris: Ministère délégué à la Recherche et aux Nouvelles Technologies.

Mistri, M. (1999). Industrial districts and local governance in the Italian experience. Human Systems Management, 18(2), 131-140.

Molina-Morales, F. X., \& Martinez-Fernandez, M. T. (2003). The impact of industrial district affiliation on firm value creation. European Planning Studies, 11(2), 155-170.

Morgan, K., \& Nauwelaers, C. (2003 (1999)). A regional perspective on innovation: From theory to strategy. In K. Morgan \& C. Nauwelaers (Eds.), Regional Innovation Strategies: The Challenge for Less-favoured Regions. London: Routledge.

Morris, L. (2002). Social Design: The Link Between Facility Design, Organization Design, and Corporate Strategy Walnut Creek, California: InnovationLabs LLC

Morrison, A., \& Rabellotti, R. (2009). Knowledge and information networks in an Italian wine cluster. European Planning Studies, 17(7), 983-1006.

Motoyama, Y. (2008). What Was New About the Cluster Theory? What Could It Answer and What Could It Not Answer? Economic Development Quarterly, 22(4), 353-363.

Muller, E. (2011). Clusters et politiques de clusters : regards croisés sur l'Allemagne et le Canada. Paris: Séminaire de l'Observatoire des pôles de compétitivité, Mines ParisTech.

Mulrow, C. D. (1994). Rationale for systematic reviews. BMJ: British Medical Journal, 309(6954), 597-599.

Murphy, J. T. (2006). Building trust in economic space. Progress in Human Geography, 30(4), 427-450.

Nathan, M., \& Overman, H. (2013). Agglomeration, clusters, and industrial policy. Oxford Review of Economic Policy, 29(2), 383-404.

Nauwelaers, C. (2001). Path-dependency and the role of institutions in cluster policy generation: Nordregio Report.

Nauwelaers, C., \& Pellegrin, J. (2004). Evaluation des expériences de clustering en Région wallonne. Maastricht: MERIT, Maastricht University.

Nietzsche, F. (1969). Ecco homo. New York: Vintage.

Niosi, J. (2011). Building innovation systems: an introduction to the special section. Industrial and Corporate Change, 20(6), 1637-1643.

Nishimura, J., \& Okamuro, H. (2011a). R\&D productivity and the organization of cluster policy: An empirical evaluation of the Industrial Cluster Project in Japan. The Journal of Technology Transfer, 36(2), 117-144. 
Nishimura, J., \& Okamuro, H. (2011b). Subsidy and networking: The effects of direct and indirect support programs of the cluster policy. Research Policy, 40(5), 714-727.

Nonaka, I. (1991). The knowledge creating company. Harvard Business Review, 69(6), 96104.

Nonaka, I., \& Konno, N. (1998). The Concept of "Ba": Building a foundation for knowledge creation. California Management Review, 40(3), 40-54.

Nonaka, I., \& Takeuchi, H. (1995). The knowledge-creating company. New York: Oxford University Press.

North, D. C. (1986). The New Institutional Economics. Journal of Institutional and Theoretical Economics (JITE) / Zeitschrift für die gesamte Staatswissenschaft, 142(1), 230-237.

North, D. C. (1989). Institutions and economic growth: An historical introduction. World development, 17(9), 1319-1332.

North, D. C. (1990). Institutions, institutional change and economic performance. Cambridge: Cambridge University Press.

North, D. C. (1991). Institutions. Journal of Economic Perspectives, 5(1), 97-112.

Noteboom, B. (2004). Inter-firm Collaboration, Learning \& Networks. An Integrated Approach. London and New York: Routledge.

Oakey, R. P. (1984). Innovation and regional growth in small high technology firms: evidence from Britain and the USA. Regional Studies, 18(3), 237-251.

Oakey, R. P., Thwaites, A. T., \& Nash, P. (1980). The regional distribution of innovative manufacturing establishments in Britain. Regional Studies, 14(3), 235-253.

OECD. (1999). Boosting Innovation: The Cluster Approach. Paris: OECD.

OECD. (2001). Enhancing SME Competitiveness: The OECD Bologna Ministerial Conference. Paris: OECD Publishing.

OECD. (2002). Frascati Manual 2002: Proposed Standard Practice for Surveys on Research and Experimental Development. Paris: OECD.

OECD. (2004). Les partenariats public-privé pour la recherche et l'innovation: une évaluation de l'expérience française. Paris: OECD.

OECD. (2005). Business Clusters: Promoting Enterprise in Central and Eastern Europe. Paris: OECD Local Economic and Employment Development (LEED) Programme.

OECD. (2007). Competitive Regional Clusters: National Policy Approaches. Paris: OECD.

OECD. (2009). Clusters, Innovation and Entrepreneurship. Paris: OECD Local Economic and Employment Development (LEED) Programme.

OECD. (2010). Regional Development Policies in OECD Countries. Paris: OECD.

OECD, \& Eurostat. (2005). Oslo Manual - Guidelines for collecting and interpreting innovation data. Paris: OECD \& Eurostat.

Ohlin, B. (1933). Interregional and International Trade. Cambridge: Harvard University Press.

Ottati, G. D. (1994). Trust, interlinking transactions and credit in the industrial district. Cambridge journal of economics, 18(6), 529-546.

Outhwaite, W., \& Turner, S. P. (2007). The SAGE handbook of social science methodology. London: SAGE Publications Ltd.

Pallez, F. (2014a). La recherche partenariale est-elle soluble dans les politiques publiques de recherche? Paper presented at the Annales des Mines-Réalités industrielles.

Pallez, F. (2014b). La recherche partenariale est-elle soluble dans les politiques publiques de recherche? Paper presented at the Annales des Mines - Réalités industrielles.

Paniccia, I. (2006). Cutting Through the Chaos: Towards a new typology of industrial districts and clusters. In B. T. Asheim, P. Cooke \& R. Martin (Eds.), Clusters and 
regional development : critical reflections and explorations (pp. 90-114). New York: Routledge.

Pellenbarg, P. H., \& Van Steen, P. J. (2001). Making space, sharing space: The new memorandum on spatial planning in the Netherlands. Tijdschrift voor economische en sociale geografie, 92(4), 503-512.

Pellenbarg, P. H., \& Van Steen, P. J. (2003). Spatial perspectives on firm dynamics in the Netherlands. Tijdschrift voor economische en sociale geografie, 94(5), 620-630.

Peng, M. W. (2004). Outside directors and firm performance during institutional transitions. Strategic Management Journal, 25(5), 453-471.

Penrose, E. (1959). The Theory of the Growth of the Firm. New York: John Wiley and Sons.

Perrat, J. (2007). Les pôles de compétitivité. Ceras - revue, Projet $N^{\circ} 301$. Retrieved from http://www.ceras-projet.com/index.php?id=2744

Perret, B. (2001). L'Evaluation des politiques publiques. Paris: La Découverte.

Perret, B. (2008). L'évaluation des politiques publiques (2 ed.). Paris: La Découverte.

Perret, B. (2008). L'Evaluation des politiques publiques: Entre culture du résultat et apprentissage collectif. Esprit (350), 142-159.

Perry, M. (2005). Clustering small enterprise: lessons from policy experience in New Zealand. Environment and Planning C: Government \& Policy, 23(6), 833-850.

Perry, M. (2007). Business environments and cluster attractiveness to managers. Entrepreneurship and Regional Development, 19(1), 1-24.

Peters, D. J. (2005). Using labor-based industry complexes for workforce development in Missouri. Economic Development Quarterly, 19(2), 138-156.

Pfeffer, J. (1972). Size and composition of corporate boards of directors: The organization and its environment. Administrative Science Quarterly, 17(2), 218-228.

Pfeffer, J. (1973). Size, composition, and function of hospital boards of directors: A study of organization-environment linkage. Administrative Science Quarterly, 18(3), 349-364.

Pfeffer, J., \& Salancik, G. R. (2003 (1978)). The external control of organizations: a resource dependence perspective. Stanford: Stanford University Press.

Piore, M. J., \& Sabel, C. F. (1984). The second industrial divide. Possibilities for Prosperity. New York: Basic Book.

Pittaway, L., \& Cope, J. (2007). Entrepreneurship Education A Systematic Review of the Evidence. International Small Business Journal, 25(5), 479-510.

Pittaway, L., Robertson, M., Munir, K., Denyer, D., \& Neely, A. (2004). Networking and innovation: a systematic review of the evidence. International Journal of Management Reviews, 5(3, Ä̂े4), 137-168.

Plottu, B., \& Plottu, E. (2009). Contraintes et vertus de l'évaluation participative. Revue française de gestion (192), 31-58.

Plunket, A., \& Torre, A. (2009). Les poles de compétitivité ou le retour ambigu des déclinaisons locales de la politique industrielle française. Economia e politica industriale(3).

Polanyi, M. (1966). The Tacit Dimension. Chicago: The University Of Chicago Press.

Pollard, A. (2009). Field of screams: difficulty and ethnographic fieldwork. Anthropology Matters, 11(2).

Pommier, P., \& Boilève, M. (2002). Les systèmes productifs locaux. Paris: La documentation française.

Popp, A., Toms, S., \& Wilson, J. (2006). Industrial districts as organizational environments: Resources, networks and structures. Management \& Organizational History, 1(4), 349-370.

Popper, K. (1959). The logic of scientific discovery. New York: Basic Books. 
Porcher, S., Glaser, A., \& Saussois, J.-M. (2010). Reframing industrial policy. Paper presented at the Society for the Advancement of Socio-Economics (SASE).

Porter, M. E. (1976). Interbrand choice, strategy, and bilateral market power. Cambridge, MA: Harvard University Press.

Porter, M. E. (1980 (1998)). Competitive strategy: Techniques for analyzing industries and competitors. New York: The Free Press.

Porter, M. E. (1981). The contributions of industrial organization to strategic management. Academy of Management Review, 6(4), 609-620.

Porter, M. E. (1985 (1998)). Competitive advantage: creating and sustaining superior performance. New York: The Free Press.

Porter, M. E. (1990). The Competitive Advantage of Nations. Harvard Business Review, March-April, 73-91.

Porter, M. E. (1990 (1998)). The Competitive Advantage of Nations. London: Macmillan (ebook version, no pager numbers).

Porter, M. E. (1991). Canada at the crossroads: The reality of a new competitive environment (No. 0662192184). Ottawa: Business Council on National Issues and Minister of Supply and Services.

Porter, M. E. (1998a). The Adam Smith address: Location, clusters, and the "new" microeconomics of competition. Business Economics, 33(1), 7-13.

Porter, M. E. (1998b). Clusters and Competition. New Agendas for Companies, Governments, and Institutions. In M. E. Porter (Ed.), On Competition. Boston: Harvard Business School.

Porter, M. E. (1998c). Clusters and the new economics of competition. Harvard Business Review, Nov.-Dec., 77-90.

Porter, M. E. (2000a). Location, Competition, and Economic Development: Local Clusters in a Global Economy. Economic Development Quarterly, 14(1), 15-34.

Porter, M. E. (2000b). Locations, clusters, and company strategy. In G. L. Clark, M. P. Feldman \& M. S. Gertler (Eds.), The Oxford handbook of economic geography (pp. 253-274). Oxford: Oxford University Press.

Porter, M. E. (2001). Clusters of innovation: Regional Foundations of U.S. Competitiveness. Washington: Council on Competitiveness.

Porter, M. E. (2008). Clusters and Competition: New Agendas for Companies, Governments, and Institutions. In M. E. Porter (Ed.), On Competition (pp. 213-304). Boston: Harvard Business School Publishing.

Porter, M. E. (Ed.). (1998d). On Competition. Boston: Harvard Business Press.

Porter, M. E., \& Stern, S. (2001). Innovation: Location Matters. MIT Sloan management review, 42(4), 28-36.

Potter, P. (2005). Facilitating Transferable Learning through Cluster Evaluation : New Opportunities in the Development Partnerships of the EU 'EQUAL' Programme. Evaluation, 11(2), 189-205.

Powell, W. W. (1998). Learning From Collaboration: Knowledge and Networks in the Biotechnology and Pharmaceutical Industries. California Management Review, 40(3), 228-240.

Powell, W. W., Koput, K. W., \& Smith-Doerr, L. (1996). Interorganizational collaboration and the locus of innovation: Networks of learning in biotechnology. Administrative Science Quarterly, 41(1), 116-145.

Powell, W. W., \& Snellman, K. (2004). The Knowledge Economy. Annual Review of Sociology, 30.

Provan, K. G. (1980). Board power and organizational effectiveness among human service agencies. Academy of Management Journal, 23(2), 221-236. 
Provan, K. G., Fish, A., \& Sydow, J. (2007). Interorganizational networks at the network level: A review of the empirical literature on whole networks. Journal of Management, 33(3), 479-516.

Putnam, R. D. (1993). Making Democracy Work: Civic Traditions in Modern Italy. Princeton, New Jersey: Princeton University Press.

Pyke, F., Becattini, G., \& Sengenberger, W. (Eds.). (1990). Industrial Districts and Inter-firm Cooperation in Italy. Geneva: International Labour Organisation (International Institute for Labour Studies).

Raines, P. (2003). Cluster behaviour and economic development: new challenges in policy evaluation. International Journal of Technology Management, 26(2), 191-204.

Rallet, A., \& Torre, A. (2005). Proximity and localization. Regional Studies, 39(1), 47-60.

Reilly, T. (2001). Collaboration in action: An uncertain process. Administration in Social Work, 25(1), 53-74.

Reinau, K. H., \& Dalum, B. (2008). The Role of Governance in Cluster Typologies: A Missing Link. Paper presented at the DRUID-DIME PhD Conference, Rebild, Denmark.

Retour, D. (2009a). La rencontre précède l'idée. Revue française de gestion(10), 163-168.

Retour, D. (2009b). Minalogic est un véritable écosystéme d'innovation. Revue française de gestion (10), 169-177.

Retour, D. (2009c). Pôles de compétitivité, propos d'étape. Revue française de gestion (190), 93-99.

Ricardo, D. (1817 (1821)). On the Principles of Political Economy and Taxation. London: John Murray (online version: http://www.econlib.org/library/Ricardo/ricP.html ; accessed 08/05/2014).

Rocha, H. O. (2013). Entrepreneurship and regional development: The role of clusters. New York: Palgrave Macmillan.

Rogers, E. M., \& Larsen, J. K. (1984). Silicon Valley fever: Growth of high technology culture. New York: Basic Books.

Romer, P. M. (1986). Increasing returns and long-run growth. The journal of political economy, 94(5), 1002-1037.

Romer, P. M. (1994). The origins of endogenous growth. The Journal of Economic Perspectives, 8(1), 3-22.

Rosch, E. (1999). Principles of categorization. In E. Margolis \& S. Laurence (Eds.), Concepts: core readings (pp. 189-206). Cambridge, MA: MIT Press.

Rosenberg, D. (2002). Cloning Silicon Valley: The Next Generation High Tech Hotspots. London: Pearson Education Ltd.

Rosenberg, N. (1982). Inside the black box: technology and economics. Cambridge: Cambridge University Press.

Rosenfeld, S. (2005). Industry clusters: business choice, policy outcome, or branding strategy? Journal of New Business Ideas and Trends, 3(2), 4-13.

Rugman, A. M. (1992). Porter takes the wrong turn. Business Quarterly, 56(3), 59-64.

Russo, M., \& Rossi, F. (2009). Cooperation networks and innovation: A Complex Systems Perspective to the Analysis and Evaluation of Regional Innovation Policy Programme. Evaluation, 15(1), 75-99.

Rutherford, T. D., \& Holmes, J. (2007). "We simply have to do that stuff for our survival": labour, firm innovation and cluster governance in the Canadian automotive parts industry. Antipode, 39(1), 194-221.

Ryan, J. C., \& Hurley, J. (2007). An empirical examination of the relationship between scientists' work environment and research performance. R\&D Management, 37(4), 345-354. 
Sabel, C. F. (1984). Industrial Reorganization and Social Democracy in Austria. Industrial Relations: A Journal of Economy and Society, 23(3), 344-361.

Sabel, C. F. (1993). Studied trust: building new forms of cooperation in a volatile economy. Human Relations, 46(9), 1133-1170.

Sadler, D. (2004). Cluster evolution, the transformation of old industrial regions and the steel industry supply chain in North East England. Regional Studies, 38(1), 55-66.

Saives, A.-L., \& Desmarteau, R. H. (2005). Comprendre l'ancrage territorial d'une bioindustrie: le cas de la grappe biopharmaceutique de la région de Montréal (Canada). Revue internationale PME: économie et gestion de la petite et moyenne entreprise, 18(2), 75-108.

Saives, A.-L., Ebrahimi, M., Desmarteau, R. H., \& Garnier, C. (2007). Knowledge creation dynamics and financial governance: crisis of growth in biotech firms. Challenges in the Management of New Technologies, 1, 17.

Salazar, M., \& Holbrook, A. (2007). Canadian science, technology and innovation policy: the product of regional networking? Regional Studies, 41(8), 1129-1141.

Salman, N., \& Saives, A.-L. (2005). Indirect networks: an intangible resource for biotechnology innovation. R\&D Management, 35(2), 203-215.

Sanderson, I. (2001). Performance management, evaluation and learning in 'modern' local government. Public Administration, 79(2), 297-313.

Santisteban, M. A. (2006). Business systems and cluster policies in the Basque Country and Catalonia (1990-2004). European Urban and Regional Studies, 13(1), 25-39.

Saublens, C. (2007). Regional Research Intensive Clusters and Science Parks. Brussels: European Commission.

Saublens, C., Bonas, G., Husso, K., Komarek, P., Koschatzky, K., Oughton, C., et al. (2007). Regional Research Intensive Clusters and Science Parks. Brussels: European Commission.

Saussois, J.-M. (1988). L'apport de la démarche comparative: universitaires américaines et fançais à la recherche de la politique industrielle France-USA: les crises du travail et de la production (pp. 145-158). Paris: Méridiens Klincksieck.

Saussois, J.-M. (1990). L'Etat dans l'industrie américaine. In C. Durand (Ed.), De l'économie planifiée à l'économie de marché: l'intervention de l'Etat dans l'industrie, comparaisons internationales (pp. 167-196). Paris: Publisud.

Saussois, J.-M. (2000). Presentation of Experts Reports on the Management of Knowledge Knowledge management in the learning society: Centre for Educational Research and Innovation; OECD - Organisation for Economic Co-operation and Development.

Saussois, J.-M. (2008). Théories des organisations et management public: quel rapport? Politiques et management public, 26(3), 101-109.

Saxenian, A. (1983). The genesis of silicon valley. Built Environment, 9(1), 7-17.

Saxenian, A. (1990). Regional Networks and the Resurgence of Silicon Valley. California Management Review, 33(1).

Saxenian, A. (1991). The origins and dynamics of production networks in Silicon Valley. Research Policy, 20(5), 423-437.

Saxenian, A. (1994). Regional advantage: culture and competition in Silicon Valley and Route 128. Cambrige, MA: Harvard University Press.

Scandella, J.-S. (2008). Les pôles, réseaux d'excellence et d'innovation: enquête sur les pôles de compétitivité. Paris: Ed. Autrement.

Schmidt, J. C. (2007). Knowledge politics of interdisciplinarity. Innovation, 20(4), 313-328.

Schmiedeberg, C. (2010). Evaluation of Cluster Policy: A Methodological Overview. Evaluation, 16(4), 389-412. 
Schmitt, A. (2011). Les pôles de compétitivité, moteurs de la croissance verte. Responsabilité et environnement (1), 98-104.

Schofield, J. (2001). Time for a revival? Public policy implementation: a review of the literature and an agenda for future research. International Journal of Management Reviews, 3(3), 245-263.

Schwab, D. P. (2005). Research methods for organizational studies. Mahwah, New Jersey: Lawrence Erlbaum.

Scott, A. J. (1988a). Flexible production systems and regional development: the rise of new industrial spaces in North America and western Europe. International Journal of Urban and Regional Research, 12(2), 171-186.

Scott, A. J. (1988b). New Industrial Spaces: Flexible Production Organization and Regional Development in North America and Western Europe. London: Pion.

Scott, W. R. (1987). The adolescence of institutional theory. Administrative Science Quarterly, 32(4), 493-511.

Sellar, C., Emilova, M., Petkova-Tancheva, C. D., \& Mcneil, K. (2011). Cluster Policies in Bulgaria: European Integration, Postsocialist Dynamics and Local Level Initiatives. International Journal of Urban and Regional Research, 35(2), 358-378.

Selznick, P. (1949). TVA and the grass roots: A study of politics and organization. Berkley: Univ of California Press.

Sennett, R. (1992 (1977)). The Fall of Public Man. New York: WW Norton \& Company.

Sennett, R. (2012). Together: The Rituals, Pleasures and Politics of Cooperation. New Haven: Yale University Press.

Shapira, P., \& Kuhlmann, S. (2003). Learning from science and technology policy evaluation: Experiences from the United States and Europe. Cheltenham, UK: Edward Elgar Publishing.

Sharf, S. (2012). The Ten Most Innovative Companies In Europe. Forbes. Retrieved from http://www.forbes.com/sites/samanthasharf/2012/09/05/the-ten-most-innovativecompanies-in-europe/

Shearmur, R. (2011a). Creativity, innovation and regional policies. Paper presented at the Séminaire evoReg.

Shearmur, R. (2011b). Innovation, regions and proximity: From neo-regionalism to spatial analysis. Regional Studies, 45(9), 1225-1243.

Shipp, S., Chang, C., \& Wisniewski, L. (2005). Evaluation Best Practices and Results: The Advanced Technology Program. Gaithersburg, Maryland: National Institute of Standards and Technology.

Simon, H. A. (1955). A behavioral model of rational choice. The quarterly journal of economics, 69(1), 99-118.

Skelcher, C. (2000). Changing images of the state: overloaded, hollowed-out, congested. Public policy and administration, 15(3), 3-19.

Smith-Doerr, L., \& Powell, W. W. (2005). Networks and economic life. In N. Smelser \& R. Swedberg (Eds.), The handbook of economic sociology (Vol. 2, pp. 379-402). Princeton, NJ: Russell Sage Foundation/Princeton University Press.

Snowdon, B. (2006). The Enduring Elixir of Economic Growth. World Economics, 7(1), 73130.

Solow, R. M. (1956). A contribution to the theory of economic growth. The quarterly journal of economics, 70(1), 65-94.

Solow, R. M. (1957). Technical Change and the Aggregate Production Function. The review of Economics and Statistics, 39(3), 312-320.

Sölvell, Ö. (2008). Clusters - Balancing evolutionary and constructive forces. Stockholm: Ivory Tower Publishers. 
Sölvell, Ö., Lindqvist, G., \& Ketels, C. (2003). The Cluster Initiative Greenbook. Stockholm: ๘ם】 Ivory Tower Publishers.

Sölvell, Ö., \& Williams, M. (2013). Building the Cluster Commons. An Evaluation of 12 Cluster Organizations in Sweden 2005-2012. Stockholm: Ivory Tower Publishers.

Sotarauta, M. (2012). Policy learning and the 'cluster-flavoured innovation policy' in Finland. Environment and Planning C: Government and Policy, 30(5), 780-795.

St. John, C. H., \& Pouder, R. W. (2006). Technology clusters versus industry clusters: Resources, networks, and regional advantages. Growth and Change, 37(2), 141-171.

Staehler, T., Dohse, D., \& Cooke, P. (2007). Evaluation der Fördermaßnahmen BioRegio und BioProfile: Institut für Weltwirtschaft an der Universität Kiel (IfW), Centre for Advanced Studies in the Social Sciences (CASS), Consulting für Innovations- und Regionalanalysen (CIR).

Stame, N. (2009). Avantages et inconvénients des différentes méthodes d'évaluation : comment choisir? In S. Trosa (Ed.), Evaluer les politiques publiques pour améliorer l'action publique - Une perspective internationale (pp. 35-58). Paris: Comité pour l'histoire économique et financière de la France.

Star, S. L., \& Griesemer, J. R. (1989). Institutional ecology, 'translations' and boundary objects: Amateurs and professionals in Berkeley's Museum of Vertebrate Zoology, 1907-39. Social studies of science, 19(3), 387-420.

Steinle, C., Schiele, H., \& Mietzner, K. (2007). Merging a firm-centred and a regional policy perspective for the assessment of regional clusters: concept and application of a "dual" approach to a medical technology cluster. European Planning Studies, 15(2), 235-251.

Sternberg, R., Kiese, M., \& Stockinger, D. (2010). Cluster policies in the US and Germany: Varieties of capitalism perspective on two high-tech states. Environment and Planning C: Government and Policy, 28(6), 1063-1082.

Storper, M. (1995). The resurgence of regional economies, ten years later the region as a nexus of untraded interdependencies. European Urban and Regional Studies, 2(3), 191-221.

Storper, M. (1997). The regional world: territorial development in a global economy. New York: The Guilford Press.

Storper, M., \& Christopherson, S. (1987). Flexible specialization and regional industrial agglomerations: the case of the US motion picture industry. Annals of the Association of American Geographers, 77(1), 104-117.

Storper, M., \& Venables, A. J. (2004). Buzz: face-to-face contact and the urban economy. Journal of Economic Geography, 4(4), 351-370.

Study Group - Washington Association of Scientists. (1947). Toward a National Science Policy? Science, 106(2756), 385-387.

Sullivan, H., \& Skelcher, C. (2002). Working across boundaries: collaboration in public services. Basingstoke: Palgrave Macmillan.

Swan, T. W. (1956). Economic growth and capital accumulation. Economic record, 32(2), 334-361.

Swann, G. M. P. (2009). The Economics of Innovation: An Introduction. Cheltenham: Edward Elgar Publishing.

Swedberg, R. (2003). Principles of economic sociology. Princeton: Princeton University Press.

Swords, J. (2013). Michael Porter's cluster theory as a local and regional development tool: The rise and fall of cluster policy in the UK. Local Economy, 28(4), 369-383.

Tallman, S., Jenkins, M., Henry, N., \& Pinch, S. (2004). Knowledge, clusters and competitive advantage. Academy of Management Review, 29(2), 258-271. 
The High Level Advisory Group on Clusters. (2008). The European Cluster Memorandum: Promoting European Innovation through Clusters: An Agenda for Policy Action

Therme, J. (2008). Minalogic et l'écosystéme économique grenoblois. Réalités industrielles(2), 29-33.

Thibault, G. (2008). Quelle stratégie industrielle pour la France face à la mondialisation? Paris: Editions Technip.

Thoenig, J.-C. (2002). L'évaluation en actes : Leçons et perspectives. Politiques et managmenet public, 20(4), 33-50.

Thorpe, R., Holt, R., Macpherson, A., \& Pittaway, L. (2005). Using knowledge within small and medium-sized firms: A systematic review of the evidence. International Journal of Management Reviews, 7(4), 257-281.

Thurow, L. C. (1992 (1993)). Head to head: The coming economic battle among Japan, Europe, and America. New York: Warner Books.

Time Magazine. (1983). The Computer, Machine of the Year: The computer moves in, 3rd of January.

Tödtling, F., \& Kaufmann, A. (2001). The role of the region for innovation activities of SMEs. European Urban and Regional Studies, 8(3), 203-215.

Tödtling, F., Lehner, P., \& Kaufmann, A. (2009). Do different types of innovation rely on specific kinds of knowledge interactions? Technovation, 29(1), 59-71.

Torre, A. (2008). On the role played by temporary geographical proximity in knowledge transmission. Regional Studies, 42(6), 869-889.

Tranfield, D., Denyer, D., \& Smart, P. (2003). Towards a methodology for developing evidence-informed management knowledge by means of systematic review. British journal of management, 14(3), 207-222.

Trigilia, C. (1986). Small-firm development and political subcultures in Italy. European sociological review, 2(3), 161-175.

Trosa, S. (2009). Evaluer les politiques publiques pour améliorer l'action publique: une perspective internationale. Paris: Comité pour l'histoire économique et financière de la France.

Tuppen, J. N., \& Thompson, I. B. (1994). Industrial restructuring in contemporary France: spatial priorities and policies. Progress in Planning, 42, 99-172.

Uhlmann, L. (1975). Innovation in industry: a discussion of the state-of-art and the results of innovation research in german-speaking countries. Research Policy, 4(3), 312-327.

Uzawa, H. (1965). Optimum technical change in an aggregative model of economic growth. International economic review, 6(1), 18-31.

Vaessen, A. (2010). Mise en auvre des Actions prioritaires pour l'Avenir wallon 2006-2009, Rapport de cloture. Belgique: Service public de Wallonie, Secrétariat général - Cellule des Stratégies Transversales.

Van de Ven, A. H., Polley, D. E., Garud, R., \& Venkataraman, S. (1999). The innovation journey. New York: Oxford University Press.

Van Haeperen, B., Lefèvre, M., \& Dejardin, M. (2009). Plan Marshall wallon: une évaluation ex ante en référence à la politique industrielle et d'innovation. Reflets et perspectives de la vie économique, XLVIII(1), 161-177.

Van Klink, A., \& De Langen, P. (2001). Cycles in industrial clusters: The case of the shipbuilding industry in the Northern Netherlands. Tijdschrift voor economische en sociale geografie, 92(4), 449-463.

Vedung, E. (2009). Public policy and program evaluation (4 ed.). New Brunswisck, New Jersey Transaction Books.

Verganti, R. (2011). Radical design and technology epiphanies: a new focus for research on design management. Journal of Product Innovation Management, 28(3), 384-388. 
Vibert, I., \& Dupont, J. B. (2008). Étude portant sur l'évaluation des systèmes productifs locaux. Paris: Bernard Brunhes Consultants, Groupe BPI.

Visser, E.-J. (2009). The complementary dynamic effects of clusters and networks: research paper. Industry and Innovation, 16(2), 167-195.

Visser, E.-J., \& de Langen, P. (2006). The importance and quality of governance in the Chilean wine industry. GeoJournal, 65(3), 177-197.

Von Krogh, G., Nonaka, I., \& Ichijo, K. (1997). Develop knowledge activists! European Management Journal, 15(5), 475-483.

Waxell, A., \& Malmberg, A. (2007). What is global and what is local in knowledgegenerating interaction? The case of the biotech cluster in Uppsala, Sweden. Entrepreneurship and Regional Development 19(2), 137-159.

WEF. (2011). The Global Competitiveness Report 2011-2012. Geneva: World Economic Forum.

Weick, K. E., Sutcliffe, K. M., \& Obstfeld, D. (2005). Organizing and the process of sensemaking. Organization Science, 16(4), 409-421.

Weil, D. N. (2012). Economic Growth (3 ed.). New York: Prentice Hall.

Weil, T. (2010). Des histoires de la Silicon Valley. Entreprises et histoire (58), 129-149.

Weil, T., \& Fen Chong, S. (2008). Les pôles de compétitivité français. Futuribles, June(342), $5-26$.

Weil, T., \& Fen Chong, S. (2009). Multi-level learning in the French cluster policy. Paper presented at the 3ème Atélier "Stratégies, Espaces et Territoires" ( AIMS et l'Association de Science Régionale de Langue Française).

Weil, T., Gallié, E.-P., Glaser, A., Lefebvre, P., Mérindol, V., \& Pallez, F. (2010a). Can we explain a network's outcome from its resources and characteristics? The case of French innovation clusters. Paper presented at the European Academy of Management (EURAM) Conference.

Weil, T., Gallié, E.-P., Glaser, A., Lefebvre, P., Mérindol, V., \& Pallez, F. (2010b). Why are good comparative studies of networks so rare? Practical lessons from a study on clusters. Paper presented at the European Group for Organizational Studies (EGOS) Conference.

Weinberg, S. L., \& Abramowitz, S. K. (2002). Data analysis for the behavioral sciences using SPSS. Cambridge: Cambridge Univiersity Press.

Weiss, C. H. (1997). Theory-based evaluation: Past, present, and future. New Directions for Evaluation (76), 41-55.

Wernerfelt, B. (1984). A Resource-based View of the Firm. Strategic Management Journal, $5(2), 171-180$.

Williamson, O. E. (1973). Markets and hierarchies: some elementary considerations. The American Economic Review, 63(2), 316-325.

Williamson, O. E. (1985). The economic institutions of capitalism : firms, markets, relational contracting. New York: The Free Press.

Wolman, H. (1981). The determinants of program success and failure. Journal of Public Policy, 1(4), 433-464.

Wu, X., Geng, S., Li, J., \& Zhang, W. (2010). Shared Resources and Competitive Advantage in Clustered Firms: The Missing Link. European Planning Studies, 18(9), 1391-1410.

Yifu Lin, J., \& Rosenblatt, D. (2012). Shifting Patterns of Economic Growth and Rethinking Development. World Bank.

Yin, R. K. (2009). Case study research: Design and methods. Thousand Oaks, California: Sage Publications, Inc.

Yin, R. K. (2012). Applications of Case Study Research. Thousand Oaks, CA: SAGE Publication. 
Yin, R. K. (2013). Case Study Research: Design and Methods. Thousand Oaks, California: SAGE Publications.

Younès, D. (2011). Créer la coopération ? Les dynamiques de partenariat sur le pôle de compétitivité du plateau de Saclay. Paris Institute for Political Studies, Paris.

Younès, D. (2012). Why is intersectoral cooperation difficult to maintain? Insights from French cluster policy. Environment and Planning C: Government and Policy, 30(5), 835-847.

Zabala-Iturriagagoitia, J. M., Voigt, P., Gutiérrez-Gracia, A., \& Jiménez-Saez, F. (2007). Regional Innovation Systems: How to Assess Performance. Regional Studies, 41(5), 661-672.

Zahra, S. A., \& Pearce, J. A. (1989). Boards of directors and corporate financial performance: A review and integrative model. Journal of Management, 15(2), 291-334.

Zhang, J. (2003). Growing Silicon Valley on a landscape: an agent-based approach to hightech industrial clusters. Journal of Evolutionary Economics, 13(5), 529-548. 


\section{DETAILED TABLE OF CONTENTS}

PREFACE iii

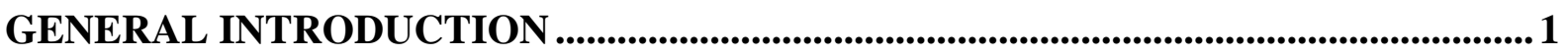

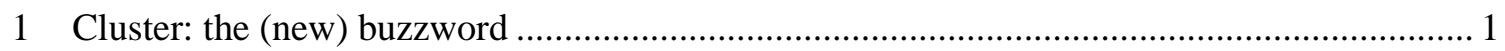

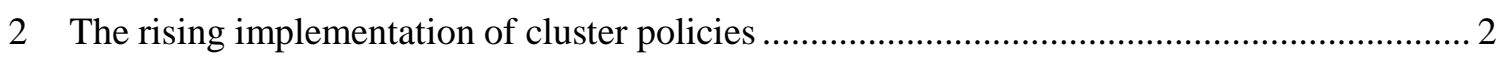

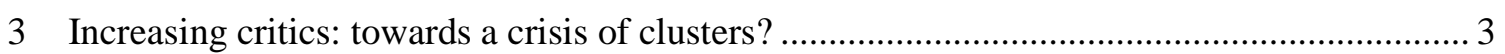

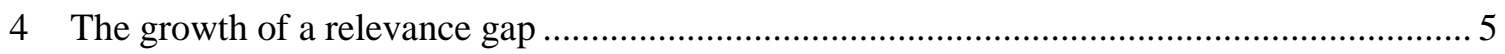

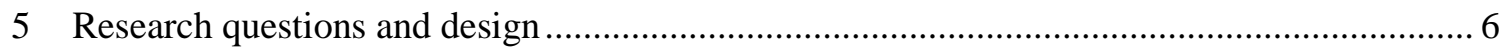

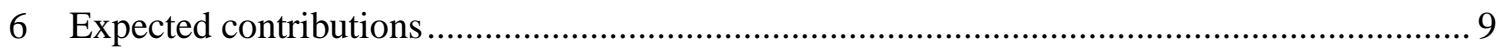

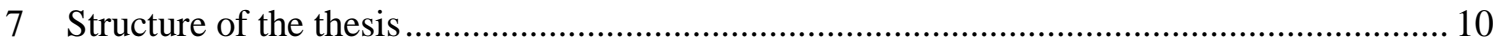

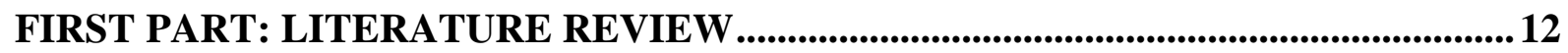

Chapter 1: An archaeology of cluster research ....................................................................... 13

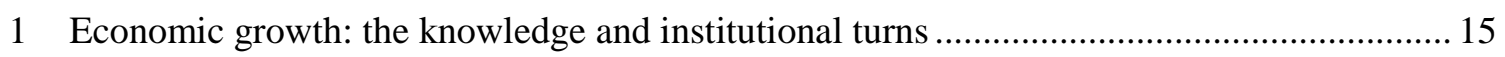

1.1 Economic growth: performed through indicators ..................................................... 15

1.2 Economic growth models: from exogenous to endogenous ........................................... 16

1.2.1 The neoclassical (or exogenous) economic growth model................................................... 17

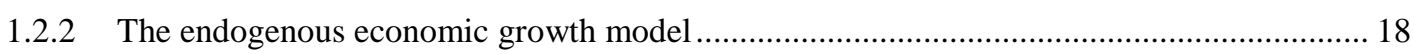

1.3 Economic growth: the rising importance of institutions .............................................. 20

2 The emergence of regions as economic organizations ......................................................... 23

2.1 The rise and fall of Marshall's industrial district........................................................... 23

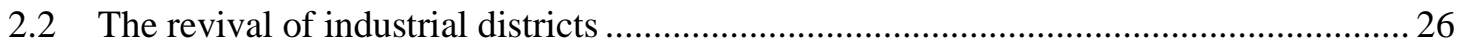

2.2.1 The region, a locus for flexible specialization.................................................................. 26

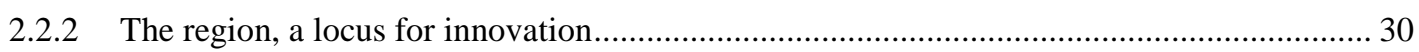

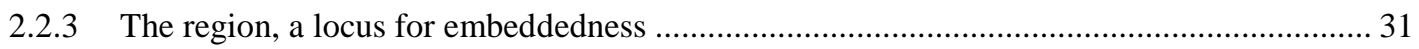

2.3 The stabilisation of regional "role models" in the 1980s ................................................ 33

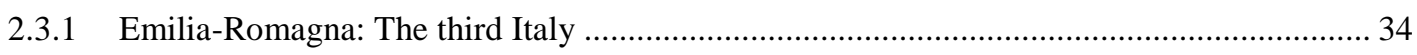

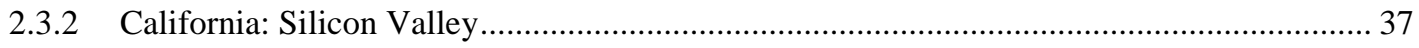

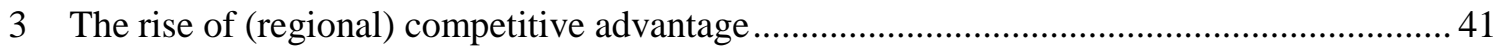

3.1 The birth of Porter's business approach to clusters ...................................................... 42

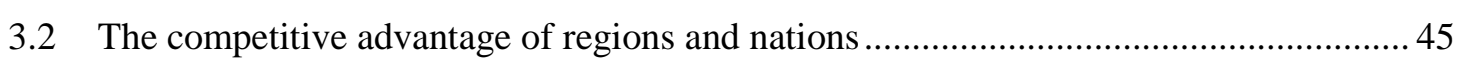

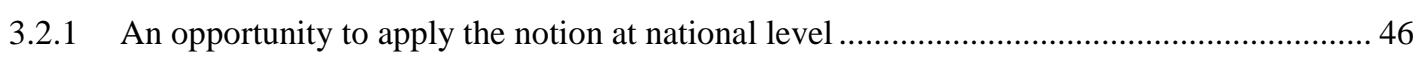

3.2.2 From "comparative advantage" to "competitive advantage of nations"................................. 48 


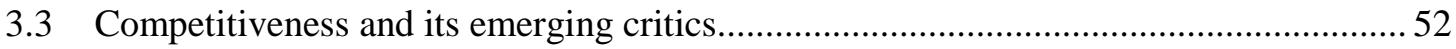

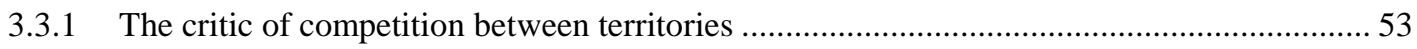

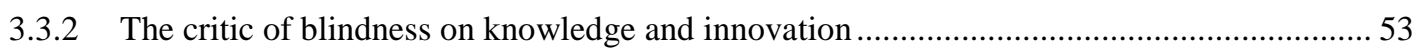

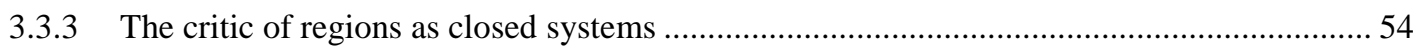

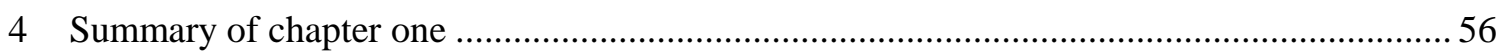

Chapter 2: Dilemmas and pathologies in policy-driven clusters .....................................59

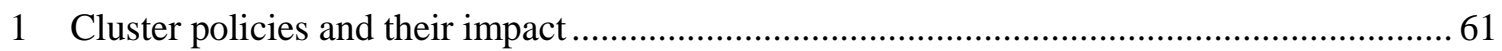

1.1 Cluster policies: a new weapon to succeed in a globalized world? ................................61

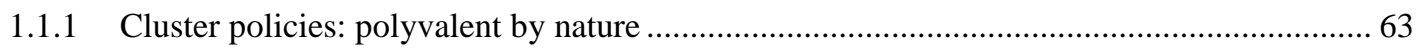

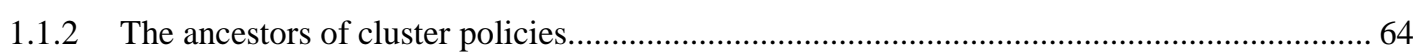

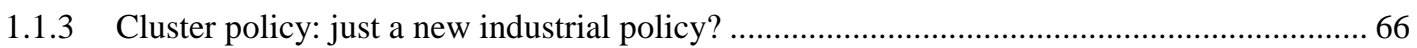

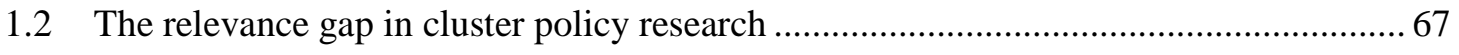

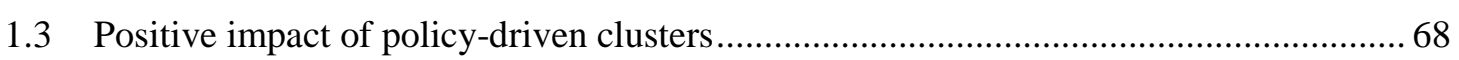

2 Identifying cluster dilemmas \& pathologies: a systematic review .......................................... 71

2.1 What is cluster dilemmas and pathology?............................................................. 72

2.2 The need for a review of policy-driven cluster dilemmas and pathologies .................... 74

2.3 A Systematic Literature Review …………….......................................................... 74

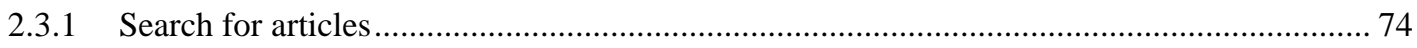

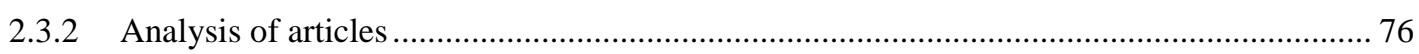

2.4 Organisational dilemmas as drivers of cluster pathologies........................................... 79

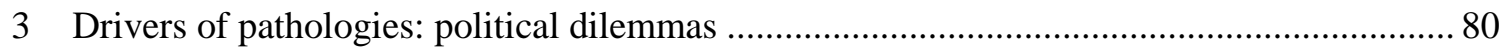

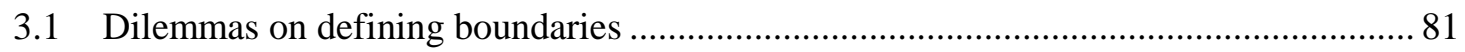

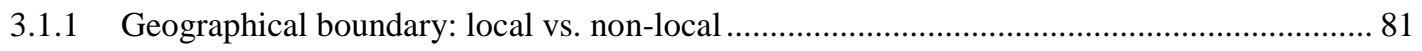

3.1.1.1 The benefits of non-local networks ................................................................................... 82

3.1.1.2 Public authorities insist on fostering local networks for policy-driven clusters .....84

3.1.1.3 Going beyond the local vs. non-local collaboration dichotomy .....................................86

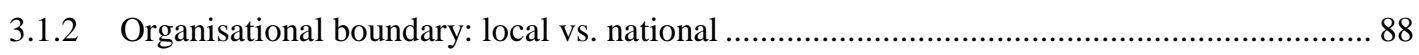

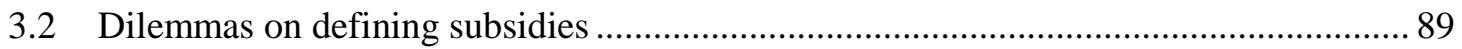

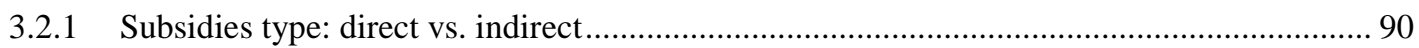

3.2.2 Subsidies structure: one-shop vs. multiple shop strategies.................................................. 92

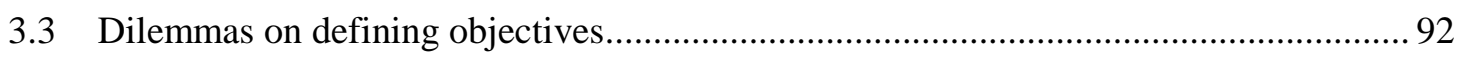

3.3.1 General objective: industrial excellence vs. regional development....................................... 93

3.3.2 Motivation: intrinsic motivation vs. policy prescription ....................................................... 96

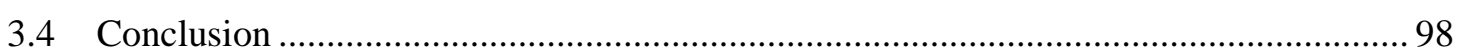

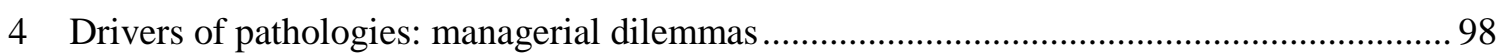

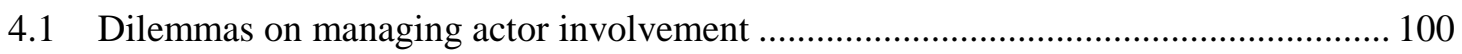

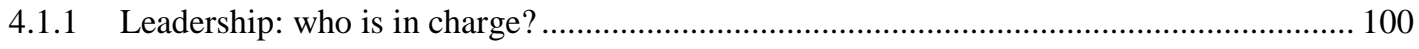

4.1.2 Learning: learning capacity vs. administrative straightjacket ........................................... 102 


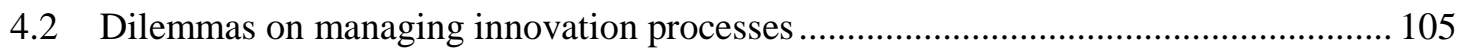

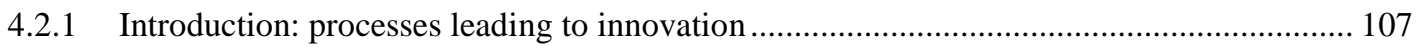

4.2.2 Which stage matters most? - Creativity vs. Research vs. Development .............................. 109

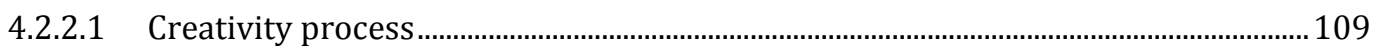

4.2.2.2 Research process ......................................................................................................... 112

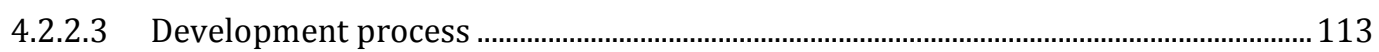

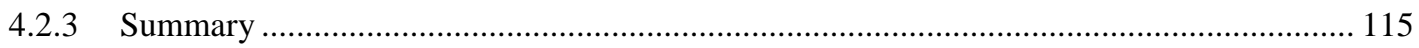

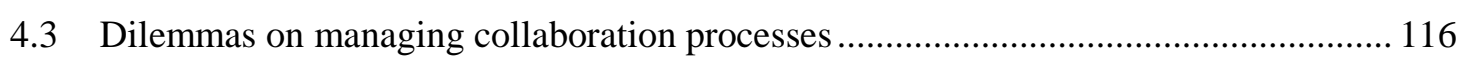

4.3.1 How to foster collaboration? - People-driven vs. Space-driven .......................................... 117

4.3.1.1 People ........................................................................................................................... 118

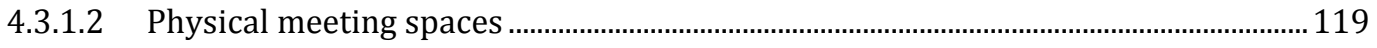

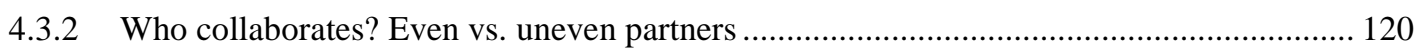

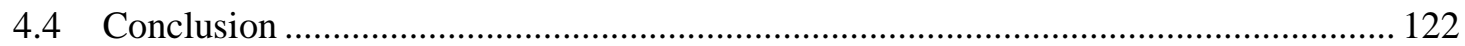

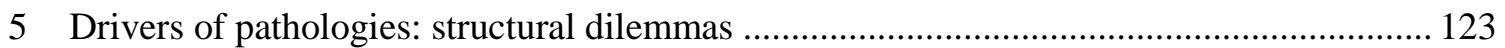

5.1 Dilemmas on adapting to life-cycle stages .............................................................. 123

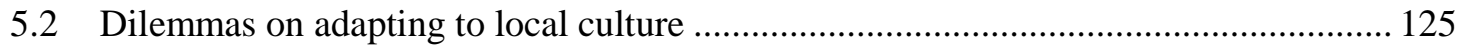

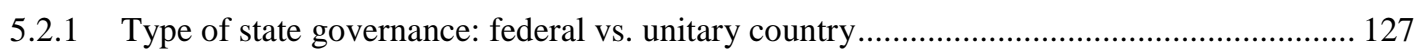

5.2.2 Type and sector of activity of policy-driven cluster actors …………………………....... 128

5.2.3 Degree of closeness between regional actors .................................................................... 129

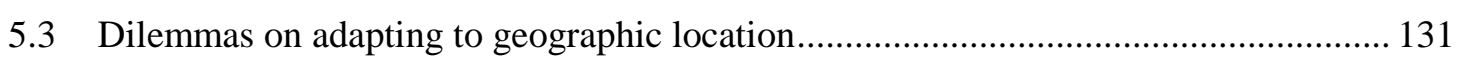

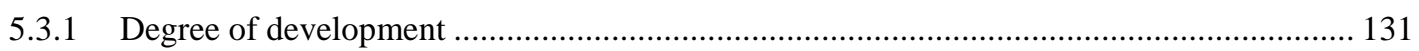

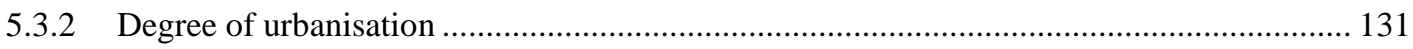

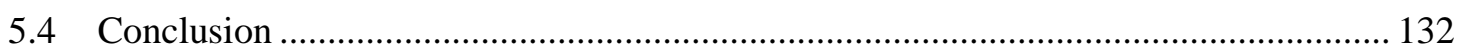

6 Summary of chapter two: overview of organisational dilemmas ....................................... 132

Chapter 3: Literature gap and problem statement ...................................................... 135

SECOND PART: RESEARCH DESIGN AND EMPIRICAL CONTEXT................... 139

Chapter 4: Research design ...................................................................................................... 140

1 Using a "case study" approach: justification and usefulness ............................................ 141

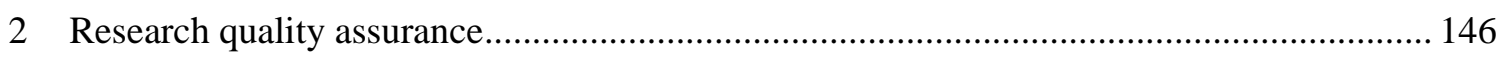

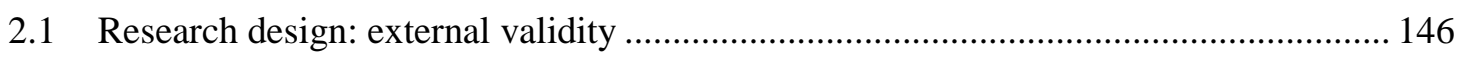

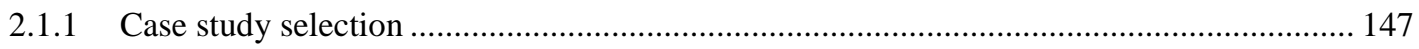

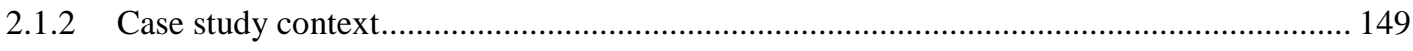

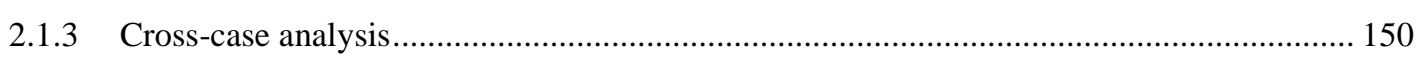

2.2 Data collection: construct validity and reliability .................................................... 150

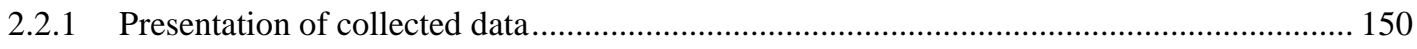

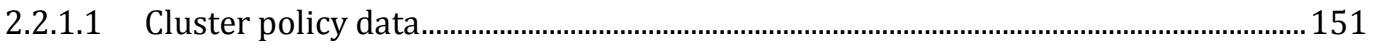

2.2.1.2 Policy-driven cluster data: the organisation ..................................................................152 
2.2.1.3 Policy-driven cluster data: the members ................................................................... 155

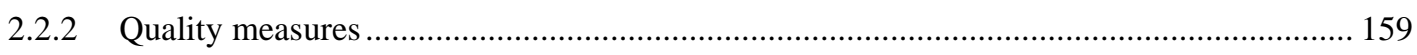

2.2.2.1 Construct validity: data triangulation and chain of evidence ................................... 159

2.2.2.2 Reliability: Case study protocol and database .................................................................. 160

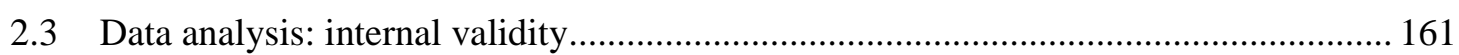

Chapter 5: Cluster policies in Europe: complexification and saturation................... 162

1 European Union and the saturation of cluster policies....................................................... 163

1.1 A multiplication of coordination structures ................................................................ 163

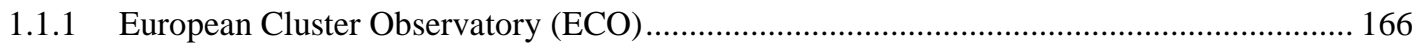

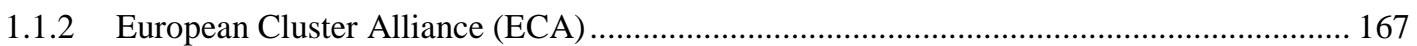

1.1.3 European Cluster Excellence Initiative ……………………........................................... 167

1.2 Towards a saturation of policy-driven clusters ……................................................... 169

2 France and cluster policies: traditions and renewal......................................................... 170

2.1 The French way towards decentralisation............................................................. 170

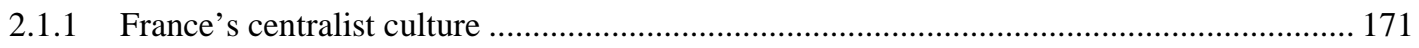

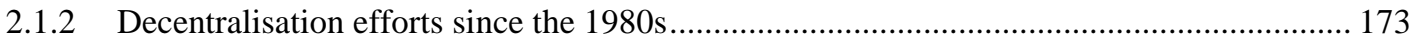

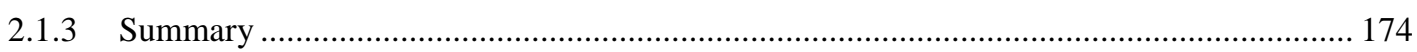

2.2 Between centralisation and decentralisation: living the cluster policy ........................ 174

2.2.1 National open calls for tender: Bottom-up or top-down initiatives? .............................. 176

2.2.2 Large variety of "regional system" initiatives ........................................................... 177

Chapter 6: The case of the French "competitiveness cluster" policy .......................... 181

1 The specificities of the French "competitiveness cluster" policy........................................... 182

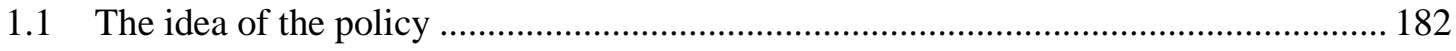

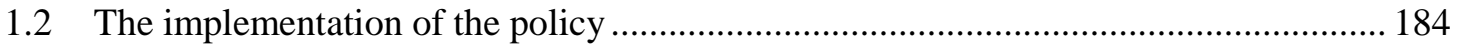

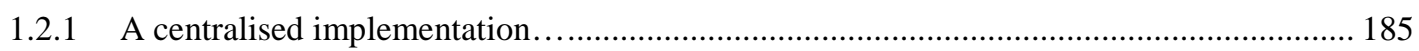

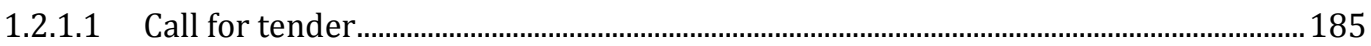

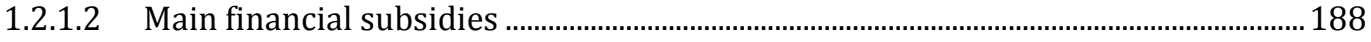

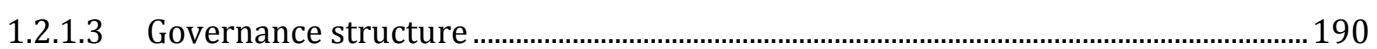

1.2.2 ...that generates emerging organisational dilemmas ...................................................... 191

1.2.2.1 State influence on the composition of the governance ................................................. 192

1.2.2.2 Role of the regional authorities in the governance structure ....................................192

1.2.2.3 Conflicting opinions around the set up of the R\&D zone.............................................. 193

1.2.2.4 Financial resources are dependent on national authorities........................................ 193

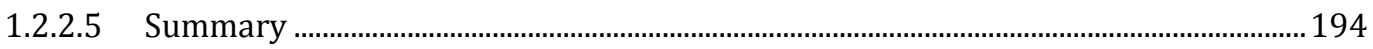

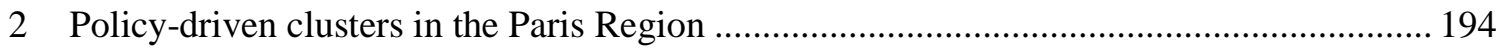

2.1 The economic context of the Paris Region ……............................................................ 195

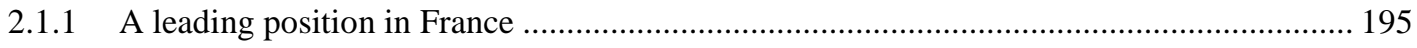

2.1.2 A comparison to other high performing European regions ............................................... 196 


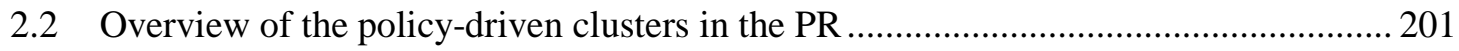

3 Presentation of HealthCluster Paris Region ........................................................................ 203

3.1 Type of members and member evolution ………........................................................ 203

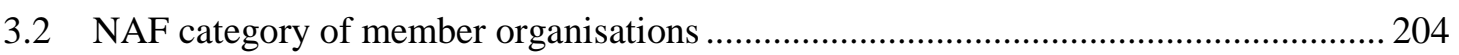

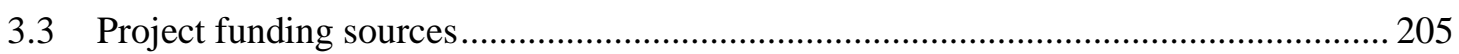

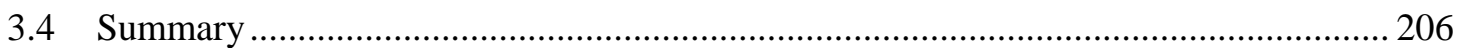

THIRD PART: EMPIRICAL CASE STUDY - RESULTS \& DISCUSSION................ 210

Chapter 7: HCPR's governance: facing dilemmas \& developing pathologies .......... 211

1 Defining objectives, a difficult task: HCPR's performance contract ................................... 212

1.1 The official discourse: building innovation and trust ............................................... 212

1.2 The content of the performance contract: focalisation on R\&D objectives ................... 214

1.2.1 HCPR's R\&D objectives: a detailed description................................................................. 215

1.2.2 HCPR's animation \& development objectives: a more superficial description.................... 216

1.3 Power games behind the scene: the set-up of the contract and it's visibility ................ 218

1.3.1 Presentation of HCPR's governance structure: the 4-dimensional matrix system ............... 218

1.3.2 The authors of the performance contract: ignoring the operational team ............................ 222

1.3.3 The (in)visibility of the performance contract: secretiveness.............................................. 223

2 Managing the ecosystem: A cluster stuck in organisational dilemmas? ................................ 224

2.1 Mapping the Paris Region: who are the "clients"? ..................................................... 225

2.1.1 The inventory: the pride of the development \& animation team.......................................... 225

2.1.2 Invisibility of the inventory beyond the development \& animation team's office ............... 227

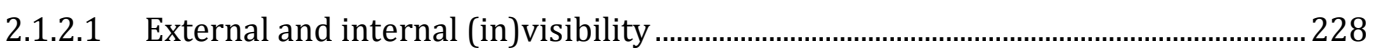

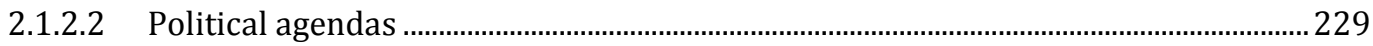

2.2 Developing services: torn apart between different objectives ................................... 231

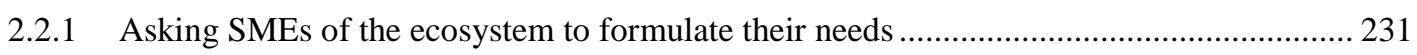

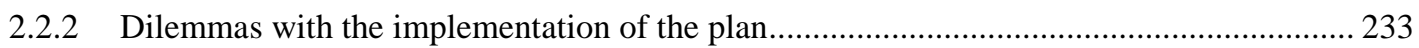

2.2.2.1 Sharing responsibilities with established actors of the region ..................................2.233

2.2.2.2 Representing the members or the ecosystem? .............................................................2. 234

2.3 Developing inter-cluster collaborations: implementation difficulties.......................... 238

2.3.1 Characteristics of the inter-cluster collaboration and set-up difficulties ............................ 239

2.3.2 MPRs conflicting relationship with the ICT \& Health initiative......................................... 242

2.3.2.1 HCPR's lack in competence in the ICT domain ...............................................................243

2.3.2.2 Non-relevance of ICT \& Health projects for HCPR's research agenda ....................... 243

2.3.3 Conclusion: different impacts, depending on policy-driven cluster ..................................... 244

Chapter 8: Which role does HCPR play in the set-up of R\&D projects? ................. 246

1 Overview of ICT \& Health project leaders and their organisations .................................... 248

1.1 Presentation of the project leaders' organisations......................................................... 248 


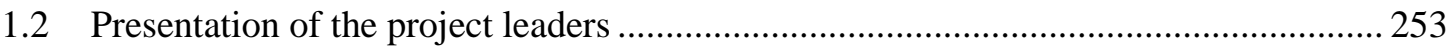

1.3 Conclusion: the particularities of the $\mathrm{R} \& \mathrm{D}$ project leaders …..................................... 257

2 Finding subsidies: Being friend and judge - a schizophrenic situation .............................. 258

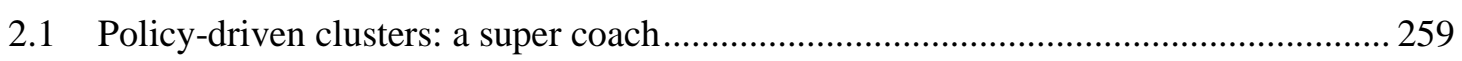

2.2 Policy-driven clusters: biased judges and ambiguous objectives ............................... 260

2.2.1 Biased behaviour of the evaluation committee in policy-driven clusters ............................ 260

2.2.2 Decision inconsistency: labelling then not labelling ………............................................ 262

2.2.3 FUI: ambiguous objectives and complex set-up............................................................... 263

2.2.4 Consequence: abandoning policy-driven clusters or intensive lobbying.............................. 266

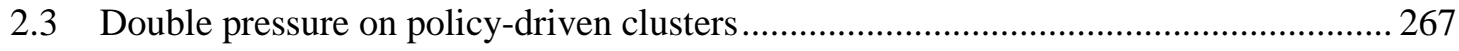

2.3.1 Bottom-up pressure from companies: want to get labelled and financed ............................. 268

2.3.2 Top-down pressure from government: performance evaluations ........................................ 271

2.4 Conclusion: the finding subsidies' dilemmas of HCPR ……………………................ 272

3 Finding partners: "Las Vegas" weddings thanks to "Meetic"............................................... 273

3.1 Project leaders learn but have difficulties to find certain partners ............................... 274

3.1.1 Project leaders' learning curve for finding partners ............................................................ 275

3.1.1.1 Project partners, colleagues, and acquaintances ( $1^{\text {st }}$ step)........................................2. 277

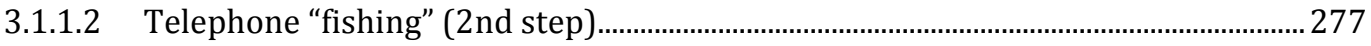

3.1.1.3 Event "fishing" ( $3^{\text {rd }}$ step) …........................................................................................... 279

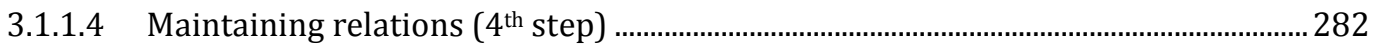

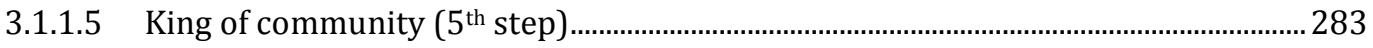

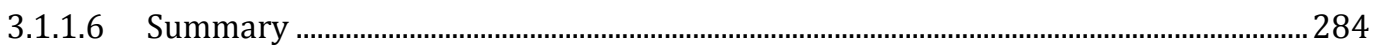

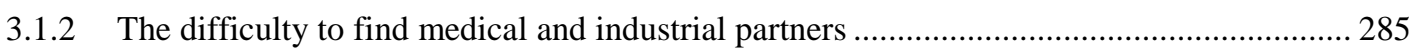

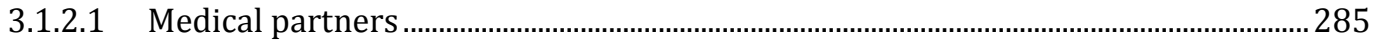

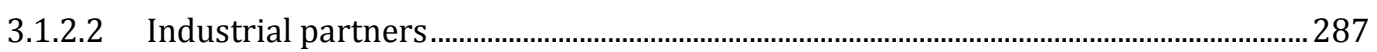

3.1.3 The difficulty to find project partners situated in the same region ...................................... 289

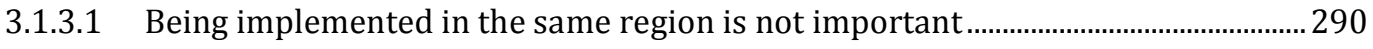

3.1.3.2 Being occasionally close is important ..........................................................................2292

3.2 HCPR's difficult role in the finding partners phase......................................................293

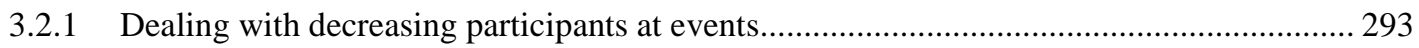

3.2.2 Struggling to integrate medical and industrial partners in events...................................... 296

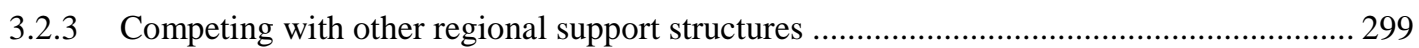

3.3 Conclusion: the finding partners' dilemmas of HCPR …………………....................... 304

4 Finding ideas: Doctors can't be find at "Meetic" events......................................................... 306

4.1 Project leaders' idea generation moments .................................................................... 306

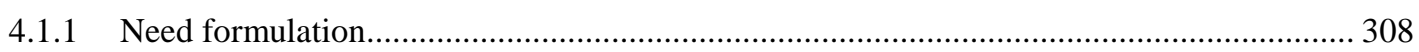

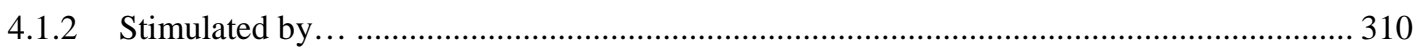

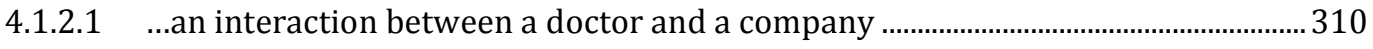

4.1.2.2 ...a public project call ......................................................................................................... 312 
4.1.2.3 ...a previous collaborative research project .................................................................... 313

4.2 Absence of HCPR in the ideas quest phase ........................................................ 313

4.2.1 Struggling to attract others than business-driven companies ............................................ 314

4.2.2 Danger of fashionable innovations ............................................................................. 315

4.3 Conclusion: the finding ideas' dilemmas of HCPR ............................................ 316

Chapter 9: Discussion: how dilemmas drove cluster pathologies in HCPR .............. 320

1 The identification of HCPR's four side-effect pathologies ................................................... 323

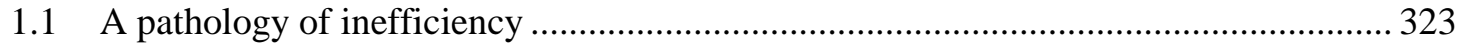

1.1.1 Results: Leadership dilemma contribute to cluster inefficiency ................................... 323

1.1.2 Discussion: No civic entrepreneur, no external challenge, unitary country ...................... 326

1.1.2.1 Leadership dilemma within the cluster's governance structure...............................329

1.1.2.2 Leadership dilemma among regional policy-driven clusters ...................................... 330

1.1.2.3 Leadership dilemma between the cluster and the national government.................330

1.1.2.4 Leadership dilemma among the different ministries ................................................. 330

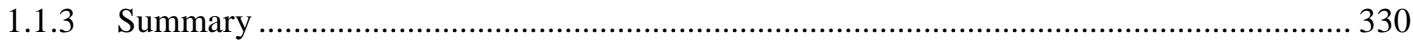

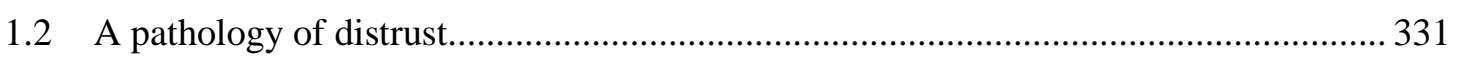

1.2.1 Results: Subsidies dilemma (also) drives cluster distrust ............................................ 331

1.2.2 Discussion: Theoretical "trust facilitator" struggles with trust issues ............................. 334

1.2.2.1 Subsidies dilemma drives inefficiency (complexity of support structure)..............336

1.2.2.2 Subsidies dilemma favour low-risk projects (risk-aversion of cluster org.)........... 337

1.2.2.3 Subsidies dilemma drives distrust (policy-driven cluster involved in subsidies) 337

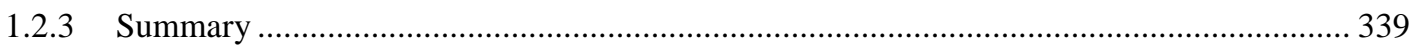

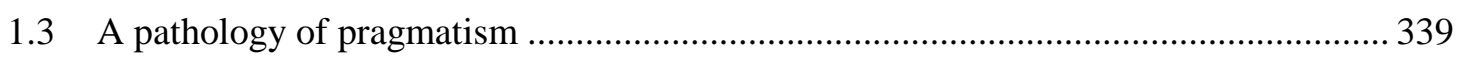

1.3.1 Results: Dilemma on innovation\&collaboration management drives pragmatism .............340

1.3.2 Discussion: Doctors, a specie difficult to meet?...................................................... 343

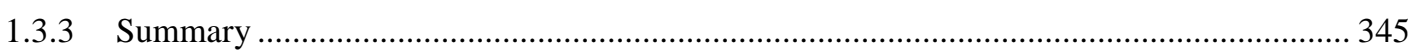

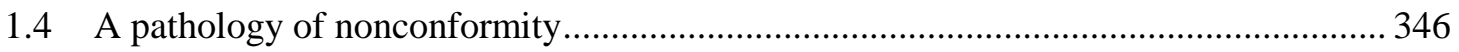

1.4.1 Results: Structural dilemmas drive cluster nonconformity ........................................... 346

1.4.2 Discussion: The challenge of trying to be conform to national cluster policy rules............ 348

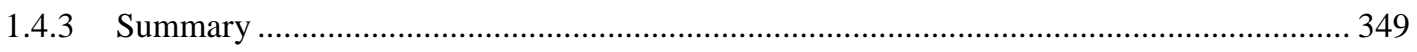

2 Existence beyond difficulties: an organisation of hypocrisy? ............................................... 349

3 Enriching the "management model" of cluster policy evaluations ..................................... 352

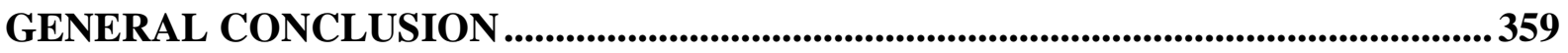

1 Theoretical, methodological and managerial contributions .............................................. 359

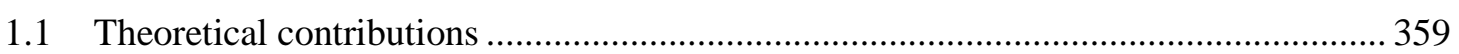

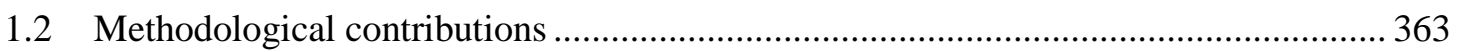

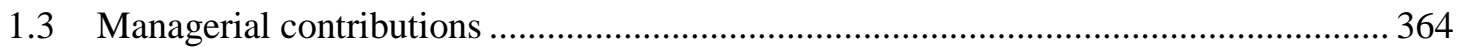

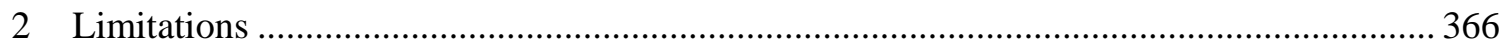




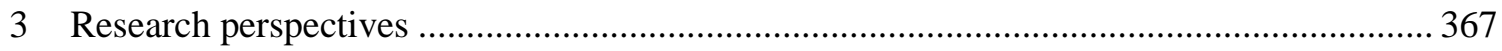

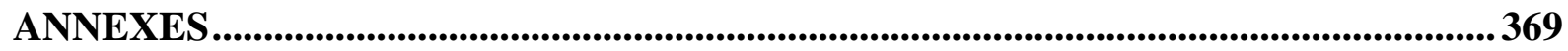

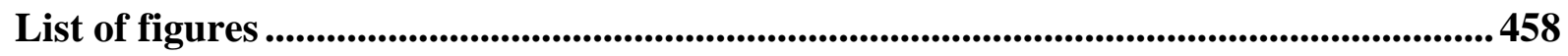

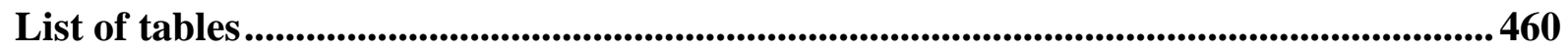

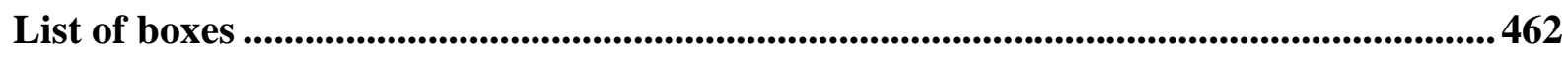

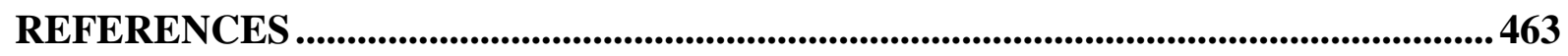

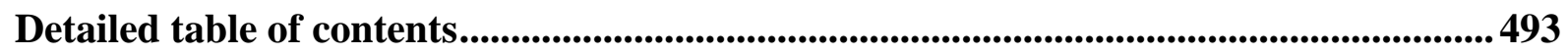




\title{
LA MISE EN OEUVRE DES POLITIQUES DE CLUSTER : DILEMMES ORGANISATIONNELS, PATHOLOGIES ET EVALUATION. LE CAS D'UN POLE DE COMPETITIVITE FRANCAIS.
}

\begin{abstract}
Résumé : Confrontés au succès du concept de "cluster », les gouvernements du monde entier mettent aujourd'hui en œuvre des politiques de cluster. Cependant, l'écart entre la recherche et la pratique ne cesse de grandir. Tandis que les chercheurs élaborent des théories présentant les clusters comme des entités permettant de susciter efficacement innovation et compétitivité, les praticiens des clusters gouvernements, animateurs de pôles de compétitivité et entreprises membres - semblent se débattre dans la gestion de ces objets particulièrement entremêlés. Notre thèse porte sur ce " relevance gap ». Une étude systématique de la littérature (SLR) est menée sur les politiques de cluster : elle démontre que les animateurs de clusters font constamment face à une multitude de dilemmes organisationnels, c'est-à-dire un ensemble de décisions et de choix pour lesquels il n'existe pas une réponse rationnelle unique. Ces dilemmes portent sur la mise en œuvre de la politique, sur la gestion des membres des pôles de compétitivité, et sur l'adaptation structurelle du pôle aux réalités locales. Apporter des réponses à ces dilemmes est évidemment du ressort des pôles de compétitivité, mais cela génère des effets secondaires et pathologies, qui doivent être pris en compte et évalués. Dans cette thèse, nous développons une étude de cas qualitative d'un pôle de compétitivité situé en région parisienne: nous analysons en détail dilemmes et pathologies. Quatre pathologies sont identifiées : l'inefficacité (suscitée par des dilemmes de leadership), la méfiance (suscitée par les dilemmes autour des subventions), la non-conformité (suscitée par des dilemmes structurels) et le pragmatisme (suscité par des dilemmes managériaux et de collaboration). Cette pathogénèse peut contribuer à améliorer la mise en œuvre et l'évaluation des politiques de cluster. Enfin, la thèse invite les chercheurs à passer de l'étude de l' " anatomie des clusters » à celle des " pathologies des clusters».
\end{abstract}

Mots clés: Pôle de compétitivité, mise en œuvre de politique, évaluation de cluster, dilemme organisationnel, pathologie

\section{IMPLEMENTING CLUSTER POLICIES: ORGANIZATIONAL DILEMMAS, PATHOLOGIES AND EVALUATION. THE CASE OF A FRENCH POLICY-DRIVEN CLUSTER.}

\begin{abstract}
As "cluster" became a new buzzword, governments around the world increasingly implement cluster policies. However, a relevance gap is growing between cluster research and practice. Scholars build theories about the roles of clusters as powerful entities fostering innovation and competitiveness. Meanwhile, governments and policy-driven cluster organizations struggle to manage these highly entangled objects. This thesis addresses such a relevance gap. A systematic literature review (SLR) is conducted on cluster policy research, which demonstrates that governments and policy-driven cluster managers constantly face a multitude of organizational dilemmas, i.e. a set of decisions and choices for which there is no "one best choice", in matters such as how to implement cluster policy (political dilemmas), how to manage policy-driven cluster members (managerial dilemmas) and how to adapt the policy-driven cluster to the local reality (structural dilemmas). Answering these dilemmas is constitutive of the management of policy-driven clusters, but it generates side-effect pathologies that need to be monitored and evaluated. In this thesis, we conduct a qualitative empirical investigation of a French policy-driven cluster located in the Paris Region: we analyse in detail the organisational dilemmas and their related side-effect pathologies. Four different pathologies are identified: inefficiency (driven by leadership dilemmas), distrust (driven by subsidies dilemmas), non-conformity (driven by structural dilemmas), and pragmatism (driven by managing innovation and collaboration dilemmas). The deeper knowledge of these pathologies contributes to improve cluster policy implementation and cluster evaluations. Finally, this thesis argues that academics need to shift from studying the "anatomy of clusters" to studying the "pathology of clusters".
\end{abstract}

Keywords: Policy-driven cluster, policy implementation, cluster evaluation, organizational dilemma, pathology 